\title{
THE ORIGIN OF VERTEBRATES
}

\section{WALTER HOLBROOK GASKELL}





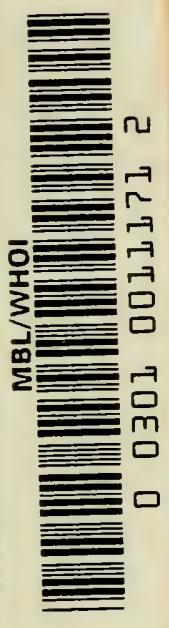





THE

ORIGIN OF VERTEBRATES 



\section{T H E}

\section{ORIGIN OF VERTEBRATES}

BY

\section{IVALTER HOLBROOK GASKELL}

M.A., M.D. (CANTAB.), LL.D. (EDIN. AND MCGILL UNIY.); F.R.S. ; FELLOW OF TRINITY HALL AND UNIYERSITY L.ECTURER IN PHYSIOLOGY, CAMBRIDGE; HONORARY FELLOW OF THE ROYAL MEDICAL AND CHIRURGICAL SOCIETY; CORRESPONDING MEMBER of the IMPERIAL MILITARY ACADEMY OF MEDICINE, ST. PETERSBlig, etC.

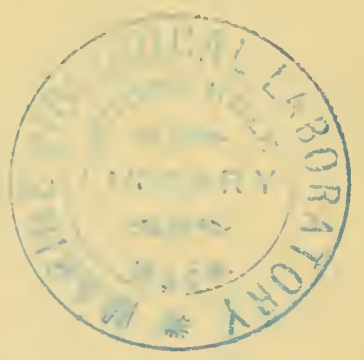

L O N G A NS, GREEN, A N D CO.

39 PATERNOSTER ROW, LONDON NEW YORK, BOMLAY, AND CALCUTTA

1908

All rights reserved 



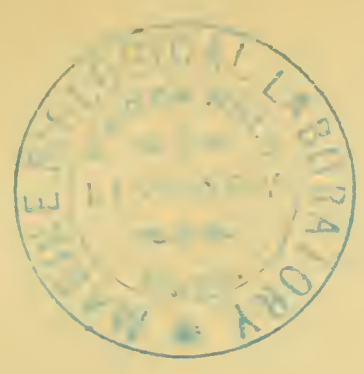

\section{CONTENTS}

INTRODUCTION

\section{CHAPTER I}

\section{The Evidence of the Central Nervous Systey}

Theories of the origin of rertebrates-Importance of the central nervous system -Evolution of tissues-Evidence of Palæontology-Reasons for choosing Ammocetes rather than Amphioxus for the investigation of this problemImportance of larval forms - Comparison of the vertebrate and arthropod central nervous systems-Antagonism between cephalization and alimentation-Life-history of lamprey, not a degenerate animal-Brain of Ammoceetes compared with brain of arthropod-Summary . . . . .

\section{CHAPTER II}

\section{The Evidexce of the Organs of Vision}

Different kinds of eye-Simple and compound retinas-Upright and inverted retinas-Median eyes-Median or pineal eyes of Ammocoetes and their optic ganglia-Comparison with other median eyes-Lateral eyes of vertebrates compared with lateral eyes of crustaceans-Peculiarities of the lateral eye of the lamprey-Meauing of the optic diverticnla-Evolution of vertebrate eyes-Summary

\section{CHAPTER III}

\section{The Evidence of the Skeletow}

The bony and cartilaginous skeleton considered, not the notochord-Nature of the earliest cartilaginons skeleton-The mesosomatic skeleton of Ammocotes; its topographical arrangement, its structure, its origin in mucocartilage-The prosomatic skeleton of Ammocœes; the trabeculæ and parachordals, their structure, their origin in white fibrous tissue-The mesosomatic skeleton of Limulus compared with that of Ammocœtes; similarity of position, of structure, of origin in muco-cartilage-The prosomatic skeleton of Limulus; the entosternite, or plastron, compared with the trabeculie of Ammocetes; similarity of position, of structure, of origin in fibrous tissue-Summary . 


\section{CHAPTER IV}

\section{The Evidexce of thl: Respinatory Apparatus}

Branchix considered as internal hranchial appendages-Innervation of branchial segments-Cranial region older than spinal-Thrce-root system of cranial nerves: dorsal, lateral, ventral-Explanation of van Wijhe's segments-Lateral mixed root is appendage-nerve of invertebrate-The branchial chamber of Ammocotes - The branchial unit, not a pouch but an appendage - The origin of the branchial musculature-The branchial circulation--The branchial heart of the vertebrate-Not homologous with the systemic heart of the artbropod-Its formation from two longitudinal venous sinusesSummary

\section{CHAPTER V}

\section{The Evidence of tile Thyroid Gland}

The value of the appendage-unit in non-branchial segments-The double nature of the byoid segment-Its branchial part-Its thyroid part-The double nature of the opercular appendage-Its branchial part-Its genital part- Unique character of the thyroid gland of Ammocoetes-Its structureIts openings-The nature of the thyroid segment-The uterus of the scorpion-Its glands - Comparison with the thyroid gland of AmmocotesCephalic generative glands of Limulus - Interpretation of glandular tissue filling up the brain-case of Ammocotes-Function of thyroid glandRelation of thyroid gland to sexual functions-Summary . . .

\section{CHAPTER VI}

\section{The Evidence of the Olfactory Apparatus}

Fishes divided into Amphirhinæ and Monorhinæ-Nasal tube of the lamprey - Its termination at the infundibulum-The olfactory organs of the scorpion group - The camerostome-Its formation as a tube - Its derivation from a pair of antennie-Its termination at the true month-Comparison with the olfactory tube of Ammocotes-Origin of the nasal tube of Ammoccetes from the tube of the hypophysis-Direct comparison of the hypophysial tube with the olfactory tube of the scorpion group-Summary . . . . .

\section{CHAP'TER VII}

\section{Tie Prosomatic Seguents of Limulus and its Allies}

Comparison of the trigeminal with the prosomatic region-The prosomatic appendages of the Gigantostraca-Their number and nature-Endognaths and ectognath-The metastoma-The coxal glands-Prosomatic rogion of Eurypterus compared with that of Ammocetes-Prosomatic segmentation shown by marks on carapace-Evidence of cœlomic carities in Limulussummary 


\section{CHAPTER VIII}

\section{The Segments belonging to the Trigeminal Nerve-Group}

The prosomatic segments of the vertebrate-Number of segments belonging to the trigeminal nerve-group-History of cranial segments-Eye-muscles and their nerves-Comparison with the dorso-ventral somatic muscles of the scorpion-Explanation of the oculomotor nerve and its group of musclesExplanation of the trochlear nerve and its dorsal crossing-Explanation of the abducens nerve-Number of segments supplied by the trigeminal nerves-Evidence of their motor nuclei-Evidence of their sensory ganglia - Summary . . . . . . . . . . . .

\section{CHAPTER IX}

\section{The Prosomatic Segments of Ammocetes}

The prosomatic region in Ammocotes-The suctorial apparatus of the adult Petromyzon-Its origin in Ammocetes-Its derivation from appendagesThe segment of the lower lip or the metastomal segment-The tentacular segments-The tubular muscles-Their segmental arrangement-Their peculiar innervation-Their correspondence with the system of reno-pericardial muscles in Limulus-The old mouth or palæostoma-The pituitary gland-Its comparison with the coxal gland of Limulus-Summary . .

\section{CHAPTER X}

\section{The Relationship of Anmocetes to the yost Axcient Fishes 一THE OSTRACODERHATA}

The nose of the Osteostraci-Comparison of head-shield of Ammocetes and of Cephalaspis-Ammocœtes only living representative of these ancient fishes -Formation of cranimm-Closure of old mouth-Rohon's primordial cranium-Primordial cranium of Phrynus and Galeodes-Summary . .

\section{CHAPTER XI}

\section{The Evinence of the Auditory Apparatus and the Organs of the Lateral Line}

Lateral line organs-Function of this group of organs-Poriferous sense-organs on the appendages in Limulus-Branchial sense-organs-Prosomatic senseorgans-Flabellum-Its structure and position-Sense-organs of mandibles - Auditory organs of insects and arachnids-Poriferous chordotonal organsBalancers of Diptera-Resemblance to organs of flabellum - Racquet-organs of Galeodes-Pectens of scorpions-Large size of nerve to all these special sense-organs-Origin of parachordals and auditory capsule-Reason why VIIth nerve passes in and out of capsule-Evidence of AmmocetesIntrusion of glandular mass round brain into auditory capsule-Intrusion of generative and hepatic mass round brain into base of flabellumSummary 


\section{CHAPTER XII}

\section{The Region of the Spinal Cord}

Difference between cranial and spinal regions-Absence of lateral root-Meristic variation-Segmentation of cœlom-Segmental excretory organs-Development of nephric organs; pronephric, mesonephric, metanephric-Excretory organs of Amphioxus-Solenocytes-Excretory organs of Branchipus and Peripatus, appendicular and somatic-Comparison of cœlom of Peripatus and of vertebrate-Pronephric organs compared to coxal glands-Origin of vertebrate body-cavity (metacœle) - Segmental duct-Summary of formation of excretory organs-Origin of somatic trunk-musculature-Atrial cavity of Amphioxus-Pleural folds-Ventral growth of pleural folds and somatic musculature-Pletral folds of Cephalaspidæ and of Trilobita-Meaning of the ductless glands-Alteration in structure of excretory organs which have lost their duct in vertebrates and in invertehrates-Formation of lymphatic glands-Segmental coxal glands of arthropods and of vertebrates-Origin of adrenals, pituitary body, thymus, tonsils, thyroid, and other ductless glands -Summary

\section{CHAPTER XIII}

\section{The Notochord and Alimentary Canal}

Relationship between notochord and gut-Position of unsegmented tube of notochord-Origin of notochord from a median groove-Its function as an accessory digestive tube-Formation of notochordal tissue in invertebrates from closed portions of the digestive tube-Digestive power of the skin of Ammocœes-Formation of new gut in Ammocetes at transformationInnervation of the vertebrate gut - The three outflows of efferent nerves belonging to the organic system-The original close contiguity of the respiratory chamber to the cloaca-The elongation of the gut-Conclusion

\section{CHAPTER XIV}

\section{T'he Principles of Embryology}

The law of recapitulation-Vindication of this law by the theory advanced in this book-. The germ-layer theory--Its present position-A physiological not a morphological conception-New fundamental law required-Composition of adult body-Neuro-epithelial syncytium and free-living cellsMeaning of the blastula-Derivation of the Metazoa from the ProtozoaImportance of the central nervous system for Ontogeny as well as for Phylogeny-Derivatiou of free-living cells from germ-cells-Meaning of colom-Formation of neural canal-Gastrula of Amphioxus and of Lueifer

-Summary . . . . . . . . . . . . . 


\section{CHAPTER XV}

\section{Final Remarks}

PAGE

Problems requiring investigation-

Giant nerve-cells and giant nerve-fibres; their comparison in fishes and arthropods; blood-and lymph-corpuseles; nature of the skin; origin of system of unstriped muscles; origin of the sympathetic nervous system; biological test of relationship.

Criticisms of Balanoglossus theory-Theory of parallel development-Importance of the theory advocated in this book for all problems of Evolution

Bibliography AND Index of Atthors . . . . . . . . 501

General Index . . . . . . . . . . . . . 517

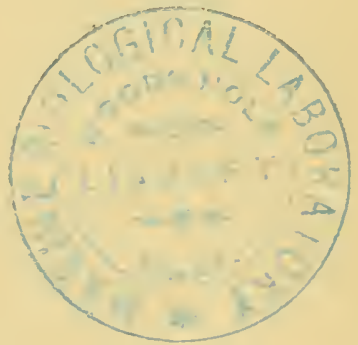


"GO ON AND PROSPER; THERE IS NOTHING SO USEFUL IN SCIENCE AS ONE OF THOSE EARTHQUAKE HYPOTHESES, IVIICH OBLIGE ONE TO FACE THE POSSIBILITY THAT THE SOLIDEST-LOOKING STRUCTURES MAY COLLAPSE."

Letter from Prof. Huxley to THE AUthor. JUNE 2, IS\&9. 


\section{ORIGIN OF VERTEBRATES}

\section{INTRODUCTION}

Is former days it was possible for a nan like Johannes Müller to be a leader both in physiology and in comparative anatomy. Nowadays all scientific knowledge has increased so largely that specialization is inevitable, and every investigator is confined more and more not only to one department of science, but as a rule to one small portion of that departinent. In the case of such cognate sciences as physiology and comparative anatomy this limiting of the scope of view is especially deleterions, for zoology without physiology is dead, and physiology in many of its departments without comparative anatomy can advance but little. Then, again, the too exclusive study of one subject always tends to force the mind into a special groove-into a line of thought so deeply tinged with the prevalent teaching of the subject, that any suggestions which arise contrary to such teaching are apt to be dismissed at once as heretical and not worthy of further thought; whereas the same suggestion arising in the mind of one outside this particular line of thought may give rise to new and valuable scientific discoveries.

Nothing but good can, in my opinion, result from the incursion of the non-specialist into the realm of the specialist, provided that the former is in earnest. Over and over again the chemist has given valuable help to the physicist, and the physicist to the chemist, so closely allied are the two subjects; so also is it with physiology and anatomy, the two subjects are so interdependent that a worker in the one may give valuable aid towarls the solution of some large problem which is the special territory of the other.

It has been a matter of surprise to many how it came about that 
I, a worker in the physiological laboratory at Cambridge ever since Foster introduced experimental physiology into English-speaking nations, should have devoted so much time to the promulgation of a theory of the origin of vertebrates - a subject remote from physiology, and one of the larger questions appertaining to comparative anatomy. By what process of thought was I led to take up the consideration of a subject apparently so remote from all iny previous work, and so foreign to the atmosphere of a physiological laboratory?

It may perhaps be instructive to my readers to see how one investigation leads to another, until at last, nolens volcns, the worker finds himself in front of a possible solution to a problem far removed from his original investigation, which by the very magnitude and importance of it forces him to devote his whole energy and time to seeing whether his theory is gool.

In the years 1880-1884 I was engaged in the investigation of the action of the heart, and the nature of the nerves which regulate that action. In the course of that investigation I was struck by the ease with which it was possible to distinguish between the fibres of the vagus and accelerator nerves on their way to the heart, owing to the medullation of the former and the non-medullation of the latter. This led me to an investigation of the accelerator fibres, to find out how far they are non-medullated, and so to the discovery that the rami comminicuntes connecting together the central nervous system and the sympathetic are in reality single, not double, as had hitherto been thought; for the grey rumus communicuns is in reality a peripheral nerve which supplies the blood-vessels of the spinal cord and its nembranes, and is of the same nature as the grey accelerators to the heart.

This led to the conclusion that there is no give and take between two independent nervous systems, the cerebro-spinal and the sympathetic, as had been taught formerly, but only one nervous system, the cerebro-spinal, which sends special medullated nervefibres, characterized by their smallness, to the cells of the sympathetic system, from which fibres pass to the periphery, usually nonmedullated. These fine medullated nerves form the system of white rami communicantes, and have since been called by Langley the preganglionic nerves. Further investigation showed that such white rami are not universally distributed, but are confined to the thoracico-lumbar region, where their distributiou is easily seen in 
the ventral roots, for the cells of the sympathetic system are entirely efferent in nature, not afferent; therefore, the fibres entering into them from the central nervous system leave the spinal cord by ventral, not dorsal roots.

Following out this clue, I then found that in addition to this thoracico-lumbar ontflow of efferent ganglionated visceral nerves, there are similar outflows in the cranial and sacral regions, belonging in the former case especially to the vagus system of nerves, and in the latter to the system of nerves which pass from the sacral region of the cord to the ganglion-cells of the hypogastric plexus, and from them supply the bladder, rectum, etc. To this system of nerves, formerly called the nervi erigntes, I gave the name pelvic splanchnics, in order to show their uniformity with the abdominal splanchnics. These investigations led to the conclusion that tho organic system of nerves, characterized by the possession of efferent nerve-cells situated peripherally, arises from the central nervous system by three distinct outflows-cranial, thoracico-lumbar, and sacral, respectively. To this system Langley has lately given the name 'autonomic.' These three outflows are separated by two gaps just where the plexuses for the anterior and posterior extremities come in.

This peculiar arrangement of the white rami communicuntes set me thinking, for the gaps corresponded to an increase of somatic musculature to form the muscles of the fore and hind limbs, so that if, as seemed probable, the white rami communicuntes arise segmentally from the spinal cord, then a marked distinction must exist in structure between the spinal cord in the thoracic region, where the visceral efferent nerves are large in amount and the body muscnlature scanty, and in the cervical or lumbar swellings, where the somatic musculature abounds, and the white rami communicuntes scarcely exist.

I therefore directed my attention in the next place to the structure of the central mervous system in the endeavour to associate the topographical arrangement of cell-groups in this system with the outflow of the different kinds of nerve-fibres to the peripheral organs.

This investigation forcibly impressed upon my mind the uniformity in the arrangement of the central nervous system as far as the centres of origin of all the segmental nerves are concerned, 
both cranial and spinal, and also the original segmental character of this part of the nervous system.

I could not, therefore, help being struck by the force of the comparison between the central nervous systems of Vertebrata and Appendiculata as put forward again and again by the past generation of comparative anatomists, and wondered why it had been discredited. There in the infundibulum was the old cesophagus, there in the cranial segmental nerves the infracesophageal ganglia, there in the cerebral hemispheres and optic and olfactory nerves the supracesophageal ganglia, there in the spinal cord the ventral chain of ganglia. But if the infundibulum was the old oesophagus, what then? The old cesophagus was continuous with and led into the cephalic stomach. What about the infundibulum? It was continuous with and led into the ventricles of the brain, and the whole thing became clear. The ventricles of the brain were the old cephalic stomach, and the canal of the spinal cord the long straight intestine which led originally to the anus, and still in the vertebrate embryo opens out into the anus. Not having been educated in a morphological laboratory and taught that the one organ which is homologous throughout the animal kinglom is the gut, and that therefore the gut of the invertebrate ancestor must continue on as the gut of the vertebrate, the conception that the central nervous system has grown round and enclosed the original ancestral gut, and that the vertebrate has formed a new gut did not seem to me so impossilble as to prevent my taking it as a working hypothesis, and seeing to what it would lead.

This theory that the so-called central nervous system of the vertebrate is in reality composed of two separate parts, of which the one, the segmented part, corresponds to the central nervous system of the highest invertebrates, while the other, the unsegmented tube, was originally the alimentary canal of that same invertebrate, came into my mind in the year 1887. The following year, on June 23, 1888, I read a paper on the subject before the Anatomical Society at Cambridge, which was published in the Journal of Anatomy and Physiology, vol. 23, and more fully in the Journal of Physiology, vol. 10. Since that time I have been engaged in testing the theory in every possible way, and have published the results of my investigations in a series of papers in different journals, a list of which I append at the end of this introductory chapter. 
It is now twenty year's since the theory first came into my mind, and the work of those twenty years has convinced me more and inore of its truth, and yet during the whole time it has been ignored by the morphological world as a whole rather than criticized. Whatever may have been the causes for such absence of criticism, it is clear that the serial character of its publication is a hindrance to criticism of the theory as a whole, and I hope, therefore, that the publication of the whole of the twenty years' work in book-form will induce those who differ from my conclusions to come forward and show me where I am wrong, and why my theory is untenahle. Any one who has been thinking over any one problem for so long a time becomes obsessed with the infallibility of his own views, and is not capable of criticizing his own work as thoroughly as others would do. I have been told that it is impossible for one man to consider so vast a subject with that thoroughness which is necessary, before any theory can be accepter as the true solution of the problem. I acknowledge the vastness of the task, and feel keenly enough my own shortcomings. For all that, I do feel that it can only be of advantage to scientific progress and a help to the solution of this great problem, to bring together in one book all the facts which I have been able to collect, which appeal to me as having an important bearing on this solution.

In this work I have been helped throughout by Miss R. Alcock. It is not too much to say that without the assistance she has given me, many an important link in the chain of evidence would have been missing. With extraordinary patience she has followerl, section by section, the smallest nerves to their destination, and has largely helped to free the transformation process in the lamprey from the mystery which has hitherto enveloped it. She has drawn for me very many of the illustrations scattered through the pages in this book, and I feel that her aid has been so valuable and so continuous, lasting as it does over the whole period of the work, that her name ought fittingly to be associated with mine, if perchance the theory of the Origin of Vertebrates, advocated in the pages of this book, gains acceptance.

I am also indebted to Mr. J. Stanley Gardiner and to Dr. A. Sheridan Lea for valuable assistance in preparing this book for the press. I desire to express my grateful thanks to the former for valuable criticism of the scientific evidence which I have bronght 
forward in this book, and to the latter for his great kindness in undertaking the lalorious task of correcting the proofs.

\section{LIST OF PREVIOUS PUBLICATIONS BY THE AUTHOR, CON. CERNING THE ORIGIN OF VER'TEBRATES.}

1888. "Spinal and Cranial Nerves." Proceedings of the Anatomical Society. June, 1888. Journal of Anatomy and Physiology, vol. xxiii.

1889. "On the Relation between the Structure, Function, Distribution, and Origin of the Cranial Nerves; together with a Theory of the Origin of the Nervons System of Vertebrata." Jourmal of Physiology, vol. x., p. 153.

1889. "On the Origin of the Central Nerrons System of Vertebrates." Brain, rol. xii.. p. 1.

1890. "On the Origin of Vertebrates from a Crustacean-like Ancestor." Quarterly Journal of Microscopical Science, rol. xxxi.. p. 379.

189.5. "The Origin of Vertebrates." Proceedings of the Cumbridge Philnsophical Society, vol. ix., p. 19.

1896. Presidential Address to Section I. at the meeting of the British Association for the Advancement of Science in Liverpool. Report of the British Association. 1896. p. 942.

1899. "On the Meaning of the Cranial Nerves." Presidential Address to the Neurological Society for the year 1899. Brrin, vol. xxii., p. 329.

A series of papers on "The Origin of Vertebrates, dednced from the study of Ammocoetes," in the Journal of Anutomy and Physiology, as follows :-

1898. Part I. "The Origin of the Brain." rol. xxxii., p. 513.

.. II. "The Origin of the Vertebrate Cranio-facial Skeleton." rol. xxxii., p. 553 .

.. $\quad$ III. ". The Origin of the Branchial Segmentation," vol, xxxiii.. p. 154.

1899. .. IV. " The Thyroid, or Opercular Segment: the Meaning of the Facial Nerve," vol. xxxiii., p. 638.

1900. .. V. " The Origin of the Pro-otic Segmentation: the Meaning of the Trigeminal and Eye-muscle Nerres," rol. xxxiv.. p. 465.

1900. .. VI. ". The Old Mouth and the Olfactory Organ: the Meaning of the First Nerve," vol. xxxiv., p. 514.

1900. .. VII. "The Evidence of Prosomatic Appendages in Ammocoetes, as given by the Course and Distribution of the Trigeminal Nerre." rol. xxxir., p. 537.

1900. .. VIII. "The Palæontological Evidence: Ammocœetes a Cephalaspid," vol. xxxiv., p. 562 .

1901. .. IX. "The Origin of the Optic Apparatns: the Meaning of the Optic Nerves," vol. xxxr., p. 2.2.t. 
1902. Part X. "The Origin of the Auditory Organ: the Meaning of the VIIIth Cranial Nerve," rol. xxxvi., p. 164.

1903. . XI. "The Origin of the Vertebrate Body-cavity and Excretory Organs: the Meaning of the Somites of the Trunk and of the Ductless Glands," rol. xxxvii., p. 168.

190.5. . . X XII. “ The Principles of Embryology," vol. xxxix., p. 371.

1906. ." XIII. ". The Origin of the Notochord and Alimentary Canal," rol. xl., p. 30.5 . 


\section{CHAPTER I}

THE EVIDENCE OF THE CENTRAL NERVOUS SYSTEMI

Theories of the origin of rertebrates.-Importance of the central nerrous system.-Erolution of tissues.-Evidence of Palrentology.-Reasons for choosing Ammocotes rather than Amphioxus.- Importance of larral forms. - Comparison of the vertebrate and arthropod central nerrous systems.Antagonism between cephalization and alimentation.--Life-history of lamprey : not a degenerate animal.-Brain of Ammocotes compared with brain of arthropod.-Snmmary.

A $\mathrm{T}$ the present time it is no longer a debatable question whether or no Evolution has taken place. Since the time of Darwin the accumulation of facts in its support has been so overwhelming that all zoologists look upon this question as settled, and desire now to find out the mammer in which such evolution has taken place. Here two problems offer themselves for investigation, which can be and are treated separately - the one dealing with the question of those laws of heredity and variation which have brought about in the past and are still causing in the present the evolution of living beings, i.e. the causes of evolution; the other concernerl with the relationship of animals, or groups of animals, rather than with the causes which have brought about such relationship, i.e. the sequence of evolution.

It is the latter problem with which this book deals, and, indeed, not with the whole question at all, but only with that part of it which concerns the origin of vertebrates.

This problem of the sequence of evolution is of a twofold character : first, the finding out of the steps by which the higher forms in any one groul of animals have been evolved from the lower; and secondly, the evolution of the group itself from a lower group.

In any classification of the animal kingdom, it is clear that large groups of animals exist which have so many common characteristics as to necessitate their being placed in one larger group or kingdon; 
thus zoologists are able to speak definitely of the Vertebrata, Arthropoda, Annelida, Eehinodermata, Porifera, Cœlenterata, Mollusea, etc. In each of these groups affinities can be traced between the members, so that it is possible to speak of the progress from lower to higher members of the group, and it is conceivable, given time to work out the details, that the natural relationships between the members of the whole group will nltimately be discovered.

Thus no one can doubt that a sequence of the kind has taken place in the Vertebrata as we trace the progress from the lowest fishes to man, and already the discoveries of palæontology and anatomy give us a distinet elue to the sequence from fish to amphibian, from amphibian to reptile, from reptile to mammal on the one hand, and to bird on the other. That the different members of the vertebrate group are related to each other in orderly sequence is no longer a matter of doubt; the connected problems are matters of detail, the solution of which is eertain sooner or later. The same may be said of the nembers of any of the other great natural groups, such as the Arthropoda, the Annelida, the Echinodermata, ete.

It is different, however, when an attempt is made to connect two of the main divisions themselves. It is true enough that there is every reason to believe that the arthropod group has been evolved from the segmented annelid, and so the whole of the segmented invertebrates may be looked on as forming one big division, the Appendieulata, all the members of which will some day be arranged in orderly sequence, but the same feeling of certainty does not exist in other cases.

In the very case of the origin of the Appendiculata we are confronted with one of the large problems of evolution-the origin of segmented from non-segmented animals-the solution of which is not yet known.

\section{Theories of the Origin of Vertebrates.}

The other large problem, perhaps the most important of all, is the question of the relationship of the great kingdom of the Tertebrata: from what invertebrate group did the vertebrate arise?

The great difficulty which presents itself in attempting a solution of this question is not so much, as used to be thought, the diffienlty of deriving a group of animals possessing an internal bony and 
cartilaginous skeleton from a group possessing an external skeleton of a calcareous or chitinous nature, but rather the difficulty caused by the fundamental difference of arrangement of the important internal organs, especially the relative positions of the central nervous system and the digestive tube.

Now, if we take a broad and comprehensive view of the invertebrate kingdom, without arguing out each separate case, we find that

A

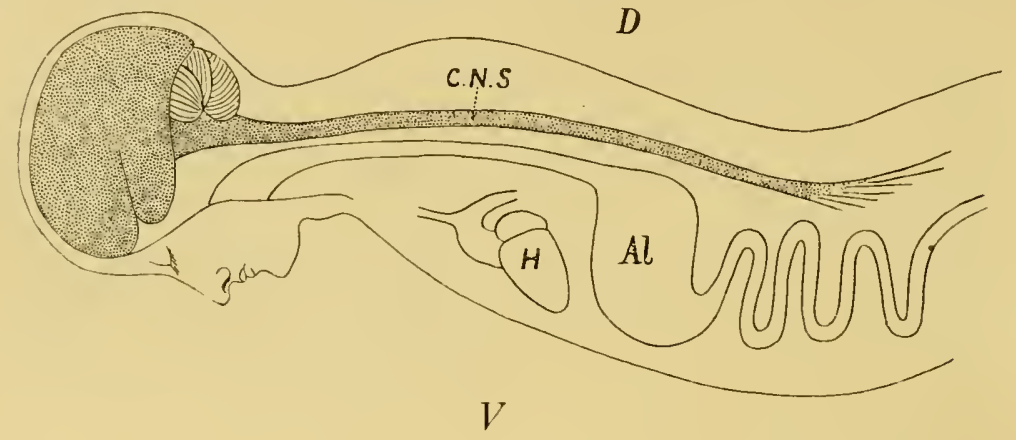

$D$

B

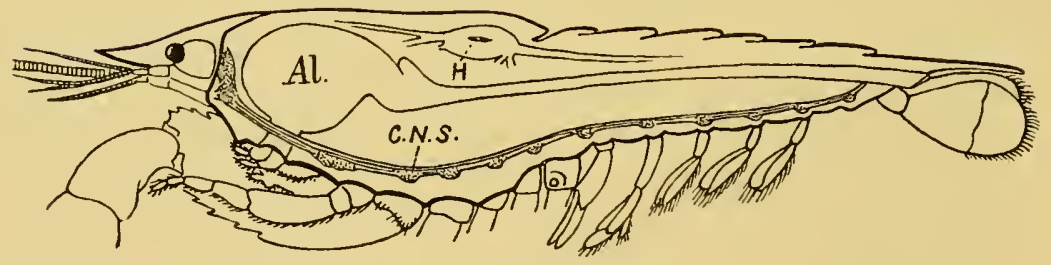

V

Fig. 1.-Arrangenent of Organs in the Vertebrate (A) and arthropod (B). $A l$, gut; $H$, heart; C.N.S., central nervous system; $\mathrm{V}$, ventral side; $\mathrm{N}$, dorsal side.

it bears strongly the stamp of a general plan of evolution derived from a colenterate animal, whose central nervous system formed a ring surrounding the mouth. Then when the radial symmetry was given up, and an elongated, bilateral, segmented form evolved, the central nervous system also became elongated and segmented, but, owing to its derivation from an oral ring, it still surrounded the mouth-tube, or cesophagus, and thus in its highest forms is divided into supra-œsophageal and infra-œsophageal nervous masses. These latter 
nervous masses are of necessity ventral to the digestive tube, because the mouth of the cœlenterate is on the ventral side. The striking characteristic, then, of the invertebrate kingdom is the situation of a large portion of the central nervous system ventrally to the alimentary canal and the piercing of the nervous system by a tube-the cesophagus-leading from the mouth to the alimentary canal. The equally striking characteristic of the vertebrate is the dorsal position of the central nervous system and the ventral position of the alimentary canal combined with the absence of any piercing of the central nervous system by the cesophagus.

So fundamentally different is the arrangement of the important organs in the two groups that it might well give rise to a fceling of despair of ever hoping to solve the problem of the Origin of Tertebrates; and, to my mind, this is the prevalent feeling among morphologists at the present time. Two attempts at solution have been made. The one is associated with the name of Geoffrey St. Hilaire, and is based on the supposition that the vertebrate has arisen from the invertebrate by turning over on its back, swimming in this position, and so gradually converting an originally dorsal surface into a ventral one, and vice versî́; at the same time, a new mouth is supposed to have been formed on the new ventral side, which opened directly into the alimentary canal, while the old mouth, which had now become dorsal, was obliterated.

The other attempt at solution is of much more recent clate, and is especially associated with the name of Bateson. It supposes that bilaterally symmetrical, elongated, segmented animals were formed from the very first in two distinct ways. In the one case the digestive tube pierced the central nervous system, and was situated dorsally to its main mass. In the other case the segmented central nervous system was situated from the first dorsally to the alimentary canal, and was not pierced by it. In the first case the highest result of evolution led to the Arthropoda; in the second case to the Vertebrata.

Neither of these views is based on evidence so strong as to cause miversal acceptance. The great difficulty in the way of accepting the second alternative is the complete absence of any evidence, either among animals living on the earth at the present day or among those known to have existed in the past, of any such chain of internediatc animal forms as must, on this hypothesis, have existed in order to link together the lower forms of life with the vertebrates. 
It has been supposed that the Tunicata and the Enteropneusta (Balanoglossus) (Fig. ') are members of this missing chain, and that

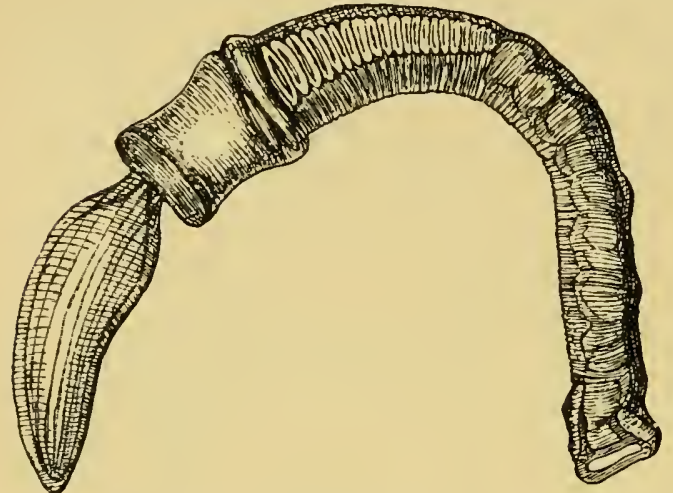

Fig. 2.-Larvat Batanoglossus (from the Royal Natural History). in Amphioxus the vertebrate approaches in organization to these low invertebrate forms. The tunicates, indeed, are looked upon as degenerate members of an early vertebrate stock, which may give help in picturing the nature of the vertebrate ancestor but are not themselves in the direct line of descent. Balanoglossus is supposed to have arisen from the Echinodermata, or at all events to have affinities with them, so that to fill up the enormous gap between the Echinorlermata and the Vertebrata on this theory there is absolutely nothing living on the earth except Balanoglossus, Phabdopleura, and Cephalodiscus. The characteristics of the vertebrate upon which this second theory is based are the notochord, the respiratory character of the anterior part of the alimentary canal, and the tubular nature of the central nervous system; it is claimed that in Balanoglossus the beginnings of a notochord and a tubular central nervous system are to be found, while the respiratory portion of the gut is closely comparalle to that of Amphioxus.

The strength of the first theory is essentially based on the comparjson of the vertebrate central nervous system with that of the segmented invertebrate, annelid or arthropod. In the latter the central nervous system is composer of-

1. The supra-øsophageal ganglia, which give origin to the nerves of the eyes and antennules, i.e. to the optic and olfactory nerves, for the first pair of antennic are olfactory in function. These are connected with the infra-œsophageal ganglia by the œsophageal commissures which encircle the osophagus.

2. The infra-esophageal ganglia and the two chains of ventral ganglia, which are segmentally-arranged sets of ganglia. Of these, 
each pair gives rise to the nerves of its own segment, and these nerves are not nerves of special sense as are the supra-cesophageal nerves, but motor and sensory to the segment; nerves by the agency of which food is taken in and masticated, respiration is effected, and the animal moves from place to place.

In the vertebrate the central nervous system consists of-

1. The brain proper, from which arise only the olfactory and optic nerves.
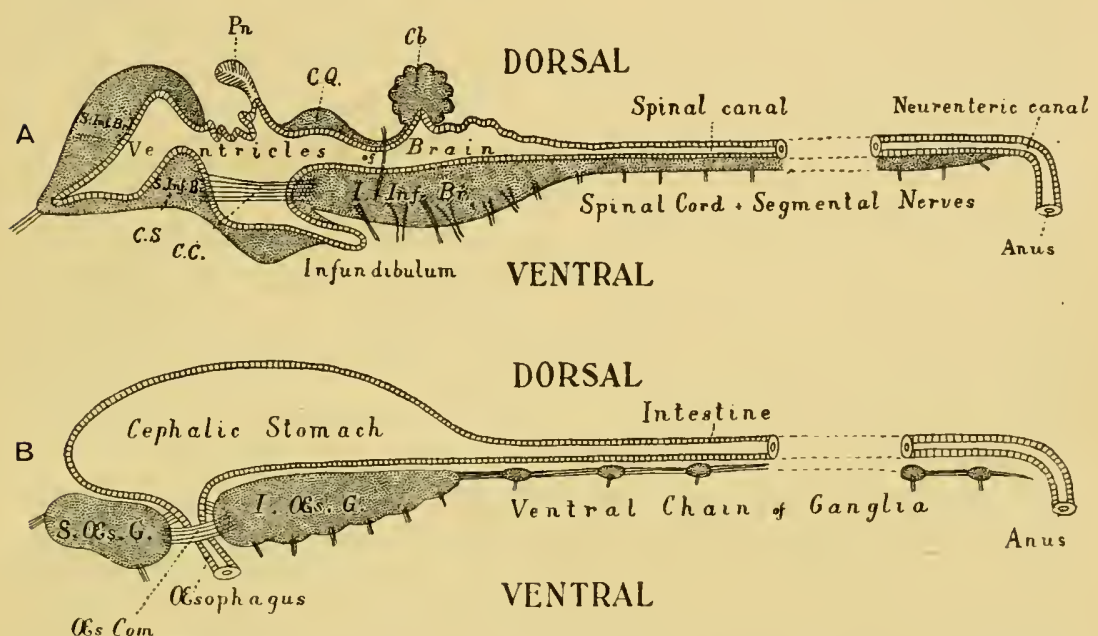

Fig. 3.- Tertebrate Cextral Neryous System compared with the Central Nervous System and Alimentary Canal of the Arthropod.

A. Vertebrate central nervous system. S. Inf. $B r$., supra-infundibular brain; I. Inf. Br., infra-infundibular brain and eranial segmental nerves; C.Q., corpora quadrigemina; $\mathrm{Cb}$., cerebellum; C.C., crura cerebri; C.S., corpus striatum; $P_{n \text {.s }}$ pineal gland.

B. Invertebrate central nervous system. S. LEs. G., supra-œsophageal ganglia; I. Ess. G., infra-cesophageal ganglia; CEs. Com., wesophageal commissures.

2. The region of the mid-brain, medulla oblongata, and spinal cord; from these arises a series of nerves segmentally arranged, which, as in the invertelrate, gives origin to the nerves governing mastication, respiration, and locomotion.

Further, the vertebrate central nervous system possesses the peculiarity, found nowhere else, of being tubular, and the tube is of a striking character. In the spinal region it is a small, simple canal of uniform calibre, which at the front end dilates to form the ventricles of the region of the brain. From that part of this dilated 
portion, known as the third ventricle, a narrow tulue passes to the ventral surface of the brain. This tube is called the infundibulum, and, extraordinary to relate, lies just anteriorly to the exits of the third cranial or oculomotor nerves; in other words, it marks the termination of the series of spinal and cranial seginental nerves. Further, on each side of this infundibular tube are lying the two thick masses of the crurce cerclri, the strands of fibres which counect the higher brain-region proper with the lower region of the medulla oblongata and spinal cord. Not only, then, are the nerve-masses in the two systems exactly comparable, but in the very place where the cesophageal tube is found in the invertebrate, the infundibular tube exists in the vertebrate, so that if the words infundibular and csophageal are taken to be interchangable, then in every respect the two central nervous systems are comparable. The brain proper of the vertebrate, with its olfactory and optic nerves, becomes the direct descendant of the supra-cesophageal ganglia; the crura cerebri become the asophageal commissures, and the cranial and spinal segmental nerves are respectively the nerves belonging to the infraosophageal and ventral chain of ganglia.

This overwhelmingly strong evidence has always pointed directly to the origin of the vertebrate from some form among the segmented group of invertebrates, annelid or arthropod, in which the original cesophagus had become converted into the infundibulum, and a new mouth formed. So far, the position of this school of anatomists was extremely sound, for it is impossible to dispute the facts on which it is based. Still, however, the fact remained that the gut of the vertebrate lies ventrally to the nervous system, while that of the invertebrate lies dorsally; consequently, since the infundibulum was in the position of the invertebrate esophagus, it must originally have entered into the gut, and since the vertebrate gut was lying ventrally to it, it could only have opened into that gut in the invertebrate stage by the shifting of dorsal and ventral surfaces. From this argument it followed that the remains of the original mouth into which the infundibulum, i.e. cesophagus, opened were to be sought for on the dorsal side of the vertelnate brain. Here in all vertebrates there are two spots where the roof of the brain is very thin, the one in the region of the pineal body, and the other constituting the roof of the fourth ventricle. Both of these places have had their advocates as the position of the old mouth, the former being upheld by Owen, the latter by Dohrn. 
The discovery that the pineal body was originally an eye, or, rather, a pair of eyes, has perhaps more than anything else proved the impossibility of accepting this reversal of surfaces as an explanation of the genesis of the vertebrate from the annelid group. For whereas a pair of eyes elose to the mid-dorsal line is not only likely enough, but is actually found to exist among large numbers of arthropods, both living and extinet, a pair of eyes situated close to the mid-ventral line near the mouth is not only unheard of in nature, lut so improbable as to render impossible the theory which necessitates such a position.

Yet this very discovery gives the strongest possible additional support to the elose identity in the plan of the central nervous system of vertebrate and appendiculate.

A truly paradoxical situation! The very discovery which may almost be said to prove the truth of the hypothesis, is the very one which has done most to diseredit it, because in the miuds of its authors the only possible solution of the transition from the one group to the other was by means of the reversal of surfaces.

Still, as already said, even if the theory advanced to explain the facts be discredited, the facts remain the same; and still to this day an explanation is required as to why such extraordinary resemblanees should exist between the two nervous systems, unless there is a genetic connection between the two groups of animals. An explanation may still be found, and must be diligently sought for, which shall take into aecount the strong evidence of this relationship between the two groups, and yet not neeessitate any reversal of surfaces. It is the oljject of this book to eonsider the possibility of such an explanation.

What are the lines of investigation most likely to meet with success? Is it possible to lay down any laws of evolution? It is instruetive to eonsider the nature of the investigations which have led to the two theories just mentioned, for the fundamental starting-point is remarkably different in the two eases. The one theory is based upon the study of the vertebrate itself, and especially of its central nervous system, and its supporters and mpholders have been and are essentially anatomists, whose ehief study is that of vertebrate and human anatomy. The other theory is based upon the study of the invertebrate, and consists especially of an attempt to find in the invertebrate some structure resembling a notochord, such 
organ being considered by them as the great characteristic of the vertebrate; indeed, so much is this the case, that a large number of zoologists speak now of Chordata rather than of Vertel,rata, and in order to emphasize their position follow Bateson, and speak of the Tunicata as Uro-chordata, of Amphioxus as Cephalo-chordata, of the Enteropnensta as Hemi-chordata, and even of Actinotrocha (to use Masterman's term), as Diplo-chordata.

The upholders of this theory lay no stress on the nature of the central nervous system in vertebrates, they are essentially zoologists who have made a special study of the invertebrate rather than of the vertebrate.

Of these two methods of investigating the problem, it must be conceded that the former is more likely to give reliable results. By putting the vertebrate to the question in every possible way, by studying its anatomy and physiology, both gross and minute, by inquiring into its past history, we ean reasonally hope to get a clue to its origin, but by no amount of investigation can we tell with any certainty what will be its future fate; we can only guess and prophesy in an uncertain and hesitating manner. So it must be with any theory of the origin of vertebrates, based on the study of one or other invertebrate group. Such theory must partake rather of the nature of prophecy than of deduction, and ean only be placed on a firm basis when it so happens that the investigation of the vertebrate points irresistibly to its origin from the same group; in fact, "never prophesy unless you know."

The first prineiple, then, I would lay down is this: In order to find out the origin of vertebrates, inquire, in the first place, of the vertebrate itself.

\section{Importance of the Central Nervous Systen.}

Does the history of evolution pick out any particular organ or group of organs as more necessary than another for upward progress? If so, it is upon that organ or group of organs that special stress must be laid.

Since Darwin wrote the "Origin of Species," and laid down that the law of the 'survival of the fittest' is the factor upon which evolution depends, it has gradually dawned upon the scientifie mind that 'the fittest' may be produced in two diametrically opposite ways: 
either by progress upwards to a superior form, or by degeneration to a lower type of animal. The principle of degeneration as a factor in the formation of groups of animals, which are thereby enabled to survive, is nowadays universally admitted. The most striking example is to be found in the widely distributed group of Tunicata, which live, in numbers of instances, a sedentary life upon the rocks, have the appearance of very low forms of animal life, propagate by budding, have lost all the characteristics of higher forms, and yet are considered to be derived from an original vertebrate stock. Such degenerate forms remain degenerate, and are never known to regenerate and again to reach the higher stage of evolution from which they arose. Such forms are of considerable interest, but cannot help, except negatively, to decide what factor is especially important for upward progress.

At the head of the animal race at the present day stands man, and in mankind itself some races are recognized as higher than others. Such recognition is given essentially on account of their greater brain-power, and without doubt the great characteristic which puts man at the head is the development of his central nervous system, especially of the region of the brain. Not only is this point most manifest in distinguishing man from the lower animals, but it applies to the latter as well. By the amount of convolution of the brain, the amount of grey matter in the cerebral hemispheres, the enlargement and increasing complexity of the higher parts of the central nervous system, the anthropoid apes are differentiated from the lower forms, and the higher mammals from the lower. In the recent work of Elliot Smith, and of Edinger, most conclusive proof is given that the upward progress in the vertebrate phylum is correlated with the increase of brain-power, and the latter writer shows how steady and remarkable is the increase in substance and in complexity of the brain-region as we pass from the fishes, through the amphibians and reptiles, to the birds and mammals.

The study of the forms which lived on the earth in past ages confirms and emphasizes this conclusion, for it is most striking to see how small is the cranium among the gigantic Dinosaurs; how in the great reptilian age the denizens of the earth were far inferior in brainpower to the lords of creation in after-times.

What applies to the vertebrate phylum applies also to the invertebrate groups. Here also an upward progress is recognized as we 
pass from the sponges to the arthropods-a progress which is manifested, first by the concentration of nervous material to form a central nervous system, and then by the increase in substance and complexity of that nervous system to form a higher and a higher type, until the culmination is reached in the nervous system of the scorpions and spiders. No upward progress is possible with degeneration of the central nervous system, and in all those cases where a group owes its existence to degeneration, the central nervous system takes part in the degeneration.

This law of the paramountimportance of the growth of the central nervous system for all upward progress in the evolntion of animals receives confirmation from the study of the development of individuals, especially in those cases where a large portion of the life of the animal is spent in a larval condition, and then, by a process of transformation, the larva changes into the adult form. Such cases are well known among Arthropoda, the familiar instance being the change from the larval caterpillar to the adult imago. Among Vertebrata, the change from the tadpole to the frog, from the larval form of the lamprey (Ammocates) to the adult form (Petromyzon), are wellknown instances. In all such cases the larva shows signs of having attained a certain stage in evolution, and then a remarkable transformation takes place, with the result that an adult animal emerges, whose organization reaches a higher stage of evolution than that of the larva.

This transformation process is characterized by a very great destruction of the larval tissues and a subsequent formation of new adult tissues. Most extensive is the destruction in the caterpillar and in the larval lamprey. But one organ never shares in this process of histolysis, and that is the central nervous system; amidst the ruins of the larva it remains, leading and directing the process of re-formation. In the Arthropoda, the larval alimentary canal may be entirely destroyed and eaten up by phagocytes, but the central nervous system not only remains intact but increases in size, and by the concentration and cephalization of its infra-œsophageal ganglia forms in the adult a central nervous system of a higher type than that of the larva.

So, too, in the transformation of the lamprey, there is not the slightest trace of any destruction in the central nervous system, but simply a development and increase in nervous material, which 
results in the formation of a brain region more like that of the higher vertebrates than exists in Ammocœetes.

In these cases the development is upward-the adult form is of a higher type than that of the larva. It is, however, possible for the reverse to occur, so that the individual development leads to degeneration, not to a higher type. Instances are seen in the Tunicata, and in various parasitic arthropod forms, such as Lernæa, etc. In these cases, the transformation from the larval to the adult form leads to degradation, and in this degradation the central nervous system is always involved.

It is perhaps a truism to state that upward progress is necessarily accompanied by increased development of the central nervous system ; but it is necessary to lay special stress upon the importance of the central nervous system in all problems of evolution, because there is, in my opinion, a tendency at the present time to ignore this factor to too great an extent.

The law of progress is this-The race is not to the swift, nor to the strong, but to the wise.

This law carries with it the necessary corollary that the immediate ancestor of the vertebrate must have had a central nervous system nearly approaching that of the lowest undegenerated vertebrate. Among all the animals living on the earth at the present time, the highest invertebrate group, the Arthropoda, possesses a central nervous system most closely resembling that of the vertebrate.

The law, then, of the paramount importance of a steady development of the central nervous system for the upward progress of the animal kingdom, points directly to the arthroporl as the most probable ancestor of the vertebrate.

\section{Evolution of Tissues.}

In the whole scheme of evolution we can recognize, not only an upward progress in the organization of the animal as a whole, but also a distinct advance in the structure of the tissues composing an individual, which accompanies that upward progress. Thus it is possible to speak of an evolution of the supporting tissues from the simplest form of connective tissue up to cartilage and thence to bone; of the contractile tissties, from the simplest contractile protoplasm 
to unstriped muscle, and thence to the highest forms of striated muscle; of the nervous connecting strands, from undifferentiated to fine strands, then to thicker, more separated ones, resembling nonmedullated fibres, and finally to well-differentiated separate fibres, each enclosed in a medullated sheath.

In the connective tissue group, bone is confined to the vertebrates, cartilage is found among invertebrates, and the closest resemblance to vertebrate embryonic or parenchymatous cartilage is found in the cartilage of Limulus. Also, as Gegenbaur has pointed out, Limulus, more than any other invertebrate, possesses a fibrous connective tissue resembling that of rertebrates.

In the muscular group, Biedermann, who has made a special study of the physiology of striated muscle, says that among invertebrates the striated muscle of the arthropod group resembles most closely that of the vertebrate.

In the nervous group the resemblance between the nerve-fibres of Limulus and Ammocoetes, both of which are devoid of any marked medullary sheath, is very apparent, and Retzius points out that the only evidence of medullation, so characteristic of the vertebrates, is found in a species of prawn (Palamon). In all these cases the nearest resemblance to the vertebrate tissues is to be found in the arthropod.

\section{The Eridence of Palfontology.}

Perhaps the most importint of all the clues likely to help in the solution of the origin of rertebrates is that afforded by Geology, for although the geological record is admittedly so imperfect that we can never hope by its means alone to link together the animals at present in existence, yet it does undoubtedly point to a sequence in the evolution of animal forms, and gives valuable information as to the nature of such sequence. In different groups of animals there are times when the group can be spoken of as having attained its most flourishing period. During these geological epochs the distribution of the group was universal, the numbers were very great, the number of species was at the maximum, and some of them had attained a maximal size. Such races were at that time dominant, and the struggle for existence was essentially among members of the same group. At the present time the dominant race is man, and the 
struggle for existence is essentially between the members of that race, and not between them and any inferior race.

The effect of such conditions is, as Darwin has pointed out, to cause great variation in that group; in consequence of that variation and that dominance the evolution of the next higher group is brought about from some member of the dominant group. Thus the present age is the outeome of the Tertiary period, a time when giant mammals roamed the earth and left as their successors the mammals of the present day; a time of dominance of quadruped mammals; a time of which the period of maximum development is long past, and we now see how the dominance of the biped mammal, man, is accompanied by the rapid diminution and approaching extermination of the larger mammals. No question can possibly arise as to the immediate ancestor of the biped mammal; he undoubtedly arose from one of the dominant quadrupedal mammals.

Passing along to the next eviclence of the rocks, we find an age of reptiles in the Mesozoic period. Here, again, the number and variety is most striking; here, again, the size is enormous in comparison with that of the present-day members of the group. This was the dominant race at the time when the birds and mammals first appeared on the earth, and anatomists recognize in these extinct reptilian forms $t$ wo types; the one bird-like, the other more mammalian in character. From some members of the former group birds are supposed to have been erolved, and mammals from members of the other group. There is no question of their origin directly from lower fish-like forms; the time of their appearance on the earth, their structure, all point irresistibly to the same conclusion as re have arrived at from the consideration of the origin of the biped from the quadruped mammal, viz. that birds and mammals arose, in consequence of the struggle for existence, from some nembers of the reptilian race which at that time was the dominant one on earth.

Passing down the geological record, we find that when the reptiles first appear in the Carboniferous age there is abundant evidence of the existence of numbers of amphibian forms. At this time the giant Labyrinthodonts flourished. Here among the swamps and marshes of the coal-period the prevalent rertebrate was amphibian in structure. Their variety and number were rery great, and at that period they attained their greatest size. Here, again, from the geological record we draw the same conclusion as before, that the 


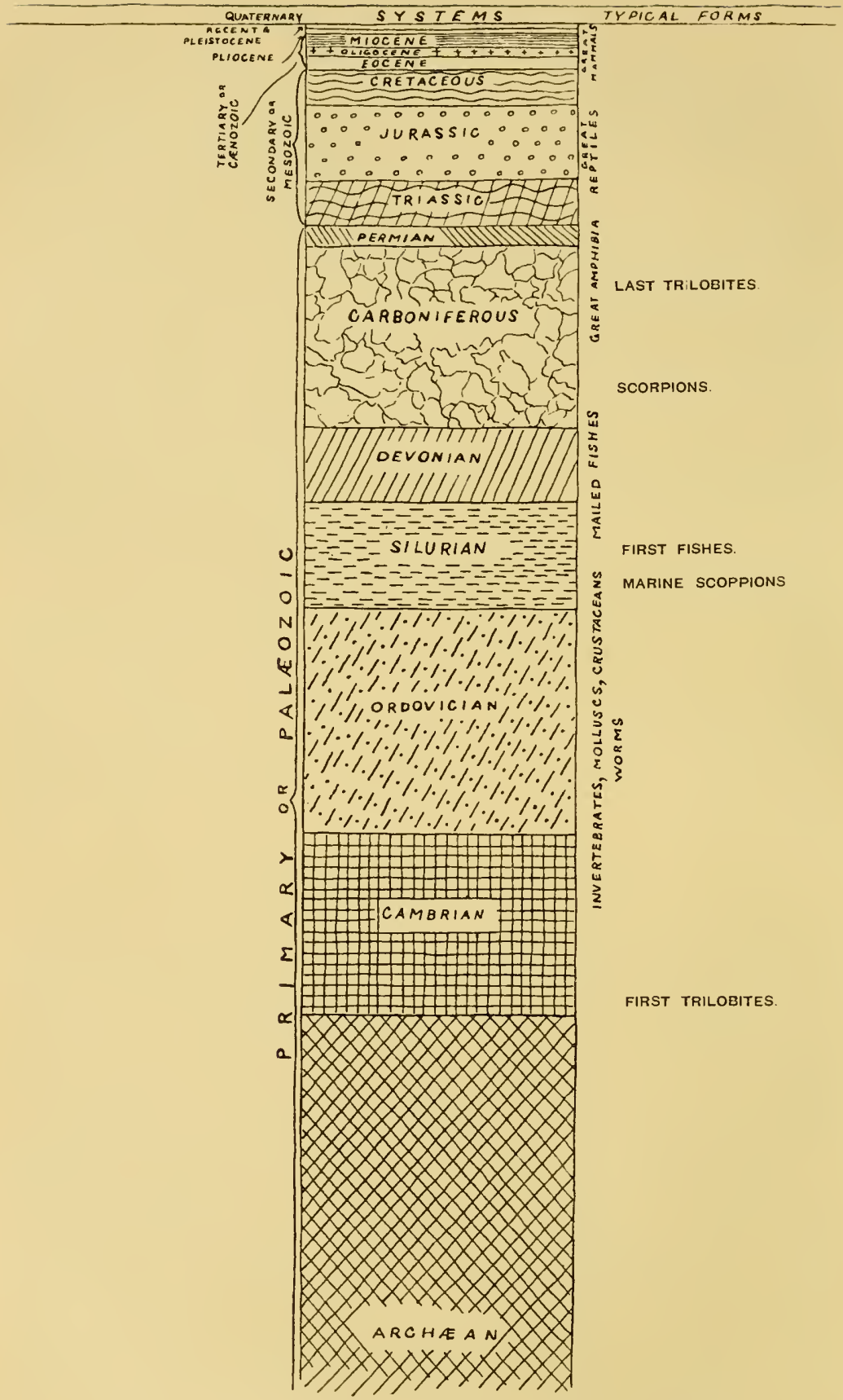

Fig. 4.-Plan of Geological Strata. (From Lankester.) 
reptiles arose from the race which was then predominant on the earth - the Amphibia.

Again, another point of great interest is seen here, and that is that these Labyrinthodonts, as Huxley has pointed out, possess characters which bring them more closely than the amphibians of the present day into connection with the fishes; and further, the fish-like characters they possessed are those of the Ganoids, the Marsipobranchs, the Dipnoans, and the Elasmobranchs, rather than of the Teleosteans.

Now, it is a striking fact that the ancient fishes at the time when the amphibians appeared had not reached the teleostean stage. The ganoids and elasmobranchs swarmed in the waters of the Devonian and Carboniferous times. Dipnoans and marsipobranchs were there, too, in all probability, but teleosteans do not appear until the Mesozoic period. The very kinds of fish, then, which swarmed in the seas at that time, and were the predominant race before the Carboniferous epoch, are those to which the amphibians at their first appearance show the elosest affinity. Here, again, the same law appears; from the predominant race at the time, the next higher race arose, and arose by a most striking modification, which was the consequence of altering the medium in which it lived. By coming out of the water and living on the land, or, rather, being able to live partly on land and partly in the water, by the acquisition of airbreathing respiratory organs or lungs in addition to, and instead of, water-breathing organs or gills, the amphibian not only arose from the fish, but made an entirely new departure in the sequence of progressive forms.

This was a most momentous step in the history of evolutionone fraught with mighty consequences and full of most important suggestions.

From this time onwards the struggle for existence by which upward progress ensued took place on the land, not in the sea, and, as has been pointed out, led to the evolution of reptiles from amphibians, birds and quadrupedal mammals from reptiles, and man from quadrupeds. In the sea the fishes were left to multiply and struggle among themselves, their only opponents being the giant cephalopods, which themselves had been evolved from a continual succession of the Mollusca. For this reason the struggle for existence between the fishes and the higher race evolved from them did not 
take place until some members of that higher race took again to the water, and so competed with the fish-tribe in their own element.

Another most important conclusion to be derived from the uprisiug of the Amphibia is that at that time there was no race of animals living on the land which had a chance against them. No race of land-living animals had been evolved whose organization enabled them to compete with and overcome these intruclers from the sea in the struggle for existence. For this reason that the whole land was their own, and no serious competition could arise from their congeners, the fish, they took possession of it, and increased mightily in size; losing more and more the habit of going into the water, becoming more and more truly terrestrial animals. Henceforth, then, in trying to find out the sequence of evolution, we must leave the land and examine the nature of the animals living in the sea ; the air-breathing anirnals which lived on the land in the Upper Silurian and Devonian times cannot have reached a stage of organization comparable with that of the fishes, seeing how easily the amphibians became dominant.

We arrive, then, at the conclusion that the ancestors of the fishes must have lived in the sea, and applying still the same principles that have held good up to this time, the ancestors of the fishes must have arisen from some member of the race predominant at the time when they first appeared, and also the earliest fishes must have much more closely resembled the ancestral form than those found in later times or at the present day.

What, then, is the record of the rocks at the time of the first appearance of fish-like forms? What kind of fishes were they, and what was the predominant race at the time?

We have now reached the Upper Silurian and Lower Devonian times, and most instructive and suggestive is the revelation of the rocks. Here, when the first vertebrates appeared, the sea was peopled with corals, brachiopods, early forms of cephalopods, and other invertebrates; but, above all, with the great tribe of trilobites (Fig. 6) and their successors. From the trilobites arose, as evidenced by their larval form, the king-crab group, called the Xiphosura (Fig. 5). Closely connected with them, and forming intermediate stages between trilobites and king-crabs, numerons forms have been discovered, known as Belinurus, Prestwichia, Hemiaspis, Bunodes, etc. (Fig. 5 and Fig. 12). From them also arose the most striking group 
of animals which existed at this period-the giant seit-scorpions, or Gigantostraca. This group was closely associated with the kingcrabs, and the two groups together are classified muder the title Merostomata.

The appearance of these sea-scorpions is given in Figs. 7 and 8 , representing Stylonurus, Slimonia, Pterygotus, Eurypterus. They

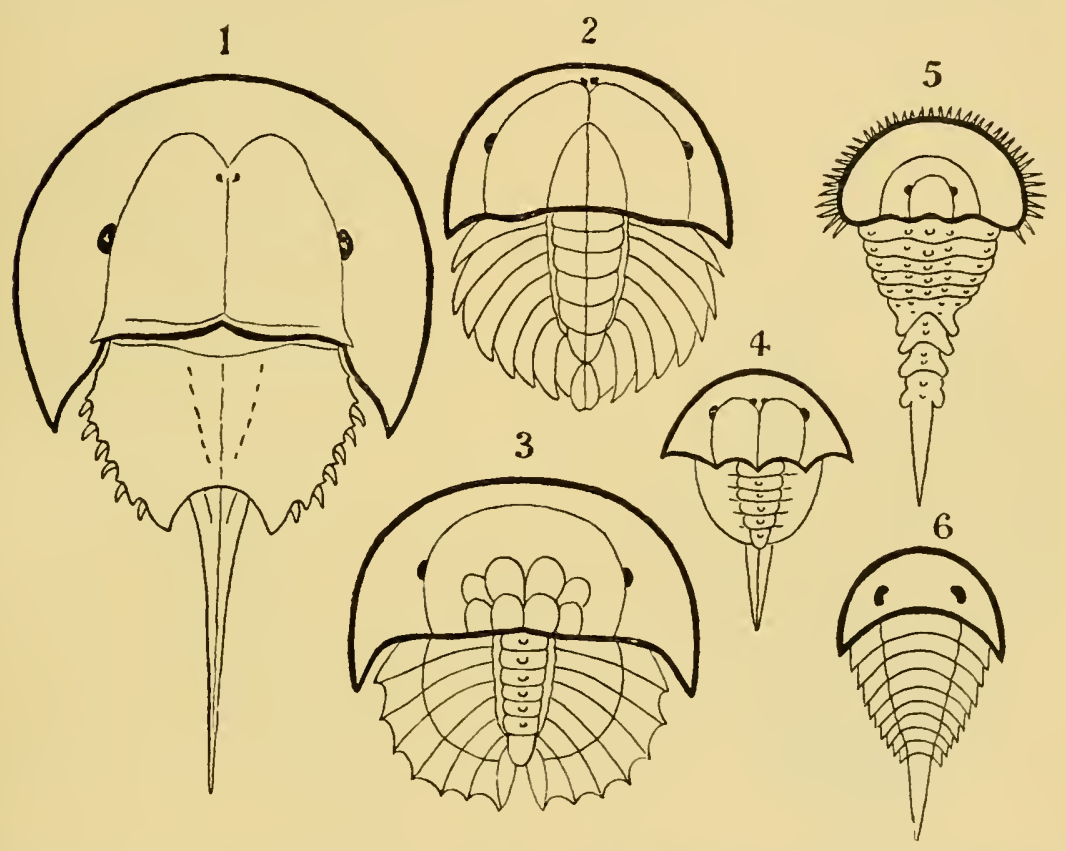

Fig. 5 (from H. WoodWard).-1. Limulus polyphemus (dorsal aspect). 2. Limulus, young, in trilobite stage. 3. Prestwichia rotundata. 4. Prestuichia Birtuelli. 5. Hemiaspis limuloides. 6. Pseudoniseus aculeatus.

must have been in those days the tyrants of the deep, for specimens of Pterygotus liave been found over six feet in length.

At this time, then, by every criterion hitherto used, by the multitude of species, by the size of individual species, which at this period reached the maximum, by their subsequent decay and final extinction, we must conclude that these forms were in their zenith, that the predominant race at this time was to be found in this group of arthropods. Just previonsly, the sea swarmed with trilobites, and right into the period when the Gigantostraca flourished, the tril obites 
are still found of countless forms, of great difference in size. The whole period may be spoken of as the great trilobite age, just as the Tertiary times form the manmalian age, the Mesozoic times the reptilian age, etc. From the trilobites the Gigantostraca and Xiphosura arose, as evidenced by the embryology of Limulus, and, therefore, in the term trilobite age would be included the whole of those peculiar forms which are classified by the names Trilobita,

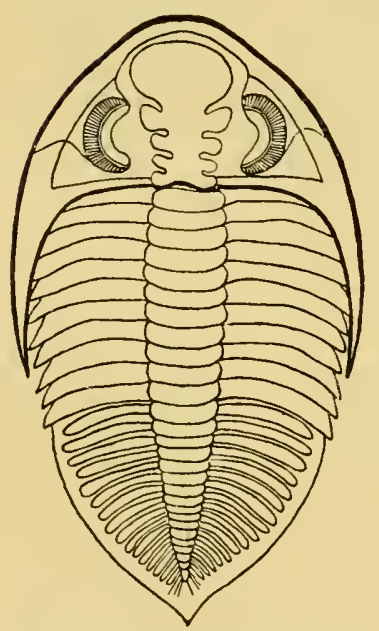

Fig. 6.-A Trilobite (Dalmatites) (after Piстет). Dorsal view.

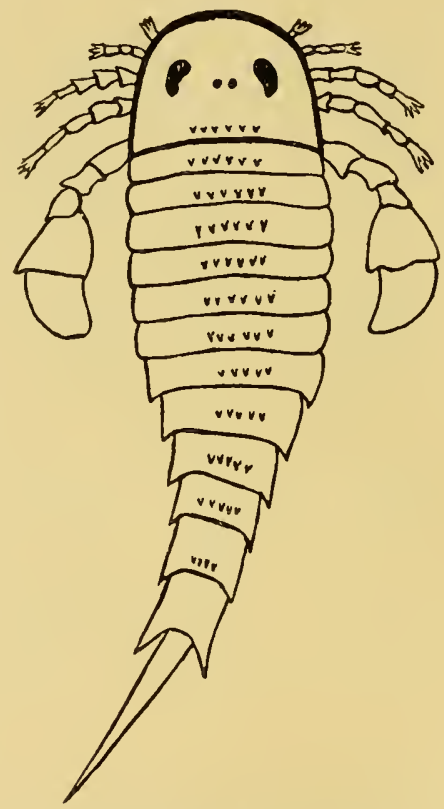

Fig. 7.--Eurypterus remipes (after Nieskowski). Dorsal view.

Gigantostraca, Xiphosura, etc. Of all these the only nember alive at the present time is Limulus, or the King-Crab.

As, however, the term 'trilobite' does not inclucle the members of the king-crab or sea-scorpion groups, it is advisable to use some other term. to represent the whole group. They cannot be called crustaceans or arachnids, for in all probability they gave origin to both; the nearest approach to the T'rilobite stage of development at the present time is to be found perhaps in Branchipus (Fig. 10) and Apus (Fig. 9), just as the nearest approach to the Eurypterid 
THE EVIDENCE OF THE CENTRAL NERVOUS SYSTEM 27

form is Limulus. Crustaceans such as crabs and lobsters are of much later origin, and do not occur in any quantity until the late

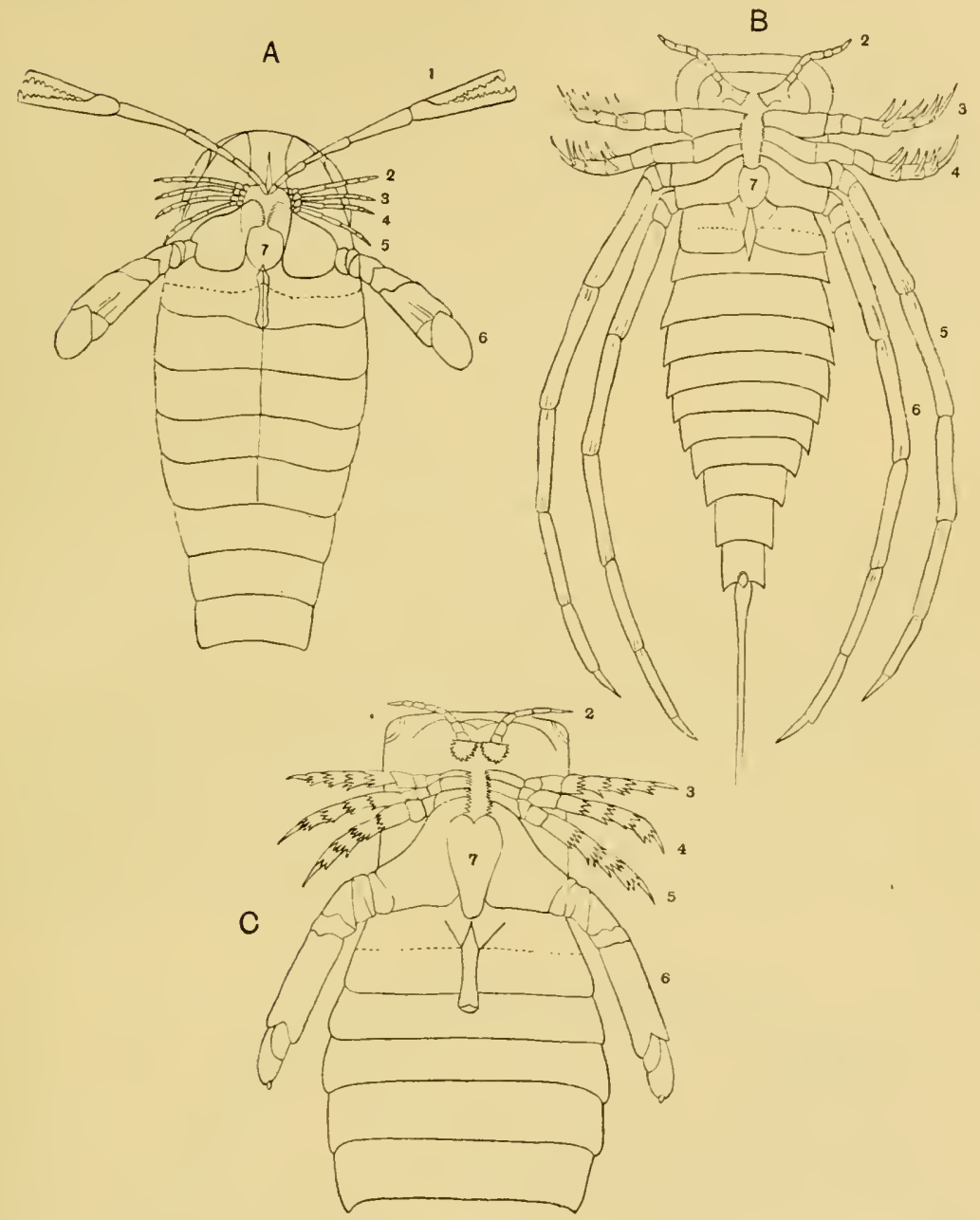

Fig. 8.-A, Pterygotus Osiliensis (from Schмidt). B, Stylonurus Logani from WoOdWARD). C, Slimonia acuminata (from WoOdWARD).

Mesozoic period. The earliest found, a kind of prawn, occurs in the Carboniferous age.

Korschelt and Heider have accordingly suggested the name Palceostraca for this whole group, and Protostraca for the still earlier 
arthropod-like animals which gave origin to the trilobites themselves. This name I shall adopt, and speak, therefore, of the Palcostrace as

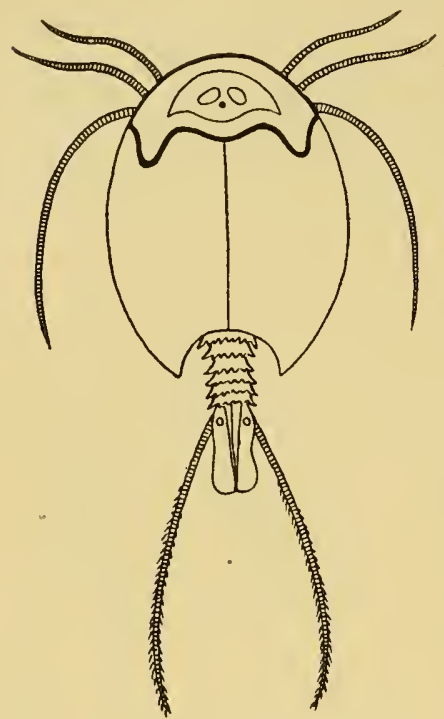

Fig. 9.-Apus (from the Royal Natural History). Dorsal view. the dominant race at the time when vertebrates first appeared.

If, then, there is no break in the law of evolution here, the race which was predominant at the time when the vertebrate first appeared must have been that from which the first fishes arose, and these fishes must have resembled, not the crustacean proper, or the arachnid proper, but a member of the palieostracan group. Moreover, just as the Labyrinthodonts show special affinities to the fishes which were then living, so we should expect that the forms of the earliest fish would resemble the arthropodan type dominant at the time more closely than the fish of a later era.

At first sight it seems too great an absurdity even to imagine the possibility of any genetic connection between a fish and an arthropod, for to the mind's eye there arises immediately the picture of a salmon or a shark and a lobster or a spider. So different in alpear-

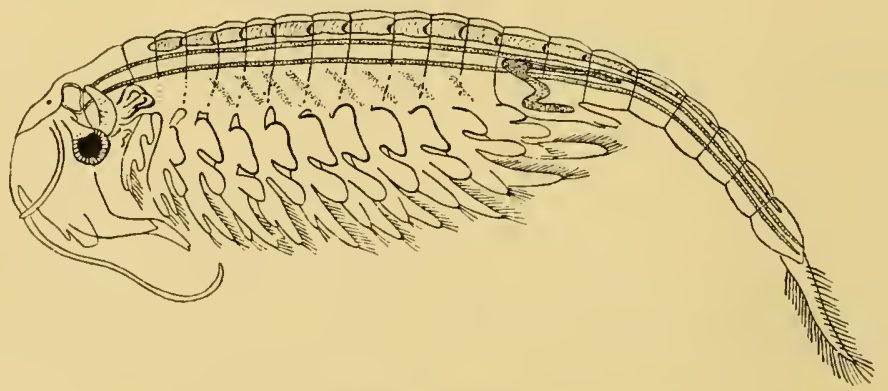

Fig. 10.-Branchipus stagnalis. (From Claus.)

ance are the two groups of animals, so different their methods of locomotion, that it is apparently only an inmate of a lunatic asylum 
who could possibly suggest such a connection. Much more likely is it that a fish-like form should have been developed out of a smooth, wriggling, worm-like animal, and it is therefore to the annelicls that the upholders of the theory of the reversal of surfaces look for the ancestor of the vertebrate.

We must endeavour to dismiss from our imagination such forms as the salmon and shark as representatives of the fish-tribe, and the lobster and spider of the arthropods, and try to picture the kind of animals living in the seas in the early Devonian and Upper Silurian times, and then we find, to our surprise, that instead of the contrast between fishes and arthropods being so striking as to make any comparison between the two seem an absurdity, the difficulty in the last century, and even now, is to decide in many cases whether a fossil is an arthropod or a fish.

I have shown what kind of animal the palæostracan was like. What information is there of the nature of the earliest vertebrate?

The most ancient fishes hitherto discovered have been classified by Lankester and Smith Woodward into the three orders, Heterostraci, Osteostraci, and Antiarcha. Of these the Heterostraci contain the genera Pteraspis and Cyathaspis, and are the very earliest vertebrates yet discorered, being found in the Lower Silurian. The Osteostraci are divided into the Cephalaspidæ, Tremataspidæ, etc., and are found in the Upper Silurian and Devonian beds. The Antiarcha, comprising Pterichthys and Bothriolepis, belong to the Devonian and are not found in Silurian deposits. This, then, is the order of their appearance-Pteraspis, Cephalaspis, and Pterichthys.

In none of these families is there any resemblance to an ordinary fish. In no case is there any sign of vertebre or of jaws. They, like the lampreys, were all agnathostomatous. Strange indeed is their appearance, and it is no wonder that there should have been a difficulty in deciding whether they were fish or arthropod. Their great characteristic is their buckler-plated cephalic shield, especially conspicuous on the dorsal side of the head. Figs. 11, 14, 15, 16, give the dorsal shields of Pteraspis, Anchenaspis, Pterichthys, and Bothriolepis.

In 1904, Drevermann discovered a mass of Pteraspis Dunensis embedded in a single stone, showing the same kind of head-shield as $P$. rostrata, but the rostrum was longer and the spine at the extremity of the head-shield much longer and more conspicuous. 


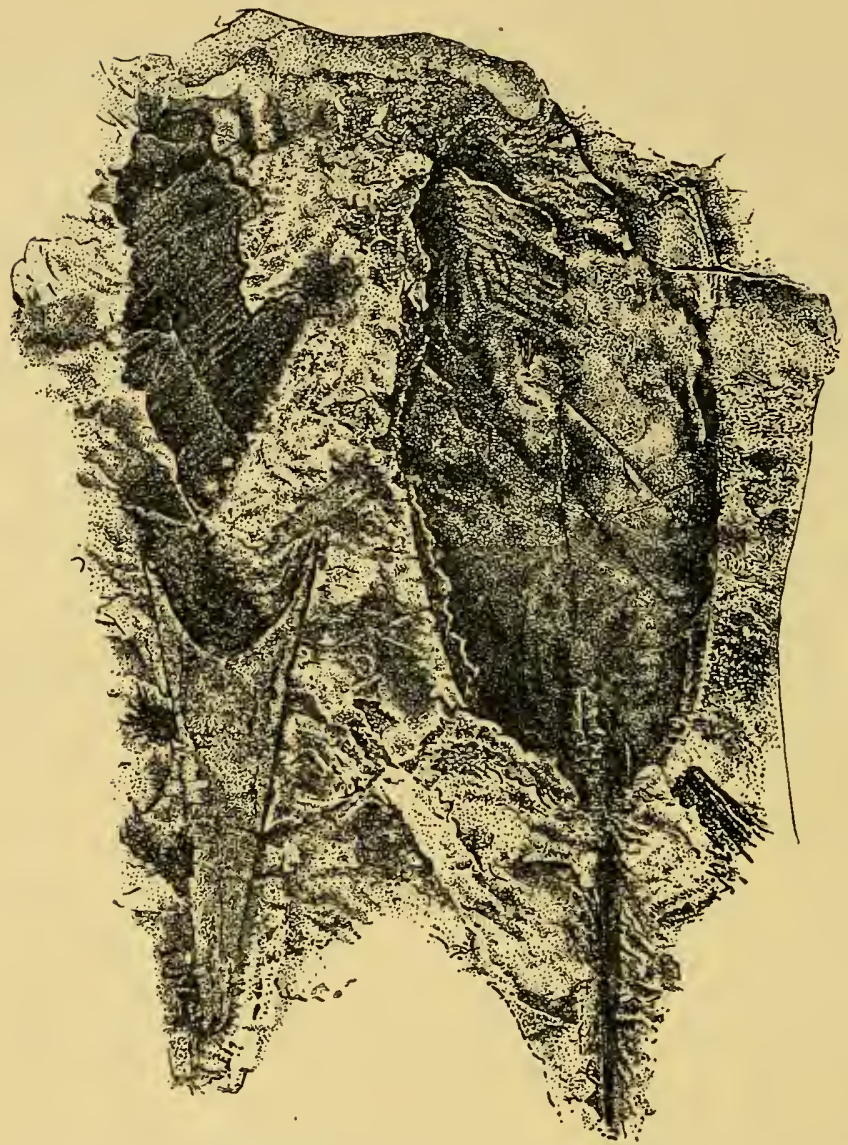

Fig. 11.-Pteraspis dunensis (from Dreverhans). Dorsal view of body and spine on the right side. Head-end, showing long rostrum on the left side.

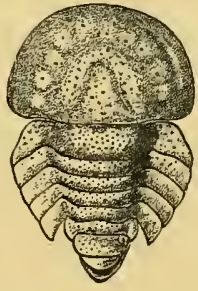

FIG. 12.-Bunodes lunula. (From SCHMIDT.)

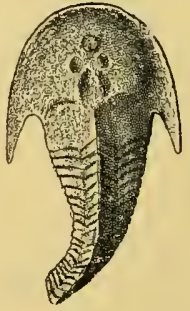

Fig. 13.-Auchenaspis (Thyyestes) verrucosus, natural size. (From WoodWARD.) 
The whole shape of the animal as seen in this photograph recalls the shape of a Hemiaspid rather than of a fish. It is, then, natural enough for the earlier observers to have looked upon such a fossil as related to an arthropod rather than a fish.

In Figs. 12 and 13 I have placed side by side two Silurian fossils which are found in the same geological horizon. They are both life size and possess a general similarity of appearance, yet the one is a

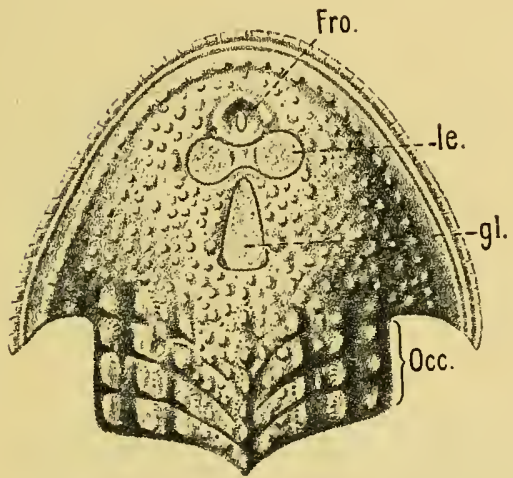

Fig. 14.-Dorsal Heap-Shield of Thy cstes (Auchenaspis) verrucosus. (From Rоном.)

Fro., narial opening; l.e., lateral eyes; $g l$., glabellum or plate over brain; Occ., occipital region.

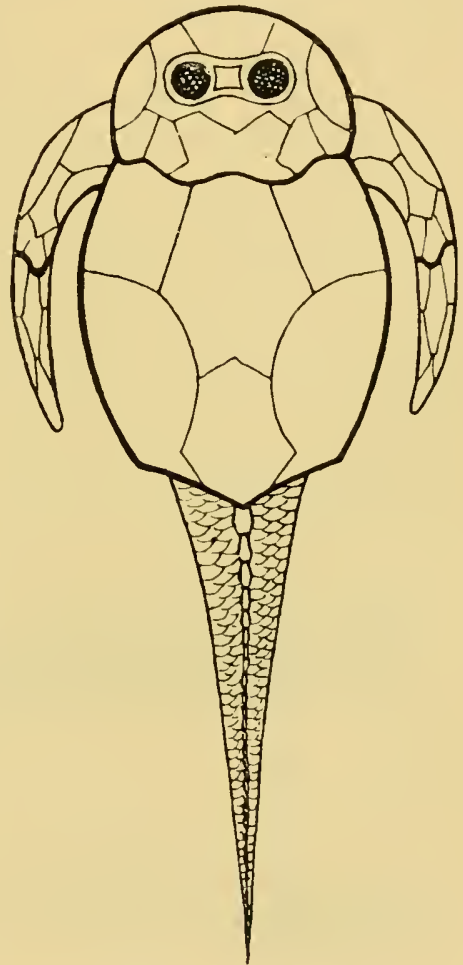

FIG. 15.-Plericthys.

Cephalaspidian fish known by the name of Auchenaspis or Thyestes verrueosa, the other a Palieostracan called Bunodes lunula.

In a later chapter I propose to discuss the peculiarities and the nature of the head-shields of these earliest fishes, in connection with the question of the affinities of the animals which bore them. At this point of my argument I want simply to draw attention to the undoubted fact of the striking similarity in appearance between the 
earliest fishes and members of the Palæostraca, the dominant race of arthropods which swarmed in the sea the time: a similarity which conld never have been suspected by any amount of investigation

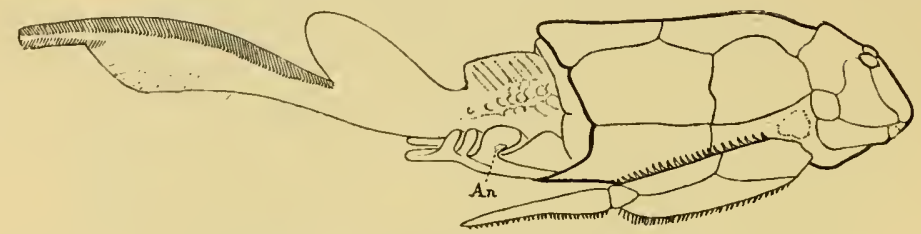

Fig. 16.-Bothriolepis. (After Patten.)

An., position of anus.

among living forms, but is immediately revealed when the ages themselves are questioned.

I have not reproduced any of the attempted restorations of these old forms, as usually given in the text-books, because all such restorations possess a large element of fancy, due to the personal bias of the observer. I have put in Rohon's idea of the general shape of Tremataspis (Fig. 17) in order to draw attention to the lamprey-like appearance of the fish according to his researches ( $c f$. Fig. 18).

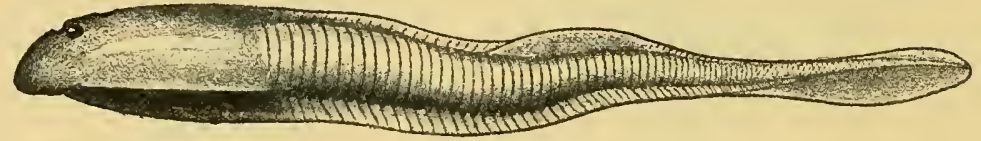

Fig. 17.-Restoration of Tremataspis. (After Rohon, slightly modified.)

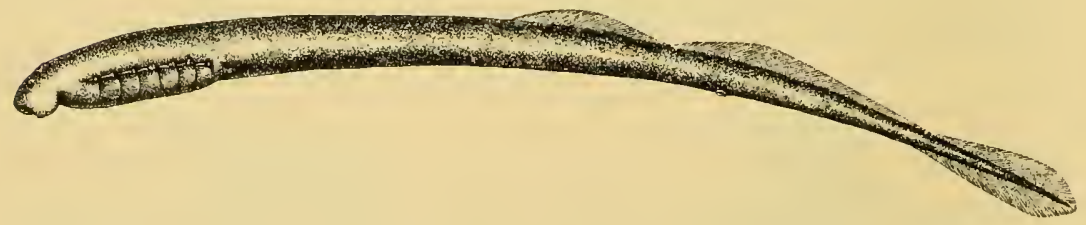

Fig. 18.-Ammoccetes.

The argument, then, from geology, like that from comparative anatomy and from the consideration of the importance of the central nervous system in the upward developinent of the animal race, not only points directly to the arthropod group as the ancestor of the 
vertebrate, but also to a distinet ancient type of arthropod, the Palieostracan, the only living example of which is the King-Crab or Limulus; while the nearest approach to the trilobite group among living arthropods are Branchipus and Apus. It follows, therefore, that for the following up of this clue, Limulus especially must be taken into consideration, while Branchipus and Apus are al ways to be kept in mind.

Aymocetes rather than Ampinoxus is the Best Subject for INVESTIGATION.

It is not, however, Limulus that must be investigated in the first instance, but the vertebrate itself ; for it can never be insisted on too often that in the vertebrate itself its past history will be found, but that Limulus cannot reveal the future of its race. What vertebrate must be chosen for investigation? Reasons have been given why our attention should be fixed upon the king-crab rather than on the lobster on the invertebrate side; what is the most likely animal on the vertebrate side?

From the evidence already given it is manifest that the earliest mammal belonged to the lowest group of mammals; that the birds on their first appearance presented reptilian characteristics, that the earliest reptiles belonged to a low type of reptile, that the amphibians at their first appearance were nearer in type to the fishes than were the later forms. As each of these groups advances in number and power, specialization takes place in it, and the latest developed members become further and further removed in type from the earliest. So also it must have been with the origin of fishes: here too, in the quest for information as to the structure and nature of the first-formed fishes, we must look to the lowest rather than to the highest living meinbers of the group.

The lowest fish-like animal at present living is Amphioxus, and on this ground it is argned that the original vertebrate must have approached in organization to that of Amphioxus; it is upon the comparison between the strueture of Amphioxus and that of Balano. glossus, that the theory of the origin of vertebrates from forms like the latter animal is based. For my own part, I think that in the first instance, at all events, Amphioxus should be put on one side, although of course its structure must always be kept in mind, for the following reasons:- 
Amphioxus, like the tunicates, does not possess the characteristics of other vertebrates. In all rertebrates above these forms the great characteristic is a well-defined brain-region from which arise nerves to organs of special sense, the eyes and nose. In Amphioxus no eyes exist, for the pigmented spot at the anterior extremity of the brain-region is no eye but only a mass of pigment, and the so-called olfactory pit is a very rudimentary and inferior organ of smell. In connection with the nearly complete absence of these two most important sense-organs, the most important part of the central nervous system, the region corresponding to the cerebral hemispheres, is also nearly completely absent.

Now, the history of the evolution of the central nervous system in the animal race points directly to its formation as a concentrated mass of nervous material at the anterior extremity of the body, in consequence of the formation of special olfactory and visual organs at that extremity. As already stated, the concentration of nervous material around the mouth as an oral ring was its beginning. In connection with this there arose special sense-organs for the guidance of the animal to its food which took the form of olfactory and optic organs. With the shifting from the raclial to the elongated form these sense-organs remained at the anterior or mouth-end of the animal, and owing to their immense importance in the struggle for existence, that part of the central nervous system with which they were connected developed more than any other part, became the leader to which the rest of the nervous system was subservient, and from that time onwards the development of the brain-region was ineritably associated with the upward progress of animal life.

To those who believe in Evolution and the Darwinian theory of the survival of the fittest, it is simply inconceivable that a soft-bodied animal living in the mud, blind, with a rudimentary l,rain and rudimentary olfactory organs, such as is postulated when we think of Balanoglossus and Amphioxus, should hold its own and come victorious out of the struggle for existence at a time when the sea was peopled with powerful predaceous scorpion- and crab-like armour-plated animals possessing a well-developed brain, good eyes and olfactory organs, and powerful means of locomotion. Wherever in the scale of animal development Amphioxus may ultimately be placed, it cannot be looked upon as the type of the earliest formed fishes such as appeared in Silurian times. 
The next lowest group of living fishes is the Marsipobranchii which include the lampreys and hag-fishes. To these naturally we must turn for a clue as to the organization of the earliest fish, for here we find all the characteristics of the vertebrates represented: a well-formed brain-region, well-developed eyes and nose, cranial nerves directly comparable with those of other vertebrates, and even the commencement of vertebrie.

Among these forms the lamprey is by far the best for investigation, not only because it is easily obtainable in large quantities, but especially because it passes a large portion of its existence in a larval condition, from which it emerges into the adult state by a wonderful process of transformation, comparable in extent with the transformation of the larval caterpillar into the adult imago. So long does the lamprey live in this free larval condition, and so different is it in the adult stage, that the older anatomists considered that the two states were realiy different species, and gave the name of $\mathrm{Am}$ moecetes branchialis to the larval stage, while the adult form was called Petromyzon planeri, or Petromyzon furiatilis.

This long-continued free-living existence in the larval or Ammocctes stage makes the lamprey, more than any other type of lowly organized fish, invaluable for the present investigation, for throughout the animal kingdom it is recognized that the larval form approaches nearer to the ancestral type than the adult form, whether the latter is progressive or degenerate. Not only are the tissues formed during the stages which are passed through in a free-living larval form, serviceable tissues comparable to those of adult life, but also these stages proceed at so much slower a rate than do those in the embryo in utero or in the egg, as to make the larval form much more suitable than the embryo for the investigation of ancestral problems. It is true enough that the free life of the larva may bring about special adaptations which are not of an ancestral character, as may also occur during the life of the adult; but the evidence is very strong that although some of the peculiarities of the larva may be due to such cœnogenetic factors, yet on the whole many of them are due to ancestral characters, which disappear when transformation takes place, and are not found in the adult.

Thus if it be supposed that the amphibian arose from the fish, the tadpole presents more resemblance to the fish than the frog. If 
it be supposed that the arthropod arose from the segmented worm, the caterpillar bears out the suggestion better than the adult imago. If it be supposed that the tunicate arose from a stock allied to the vertehrate, it is because of the peculiarities of the larva that such a supposition is entertained. So, too, if it be supposed that the fish arose from a member of the arthropod group, the larval form of the fish is most likely to give decisive information on the point.

For all these reasons the lowest form of fish to be investigated, in the hopes of finding ont the nature of the earliest formed fish, is not Amphioxus, but Ammocotes, the larval form of the lamprey-a form which, as I hope to satisfy my reader after perusal of subsequent pages, more nearly resembles the ancient Cephalaspidian fishes than any other living vertebrate.

\section{Comparison of Central Nervous Systems of Vertebrate axd}

Arthropod without Reversal of Surfaces.

So far different lines of investigation all point to the origin of the vertebrate from arthropods, the group of arthropods in question being now extinct, the nearest living representative being Limulus; also to the fact that of the two theories of the origin of vertebrates, that one which is based on the resemblance between the central nervous systems of the Vertebrata and the Appendiculata (Arthropoda and Annelida) is more in accordance with this evidence than the other, which is based mainly on the supposed possession of a notochord among certain animals.

How is it, then, that this theory has been discredited and lost ground? Simply, I imagine, becanse it was thonght to necessitate the turning over of the animal. Let us, then, again look at the nervons system of the vertebrate, and see whether there is any such necessity.

As previously mentioned, the comparison of the two central nervous systems showed such close resemblances as to force those anatomists who supported this theory to the conclusion that the infundibular tube was in the position of the original œsophagus; they therefore looked for the remains of a mouth opening in the dorsal roof of the brain, but did not attempt to explain the extraordinary fact that the infundibular tube is only a ventral offshoot from the tube of the central nervous system. Yet this latter tube 
is one, if not the most striking, of the peculiarities which distinguish the vertebrate; a tubular central nerrous system such as that of the vertebrate is totally unlike any other nervous system, and the very fact that the two nerrous systems of the vertebrate and arthropod are so similar in their nervous arrangements, makes it still more extraordinary that the nervous system should be grouped round a tube in the one case and not in the other.

Now, in the arthropod the oesophagus leads directly into the stomach, which is situated in the head-region, and from this a straight intestine passes directly along the length of the body to the anus, where it terminates. The relations of mouth, oesophagus, alimentary canal, and nervous system in these animals are represented in the diagram (Fig. 3).

Any tube, therefore, such as that of the infundibulum, which would represent the œesophagus of such an animal, must have opened into the montl on the ventral side, and into the stomach on the clorsal side, and the lining epithelium of such an cesophagus must have been continuous with that of the stomach, and so of the whole intestinal tract.

Supposing, then, the animal is not turned over, but that the dorsal side still remains dorsal and rentral ventral, then the original mouthopening of the cesophagus must be looked for on the ventral surface of the vertebrate brain in the region of the pituitary body or hypophysis, and on the dorsal side the tube representing the cesophagus must be continuous with a large cephalically dilated tulse, which ought to pass into a small canal, to run along the length of the bocky and terminate in the anus.

This is exactly what is found in the vertebrate, for the infundibular tube passes into the third ventricle of the brain, which forms, with the other ventricles of the brain, the large dilated cephalic portion of the so-called nerve tube, and at the junction of the medulla oblongata and spinal cord, this dilated anterior part passes into the small, straight, central canal of the spinal cord, which in the embryo terminates in the anus by way of the neurenteric canal. If the animal is regarded as not having been turned over, then the conclusion that the infundibulum was the original œsophagus leads immediately to the further conclusion that the ventricles of the vertebrate brain represent the original cephalic stomach, and the central canal of the spinal cord the straight intestine of the arthropod ancestor. 
Fur the first time a logical, straightforward explanation is thus given of the peculiarities of the tube of the central nervous system, with its extraordinary termination in the anus in the embryo, its smallness in the spinal cord, its largeness in the brain region, and its offshoot to the ventral side of the brain as the infundibular channel. It is so clear that, if the infundibular tube be looked on as the old cesophagus, then its lining epithelium is the lining of that osophagus ; and the fact that this lining epithelium is continuous with that of the third ventricle, and so with the lining of the whole nerve-tube, must he taken into account and not entirely ignored as has hitherto been the case. If, then, we look at the central nervous system of the vertelurate in the light of the central nervous system of the arthropod without turning the animal over, we are led immediately to the conclusion that what has hitherto been called the vertebrate nervous system is in reality composed of two parts, viz. a nervous part comparable in all respects with that of the arthropod ancestor, which has grown over and included into itself, to a greater or less extent, a tubular part comparable in all respects with the alimentary canal of the aforesaid ancestor. If this conclusion is correct, it is entirely wrong to speak of the rertebrate central nervous system as being tubular, for the tube does not belong to the nervous system, but was originally a simple epithelial tube, such as eharacterizes the wophagus, cephalic stomach, and straight intestine of the arthropod.

Here, then, is the crux of the position--either the so-called nervous tube of the vertel,rate is composed of two separate factors, consisting of a true non-tubular nervous system and a non-nervous epithelial tube, these two elements having become closely connected together; or it is composed of one factor, an epithelial tube which constitutes the nervous system, its elements being all nervous elements.

If this latter hypothesis be accepted, then it is necessary to explain why parts of that tube, such as the roof of the fourth ventricle, the choroid plexuses of the various ventricles, which are parts of the original roof inserted into the ventricles, are not composed of nervous inaterial, but form simple single-layered ejithelial sheets, which by no possibility ean be included among functional nervous structures. The upholders of this hypothesis can only explain the nature of these thin epithelial parts of the nervous tube in one of two ways; either the tube was originally formed of nerrous 
material throughout, and for some reason parts of it have lost their nervous function and thimned down; or else these thin epithelial parts are on their way to become nervous material, are still in an embryonic condition, and are of the nature of epiblast-epithelium, from which the central nervous system originally arose.

The first explanation is said to be supported by embryology, for at first the nerve-tube is formed in a uniform manner, and then later, parts of the roof appear to thin out and so form the thin epithelial parts. If this were the right explanation, then it ought to be found that in the lowest vertelorates there is greater evidence of a uniformly nervous tube than in the higher member's of the group: while conversely, if, on the contrary, as we descend the vertebrate phylum, it is found that more and more of the tube presents the appearance of a single layer of epithelium, and the nervous material is limited more and more to certain parts of that tube, then the evidence is strong that the tubular character of the central nervous system is not dne to an original nervous tube, but to a non-nervous epithelial tube with which the original nervous system has become closely connected.

The comparison of the brain region of the different groups of vertebrates (Fig. 19) is most instructive, for it demonstrates in the most conclusive manner how the roof of the nervous tube in that region loses more and more its nervous character, and takes on the appearance of a simple epithelial tube, as we descend lower and lower; until at last, in the brain of Ammoccetes, as represented in the tigures, the whole of the brain-roof, from the region of the pineal eye to the commencement of the spinal cord, is eomposed of fold upon fold of a thin epithelial membrane forming an epithelial bag, which is constricted in only one place, where the fourth cranial nerve crosses over it.

Further, the brain of Ammocotes (Fig. 20) shows clearly not only that it is composed of two parts, an epithelial tube and a nerrous system, but also that the nerve-masses are arranged in the same relative position with respect to this tube as are the nerve-masses in the invertelorate with respect to the cephalic stomach and oesophagus. This evidence is so striking, so conclusive, that it is impossible to resist the conclusion that the tube did not originate as part of the central nervous system, but was originally inclependent of the centrai nervous system, and has been invaded by it. 
MAMMALIA.

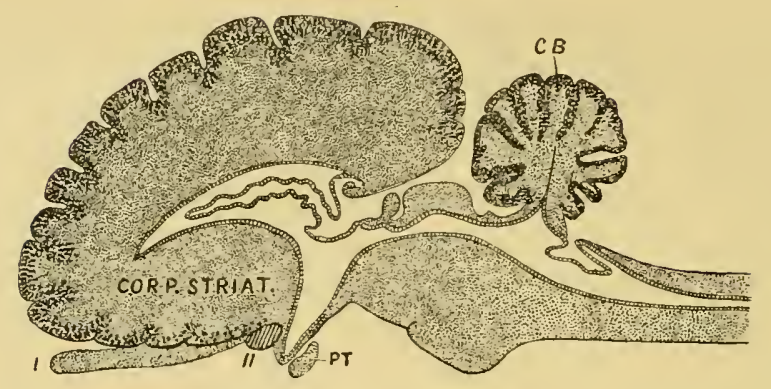

REPTILIA

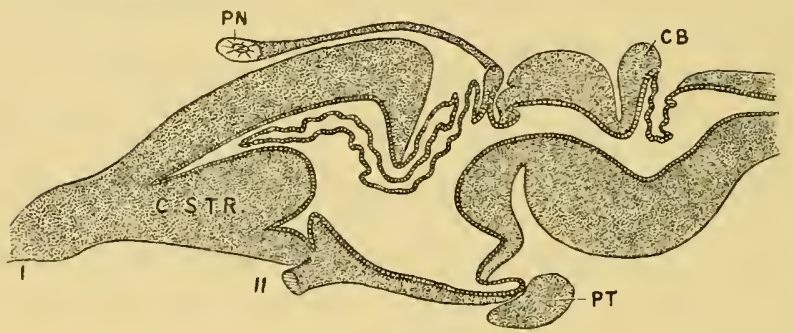

AMPHIBIA.
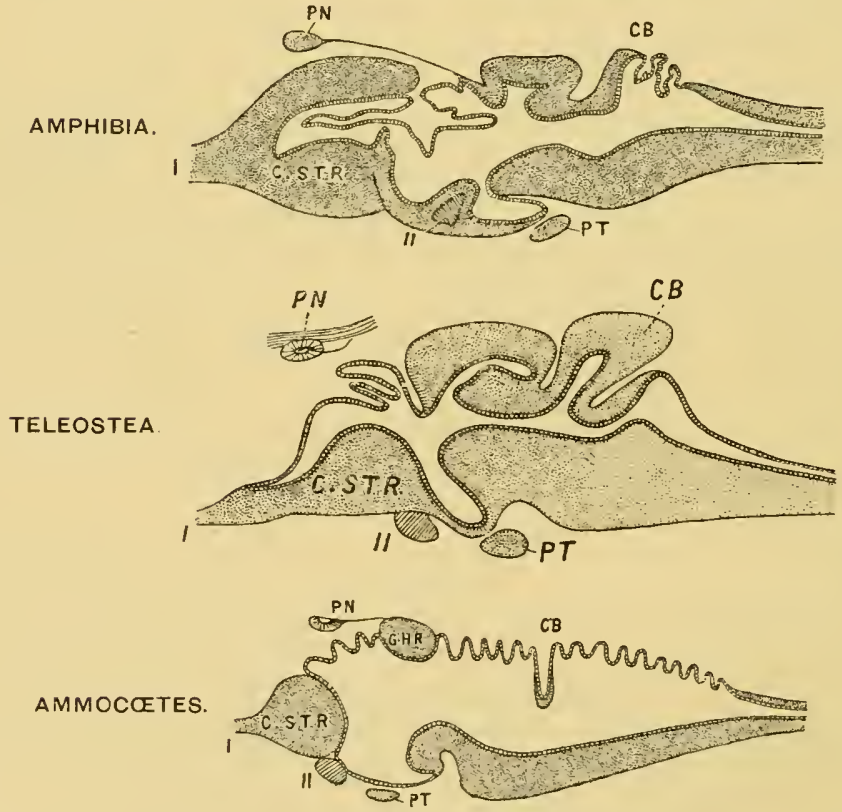

Fig. 19. - Comparison of Vertebrate Brains.

$C B$., cerebellum; PT., pituitary body ; PN., pineal body; C. STR., corpus striatum ;

G.II.R., right ganglion habenule. I., olfactory; II., optic nerves. 

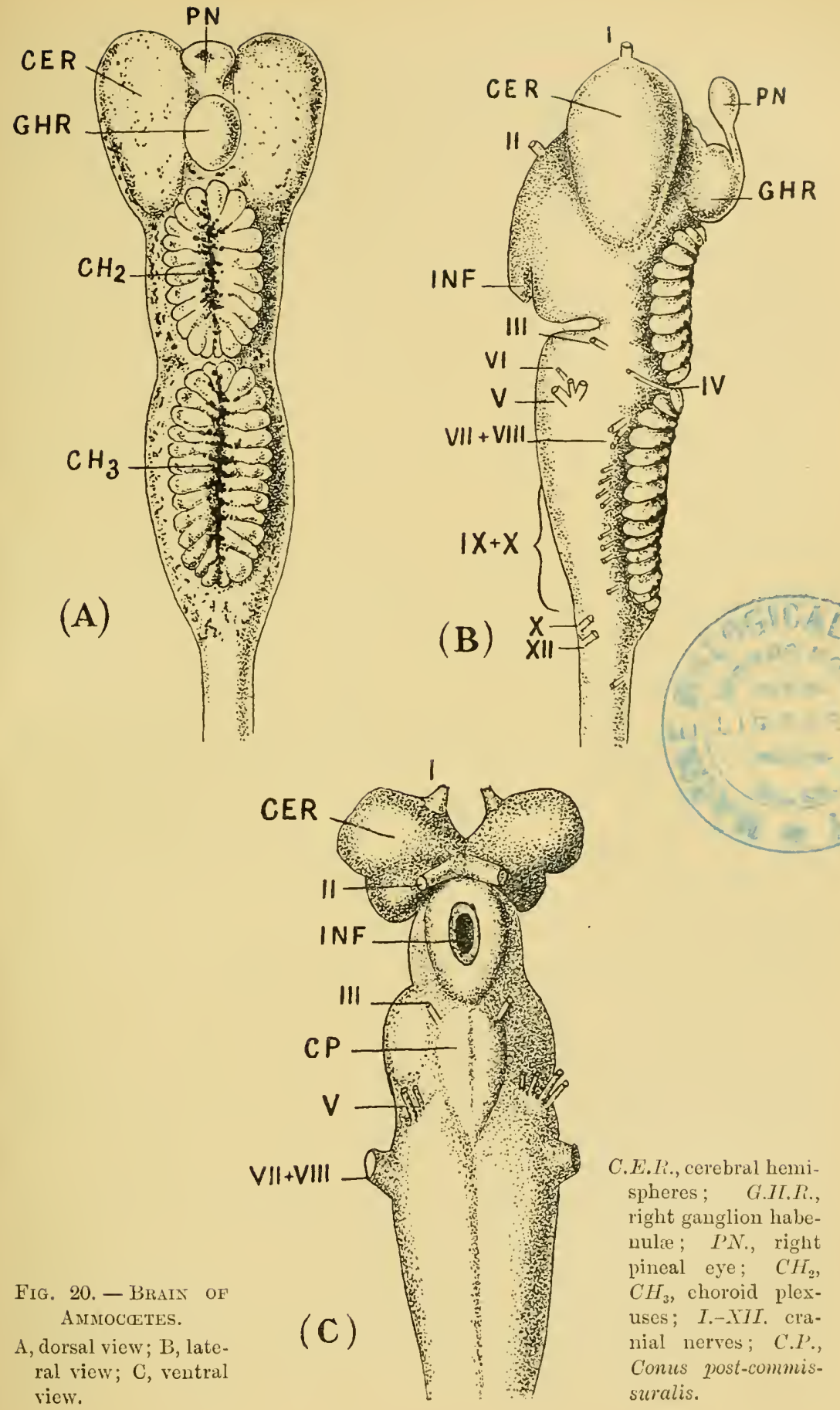
The seeond explanation is hardly worth serious consideration, for it supposes that the nervous system, for no possible reason, was laid down in its most important parts-the brain-region-as an epithelial tube with latent potential nervous functions; that even up to the highest vertebrate yet evolved these nervous functions are still in abeyance over the whole of the choroid plexuses and the roof of the fourth ventricle. Further, it supjoses that this prophetic epithelial tube originally developed into true nervous material only in eertain parts, and that these parts, curiously enough, formed a nervous system absolutely comparable to that of the arthropod, while the dormant prophetic epithelial part was formed so as just to mimic, in relation to the nervous part, the alimentary canal of that same arthropod.

The mere facts of the case are sufficient to show the glaring alssurdity of such an explanation. 'This is not the way Nature works; it is not consistent with natural seleetion to suppose that in a low form nervous material can be laid down as non-nervous epithelial material in order to provide in some future ages for the great increase in the nervous system.

Every method of investigation points to the same conclusion, whether the method is embryological, anatomical, or pathological.

First, take the embryological evidence. On the ground that the individual development reproduces to a certain extent the phylogenetic development, the peculiarities of the formation of the central nervous system in the vertebrate embryo ought to receive an appropriate explanation in any theory of phylogenetic development. Hitherto such explanation has been totally lacking; any suggestion of the manner in which a tubular nervous system may have been formed takes no account whatever of the differences between different parts of the tube; its dilated cephalie end with its infundibular projection ventrally, its small straight spinal part, and its termination in the anus. My theory, on the other hand, is in perfect harmony with the embryological history, and explains it point by point.

From the very first origin of the central nervous system there is evidence of two structures-the one nervous, and the other an epithelial surface-layer which ultimately forms a tube; this was first described by Scott in Petromyzon, and later by Assheton in the frog. In the latter case the extcrnal epithelial layer is pigmented, while the underlying nervous layer contains no pigment; a marked 
and conspicuous demarcation exists, therefore, between the two layers from the very beginning, and it is easy to trace the subsequent fate of the two layers owing to this difference of pigmentation. The pigmented cells form the lining cells of the central canal, and becoming elongated, stretch out between the cells of the nervous layer; while the latter, on their side, invade and press between the pigmented cells. In this case, owing to the pigmentation of the epithelial layer, embryology points ont in the clearest possible manner how the central nervous system of the vertebrate is composed of two structures-an epithelial non-nervous tube, on the outside of which the central nervous system was originally grouped; how, as development proceeds, the elements of these two structures invade each other, until at last they become so involved together as to give rise to the conception that we are dealing with one single nerve tube. It is impossible for embryology to give a clearer clue to the past history than it does in this case, for it actually shows, step by step, how the amalgamation between the central nervous system and the old alimentary canal took place.

Further, consider the shape of the tube when it is first formed, how extraordinary and significant that is. It consists of a simple dilated anterior end leading into a straight tube, the lumen of which is much larger than that of the ultimate spinal canal, and terminates by way of the neurenteric canal in the anus.

Why should the tube take this peculiar shape at its first formation? No explanation is given or suggested in any text-book of embryology, and yet it is so natural, so simple: it is simply the shape of the invertebrate alimentary canal with its cephalic stomach and straight intestine ending in the anus. Again embryology indicates most unmistakably the past history of the race. How are the nervous elements grouped round this tube when it is first formed? Here embryology shows that a striking difference exists between the part of the tube which forms the spinal cord and the dilated cephalic part. Fig. 21, A (2), represents the relation between the nerrous masses and the epithelial tube in the first instance. At this stage the nervous material in the spinal cord lies laterally and ventrally to this tube, and at a very early stage the white anterior commissmre is formed, joining together these two lateral masses; as yet there is no sign of any pusterior fissure, the tube with its open lumen extends right to the dorsal surface. 
The interpretation of this stage is that in the invertebrate ancestor the nerve-masses were situated laterally and ventrally to the epithelial tube, and were connected together by commissures on the ventral side of the tulue (Fig. 21, A (1)); in other words, the chain of ventral ganglia and their transverse commissures lying just ventrally to the intestine, which are so characteristic of the arthropod nervous system, is represented at this stage.

Subsequently, by the growth dorsalwards of nervous material to form the posterior columns, the original epithelial tube is compressed dorsally and laterally to such an extent that those parts lose all signs of lnmen, the one becoming the posterior fissure and the others the

A
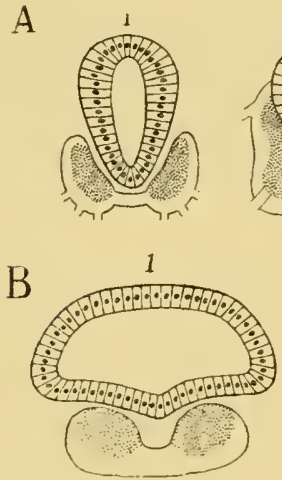
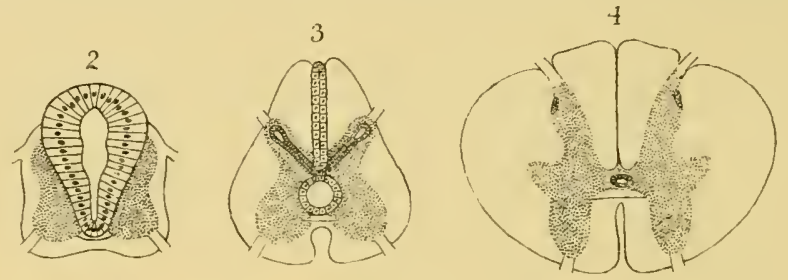

2

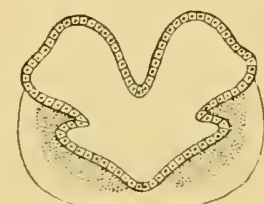

3

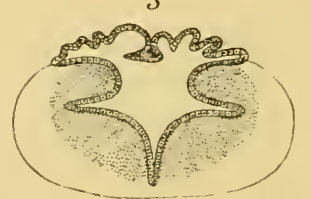

Fig. 21.-A, Method of Fornation of the Vertebrate spinal Cord front the

Tentral Chain of Ganglia axd the Intestine of an Arthropod, RerieSexted in 1 ; B, Method of Formation of the Vertebrate Medulia Oblongata pron the INFra-gsophageal Ganglia and the Cerhalic Stomach of aN ARthropod.

substantia gelatinosa Rolandi on each side. The original tube is thus reduced to a small canal formed by its ventral portion only (Fig. 21, A (3)). In this way the spinal cord is formed, and the walls of the original epithelial tube are finally visible only as the lining of the central canal (Fig. 21, A (4)).

When we pass to the brain-region, to the anterior dilated portion of the tube, embryology tells a different story. Here, as in the spinal cord, the nervous masses are grouped at first laterally and ventrally to the epithelial tube, as is seen in Fig. 21, B (2), but owing to the large size of its lumen here, the nervous material is not able to enclose it completely, as in the case of the spinal cord; 
consequently there is no posterior fissure formed ; but, on the contrary, the dorsal roof, not enclosed by the nerve-masses, remains epithelial, and so forms the membranous roof of the fourth ventricle and of the other ventricles of the brain (Fig. 21, B (3)). In the higher animals, owing to the development of the cerebrum and cerebellum, this membranous roof becomes pushed into the larger brain cavity, and thus forms the choroid plexuses of the thirr and lateral rentricles. In the lower vertebrates, as in Ammocœtes and the Dipnoi, it still remains as a dorsal epithelial roof and forms a most striking characteristic of such brains.

In this part of the nervous system, then, the nervous material is all grouped in its original position on the ventral side of the tube; and yet it is the same nervous material as that of the spinal cord, all the elements are there, giving origin here to the segmental cranial nerves just as lower down they give rise to the segmental spinal nerves, connecting together the separate segments each with the other and all with the higher brain-centres-the supra-infundibular centres -just as they do in the spinal region.

Why should there be this striking difference between the formation of the infra-infundibular region of the brain and that of the spinal cord? Do the advocates of the origin of vertebrates from Balanoglossus give the slightest reason for it? They claim that their view also provides a tubular nervous system for the vertebrate, but give not the slightest sign or indication as to why the nerrous material should bo grouper entirely on the ventral side of an epithelial tube in the infra-infundibular region and yet surround it in the spinal cord region. And the explanation is so natural, so simple: embryology does its very best to tell us the past history of the race, if only we look at it the right way.

The infra-infundibular nervous mass is natmally confined to the ventral side of the epithelial tube, because it represents the infracesophageal ganglia, situated as they are on the ventral side of the cephalic stomach, and, owing to the size of the stomach, they could not enclose it by dorsal growth, as they do in the case of the formation of the spinal cord (Fig. 21, B (1)). Still these nervous masses have grown dorsalwards, have commenced to involve the walls of the cephalie stomach eren in the lowest vertebrate, as is seen in Ammocotes, in which animal a ventral portion of the epithelial bag has been evidently compressed and its lumen finally obliterated 
by the growth of the nerve-masses on each sicle of it. Throughout the whole vertebrate kingdom this obliterated portion still leaves

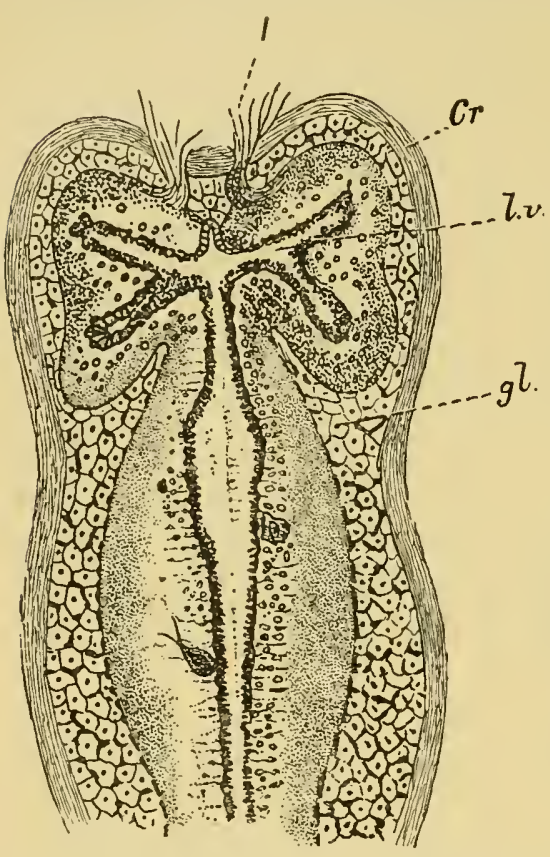

Fig. 22.-Horizontal Section througir the Brain of Ammocetes.

$\mathrm{Cr}$., membranous cranium; $I$, olfactory nerves; l.v., lateral ventricles; gl., glandular tissue which fills up the cranial cavity. its mark as the raphé or seam, which is so characteristic of the infra-infundibular portion of the brain.

Here, again, it is seen how simple is the explanation of a peculiarity which has always puzzled anatomists - why should there be this seam in the infra-infundibular portion of the brain and not in the supra-infundibular or in the spinal cord? The corresponding compression in the upper braill-region forms the lateral ventricles, as is seen in the accompanying figure of the brain of Ammocotes (Fig. 22).

In yet another instance it is seen how markedly the nervous masses are arranged in the same position with respect to the central tube as are the nerve ganglia with respect to the intestinal tube in the case of the invertebrate. Thus in birds a portion of the spinal cord in the lumbo-sacral region presents a very different appearance

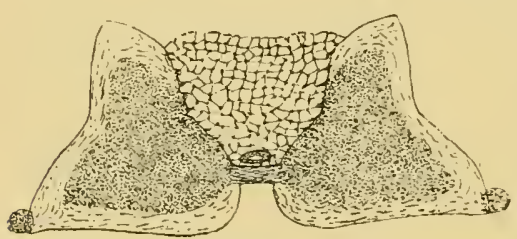
Sirus OF BIRD.

from the rest of the cord; it is known as the rhomboidal sinus, and a section of the cord of an adult pigeon across this region is given in Fig. 23. As is seen, the nervous portions are entirely confined to two masses connected together by the white anterior commissures which are situated laterally and ventrally to a median gelatinous mass; the small central canal is visible and 
the whole dorsal area of the cord is taken up by a peculiar nonnervous wedge-shaped mass of tissue. At its first formation this portion of the cord is formed exactly in the same manner as the rest of the cord; insteal, however, of the nervous material invading the dorsal part of the tube to form the posterior fissure, it has been from some cause unable to do so, the walls of the original non-nervous tube have become thickened dorsally, been transformed into this peculiar tissue, and so caused the peculiar appearance of the cord here. The nervous parts have not suffered in their development; the mechanism for walking in the bird is as well developed as in any other animal ; their position only is different, for they still retain the original ventro-lateral position, but the non-nervous tube, the remains of the old intestine, has nndergone a peculiar gelatinous degeneration just where it has remained free from invasion by the nervous tissue.

Throughout the whole of that part of the nervous system which gives origin to the cranial and spinal segmental nerves, the evidence is absolutely uniform that the nervous material was originally arranged bilaterally and ventrally on each side of the central tube, exactly in the same way as the nerve-masses of the infra-cesophageal and ventral chain of ganglia are arranged with respect to the cephalic stomach and straight intestine of the arthropod. But, in addition, we find in the vertebrate nervous masses, the cerebral hemispheres, the corpora quadrigemina and the cerebellum situated on the dorsal side of the central tube in the brain-region; this nervous material is, however, of a different character to that which gives origin to the spinal and cranial segmental nerves. How is the presence of these dorsal masses to be explained on the supposition that the dilated anterior part of the nerve-tube was originally the cephalic stomach of the arthropod ancestor? The cerebral hemispheres are simple enough, for they represent the supra-œsophageal ganglia, which of necessity, as they increased in size, would grow round the anterior end of the cephalic stomach and become more and more dorsal in position.

The difficulty lies rather in the position of the cerebellum and corpora quadrigemina, and the solution is as simple as it is conclusive.

Let us again turn to embryology and see what help it gives. In all vertebrates the dilated anterior portion of the nerve-tube does not, 
as it grows, increase in size uniformly, but a constriction appears on its dorsal surface at one particular place, so as to divide it into an anterior and posterior vesicle; then the latter becomes divided into two portions by a second constriction. In this way three cerebral vesicles are formed; these thrce primary cerebral vesicles indicate the region of the fore-brain, mid-brain, and hind-brain respectively. Sulusequently the first cerebral vesicle becomes divided into two to form the prosencephalon and thalamencephalon, while the third cerebral vesicle is also divided into two to form the region of the cerebellum and medulla oblongata.

These constrictions are in the position of commissural bands of nervous matter; of these the limiting nervous strands between the thalamencephalon and mesencephalon and between the mesencephalon and the hind-brain are of primary importance. The first of these commissural bands is in the position of the posterior commissure connecting the two optic thalami. In close connection with this are found, on the mid-dorsal region, the two pineal eyes with their optic ganglia, the so-called ganglia habenule. From these ganglia a peculiar tract of fibre, known as Meynert's bundle, passes on each side to the ventral infra-infundibular portion of the brain. In other words, the first constriction of the dilated tube is due to the presence and growth of nervous material in connection with the median pineal eyes. Here in precisely the same spot, as will be fully explained in the next chapter, there existed in the arthropod ancestor a pair of median eyes situated dorsally to the cephalic stomach, the preexistence of which explains the reason for the first constriction.

The second primary constriction separating the mid-brain from the hind-brain is still more interesting, for it is coincident with the position of the trochlear or fourth cranial nerve. In all vertebrates without exception this nerve takes an extraordinary course; all other nerves, whether cranial or spinal, pass ventralwards to reach their destination. This nerve passes dorsalwards, crosses its fellow middorsally in the valve of Vieussens, where the roof of the brain is thin, and then passes ont to supply the superior oblique muscle of the eye of the opposite side. The two nerves form an arch constricting the dilated tube at this place. In the lowest vertebrate (Ammocotes) the constriction formed by this nerve-pair is evident not only in the embryonic condition as in other vertebrates, but during the whole larval stage. As Fig. 20, A and B, shows, the whole of the dorsal 
region of the brain up to the region of the pineal eye and ganglion habenulce is one large membranous bag, except for the single constriction where the fourth nerve on each side crosses over. The explanation of this peculiarity is given in Chapter VII., and follows simply from the facts of the arrangenent of that musculature in the scorpion-group which gave rise to the eye-muscles of the vertebrate.

In Ammocuetes both cerebellum and posterior corpora quadrigemina can hardly be said to exist, but upon transformation a growth of nerrous material takes place in this region, and it is seeu that this commencing cerebellum and the corpora quadrigemina arise from tissue that is present in Ammocetes along the course of the fourth nerve.

Here, then, again Embryology does its best to tell us how the vertebrate arose. The formation of the two primary constrictions in the dilated anterior resicle whereby the brain is divided into fore-brain, mid-brain, and hind-brain is simply the representation ontogenetically of the two nerve-tracts which crossed over the cephalic stomach in the prevertebrate stage, in consequence of the mid-rlorsal position of the pineal eyes and of the insertion of the original superior oblique muscles.

The subsequent constriction by which the prosencephalon is separated from the thalanencephalon is in the position of the anterior commissure, that commissure which connects the two suprainfundibular nerre-masses, and is one of the first-formed commissures in every vertebrate. This naturally is simply the commissure between the two supra-cesophageal ganglia; anterior to it, in the middle line, equally naturally, the anterior end of the old stomach wall still exists as the laminu terminalis.

The other division in the hind-brain region, which separates the region of the cerebellum from the medulla oblongata, is due to the growth of the cerebellum, and indicates its posterior limit. In such an animal as the lamprey, where the cerebellum is only commencing, this constriction does not occur in the embryo.

From such simple beginnings as are seen in Ammocoetes, the higher forms of brain have been evolved, to culminate in that of mau, in which the massive cerebrum and cerebellum conceals all sign of the dorsal membranous roof, those parts of the simple epithelial tube which still remain being tucked away into the cavities to form the various choroid plexuses. 
In the whole evolution from the brain of Ammocoetes to that of man, the sane process is plainly visible, viz. growth and extension of nervous inaterial over the epithelial tube; extension dorsally and posteriorly of the supra-infundibular nervous masses (as seen in Fig. 19), combined with a dorsal growth of parts of the infrainfundibular nervous masses to form the cerebellum and yosterior corpora quadrigemina.

Especially instructive is the formation of the cerebellum. It consists at first of a small mass of nervous tissue accompanying the

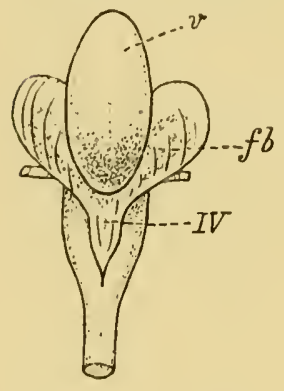

Fig. 24. - CERribeLUM OF DOG-FISH.

$v$, worm of cerebellum; $I V^{*}$., membranous roof of fourth ventriclo continuous with the nembranous folds on each side. Through these the fimbrix ( $f l$. $)$ can bo dimly seen. fourth nerve, then by the growth of that mass surrounding and constricting a fold of the membranous roof, the worm of the cerebellum is formed, as in the dog-fish. This very constriction eauses the membrane to be thrown into a lateral fold on each side, as seen in Fig. 24, and in the dog-fish the nervous material on each side, known as the fimbrice, is already commencing to grow from the ventral mass of the medulla olilongata to surround these lateral membranous folds. These fimbrixe develop more and more in ligher forms, and thus form the cerebellar hemispheres.

Not only does comparative anatomy contirm the teachings of embryology, but also pathology gives its quota in the same direction.

One of the striking facts about malformations and disease of the central nervous system is the frequency of cystic formations; spince bifule is a well-known instance. These cysts are merely epithelial nou-nervous cysts formed from the epithelium of the central canal, difficult to understand if the whole nerve tube is one and entirely nervous, either actually or potentially, but natural and eisy if we are really dealing with a simple epithelial tube on the outside of which the nervous material was originally grouped. The cystic formation belongs naturally enough to this tube, not to the nervous system.

Again, where animals such as lizards have grown a new tail, owing to the breaking off of the original one, it is found that the central canal extends into this new tail for some distance, but not 
the nervous material smromding it; all the nerves supplying the new tail arise from the uninjured spinal cord above, the central canal with its lining layer of epithelial cells alone grows into the new-formed appendage.

To all intents and purposes the same thing is seen in the termination of the spinal cord in a birl-embryo; nore and more, as the end of the tail is approached, does the nervous matter of the spinal cord grow less and less, until at last a naked central canal with its lining epithelium is alone left to represent the so-called nervetube.

All these different methods of investigation lead irresistibly to the one conclusion that the tubular nature of the central nervous system has been caused by the central nervous system enclosing to a greater or less extent a pre-existing, non-nervous, epithelial tube.

This must always be borne strictly in mind. The problem, therefore, which presents itself is the comparison of these two factors separately, in order to find out the relationship of the vertebrate to the invertebrate. The nervous system without the tube must be compared to other nervous systems, and the tube must be considered apart from the nervous system.

\section{Tie Principle of Concevtration and Cephalization.}

The central nervous system of the vertebrate resembles that of all the Appendiculata in the fact that it is composed of segments joined together which give origin to segmental nerves. There is, however, a great difference between the two systems: the division into separate segments is not obvious to the eye in the vertebrate nervous system, while in the invertebrate we can see that it is composed of a series of separate pairs of ganglia joined together longitudinally by nervous strands known as connectives and transversely by the nerve-commissures. Such a simple segmented system is found in the segmented worms, and in the lower arthropods, such as Branchipus, no great advance has been made on that of the annelid. In the higher forms, however, a greater and greater tendency to fusion of separate ganglia exists, especially in the head-region, so that the infra-resophageal ganglia, which, in the lower forms are as separate as those of the rentral chain, in the higher forms are fused together to form a single nervous mass. 
This is the great characteristic of the advancement of the central nervous system among the Invertebrata, its concentration in the region of the head. It may be called the principle of cephalization, and is characteristic not only of higher organization in a group, but also of the adult as distinguished from the larval form. Thus in the imago greater concentration is found than in the caterpillar.

The segmented annelid type of nervous system consists of a supra-œesophageal ganglion, composed of the fused ganglia belonging to the pre-oral segments, and an infra-œsophageal chain of separate ganglia. With the concentration and modification around the mouth of the most anterior locomotor appendages to form organs for prehension and mastication of food, a corresponding concentration and fusion of the ganglia belonging to these segments takes place, so that finally, in the higher annelicls, and in most of the great arthropod group, a fusion of a number of the most anterior ganglia has taken place to form the infra-œsophageal ganglion-rnass.

The infra-cesophageal ganglia which are the first to fuse are those which supply the most anterior portion of the animal with nerves, and include always those anterior appendages which are modified for mastication purposes. To this part the name prosoma has been given; in many cases it forms a well-defined, distinct portion of the animal.

Succeeding this prosoma or masticatory region, there occurs in all gill-bearing arthropods a respiratory region, in many cases more or less distinctly defined, which has received the name of mesosoma. The rest of the body is called the metasoma.

In accordance with this nomenclature the central nervous system of many of the Arthropoda may be divided as follows :-

1. Pre-oral, or supra-œsophageal ganglia.

2. Infra-oral, or infra-cesophageal ganglia and ventral chain, which consist of three groups: prosomatic, mesosomatic, and metasomatic ganglia.

The infra-œsophageal ganglion-mass, then, in most of the Arthropoda may be spoken of as formed by the fusion of the prosomatic or mouth-ganglia, the mesosomatic and metasomatic remaining separate and distinct. The number of ganglia which lave fusecl may be observed by examination of the embryo, in which it is easy to see indications of the individual ganglia or neuromeres, although all such indication has disappeared in the adult; thus the infra-øoso- 
phageal ganglia of the cray-fish have been shown to be constitutel of six prosomatic ganglia.

In Fig. 25 I give figures of the central nervous system (with the exception of the abdominal or metasomatic ganglia) of Branchipus, Astacus, Limulus, Scorpio, Androctonus, Thelyphomus, and Ammocotes. In all the figures the supra-œsophageal ganglia are lined horizontally, and their nerves shown, viz. optic (lateral eyes (II) and median eyes (II')), olfactory (l) (first antennx, camerostome, nose); then come the prosomatic ganglia (dotted), with their nerves (A) supplying the mouth parts, and the second antennse or chelicerse; then the mesosomatic (lined horizontally), with their nerves (B) supplying respiratory appendages. These figures show that the concentrated brain mass around the cesophagus of an arthropod which has arrived at the stage of Astacus, is represented by the supracesophageal ganglia and the fused prosomatic ganglia.

The next stage in the evolution of the brain is seen in the gradual in lusion of the mesosomatic ganglia, one after the other, into the infra-csophageal mass of the already fused prosomatic ganglia. With this fusion is assaciated the loss of locomotion in these mesosomatic appendages, and their entire subservience to the function of respiration. Dana urges that cephalization is a consequence of functional alteration in the appendages, from organs of loconiotion to those of mastication and respiration. Whether this be true or not, it is certainly a fact that in Limulus, the ganglion supplying the first mesosomatic appendage has fused with the prosomatic, infra-cesophageal mass. It is also a fact that the prosomatic appendages are the organs of mastication, their basal parts being arranged round the mouth so as to act as foot-jaws, while the mesosomatic appendages, though still free to move, have been reduced to such an extent as to consist mainly of their basal parts, which are all respiratory in function, except in the case of the first pair, where they carry the terminal ducts of the genital organs. In the next stage, that, of the scorpion, in which the mesosomatic appendages have lost all power of free locomotion, and have become internal branchix, another mesosomatic ganglion has fused with the brain mass, while in Anclroctonus two of the branchial mesosomatic ganglia have fused; and finally, in Thelyphonus and Phrynus, all the mesosomatic ganglia have coalesced with the fused prosomatic ganglia, while the metasomatic ganglia have themselves fused 


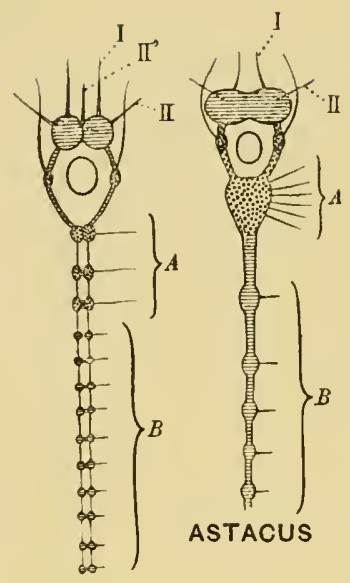

BRANCHIPUS
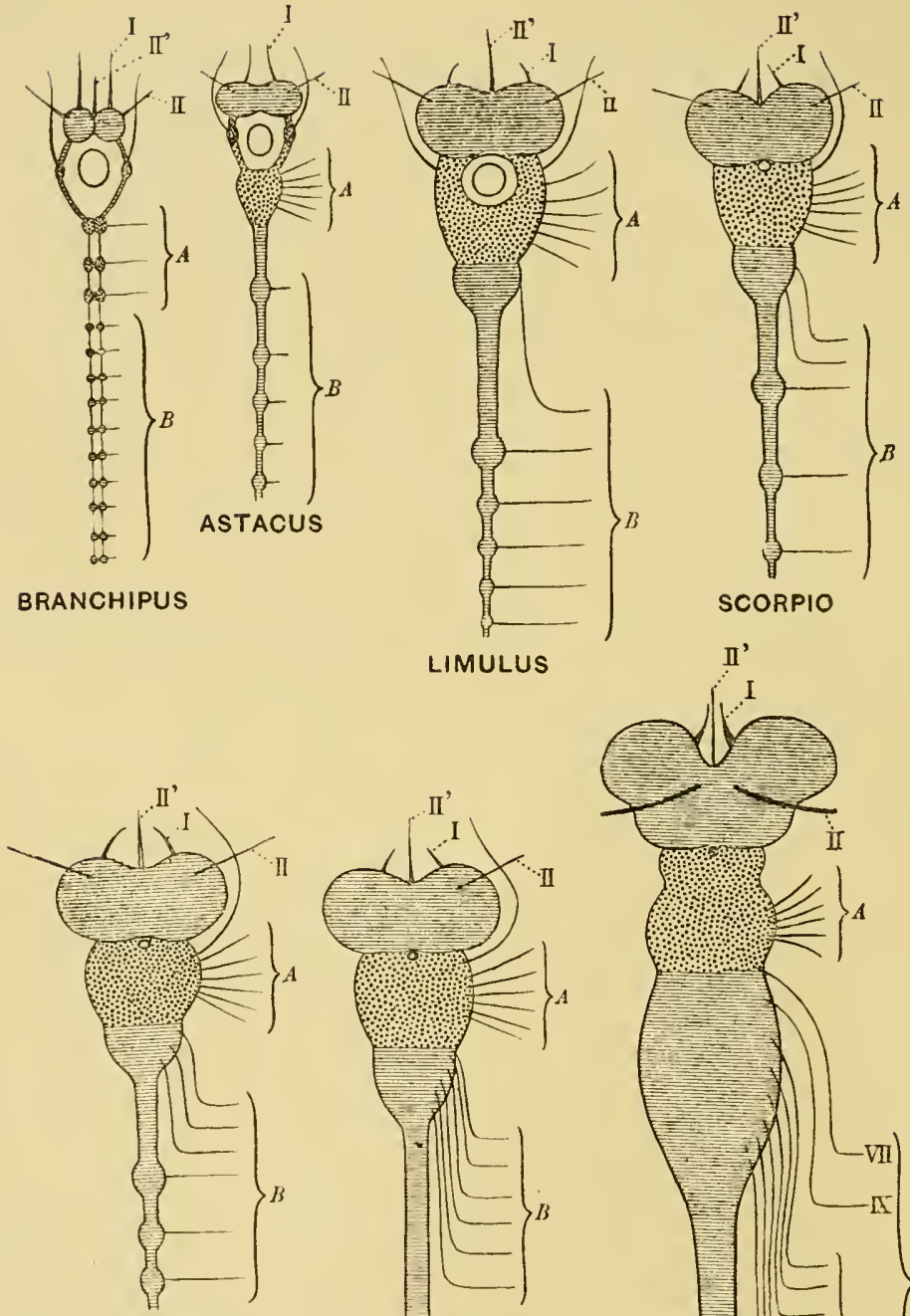

ANDROCTONUS
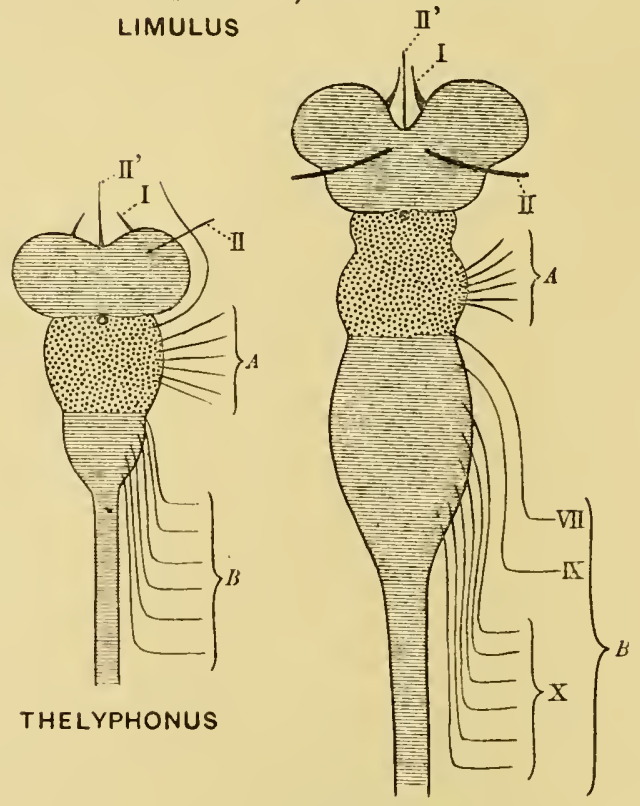

AMMOCCETES

Fig. 25.-Conpatison of Invertebrate Bratns from Branchipts to AMMOCETES. 
together in the candal region to form what is known as the candal brain.

The brain in these animals may be spoken of as composer of three parts-(1) the fused supra-cesophageal ganglia, (2) the fused prosomatic ganglia, and (3) the fused mesosomatic ganglia. Such a brain is strictly homologous with the vertebrate brain, which also is built up of three parts-(1) the part in front of the notachord, the prechordal or supra-infundibular brain, which consists of the cerebral hemispheres, together with the basal and optic ganglia and corresponds, therefore, to the supra-cesophageal mass, with its olfactory and optic divisions lying in front of the cesophagus; (2 and 3) the epichordal brain, composed of (2) a trigeminal and (3) a vagus division, of which the first corresponds strictly to the fused prosomatic ganglia, and the second to the fused mesosomatic ganglia. Further, just as in the embryo of an arthropod it is possible, with more or less accuracy, to see the number of neuromeres or original ganglia which have fused to form the supra- and infra-cesophageal portions of its brain, so also in the embryo of a vertebrate we are able at an early stage to gain an indication, more or less accurate, of the number of neuromeres which have built up the vertebrate brain. The further consideration of these neuromeres, and the evidence they afforc as to the number of the prosomatic and mesosomatic ganglia which have formed the epichordal part of the vertebrate brain, must be left to the chapter on the segmentation of the cranial nerves.

The further continuation of this process of concentration of separate segments, together with the fusion of the nervous system with the tube of the alimentary canal, leads in the simplest mamer to the formation of the spinal cord of the vertebrate from the metasomatic ganglia of the ventral chain of the arthropod.

\section{The Antagonism between Cephalization axd Almentation.}

This concentration of the nervous system in the heal-region, together with an actual increase in the bulk of the cephalic nervous masses, constitutes the great principle upon which the law of upward progress or evolution in the animal kingdom is based, and it illustrates in a striking manner the blind way in which natural selection works; for, as already explained, the central nervous system arose as a ring round the mouth, in consequence of which, with the progressive 
evolution of the animal kingdom, the oesophagus necessarily pierced the central nervous system at the cephalic end. At the same time, the very fact that the evolution was progressive necessitated the concentration and increase of the nervous masses in this very same resophageal region.

Progress on these lines must result in a crisis, owing to the inevitable squeezing out of the food-channel by the increasing nervemass; and, indeed, the fact that such a crisis had in all probability arisen at the time when rertebrates first appeared is apparent when we examine the conditions at the present time.

Those invertebrates whose central nervous system is most concentrated at the cephalic end belong to the arachuid group, among which are included the various living scorpion-like animals, such as Thelyphonus, Androctonus, etc.

As already mentioned, the giants of the Palæostracan age were Pterygotus, Slimonia, etc., all animals of the scorpion-type-in fact,

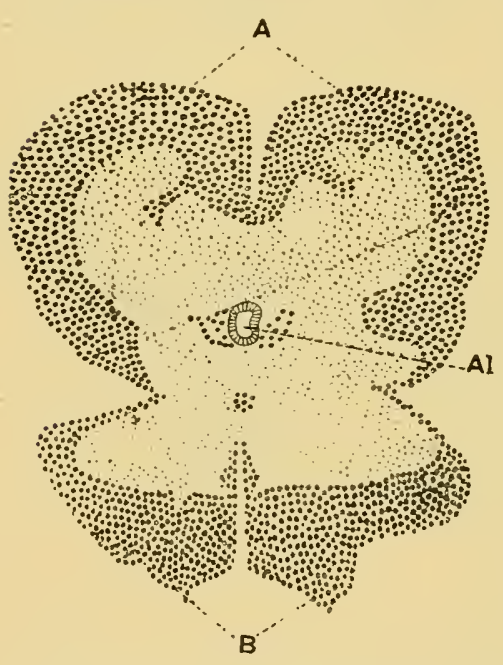

Fig. 26. - Transterse Section throdgh the Brain of a Yotxg Thelyphoxts.

$A$, supra-nsophageal ganglia; $B$, infraœsophageal gauglia; $A l$, œsophagus. sea-scorpions. Now, all these animals, spiders and scorpions, without exception, are blood suckers, and in all of them the concentrated cephalic mass of nervous material surrounds an œesophagus the calibre of which is so small that nothing but a fluid pabulum can be taken into the alimentary canal; and even for that purpose a special suctorial apparatus has in some species been formed on the gastric side of the osophagus for the purpose of drawing blood through this exceedingly narrow tule.

In Fig. 25 this increasing antagonism between brain-power and alimentation, as we pass from such a form as Branchipus to the scorpion, is illustrated, and in Fig. 26 the relative sizes of the esophagus and the brain-mass surrounding it is shown. The section shows that the food channel is surrounded by the white and grey 
matter of the brain as completely as the central canal of the spinal cord of the vertebrate is surrounded by the white and grey nervous material.

Truly, at the time when vertebrates first appeared, the direction and progress of variation in the Arthropoda was leading, owing to the manner in which the brain was pierced by the cesophagus, to a terrible dilemma-either the capacity for taking in food without sufficient intelligence to capture it, or intelligence sufficient to capture food and no power to consume it.

Something had to be done-some way had to be found out of this difficulty. The atrophy of the brain meant degeneration and the reduction to a lower stage of organization, as is seen in the Tunicata. The further development of the brain necessitated the establishment of a new method of alimentation and the closure of the old cesophagus, its vestiges still remaining as the infundibular canal of the vertebrate, meant the enormous upward stride of the formation of the vertebrate.

At first sight it might appear too great an assumption even to imagine the possibility of the formation of a new gut in an animal so highly organized as an arthropod, but a little consideration will, I think, show that such is not the case.

In the higher animals we are accustomed to speak of certain organs as vital and necessary for the further existence of the animal ; these are essentially the central nervous system, the respiratory system, the circulatory system, and the digestive system. Of these four vital systems the first cannot be touched without the chance of regeneration; but that is not the case with the second. The passage from the fish to the amphibian, from the water-breathing to the air-breathing animal, has actually taken place, and was effected by the modification of the swim-bladder to form new respiratory organs-the lnngs; the old respiratory organs-the gills-becoming functionless, but still persisting in the embryo as vestiges. The necessity arose in consequence of the passage of the animal from water to land, and with this necessity nature found a means of overcoming the difficulty; air-breathing vertebrates arose, and from the very fact of their being able to extend over the land-surfaces, increased in numbers and developed in complexity in the manner alrearly sketched out.

For a respiratory system all that is requirer is an arrangement 
by means of which blood should be brought to the surface, so as to interchange its gases with those of the external medium; and it is significant to find that of all vertebrates the Amphibia alone are capable of an effective respiration by means of the skin.

As to the circulatory system, it is exceedingly easily modified. An animal such as Amplioxus has no heart; in some the heart is systemic, in others branchial; in some there are more than one heart; in others there are contractile veins in addition to a heart. There is no difficulty here in altering and modifying the system according to the needs of the individual.

For a digestive system all that is required is an arrangement for the digestion and absorption of food, a mechanism which can arise easily if some of the cells of the skin possess digestive power. Now Miss Alcock has shown that some of the surface-cells of crustacenns secrete a fluid which possesses digestive powers, and she has also shown that certain of the cells in the skin of Ammocretes possess digestive power.

The difficulty, then, of forming a new digestive system in the passage from the arthropod to the vertebrate is very much the same as the difficulty in forming a new respiratory system in the passage from the water-breathing fish to the air-breathing amphibian-a change which does not strike us as inconceivable, because we know it has taken place.

The whole argument so far leads to the conclusion that vertebrates arose from ancient forms of arthropods by the formation of a new alimentary canal, and the enclosure of the old canal by the growing central nervous system. If this conchusion is true, then it follows that re possess a well-chefined starting-point from which to compare the separate organs of the arthropod with those of the vertebrate, and if, in consequence of such working liypothesis, each organ of the arthropod is found in the vertebrate in a corresponding position and of similar structure, then the truth of the starting-point is proved as fully as can possibly be expected by deductive methods. It is, in fact, this method of comparative anatomy which has proved the descent of man from the ape, the frog from the fish, ete.

Let its, then, compare all the organs of such a low vertebrate as Ammocnetes with those of an arthropod of the ancient type. 


\section{Life History of the L.hiprey- not a Degenerate Animal.}

The striking peculiarity of the lamprey is its life-history. It lives in fresh water, spending a large portion of its life in the mud during the period of its larval existence: then comes a somewhat sudden transformation-stage, characterized, as in the lepidopterous larva, by a process of histolysis, by which many of the larval tissues are destroyed and new ones formed, with the result that the larval lamprey, or Ammocnetes, is transformed into the adult lamprey, or Petromyzon. This transformation takes place in August, at all events in the neighbourhood of Cambridge, and later in the year the transformed lamprey migrates to the sea, grows in size and maturity, and returns to the river the following spring up to its spawning beds, where it spawns and forthwith dies. How long it lives in the Ammocotes stage is unknown; I myself have kept some without transformation for four years, and probably they live in the rivers longer than that before they change from their larval state. It is absolutely certain that very much the longest part of the animal's life is spent in the larval stage, and that with the maturity of the sexual organs and the production of the fertilized ora the life of the individual ends.

Now, the striking point of this transformation is that it produces an animal more nearly comparable with higher vertebrates than is the larval form; in other words, the transformation from larva to adult is in the direction of upward progress, not of degeneration. It is, therefore, inaccurate to speak of the adult lamprey as degenerate from a higher race of fishes represented by its larval form -Ammocoetes. Its transformation does not resemble that of the tunicates, but rather that of the frog, so that, just as in the case of the tadpole, the peculiarities of its larval form may be expected to afford valualle indications of its immediate ancestry. The very peculiarities to which attention must especially be paid are those discarded at transformation, and, as will be seen, these are essentially characteristic of the invertebrate and are not found in the higher vertebrates. In fact, the transformation of the lamprey from the Ammoccetes to the Petromyzon stage may be described as the casting off of many of its ancestral invertebrate characters and the putting on of the characteristics of the vertebrate type. It is this double individuality of the lamprey, together with its long-continued existence in the larval form, which makes Ammocœetes more 
valuable than any other living vertebrate for the study of the stock from which vertebrates sprang.

Many authorities hold the view that the lamprey, like Amphioxus, must be looked upon as degenerate, and therefore as no more suitable for the investigation of the problem of vertebrate ancestry than is Amphioxus itself. This clarge of degeneracy is based on the statement that the lamprey is a parasite, and that the eyes in Ammocotes are under the skin. The whole supposition of the degeneracy of the Cyclostomata arose because of the prevailing belief of the time that the earliest fishes were elasmobranchs, and therefore gnathostomatous. From such gnathostomatous fishes the cyclostomes were supposed to have descended, having lost their jaws and become suctorial in habit in consequence of their parasitism.

The charge of parasitism is brought against the lamprey because it is said to suck on to fishes and so obtain nutriment. It is, however, undoubtedly a free-swimming fish; and when we see it coming up the rivers in thousands to reach the spawning-beds, and sucking on to the stones on the way in order to anchor itself against the current, or holding on tightly during the actual process of spawning, it does not seem justifiable to base a charge of degeneration upon a parasitic habit, when such so-called habit simply consists in holding on to its prey until its desires are satisfied. If, of course, its suctorial mouth had arisen from an ancestral gnathostomatous mouth, then the argument would have more force.

Dohrn, however, gives absolutely no evidence of a former gnathostomotous condition either in Petromyzon or, in its larval state, Ammocetes. He simply assumes that the Cyclostomata are legenerated fishes and then proceeds to point out the rudiments of skeleton, etc., which they still possess. Every point that Dohrn makes can be turned round; and, with more probability, it can be argued that the various structures are the commencement of the skeletal and other structures in the higher fishes, and not their degenerated remnants. Compare the life-history of the lamprey and of the tunicate. In the latter case we look upon the animal as a degenerate vertebrate, because the larval stage alone shows vertebrate characteristics; when transformation has taken place, and the alult form is reached, the vertebrate characteristics have vanished, and the animal, instead of reaching a higher grade, has sunk lower in the scale, the central nervons system especially having lost all 
resemblance to that of the veriebrate. In the former case a transformation also takes place, a marvellous transformation, characterized by two most striking facts. On the one hand, the resulting animal is more like a ligher vertebrate, for, by the formation of new cartilages, its cranial skeleton is now comparable with that of the higher forms, and the beginnings of the spinal vertebre appear; by the increased formation of nervons material, its brain increases in size and complexity, so as to compare more closely with higher vertebrate brains; its eyes become functional, and its branchiæ are so modified, simultaneously with the formation of the new alimentary canal in the cranial region, that they now snrround branchial pouches which are directly comparable to those of higher vertebrates. On the other hand, the transformation process is equally characterized by the throwing off of tissues and organs, one and all of which are comparable in structure and function with corresponding structures in the Arthropoda-the thyroid of the Ammocoetes, the tentacles, the muco-cartilage, the tubular muscles, all these structures, so striking in the Ammocoetes stage, are got rid of at transformation. Here is the true clue. Here, in the throwing off of invertebrate characters, and the taking on of a higher vertebrate form, especially a higher brain, not a lower one, Petromyzon proclaims as clearly as is possible that it is not a degenerate elasmobranch, but that it has arisen from Ammocotes-like ancestors, even though Myxine, Amphioxus, and the tunicates be all stages on the downward grade from those same Ammocœtes-like ancestors.

As to the eyes, they are functional in the adult form and as serviceable as in any fish. There is no sign of degeneracy; it is only possible to speak of a retarded development which lasts through the larval stage.

\section{Comparison of Brain of Amiocetes wht that of aN Arthropod,}

Seeing that the steady progress of the development of the central nervous system is the most important factor in the evolution of animals, it follows that of all organs of the boly, the central nervous system must be most easily comparable with that of the supposed ancestor. I will, therefore, start by comparing the brain of Ammocoetes with that of arthropods, especially of Limulus and of the scorpion-groul. 
The supra-infundibular portion of the brain in vertebrates corresponds elearly to the supra-cesophageal portion of the invertebrate brain in so far that in both cases here is the seat of the will. Voluntary action is as impossible to the arthropod deprived of its supra-cesophagreal ganglia as to the vertebrate deprived of its cerebrum. It eorresponds, also, in that from it arise the nerves of sight and smell and no other nerves; this is also the ease with the supracesophageal ganglia, for from a portion of these ganglia arise the nerves to the eyes and the nerves to the first antenne, of which the latter are olfactory in function. Thus, in the aecompanying figure, taken from Bellonci, it is seen that the supra-œsoplrageal ganglia eonsist

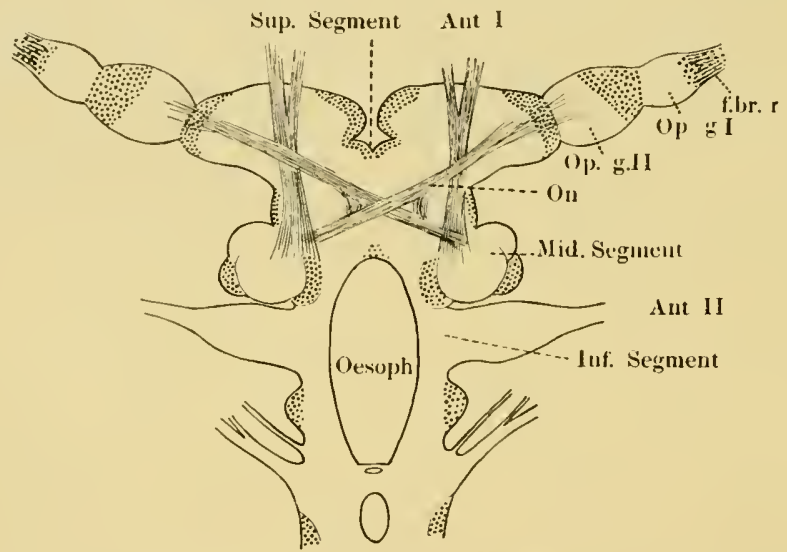

Fig. 27.-The Brain of Spharoma serratum. (After Bellonci.)

Ant. I. and $1 n t . I T$., nerves to 1 st and 2 nd antenne. f.br.r., terminal fibre layer of retina; $O p . g$. I., first optic ganglion; $O p . g . I I$., second optic ganglion; $O . n$., optic nerve-fibres forming an optic chiasma.

of a superior segment eorresponding to the cerebrum, a middle segment from which arise the nerves to the lateral eyes and to the olfactory antemne, corresponding to the basal ganglia of the brain and the optic lobes, and, according to Bellonci, of an inferior segment from which arise the nerves to the second pair of antennæ. This last segment is not supra-cesophageal in position, but is situated on the oesophageal commissures. It has been shown by Lankester and Braner in Limulus and the seorpion to be in reality the first ganglion of the infra-cesophageal series, and not to belong to the supraresophageal group.

Further, in Limulus, in the scorpion-group, and in all the extinct 
Eurypterida-in fact, in the Palieostraca generally-there are two median eyes in addition to the lateral eyes, which were innervated from these ganglia.

In Ammocates, then, if the supra-infundibular portion of the brain really corresponds to the supra-œsophageal of the palæostracan group, we ought to find, as incleed is the case, an optic apparatus consisting of two lateral eyes and two median eyes, innervated from the supra-infundibular brain-mass, and an olfactory apparatus built up on the same lines as in the scorpion-group, also innervated from this region. If, in addition, it be found that those two median eyes are degenerate eyes of the same type as the median eyes of Limulus and the scorpion-group, then the evidence is so strong as to amount to a proof of the correctness of the theory. This evidence is precisely what has been obtained in recent years, for the rertebrate did possess two median eyes in addition to the two lateral ones, and these two median eyes are degenerate eyes of the type found in the median eyes of arthropods and are not of the vertebrate type. Moreover, as ought also to be the case, they are most evilent, and one of the pair is most nearly functional in the lowest perfect vertebrate, Ammocoetes.

Of all the discoveries made in recent years, the discovery that the pineal gland of the vertebrate brain was originally a pair of median eyes is by far the most important clue to the ancestry of the vertebrate, for not only do they correspond exactly in position with the median eyes of the invertebrates, but, being already degenerate and functionless in the lowest vertebrate, they must have been functional in a pre-vertebrate stage, thus giving the most direct clue possible to the nature of the pre-vertebrate stage. It is especially significant that in Limulus they are already partially degenerated. What, then, ought to be the structure and relation to the brain of the median and lateral eyes of the vertebrate if they originated from the corresponding organs of some one or other member of the palæostracan group?

This question will form the subject of the next chapter.

\section{SUMMLRY.}

The object of this book is to attempt to find out from what group of invertebrates the rertebrate arose: no attempt is made to speculate upon the causes of variation by means of which evolution takes place. 
A review of the animal kingdom as a whole learls to the conclusion that the upwar development of animals from an original coelenterate stock, in which the central nerrons system consists of a ring of nervons material surrounding the mouth. has led. in consequence of the elaboration of the central nerrous system, to a general plan among the higher groups of invertebrates in the topographical arrangement of the important organs. The month is situated ventrally, and leads by means of the oesophagns into an alimentary canal which is situated dorsally to the central nervous system. Thus the oesophagus pierces the central nervous system and divides it into two parts, the supra-oesophageal ganglia and the infra-cesophageal granglia. This is an 'almost universal plan among invertebrates, but apparently does not hold for vertebrates, for in them the central nervous system is always situated dorsally and the alimentary canal rentrally, and there is no piercing of the central nerrous system by an oesophagus.

Yet a remarkable resemblance exists between the central nerrous system of the vertebrate and that of the higher invertebrates, of so striking a character as to compel one school of anatomists to attempt the derivation of vertebrates from ammelids. Now, the central nervous system of vertebrates forms a hollow tube, and a diverticulum of this hollow tube. known as the intundibulum, passes to the ventral surface of the brain in the very position where the aesophagns wonld have been if that brain had belonged to an annelid or an arthropod. This school of anatomists therefore conchded that this infundibular tube represented the original inrertebrate osophagus which had become closed and no longer opened into the alimentary canal owing to the formation of a new month in the vertebrate. As, however. the alimentary canal of the vertelmate is ventral to the central nervons system. and not dorsal, as in the invertebrate, it follows that the remains of the original invertebrate month into which the œsopliagus (in the vertebrate the infundibular tube) must have opened must be searched for on the dorsal side of the rertebrate; and so the theory was put forward that the vertebrate had arisen from the ammelid by the reversal of surfaces, the back of the one animal becoming the front of the other.

The difficulties in the way of accepting such reversal of surfaces have proved insuperable, and another school has arisen which suggests that evolntion has throughout proceeded on two lines. the one forming grons of animals in which the central nerrons system is pierced by the food-chamnel and the gut therefore lies dorsally to it, the other in which the central nerrous system always lies dorsally to the alimentary eanal and is not pierced by it. In both cases the highest prodncts of the evolntion have become markedly segmented auimals. in the former, ammelids and arthropods; in the latter, vertebrates. The only evidence on which such theory is based is the existence of low forms of animals. known as the Enteropneusta, the best known example of which is callerl Buldnoglossus; they are looker mpon as aberrant ammelid forms by many observer's.

This theory does not attempt to explain the peculiarities of the tube of the vertebrate central nerrous system, or to account for the extraordinary resemblance between the structure and arrangement of the central nerrous systems of rertebrates and of the highest inrertebrate gromp.

Neither of these theories is satisfactory or has secured miversal acceptance. The problem must be considered entirely anew. What are the guiding principles in this investigation: 
The erolution of animal life on this earth can clearly, on the whole, be described as a process of upward progress culminating in the highest formman; but it must always be remembered that whole gromps of animals such as the 'Tunicata have been able to survire owing to a reverse process of degeneration.

If there is one organ more than another which increases in complexity as erolution proceeds, which is the most essential organ for upward progress, surely it is the central nerrous system, especially that portion of it called the brain. This consideration points directly to the origin of rertebrates from the most highly organized insertebrate group - the Arthropoda-for among all the groups of animals living on the earth in the present day they alone possess a central nerrous system closely comparable with that of rertebrates. Not only has an npward progress taken place in animals as a whole, but also in the tissues themselves a similar erolution is apparent, and the eridence shows that the rertebrate tissues resemble more closely those of the arthropod than of any other invertebrate group.

The evidence of geology points to the same conclusion. for the evidence of the rocks shows that before the highest mammal-man-appeared, the dominant race was the mammalian quadruped, from whom the highest mammal of allman-sprung; then comes, in Mesozoic times, the age of reptiles which were dominant when the mammal arose from them. Preceding this era we find in Carboniferous times that the amphibian was dominant, and from them the next higher group - the reptiles - arose. Below the Carboniferous come the Devonian strata with their evidence of the dominance of the fish, from whom the amphibian was directly evolred. The evidence is so clear that each succeeding higher form of rertebrate arose from the highest stage reached at the time, as to compel one to the conclusion that the fishes arose from the race which was dominant at the time when the fishes first appeared. This brings us to the Silurian age, in which the evidence of the rocks points unmistakably to the seascorpions, king-crabs, and trilobites as being the dominant race. It was preceded by the great trilobite age, and the whole period, from the first appearance of the trilobite to the time of dwindling away of the sea-scorpions, may be designated the Palæostracan age, using the term Palæostraca to inchude both trilobites and the higher scorpion and king-crab forms evolved from them. The eridence of geology then points directly and strougly to the origin of rertebrates from the Palaostraca-arthropod forms which were not crustacean and not arachnid. but gave origin both to the modern-day crustaceans and arachnids. The history of the rocks further shows that these ancient fishes, when they first appeared, resembled in a remarkable manner members of the palrestracan group, so that again and again palæontologists have found great difficulty in determining whether a fossil is a fish or an arthropod. Fortunately, there is still alive on the earth one member of this remarkable group-the Limulus, or KingCrab. On the rertebrate side the lowest non-degenerate rertebrate is the lamprey, or Petromyzon, which spends a large portion of its existence in a larval stage, known as the Ammocotes stage of the lamprey, because it was formerly considered to be a separate species and received the name of Ammocoetes. The larval stages of any animal are most raluable for the study of ancestral problems, so that it is most fortunate for the solution of the ancestry of vertebrates that Limulns on the one side and Ammocoetes on the other are 
arailable for thorough investigation and comparison. There are no trilobites still alire, but in Branchipus and Apus we possess the nearest approach to the trilobite organization among living erustaceans.

So strongly do all these different lines of argument point to the origin of rertebrates from arthropods as to make it imperative to reconsider the position of that school of anatomists who derifed rertebrates from annelids by reversing the back and front of the animal. Let us not turn the animal orer, but re-consider the position, the infundibular tube of the vertebrate still representing the osophagus of the inrertebrate, the cerebral hemispheres and basal ganglia the supra-cesophageal ganglia, the crura cerebri the osophageal commissures, and the infra-infundibular part of the brain the infra-œsophageal ganglia. It is immediately apparent that just as the invertebrate oesophagus leads into the large cephalic stomach. so the infundibular tube leads into the large cavity of the brain known as the third ventricle, which. together with the other ventricles, forms in the embryo a large anterior dilated part of the neural tube. In the arthropod this cephalic stomach leads into the straight narrow intestine; in the vertebrate the fourth ventricle leads into the straight narrow canal of the spinal cord. In the arthropod the intestine terminates in the anus; in the rertebrate embryo the canal of the spinal cord terminates in the anus by way of the neurenteric canal. Keep the animal unreversed, and immediately the whole mystery of the tubular nature of the central nerrous system is revealed, for it is seen that the nervous matter, which corresponds bit by bit with that of the arthropod. has surrounded to a greater or less extent and amalgamated with the tube of the arthropod alimentary canal, and thus formed the so-called central nerrous system of the rertebrate.

The manner in which the nervons material has invaded the walls of the tube is clearly shown both by the study of the comparative auatomy of the central nervous system in the vertebrate and also by its development in the embryo.

This theory implies that the vertebrate alimentary canal is a new formation necessitated by the urgency of the case, and, indeed, there was canse for urgency, for the general plan of the evolution of the invertebrate from the coelenterate involved the piercing of the anterior portion of the central nerrous system by the osophagus, while, at the same time, upward progress meant brain-development; brain-derelopment meant concentration of nervous matter at the anterior end of the animal, with the result that in the highest scorpion and spider-like animals the brain-mass has so grown round and compressed the food-tube that nothing but fluid pabulum can pass through into the stomach; the whole group have become blood-suckers. These kinds of animals-the sea-scorpions-were the dominant race when the vertebrates first appeared: here in the natural competition among members of the dominant race the difficulty must have become acute. Further upward evolution demanded a larger and larger brain with the ensuing consequence of a greater and greater difficulty of food-supply. Nature's mistake was rectified and further evolution secured, not by degeneration in the brain-region, for that means degradation not upward progress. but by the formation of a new food-channel, in consequence of which the brain was free to develop to its fullest extent. Thus the great and mighty kingdom of the Vertebrata was evolved with its culminating organism-man-whose massive brain with all its possibilities could never have been evolved if he had still been 
compelled to pass the whole of his food throngh the narrow cesophageal tube. still existent in him as the infundibular tube. This, then, is the working hypothesis upon which this book is written. If this riew is right, that the Vertebrate was formed from the Paleostracan withont any reversal of surfaces, but by the amalgamation of the central nerrous system and alimentary canal, then it follows that we have varions fixed points of comparison in the central nervous systems of the two gromps of animals from which to search for further clues. It further follows that from such starting-point every organ of importance in the body of the arthropod ought to be visible in the corresponding position in the vertebrate, either as a functional or rudimentary organ. The subsequent chapters will deal with this detailed comparison of organs in the arthropod and rertebrate respectively. 


\section{CHAPTER II}

\section{THE EVIDENCE OF THE ORGANS OF VISION}

Different kinds of eye-Simple and compound retinas. - Upright and inverted retinas.-Median eyes.-Median or pineal eyes of Ammocotes and their optic ganglia.-Comparison with other median eyes.-Lateral eyes of vertebrates compared with lateral eyes of crustaceans.-Peculiarities of the lateral eye of the lamprey.-Meaning of the optic diverticula.-Erolntion of vertebrate eyes.-Summary.

\section{The Different Kinds of Eye.}

Is all animals the eyes are composed of two parts. 1. A set of special sensory cells called the retina. 2. A dioptric apparatus for the purpose of forming an image on the sensory cells. The simplest eye is formed from a modified patch of the surface-epithelium; certain of the hypodermal cells, as they are called, elongate, and their cuticular surface becomes bulged to form a simple lens. These elongated cells form the retinal cells, and are connected with the central nervous system by nerve-fibres which constitute an optic nerve; the cells themselves may contain pigment.

The more complicated eyes are modifications of this type for the purpose of making hoth the retina and the dioptric apparatus more perfect. According to a very prevalent view, these modifications have been brought about by invaginations of the surface-epithelinm. Thus if ABCD) (Fig. 28) represents a portion of the surface-epithelium, the chitinous cuticle being represented by the dark line, with the hypodermal cells beneath, and if the part $\mathrm{C}$ is modified to form an optic sense-plate, then an invagination occurring between $\mathrm{A}$ and $\mathrm{B}$ will throw the retinal sense-cells with the optic nerve further from the surface, and the layers $B$ and $A$ between the retina and the source of light will be available for the formation of the dioptric apparatus. The lens is now formed from the cuticular surface of $A$, and the 
hypodermal cells of A elongate to form the layer known by the name of corneagen, or vitreogen, the cells of B remaining small and forming the pre-retinal layer of cells. The large optic nerve end-cells of the retinal layer, C, take up the position shown in the figure, and their cuticular surface becomes modified to form rods of varying shape called rhabdites, which are attached to the retinal cells. Frequently the rhabdites of neighbouring cells form definite groups, each group being called a rhabdome. Whatever shape they take it is invariably found that these little rods (bacilli), or rhabdites, are modifications of the cuticular surface of the cells which form the retinal layer. Also, as must necessarily be the case from the method of formation, the optic nerve arises from the nuclear end of the retinal cells, never from
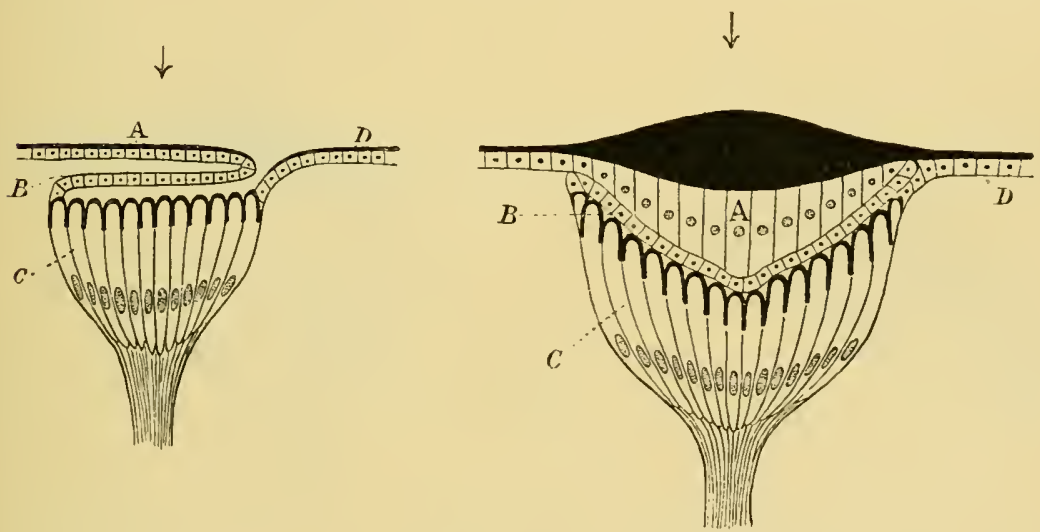

Fig. 28.-Diagram of Formation of an Upright Simple Retina.

the bacillary end. As in the case first mentioned, so in this case, the light strikes direct upon the bacillary end of the retinal cells; such eyes, therefore, are eyes with an upright retina.

It may happen that the part invaginated is the optic sense-plate itself, as would be the case if in the former figure, instead of $\mathrm{C}$, the part $\mathrm{B}$ was modified to form a sense-plate. This will give rise to an eye of a character different from the former (Fig. 29). The optic nerve-fibres now lie between the source of light and the retinal endcells, the layer $\mathrm{A}$ as before forms the cuticular lens, and its hypodermal cells elongate to form the corneagen; there is no pre-retinal layer, but, on the contrary, a post-retinal layer, C, called the tapetum, and, as is seen, the light passes through the retinal layer to the 
tapetum. The cuticular surface of the retinal cells forming the rods or bacilli is directed towards the tapetal layer away from the source of light, and the nuclei of the retinal cells are pre-bacillary in position, in contradistinction to the upright eye, where they are post-bacillary. The retinal end-cells are devoid of pigment, the pigment being in the tapetal layer.

Such an eye, in contradistinction to the forner type, is an eye with an invertcd retina; but still the same law holds as in the former case-the optic nerve-fibres enter at the nuclear ends of the cells, and the rods are formed from the cuticular surface.

In these eyes the pigmented tapetal layer is believed to act as a looking-glass; the dioptric apparatus throws the image on to its
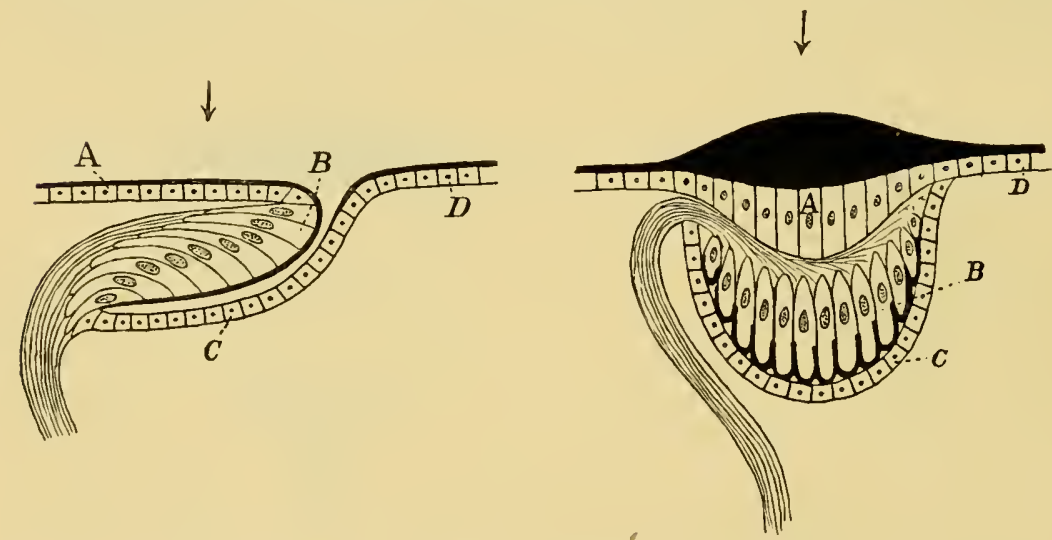

Fig. 29.-Diagram of Formation of an Inverted Simple Retina.

The arrow shows the direction of the source of light in this as in the preceding figure.

In both figures the cuticular rhabdites are represented by thick black lines.

shiny surface, from whence it is reflected directly on to the rods, which are in close contact with the tapetum. A similar proeess has been suggested in the case of the mammalian lateral eye, with its inverted retina. Johnson describes the post-retinal pigmented layer as being frequently coloured and shiny, and imagines that it reflects the image directly back on to the rods.

Thus we see that eyes can be placed in different categories, e.g. those with an upright retina and those with an inverted retina; also, according to the presence or absence of a tapetum, eyes have been grouped as tapetal or non-tapetal. All the eyes considered so far are called simple eyes, or ocelli; and a number of ocelli may be 
contiguous though separate, as in the lateral eyes of the scorpion. They may, however, come into close contact and form one single, large, compound eye. Such ocelli, in a very large number of cases, retain each its own dioptric apparatus, and therefore the external appearance of the compound eye represents not a single lens, but a large number of facets, as is seen in the eyes of insects. Owing to these differences, eyes have been divided into simple and compound, and into facetted and non-facetted.

Yet another complication occur's in the formation of eyes, which is, perhaps, the most important of all : the retinal portion of the eye, instead of consisting of simple retinal cells, with their accompanying rhabdites, may include within itself a portion of the central nervous system.

The rationale of such a formation is as follows: The external covering of the body is formed by a layer of external epithelial cells - the ectodermal cell-layer-and an underlying neural layer, of which the latter gives origin to the central nervous system. As development proceeds, this central nervous system sinks inwards, leaving as its connection with the ectoderm the sensory nerves of the skin. That part of the neural layer which underlies the optic plate forms the optic ganglion, and when the central nervous system leaves the surface to take up its deeper position, the strand of nerve-fibres known as the optic nerve, is left connecting it with the retinal cells as seen in Figs. 28, 29. It may, however, happen that part of the optic ganglion remains at the surface, in close connection with the retinal end-cells, when the rest of the central nervous system sinks inwards. The retina of such an eye is composed of the combined optic ganglion and retinal end-cells; the strand of nerve-fibres which is left as the connection between it and the rest of the brain, which is also called the optic nerve, is not a true peripheral nerve, as in the first case, but rather a tract of fibres connecting two parts of the brain, of which one has remained at the periphery. Such a retina, in contradistinction to the first kind, may be called a compound retina.

The optic ganglion, as seen in eyes with a simple retina, consists of a cortical layer of small, round nerve-cells, and an internal medulla of fine nerve-fibres, which form a thick network known as 'Punctsubstanz,' or in modern terminology, 'Neuropil.' Fibres which pass into this 'neuropil' from other parts of the brain connect them with the optic ganglion. 
At the present time, owing to the researches of Golgi, Ramón y Cajal, and others, the nervous system is considered to be composed of a number of separate nerve-units, called neurones, each neurone consisting of a nerve-cell with its various processes; one of these -the neuraxon-constitutes the nerve-fibre belonging to that nervecell, the other processes-the dendrites-establish communication with other neurones. The place where these processes come together is called a synapse, and the tangle of fine fibres formed at a number of synapses forms the 'neuropil.'

When, therefore, a compound retina is formed by the amalgamation of the ectodermal part-the retinal cells proper-with the neurodermic part-to which the name 'retinal ganglion' may be
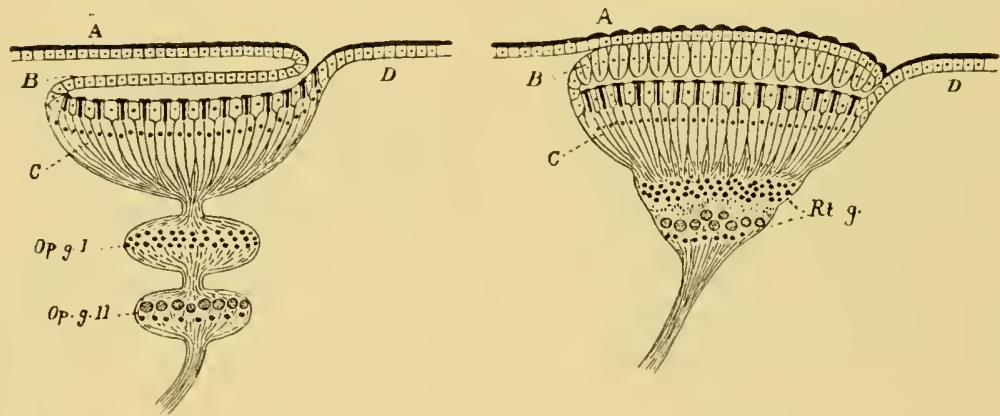

Fig. 30.-Diagram of Formation of ax Ujright Compondid Retina.

$A B C D$, as in Fig. 28. Op.g. I. and $O p . g . I I$., two optic ganglia which combine to form the retinal ganglion, Rt. $g$.

given,-such a retina consists of neuropil substance and nerve-cells, as well as the retinal end-cells. In all such compound retinas, the retinal ganglion is not single, but two optic ganglia at least are included in it, so that there are two sets of nerve-cells and two synapses are always formed; one between the retinal end-cells and the neurones of the first optic ganglion, which may be called the ganglion of the retina, the other between the first and second ganglia, which, seeing that the neuraxons of its cells form the optic nerve, may be called the ganglion of the optic nerve. The 'neuropil' formed by these synapses forms the molecular layers of the compound retina, and the cells themselves form the nuclear layers. Thus an upright compound retina, formed in the same way as the upright simple retina, would be illustrated by Fig. 30 . 
Further, in precisely the same way as in the case of the simple retina, such a compound retina may be upright or inverted. Thus, in the lateral eyes of crustaceans and insects, a compound retina of this kind is formed, which is upright; while in the vertebrates the compound retina of the lateral eyes is inverted.

The compound retina of vertebrates is usually described as composed of a series of layers, which may be analyzed into their several componeuts as follows:-

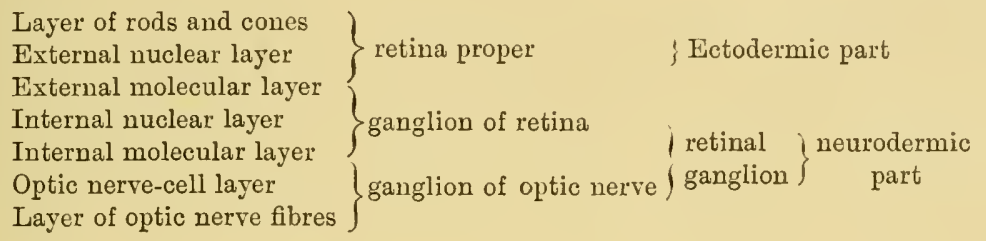

The difference between the development of these two types of eye-those with a simple retina and those with a compound retinahas led, in the most natural manner, to the conception that the retina is developed, in the higher animals, sometimes from the cells of the peripheral epidermis, sometimes from the tissue of the brain-two modes of development termed by Balfour 'peripheral' and 'cerebral.' An historical survey of the question shows most conclusively that all investigators are agreed in ascribing the origin of the simple retina to the peripheral method of development, the retina being formed from the hypodermal cells by a process of invagination, while the cerebral type of development has been described only in the development of the compound retina. The natural conclusion from this fact is that, in watching the development of the compound retina, it is more difficult to differentiate the layers formed from the epidermal retinal cells and those formed from the epidermal optic ganglioncells, than in the case of the simple retina, where the latter cells withdraw entirely from the surface. This is the conclusion to which Patten has come, and, indeed, judging from the text-book of Korschelt and Heider, it is the generally received opinion of the day that, as far as the Appendiculata are concerned, the retina, in the true sense-the retinal end-cells, with their cuticular rods,-is formed, in all cases, from the peripheral cells of the hypodermal layer, the cuticular rods being modifications of the general cuticular surface of the body. The apparent cerebral development of the crustacean 
retina, as quoted from Bobretsky by Balfour, is therefore in reality the development of the retinal ganglion, and not of the retina proper.

There is, I imagine, a universal belief that the natural mode of origin of a sense-organ, such as the eye, must always have been from the cells forming the external surface of the animal, and that direct origin from the central nervous system is a priori most improbable. It is, therefore, a matter of satisfaction to find that the evidence for the latter origin has universally broken down, with the single exception of the eyes of vertebrates and their degenerated allies; a fact which points strongly to the probability that a reconsideration of the evidence upon which the present teaching of the origin of the vertebrate eye is based will show that here, too, a confusion has arisen between that part formed from the epidermal surface and that from the optic ganglion.

\section{The Median or Pineal Eyes.}

Undoubtedly, in recent times, the most important clue to the ancestry of vertebrates has been given by the discovery that the so-called pineal gland in the vertebrate brain is all that remains of a pair of median or pineal eyes, the existence of which is manifest in the earliest vertebrates; so that the vertebrate, when it first arose, possessed a pair of median eyes as well as a pair of lateral eyes. The ancestor of the vertebrate, therefore, must also have possessed a pair of median eyes as well as a pair of lateral eyes.

Very instructive, indeed, is the evidence with regard to these median eyes, for one of the great characteristics of the ancient paliostracan forms is the invariable presence of a pair of median eyes as well as a pair of lateral eyes. In the living representative of such forms-Limulus-the pair of median eyes (Fig. 5) is well shown, and it is significant that here, according to Lankester and Bourne, these eyes are already in a condition of degeneration; so also in many of the Palæostraca (Fig. 7) the lateral eyes are the large, well-developed eyes, while the median eyes resemble those of Limulus in their insignificance.

We see, then, that in the dominant arthropod race at the time when the fishes first appeared, the type of eyes consisted of a pair of well-developed lateral eyes and a pair of insignificant, partially degenerated, median eyes. Further, according to all palicontologists, 
in the best-preserved head-shields of the most ancient fishes, especially well seen in the Osteostraci, in Cephalaspis, Tremataspis, Auchenaspis, Keraspis, a pair of large, prominent lateral eyes existed, between which, in the mid-line, are seen a pair of small, insignificant median eyes.

The evidence of the rocks, therefore, proves that the pair of median eyes which were originally the principal eyes (Hauptaugen), had already, in the dominant arthropod group been supplanted by a pair of lateral eyes, and had, in consequence, become small and insignificant, at the time when vertebrates first appeared. This dwindling process thus initiated in the arthropod itself has steadily continued ever since through the whole development of the vertebrates, with the result that, in the highest vertebrates, these median or pineal eyes have become converted into the pineal gland with its 'brain-sand.'

In the earliest vertebrate these median eyes may have been functional; they certainly were more conspicuous than in later forms. Alone among living vertebrates the right median eye of Ammoccetes is so perfect and the skin covering it so transparent that I have always felt doubtful whether it may not be of use to the animal, especially when one takes into consideration the undeveloped state of the lateral eyes in this animal, hidden as they are under the skin. Thus the one living vertebrate which is comparable with these extinct fishes is the one in which one of the pineal eyes is most well defined, most nearly functional.

Before passing to the consideration of the structure of the median eyes of Ammocoetes, it is advisable to see whether these median eyes in other animals, such as arachnids and crustaceans, belong to any particular type of eyes, for then assuredly the median eyes of Ammocates ought to belong to the same type if they are derived from them.

In the specialized crustacean, as in the specialized vertebrate, the median eyes have disappeared, at all events in the adult, but still exist in the primitive forms, such as Branchipus, which resemble the trilobites in some respects. On the other hand, the median eyes have persisted, and are well developed in the arachnids, both scorpious and spiders possessing a well-developed pair. The characteristics of the median eyes must then be especially sought for in the arachnid group.

Both scorpions and spiders possess many eyes, of which two are 
always separate and median in position, while the others form lateral groups; all these eyes possess a simple retina and a simple corneal lens. Gronacher was the first to point out that in the spiders two very distinct types of eye are found. In the one the retina is upright; in the other the retina is inverted, and the eye possesses a tapetal layer. The distribution of these two types is most suggestive, for the inverted retina is always found in the lateral eyes, never in the two median eyes; these always possess a simple upright retina.

In the crustaceans, the lateral eyes differ also from the median eyes, but not in the same way as in the arachnids; for here both types of eye possess an upright retina, but the retina of the lateral eyes is compound, while that of the median eyes is simple. In other words, the median eyes are in all cases eyes with a simple upright retina and a simple cuticular lens, while the retina of the lateral eyes is compound or may be inverted, according as the animal in question possesses crustacean or arachnid affinities. The lateral eye of the vertebrate, possessing, as it does, an inverted compound retina, indicates that the vertebrate arose from a stock which was neither arachnid nor crustacean, but gave rise to both groups-in fact, was a member of the great palæostracan group. What, then, is the nature of the median eyes in the vertebrate?

\section{The Median Eyes of Ammoccetes.}

The evidence of Ammocetes is so conclusive that I, for one, cannot conceive how it is possible for any zoologist to doubt whether the parietal organ, as they insist on calling it, had ever been an eye, or rather a pair of eyes.

Any one who examines the head of the larval lamprey will see on the dorsal side, in the median line, first, a somewhat circular orifice - the unpaired nasal opening; and then, tailwards to this, a wellmarked circular spot, where the skin is distinctly more transparent than elsewhere This spot coincides in position with the underlying dorsal pineal eye, which shines out conspicuously owing to the glistening whiteness of its pigment. Upon opening the brain-case the appearance as in Fig. 20 is seen, and the mass of the right ganglion habenulce (G.H.R.), as it has been called, stands ont conspicuously as well as the right or dorsal pineal eye $(P n$. $)$. Both eye and ganglion appear at first sight to be one-sided, but further examination shows that a left ganglion habenule is present, though much smaller than on 
the right side. In connection with this is another eye-like organ-the left or ventral pineal eye,-much more aborted, much less like an eye than the dorsal one; so also there are two bundles of peculiar fibres

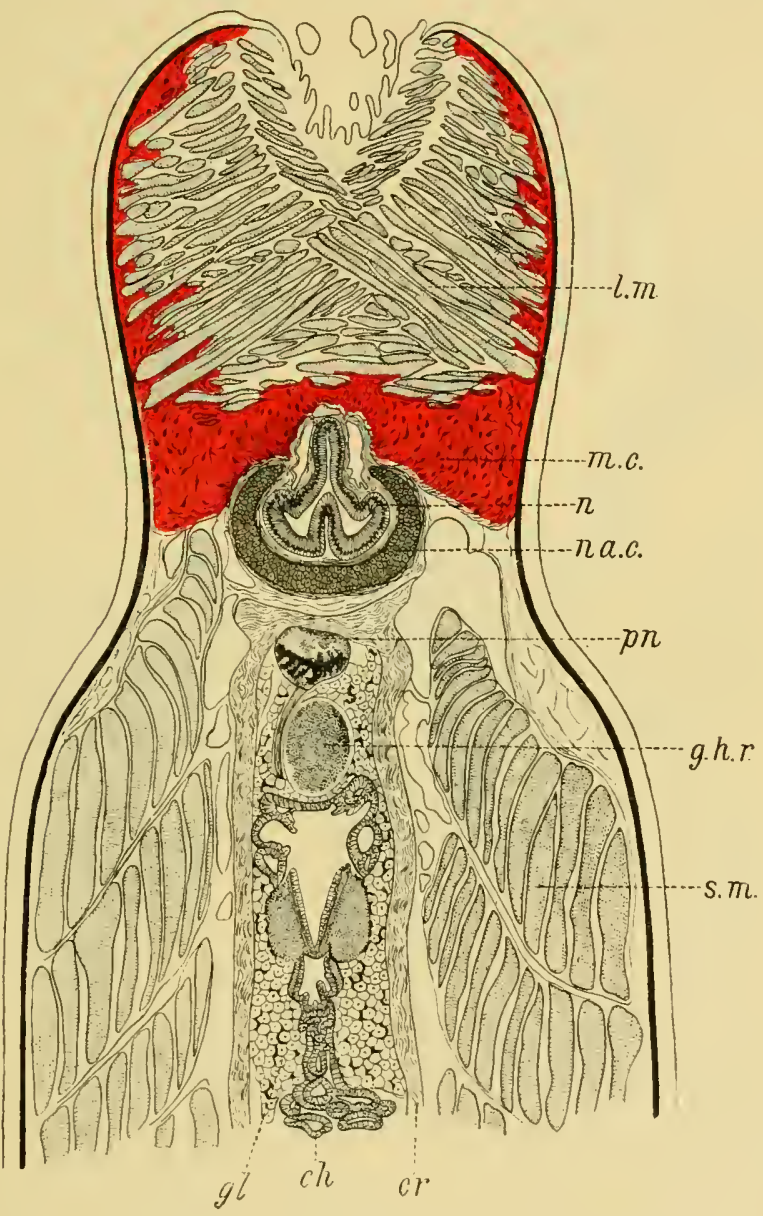

Fig. 31.-One of a Series of Horizontal Sections throcgh the Head of A Hinocetes.

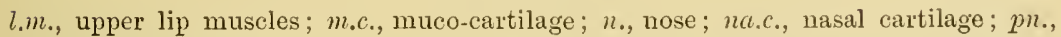
right pineal eye and nerve; g.h.r., right ganglion habenulre; s.m., somatic muscles; cr., membranous wall of cranium; ch., choroid plexus; gl., glandular substance and pigment filling up brain-case.

called Meynert's bundles, which connect this region with the infrainfundibular region of the brain; of these, the right Meynert's bundle 
is much larger than the left. This difference between right and left indicates a greater degeneration on the left side, and points distinctly to a close relationship between the nerve-masses known as ganglia habenulce and the median eyes. In my opinion this ganglion is, in part, at all events, the optic ganglion of the median eye on each side. It is built up on the same type as the optic ganglia of invertebrate
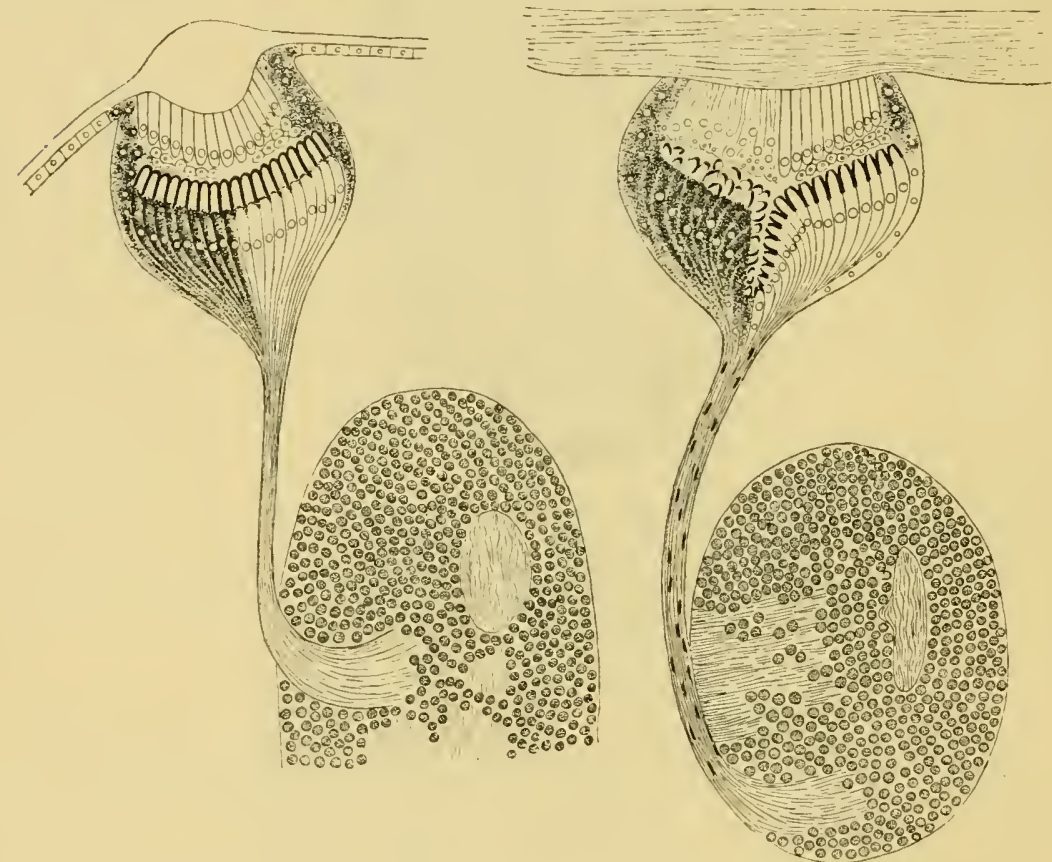

Fif. 32.-Eye of Acilius LaRYa, with its Optic Ganglion.

On the right side the nerve end-cells have been drawn free from pigment.
Fig. 33.-Pineal Eye of Ammochtes, WiTII ITS Ganglion Habenula.

On the left side the eye is drawn as it appeared in the section. On the right side I have removed the pigment from the nerve end-cells, and drawn the eye as, in my opinion, it would appear if it were functional.

simple eyes, with a cortex of small round cells and a merlulla of fine nerve-fibres. Into this ganglion, on the right side, there passes a very well-rlefined nerve-the nerve of the dorsal eye. The eye itself with its nerve, pm., and its optic ganglion, g.h.r., is beautifully shown by means of a horizontal section through the head of Ammocotes (Fig. 31). Originally, as described by Scott, the eye stood vertically 
above its optic ganglion, and presented an appearance remarkably like Fig. 32, which represents one of the simple eyes and optic ganglia of a larva of Acilius as described by Patten; then, with the forward growth of the upper lip, the right pineal eye was dragged forward and its nerve pulled horizontally over the ganglion havenulce. For this reason the eye, nerve, and ganglion are better shown in a nearly horizontal than in a transverse section.

The optic nerve belonging to this eye is most evident and clearly shown in Fig. 31, and in the series of consecutive sections which follow upon this section; no doubt can arise as to the structure in question having been the nerve of the eye, even though, as is possible, it does not contain any functional nerve-fibres.

The second, ventral or left, eye, belonging to the left ganglion habenulie is very different in appearance, being much less evidently an eye. Fig. 34 is one of the same

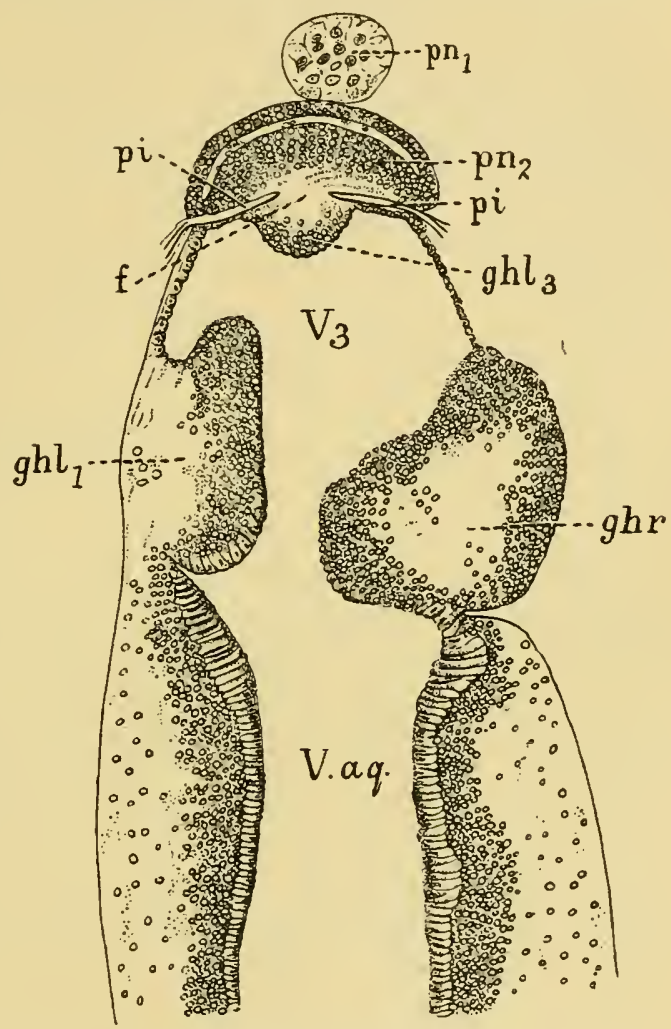

Fig. 34.-Horizontal Section throvgh Brain of Amocetes, to show the Left, OR Vextral Pineal Eve.

$p n_{.2}$, left or ventral pineal eye; $p n_{\cdot 1}$, last remnant of right, or dorsal pineal eye; g.h.r., right ganglion habenula; g.h.l... g.h.l..$_{3}$, parts of left ganglion habenule; pi., fold of pia mater which separates the left ganglion habenula from the left pineal eye; $f_{.}$, strands of nerve-fibres connecting the left eye with its ganglion, g.h.l..$_{3} ; V_{3}$, third

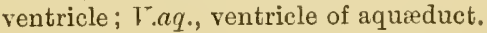

series of horizontal sections as Fig. $31, p n_{.1}$ being the last remnant of the right, or dorsal, eye, while $p n_{.2}$ shows the left, or ventral, eye with its connection with the left ganglion habenule. 
In a series of sections I have followed the nerve of the right pineal eye to its destination, as described in my paper in the Quarterly Journal of Microscopical Science, and have found that it enters into the ganglion habenule just as the nerve to any simple eye enters into its optic ganglion. This nerve, as I have shown, is a very distinct, well-defined nerve, with no admixture of ganglion-cells or of connective tissue, very different indeed to the connection between the left pineal eye and its optic ganglion. Here there is no defined nerve at all; but the cells of the ganglion habcnula stretch right up to the remains of the eye itself. Seeing, then, that both the eye and ganglion on this side have reached a much further grade of degeneration than on the right side, it may be fairly concluded that the original condition of these two median eyes is more nearly represented by the right eye, with its well-defined nerve and optic ganglion, than by the left eye, or by the eyes in lizards and other animals which do not show so well-defined a nerve as is possessed by Ammoccetes. Quite recently Dendy has examined the two merlian eyes in the New Zealand lamprey Geotria australis. In this species the second eye is much better defined than in the European lamprey, and its connection with the ganglion habenulce is more nerve-like. In neither eye, however, is the nerve so clean cut and isolated as is the nerve of the dorsal, or right, eye in the Ammocetes stage of Petromyson Planeri; in both, cells resembling those of the cortex of the ganglion habenulce and connective tissues are mixed up with the nerre-fibres which pass from each eye to its respective optic ganglion.

\section{The Right Pineal Eye of Ammoceetes.}

The optic fibres of the right median eye of Ammocoetes are connected with a well-defined retina, the limits of which are defined by the white pigment so characteristic of this eye. This pigment is apparently calcium phosphate, which still remains as the 'brain-sand' of the human pineal gland. The cells, which are hidden by this pigment, were described by me in 1890 as the retinal end-cells with large nuclei. In 1893, Studniçka examined them more closely, and concluded that the retinal cells are of two kinds: the one, nerve end-cells, the sensory cells proper; the other, pigmented epithelial cells, which surround the sense-cells. The sense-cells may contain some of the white pigment, but not so much as the other cells. Similarly, in the 
median eyes of Limulus, Lankester and Bourne find it difficult to determine how far the retinal end-cells contain pigment and how far that pigment really is in the cells surrounding these nerve end-cells.

The interior of the eye presents the appearance of a cavity in shape like a cornucopia, the stalk of which terminates at the place where the nerve enters. This cavity is not empty, but the posterior part of it is filled with the termination of the nerve end-cells of the retina, as pointed out by me and confirmed by Studniçka. These terminations are free from pigment, and contain strikingly translucent bodies, which I have described in my paper in the Qucerterly Joumal, and called rhabdites, for they present the same appearance and are situated in the same position as are many of the rhabdites on the terminations of the retinal eud-cells of arthropod eyes. Studniçka has also seen these appearances, and figures them in his second paper on the nerve end-cells of the pineal eye of Ammoccetes.

$\mathrm{Up}_{\mathrm{p}}$ to this point the following conclusions may be drawn :-

1. Ammocoetes possesses a pair of median eyes, just as was the case with the most ancient fishes, and with the members of the contemporary palieostracan group.

2. The retina of one of these eyes is well-defined and upright, not inverted, and therefore in this respect agrees with that of all median eyes.

3. The presence of nerve end-cells, with pigment either in them or in cells around them, to the unpigmented ends of which translucent bodies resembling rhabdites are attached, is another proof that this retina agrees with that of the median eyes of arthropods.

4. The simple nature of the nerve with its termination in an optic ganglion closely resembling in structure an arthroporl optic ganglion, together with Studniçka's statement that the nerve end-cells pass directly into the nerve, points directly to the conclusion that this retina is a simple, not a compound, retina, and that it therefore in this respect also agrees with the retina of all median eyes.

With respect to this last conclusion, neither I myself nor Studnicka have been able to see any definite groups of cells between the nerve end-cells and the optic nerve such as a compound retina necessitates. 
On the other hand, Dendy describes in the New Zealand lamprey, Gcotria australis, a cavity where the nerve enters into the eve, which he calls the atrium. This cavity is distinct from the main cavity of the eye, and is separated from it by a mass of cells similar in appearance to those of the cortex of the ganglion habenula. In these two eyes then, groups of cells, resembling in appearance those helonging to an optic ganglion, exist in the eyes themselves. This atrium is evidently that part of the central cavity which I have. ealled the handle of the cornucopia in the European lamprey, and the very fact that it is separated from the rest of the central cavity is evidence that we are dealing here with a later stage in the history of the pineal eyes than in the case of the Ammocoetes of Pctromy:on Ilaneri. Taking also into consideration the continuity of the mass of small ganglion-cells which surround this atrium with the cells of the ganglion habenule by means of the similar cells scattered along the course of the nerve, and also bearing in mind the fact already stated that in the more degenerate left eye of Ammocotes the cells of the ganglion labenula extend right up to the eye itself, it seems more likely than not that these cells do not represent the original optic ganglion of a compound retina, but rather the subsequent invasion, by way of the pineal nerve, of ganglion-cells belonging to a portion of the brain. In the last chapter it has been suggested that the presence of the trochlear or fourth cranial nerve has given rise to the formation of the cerebellum by a similar spreading.

There is certainly no appearance in the least resembling a compound retina such as is seen in the vertebrate or crustacean lateral eye. In the median eyes of scorpions and of Limulus, cells are found within the capsule of the eye among the nerve-fibres and the nerve end-cells. These are especially numerous in the median eyes of Limulus, as described by Lankester and Bourne, and are called by them intrusive connective tissue cells. The meaning of these cells is not, to my mind, yet settled. It is sufficient for my purpose to point out that the presence of cells interneural in position among the nerve end-cells of the retina of the median eyes of Ammoceetes is more probable than not, on the assumption that the retina of these eyes is built up on the same plan as that of the median eyes in Limulus and the scorpions.

It is further to be borne in mind that these specimens of Gcotria worked at by Dendy were in the 'Velasia' stage of the New Zealand 
lamprey, and correspond, therefore, more nearly to the P'etromyzon than to the Ammoccetes stage of the European lamprey.

\section{The Dioptilc Apparatus.}

Besides the retina, all eyes possess a dioptric apparatus. What is the evidence as to its nature in these vertebrate median eyes? Lankester and Bourne have divided the eyes of seorpions and

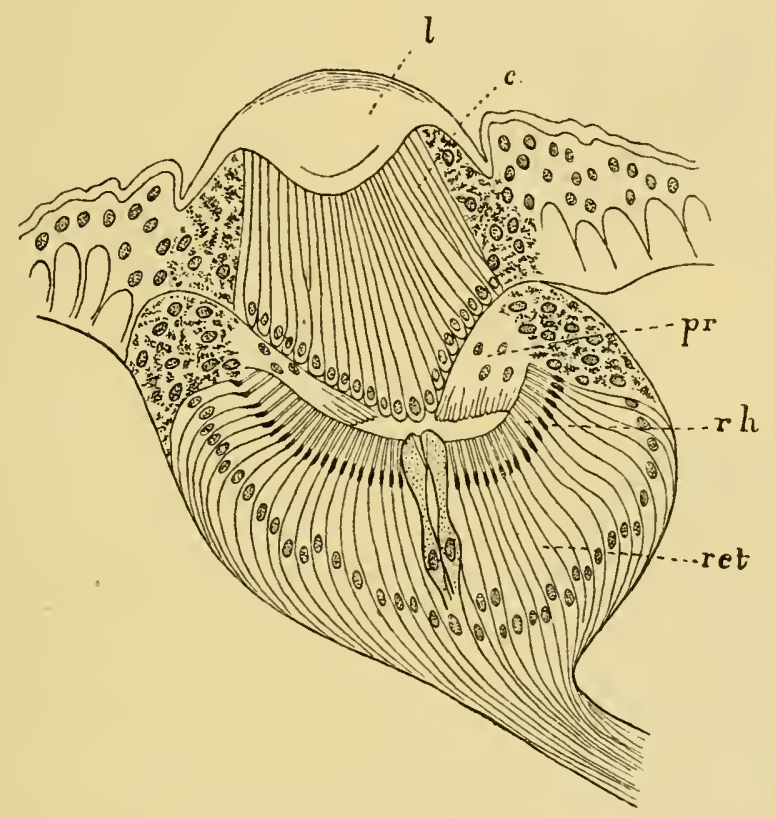

Fig. 35.-Eye of Acilius Larvai. (After Pattex.)

$l$., chitinous lens ; $c$., corneagen ; $m$., pre-retinal layer; $r h$, rhabdites ; ret., retinal end-cells.

Limulus into two kinds, monostichous and diplustichous. In the first the retinal cells are supposed to give rise to not only rhabdites but also the cuticular chitinous lens, so that the eye is one-layered; in the second the lens is formed by a well-marked hypoclermal layer, in front of the retina, composed of elongated cells, so that these eyes are two-layered or diplostichous. The lateral eyes, according to them, are all monostichous, but the median eyes are diplostichous.

This distinetion is not considered valid by other observers. Thus, 
as already indieated, P'atten looks on all these eyes as three-layered, and states that in all cases a corneagen or vitreogen layer exists, which gives origin to the lens. For my own part I agree with

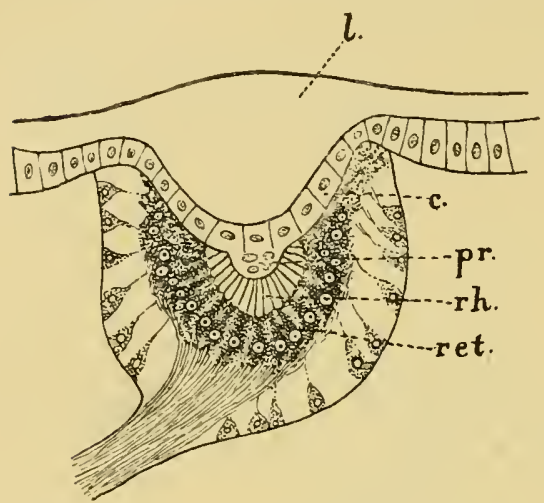

Fig. 36.-Ere of Hrdrophilus Larva, with the Pigment over the Retinal END-CELLS.

l., chitinous lens; c., corneagen; pr., preretinal layer; $r \cdot h_{\text {., }}$ rhabdites; ret., retinal end-cells.

Patten, but we are not con. cerned here with the lateral eyes. It is sufficient to note that all olsservers are agreed that the median eyes are characterized by this well marked cell-layer, the so-called vitreous or corneagen layer of cells.

This layer (c., Fig. 35) is composed of much-elongated cells of the hypodermal layer, in each of which the large nucleus is always sitnated towards the base of the cell. The space between it and the retina contains, according to Patten the cells of the pre-

retinal layer $(j r$.$) . These may be so few and insignificant as to give$ the impression that the vitreous layer is immediately adjacent to the retina (ret.).

Let us turn now to the right pineal eye of Ammocoetes (Fig. 37) and see what its further structure is. The anterior part of the eye is free from pigment, and is composed, as is seen in hæmatoxylin or carmine specimens, of an inner layer of nuclei which are frequently arranged in a wavy line. From this nucleated layer, strands of tissue, free from nuclei, pass to the anterior edge of the eye.

In the horizontal longitudinal sections it is seen that these strands are confined to the middle of the eye. On each side of them the nuclear layer reaches the periphery, so that if we consider these strands to represent long cylindrical cells, as described by Beard, then the anterior wall may be described as consisting of long cylindrical cells, which are flanked on either side by shorter cells of a similar kind. The nuclei at the base of these cylindrical cells are not all alike. We see, in the first place, large nuclei resembling the large nuclei belonging to the nerve end-cells; these are the nuclei of 
the long cylindrical cells. We see also smaller nuclei in among these larger ones, which look like nuclei of intrusive connective tissue, or may perhaps form a distinct layer of cells, situated between the cells of the anterior wall and the terminations of the nerve end-cells already referred to.

These elongated cells are in exactly the same position and present the same appearance as the cells of the corneagen layer of any median eye. Like the latter they are free from pigment and never show with osmic staining any sign of the presence of translucent rhabdite-like bodies, sucl as are seen in the termination of the retinal cells, and like the latter their nuclei are at the base. The resemblance between this layer and the corneagen cells of any median eye is absolute. Between it and the terminations of the retinal cells there exists some ill-defined material certainly containing cells which may well correspond to Patten's pre-retinal layer of cells.

Retina, corneagen, nerve, optic ganglion, all are there, all in their right position, all of the right structure, what more is neerled to complete the

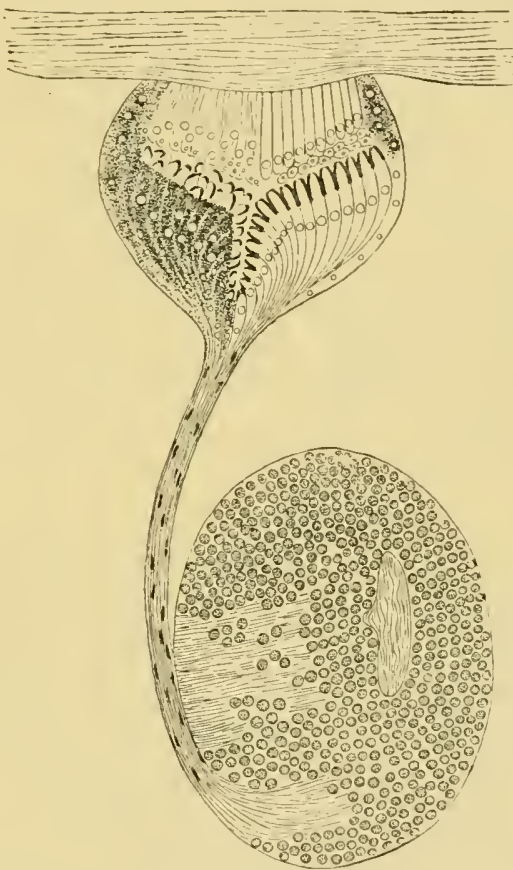

Fig. 37.-Pineal Eye of Amocetes, WiтH iтs Ganglion Habenule. picture?

In order to complete the dioptric apparatus a lens is necessary. Where, then, is the lens in these pineal eyes? In all the arachnid eyes, whether median or lateral, the lens is a single corneal lens composed of the external cuticle, which is thickened over the corneagen cells. This thickened cuticle is composed of chitin, and is not cellular, but is dead material formed out of the living underlying corneagen cells. Such a lens is in marked contrast to the lens of the lateral vertebrate eye, which is formed by living cells themselves. This 
thickening of the cuticular layer to form a lens could only exist as long as that layer is ahsolutely external, so that the light strikes immediately upon it; for, if from any cause the cye became situated internally, the place of such a lens must be filled by the structures situated between it and the surface, and the thickened cuticle would no longer be formed.

In all vertebrates these pineal eyes are separated from the external surface by a greater or less thickness of tissues; in the case of Ammocotes, as is seen in Fig. 31, the eye lies within the membranous cranial wall, and is attached closely to it. The position, then, of the cuticular, or corneal lens, as it is often called, on the supposition that this is a median eye of the arachnid type, is taken by the membranous cranium, and, as I have described in my paper in the Quarterly Journal, on carefully lifting the eye in the fresh condition from the cranial wall, it can be seen under a dissecting microscope that the cranial wall often forms at this spot a lens-like bulging, which fits the shallow concavity of the surface of the eye, and requires some little force to separate it from the eye.

As will appear in a subsequent chapter, this cranial wall has been formed by the growth, laterally and dorsally, of a skeletal structure known by the name of the plastron. The last part of it to be completed would be that part in the mid-dorsal line, where apparently, in consequence of the insinking of the degenerating eyes, a dermal and subdermal layer already intervened between the source of light and the eyes themselves.

When the membranous cranium was completed in the mid-dorsal region, it was situated here as elsewhere just internally to the subdermal layer, and therefore enclosed the pineal eyes. This, to my mind, is the reason why the pineal eyes, which, in all other respects, conform to the type of the median eyes of an arachnid-like animal, (lo not possess a cuticular lens. Other observers have attempted to make a lens out of the elongated cells of the anterior wall of the eye (my corneagen layer), but without success.

Studniçka, who calls this layer the pellucida, does not look upon it as the lens, but considers, strangely enough, that the transhicent appearances at the ends of each nerve end-cell represent a lens for that cell, so that every nerve end-cell has its own lens. Still more strange is it that, holding this view, he should yet consider these knobs 
to be joined by filaments to the cells in the anterior wall of the eye, a conception fatal to the action of such knobs as lenses.

The discovery that the vertebrate possesses, in addition to the lateral eyes, a pair of median eyes, which are most conspicuous in the lowest living vertebrate, together with the fact that such eyes are built up on the same plan as the median eyes of living crustaceans or arachnids, not only with respect to the eye itself but also to its nerve and optic ganglion, constitutes a fact of the very greatest importance for any theory of the origin of vertebrates; especially in view of the further fact, that similar eyes in the same position are found not only in all the members of the Palienstraca, but also in all those ancient forms (classed as fishes) which lived at that time. At one and the same moment it proves the utter impossibility of reversing dorsal and ventral surfaces, points in the very strongest manner to the origin of the vertcbrate from some member or other of the palrostracan group, and insists that the advocates of the origin of vertebrates from the Hemichordata, etc., should give an explanation of the presence of these two median eyes of a more convincing character than that given here.

\section{The Laterat Eyes.}

Turning now to the consideration of the lateral eyes, we see that these eyes in the arachnids often possess an inverted retina, in the crustaceans always an upright retina. In the arachnids they possess a simple retina, while in the crustaceans their retina is compound; so that in the latter case the so-called optic nerve is in reality a tract of fibres connecting together the brain-region with a variable number of optic ganglia, which have been left at the periphery in close contact with the retinal cells, when the brain sunk away from the superficial epithelial covering.

There is, then, this difference between the lateral eyes of crustaceans and arachnids, that the retina of the former is compound, but never inverted, while that of the latter may be inverted, but is always simple.

The retina of the lateral eyes of the vertebrate resembles both of these, for it is compound, as in the crustacean, and inverted as in the arachnicl.

It must always be borne in mind that in the palrostracan epoch 
the dominant race was neither crustacean nor arachnid, but partook of the characters of both; also, as is characteristic of dominance, there was very great variety of form, so that it seems more probable than not that some of these forms may have combined the arachmid and crustacean characteristics to the extent of possessing lateral eyes with an inverted yet compound retina. A certain amount of evidence points in this direction. As already stated, the compound retina which characterizes the vertebrate lateral eyes is characteristic of all facetted eyes, and in the trilobites facetted lateral eyes are commonly found. From this it may be concluded that many of the trilolites possessed eyes with a compound retina. There lave, however, been found in certain species, e.g. Harpes vittatus and Hrippes ungulu, lateral eyes which were not facetted, and are believed by Korschelt and Heider to be of an arachnid nature. They say, "Palæontologists have appropriately described them as ocelli, although, from a zoological point of view, they do not deserve this name, having most probably arisen in a way similar to that conjectured in connection with the lateral eyes of scorpions." If this conjecture is right, then in these forms the retina may have been inverted, hut because they belonged to the trilobite group, the retina was most probably compound, so that here we may have had the combination of the arachnid and crustacean characteristics. On the other hand, in some forms of Branchipus, and many of the Gammaricle, a single comeal lens is found in conjunction with an eye of the crustacean type, so that a non-facetted lateral eye, found in a fossil form, would not necessarily imply the arachinil type of eye with the possibility of an inverted retina. Whatever may be the ultimate decision upon these particular forms, the striking fact remains, that both in the vertebrate and in the arachnid the median eyes possess a simple upright retina, while the lateral eyes possess an inverted retina, and that both in the rertebrate and the crustacean the median eyes possess a simple upright retina, while the lateral eyes possess a compound retina.

The resemblance of the retina of the lateral eyes of vertebrates to that of the lateral eyes of many arthropods, especially crustaceans, has been pointed out by nearly every one who lias worked at these invertebrate lateral eyes. The foundation of our knowledge of the compound retina is Berger's well-known paper, the results of which are summed $n$, by him in the following two main conclusions. 
1. The optic ganglion of the Arthropoda consists of two parts, of which the one stands in direct inseparable connection with the facetted eye, and together with the layer of retinal rods forms the retina of the facetted eye, while the other part is connected rather with the brain, and is to be considered as an integral part of the brain in the narrower sense of the word.

2. In all arthropods examined by hin, the retina consists of five layers, as follows:-

(1) The layer of rods and their nuclei.

(2) The layer of nerve-bundles.

(3) The nuclear layer.

(4) The molecular layer.

(5) The ganglion cell layer.

Berger passes under review the structure and arrangement of the optic ganglion in a large number of different groups of arihropods, and concludes that in all cases one part of the optic ganglion is always closely attached to the visual end-cells, and this combination he calls the retina. On the other hand, the nerve-fibres which connect the peripheral part of the optic ganglion with the brain, the socalled optic nerve, are by no means homologous in the different groups; for in some cases, as in many of the stalk-eyed crustaceans, the whole optic ganglion is at the pe-

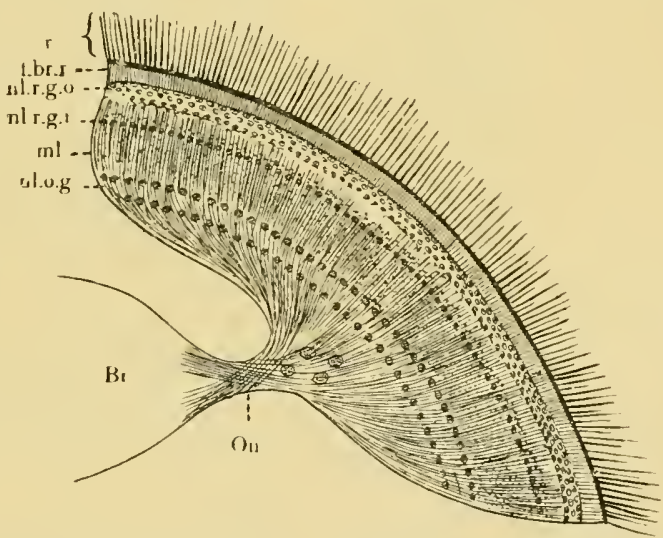

Fir. 38.--The Retina of Miusca. (After Berger.)

$\mathrm{Br}$., brain; O.n., optic nerve; n.l.o.g., nuclear layer of ganglion of optic nerve; m.l., molecular layer (Punktsubstanz); n.l.r.g.i. and n.l.r.g.o., inner and outer nuclear layers of the ganglion of the retina; f.lr.r., terminal fibre-layer of retina; $r$, layer of retinal end-colls (indicated only).

riphery, while in others, as in the Diptera, only the retinal ganglion is at the periphery, and the nerve-stalk connects this with the rest of the optic ganglion, the latter being fused with the nain brainmass. In the I)iptera, in fact, according to Terger, the optic nerve 
and retina are most nearly comparable to those of the vertebrate. For this reason I give Berger's picture of the retina of Musca (Fig. 38), in order to show the arrangement there of the retinal layers.

In Branchipus and other primitive Crustacea, Berger also finds the same retinal layers, but is unable to distinguish in the brain the rest of the optic ganglion. Judging from Berger's description of Branchipus, and Bellonci's of Sphæroma, it would almost appear as though the cerebral part of the retina in the ligher forms originated from two ganglionic enlargements, an external and

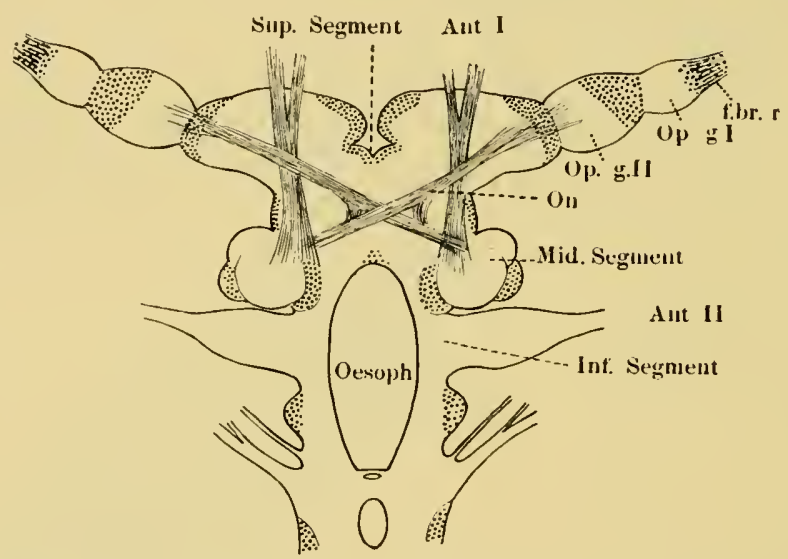

Fig. 39.-The Brain of Spharoma serratum. (After Bellonci.)

Ant. $I$. and Ant. $I I$, nerves to 1st and 2nd antennæ. f.br.r., terminal fibre-layer of retina; Op. g. I., first optic ganglion; Op.g. II., second optic ganglion; O.n., optic nerve-fibres forming an optic chiasma.

internal enlargement, as Bellonci calls them. The external ganglion (Op.g. I., Fig. 39) may be called the ganglion of the retina, the cells of which form the nuclear layer of the higher forms, and the internal ganglion $(O p . g . I I$., Fig. 39), from which the optic nerve-fibres to the brain arise, may therefore be called the ganglion of the optic nerve. Bellonci describes how in this latter ganglion cells are found very different to the small ones of the external ganglion or ganglion of the retina. So also in Branchipus, judging from the pictures of Berger, Claus, and from my own observations ( $c f$. Fig. 46 , in which the double nature of the retinal ganglion is indicated), the peripheral part of the optic ganglion-i.e. the retinal ganglion-may be spoken 
of as composed of two ganglia. The external of these is clearly the ganglion of the retina; its cells form the nuclear layer, the striking character of which, and close resemblance to the corresponding layer in vertebrates, is shown by Claus' picture, which I reproduce (Fig. 40). The internal ganglion with which the optic nerve is in connection contains large ganglion cells, which, together with smaller ones, form the ganglionic layer of Berger.

The most recent olsservations of the structure of the compound retina of the crustacean eye are those of Parker, who, by the use of the methylene blue method, and Golgi's method of staining, has been able to follow ont the structure of the compound retina in the arthropod on the same lines as had already been done for the vertebrate. These two methods have led to the conclusion that the arthropod central nervous system and the vertebrate central nervous system are built up in the same manner-viz. by means of a series of ganglia connected together, each ganglion being composed of nerve-cells, nerve-fibres, and a fine reticulated substance called by Leydig in arthropods 'Punktsubstanz,' and known in vertebrates and in invertebrates at the present time as 'neuropil.' A further analysis resolves the whole system into a combination of groups of neurones, the cells and fibres of which form the cells and fibres of the ganglia, while their denclritic

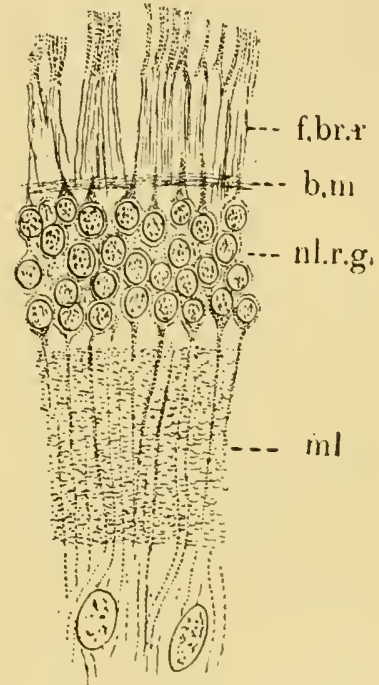

Fig. 40.-Bipolar Cells of Nuclear Layer in Retina of Branchipts. (After Claus.)

f.br.r., terminal fibre-layer of retina; n.l.r.g., bipolar cells of the ganglion of the retina $=$ inner nuclear layer; m.l., Punktsubstanz $=$ inner molecular layer ; b.m., base. ment membrane formed by neurilemma round central nervous system. connections with the terminations of other neurones, together with the neuroglia-cells form the 'neuropil.' As is natural to expect, that part of the central nervous system which helps to form the compound retina is built up in the same manner as the rest of the central nervous system.

Thus, according to Parker, the mass of nervous tissue which occupies the central part of the optic stalk in Astacus is composed 
of four distinct ganglia; the retina is connected with the first of these by means of the retinal filures, and the optic nerve extends proximally from the fourth ganglion to the brain. Each ganglion consists of ganglion-cells, nerve-fibres, and 'neuropil,' and, in ardition, supporting cells of a neuroglial type. By means of the methylene blue method and the Golgi method, it is seen that the retinal endcells, with their visual rods, are connected with the fibres of the optic nerve by means of a system of neurones, the synapses of which take place in and help to form the 'neuropil' of the various ganglia. Thus, an impulse in passing from the retina to the brain would ordinarily travel over five neurones, beginning with one of the first order and ending with one of the fifth. He makes five neurones although there are only four ganglia, because he reckons the retinal cell with its elongated fibre as a neurone of the first order, such fibre terminating in dendritic processes which form synapses in the 'neuropil' of the first ganglion with the neurones of the second order.

Similarly the neurones of the second order terminate in the 'neuropil' of the second ganglion, and so on, until we reach the nemrones of the fifth order, which terminate on the one hand in the 'neuropil' of the fourth ganglion, and on the other pass to the optic lobes of the brain by their long neuraxons-the fibres of the optic nerve.

He compares this arrangement with that of Branchipus, Apus, Estheria, Daphnia, etc, and shows that in the more primitive crustaceans the peripheral optic apparatus was composerl, not of four but of two optic ganglia, not, therefore, of five but of three neurones, viz.-

1. The neurone of the first order-i.c. the retinal cell with its fibre terminating in the 'neurnpil' of the first optic ganglion (ganglion of the retina).

2. The neurone of the second order, which terminates in the 'neuropil' of the second ganglion (ganglion of the optic nerve).

3. The neurone of the third order, which terminates in the optic lobes of the brain by means of its neuraxons (the optic nerve).

We see, then, that the most recent researches agree with the older ones of Berger, Claus, and Bellonci, in picturing the retina of the primitive crustacean forms as formed of two ganglia only, and not of four, as in the specialized crustacean group the Malacostraca. 
The comparison of the arthropod compound retina with that of the vertebrate shows, as one would expect upon the theory of the origin of vertebrates put forward in this book, that the latter retina is built up of two ganglia, as in the more primitive less specialized crustacean forms. The modern description of the rertebrate retina, based upon the Golgi method of staining, is exactly Parker's description of the simpler form of crustacean retina in which the 'neuropil' of the first ganglion is represented by the external molecular layer, and that of the second ganglion by the internal molecular layer; the three sets of neurones being, according to Parker's terminology :-

1. The neurones of the first order-viz, the visual cells-the nuclei of which form the external nuclear layer, and their long attenuated processes form syuapses in the external molecular layer with

2. The neurones of the second order, the cells of which form the internal nuclear layer, and their processes form synapses in the internal molecular layer with

3. The neurones of the third order, the cells of which form the ganglionic layer and their neuraxons constitute the fibres of the optic nerve which end in the optic lobes of the brain.

Strictly speaking, of course, the visual cells with their elongated processes have no right to be called neurones: I only use Iarker's phraseology in order to show how closely the two retinas agree even to the formation of synapses between the fine drawn-out processes of the visual cells and the neurones of the ganglion of the retina.

\section{The Ritina of the Lateral Eye of Ammocetes.}

As in the case of all other organs, it follows that if we are dealing here with a true genetic relationship, then the lower we go in the vertebrate kingdom the more nearly onght the structure of the retina to approach the arthropod type. It is therefore a matter of intense interest to determine the nature of the retina in Ammocates in order to see whether it differs from that of the higher vertebrates, and if so, whether such differences are explicable by reference to the structure of the arthropod eye.

Before describing the structure of this retina it is necessary to clear away a remarkable misconception, shared among others by 
Balfour, that this eye is an aborted eye, and that it cannot be considered as a primitive type. Thus Balfour says: "Considering the degraded character of the Ammocote eye, evidence derived from its structure must be received with caution," and later on, "the most interesting cases of partial degeneration are those of Myxine and the Ammocoete. The development of such aborted eyes has as yet been studied only in the Ammocote, in which it resembles in most important features that of other Vertebrata."

Again and again the aborted character of the eye is stated to be evidence of degeneration in the case of the lamprey. What such a statement means, why the eye is in any way to be considered as aborted, is to me a matter of absolute wonderment: it is true that in the larval form it lies under the skin, but it is equally true that at transformation it comes to the surface, and is most evidently as perfect an eye as could be clesired. There is not the slightest sign of ally degeneration or abortion, but simply of normal development, which takes a louger time than usual, lasting as it does throughout the life-time of the larval form.

Kohl, who has especially studied degenerated vertebrate eyes, discusses with considerable fulness the question of the Ammocetes eye, and concludes that in aborted eyes a retarded development occurs, and this applies on the whole to Ammocotes, "but with the important difference that in this case the period of retarded development is not followed by a stoppage, but on the contrary by a period of very highly intensified progressive development during the metamorphosis," with the result that "the aclult eye of Petromy:on Planeri does not diverge from the ordinary type."

Referring in his summing up to this retarded development, he says: "Such reminiscences of embryonic conditions are after all present here and there in normally developed organs, and by no means entitle us to speak of abnormal development."

The evidence, then, is quite clear that the eye of Petromyzon, or, indeed, of the full-glown Ammocetes, is in no sense an abnormal eye, but simply that its development is slow during the ammoccete stage. The retina of Petromyzon was figured and described by Langerhans in 1873. He describes it as composed of the following layers :-

(1) Membrana limitans interna.

(2) Thick inner molecular layer. 
(3) Optic fibre layer.

(4) Thick inner nuclear layer.

(5) Peculiar double-layered ganglionic layer.

(6) External molecular layer.

(7) External nuclear layer.

(8) Membrana limitans externe.

(9) Layer of rods.

(10) Pigment-epithelium.

He points out especially the peculiarity of layer (2) (2, Fig. 41), the inner molecular, in which two rows of nuclei are arranged with great

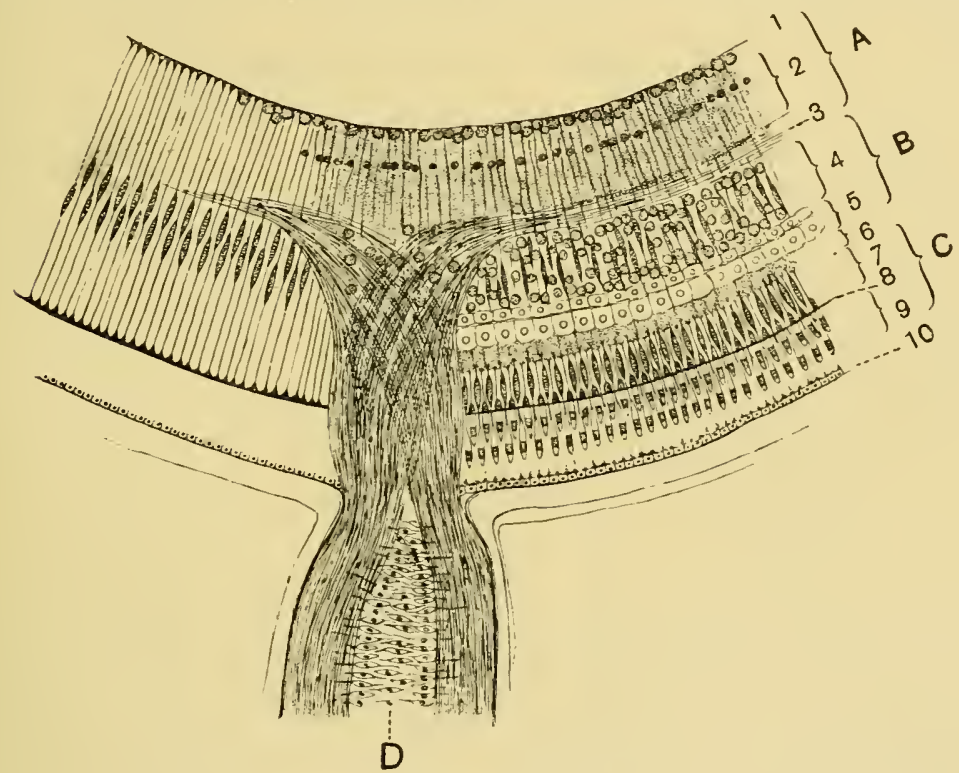

Fig. 41.-Retina and Optic Nerve of Petromyzon. (After Müller axd LANGERHANS.)

On the left side the Müllerian fibres and pigment-epithelium are represented alone.

The retina is divided into an epithelial part, $C$ (the layer of visual rod-cells), and a neurodermal or cerebral part which is formed of, $A$, the ganglion of the optic nerve and, $B$, the ganglion of the retina. 1 , int. limiting membrane; 2 , int. molecular layer with its two layers of cells; 3, layer of optic nerve fibres; 4 , int. nuclear layer; 5 , double row of tangential fulcrum cells; 6 , layer of terminal retinal fibres; 7 , ext. nuclear layer; 8 , ext. limiting membrane; 9, layer of rods; 10 , layer of pigment-epithelium. $D$, axial cell layer (Axenstrang) in optic nerve. The layer 6 is drawn rather too thick.

regularity, the one row closely touching the membrana limitans interna, the other at the inner boundary of the middle third of the 
moleenlar layer. Of these two rows of nuclei, he describes the innermost as eomposed almost entirely of large nuelei belonging to ganglion cells, while the outermost is eomposed mainly of distinetly smaller nuclei, which in staining and appearanee appear to belong not to nerve-cells but to the true retieular tissue of the moleeular layer.

He also draws speeial attention to the remarkable layer (5) (5, Fig. 41), which is not found in the retina of the higher vertebrates, the eells of which, in his opinion, are of the nature of ganglion-eells.

W. Müller, in 1874, gave a most careful description of the eye of Ammoecetes and Petromyzon, and traced the development of the retina; the subsequent paper of Kohl does not add anything new, and his drawings are manifestly diagrams, and do not represent the appearances so aceurately as Müller's illustrations. In the aceompanying figure (Fig. 41) I reproduce on the right-hand side Müller's picture of the retina of Petromyzon, but have drawn it, as in Langerhans' picture, at the place of entry of the optie nerve.

From his comparison of this retina with a large number of other rertebrate retinas, he eomes to the eonelusion that the retina of all vertebrates is divisible into

A. An eetodermal (epithelial) part consisting of the layer of the visual cells, and

B. A neurodermal (eerebral) part which forms the rest of the retina.

Further, Miiller points ont that the neuroderm gives origin thronghout the central nervous system to two totally different struetures, on the one hand to the true nervous elements, on the other to a system of supporting cells and fibres which cannot be classed as conneetive tissue, for they do not arise from mesoblast, and are therefore ealled by him 'fulerum-eells.' In the retina he recognizes two distinet groups of such supporting structures-(1) a system of radial fibres with well-marked elongated nuclei, which extend between the two limiting layers, and form at their outer ends a membrane-like expansion which was originally the outer limit of the retina, but becomes afterwards eo-terminous with the membrana limitans externu, owing to the piereing throngh it of the external limbs of the rods. This system, which is known by the name of the radial Müllerian fibres (shown on the left-hand side of Fig. 41), has no eonnection with (2) the spongioblasts and nemrospongium, which form a framework of neuroglia, in which the terminations of the 
optic ganglion and of the retinal ganglion ramify to form the molecular layers.

It is evident from Fig. 41 that the retina of Ammocretes and Petromyzon differs in a striking manner from the typical vertebrate retina. The epithelial part (C) remains the same-riz. the visnal rouls, the external limiting membrane, and the external nuclear layer; but the cerebral part, the retinal ganglion (A and $\mathrm{B}$ ), is remarkably different. It is true, it consists in the main of the small-celled mass known as the inner nuclear layer, and of the reticulated tissue or 'neuropil' known as the inner molecular layer, just as in all other compound retinal eyes; but neither the ganglion cell-layer nor the optic fibre-layer is clearly defined as separate from this molecular layer; on the contrary, it is matter of dispute as to what cells represent the ganglionic layer of higher vertebrates, and the optic fibres do not form a distinct innermost layer, but pass into the inner molecular layer at its junction with the inner nuclear layer. A comparison of this innermost part of the retina (A, Fig. 41), with the corresponding part in Berger's picture of Musca (n.l.o.g., Fig. 38), shows a most striking similarity between the two. In both cases the fibres of the optic nerve (O.n., Fig. 38) which cross at their entrance pass into the 'neuropil' of this part of the retinal ganglion, and are connected probably (though that is not proved in either case) with the cells of the ganglionic layer. In both cases we find two well-marked parallel rows of cells in this part of the retina, of which one, the innermost, is composed in Anmocotes of large ganglion-cells, and the other mainly of smaller, deeper staining cells apparently supporting in function. Similarly, also, in Branchipus, as I conclude from my own observations as well as from those of Berger aud Claus, the ganglionic layer is composed partly of true ganglioncells and partly of supporting cells arranged in a distinct layer. This part, then, of the retina of Ammocotes is remarkably like that of a typical arthropod retina, and forms that part of the retinal ganglion which may be called the ganglion of the optic nerve.

Next comes the ganglion of the retina (B, Fig. 41) (Parker's first optic ganglion), the cells of which form the small bipolar granulecells of the inner nuclear layer; granule-cells arranged in rows just as they are shown in Claus' picture of the same layer in the retina of Branchipus (Fig. 40), just as they are found in the cortical layers of the optic ganglion of the pineal eye (ganglion habenule), in the 
optic lobes and other parts of the Ammocotes brain, or in the cortical layers of the optic ganglia of all arthropods.

Between this small-celled nuclear layer (4, Fig. 41) and the layer of nuclei of the visual rod cells (7, Fig. 41) (the external nuclear layer), we find in the eye of Ammocertes and Petromyzon two wellmarked rows of cells of a most striking character-viz. the two remarkably regular rows of large epithelial-like cells with large conspicuous nuclei, which give the appearance of two opposing rows of limiting epithelium (5, Fig. 41), already mentioned in connection with the researches of Langerhans and W. Müller. Here, then, is a striking peculiarity of the retina of the lamprey, and according to Müller the obliteration of these two layers ean be traced as we pass upwards in the vertebrate kingdom. Among fishes, they are especially well seen in the perch; in the higher vertebrates the whole layer is only a rudiment represented, he thinks, by the simple layer of round cells which lies close against the inner surface of the layer of terminal fibres (Nervenansätze), and is especially evident in birds and reptiles. In man and the higher mammals they are probably represented by the horizontal cells of the outer part of the inner nuclear layer.

Seeing, then, that they are most evident in Ammocoetes, and become less and less marked in the higher vertebrates, it is clear that their origin cannot be songht among the animals higher in the scale than Ammocoetes, but must, therefore, be searched for in the opposite direction.

Miiller describes them as forming a very conspicuous landmark in the embryology of the retina, dividing it distinctly into two parts, an outer thinner, and an inner somewhat thicker part, the zone formed by them standing out conspicuously on account of the size and regularity of the cells and their lighter appearance when stained. Thus in his description of the retina of an Ammocotes $95 \mathrm{~mm}$. in length, he says, "The layer of pale tangentially elongated cells formed a double layer and produced the appearance of a pale, very characteristic zone between the outer and inner parts of the retina."

Let us now turn to the retina of the crustacean and see whether there is any evidence there that the retina is divisible into an outer and inner part, separated by a zone of characteristically pale staining cells with couspicuous nuclei. The most elaborate description of the development of the retina of Astacus is given by Reichenbach, 
according to whom the earliest sign of the formation of the retina is an estodermic involution (Augen-einstiilpung), which soon closes, so that the retinal area appears as a thickening. In close contiguity to this thickening, the thickening of the optic ganglion arises, so that that part of the optic ganglion which will form the retinal ganglion fuses with the thickened optic plate and forms a single mass of tissue. Later on a fuld (Augen-falte) appears in this mass of tissue, in consequence of which it becomes divided into two parts. The lining walls of this fold form a double row of cells, the nuclei of which are most conspicuous because they are larger and lighter in colour than the surrounding nuclei, so that by this fold the retina is divided into an outer and an inner wall, the line of demarcation being conspicuous by reason of these two rows of large, lightly-staining nuclei.

Reichenbach is unable to say that this secondary fold is coincident with the primary involution, and that therefore the junction between the two rows of large pale nuclei is the line of junction between the retinal ganglion and the retina proper, becanse all sign of the primary involution is lost before the secondary fold appears.

Parker compares the appearances in the lobster with Reichenbach's description in the crayfish, and says that he finds only a thickening, no primary involution; at the same time he expressly states that in the very early stages his material was deficient, and that he had not grounds sufficient to warrant the statement that no involution occurs. He also finds that in the lobster the ganglionic tissue which arises by proliferation is divided into an onter and inner part; the separation is effected by a band of large, lightly-staining nuclei, which, in position and structure, resemble the band figured by Reichenbach. According to Parker, then, the line of separation indicated in the development by Reichenbach's outer and inner walls is not the line of junction between the retina and the retinal ganglion, as Reichenbach was inclined to think, but rather a separation of two rows of large ganglion-cells belonging to the retinal ganglion.

The similarity between these conspicuous layers of lightlystaining cells in Ammocetes and in crustaceans is remarkably close, and in both cases observers have found the same difficulty in interpreting their meaning. In each case one group of observers looks upon them as ganglion-cells, the other as supporting structures. Thus in the lamprey, Müller considers them to belong to the supporting elements, while Langerhans and Kohl describe them as a double 
layer of ganglion-cells. In the crustacean, Berger in Squilla, Grenacher in Mrsis, and Parker in Astacus, look upon them as supporting

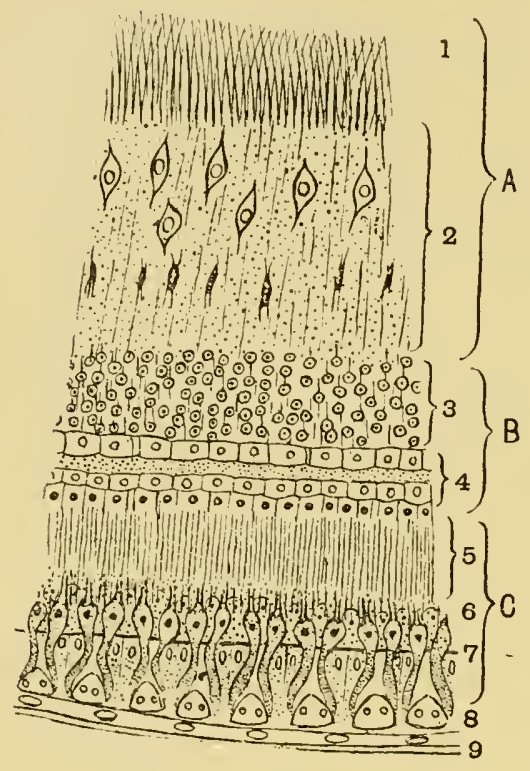

Fig. 42.-Ideal Diagram of the Layers in a Crustacean Eye.

The retina is divided into an epithelial part, $C$ (the layer of retinular cells and rhabdomes), and a neurodermal or cerebral part, which is formed of, $A$, the ganglion of the optic nerve, aud, $B$, the ganglion of the retina. 1, optic nerve fibres which cross at their entrance into the retina; 2 , int. molecular layer with its two rows of cells; 3 , int. nuclear layer; 4, Reichenbach's double row of large lightly-staining cells; 5, layer of terminal retinal fibres; 6 , ext. nuclear layer; 7, ext. limiting membrane; 8 , layer of crystalline cones; 9 , cornea. elements, while Viallanes in Palinurus considers them to be true ganglionic cells.

Whatever the final interpretation of these cells may prove to be, we may, it seems to me, represent an ideal compound retina of the crustacean type by combining the investigations of Berger, Claus, Reichenbach, and Parker in the following figure.

The comparison of this figure (Fig. 42) with that of the Petromyzon retina (Fig. 41) shows how great is the similarity of the latter with the arthropod type, and how the very points in which it deviates from the recognized vertebrate type are explainable by comparison with that of the arthropod. The most striking difference between the retinas in the two figures is that the layer of terminal nerve fibres (5, Fig. 42), which, after all, are only the elongated terminations of the retinal cells belonging to Parker's neurones of the first order, is very much longer than in Petromyzon or in any vertebrate, for the extermal molecular layer (6, Fig. 41) (Müller's layer of Nervenansätze) is very short and inconspicuous (in Fig. 41 it is drawn too thick).

Turning from the retina to the fibres of the optic nerve we again find a remarkable resemblance, for in Ammocretes, as pointed out by 
Langerhans and carefully figured by Kohl, a crossing of the fibres of the optic nerve occurs as the nerve leaves the retina, just as is so universally the case in all compound retinas. To this erossing Kohl has given the name chiusma norri optici, in distinction to the cerebral chiasma, which he calls chiasma nervorum opticorum. Further, we find that even this latter chiasma is well represented in the arthropod brain; thus Bellonei in Sphæroma, Berger, Dietl, and Krieger in Astacus, all describe a true optic chiasma, the only difference in opinion being, whether the crossing of the optic nerres is complete or not. Especially instructive are Bellonci's figures and description. He describes the brain of Sphroma as composed of three segments -a superior segment, the cerebrum proper, a middle segment, and an inferior segment; the optic fibres, as is seen in Fig. 39, after crossing, pass direct into the middle segment, in the ganglia of which they termiuate. From this segment also arises the nerve to the first antenna of that sicle-i.e. the olfactory nerve. The optic part, then, of this middle segment is clearly the brain portion of the optic ganglionic apparatus, and may be called the optic lobes, in contradistinction to the peripheral part, which is usually called the optic ganglion, and is composed of two ganglia, Op. g. I. and Op.g. II., as already mentioned. These optic lobes are therefore homologous with the optic lobes of the vertebrate brain.

The resemblance throughout is so striking as to force one to the conclusion that the retina of the vertebrate eye is a compound retina, composed of a retina and retinal ganglion of the type found in arthropods. From this it follows that the development of the vertebrate retina ought to show the formation of (1) an optic plate formed from the peripheral epidermis and not from the brain; (2) a part of the brain elosely attached to this optic plate forming the retinal ganglion, which remains at the surface when the rest of the optic ganglion withdraws; (3) an optic nerve formed in consequence of this withdrawal, as the connection between the retinal and cerebral parts of the optic ganglion.

This appears to me exactly what the developmental process does show according to Götte's investigations. IIe asserts that the retina arises from an optic plate, being the optical portion of his 'Sinnesplatte.' At an early stage this is separated by a furrow (Furche) from the general mass of epidermal cells which ultimately form the brain. This separation then vanishes, and the retina and brain-mass 
become inextricably united into a mass of cells, which are still situated at the surface. By the closure of the cephalic plate and the withdrawal of the brain away from the surface, a retinal mass of cells is left at the surface connected with the tubular central nervous system by the hollow optic diverticulum or primary optic vesicle. If we regard only the retinal and nervous elements, and for the moment pay no attention to the existence of the tube, Götte's observation that the true retina has been formed from the optic plate (Sinnes-platte) to which the retinal portion of the brain (retinal ganglion) has become firmly fixed, and that then the optic nerve has been formed by the withdrawal of the rest of the brain (optic lobes), is word for word applicable to the description of the development of the compound retina of the arthropod eye, as has been already stated.

\section{The Significance of the Optic Diverticula.}

The origin of the retina from an optic epiclermal plate in vertebrates, as in all other animals, brings the cephalic eyes of all animals into the same category, and leaves the vertebrate eye no longer in an isolated and unnatural position. In one point the retina of the vertebrate eye differs from that of a compound retina of an invertebrate; in the former, a striking supporting tissue exists, known as Müller's fibres, which is absent in the latter. This difference of structure is closely associated with another of the same character as in the central nervous system, viz. the apparent development of the nervous part from a tube. We see, in fact, that the retinal and nervous arrangements of the vertebrate eye are comparable with those of the arthropod eye, in precisely the same way and to the same extent as the nervous matter of the brain of the vertebrate is comparable with the brain of the arthropod. In both cases the nervous matter is, in structure, position, and function, absolutely homologous; in both cases there is found in the vertebrate something extra which is not found in the invertebrate -viz. a hollow tube, the walls of which, in the case of the brain, are utilized as supporting tissues for the nerve structures. The explanation of this difference in the case of the brain is the fundamental idea of my whole theory, namely, that the hollow tube is in reality the cephalic stomach of the invertebrate, around which the nervous brain-matter was originally grouped in precisely the same manner as in the invertebrate. What, then, are the optic diverticula? 
"The formation of the eye," as taught by Balfour, "commences with the appearance of a pair of hollow outgrowths from the anterior' cerebral vesicle. These outgrowths, knowu as the optic vesicles, at first open freely into the cavity of the anterior cerebral vesicle. From this they soon, however, become partially constricted, and form vesicles united to the base of the brain by comparatively narrow, hollow stalks, the rudiments of the optic nerves."

"After the establishment of the optic nerves, there takes place (1) the formation of the lens, and (2) the formation of the optic cup from the walis of the primary optic vesicle."

He then goes on to explain how the formation of the lens forms the optic cup with its double walls from the primary optic vesicle, and says-

"Of its double walls, the inner, or anterior, is formed from the front portion, the outer, or posterior, from the hind portion of the wall of the primary optic vesicle. The inner, or anterior, which very speedily becomes thicker than the other, is converted into the retina; in the outer, or posterior, which remains thin, pigment is eventually deposited, and it ultimately becomes the tesselated pigment-layer of the choroid."

The difficulties in connection with this view of the origin of the eye are exceedingly great, so great as to have caused Balfour to discuss seriously Lankester's suggestion that the eye must have been at one time within the brain, and that the ancestor of the vertebrate was therefore a transparent animal, so that light might get to the eye through the outer covering and the brain-mass; a suggestion, the unsatisfactory nature of which Balfour himself confessed. Is there really evidence of any part of either retina or optic nerve being formed from the epithelial lining of the tube?

This tube is formed as a direct continuation of the tube of the central nervons system, and we can therefore apply to it the same arguments as have been used in the discussion of the meaning of the latter tube. Now, the striking point in the latter case is the fact that the lining membrane of the central canal is in so many parts absolutely free from nervous matter, and so shows, as in the so-called choroid plexuses, its simple, non-nervous epithelial structure. This also we find in the optic diverticulum. Where there is no evidence of any invasion of the tube by nervous elements, there it retains its simple non-nervous character of a tube composed of a single layer of 
epithelial cells-viz. in that part of the tube which, as Balfour says, remains thin, in which pigment is eventually deposited, and which ultimately becomes the tesselated pigment-layer of the choroid. Nobody has ever suggested that this pigment-layer is nervous matter, or ever was, or ever will be, nervous matter; it is in precisely the same category as the membranous roof of the brain in Ammocotes, which never was, and never will be, nervous matter. Yet, accordiug to the old embryology both in the case of the eye and the brain, the pigment-layer and the so-called choroid plexuses are a part of the tubular nervous system.

Turning now to the optic nerve, Balfour describes it as derived from the hollow stalk of the optic vesicle. He says-

"At first the optic nerve is equally contimuous with both walls of the optic cup, as must of necessity be the case, since the interval which primarily exists between the two walls is continuous with the carity of the stalk. When the eavity within the optic nerve ranishes, and the fibres of the optic nerve appear, all connection is ruptured between the outer wall of the optic cup and the optic nerve, and the op,tic nerve simply perforates the onter wall, and becomes continuous with the inner one."

In this description Balfour, because he derived the optic nerve fibres from the epithelial wall of the optic stalk, of necessity supposed that such fibres originally supplied both the outer and inner walls of the optic cup and, therefore, seeing that when the fibres of the optic nerve appear they do not supply the outer wall, he supposes that their original connection with the outer wall is ruptured, because a liscontinuity of the epithelial lining takes place coincidently with the appearance of the optic nerve-fibres, and, according to him, the optic nerve simply perforates the outer wall and becomes continuous with the inner one. This last statement is very difficult to understand. I presume he meant that some of the fibres of the optic nerve supplied from the beginning the inner wall of the optic cup, but that others which originally supplied the onter wall were first ruptured, then perforated the outer wall, and finally completed the supply to the inner wall or retina.

This statement of Balfour's is the necessary consequence of his belief, that the epithelial cells of the optic stalk gave rise to the fibres of the optic nerve. If, instead of this, we follow Kölliker and His, who state that the optic nerve-filures are formed outside the 
epithelial walls of the optie stalk, and that the cells of the latter form supporting structures for the nerve-fibres, then the position of the optic nerve becomes perfeetly simple and satisfactory without any rupturing of its connection with the outer wall and subsequent perforation, for the optic nerve-fibres from their very first appearance pass directly to supply the retina-i.e. the inner wall of the optic eup and nothing else.

They pass, as is well known, without any perforation by way of the choroidal slit to the inner surface of the inner wall (retina) of the optic eup; then, when the ehoroidal slit becomes elosed by the expansion of the optic cup, the optic nerve naturally becomes situated in the centre of the base of the eup and spreads over its inner surface as that surface expands.

A section across the optie cup at an early stage at the junction of the optie stalk and optic cup would be represented by the uper diagram in Fig. 43 ; at a later stage, when the choroidal slit is elosed, by the lower diagram.

The evident truth of this manner of looking at the origin of the optie nerve is demonstrated by the appearance of the optie nerve in Ammoecetes and Petromyzon. In the latter, althongh the development is complete, and the eye, and consequently also the optic nerve-fibres, are fully functional, there is still present in the axial eore of the nerve a row of epithelial cells (Axenstrang) which are altered so as to form supporting structures, in the
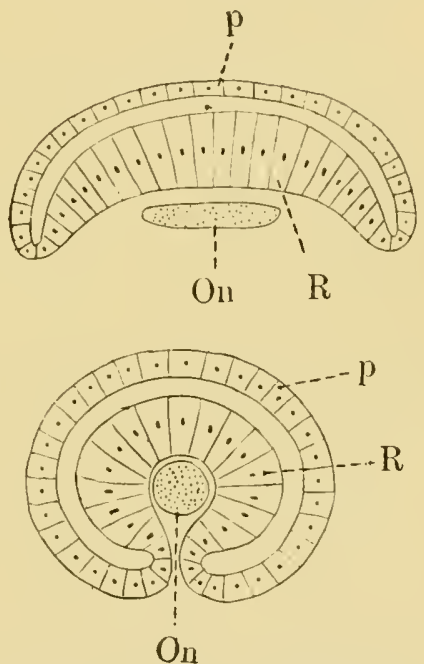

Fig. 43.-Diagiram of the Relation of the Optic NerYe to the Optic Cup.

The upper diagram represents a stage before the formation of the choroidal slit, the lower one the stage of closure of the choroidal slit. $R$., retina; O.n., optic nerve; $p$. pigment epithelium. same way as a row of epithelial cells in the retina is altered to form the system of supporting cells known by the name of the Miillerian fibres.

The origin of this axial core of eells is perfectly clear, as has been pointed out by W. Müller. Hie says-

"The development of the optie nerve shows peculiarities in 
Petromyzon of such a character as to make this animal one of the most valuable objects for deciding the various controversial questions connected with the genesis of its elements. The lumen of the stalk of the primary optic vesicle is obliterated quite early by a proliferation of its lining epithelium. Also the original continuity of this epithelium with that of the pigment-layer is at an early period interrupted at the point of attachment of the optic stalk. This interruption occurs at the time when the fibres of the optic nerve first become visible."

Further on he says-

"The epithelium of the optic stalk develops entirely into supporting cells, which in Petromyzon fill up the original lumen and so form an axial core (Axenstrang) to the nerve-fibres which are formed entirely outside them; the projections of these supporting cells are directed towarls the periphery, and so separate the bundles of the optic nerve-fibres. The mesodermal coat of the optic stalk takes no part in this separation; it simply forms the connective tissue sheath of the optic nerve. The development of the optic nerve in the higher vertebrates also obeys the same law, as I ain bound to conclude from my own observations."

The evidence, then, of Ammocetes is very conclusive. Originally a tube composed of a single layer of epithelial cells became expanded at the anterior end to form a bulb. On the outside of this tube or stalk the fibres of the optic nerve make their appearance, arising from the ganglion-cell layer of the retina, and, passing over the surface of the epithelial tube at the choroidal fissure, proceed to the brain by way of the optic chiasma. Owing to the large number of fibres, their crossing at the junction of the stalk with the bulb, and the narrowness at this neck, the obliteration of the lumen of the tube which takes place in the stalk is carried out to a still greater extent at this narrow part. The result of this is that all continnity of the celllayers of the original tube of the optic stalk with those of both the inner and outer walls of the bulb is interrupted, and all that remains in this spot of the original continuous line of cells which connected the tube of the stalk with that of the bulb are possibly some of the groups of cells which are found scattered among the fibres of the optic nerve at their entrance into the retina. Such separation of the originally continuous elements of the epithelial wall of the optic stalk, which is apparent only at this neck of the nerve in Petromyzon, takes place 
along the whole of the optic nerve in the higher vertebrates, so that no continuous axial core of cells exist, but only scattered supporting cells.

If further proof in support of this view be wanted, it is given by the evidence of physiology, which shows that the filores of the optic nerve are not different from other nerve-fibres of the central nervous system, but that they degenerate when separated from their nervecell, and that the nerve-cell of which the optic nerve-fibre is a process is the large ganglion-cell of the ganglionic layer of the retina. The origin of the ganglionic layer of the retina cannot therefore be separated from that of the optic nerve-fibres. If the one is outside the epithelial tube, so is the other, and what holds true of the ganglionic layer must hold good of the rest of the retinal ganglion and, from all that has been said, of the retina itself. We therefore come to the conclusion that the evidence is distinctly in favour of the view, that the retina and optic nerve in the true sense are structures which originally were outside a non-nervous tube, but, just like the central nervous system as a whole, have amalgamated so closely with the elements of this tube as to utilize them for supporting structures. One part of this non-nervous tube, its dorsal wall, like the corresponding part of the brain-tube, still retains its original character, and by the deposition of pigment has been pressed into the service of the eye to form the pigmented epithelial layer:

We can, however, go further than this, for we know definitely in the case of the retina what the fate of the epithelial colls lining this tube has been. They have become the system of supporting structures known as Müllerian fibres.

The epithelial layer of the primary optic vesicle can be traced into direct continuity with the lining epithelium of the brain cavity, as a single layer of epithelial cells in the core of the optic nerve, forming the optic stalk, which, in consequence of close contact, becomes the well-known axial layer of supporting cells. This epithelial layer of the optic stalk then expands to form the optic bulb, the outer or dorsal wall of which still remains as a single layer of epithelium and becomes the layer of pigment epithelium. This layer of epithelium becomes doubled on itself by the approximation of the inner or ventral wall of the optic cup to the outer or dorsal wall in consequence of the presence of the lens, and still remaining a single layer, forms the pars ciliuris retina; then suddenly, at the ore 
serruta, the single epithelial layer vanishes, and the layers of the retina take its place. It has long been known, however, that even thronghout the retina this single epithelial layer still continues, being known as the fibres of Müller. This is how the fact is described in the last edition of Foster's "Text-book of Physiology," p. 1308-

"Stretching radially from the inner to the outer limiting membrane in all regions of the retina are certain peculiar-shaped bodies known as the radial fibres of Müller. Each fibre is the outcome of the changes undergone by what was at first a simple columnar

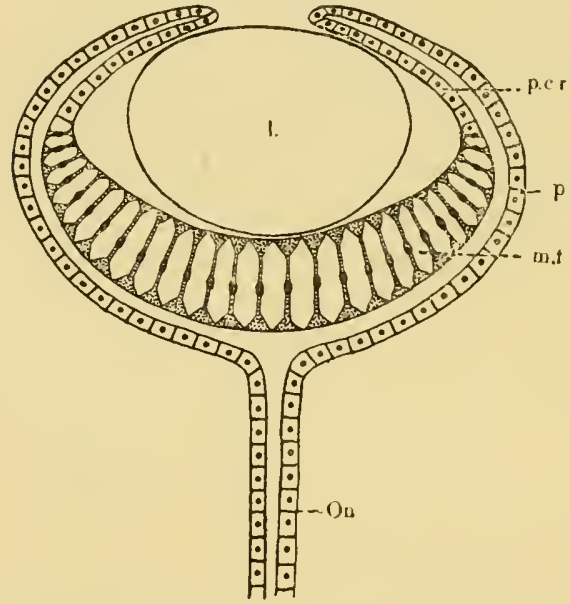

Fig. 44.-Diagrant iepresenting the Single-layered Epithelial Tube of the Vertebrate Ere after resioval or the Nervols and Retinal Elements.

O.n., axial core of cells in optie nerve; $p$., pigment epithelium; p.c.r., pars ciliaris retince; $m . f .$, Mïllerian fibres; $l$., lens. epithelial cell. The changes are, in the main, that the columnar form is elongated into that of a more or less prismatic fibre, the edges of which become variously branched, and that while the nueleus is retained the cell substance becomes eonverted into neuro-keratin. And, indeed, at the ora serrata the fibres of Müller may be seen suddenly to lose their peculiar features and to pass into the ordinary columnar cells which form the pars ciliaris retina."

It is then absolutely elear that the essential parts of the eye may be considered as composed of two parts-

1. A tube or diverticulum from the tube of the central nervous system, composed throughont of a single layer of epithelium, which forms the supporting axial cells in the optic nerve, the pigment epithelium and the Müllerian fibres of the retina. Such a tube would be represented by the aceompanying Fig. 44, and the left side of Fig. 41.

2. The retina proper with the retinal ganglion and the optic nerve-fibres as already described. In this part supporting elements are found, just as in any other compound retina, of the nature of nemroglia, which are independent of the Müllerian fibres. 
Of these two parts we have already seen that the second is to all intents and purposes a compound retina of a crustacean eye, and seeing that the single-layered epithelial tube is continuous with the single-layered epithelial tube of the central nervous system-i.e. with the cephalic part of the gut of the arthropod ancestor-it follows with certainty that the ancestor of the vertebrates must have possessed two anterior diverticula of the gut, with the wall of which, near the anterior extremity, the compound retina has amalgamated on either side, just as the infra-osophageal ganglia have amalgamated with the ventral wall of the main gut-tube. In this way, and in this way alone, does the interpretation of the structure of the vertebrate lateral eye harmonize in the most perfect manner with the rest of the conclusions already arrived at.

The question therefore arises :- Have we any grounds for believing that the ancient forms of primitive crustaceans and primitive arachnids, which were so abundant in the time when the Cephalaspids appeared, possessed two anterior diverticula of the stomach, such as the consideration of the vertebrate eye strongly indicates must have been the case?

The beautiful pictures of Blanchard, and his description, show how, on the arachnid side, paired diverticula of the stomach are nearly universal in the group. Thus, although they are not present in the scorpions, still, in the Thelyphonidæ, Phrynidx, Solpugidx, Mygalidæe, the most marked characteristic of the stomach-region is the presence of four pairs of ccecal diverticula, which spread laterally over the prosomatic region. In the spiders the number of such diverticula increases, and the whole prosomatic region becomes filled up with these tubes. Blanchard considers that they form nutrient tubes for the direct nutrition of the organs in the prosoma, especially the important brain-region of the central nervous system. He points out that these animals are blood-suckers, and that, therefore, their food is already in a suitable form for purposes of nutrition when it is taken in by them, so that, as it were, the anterior part of the gut is transformed into a series of vessels or diverticula conveying blood directly to the important organs in the prosoma, by means of which they obtain nourishment in addition to their own blool-supply.

The universality of such diverticula among the arachnids makes it highly probable that their progenitors did possess an alimentary canal with one or more pairs of anterior diverticula. In the 
vertebrate, however, the paired diverticula are associated with a compound retina, a combination which does not occur among living arachnids; we must, therefore, examine the crustacean group for the desired combination, and naturally the most likely group to examine is the Phyllopoda, especially such primitive forms as Branchipus and Artemia, for it is universally acknowledged that these forms are

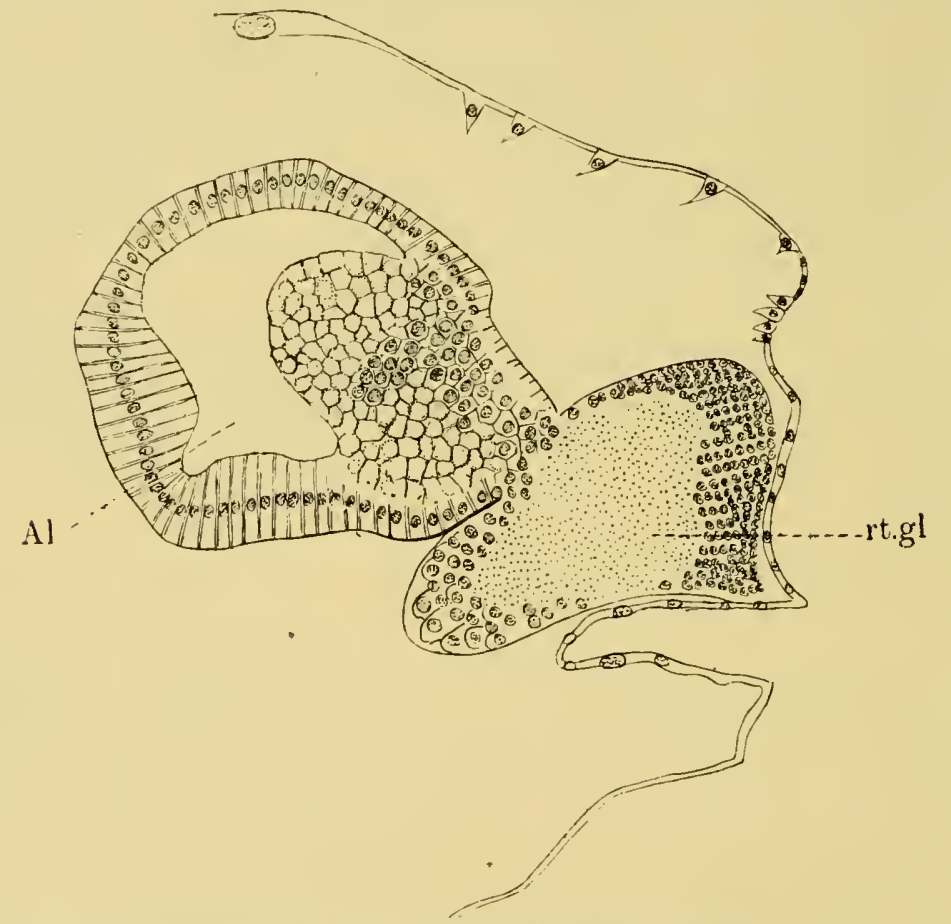

Fig. 45.-Section through one of the two Anterior Diverticula of the Gut in artemia and the Retinal Ganglion.

The section is through the extreme anterior end of the diverticulum, thus cutting through many of the columnar cells at right angles to their axis. Al., gut diverticulum; $r t$. gl., retinal ganglion.

the nearest living representatives of the trilobites. If, therefore, it be found that the retina and optic nerve in Artemia is in specially close connection with an anterior diverticulum of the gut on each side, then it is almost certain that such a combination existed also in the trilobites.

My friend Mr. W. B. Hardy has especially investigated the nervous system of Artemia. In the course of his work he cut serial 
sections through the whole animal, and, as mentioned in my paper in the Journal of Anatomy and Physiology, he discovered that the retinal ganglion of each lateral eye is so closely attached to the end of the corresponding diverticulum of the gut that the lining cells of the ventral part of the diverticulum form a lining to the retinal ganglion (Fig. 45). In this animal there are only two gut-diverticula, which are situated most anteriorly. I have plotted out this series of sections by means of a camera lucida, with the result that the retina appears as a bulging attached ventro-

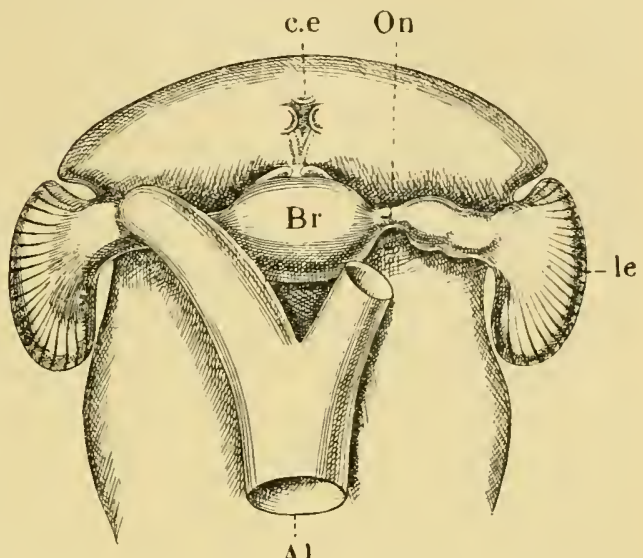

A)

Fig. 46.-The Brain, Eyes, and Anterior Termination of the Alimentary Canal of Artemia, viewed fron the Dorsal Aspect.

$B r$., brain; l.e., lateral eyes; c.e., median eyes; Al., alimentary canal.

laterally to the extremity of each gut-diverticulum, as is shown in

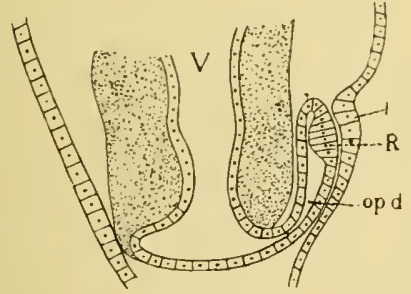

A

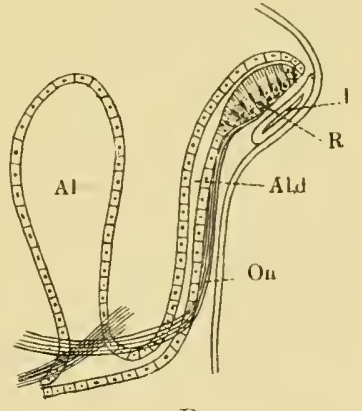

P

Fig. 47.-A, The Formation of the Remina of the Ere of Amocetes (after Scott); B, The Formation of the Retina of the Ere of Ammocetes, ox MY THEORY.

$R$., retina; $l$., lens; $O . n$., optic nerve fibres; $A l$., cephalic end of invertebrate alimentary canal; V., cavity of ventricles of brain; Al.d., anterior diverticulum of alimentary canal; op.d., optic diverticulum.

Fig. 46. It is instructive to compare with this figure Scott's picture of the developing eye in Ammocotes, where he figures the retina as 
a bulging attached ventrally to the extremity of the narrow tube of the optic diverticulum. In Fig. 47, A, I reproduce this figure of Scott, and by the side of it, Fig. $47, \mathrm{~B}, \mathrm{I}$ have represented the origin of the vertebrate eye as I believe it to have ocenrres.

We see, then, this very striking fact, that in the most primitive of the Crustacea, not only are there two anterior diverticula of the gut, but also the retinal ganglion of the lateral eye is in specially close connection with the end of the diverticulum on each side. In fact, we find in the nearest living representative of the trilobites a retina and retinal ganglion and optic nerve, closely resembling that of the vertebrate, in close connection with an epithelial tube which has nothing to do with the organ of sight, but is one of a pair of anterior gut-diverticula. It is impossible to obtain more decisive evidence that the trilobites possessed a pair of gut-diverticula surrouncled to a greater or less extent by the retina and optic nerve of each lateral eye.

Such anterior diverticula are commonly found in the lower Crustacea; they are usually known by the name of liver-diverticula, but as they take no part in digestion, and, on the contrary, represent that part of the gut which is most active in absorption, the term liver is not appropriate, and it is therefore better to call them simply the pair of anterior diverticula. Our knowledge of their function in Daphnia is given in a paper by Hardy and $\mathrm{M}$ 'Dougall, which does not appear to be widely known. Hardy succeeded in feeding Daphnia with yolk of egg in which carmine grains were mixed, and was abie in the living animal to watch the whole process of deglutition, digestion, and absorption. The food, which is made into a bolus, is moved down to the middle region of the gut, and there digestion takes place. Then by an antiperistaltic movement the more fluid prorlucts of the digestion-process are sent right forward into the two anterior diverticula, where the single layer of columnar cells lining these diverticula absorbs these products, the cells becoming thickly studded with fat-drops after a feed of yolk of egg. The carmine particles, which were driven forward with the proteid- and fatparticles, are not absorbed, but are at intervals driven back by contractions of the anterior diverticula to the middle region of the gut.

These observations prove most clearly that the anterior diverticula have a special nutrient function, being the main channels by which new nutrient material is brought into the body, and, as 
pointed out by the authors, it is a remarkable exception in the animal kingdom that absorption should occur in that portion of the gut which is anterior to the part in which digestion occurs. In all these animals the two anterior diverticula extend forwards over the brain, and, as we have seen in Artemia, the anterior extremity of each one is so intimately related to a part of the brain-viz. the retinal ganglion-as to form a lining membrane to that mass of nerve-cells. It follows, therefore, that the nutrient fluid absorber by the cells of this part of the gut-diverticulum must be primarily for the service of the retinal ganglion. In fact, the relations of this anterior portion of the gut to the brain as a whole suggest strongly that the marked absorptive function of this anterior portion of the gut exists in order to supply nutrient material in the first place to the most vital, most important=organ in the animal-the brain and its sense-organs. This conclusion is borne out by the fact that in these lower crustaceans the circulation of blood is of a very inefficient character, so that the tissues are mainly dependent for their nutrition on the fluid immediately surrounding them. It stands to reason that the establishment of the anterior portion of the gut as a nutrient tube to the brain would necessitate a closer and closer application of the brain to that tube, so that the process of amalgamation of the brain with the single layer of columnar epithelial cells which constitutes the wall of the gut (which we see in its initial stage in the retinal ganglion of Artemia), would tenc rapidly to increase as more and more demands were made upon the brain, until at last both the supra- and infra-osophageal ganglia, as well as the retiual ganglia and optic nerves, were in such close intimate connection with the ventral wall of the anterior portion of the gut and its diverticula as to form a brain and retina closely resembling that of Ammocotes.

Such an origin for the lateral eyes of the vertebrate explains in a simple and satisfactory manner why the vertebrate retina is a compound retina, and why both retina and optic nerve have an apparent tubrilar development.

At the same time one discrepancy still exists which requires consicleration-viz. in no arthropod eye possessing a compound retina is the retina inverted. All the known cases of inversion among arthropods occur in eyes, the retina of which is simple, and are all natural consequences of the process of invagination by which 
the retina is formed. On the other hand, eyes with an inverted compound retina are not entirely unknown among invertebrates, for the eyes of Pecten and of Spondylus possess a retina which is inverted after the vertebrate fashion and still may be spoken of as compound rather than simple. It is clear that an invagination, the effect of which is an inversion of the retinal layer, would lead to the same result, whether the retinal optic nerves were short or long, whether, in fact, a retinal ganglion existed or not. Undoubtedly the presence of the retinal ganglion tends greatly to obscure any process of invagination, so that, as already mentioned, many observers, with Parker, consider the retina of the crustacean lateral eye to be formed by a thickening only, without any invagination, while Reichenbach says an obscure invagination does take place at a very early stage. So in the vertebrate eye most observers speak only of a thickening to form the retina, but Götte's observation points to an invagination of the optic plate at an early stage. So also in the eye of Pecten, Korschelt and Heider consider that the thickening, by which the retina is formed according to Patten, in reality hicles an invagination process by means of which, as Bütschli suggests, an optic vesicle is formed in the usual manner. The retina is formed from the anterior wall of this vesicle, and is therefore inverted.

The origin of the inverted retina of the vertebrate eye does not seem to me to present any great difficulty, especially when one takes into consideration the fact that the retina is inverted in the arachnid group, only in the lateral eyes. The inversion is usually regarded as associated with the tubular formation of the vertebrate retina, and it is possible to suppose that the retina became inverted in consequence of the involvement of the eye with the gutdiverticulum. I do not myself think any such explanation is at all probable, because I cannot conceive such a process taking place without a temporary derangement-to say the least of it-of the power of vision, and as I do not believe that evolution was brought about by sudden, startling changes, but by gradual, orderly adaptations, and as 1 also believe in the paramount importance of the organs of vision for the evolution of all the higher types of the animal kingdom, I must believe that in the evolution from the Arthropod to the Cephalaspid, the lateral eyes remained throughout functional. I therefore, for my own part, would say that the inversion of the 
retina took place before the complete amalgamation with the gutdiverticulum, that, in fact, among the proto-crustacean, protoarachuid forms there were some sufficiently arachnid to have an inverted retina, and at the same time sufficiently crustacean to possess a compound retina, and therefore a compound inverted retina after the vertebrate fashion existed in combination with the anterior gut-diverticnla. Thus, when the eye and optic nerve sank into and amalgamated with the gut-diverticulum, neither the dioptric apparatus nor the nervous arrangements would suffer any alteration, and the animal throughout the whole process would possess organs of vision as good as before or after the period of transition.

Further, not only the retina but also the dioptric apparatus of the vertebrate eye point to its origin from a type that comlined the peculiarities of the arachuids and the crustaceans. In the former it is difficult to speak of a true lens, the function of a lens being undertaken by the cuticular surface of the cells of the comeagen (Mark's 'lentigen'), while in the latter, in addition to the corneal eovering, a true lens exists in the shape of the crystalline cones. Further, these crustacean lenses are true leuses in the rertebrate sense, in that they are formed by modified hypodermal cells, and not bulgings of the cuticle, as in the arachnid. We see, in fact, that in the compound crustacean eye an extra layer of hypodermal cells has become inserted between the cornea and the retina to form a leus. So also in the vertebrate eye the lens is formed by an extra layer of the epidermal cells between the cornea and the retina. The fact that the vertebrate eye possesses a single lens, though its retina is composed of a number of ommatidia, while the crustacean eye possesses a lens to each ommatidium, may well be a consequence of the inversion of the vertebrate retina. It is most probable, as Korschelt and Heider have pointed ont, that the retina of the arachnid eyes is composed of a number of ommatidia, just as in the crustacean eyes and in the inverted eyes it is probable that the image is focussed on to the pigmented tapetal layer, and thence reflected on to the percipient visual rods. In such a method of vision a single lens is a necessity, and so it must also be if, as I suppose, eyes existed with an inverted compound retina. Owing to the crustacean affinities of such eyes, a lens would be formed and the retina would be compound : owing to the arachnid affinities, the retina would be inverted and the hypodermal cells which formed the lens would be massed 
together to form a single lons, instead of being collected in groups of four to form a series of crystalline cones.

To sum up: The study of the vertebrate eyes, both median and lateral, leads to most important conclusions as to the origin of the vertebrates, for it shows clearly that whereas, as pointed ont in this and subsequent chapters, their ancestors possessed distinct arachnid characteristics, yet that they cannot have been specialized arachnids, such as our present-day forms, but rather they were of a primitive arachnid type, with distinct crustacean characteristics: animals that were both crustacean and arachnid, but not yet specialized in either direction: animals, in fact, of precisely the kind which swarmed in the seas at the time when the vertebrates first made their appearance. In the opinion of the present day, the ancestral forms of the Crustacea, which were directly derived from the Annelida, may be classed as an hypothetical group the Protostraca, the nearest approach to which is a primitive Phyllopod.

"Starting from the Protostraca," say Korschelt and Heider, "accorling to the present condition of our knowledge, we may, as has been already remarked, assume three great series of development of the Arthropodan stock, by the side of which a number of smaller independent branches have been retained. One of these series leads throngh the hypothetical primitive Phyllopod to the Crustacea; the second through the Palreostraca (Trilobita, Gigantostraca, Xiphosura) to the Arachnida; the third through forms resembling Peripatus to the Myriapoda and the Insecta. The Pantapoda and the Tardigrada must probably be regarded as smaller independent branches of the Arthropodan stock."

To these "three great series of development of the Arthropodan stock" the evidence of Anumoccetes shows that a fourth must be added, which, starting also from the Protostraca, and closely connectod with the second, palæostracan branch, leads through the Cephalaspidæe to the great kingdom of the Vertebrata. Such a direct linking of the earliest vertebrates with the Annelida through the Protostraca is of the utmost importance, as will be shown later in the explanation of the origin of the vertebrate colom and urinary apparatus. 


\section{Sumpart.}

The most important discovery of recent years which gives a direct elue to the ancestry of the rertebrates is undoubtedly the discovery that the pineal gland is all that remains of a pair of median eyes which must have been functional in the immediate ancestor of the rertebrate, seeing how perfect one of them still is in Ammocoetes. The vertebrate ancestor, then, possessed two pairs of eyes, one pair sitnated laterally, the other median. In striking confirmation of the origin of the vertebrate from Paleostracans it is universally admitted that all the Eurypterids and such-like forms resembled Limulus in the possession of a pair of median eyes, as well as of a pair of lateral eyes. Moreorer, the ancient mailed fishes the Ostracodermata, which are the earliest fishes known, are all said to show the presence of a pair of median eyes as well as of a pair of lateral eves. This evidence directly suggests that the structure of both the median and lateral rertebrate eyes ought to be very similar to that of the median and lateral arthropod eyes. Such is, indeed, found to be the case.

The retina of the simplest form of eye is formed from a group of the superficial epidermal cells, and the rods or rhabdites are formed from the cuticular covering of these cells; the optic nerve passes from these cells to the deeper-lying brain. This kind of retina may be called a simple retina, and characterizes the eyes, both median and lateral, of the scorpion group.

In other cases a portion of the optic ganglion remains at the surface, when the brain sinks inwards, in close contigruity to the epidermal sense-cells which form the retina; a tract of tibres connects this optic ganglion with the underlying brain, and is known as the optic nerve. Such a retina may be called a compound retina and characterizes the lateral eyes of both crustaceans and vertebrates. Also, owing to the method of formation of the retina by invagination, the cuticular surface of the retinal sense-cells, from which the rods are formed, may be directed towards the source of light or away from it. In the first case the retina may be called upright, in the second inverted.

Such inverted retinas are found in the vertebrate lateral eyes and in the lateral eyes of the arachnids. but not of the crustaceans.

The evidence shows that all the invertebrate median eyes possess a simple upright retina, and in structure are remarkably like the right median or pineal eye of Ammocotes; while the lateral eyes possess, as in the crustaceans, an upright compound retina, or, as in many of the arachnids. a simple inverted retina. The lateral eyes of the vertebrates alone possess a compound inverted retina.

This retina, however, is extraordinarily similar in its strncture to the compound crustacean retina, and these similarities are more accentuated in the retina of the lateral eye of Petromyzon than that of the higher vertebrates.

The evidence afforded by the lateral eye of the vertebrate points unmistakably to the conclusion that the ancestor of the rertebrate possessed both crustacean and arachnid characters-belonged, therefore, to a group of animals which gave rise to both the crustacean and arachnid gromps. This is precisely the position of the Palrostracan group, which is regarded as the ancestor of both the crustaceans and arachnids. 
In two respects the retina of the lateral eyes of vertebrates differs from that of all arthropods, for it possesses a special supporting structure, the Müllerian fibres, which do not exist in the latter, and it is developed in comnection with a tube, the optic diverticulum, which is connected on each side with the main tube of the central nerrous system. These two differences are in reality one and the same, for the Müllerian fibres are the altered lining cells of the optic diverticulum, and this tube has the same significance as the rest of the tube of the nervous system; it is something which las nothing to do with the nerrous portion of the retina but has become closely amalgamated with it. The explanation is, word for word, the same as for the tubular nerrous system, and shows that the ancestor of the rertebrate possessed two anterior diverticula of its alimentary canal which were in close relationship to the optic ganglion and nerve of the lateral eye on each side. It is again a striking coincidence to find that Artemia, which with Branchipus represents a gronp of living crustaceans most nearly allied to the trilobites, does possess two anterior diverticula of the gut which are in extraordinarily close relationship with the optic ganglia of the retina of the lateral eyes on each side.

The evidence of the optic apparatus of the rertebrate points most remarkably to the derivation of the Vertebrata from the Palrostraca. 


\section{CHAPTER III}

\section{THE EVIDENCE OF THE SKELETON}

The bony and cartilaginons skeleton considered, not the notochord. - Nature of the earliest cartilaginous skeleton.-The mesosomatic skeleton of Ammocotes; its topographical arrangement, its structure, its origin in mucocartilage.-The prosomatic skeleton of Ammocotes; the trabecula aud parachordals, their structure, their origin in white fibrous tissue.-The mesosomatic skeleton of Limnlus compared with that of Ammocoetes: similarity of position, of structure, of origin in muco-cartilage.-The prosomatic skeleton of Limulus; the entosternite or plastron compared with the trabeculæ of Ammocotes; similarity of position, of structure, of origin in fibrous tissue.-Summary.

THE explanation of the two optic diverticula given in the last chapter accounts in the same harmonious manner for every other part of the tube around which the central nervous system of the vertebrate has been grouped. The tube conforms in all respects to the simple epithelial tube which formed the alimentary canal of the ancient type of marine arthropods such as were dominant in the seas when the vertebrates first appeared. The whole evilence so far is so uniform and points so strongly in the direction of the origin of vertebrates from these ancient arthropods, as to make it an imperative duty to proceed further and to compare one by one the other parts of the central nervous system, together with their outgoing nerves in the two groups of animals.

Before proceeding to do this, it is advisable first to consider the question of the origin of the vertebrate skeletal tissues, for this is the second of the great difficulties in the way of deriving vertebrates from arthropods, the one skeleton being an endo-skeleton composed of cartilage and bone, and the other an exo-skeleton composed of chitin. Here is a problem of a totally different kind to that we have just been considering, but of so fundamental a character that it must, if possible, be solved before passing un to the consideration of the cranial nerves and the organs they supply. 
Is there any evideuce which makes it possible to conceive the method by which the vertebrate skeleton may have arisen from the skeletal tissues of an arthropod? By the vertebrate skeleton I mean the bony and cartilaginous structures which form the backbone, the cranio-facial skeleton, the pectoral and pelvic girdles, and the bones of the limbs. I do not include the notochord in these skeletal tissues, because there is not the slightest evidence that the notochord played any part in the formation of these structures; the notochordal tissue is something sui generis, and never gives rise to cartilage or bone. The notochord happens to lie in the middle line of the body and is very conspicuous in the lowest vertebrate; with the development of the backbone the notochord becomes obliterated more and more, until at last it is visible in the higher vertebrates only in the embryo; but that obliteration is the result of the encroachment of the growing bone-masses, not the cause of their growth. Although, then, the notochord may in a seuse be spoken of as the original supporting axial rod of the vertebrate, it is so different to the rest of the endo-skeleton, has so little to do with it, that the consideration of its origin is a thing apart, and must be treated by itself without reference to the origin of the cartilaginous and buny skeleton.

\section{The Commencement of the Bony Skeleyon in tile Vertebrate.}

What is the teaching of the rertebrate? What evidence is there as to the origin of the bony skeleton in the vertebrate phylum itself?

The axial bony skeleton of the higher Mammalia consists of two parts, (1) the vertebral column with its attached bony parts, and (2) the cranio-facial skeleton. Of these two parts, the bony tissue of the first arises in the embryo from cartilage, of the second partly from cartilage, partly from membrane.

In strict accorlance with their embryonic origin is their phylogenetic origin: as we pass from the higher vertebrates to the lower these structures can be traced back to a cartilaginous and membranous condition, so that, as Parker has shown, the cranio-facial bony skeleton of the higher vertebrates can be derived directly from a non-bony cartilaginous skeleton, such as is seen in Petromyzon and the cartilaginous fishes.

Balfour, in his "Comparative Embryology," states that the 
primitive cartilaginous cranium is always composed of the following parts :-

1. A pair of cartilaginous plates on each side of the cephalic section of the notochord known as the parachordals (pa.ch., Fig. 49; iv., Fig. 48). These plates, together with the notochord (ch.) enclosed between them, form a floor for the hind and mid-brain.

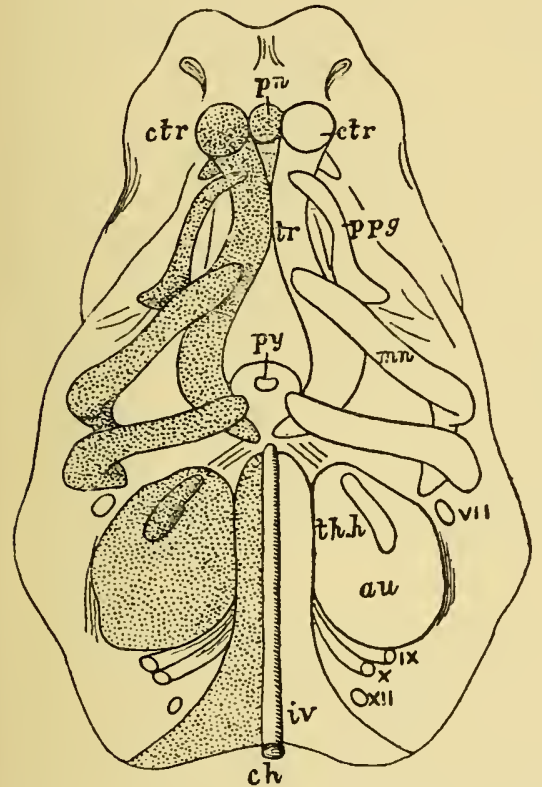

Fig. 48.-Embrio Pig, two-thirds of ax inch LONG (from Pariker), Elements of SKULL SEEN From Below.

$c h .$, notochord; $i v$. , parachordals; au., auditory capsule; $p y$. , pituitary body; tr., trabecula; ctr., trabecular cornu; pn., pre-nasal cartilage ; ppg., palato-pterygoid tract; $m n$. , mandibular arch; $t h . h .$, first branchial arch; TII.-XII., cranialnerves.

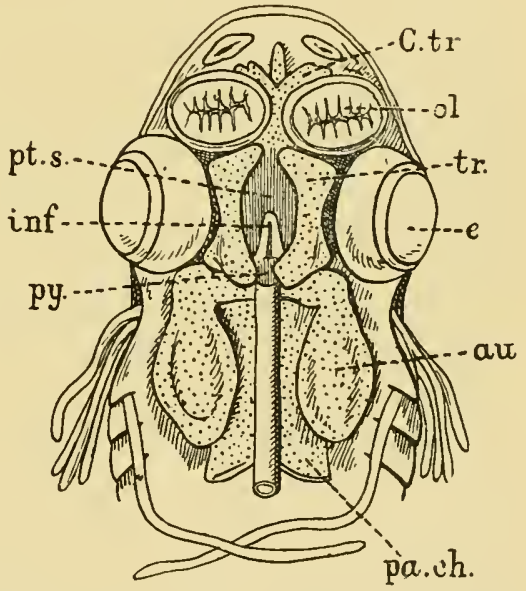

Fig. 49.-HEAD OF Eirbryo Dog-FISH (from Parker), Basal View of Crasiun FROM ABOVE.

ol., olfactory sacs; au., auditory capsule; py., pituitary body; pa.ch., parachordal cartilage; tr., trabecula; inf., infundibulum; pt.s., pituitary space; $e$., cre.

2. A pair of hars forming the floor for the fore-brain, known as the trabecula $(t r)$. These bars are continued forward from the parachordals. They meet posteriorly and embrace the front end of the notochord, and after separating for some distance bend in again in such a way as to enclose a space-the pituitary space (pt.s.). In 
front of this space they remain in contact, and generally unite. They extend forward into the nasal region $(p n$.$) .$

3. The cartilaginous capsules of the sense organs. Of these the auditory ( $a u$.) and the olfactory capsules (ol.) unite nore or less intimately with the cranial walls; while the optic capsules, forming the usually cartilaginous sclerotics, remain distinct.

The parachordals and notochord form together the basilar plate, which forms the floor for that section of the brain belonging to the primitive postoral part of the head, and its extent corresponds roughly to that of the basioccipital of the adult skull.

The trabecula, so far as their mere anatomical relations are concerned, play the same part in forming the floor for the front cerebral vesicle as do the parachordals for the mid- and hind-brain. They differ, however, from the parachordals in one important feature, viz. that except at their hinder end they do not embrace the notochord. The notochord always terminates at the infundibulum, and the trabeculae always enclose a pituitary space, in which lies the infundibulum (inf.) and the pituitary body ( $p y$.$) .$

In the majority of the lower forms the trabeculie arise quite independently of the parachordals, though the two sets of elements soon unite.

The trabecule are usually somewhat lyre-shaped, meeting in front and belind, and leaving a large pituitary space between their middle parts. Into this space the whole base of the fore-brain primitively projects, but the space itself gradually luecomes narrowed until it usually contains only the pituitary body.

The trabecular floor of the brain does not long remain simple. Its sides grow vertically upwards, forming a lateral wall for the brain, in which in the higher types, $t$ wo regions may be distiugnished, viz. au alisphenoidal region behind, growing out from what is known as the basisphenoidal region of the primitive trabecula, and an orbito-sphenoidal region in front, growing out from the presphenoidal region of the trabecula. These plates form at first a continuous lateral wall of the cranium. The cartilaginous wails which grow up from the trabecular floor of the cranium generally extend upwards so as to form a roof, though almost always an imperfect roof, for the cranial cavity.

The basi-cranial cartilaginous skeleton reduces itself always into trabeculie and parachordals with olfactory and auditory cartilaginous capsules. 
In addition, a branchial skeleton exists, which consists of a series of bars known as the branchial bars, so situated as to afford support to the successive branchial pouches. An anterior arch known as the mandibular arch (Fig. 50, $M n$.), placed in front of the hyo-mandibular cleft, and a second arch, known as the hyoid arch $(H y$.$) , placed in$ front of the hyo-branchial cleft, are developed in all types; the succeeding arches are known as the true branchial arches $(B r$.$) , and are$ only fully developed in the Ichthyopsida. In all cases of jaw-bearing (gnathosto. matous) vertebrates the first arch has become a support-

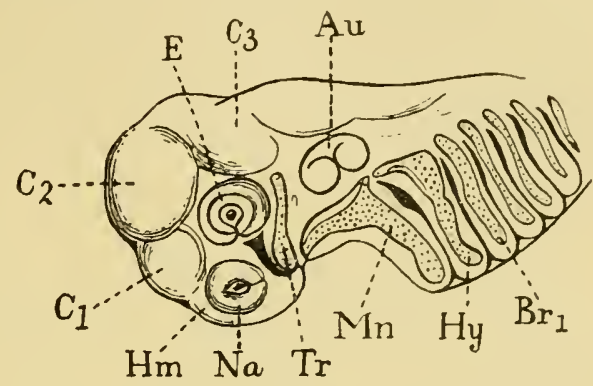

Fig. 50.-Head of Embryo Dog-Fish, ELEVEN LINES LONG. (From PAIKLR.)

$T r$., trabecula ; $N$ n., mandibular eartilage; $H y$., hyoid arcb; $\mathrm{Br}_{1}$., first branehial arch; $\mathrm{Na}$., olfactory sac ; $E$., eye ; Au., auditory eapsule; $H \mathrm{~m}$., hemisphere; $C_{1}, C_{2}, C_{3}$, cerebral vesicles. ing skeleton for the mouth (Fig. 51), and in the higher vertebrates in combination with the second or hyoid arch takes part in the formation of the ear-bones.

The true branchial arches persist, to a certain extent, in the

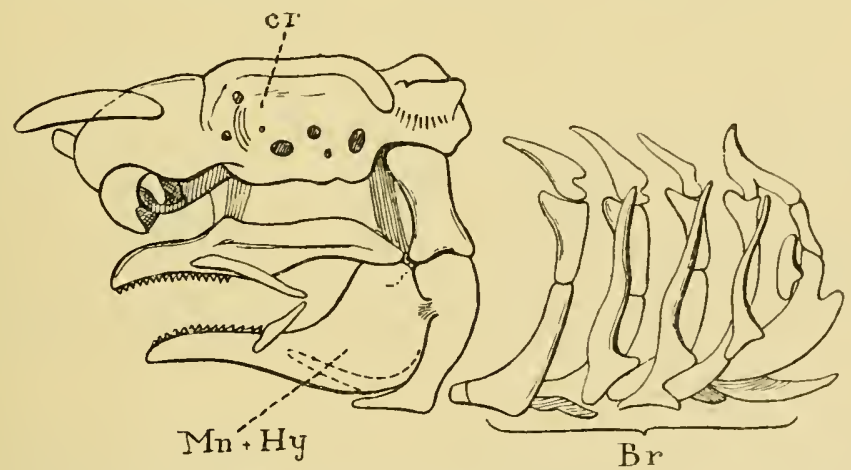

Fig. 51.--Skull of Adult Dog-kish, Side View. (From Parker.) $c r$., cranium; $\mathrm{Br}$., branchial arehes; $M n .+H y$. , mandibular and hyoid arehes.

Amphibia, and become still more degenerated in the Amniota (reptiles, birds, and mammals) in correlation with the total disappearance of a branchial respiration at all periods of their life. 
Their remmants become more or less important parts of the hyoid bone, and are employed solely in support of the tongue.

In no single animal is there any evidence that the foremost arch, the mandibular, is a true branchial arch. As low down as the Elasmobranchs it becomes divided into two elements which form respectively the upper and lower jaws; the hyoid arch, on the other land, although it has altered its form and acquired the secondary function of supporting the mandibular arch, still retains its respiratory function.

The evidence afforded by the mode of formation of the skeletal tissues of vertebrates down to the Elasmobranchs indicates that the primitive cranial skeleton arose from two paired basal cartilages, the parachordals and trabeculæ, to which were attached respectively cartilaginous cases enclosing the organs of liearing and smell. In addition, the branchial portion of the cranial region was provided with cartilaginous bars arranged serially for the support of the branchix, with the exception of the foremost, the mandibular bar, which formed supporting tissues for the mouth-the upper and lower jaws.

Just as in past times the spinal nerves and the segments they supplied were supposed to represent the type on which the original vertebrate was built, so also the spinal vertebrix afforded the type of the segmented skeleton, and the anatomists of those days strove hard to resolve the cranio-facial skeleton into a series of modified vertebre. Owing especially to the labours of Huxley, who showed that the segmentation in the head-region was essentially a segmentation due to the presence of lranchial bars, this conception was finally laid to rest and nowadays it is admitted to be hopeless to resolve the cranium into vertebral segments. Still, however, the vertebrate is a segmented animal and its segmented nature is visible in the cranial region, so far as the skeletal tissues are concerned, in the shape of the series of branchial and visceral bars.

To this segmentation the name of 'branchiomeric' has been given, while that due to the presence of vertebre is called 'mesomeric.'

As we have seen, the internal bony skeleton of the vertebrate commences as a cartilaginous and membranous skeleton. For this reason the preservation of such skeletons is impossible in the fossil form, unless the cartilage has become impregnated with lime salts, so that there is but little hope of ever obtaining traces of such 
structures in the fossils of the Silurian age either among the vertebrate or invertebrate remains. Fortunately for this investigation there are still living on the earth two representatives of that age; on the invertebrate side Limulus, and on the rertebrate side Ammocœtes.

The Elasmobranchs represent the most primitive of the gnathostomatous vertebrates. Below them come the Agnatha, known as the cyclostomatous fishes or Marsipobranchii, the lampreys (Petromyzon) and the hag-fishes (Myxine).

The skeleton of Petromyzon (Fig. כ22) consists of a cranio-facial skeleton composed of a cartilaginons unsegmented cranium, with the basal trabeculæ and parachordals and a series of branchial and visceral cartilaginous bars forming the so-called branchial basket-work; to these must be added auditory and nasal capsules. In contradistinction to this elaborate cranio-facial skeleton, the spinal vertebral

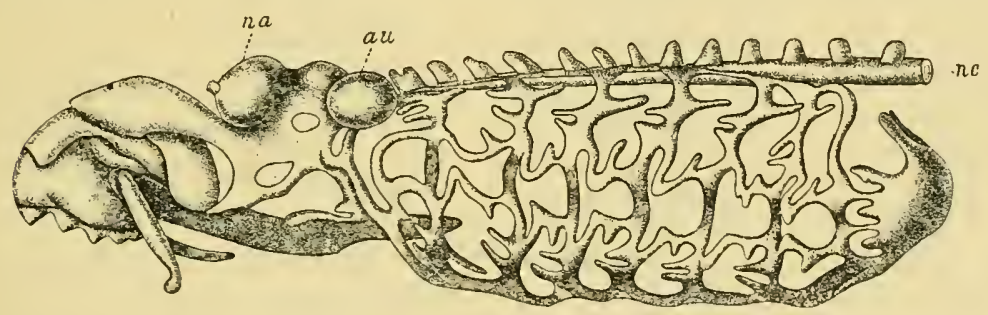

Fig. 52.-Skeletor of Petromizox. (From Parker.) na., nasal capsule; au., auditory capsule; nc., notochord.

skeleton is represented only by segmentally arranged small pieces of cartilage formed in the connective tissne dissepiments between segmented sheets of body-muscles (myotomes).

But Petromyzon is derived from Ammocretes by a remarkable process of transformation, and a most important part of that transformation is the formation of new cartilaginous structures. Thus we see that in Ammocotes there is no sign of a cartilaginous vertebral column; at transformation the rulimentary vertebre of Petromyzon are formed. In Ammocotes the brain-case is a simple fibrous membranous covering; at transformation this becomes cartilaginous. In Ammocoetes there are no cartilaginous structures corresponding to the sub-ocular arches; these are all formed at transformation. It follows, that we can trace back the bony skeleton of the vertebrate head to the skeleton of Ammocretes, and we may therefore conclude 
that the primitive cartilaginous skeleton of the vertebrate consisted of the following structures (Fig. 53, B), viz. the branchial bars

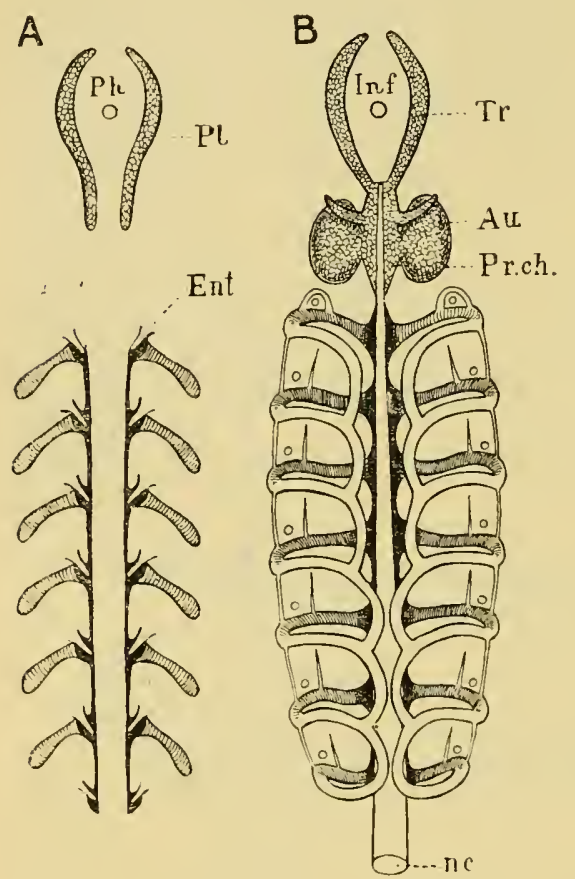

Fig. 53.-Comparison of Cartilaginous Sireleton of Linulues and Amarocetes.

A, Diagram of cartilaginons skeleton of Limulus. Soft cartilage, entapophysial ligaments, deep black; branchial bars simply hatched; hard cartilage, lateral trabeculæ of entosternite, netted; $P h_{\text {., position of }}$ pharynx.

B, Diagram of cartilaginous skeleton of Ammocotes. Soft cartilage, sub-chordal cartilaginous bands, deep black; branchial basket-work (first formed part), simply hatched; hard cartilage, cranio-facial skeleton, trabeculæ, parachordals and auditory capsules, netted; Inf., position of tube of infundibulum (old œsophagus). forming a basket-work, the trabeculie and parachordals, the auditory and nasal capsules-a clear proof that the cranial skeleton is older than the spinal. Of these structures the branchial bars are the only evidently segmented parts.

Tue Soft Calitilage of thif

Brancilial Skeleton of Ammocetes.

The study of Ammocortes gives yet another clue to the nature of the earliest skeleton, for these two marked groups of cartilage-the brauchial and basi-cranial-are characterized by a difference in structure as well as a difference in topographical position. J. Müller was the first to point out that these two sets of cartilages differ in appearance and constitution, and he gave to them the name of yellow and grey cartilage. Purker has described them fully under the terms soft and hard cartilage, terms which Schaffer has also used, and I shall also make use of them bere. The whole of the branchial cartilaginous skeleton is composed of soft cartilage, while the basi-cranial skeleton, consisting of trabeculic, parachordals, and auditory capsule, is composed 
of hard cartilage, the only soft cartilage in this region being that which forms the nasal capsule, not representer in Fig. 53, P.

These two groups of cartilage arise independently, so that at first the basi-cranial system is quite separate from the branchial, and only late in the history of the animal is a junction effected between the branchial system and the trabecule and parachordals, an initial separation which is especially striking when we consider that in this animal all the cartilaginous structures of any one system are continuous : there is no sign of anything in the nature of joints.

Of these two main groups, the branchial cartilages are formed first in the embryo, a fact which suggests that they are the most primitive of the vertebrate cartilages, and that, therefore, the first true formation of cartilage in the invertebrate ancestor may be looked for in the shape of bars supporting the branchial mechanism. The evidence of the origin of the cartilaginous structures in Ammocotes is given by Shipley in the following words:-

"The branchial bases are the first part of the skeleton to appear. They arise about the 24 th day as straight bars of cartilage, lying external and slightly posterior to the branchial vessel.

"The first traces of the basi-cranial skeleton appear on the 30th day as two rods of cartilage-the trabecula."

Our attention must, in the first place, be directed to this branchial basket-work of Ammocœes.

Underlying the skin of Ammocetes in the branchial region is situated the sheet of longitudinal body-muscles, divided into a series of segments or myotomes, which forms the somatic muscles so characteristic of all fishes. This muscular sheet is depicted on the leftland side of Fig. 5t. It does not extend over the lower lip or over that part in the middle line where the thyroid gland is situated. In these parts a sheet of peculiar tissue known by the name of mucocartilage lies immediately under the skin, covering over the thyroid gland and lower lip. The somatic muscular sheet with the superjacent skin can be stripped off very easily owing to the vascularity and looseness of the tissue immediately underlying it. When this is done the branchial basket-work comes beautifully into view as is seen on the right-hand sile of Fig. 54. It forms a cage within which the branchixe and their muscles lie entirely concealed.

This is the great characteristic of this most primitive form of the branchial cartilaginous bars and distinguishes it from the luranchial 
bars of other higher fishes, in that it forms a system of cartilages which lie external to the branchire-an extra-branchial system.

This branchial basket-work is simpler in Ammocotes than in Petromyzon, and its actual starting-point consists of a main trans-

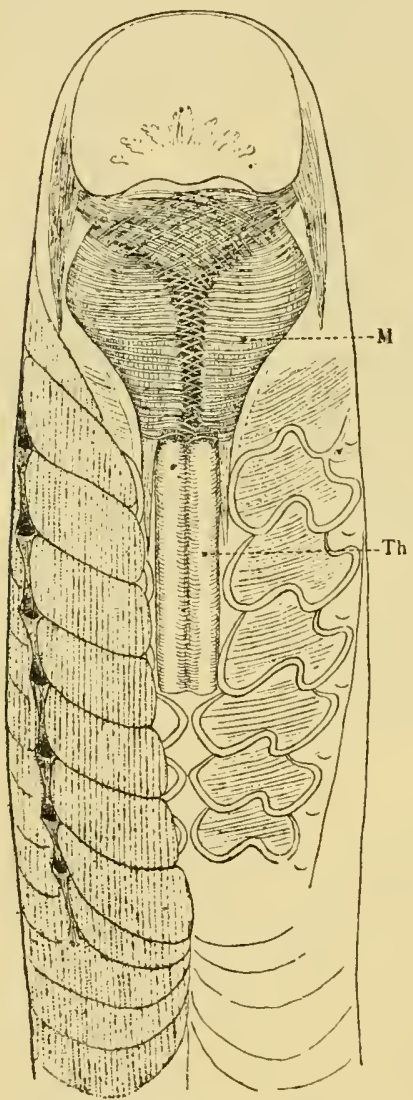

Fig. 54.-Ventral View of Head Region of Ammocertes. $T h$, thyroid gland; $M$., lower lip, with its muscles. verse bar corresponding to each branchial segment; from this transverse bar the system of longitudinal bars by which the basket-work is formed has sprung. These transverse bars arise from a cartilaginous longitudinal rod, situated close against the notochord on each side. These rods may be called the subchordal cartilaginous bands (Fig. 53), and, according to the observations of Schneider and others, each subchordal band does not form at first a contimuous cartilaginous rod, but the cartilage is conspicuous only at the places where the transverse bars arise. In the youngest Ammocoetes examined by Schaffer, he could find no absolute discontinuity of the cartilage except between the first two transverse bars, but he says that the thinning between the transverse bars was so marked as to make it highly probable that at an earlier stage there was discontinuity. The whole system of branchial bars and subchordal rods is at first absolutely disconnected from the cranial system of trabeculie and parachordals, and only later do the two systems join.

These observations on Ammocœetes lead most definitely to the conclusion that the starting-point of the whole cartilaginous skeleton of the vertebrate consisted of a series of transverse cartilaginons bars, for the purpose of supporting branchial segments; these were connected with two axial longitudinal cartilaginous rods, which at first contained cartilage only near the places of junction of the branchial 
bar's. This system may be called the mesosomatic skeleton, as it is entirely confined to the brauchial or mesosomatic region.

In addition to this primitive cartilaginous framework, which was formed for the support of the mesosomatic or respiratory segments, but at a slightly later period in the phylogenetic history, a separate cartilaginous system was formed for the support of the prosomatic segments, viz. the trabeculie and parachordals with the auditory capsules: a system which was at first entirely separated from the mesosomatic, and, as we shall see, is more advanced in structure than the branchial system. Later still, the story is completed at the time of transformation to Petromyzon by the formation of the simple cartilaginous skull and the rudimentary vertebre, the structure of which is also of a more advanced type.

\section{The Stroucture of the Soft Branchial Cartilage.}

Having considered the topographical position of the primitive branchial cartilaginous skeleton, we may now inquire, What was its structure and how was it formed?

In the higher vertebrates various forms of cartilage are described, viz. hyaline, fibro-cartilage, elastic cartilage, and parenchymatous cartilage. Of these, the parenchymatous cartilage is looked upon as the most primitive form, because it preserves without modification the characters of embryonic cartilage.

Embryology, then, would lead to the belief that the earliest form of cartilage in the vertebrate kingdom ought to be of this type, viz. large cells, each of which is enclosed in a simple capsule, so that the capsules of the cells form the whole of the matrix, and thus form a simple homogeneous honeycomb-structure, in the alveoli of which the cartilage-cells lie singly. If, then, the branchial cartilages of Ammocates are, as has just been argued, the representatives of the cartilaginous skeleton of the primitive vertebrate, it is reasonable to suppose that they should resemble in structure this embryonic cartilage. Such is undoubtedly the case: all observers who have described the branchial basket-work of Ammocates or Petromyzon have been struck with the extremely primitive character of the cartilage, and the last observer (Schaffer) describes it as composed of thin walls of homogeneous material, in which there are no lines of separation, which form a simple honeycomb-structure, in the alveoli 
of which the separate cells lie singly. These branchial cartilages are each surrounded by a layer of perichondrium, and in Fig. 55, A, I give a picture of a section of a portion of one of the bars.

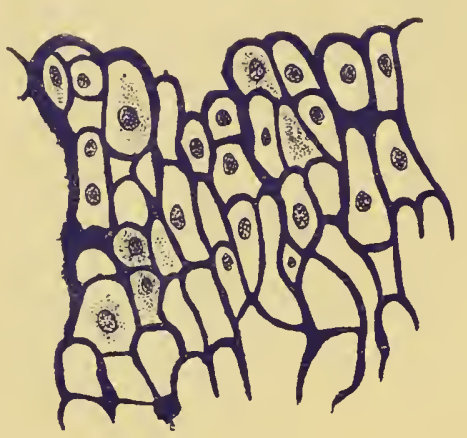

A

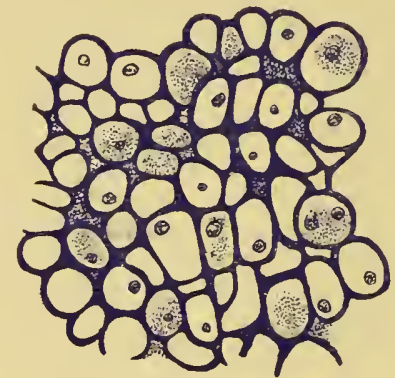

$\mathrm{B}$

Fig. 55.-A, Branchial Cartilage of Ammoceteses, stained with Thionin. B, Branchial Cartilage of Limulus, stained with Thionin.

Hence we see that strueturally as well as topographically the branchial bars of Ammocnetes justify their claim to be considered as the origin of the vertebrate cartilaginous framework.

\section{Or the Structure of tile Muco-cartilage in Amocetes.}

We can, however, go further than this, and ask how this cartilage itself is formed in Ammocetes? The answer is most definite, most instructive and suggestive, for in all cases this particnlar kind of cartilage is formed from, or at all events in, a peculiar fibrous tissue, which was called by Schneider "Schleim-Kinorpel," or muco-cartilage, a tissue which is distinguishable from other connective tissues, not only by its structural peculiarities, but also by its strong affinity for all dyes which differentiate mucoid or chondro-mucoid substances.

This muco-cartilage is thus described by Schneider:-The perichondrium in Ammocuetes is not confined to the true cartilaginous structures, but extends itself in the form of thin plates in definite directions. Between these plates of perichondrium a peculiar tissue (Fig. 56) - the muco-cartilage-exists, consisting of fibrillæ, whose direction is mainly at right angles to the planes of the perichondrial plates, with star-shaped cells in among them, and with the spaces between the fibrille filled up with a semi-fluid mass. 
From this tissue all the primitive cartilages which resemble the branchial bars are formed, either by the invasion of chondroblasts from the surromding perichondrium, or by the proliferation and encapsulation of the cells of the muco-cartilage itself.

This very distinctive tissue-the muco-cartilage-is of very great importance in all questions of the origin of the skeletal tissues. In all descriptions of the skeletal tissues it has been practically disregarded until recent years when, besides my own observations, its distribution has been mapped ont by Schaffer. Thus Parker, in his well-known description of the skeleton of the marsipobranch fishes, does not even mention its existence. Its importance is shown by its absolute disappearance at transformation and its nonoccurrence in any of the ligher vertebrates. It is entirely confined to the headregion, and its distribution there is most suggestive, for, as will be described fully later on, it forms a skeleton which both in structure and position resembles very closely the head-shields of cephalaspidian fishes. At the present part of my argument its more immediate interest lies in the metlod

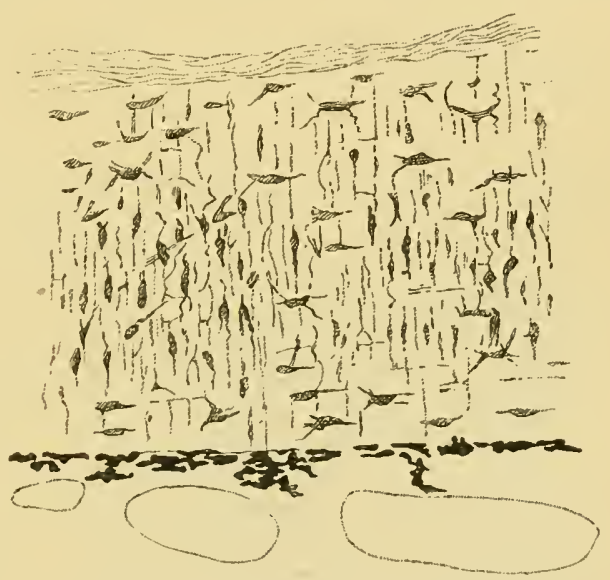

Fig. 56.-SECtion OF Muco-CARTILAgE Frou Dorsal Head-plate of Amocetes. of tracing this tissue. For this purpose I made use of the micru-chemical reaction of thionin, a dye which, as shown by Hoyer, stains all mucin-containing substances a bright purple. Schaffer made use of a corresponding basophil stain, hæmalum. When stained with thionin, the matrix, or ground-sulstance of the branchial cartilages as well as the matrix or semi-fluid substance in which the fibrils of the muco-cartilaginous cells are embedded take on a deep purple colour, while the fibrous material of the cranial walls and other connective tissue strands, such as the perichondrium, are coloured light blue. Mneo-cartilage, then, may be described as a peculiar form of connective tissue which differs from other connective tissue not only in its appearance but in 
its chemical composition, for unlike white fibrous tissue it contains a large amount of mucin, and this tissue is the forerunner of the earliest cartilaginous vertebrate skeleton, the branchial bars of Ammocutes.

The conclusions to which we are led by the study of the structure, position, and mode of origin of these primitive cartilages of Amnocotes may be thus summed up :-

1. The immediate ancestor of the vertebrate must have possessed a peculiar fibrous tissue-the ground-substance of which stained deep purple with thionin-in which cartilage arose.

2. The cartilage so formed was not like hyaline cartilage, but resembled in a striking mauner parenchymatous cartilage.

3. This cartilage was situated partly in two axial longitulinal bands, partly as transverse bars, which supported the branchial apparatus.

\section{The Prosomatic or Basi-cranial Skeleton of Ammoceteis.}

Before searching for any evidence of a similar tissue in any invertebrate group, it is advisable to consider the other portion of the cartilaginous skeleton of Ammocoetes, which consists of the trabeculæ, parachordals and auditory capsules-the basi-cranial skeleton -and is composed of hard, not soft eartilage.

This basi-cranial skeleton represented in Fig. 53, B, is confined to the region of the notochord, the cranial walls being composed entirely of a white fibrous membrane. It is separated at first entirely from the sub-chordal portion of the branchial basket-work, and is composed of a foremost part, the trabeculæ ( $T r$ r.), and of a hindermost part, the parachordals (Pr.ch.), which are characterized by the attachment on each side of the large auditory capsule (Au.). In Ammocotes the trabecular bars are continuous with the parachordals, the junction being marked by a small lateral projection on each side, which at transformation is seen to play an important part in the formation of the sub-ocular arch. The trabecular bar lies close against the notochord on each side up to its termination; it then bends away from the middle line and curves round until it meets its fellow on the opposite side, thus forming, as it were, the head of a racquet of which the notochord forms the splice in the handle. The strings of the racquet are represented by a thin membrame, in the centre of which the position of the infuncibulum $(\operatorname{Inf}$.$) of the$ 
brain can be clearly seen. In an earlier stage of Ammocotes the two trabeeular horns do not meet, but are separated by connective tissue, which afterwards becomes cartilaginous.

As far, then, as the topography of this basi-cranial skeleton is concerned, the striking points are-the shape of the trabecular portion, diverging as it does around the infundibulum, and the presence on the parachordal portion of the two large auditory capsules.

These two points indicate, on the hypothesis that infundibulum and oesophagus are convertible terms, that two supporting structures of a cartilaginous nature must have existed in the ancestor of the vertebrate, the first of which surrounded the oesophagus, and the second was in connection with its auditory apparatus.

\section{Structure of the Hard Cartihages.}

The structure of this hard cartilage of the trabecula and auditory capsules resembles that of the soft, in so far that it consists of large

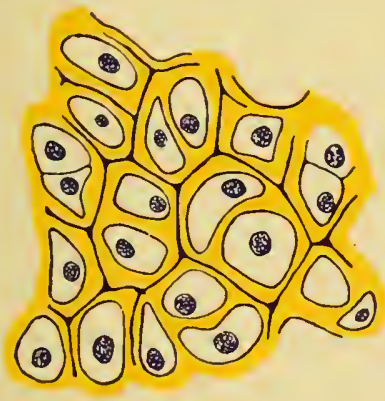

$A$

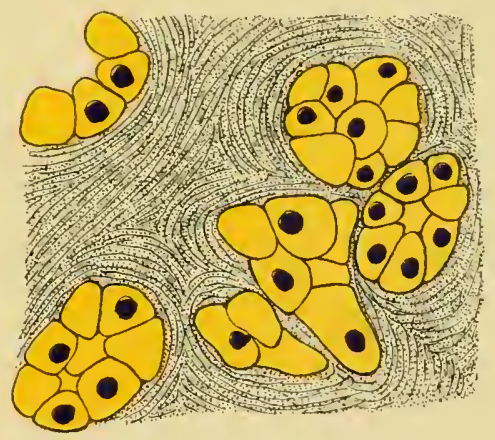

B

Fig. 57.-A, Cartilage of Trabecula of Ampocgetes, stained with H.ematoxylin and Picric Acid. P, Nests of Cartirage Celis in Fintostfirnite of Hypoctones, stained with Hamatoxylin and Picric Acid.

cells with a comparatively small amount of intercellular substance. Schaffer, who has described it lately, considers that it is a nearer approach to hyaline cartilage than the soft, but yet cannot be caller hyaline cartilage in the usual sense of the term. Its peculiarities and its differences from the soft are especially well seen by its staining reactions. I have myself been particularly struck with the effect of picrocarmine or combined hæmatoxylin and picric acid 
staining (Fig. 57). In the case of the soft cartilage the capsular substance stains respectively a brilliant red or blue, while that of the hard cartilage is coloured a deep yellow, so that the junction between the parachordals and the branchial cartilages is beantifully marked out. Then, again, with thionin, which gives so marked a reaction in the case of the soft cartilage, the hard cartilage of the auditory capsule is not stained at all, and in the trabeculæ the deep purple colour is confined to the mucoid cement-substance between the capsules, just as Schaffer lras stated. The same kinds of reactions have been described by Schaffer: thus by double staining with hremalum-eosin the hard cartilage stains red, the soft blue; and he points out that even with over-staining by hæmalum the auditory capsule remains colourless, just as I have noticed with thionin. He infers, precisely as I have done from the thionin reaction, that chondro-mucoid, which is so marked a constituent of the soft cartilage and of the muco-cartilage, is absent or present in but slight quantities in the hard cartilage. Similarly, he points out that double staining with tropoolin-methyl-violet stains the hard cartilage a bright orange colour, and the soft cartilage a violet.

The evidence, then, shows clearly that a marked chemical difterence exists between these two cartilages, which may be expressed by saying that the one contains very largely a basopliil substance, which we may speak of as belonging to the class of chondro-mucoid substances, while the other contains mainly an oxyphil substance, probably a chondro-gelatine substance.

We may perhaps go further and attribute this difference of composition to a difference of origin; for whereas the soft cartilage is invariably formed in a special tissue, the muco-cartilage, which shows by its reaction how largely it is composed of a mucoid substance, the hard cartilage is certainly, in the case of the cartilage of the cranium where its origin has been clearly made out, formed in the membranous tissue of the craninm of Ammocetes-i.e. in a tissue which stains light blue with thionin, and contains a gelatinous rather than a mucoid substratum.

The best opportunity of finding out the mode of origin of the hard cartilage is aftorded at the time of transformation, when so much of this kind of cartilage is formed anew. Unfortunately, it is very difficult to obtain the early transformation stages, consequently we cannot be said to possess any really exhanstive and 
definite account of how the new cartilages are formed. Bujor, Kaensche, and Schaffer all profess to give a more or less definite account of their formation, and the one striking impression left on the mind of the reader is how their descriptions vary. In one point only are they agreed, and in that I also agree with them, viz. the manner in which the new cranial walls are formed. Schaffer describes the process as the invasion of chondroblasts into the homogeneous fibrous tissue of the cranial walls. Such chondroblasts not only form the cartilaginous framework, but also assimilate the fibrous tissue which they invade, so that finally all that remains of the original fibrous matrix in which the cartilage was formed are these lines of cement-substance between the groups of cartilage cells, which, containing some basophil material, are marked out, as already mentioned (Fig. 57).

We may therefore conclude, from the investigation of Ammocœes, that the front part of the basi-cranial skeleton arose as two trabecular bars, to which museles were attached, situated bilaterally with respect to the central nervous system. These bars were composed of tendinous material with a gelatinous rather than a mucoid substratum, in which nests of cartilage-cells were formed, the cartilaginous material formed by these cells being of the hard variety, not staining with thionin, and staining yellow with picro-carmine, etc. By the increase of such nests and the assimilation of the intermediate fibrous material, the original fibro-cartilage was converted into the close-set semi-hyaline cartilage of the trabeculæ and auditory capsules, in which the fibrous material still marks out by its staining-reaction the limits of the cell-clusters.

Such I gather to be Schaffer's conclusions, and they are certainly borne out by my own and Miss Alcock's observations. As far as we have had an opportunity of observing at present, the first process at transformation appears to consist of the invasion of the fibrous tissue of the cranial wall by groups of cells which form nests of cells between the fibrous strands. These nests of cells form round themselves capsular material, and thus form cell-territories of cartilage, which squeeze out and assimilate the surrounding fibrous tissue, until at last all that remains of the original fibrous matrix is the lines of cement-substance which mark out the limits of the various cell-groups.

At present I am inclined to think that both soft and hard cartilage originate in a very similar manner, viz. by the formation of capsular 
material around the invading chondroblasts, and that the difference in the resulting cartilage is mainly due to the difference in chemical composition of the matrix of the connective tissue which is invaded. Thus the difference may be formulated as follows:-

The hard cartilage is formed by the invasion of chondroblasts into a fibrous tissue, which contains a gelatinous rather than a mucoid substratum, in contradistinction to the soft cartilage which is formed, probably also by the invasion of chondroblasts, in a tissue-the muco-cartilage-which contains a specially mucoid substratum.

Such, then, is the very clearly defined starting-point of the vertebrate skeleton-two distinct formations of different histological and chemical structure,- the one forming a segmented branchial skeleton, the other a non-segmented basi-cranial skeleton.

\section{The Cartilaginous Skeleton of Limulus.}

Among the whole of the invertebrates at present living on the earth, is there any sign of an internal cartilaginous skeleton that will give a direct clue to the origin of the primitive vertebrate skeleton? The answer to this question is most significant: only one animal among all those at present known possesses a cartilaginous skeleton, which is directly comparable with that of Ammocœtes, and here the comparison is very close-only one animal among the thousands of living invertebrate forms, and that animal is the only representative still surviving of the palæostracan group, which was the dominant race when the vertebrate first made its appearance. The Limulus, or king-crab, possesses a segmented branchial internal cartilaginous skeleton (Fig. 53, A), made up of the same kind of cartilage as the branchial skeleton of Ammocotes, confined to the mesosomatic or branchial region, just as in Ammocotes, forming, as in Ammocretes, cartilaginous bars supporting the branchiæ, and these bars are situated externally to the branchiæe, as in Ammocotes. In addition this animal possesses a basi-cranial internal semi-cartilaginous unsegmented plate known as the entosternite or plastron situated, with respect to the cesophagus, similarly to the position of the trabeculie with respect to the infundibulum in Ammocotes. Moreover, the cartilaginous cells in this tissue differ from those in the branchial region, in precisely the same manner as the hard cartilage cliffers from the soft in Ammocœetes. 
This plastron, it is true, is found in other animals, all of which are members of the scorpion tribe, except in one instance, and this, strikingly enough, is the crustacean Apus-a strange primitive form, which is acknowledgec to be the nearest representative of the Trilobita still living on the earth. None of these forms, however, possess any sign of an internal cartilaginous branchial skeleton, such as is possessed by Limulus. Scorpions, Apus, Limulus, are all surviving types of the stage of organization which had been reached in the aninal world when the vertebrate first appeared.

\section{The Mesosonatic or Respiratoiy Skeleton of Linulus, composed of Soft Cartilage.}

Searching through the literature of the histology of the cartilaginous tissues in invertebrate animals, to see whether any cartilage had been described similar to that seen in the branchial cartilages of Ammocates, and whether such cartilage, if found, arose in a fibrous tissue resembling muco-cartilage, I was speedily rewarded by finding, in Ray Lankester's article on the tropho-skeletal tissues of Limulus, a picture of the cartilage of Limulus, which would have passed muster for a drawing of the branchial cartilage of Ammocotes. This clue I followed out in the manner described in my former paper in the Journal of Anatomy and Physiolog!, and mapped out the topography of this remarkable tissue.

Limulus, like other water-dwelling artbropods, breathes by means of gills attached to its appendages. These gill-bearing appendages are confined to the mesosomatic region, as is seen in Fig. 59; and these appendages are very different to the ordinary locomotor appendages, which are confined to the prosomatic region. Each appendage, as is seen in Fig. 58, consists mainly of a broad, basal part, which carries the gill-book on its under surface; the distal parts of the appendage have dwindled to mere rudiments and still exist, not for locomotor purposes, but because they carry on each segment organs of special importance to the animal (see Chapter XI.). As is seen in Fig. 58, the basal parts of each pair of appendages form a broad, flattened parldle, by means of which the animal is able to swim in a clumsy fashion. Very striking and suggestive is the difference between these gill-bearing mesosomatic appendages and the non-gill-bearing locomotor appendages of the prosoma. 
At the base of each of these appendages, where it is attached to the body of the animal, the external chitinous surface is characterized
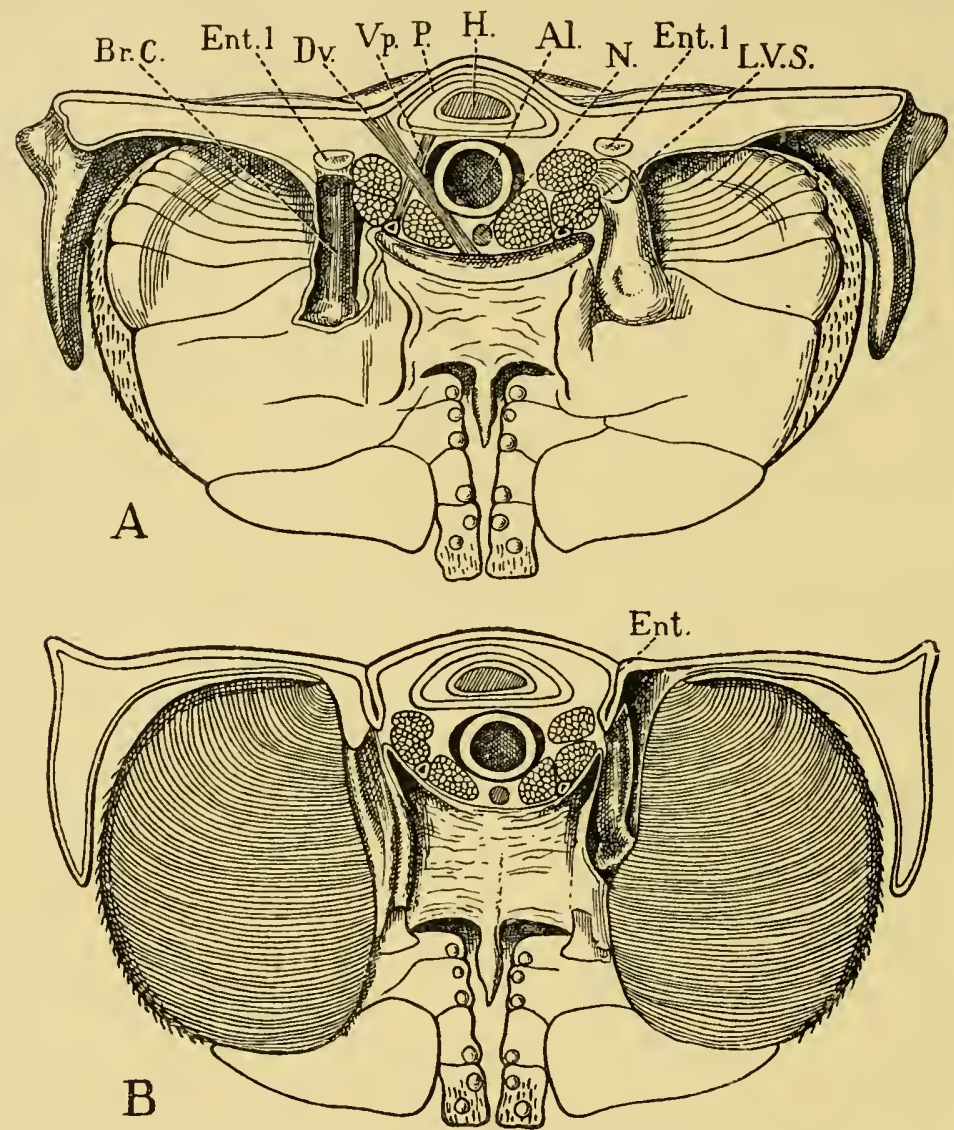

Fig. 58.-Transverse Section throvgh the Mesosoma of Limllus, to show the Antemior (A) and the Posterior (B) Surfaces of a Mesosomatic on Branchial appendage.

In each figure the branchial cartilaginous bar, $B r . C$., has been exposed by dissection on one side. Ent., entapophysis; Ent.l., entapophysial ligament cut across; $B r . C$., branchial cartilaginous bar, which springs from the entapophysis; $H$., heart; $P$., pericardium; $A l$., alimentary canal ; $N$., nerve cord ; L.I.S., longitudinal venous sinus; $D v$., dorso-ventral somatic muscle; $V p$., veno-pericardial muscle.

by a peculiar stumpy, rod-like marking, and upon removing the chitinous covering, this surface-appearance is seen to correspond to a well-marked rod of cartilage $(B r . C$.), which extends from the body 
of the animal well into each appendage. This bar of cartilage arises on each side from the corresponding entapophysis (Ent.), which is the name given to a chitinous spur which projects a short distance (Fig. 58, B) into the animal from the dorsal sicle, for the purpose of giving attachment to various segmental muscles. These entapophyses are formel by an invagination of the chitinous surface on the dorsal side and are confined to the mesosomatic region, so that the mesosomatic carapace indicates, by the number of entapophyses, the number of segments in that region, in contradistinction to the prosomatic carapace, which gives no indication on its surface of the number of its components.

Each entapophysis is hollow and its walls are composed of chitin ; but from the apex of each spur there stretches from spur to spur a band of tissue, called by Lankester the entapophysial ligament (Ent.l.) (Fig. 58), and in this tissue cartilage is formed. Isolated cartilaģinous cells, or rather groups of cells, are found here and there, but a concentration of such groups always takes place at each entapophysis, forming here a solid mass of cartilage, from which the massive cartilaginous bar of each branchial appendage arises.

Further, not only is this cartilage exactly similar to parenchymatous cartilage, as it occurs in the branchial cartilages of Ammoccetes, but also its matrix stains a brilliant purple with thionin in striking contrast to the exceedingly slight light-blne colour of the surrounding perichondrimn. In its chemical composition it shows, as might be expected, that it is a cartilage containing a very large amount of some mucin-body.

\section{The Muco-cartilage of Limeles.}

The resemblance between this structure and that of the branchial bars of Ammocretes does not end even here, for, as already mentioned, the cartilage originates in a peculiar connective tissue band, the entapophysial liganent, and this tissue bears the same relation in its chemical reactions to the ordinary connective tissue of Limulus, as muco-cartilage does to the white fibrons tissue of Ammocretes. The white connective tissue of Limulus, as already staterl, resembles that of the vertebrate more than does the connective tissue of any other invertebrate, and, similarly to that of Ammocretes, loes not stain, or gives only a light-blue tinge with thionin. The tissue of 
the entapopliysial ligament, on the contrary, just like muco-cartilage, takes on an intense purple colour when stained with thionin. It possesses a mucoid substratum, just as does muco-cartilage, and in both cases a perfectly similar soft cartilage is horn from it.

One difference, however, exists between the branchial cartilages of these two animals; the innermost axial layer of the branchial bar of

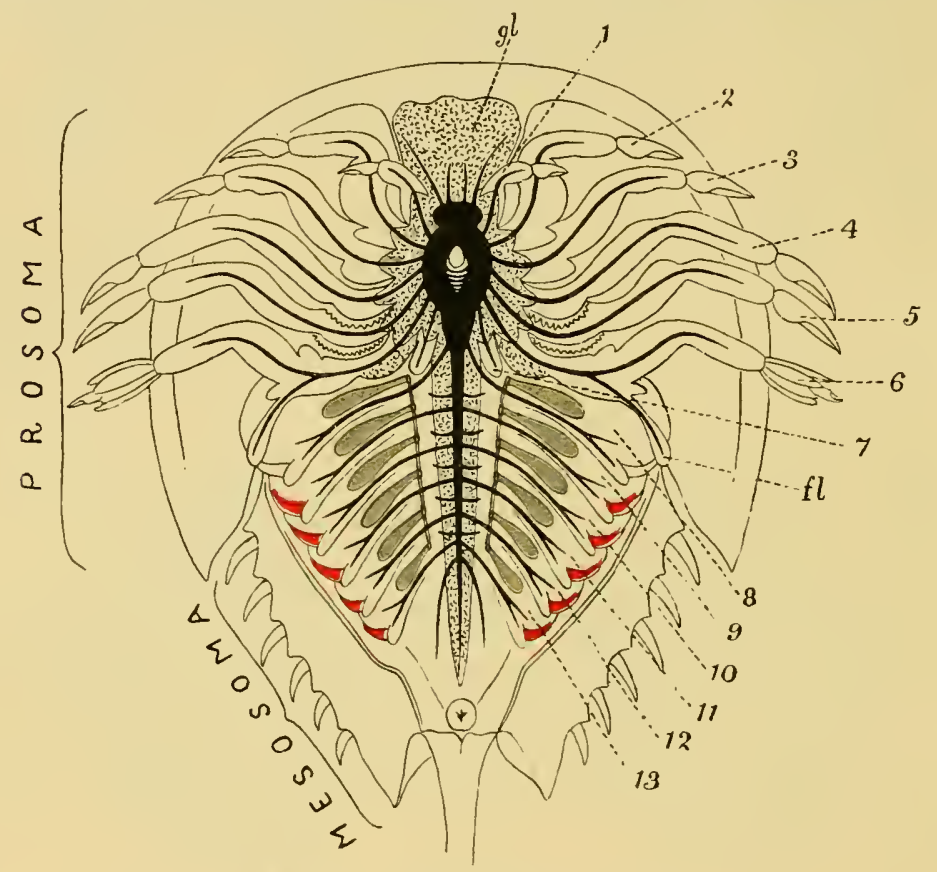

Fig. 59.-Diagran of Linfules, to show the Nerves to the Appendages (1-13) and the Branchial Cartilages.

The branchial cartilages and the entapophysial ligaments are coloured blue, the branchin red. gl., generative and hepatic glands surrounding the central nervous system and passing into the base of the flabellum $(f l$.$) .$

Limulus is very apt to contain a specially hard substance, apparently chalky in nature, so that it breaks up in sections, and gives the appearance of a loroken-down spongy mass; if, however, the tissue is first placed in a solution of hydrochloric acid, it then cuts easily, and the whole tissue is seen to be of the same structure throughont, the main difference being that the capsular spaces in the axial region are much larger and much»inore free from cell-protoplasm than are those of the smaller younger cells near the periphery. 
I have attempted in Fig. 53 to represent this close resemblanee between the segmented branchial skeleton of Limulus and of Ammocortes, a resemblance so close as to reach even to minute details, such as the thinning out of the cartilage in the subchordal bands and

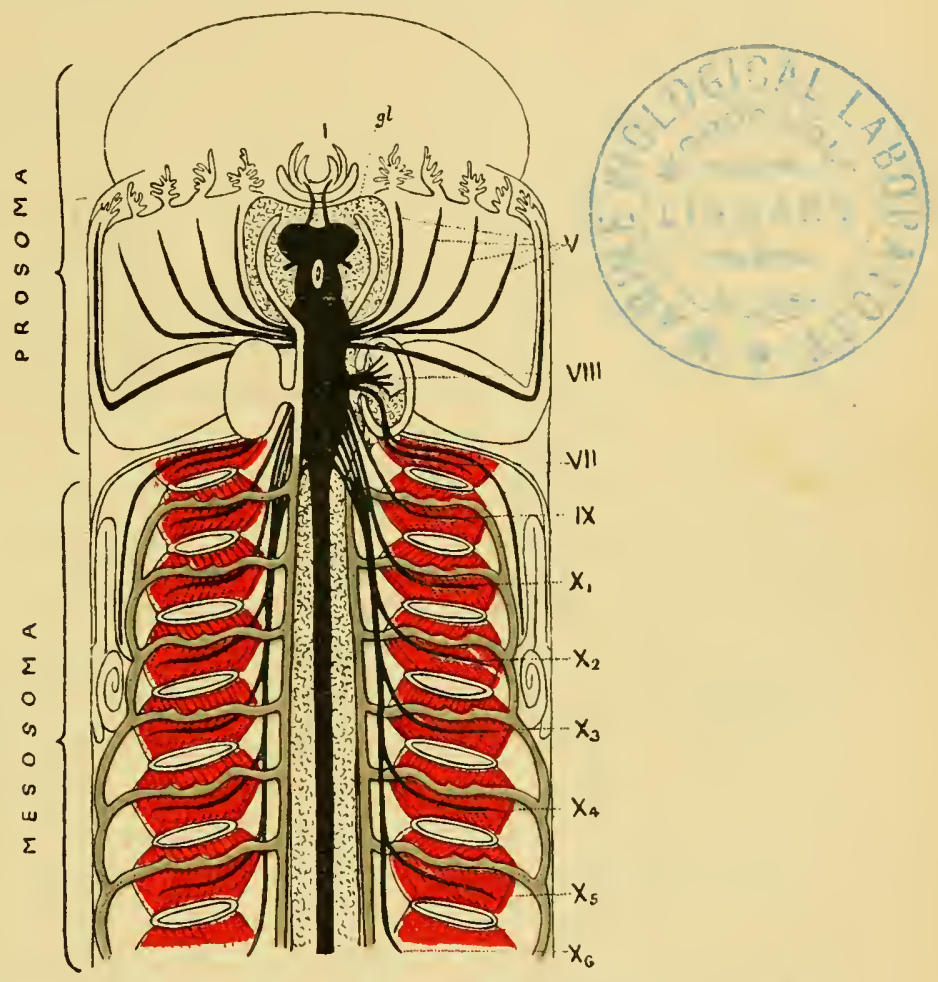

Fig. 60.-Diagram of Amocetes clt open to show the Lateral sistem of

Craxial Nerves V., VII., IX., X., and the Branchial Cartilages.

The branchial cartilages and sub-ehordal ligaments are coloured blue, the branchie red. gl., glandular substance surrounding the central nervous system and passing into the auditory capsule with the auditory nerve (IIII.).

entapophysial ligaments respectively between the places where the branchial bars come off.

In Fig. 59 I have shown the prosoma and mesosoma of Limulus, and indicated the nerves to the appendages together with the mesosomatic cartilaginous skeleton.

In Fig. 60 I have drawn a corresponding picture of the prosomatic and mesosomatic region of Ammoccetes with the corresponding nerves 
and cartilages. In this figure the animal is supposed to be slit open along the ventral mid-line and the central nervous system exposed.

\section{The Prosumatic Skeleton of Lnulue, ('omposed of Hari)} Cartillage.

The rest of the primitive vertebrate skeleton arose in the prosoinatic region, and formed a support for the base of the brain. This skeleton was composed of hard cartilage, and arose in white fibrous tissue containing gelatin rather than mucin.

Is there, then, any peculiar tissue of a cartilaginous nature in Limulus and its allies, situated in the prosomatic region, which is entirely separate from the branchial cartilaginous skeleton, which acts as a supporting internal framework, and contains a gelatinous rather than a mucoid substratum?

It is a striking fact, common to the whole of the group of animals to which our inquiries, deduced from the consideration of the structure of Ammocoetes, have, in every case, led us in our search for the vertebrate ancestor, that they do possess a remarkable internal semi-cartilaginous skeleton in the prosomatic region, called the entosternite or plastron, which gives support to a large number of the muscles of that region; which is entirely independent of the branchial skeleton, and differs markedly in its chemical reactions from that cartilage, in that it contains a gelatinous rather than a mucoid substratum.

In Limulus it is a large, tough, median plate, fibrous in character, in which are situated rows and nests of cartilage-cells. The same structure is seen in the plastron of Hypoctonus, of Thelyphomus, and to a certainty in all the members of the scorpion group. Very different is the behaviour of this tissue to staining from that of the branchial region. No part of the plastron stains purple with thionin; it hardly stains at all, or gives only a very slight blue colour. In its chemical eomposition there is a marked preponderance of gelatin with only a slight amount of a mucin-body. In some cases, as in Hypoctomus (Fig. 57, B) and Mygale, the capsules of the cartilage-cells stain a deep yellow with hrematoxylin and picric acid, while the fibres between the cell-nests stain a blue-brown colour, partly from the hrmatoxylin, partly from the picric acid.

All the evidence points to the plastron as resembling the basicranial skeleton of Ammocotes in its composition and in the origin 
of its cells in a white fibrous tissuc. What, then, is its topographical position? It is in all cases a median structure lying between the ceplalic stomach and the infra-esophageal portion of the central nervous system, and in all cases it possesses two anterior horns which pass around the cesophagus and the nerve-masses which immediately enclose the resophagus (Fig. 61, A). These lateral horns, then, which lie laterally and slightly ventral to the central nervous system, and are called by Ray Lankester and Benhan the subneural portion of the entosternite, are very nearly in exactly the position of the racquet-shaped hear of the trabeculie in Ammoccetes. It is easy to see that, with a more extensive growth of the nervous material dorsally, such lateral horns might be caused to take up a still more ventral position. Now, these two lateral horns of the plastron of Limulus are continued along its whole length so as to form two thickened lateral ridges, which are conspicuous on the flat surface of the rest of this median plate. In other cases, as in the Thelyphonidre, the plastron consists mainly of these two lateral ridges or trabeculie, as they might be called, and Schinkéwitsch,
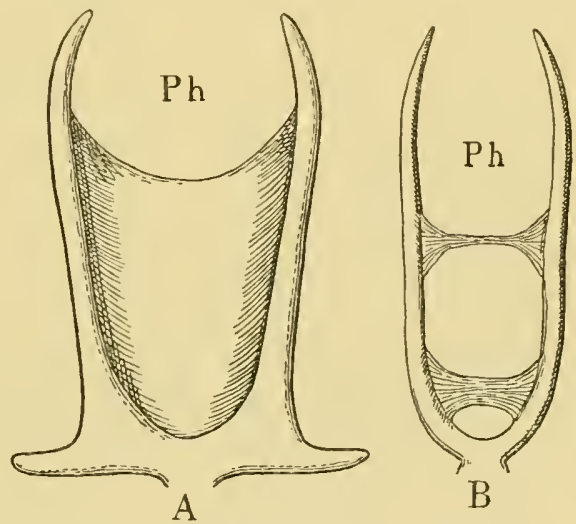

Fig. 61.-A, Extosterite of Linulus; B, Extosternite of Thetrphoxus.

Pll., position of pharynx. who more than any one else has made a comparative study of the entosternite, describes it as composed in these animals of two lateral trabeculæ crossed by three transverse trabecule. I myself can confirm his description, and give in Fig. 61, B, the appearance of the entosternite of Thelyphonus or of Hypoctonus. The supra-øesophageal ganglia and part of the infra-cesophageal ganglia fill up the space $P h$.; stretching over the rest of the infra-cesophageal mass is a transverse trabecula, which is very thin; then comes a space in which is seen the rest of the infra-œesophageal mass, and then the posterior part of the plastron, ventrally to which lies the commencement of the ventral nerve-cord.

In these forms, in which the central nervous system is more 
concentrated towards the cephalic end than in Limulus, the whole of the eoncentrated brain-1nass is separated from the gut only by this thin transverse band of tissue. Judging, then, from the entosternite of Thelyphonus, it is not difficult to suppose that a continuation of the same growth of the brain-region of the central nervons system would cause the entosternite to be separated into two lateral trabeculæ, which would then take up the ventro-lateral position of the two trabeculre of Ammocoetes.

On the other hand, it might be that two lateral trabeculæ, similar to those of Thelyphonus and situated on each side of the central uervous system, were the origiual form from which, by the addition of transverse fibres rumning between the gut and nervous system, the entosternite of Thelyphouns and of the scorpions, etc., was formed. From an extensive consideration of the eutosternite in different animals, Schimkéwitsch has come to the conclusion that this latter explanation is the true onc. He points out that the lateral trabeculæ can be distinguished from the transverse by their structure, being much more cellular and less fibrous, and the cell-cavities more rounded, or, as I should express it, the two lateral trabeculie are more cartilaginous, while the transverse are more fibrous. Schimkéwitsch, from observations of structure and from embryological investigations, comes to the conclusion that the entosternite was originally composed of two parts-

1. A transverse muscle corresyouding to the adductor muscle of the shell of certain crustaceaus, such as Nebalia.

2. A pair of longitudinal mesodernic tendons, which may have been formed originally out of a number of segmentally arranged mesodermic tendons, and are crossed by the fibrils of the transverse muscular bundles.

These paired tendons of the entosternite he considers to correspond to the intermuscular tendons, situated lengthways, which are found in the ventral longitudinal muscles of most arthropods.

It is clear from these observations of Schimkéwitsch, that the essential part of the entosternite consists of two lateral trabecule, which were originally tendinous in nature and have become of the nature of cartilaginous tissue by the increase of cellular elements in the matrix of the tissue: these two trabecule function as supports for the attachment of muscles, which are specially attached at certain places. At these places transverse fibres belonging to some 
of the muscular attachments cross between the two longitudinal trabeculie, and so form the transverse trabeculie.

I entirely agree with Schimkéwitsch that the nests of cartilagecells are much more extensive in, and indeed nearly entirely confined to, these two lateral trabecule in the entosternite of Hypoctonus. Ray Lankester describes in the entosternite of Mygale peculiar cell-nests strongly resembling those of Hypoctonus, and he also states that they are confined to the lateral portions of the entosternite.

From this evidence it is easy to see that that portion of the basicranial skeleton known as the trabeculæe may have originated from the formation of cartilage in the plastron or entosternite of a palieostracan aninal. Such an hypothesis immediately suggests valuable clues as to the origin of the cranium and of the rest of the basicranial skeleton-the parachordals and the auditory capsules. The former would naturally be a dorsal extension of the more membranous portion of the plastron, in which, equally naturally, cartilaginous tissue would subsequently develop; and the reason why it is impossible to reduce the cranium into a series of segments would be self-evident, for even though, as Schimkéwitsch thinks, the plastron may have been originally segmented, it has long lost all sign of segmentation. The latter would be derived from a second entosternite of the same nature as the plastron, but especially comected with the auditory apparatus of the invertebrate ancestor. The following out of these two clues will be the subject of a future chapter.

In our search, then, for a clue to the origin of the skeletal tissues of the vertebrate we see again that we are led directly to the palrostracan stock on the invertebrate side and to the Cyclostomata on that of the vertebrate; for in Limulus, the only living representative of the Palæostraca, and in Limulus alone, we find a skeleton marvellously similar to the earliest vertebrate skeleton-that found in Ammoccetes. Later on I shall give reasons for the belief that the earliest fishes so far found, the Cephalaspidæ, etc., were built up on the same plan as Ammocoetes, so that, in my opinion, in Limulus and in Ammocoetes we actually possess living examples allied to the ancient fauna of the Silurian times. 


\section{SUMmalis.}

The skeleton considered in this chapter is not the notochord. but that composed of cartilage. The tracing downwards of the rertebrate bony and cartilaginous skeleton to its eirliest beginnings leads straight to the skeleton of the larval lamprey (Ammocoetes), in which vertebra are not yot formed, but the cranial and branchial skeleton is well marked.

The embryological and phylogenetic histories are in complete unison to show that the cranial skeleton is older than the spinal, and this primitive branchial skeleton is also in harmony with the laws of evolution, in that its structure, even in the adult lamprey (Petromyzon), never gets beyond the stage characteristic of embryonic cartilage in the higher vertebrates.

The simplest and most primitive skeleton is that found in Ammocotes and consists of two parts: (1) a prosomatic, (2) a mesosomatic skeleton.

The prosomatic skeleton forms a non-segmented basi-cranial skeleton of the simplest kind-the trabecula and the parachordals with their attached auditory capsules, just as the embryology of the higher vertebrates teaches us must be the ense. There in the free-living, still-existent Ammocoetes we find the manifest natural outcome of the embryological history in the shape of simple trabeculie and parachordals. from which the whole complicated basi-cranial skeleton of the hioher rertebrates arose.

The mesosomatic skeleton, which is formed before the prosomatic. consisted, in the first instance, of simple branchial bars segmentally arranged, which were connected together by a longitudinal subchordal bar, situated laterally on each side of the notochord. These simple branchial bars later on form the branchial basket-work, which forms an open-work vage within which the branchia are situated.

The cartilages which compose these two skeletons respectively are markedly different in chemical constitution. in that the first (hard cartilage) is mainly composed of chondro-gelatin, the second (soft cartilage) of chondro-mucoid material.

The same kind of difference is seen in the two kinds of connective tissuc which are the forerumners of these two kinds of cartilage. Thus, the cramial walls in Ammocotes are formed of white fibrous tissue, an essentially gelatincontaining tissue; at transformation these are invaded by chondro-blasts and the cartilaginous cranium, formed of hard cartilage, results. On the other hand, the forermmer of the branchial soft curtilage is a very striking and peculiar kind of comnective tissue loaded with mucoid material. to which the name muco-cartilage has been given.

The enormous interest of this muco-cartilage consists in the fact that it forms very well-defined plates of tissue, entirely confined to the head-region, which are not found in any higher vertebrate, not even in the adult form Petromyzon, for every scrap of the tissue as such disappears at transformation.

It is this evidence of primitive non-vertebrate tissues, which occur in the larval but not in the adult form. which makes Ammocotes so raluable for the inrestigation of the origin of vertebrates.

The evidence, then, is extraordinarily clear as to the beginnings of the res tebrate skeletal tissues. 
In the invertebrate kingdom true cartilage occurs but scantily. There is a cartilaginous covering of the brain of cephalopods. It is never found in crabs, lobsters, bees, wasps, centipedes, butterflies, tlies, or any of the great group of Arthropoda, except, to a slight extent, in some members of the scorpion group, and more fully in one single animal, the King-crab or Limulus : a fact significant of itself, but still more so when the nature of the cartilage and its position in the animal is taken into consideration, for the identity both in structure and position of this interual cartilaginous skeleton with that of Ammocotes is extraordinarily great.

Here, in Limulus, just as in Ammocoetes, an internal cartilaginous skeleton is found, composed of two distinct parts: (1) prosomatic, (2) mesosomatic. As in Ammocoetes, the latter consists of simple branchial bars, segmentally arranged, which are connected together on each side by a longitudinal ligament containing cartilage-the entapophysial ligament. This cartilage is identical in structure and in chemical composition with the soft eartilage of Ammocotes. and, as in the latter case. arises in a inarkedly mucoid connective tissue. The former, as in Ammocotes, consists of a non-segmental skeleton, the plastron, composed of a white fibrous commective tissue matrix, an essentially gelatin-containing tissue, in which are found nests of cartilage cells of the hard cartilage variety.

This remarkable discovery of the branchial cartilaginous bars of Limulus, together with that of the internal prosomatic plastron, causes the original difficulty of deriving an animal such as the vertebrate from an animal resembling an arthropod to vanish into thin air, for it shows that in the past ages when the rertebrates first appeared on the earth, the dominant arthropod race at that time. the members of which resembled Limulus, had solved the question ; for, in addition to their external chitinous covering, they had manufactured an internal cartilaginous skeleton. Not only so, but that skeleton had arrived, both in structure and position, exactly at the stage at which the vertebrate skeleton starts.

What the precise steps are by which chitin-formation gives place to chondrinformation are not yet fully known, but Schmiedeberg has shown that a substance. glycosamine, is derivable from both these skeletal tissues, and he concludes his observations in the following words: "Thus, by means of glycosamine. the bridge is formed which connects together the chitin of the lower animals with the cartilage of the more highly organized creations."

The evidence of the origin of the cartilaginous skeleton of the rertebrate points directly to the origin of the vertebrate from the Paleostraca, and is of so strong a character that, taken alone, it may almost be considered as proof of such origin. 


\section{CHAPTER IV}

\section{THE EVIDENCE OF THE RESPIRATORY APPARATUS}

Branchice considered as internal branchial appendages.-Innervation of branchial segments.-Cranial region older than spinal.-Three-root system of cranial nerves, dorsal, lateral, rentral.-Explanation of van Wijhe's segments.Lateral mixed root is appendage-nerre of invertebrate.-The branchial chamber of Ammocoetes.-The branchial unit. not a ponch but an appendage.-The origin of the branchial musculature.-The branchial circulation.- The branchial heart of the vertebrate.-Not homologous with the systemic heart of the arthropod.-Its formation from two longitudinal renous sinuses.-Summary.

'TuE respiratory apparatus in all the terrestrial vertebrates is of the same kind-one single pair of lungs. These lungs originate as a diverticulum of the alimentary canal. On the other hand, the aquatic vertebrates breathe by means of a series of branchiæ, or gills, which are arranged segmentally, being supported by the segmental branchial cartilaginous bars, as already mentioned in the last chapter.

The transition from the gill-bearing to the lung-bearing vertebrates is most interesting, for it has been proved that the lungs are formed by the modification of the swim-bladder of fishes; and in a group of fishes, the Dipnoi, or lung-fishes, of which three representatives still exist on the earth, the mode of transition from the fish to the amphibian is plainly visible, for they possess both lungs and gills, and yet are not amphibians, but true fishes. But for the fortunate existence of Ceratodus in Australia, Lepidosiren in South America, and Protopterus in Africa, it would have been impossible from the fossil remains to have asserted that any fish had ever existed which possessed at the same moment of time the two kinds of respiratory organs, although from our knowlerge of the development of the amphibian we might have felt sure that such a transitional stage must have existed. Unfortunately, there is at present no likelihood of any corresponding transitional stage being discovered 
living on the earth in which both the dorsal arthropod alimentary canal and the ventral vertebrate one should simultaneously exist in a functional condition; still it seems to me that even if Ceratodus, Lepidosiren, and Protopterus had ceased to exist on the earth, yet the facts of comparative anatomy, together with our conception of evolution as portrayed in the theory of natural selection, would have forced us to conclude rightly that the amphibian stage in the evolution of the vertebrate phylum was preceded by fishes which possessed simultaneously lungs and gills.

In the preceding chapter the primitive cartilaginous vertebrate skeleton, as found in Ammocetes, was shown to correspond in a marvellous manner to the cartilaginous skeleton of Limulus. In a later chapter I will desl with the formation of the cranium from the prosomatic skeleton; in this chapter it is the mesosomatic skeleton which is of interest, and the consideration of the necessary consequences which logically follow upon the supposition that the branchial cartilaginous hars of Limulus are homologous with the branchial basket-work of Ammocotes.

\section{Internat Branctital Appendages.}

Seeing that in both cases the cartilaginous bars of Limulus and Ammocortes are confined to the branchial region, their homology of necessity implies an homology of the two lranchial regions, and leads directly to the conclusion that the branchia of the vertebrate were derived from the branchice of the arthropod, a conclusion which, according to the generally accepted view of the origin of the respiratory region in the vertebrate, is extremely difficult to accept; for the branchise of Limulus and of the Arthropoda in general are part of the mesosomatic appendages, while the branchice of vertebrates are derived from the anterior part of the alimentary canal. This conclusion, therefore, implies that the vertebrate has ntilized in the formation of the anterior portion of its new alimentary canal the branchial appendlages of the paliostracan ancestor.

Let us consicler dispassionately whether such a suggestion is a priori so impossible as it at first appears. One of the principles of evolution is that any change which is supposed to have taken place in the process of formation of one animal or group of animals from a lower group must be in harmony with changes which are known to have 
occurred in that lower group. On the assumption, therefore, that the vertebrate branchire represent the branchial portion of the arthropod mesosomatic appendages which have sunk in and so become internal, we ought to find that in members of this very group such inclusion of branchial appendages has taken place. This, indeed, is exactly what we do find, for in all the scorpion tribe, which is acknowledged to be closely related to Limulus, there are no

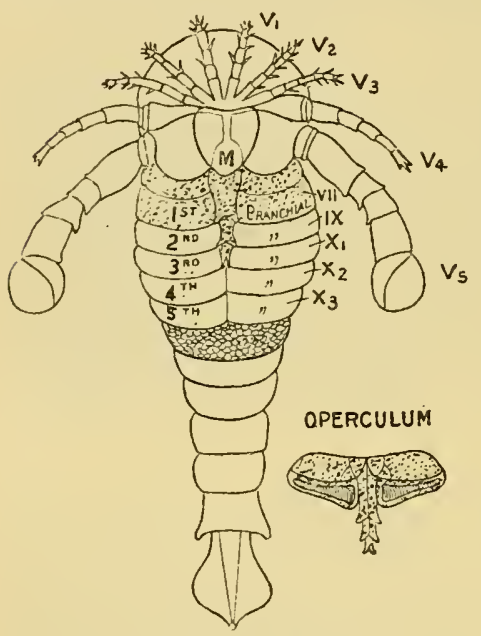

FIG. 62,-Furypterus.

The segments and appendages on the right are numbered in correspondence with the cranial system of lateral nerve-roots as found in vertebrates. ${ }_{1}$., metastoma. The surface ornamentation is represented on the first segment posterior to the branchial segments. The opercular appendage is marked out by dots.

external mesosomatic appendages, but in all cases these appendages have sunk into the body, have disappeared as such, and retainer only the vital part of them-the branchiæ. In this way the so-called lung-books of the scorpion are formed, which are in all respects homologons with the branchix or gill-books of Limulus. Now, as already mentioned, the lords of creation in the palæostracan times were the sea-scorpions, which, as is seen in Fig. 62, resembled the landscorpions of the present day in the entire absence of any external appendages on the segments of the mesosomatic region. As they lived in the sea, they must have breathed with gills, and those branchial appendages must have been internal, just as in the land-scorpions of the present time. Indeed, markings have been foumd on the internal sirle of the segments 1-5, Fig. 62, which are supposed to indicate branchire, and these segments are therefore supposed to have borne the branchire. Up to the present time no indication of gill-slits has been found, and we cannot say with certainty how these animals breathed. Further, in the Upper Silurian of Lesmahago, Lanarkshire, a scorpion (Palcopthonus Hunteri), closely resembling the modern scorpion, has been found, which, as Lankester states, was in all probability aquatic, and not terrestrial in its habits. How it 
lreathed is mnknown; it shows no signs of stigmata, such as exist in the scorpion of to-day.

Although we possess as yet no cortain knowledge of the position of the gill-openmigs in these ancient scorpion-like forms, what we can say with certainty-and that is the important fact-is, that at the time when the vertebrates appenred, a very large number of the dominant arthropod race possessed internally-situated branchir, which had been directly derived from the branchiz-bearing appendages of their Limulus-like kinsfolk.

This abolition of the branchire-bearing appendages as external organs of locomotion, with the retention of the important branchial portion of the appendage as internal branchise, is a very important suggestion in any discussion of the way vertebrates have arisen from arthropods; for, if the same principle is of universal application, it leads directly to the conclusion that whenever an appendage possesses an organ of vital importance to the animal, that organ will remain, even though the appendage as such completely vanishes. Thus, as will be shown later, special sense-organs such as the olfactory remain, though the animal no longer possesses antennæ; the important excretory organs, the coxal glands, and important respiratory organs, the branchire, are still present in the vertebrate, althongh the appendages to which they originally belonged have dwindled away, or, at all events, are no longer recognizable as arthropod appenclages.

\section{Innervation of Branchilal Segments.}

Passing from a priori considerations to actual facts, it is advisable to commence with the innervation of the branchial segments; for, seeing that the foundation of the whole of this comparative study of the vertebrate and the arthropor is based upon the similarity of the two central nervous systems, it follows that we must look in the first instance to the innervation of any organ or group of organs in order to find ont their relationship in the two gromps of animals.

The great characteristic of the vertebrate branchial organs is their segmental arrangement and their innervation by the vagus group of nerves, i.e. by the hindermost group of the cranial segmental nerves. These cranial nerves are divided by Gegenbaur into two great groups -an anterior group, the trigeminal, which supplies the muscles of mastication, and a posterior group, the vagus, which is essentially 
respiratory in function. Of these two groups, I will consider the latter group first.

In Limulus the great characteristic of the branchial region is its vronounced segmental arrangement, each pair of branchial appendages belonging to a separate segment. This group of segments forms the mesosoma, and these branchial appendages are the mesosomatic appendages. Anterior to them are the segments of the prosoma, which bear the prosomatic or locomotor appendages. The latter are provided at their base with gnathites or mastieating apparatus, so that the prosomatic group of nerves, like the trigeminal group in the vertebrate, comprises essentially the nerves subserving the important function of mastication. As already pointed out, the brain-region of the vertebrate is comparable to the supra-cesophageal and infraresophageal ganglia of the invertebrate, and it has been shown (p. 54) how, by a process of concentration and cephalization, the foremost region of the infra-resophageal ganglia becomes the prosomatic region, and is directly comparable to the trigewinal region in the vertebrate; while the hindermost region is formed from the concentration of the mesosomatic ganglia, and is direetly comparable to the medulla oblongata, i.e. to the vagus region of the vertebrate brain.

As far, then, as coneerns the centres of origin of these two groups of nerves and their exits from the central nervous system, they are markedly homologous in the two groups of animals.

\section{Comparison of the Cranial and Spinal Segmental Nerves.}

It has often been held that the arrangements of the vertebrate nervous system differ from those of other segmented animals in one important particular. The eharacteristic of the vertelsrate is the origin of every segmental nerve from two roots, of which one contains the efferent fibres, while the other possesses a sensory ganglion, and contains only afferent fibres. This arrangement, which is found along the whole spinal cord of all vertebrates, is not found in the segmental nerves of the invertebrates; and as it is supposed that the simpler arrangement of the spinal eord was the primitive arrangement from which the vertebrate central nervous system was built up, it is often concluded that the animal from which the vertebrate arose must have possessed a series of nerre-segments, from each of which there arose bilaterally ventral (efferent) and dorsal (afferent) roois. 
Now, the striking fact of the vertebrate segmental nerves consists in this, that, as far as their structure and the tissues which they innervate are concerned, the cranial segmental nerves are built np on the same plan as the spinal; but as far as concerns their exit from the central nervous system they are markedly different. A large amount of ingenuity, it is true, has been spent in the endeavour to force the cranial nerres into a series of segmental nerves, which arise in the same way as the spinal by two roots, of which the rentral series ought to be efferent and the dorsal series afferent, but without success. We must, therefore, consider the arrangement of the cranial segmental nerves by itself, separately from that of the spinal nerves, and the prohlem of the origin of the vertebrate segmental nerves admits of two solutions-either the cranial arrangement has arisen from a modification of the spinal, or the spinal from a simplification of the cranial. The first solution implies that the spinal cord arrangement is older than the cranial, the second that the cranial is the oldest.

In my opinion, the evidence of the greater antiquity of the cranial region is overwhelming.

The evidence of embryology points directly to the greater phylogenetic antiquity of the cranial region, for we see how, quite early in the development, the hear is folded off, and the organs in that region thereby completed at a time when the spinal region is only at an early stage of development. We see how the first of the trunk somites is formed just posteriorly to the head region, and then more and more somites are formed by the addition of fresh segments posteriorly to the one first formed. We see how, in Ammocretes, the first formed parts of the skeleton are the branchial bars and the basicranial system, while the rudiments of the vertebre do not appear until the Petromyzon stage. We see how, with the elongation of the animal by the later addition of more and more spinal segments, organs, such as the heart, which were originally in the head, travel down, and the vagus and lateral-line nerves reach their ultimate destination. Again, we see that, whereas the cranial nerves, viz. the ocular motor, the trigeminal, facial, anditory, glossopharyngeal, and vagus nerves, are wonderfully fixed and constant in all vertebrates, the only shifting being in the spino-occipital region, in fact, at the junction of the cranial and spinal region, the spinal nerves, on the other hand, are not only remarkably variable in number in different 
groups of animals, but that even in the same animal great variations are found, especially in the manner of formation of the limb-plexuses. Such marked meristic variation in the spinal nerves, in contrast to the fixel character of the eranial nerves, certainly points to a more recent formation of the former nerves.

Also the observations of Assheton on the primitive streak of the rabbit, and on the growth in length of the frog embryo, have led him to the conclusion that, as in the rabbit so in the frog, there is evidence to show that the embryo is derived from two definite eentres of growth: the first, phylogenetically the oldest, being a protoplasmic activity, which gives rise to the anterior end of the embryo ; the second, one which gives rise to the growth in length of the embryo. This secondary area of proliferation coincides with the area of the primitive streak, and he has shown, in a subsequent paper, hy means of the insertion of sable hairs into the unineubated blastoderm of the chick, that a hair inserted into the centre of the blastorlerm appears at the anterior end of the primitive streak, and subsequently is found at the level of the most anterior pair of somites.

He then goes on to say-

"From these specimens it seems clear that all those parts in front of the first pair of mesoblastic somites-that is to say, the heart, the brain and medulla oblongata, the olfactory, optic, auditory organs and foregut-are developed from that portion of the unincubated blastoderm which lies anterior to the centre of the blastoderm, and that all the rest of the embryo is formed by the activity of the primitive streak area."

In other words, the secondary area of growth, i.e. the primitive streak area, includes the whole of the spinal cord region, while the older primary eentre of growth is coincident with the cranial region.

In searching, then, for the origin of the segmental nerves, we must consider the type on which the eranial nerves are arranged rather than that of the spinal nerves.

The first striking fact occurs at the spino-occipital region, where the spinal cord merges into the medulla oblongata, for here in the cervical region we find each spinal segment gives origin to three distinct roots, not two-a dorsal root, a ventral root, and a lateral root. This third root gives origin to the spinal accessory nerve, and in the region of the medulla oblongata these lateral roots merge directly into the roots of the vagus nerve; more anteriorly the same system 
continues as the roots of the glossopharyngeal nerve, as the ronts of the facial nerve, and as a portion, especially the motor portion, of the trigeminal nerve. Now, all these nerves belong to a well-defined system of nerves, as Charles Bell ${ }^{1}$ pointed out in 1830, a system of nerves concerned with respiration and allied mechanisms, such as laughing, sneezing, mastication, deglutition, etc., nerves innervating a set of muscles of very different kind from the ordinary body-museles concerned with locomotion and equilibration. Also the centres from which these motor nerves arise are well defined, and form cell-masses in the central nervous system, quite separate from those which give origin to somatic muscles.

This original idea of Charles Bell, after having been ignored for so long a time, is now seen to be a very right one, and it is an extraordinary thing that his enunciation of the dual nature of the spinal roots, which was, to his mind, of subordinate importance, should so entirely have overshadowed his suggestion, that in addition to the dorsal and ventral roots, a lateral system of nerves existed, which were not exclusively sensory or exclusively motor, but formed a separate system of respiratory nerves.

Further, anatomists divide the striated muscles of the body into two great natural groups, characterized by a difference of origin and largely by a difference of appearance. The one set is concerned with the movements of internal organs, and is called visceral, the other is derived from the longitudinal sheet of musculature which forms the myotomes of the fish, and has been called parietal or somatic. The motor nerves of these two sets of muscles correspond with the lateral or respiratory and ventral roots respectively.

Finally, it has been shown that the segments of which a vertebrate is composed are recognizable in the embryo by the segmented manner in which the musculature is lail down, and van Wijhe has shown that in the cranial region two sets of muscles are laid lown segmentally, thus forming a dorsal and ventral series of commencing muscular segments. Of these the anterior segments of the dorsal series give origin to the striated muscles of the eye which are innervated by the IIIrd (oculomotor), IVth (trochlearis), and VIth (abducens) nerves, while the posterior segments give origin to the

1 N.B.-In addition to the nerves mentioned, C. Bell included, in his respiratory system of nerves, the fourth nerve or trochlearis, the phrenic and the external respiratory of Bell. 
muscles from the cranium to the shoulder-girdle, innerrated by the XIIth (hrpoglossal) nerve. The rentral series of segments give origin to the musculature supplied by the trigeminal, facial, glossopharrngeal, and vagus nerves.

Also, the afferent or sensory nerves of the skin over the whole of this head-region are supplied by the trigeminal nerve, while the afferent nerres to the risceral surfaces are supplied by the ragus, glossopharrngeal and facial nerves.

In van Wijhe's original paper he arranged the segments belonging to the cranial nerves in the following table:-

\begin{tabular}{|c|c|c|c|c|c|}
\hline Segments. & \multicolumn{2}{|c|}{$\begin{array}{l}\text { Tentral nerre-roots and muscles } \\
\text { derived from myotom.s. }\end{array}$} & Visceral clefts. & \multicolumn{2}{|c|}{ Dorsal nerve-roots and muscles. } \\
\hline 2 & III. & $\begin{array}{l}\text { I. rectus supe- } \\
\text { rior, m. rectus } \\
\text { internus, m. } \\
\text { rectus inferior, } \\
\text { m. obliquus in- } \\
\text { ferior } \\
\text { I. obliquus } \\
\text { superior }\end{array}$ & 1st Mandibular & $\begin{array}{l}\text { N. N.op- } \\
\text { thalmicus } \\
\text { profundus }\end{array}$ & $\begin{array}{l}\text { Iasticating } \\
\text { muscles. }\end{array}$ \\
\hline 3 & $\begin{array}{l}\text { VI. } \\
-\end{array}$ & $\begin{array}{l}\text { YI. rectus ex- } \\
\text { ternus }\end{array}$ & 2nd $\left\{\right.$ Hyoid $_{1}$ & $\begin{array}{l}\text { TII. }_{\cdot 3} \\
\text { TIII. }_{\cdot 3}\end{array}$ & $\left\{\begin{array}{l}\text { Facial muscles } \\
\text { (VIII. is dorsal } \\
\text { branch of VII.) }\end{array}\right.$ \\
\hline $\begin{array}{l}5 \\
6 \\
7 \\
5 \\
9\end{array}$ & $\begin{array}{l}- \\
\text { XII. } \\
\text { XII. } \\
\text { XII. }\end{array}$ & $\left|\begin{array}{c}\text { Iuscles from } \\
\text { cranium to } \\
\text { shoulder-girdle }\end{array}\right|$ & $\begin{array}{l}\text { 3rd 1st Branchial } \\
\text { 4th 2nd ", } \\
\text { 5th 3rd ", } \\
6 \text { th 4th ", } \\
\text { 7th 5th }\end{array}$ & $\begin{array}{l}I X . \\
X_{\cdot 1} \\
X_{\cdot 2} \\
X_{\cdot 3} \\
X_{\cdot 4}\end{array}$ & $\begin{array}{l}\text { Branchial and } \\
\text { risceral muscles. }\end{array}$ \\
\hline
\end{tabular}

As is seen in the table, van Wijhe attempts to arrange the cranial segmental nerres into dorsal and rentral roots, in accordance with the arrangement in the spinal region. In order to do this he calls the Vth, VIIth, IXth, and Xth nerres dorsal roots, althongh they are not purely sensory nerres, but contain motor fibres as well.

It is not accidental that he should have picked out for his dorsal roots the very nerves which form Charles Bell's lateral series of roots, inasmuch as this system of lateral roots, apart from dorsal and ventral roots, really is, as Charles Bell thought, an important separate system, dependent upon a separate segmentation in the embryo of the musculature supplied by these roots. This segmentation may receive the name of risceral or splanclinic in contradistinction to somatic, since all the muscles without exception lelong to the visceral group of striated muscles. 
These observations of van Wijhe lead directly to the following conelusion. In the cranial region there is evidence of a double set of segments, which may he called somatic and splauchnic. The somatic segments, consisting of the outer skin and the body musculature, are doubly innervated as are those of the spinal cord by a series of ventral motor roots, the oculomotor or IIIrd nerve, the trochlear or IVth nerve, the abdncens or VIth nerve, and the hypoglossal or XIIth neive, and by a series of dorsal sensory roots, the sensory part of the trigeminal or Th nerre. But the splanchnic segments are innervated by single roots, the vagus or Xth nerve, glossopharyngeal or IXth nerve, facial or VIIth nerve, and trigeminal or Vth nerve, which are mixed, containing both sensory and motor fibres, thus differing markedly from the arrangement of the spinal nerves.

From this sketch it follow's that the arrangement seen in the spinal cord, would result from the cranial arrangement if this third system of lateral roots were left out. Further, since the cranial system is the oldest, we must search in the invertebrate ancestor for a tripartite rather than a dual system of nerve-roots for each segment ; a system composed of a dorsal root supplying only the sensory nerves of the skin-surfaces, a lateral mixed root supplying the system connected with respiration with both sensory and motor fibres, and a ventral root supplying the motor nerves to the body-musculature.

Comparison of the Appexdage Nerves of Limelus and BraxchipUs to the Lateral lioot Systen of tie Vertebrate.

If the argument used so far is correct, and this tripartite system of nerve-roots, as seen in the cranial nerves of the vertebrate, really represents the original scheme of innervation in the paliestracan ancestor, then it follows that each segment of Limulus ought to be supplied by three nerves-(1), a sensory nerve supplying its own portion of the skin-surface of the prosomatic and mesosomatic earapaces; (2), a lateral mixed nerve supplying exclusively the appendage of the segment, for the appendages carry the respiratory organs; and (3), a motor nerre supplying the body-muscles of the segment.

It is a striking fact that Milne-Edwards describes the nerve-roots in exactly this manner. The great characteristic of the nerve-roots 
in Limulus as in other arthropods is the large appendage-nerve, which is always a mixed nerve; in addition, there is a system of sensory nerves to the prosomatic and mesosomatic carapaces, called by him the ejimeral nerves, which are purely sensory, and a third set of roots which are motor to the body-museles, and possibly also sensory to the ventral surface between the appenclages.

Moreover, just as in the vertebrate central nervous system the centres of origin of the motor nerves of the branchial segmentation are distinct from those of the somatie segmentation, so we find, from the researches of Hardy, that a similar well-marked separation exists between the centres of origin of the motor nerves of the appendages and those of the somatic muscles in the central nervous system of Branchipus and Astacus.

In the first place, he points out that the nervous system of Branchipus is of a very primitive arthropod type ; that it is, in fact, as good an example of an ancient type as we are likely to find in the present day; a matter of some importauce in connection with my argument, since the arthropol ancestor of the vertebrate, such as I am deducing from the study of Anmocotes, must undoubtedly have been of an ancient type, more nearly comnected with the strange forms of the trilobite era than with the crabs and spiders of the present day.

His conclusions with respect to Branchipus may be tabulated as follows :-

1. Each ganglion of the ventral chain is formed mainly for the innervation of the appendages.

2. Each ganglion is divided into an anterior and posterior division, which are connected respectively with the motor and sensory nerves of the appendages.

3. The motor nerves of the appendages arise as well-defined axiscylinder processes of nerve-cells, which are arranged in well-defined grouls in the anterior division of the ganglion.

t. A separate innervation exists for the muscles and sensory surfaces of the trunk. The trunk-muscles consist of long bundles, from which slips pass off to the skin in each segment; they are thus imperfectly segmented. In accordance with this, a diffuse system of nerve-fibres passes to them from certain cells on the dorsal surface of each lateral half of the ganglion. These cell-groups are therefore very distinct from those which give origin to the motor appendage- 
nerves, and, moreover, are not confined to the ganglion, but extend for some distance into the interganglionic region of the nerve-cords which comnect together the ganglia of the ventral chain.

Hardy's observations, therefore, combined with those of MilneEdwards, lead to the conclusion that in such a primitive arthropod type as my theory postulates, each segment was supplied with separate sensory and motor somatic nerves, and with a pair of nerves of mixed function, devoted entirely to the innervation of the pair of appendages; that also, in the central nervous system, the motor nerve-centres were arranged in accordance with a double set of segmented muscles in two separate groups of nerve-cells. These nervecells in the one case were aggregated into well-defined groups, which formed the centres for the motor nerves of the markedly segmented muscles of the appendages, and in the other case formed a system of more diffused cells, less markedly agrregated into distinct groups, which formed the centres for the imperfectly segmented somatic muscles.

Such an arrangement suggests that in the ancient arthropod type a double segmentation existed, viz. a segmentation of the body, and a segmentation due to the appendages. Undoubtedly, the segments originally corresponded absolutely as in Branchipus, and every appendage was attached to a well-defined separate body-segment. In, however, such an ancient type as Limulus, though the segmentation may be spoken of as twofold, yet the number of seginents in the prosomatic and mesosomatic regions are much more clearly marked out by the appendages than by the divisions of the soma; for, in the prosomatic region such a fusion of somatic segments to form the tergal prosomatic carapace has taken place that the segments of which it is composed are visible only in the young condition, while in the mesosomatic region the separate somatic segments, though fused to form the mesosomatic carapace, are still indicated by the entapophysial indentations.

Clearly, then, if the mesosomatic branchial appendages of forms related to Limulus were reduced to the branchial portion of the appendage, and that branchial portion became internal, just as is known to be the case in the scorpion gromp, we should obtain an animal in which the mesosomatic region wonld be characterized by a segmentation predominantly branchial, which might be termed, as in vertebrates, the branchiomeric segmentation, but yet would show 
indications of a eorresponding somatie or mesomeric seymentution. The nerve supply to these segments would consist of -

1. The epimeral purely sensory nerves to the somatic surface, equivalent in the vertebrate to the ascending root of the trigeninal.

2. The mixed nerves to the interual branchial segments, equivalent in the vertebrate to the vagus, glossopharyngeal, and facial.

3. The motor nerves to the somatic muscles, equivalent in the vertebrate to the original nerve-supply to the somatic museles belonging to these segments, i.c. to the muscles derived from van Wijhe's 4th, 5th, and 6 th somites.

Further, the centres of origin of these appendage-nerves would form centres in the eentral nervous system separate from the eentres of the motor nerves to the somatie museles, just as the eentres of origin of the motor parts of the facial, vagus, and glossopharyngeal nerves form groups of cells quite distinct from the eentres for the hypoglossal, abdueens, trochlear, and oculomotor nerves.

In fact, if the vertebrate branchial nerves are looked upon as the descendants of nerves which originally supplied branchial appendages, then every question eonnected with the branchial segmentation, with the origin and clistribution of these nerves, receives a simple and adequate solution-a solution in exact agreement with the conclusion that the vertebrate arose from a palieostraean ancestor.

It would, therefore, be natural to expect that the earliest fishes breathed by means of branchial appendages situated internally, and that the evidence for such appendages would be much stronger in them than in more recent fishes.

Although we know nothing of the nature of the respiratory apparatus in the extinet fishes of Silurian times, we have still living, in the shape of Ammoecetes, a possible representative of such types. If, then, we find, as is the ease, that the respiratory apparatus of Anmoecutes differs markedly from that of the rest of the fishes, and, indeed, from that of the adult form or Petromyzon, and that that very difference consists in a greater resemblanee to internal branehial appendages in the ease of Ammocotes, then we may feel that the proof of the origin of the branchial apparatus of the vertebrate from the internal branchial appendages of the invertebrate has gained enorinously. 


\section{The Respiratory Chamber of Amarocetes.}

In order to make clear the nature of the branchial segments in Ammocretes, I have divided the head-part of the animal by means of a longitudinal horizontal section into halves-ventral and dorsalas shown in Figs. 63 and 64 . These figures are each a combination of a section and a solid drawing. The animal was slit open by a longitudiual section in the neighbourhood of the gill-slits, and each half was slightly flattened out, so as to expose the ventral and dorsal internal surfaces respectively. The structures in the cut surface were drawn from one of a series of horizontal longitudinal sections taken through the head of the animal. These figures show that the head-region of Ammocœetes consists of two chambers, the contents of which are different. In front, an oral or stomodreal chamber, which contains the velum and tentacles, is enclosed by the upper and lower lips, and was originally separated by a septum from the larger respiratory chamber, which contains the separate pairs of branchiæ. A glance at the two drawings shows clearly that Rathke's original description of this chamber is the natural one, for he at that time, looking upon Ammocetes brenchialis as a separate species, described the branchial chamber as containing a series of paired gills, with the gill-openings between consecutive gills. His branchial unit or gill, therefore, was represented by each of the so-called diaphragms, which, as seen in Figs. 63, 64, are all exactly alike, except the first and the last. Any one of these is represented in section in Fig. 65, and represents a branchial unit in Rathke's view and in mine. Clearly, it may be described as a branchial appendage which projects into an open pliaryngeal chamber, so that the series of such appendages divides the chamber into a series of compartments, each of which communicates with the exterior by means of a gill-slit, and with each other by means of the open space between opposing appendages.

Each of these appenrlages possesses its own cartilaginous bar (Br.cart.), as explained in Chapter III. ; each possesses its own branchial or visceral muscles (coloured blue in Figs. 63 and 64), separated absolutely from the longitudinal somatic muscles (coloured dark red in Figs. 63 and 64 ) by a space (Sp.) containing blood and peculiar fat-cells, etc. Each possesses its own afferent branchial blood-vessel from the ventral aorta, and its own efferent vessel to the dorsal aorta (Fig. 65, a. br. and v. br.). Each possesses its own 


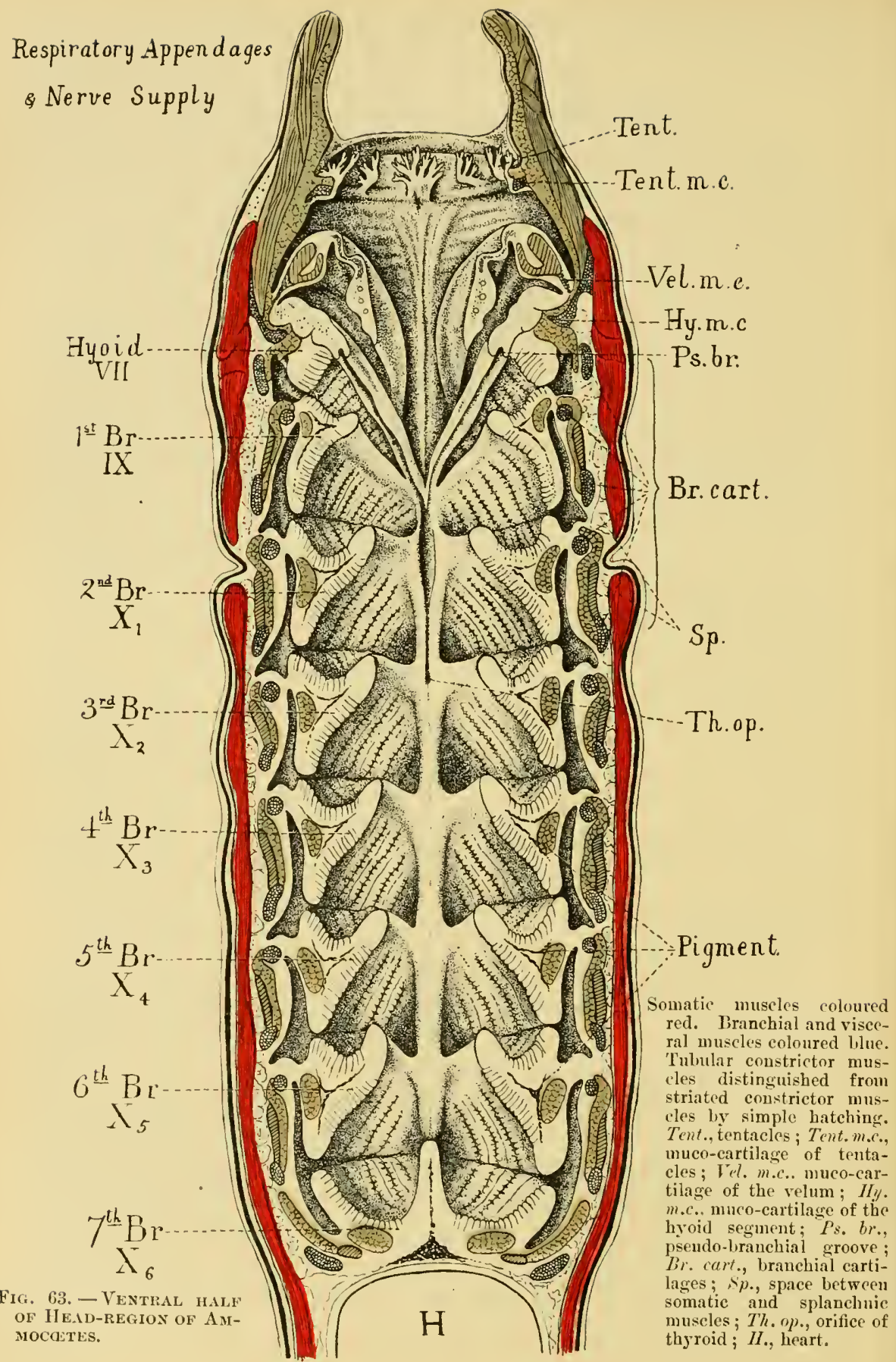




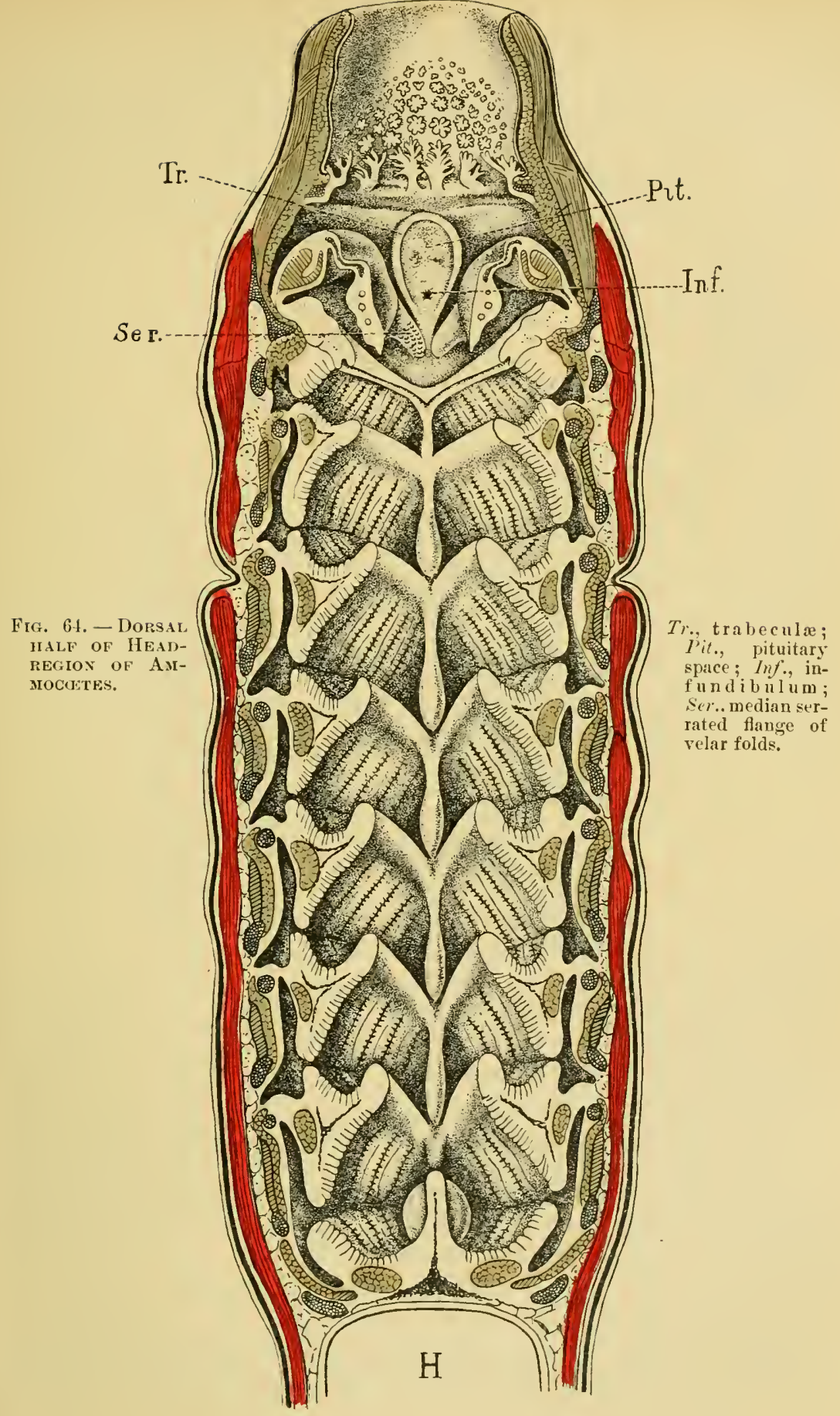


segmental nerve, which supplies its own branchial muscles and no others with motor fibres, and sends sensory fibres to the general surface of each appendage, as also to the special sense-organs in the shape of the epithelial pits (S., Fig. 65) arranged along the free edges of

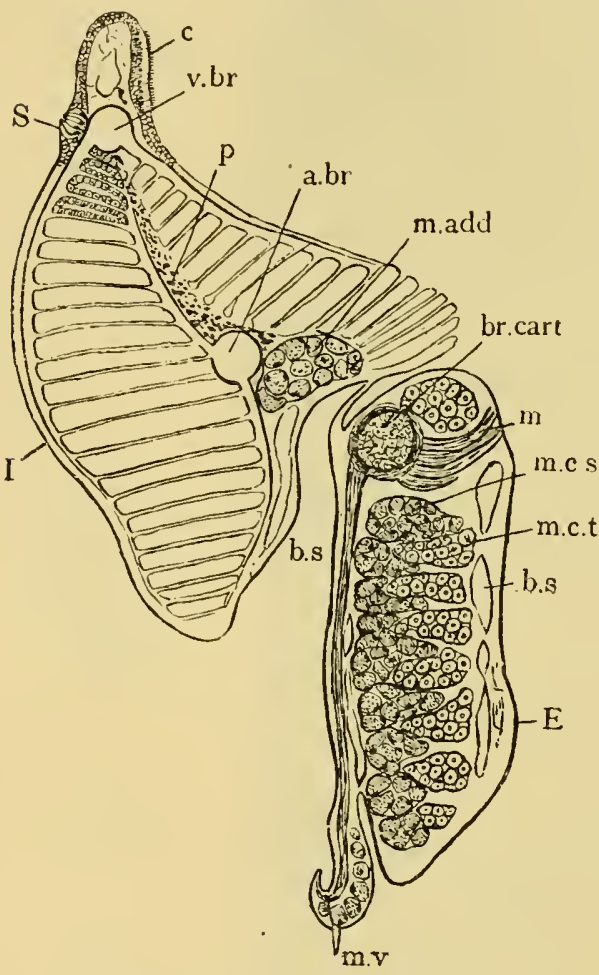

Fig. 65.-Section through Branchial ApPENDAGE OF AMMOCGTES.

br. cart., branchial cartilage; v. br., branchial vein; a. br., branchial artery; $b . s$. , bloodspaces; $p$., pigment; $S$., sense-organ; $c$., ciliated band; $E$., $I$., external and internal borders; m. add., adductor muscle; m.c.s., striated constrictor muscle; m.c.t., tubular constrictor muscle; $m$. and $m . v$., muscles of valve.

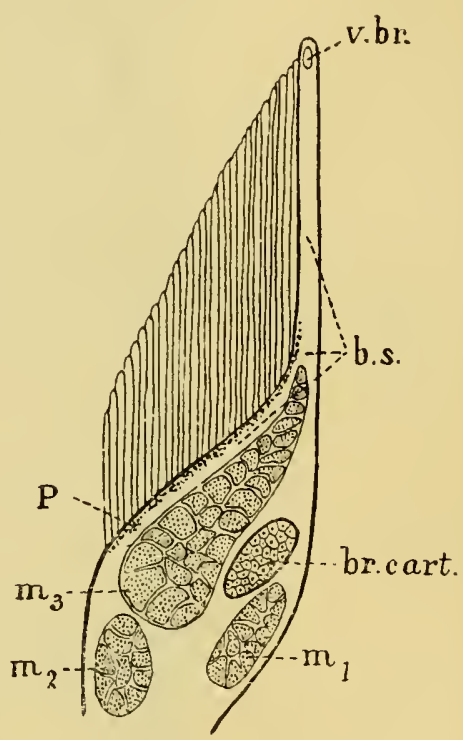

Fig. 66.-Section through BraxChial ApPendage of LindLus.

br. cart., branchial cartilage; $v . b r$, branchial vein; b.s., bloodspaces formed by branchial artery; $P$, pigment; $m_{1}$, posterior entapophysio-branchial muscle; $m_{2}$, anterior entapophysio-branchial muscle; $m_{3}$, external branchial muscle.

the diaphragms ; each of these nerves possesses its own ganglionthe epibranchial ganglion.

The work of Miss Alcock has shown that the segmental branchial nerve supplies solely and absolutely such an appendage or branchial 
segment, and does not supply any portion of the neighbouring branchial segments. The nerve-supply in Ammocates gives no countenance to the view that the original unit was a brauchial pouch, the two sides of which each nerve supplied, but is strong evidence that the original unit was a branchial appendage, which was supplied by a single nerve with both motor and sensory fibres.

Any observer having before him only this pieture of the respiratory chamber of Ammocetes, upon which to base his view of a vertebrate respiratory chamber, would naturally look upon the branchial unit of a vertebrate as a gilled appendage projecting into the open eavity of the anterior part of the alimentary canal or pharynx. This is not, however, the usual conception. The branchial unit is ordinarily described as a gill-pouch, which possesses two openings or slits, an internal one into the lumen of the alimentary canal, and an external one into the surrounding medium. This view is based upon embryological evidence of the following character :-

The alimentary canal of all vertebrates forms a tube stretching the whole length of the animal; the anterior part of this tube becomes ponched on each side at regular intervals, and the walls of each pouch becoming folded form the respiratory surfaces or gills. The openings of these separate pouches into the eentral lumen of the gut form the internal gill-pouch openings; the other extremity of the pouch approaches the external surface of the animal, and finally breaks through to form a series of external gill-pouch openings.

From the mesoblastic tissue, between each gill-pouch, there is formed a supporting eartilaginous bar, to which are attached a system of branchial muscles, with their nerves and blood-vessels. These cartilaginous bars, in all fishes above the Cyclostomata, form a supporting framework for the internal gill-slit, so that the gills are situated externally to them; the more primitive arrangement is, as already mentioned, a system of cartilaginous bars, extra-branchial in position, so that the gills are situated internally to them.

From this description of the mode of formation of the respiratory apparatus in water-breathing vertebrates the conception has arisen of the gill-pouch as the branchial unit, a conception which is absolutely removed from all idea of a branchial unit such as is found in an arthropod, viz. an appendage.

This conception of spaces as units pervades the whole of embryo$\log y$, and is the outcome of the gastrula theory-a theory which 
teaches that all animals above the Protozoa are derived from a form which by invagination of its external surface formed an interual cavity or primitive gut. From pouches of this gut other cavities were said to be formed, called colomic cavities, and thus arose the group of cœlomatous animals. To speak of the developmental history of animals in terms of spaces; to speak of the atrophy of a cavity as though such a thing were possible, is, to my mind, the wrong way of looking at the facts of anatony. It resembles the description of a net as a number of holes tied together with string, which is not usually considered the best method of description.

There are two ways in which a series of pouches can be formed from a simple tube without folding, either by a thinning at regular intervals of the original tissue surrounding the tube, or by the ingrowth into the tube of the surrounding tissue at regular intervals, thus-

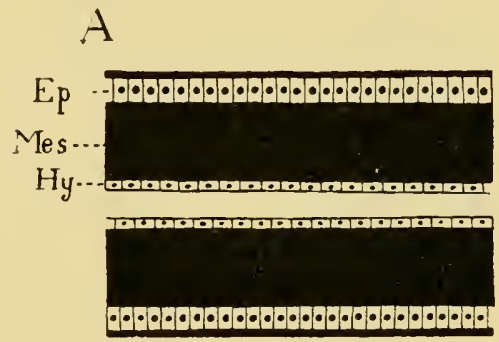

1

\section{$\mathrm{B}$}
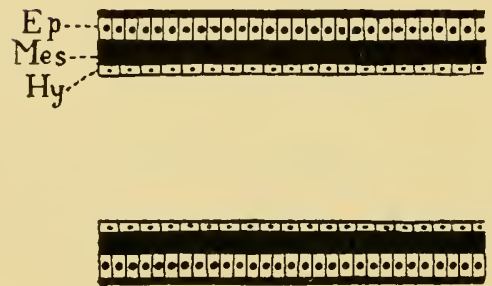

1
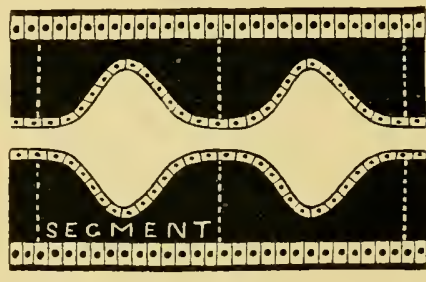

2
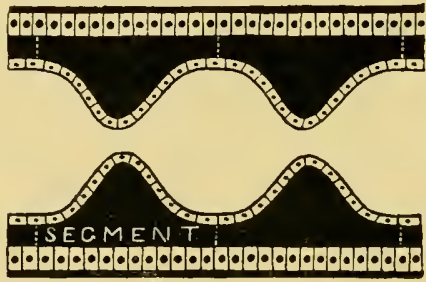

2

Fig. 67.-Diagrans to show the two methods of Polch-formation.

A, by the thinning of the mesoblast at intervals. B, by the ingrowth of mesoblast at intervals. Ep., epiblast; Mes., mesoblast; Hy., hypoblast.

In the first case $(\Lambda)$ the formation of a pouch is the significant act, and therefore the branchial segments might be expressed in terms of pouches. In the second case (B) the formation of a pouch is 
brought about in consequence of the ingrowth of the inesoblastic tissues at intervals; here, although the end-result is the same as in the first case, the ponch-formation is only secondary, the true branchial unit is the mesoblastic ingrowth.

The evidence all points directly to the second method of formation. Thus Shipley, in his description of the development of the lamprey, says-

"The gill-slits appear to me to be the result of the ventral downgrowth of mesoblast taking place only at certain places, these forming the gill-bars. Between each downgrowth the hypoblastic lining of the alimentary canal remains in contact with the epiblast; here the gill-opening subsequently appears about the twenty-second day."

Dohrn describes and gives excellent pictures of the growth of the diaphragms, as the Ammocotes grows in size, pictures which are distinctly reminiscent of the corresponding illustrations given by Brauer of the growth of the internal gills in the scorpion embryo.

Another piece of evidence confirmatory of the view that the branchial segments are really of the nature of internal appendages, as the result of which gill-pouches arc formed, is given by the presence in each of these branchial bars or diaphragms of a separate cœlomic cavity. From the walls of this cavity the branchial muscles and cartilaginous bar are formed.

Now, from an embryological point of view, the vertebrate shows that it is a segmented animal by the formation of somites, which consist of a series of divisions of the colom, of which the walls form a series of muscular and skeletal segments. In the head-region, as already mentioned, such colomic divisions form two rows-a dorsal and a ventral set. From the walls of the dorsal set the somatic musculature is formed. From those of the ventral set the branchial musculature. From the latter also the branchial cartilaginous bars are formed. Thus Shipley, in his description of the development of the lamprey, says: "The mesoblast between the gills arranges itself into head-cavities, and the walls of these cavities ultimately form the skeleton of the gill-arches."

Similarly, in the arthropod, the segments in the embryo are marked out by a series of culomic cavities and Kishinonye has described in Limulus a separate cœlomic cavity for every one of the mesosomatic or branchial segments, and he states that in Arachnida 
the segmental colomic cavities extend into the limbs. These cavities both in the vertebrate and in the arthropod disappear before the adult condition is reached.

The whole evidence thus points strongly to the conclusion that the true branchial segmental units are the branchial bars or diaphragms, not the pouches between them.

It is possible to understand why such prominence has been given to the conception of the branchial unit as a gill-pouch rather than as a gill-appendage, when the extraordinary change of appearance in the respiratory chamber of the lamprey which occurs at transformation, is taken into consideration. This change is of a very far-reaching character, and consists essentially of the formation of a new alimentary canal in this region, whereby the pharyngeal chamber of Ammoccetes is cut off posteriorly from the alimentary canal, and is confined cutirely to respiratory purposes, its original lumen now forming a tube called the bronchus, which opens into the mouth and into a series of branchial pouches.

In Fig. 68 I give diagrammatic illustrations taken from Nestler's paper to show the striking change which takes place at transformation, (A) representing three branchial segments of Ammocates, and (B) the corresponding three segments of Petromyzon. The corresponding parts in the two diagrams are shown by the cartilages (br. cart.), the sense-organs (S), and the branchial veins $(V . b r$.); the corresponding diaphragms are marked by the figures $1,2,3$ respectively. As is clearly seen, it is perfectly possible in the latter case to describe the respiratory chamber, as Nestler has done, as divided into a series of separate smaller chambers - the gill-pouches-by means of a series of diaphragms or branchial bars. The surface of these gill-pouches is in part thrown into folds for respiratory purposes, and each gillpouch opens, on the one hand, into the bronchus $\left(B r^{*} \circ\right.$.), and, on the other, to the exterior by means of the gill-slit. The branchial unit in Petromyzon is, therefore, accorting to Nestler and other morphologists, the folded opposed surfaces of two contiguous diaphragms, and each one of the diaphragms is intersegmental between two gillpouches.

Nestler then goes on to describe the arrangement in Ammocoetes in the same terms, although there is no bronchus or gill-pouch, but only an open chamber into which these gill-bearing diaphragms project, which open chamber serves both for the passage of food and 
of the water for respiration. This is manifestly the wrong way to look at the matter: the adult form is derived from the larval, not rice versâ, and the transformation process shows exactly how the gills, in Rathke's sense, come together to form the bronchus and so make the gill-pouches of Petromyzon.

When we bear in mind that almost all observers consider that the internal branchice of the scorpion group are directly derived

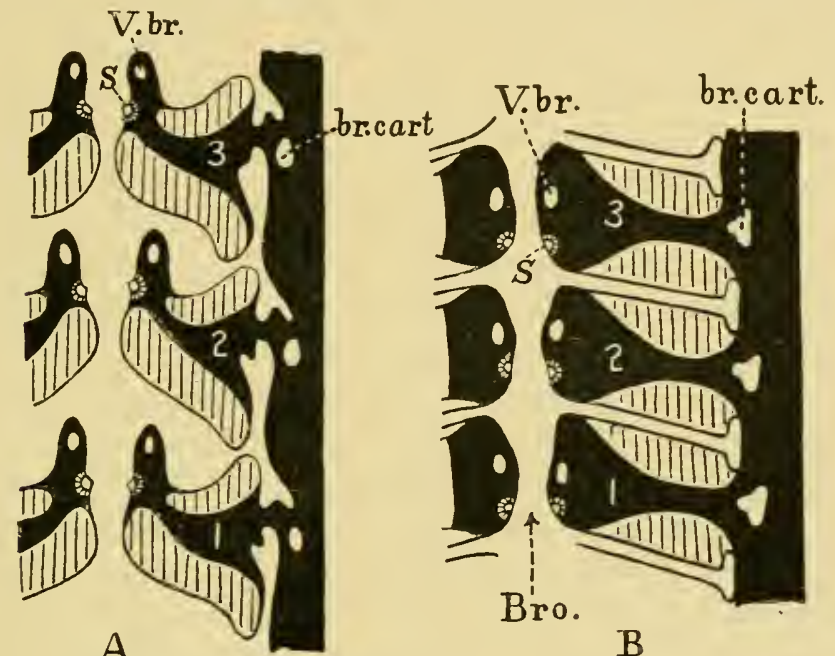

Fig. 68.-Diagram of three Branchial Segments of Ammocetes (A) compared with three Branchial Segmexts after Traxsformation (B) to show how the Branchial appexdages of Ammocates form the Branchial Pouches of Petromyzon. (After Nestler.)

In both figures the branchial cartilages (br. cart.), the branchial view $(V . b r$.$) , and the$ sense-organs $\left(S^{\prime}\right)$, are marked out in order to show corresponding points. The muscles, blood-spaces, branchial arteries, etc., of each branchial segment are not distinguished, being represented a uniform black colour. Bro., the bronchus into which each gill-pouch opens.

from branchial appendages of a kind similar to those of Limulus, it is evident that a branchial appendage such as that of Ammocotes might also have arisen from such an appendage, because in various respects it is easier to compare the branchial appendage of Ammocoetes, than that of the scorpion group, with that of Limulus.

In the case of the scorpions, various suggestions have been made as to the manner in which such a conversion may have taken place. The most probable explanation is that given by Macleod, in which 
each of the branchise of the scorpion group is directly compared with the branchial part of the Limulus appendage which has sunk into and amalgamated with the ventral surface.

According to this view, the modification which has taken place in transforming the branchial Limulus-appendage into the loranchial scorpion-appendage is a further stage of the process by which the Limulus branchial appendage itself has been formed, viz. the getting rid of the free locomotor segments of the original appendage, thus confining the appendage more and more to the basal branchial portion. So far has this process been carried in the scorpion that all the free part of the appendage has disappeared; apparently, also, the intrinsic muscles of the appendage have vanished, with the possible exception of the post-stigmatic muscle, so that any direct comparison between the branchial appendages of Limulus and the scorpions is limited to the comparison of their branchir, their nerves, and their afferent and efferent blood-vessels.

In the case of Ammocetes the comparison must be made not with air-breathing but with water-breathing scorpions, such as existed in past ages in the forms of Eurypterus, Pterygotus, Slimonia, and with the crowd of trilobite and Limulus-like forms which were in past ages so predominant in the sea; forms in some of which the branchial appendages had already become internal, but which, from the very fact of these forms being water-breathers, probably resembled, in respect of their respiratory apparatus, Limulus rather than the present-day scorpion.

On the assumption that the branchial appendages of Ammocoetes, like the branchial appendages of the scorpion group, are to a certain extent comparable with those of Limulus, it becomes a matter of great interest to inquire whether the mode in which respiration is effected in Ammoccetes resembles most that of Limulus or of the scorpion.

\section{The Origin of the Branchial Musculature.}

The difference between the movements of respiration in Limulus and those of the scorpions consists in the fact that, although in both cases respiration is effected mainly by dorso-ventral muscles, these muscles are not homologous in the two cases: in the former, the dorso-ventral appendage-museles are mainly concerned, in the latter, the dorso-ventral somatic muscles. 
The paper by Benham gives a full description of the musculature of Limulus, and according to his arrangement the muscles are divided into two sets, longitudinal and dorso-ventral. Of the latter, each mesosomatic segment possesses a pair of dorso-ventral muscles, attached to the mid-ventral mesosomatic entochondrite, and to the tergal surface (Fig. 58, Dv.). These muscles are called by Benham the vertical mesosomatic muscles. I shall call them the somatic dorso-ventral inuscles, in contradistinction to the dorsoventral muscles of the branchial appendages. Of the latter, the two chief are the external branchial (Fig. 66, $m_{3}$ ) and the posterior entapophysio-branchial (Fig. 66, $m_{1}$ ); a third muscle is the anterior entapophysio-branchial (Fig. $66, m_{2}$ ). Of these muscles, the posterior entapophysio-branchial $\left(m_{1}\right)$ is closely attached along the branchial cartilaginous bar up to its round-headed termination on the anterior surface of the appendage. The anterior entapophysio-branchial muscle $\left(m_{2}\right)$ is attached to the branchial cartilage near the entapophysis.

In the case of the scorpion, as described by Miss Beck, the branchial appendage has become reduced to the branchix, and the intrinsic appendage-muscles have entirely disappeared, with the possible exception of the small post-stigmatic muscle; on the other hand, the dorso-ventral somatic muscles, which are clearly homologous with the corresponding muscles of Limulus, have remained, and become the essential respiratory muscles.

Of these two possible types of respiratory movement it is quite conceivable that in the water-breathing scorpions of olden times and in their allies, the dorso-ventral muscles of their branchial appendages may have continued their rôle of respiratory muscles, and so have given origin to the respiratory muscles of the ancestors of Ammocoetes.

The respiratory muscles of Ammocoetes are three in number, and have been described by Nestler and Miss Alcock as the adductor muscle, the striated constrictor muscle, and the tubular constrictor muscle (Fig. 65, m. add., m.c.s., and m.c.t.). Of these, the constrictor muscle (Fig. 71, m. con. str.) is in close contact with its cartilaginous bar, while the adductor (Fig. $71, m$. culd.) is attached to the cartilage only at its origin and insertion, and the tubular muscles (Fig. 71, $m$. con. $t u b$.) have nothing whatever to do with the cartilage at all, being attached ventrally to the connective tissue in the neighbourhood 
of the ventral aorta (V.A.), and dorsally to the mid-line between the dorsal aorta (D.A.) and the notochord.

The close relationship of the constrictor muscle to the cartilaginous branchial bar does not favour the surmise that this muscle is homologous with the dorso-ventral somatic muscle of the scorpion. It is, however, directly in accordance with the view that this muscle is homologous with one of the dorso-ventral appendage-muscles, such as the posterior entapophysio-branchial muscle ( $m_{1}$, Fig. 66) of the Limulus appendage, especially when the homology of the Ammocotes branchial cartilage with the Limulus branchial cartilage is borne in mind. I am, therefore, inclined to look upon the constrictor and adductor muscles of the Ammocotes branchial segment as more likely to have been derived from dorso-rentral muscles which belonged originally to a branchial appendage, such as we see in Limulus, than from dorso-ventral somatic muscles, such as the vertical mesosomatic muscles which are found both in Limulus and scorpion. In other words, I an inclined to hold the view that the somatic dorso-ventral muscles have disappeared in this region in Ammocretes, while dorsoventral appendage-muscles have been retained, i.c. the exact reverse to what has taken place in the air-breathing scorpion.

I am especially inclined to this view becanse of the manner in which it fits in with and explains van Wijhe's results. Ever since Schneider divided the striated muscles of vertebrates into parietal and visceral, such a division has received general acceptance and, as far as the head-region is concerned, has received an explanation in van Wijhe's work; for Schneider's grouping corresponds exactly to the two segmentations of the head-mesoblast, discovered by van Wijhe, i.c. to the somatic and splanchnic striated muscles according to my nomenclature. Of these two groups the splanchnic or visceral striated musculature, immervated by the Vth, VIIth, IXth, and Xth nerves, which ought on this theory to be derived from the musculature of the corresponding appendages, is, speaking generally, dorsoventral in direction in Ammoccetes and of the same character thronghout; the somatic musculature, on the other hand, is clearly divisible, in the bead region, into two sets-a spinal and a cranial set. The somatic muscles imnervated by the spinal set of nerves, including in this term the spino-occipital or so-called hypoglossal nerves, are in Ammocates most sharply defined from all the other muscles of the body. They form the great dorsal and ventral longitudinal 
body-muscles, which extend dorsally as far forward as the nose and are developed embryologically quite distinctly from the others, being formed as inuscle-plates (Kästchen). On the other hand, the cranial somatic muscles are the eye-muscles, the formation of which resembles that of the visceral muscles, and not of the spinal somatic. Their direction is not longitudinal, but dorso-ventral ; they cannot, in my opinion, be referred to the somatic trunk-muscles, and must, therefore, form a separate group to themselves. Thus the striated musculature of the Ammocoetes must be divided into (1) the visceral muscles; (2) the longitudinal somatic muscles; and (3) the dorso-ventral somatic muscles. Of these the 1 st, on the riew just stated, represent the original appendage-muscles; the 2 nd belong to the spinal region, and will be considered with that region; the $3 \mathrm{rd}$ represent the original segmental dorso-ventral somatic muscles, which are so conspicuous in the musculature of the Limulus and the scorpion group.

The discussion of this last statement will be given when I come to deal with the prosomatic segments of Ammocœtes. I wish, here, simply to point out that van Wijhe has shown that the eye-muscles develop from his 1 st, 2 nd, and 3rd dorsal mesoblastic segments, and therefore represent the somatic muscles belonging to those segments, while no development of any corresponding muscles takes place in the 4 th, 5 th, and 6 th segments; so that if the eye-muscles represent a group of dorso-ventral somatic muscles, such muscles have been lost in the 4th, 5th, and 6 th segments. The latter segments are, however, the glossopharyugeal and vagus segments, the branchial musculature of which is derived from the ventral segments of the mesoderm. In other words, van Wijhe's observations mean that the dorso-ventral somatic musculature has been lost in the branchial or mesosomatic region, while the dorso-ventral appendage musculature has been retained, and that, therefore, the mode of respiration in Ammocotes more closely resembles that of Limulus than of Scorpio.

In addition to these branchial muscles, another and very striking set of muscles is found in the respiratory region of Ammocoetes-the so-called tubular muscles. These muscles are of great interest, but as they are especially connected with the VIIth nerve, their consideration is best postponed to the chapter dealing with that nerve.

Also, in connection with the vagus group of nerves, special senseorgans are found in the skin covering this mesosomatic region, the so-called epithelial pit-organs ( $E_{l}$. pit., Fig. 71$)$. They, too, are of 
great interest, but their consideration may also better be deferred to the chapter dealing with those special sense-systems known as the lateral line and auditory systems.

\section{Comparison of the Branchial Cimirulation in Amocotetes and}

\section{Lnulus.}

Closely bound up with the respiratory system is the nature of the circulation of blood through the gills. Before, therefore, proceeding to the consideration of the segments in front of those which carry branchix, it is worth while to compare the circulation of the blood in the gills of Limulus and of Ammocetes respectively.

In all the higher vertebrates the blood circulates in a closed system of capillaries, which unite the arterial with the venous systems. In all the higher invertebrates this capillary system can hardly be said to exist; the blood is pumped from the arterial system into blood, spaces or lacume, and thus comes into immediate contact with the tissues. From these it is collected into veins, and so returned to the heart. There is, in fact, no separate lymph-system in the higher invertebrates; the blood-system and lymph-system are not yet differentiated from each other. This also is the case in Ammocotes; here, too, in many places the blood is poured into a lacunar space, and collected thence by the venous system; a capillary system is only in its commencement and a lymph-system does not yet exist. In this part of its vascular system Ammoccetes again resembles the higher invertebrates more than the higher vertebrates.

This resemblance is still more striking when the circulation in the respiratory organs of the two animals is compared. A branchial appendage is essentially an appendage whose vascular system is arranged for the special purpose of aerating blood. In the higher vertebrates such a purpose is attained by the pulmonary capillaries, in Limulus by the division of the posterior surface of the basal part of the appendage into thin lamellar plates, the interior of each of which is filled with blood. The two surfaces of each lamella are kept parallel to each other by means of fibrous or cellular strands forming little pillars at intervals, called by Macleod "colonettes." A precisely similar arrangement is found in the scorpion gill-lamella, as seen in Fig. 69, A, taken from Macleod. In Ammocretes there are no well-defined branchial capillaries, but the blood circulates, as in 
the invertebrate gill, in a lamellar space; here, also, as Nestler has shown, the opposing walls of the gill-lamella are held in position by little pillar-like cells, as seen in Fig. 69, B, taken from his paper.

In this representative of the earliest vertebrates the method of mannfacturing an efficient gill ont of a lacunar blood-space is precisely the same as that which existed in Limulus and the scorpion, and, therefore, as that which existed in the clominant invertebrate group at the time when vertebrates first appeared. This similarity indicates a close resemblance between the circulatory systems of the two groups of animals, and therefore, to the superficial inquirer, would indicate an homology between the heart of the vertebrate and the heart of the higher invertebrate; but the former is situated ventrally to the gut and the nervous system, while the latter is composed of a long vessel which lies in the middorsal line immediately under the external dorsal covering. Indeed, this ventral position of the heart in the one group of animals and its dorsal position in the other, combined with the corresponding positions of the central nervous system, is one of the principal reasons why all the advocates of the
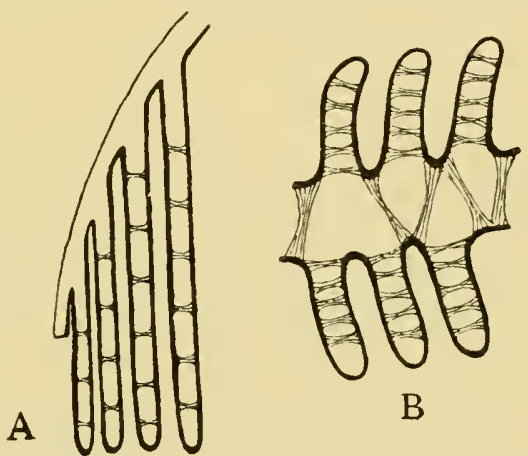

B

Fig. 69.-Comparison of Bratchial LaMelle of Lmillus and Scorpio With Branchial Lamelle of Ammocetes.

A, Branchial lamellæ of Scorpio (after Nacleod); B, Branchial lamellie of Ammocoetes (after Nestler). origin of vertebrates from the Appendiculata, with the single exception of myself, feel compelled to reverse the dorsal and ventral surfaces in deriving the vertebrate from the invertebrate. But there is one most important fact which ought to make us hesitate before accepting the homology of the dorsal heart of the arthropod with the ventral heart of the vertebrate - The heart in all invertebrates is a systemic heart, i.e. drives the arterial blood to the different organs of the body, and then the veins carry it back to the respiratory organ, from whence it passes to the heart.

The only exception to this scheme is found in the vertebrate where the heart is essentially a branchial heart, the blood being 
driven from the heart to the ventral aorta, from which by the branchial arteries it is carried to the gills, and then, after aeration, is collected into the dorsal aorta, whence it is distributed over the body. The distributing systemic vessel is the dorsal aorta, not the heart which belongs essentially to the ventral venous system. This constitutes a very strong reason for believing that the systemic heart of the invertebrate is not homologous with the heart of the vertebrate. How, then, did the vertelnate heart arise?

Let us first see how the blood is supplied to the gills in Limulus.

In Limulus the hlood flows into the lamellie from sinuses or blood-spaces (b.s., Fig. 66) at the base of each of the lamellæ, which sinuses are filled by a ressel which may be called the branchial

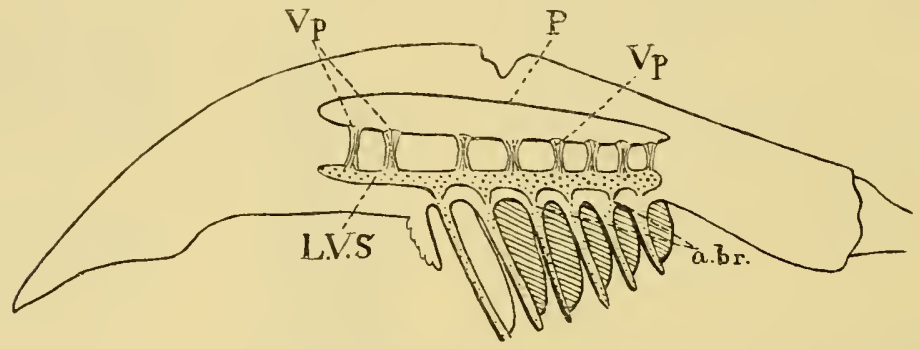

Fig. 70.-Longitudisal Dighamatic Section through the Mesosomatic

Region of Limelus, to show the origin of thf Branchial Arteries. (After Benham.)

J.T.S., longitudinal venous sinus, or collecting siuus; $a . b r$., branchial arteries; $V . p$, veno-pericardial muscles ; $P$., pericardium.

artery, since it is the afferent branchial vessel. On each side of the middle line of the ventral surface of the body a large longitudinal venous sinus exists, called by Milne-Edwards the venous collecting sinus, L.T.S., (Fig. 70 and Fig. 58), which gives off to each of the branchial appendages on that side a well-clefined afferent branchial vessel-the branchial artery $(a . b r$.). The blood of the branchial artery flows into the blood-spaces between the anterior and posterior laminæe of the appendage and thence into the gill-lamellæ, from which it is collected into an efferent vessel or branchial vein, termed by Milne-Edwards the branchio-cardiac canal, which carries it back to the dorsal heart. The position of the branchial artery and vein is shown in Fig. 66, which represents a section through the branchial appendage of Limulus at right angles to the cartilaginous branchial bar (bi: cart.), just as Fig. 65 represents a section through the 
branchial appendage of Ammocoutes at right angles to the cartilaginous branchial bar.

Further, the observations of Blanchard, Milne-Edwards, Ray Lankester, and Benham concur in showing that in both Limulus and the scorpion group a striking and most useful connection exists between the heart and these two collecting venous sinuses, in the shape of a segmentally arranged series of muscular bands ( $V . p$., Fig. 70 and Fig. 58), attached, on the one hancl, to the pericardium, and on the other to the venous collecting sinus on each side. These muscular bands, to which Lankester and Benham have given the name of 'veno-pericardial muscles,' are so different in appearance from the rest of the muscular substance, that Milne-Edwards did not recognize them as muscular, but called them 'brides transparentes.' Blanchard speaks of them in the scorpion as 'ligaments contractiles,' and considers that they play an important part in assisting the pulmonary circulation ; for, he says, "en mettant a nu une portion du cceur, on remarque que ces battements se font sentir sur les ligaments contractiles, et determinent sur les poches pulmonaires une pression qui fait anssitot refluer et remonter le sang dans les vaisseaux pneumocardiaques." Lankester, in discussing the veno-pericardial muscles of Limulus and of the scorpions, says that these muscles probably contract simultaneously with the heart and are of great importance in assisting the flow through the pulmonary system. More recently Carlson has investigated the action of these muscles in the living Limulus and found that they act simultaneously with the muscles of respiration.

Precisely the same arrangement of veno-pericardial muscles and of longitudinal venous collecting sinuses occurs in the scorpions. It is one of the fundamental characters of the group, and we may fairly assume that a similar arrangement existed in the extinct forms from which I imagine the vertebrate to have arisen. The further consideration of this group of muscles will be given in Chapter IX.

Passing now to the condition of the branchial blood-vessels of Ammocotes, we see that the blood passes into the gill-lamellie from a blood-space in the appendage, which can hardly be dignified by the name of a blood-vessel. This blood-space is supplied by the branchial artery which arises segmentally from the ventral aorta $(V . A$.), as seen in Fig. 71 (taken from Miss Alcock's paper). From the gill-lamelli the blood is collected into an efferent or branchial vein $(v . b r$.$) , which$ 
runs, as seen in Fig. 65, along the free edge of the diaphragm, and terminates in the dorsal aorta.

The ventral aorta is a single vessel near the heart, but at the eommencement of the thyroid it divides into two, and so forms two ventral longitudinal vessels, from which the branchial arteries arise segmentally.

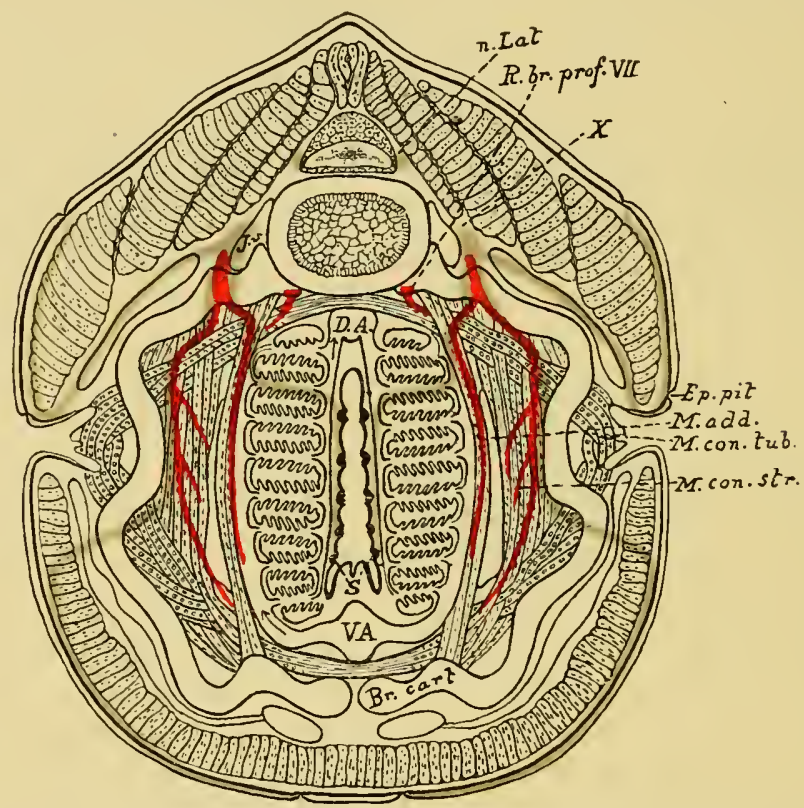

Fig. 71.--Diagram constructed from a series of Transverse Sections throvgh a Branchial Segment, showing the arRangement and relative positions of the Cartilage, Muscles, Nerves, and Blood-Vessels.

Nerves coloured red are the motor nerves to the branchial muscles. Nerves coloured blue are the internal sensory nerves to the diaphragms and the external sensory nerves to the sense-organs of the lateral line system. Br. cart., branchial cartilage; $M$. con. str., striated constrictor muscles; $M$. con. $t u b$., tubular constrictor muscles; M. add., adductor muscle; D.A., dorsal aorta ; V.A., ventral aorta; $S$., sense-organs on diaphragm; $n$. Lat., lateral line nerve; $X$., epibranchial ganglia of vagus; $R$. br. prof. VII., ramus branchialis profundus of facial; J.v., jugular vein ; Ep. pit., epithelial pit.

From this description it is elear that the vascular supply of the branchial segment of Ammocotes would resemble most closely the vascular supply of the Limulus branchial appendage, if the ventral aorta of the former was derived from two longitudinal veins, homologous with the paired longitudinal venous sinuses of the latter. 
A priori, such a derivation seems highly improbable; and yet it is precisely the manner in which embryology teaches us that the heart and ventral aorta of the vertebrate have arisen.

\section{The Origin of tile Invertebrate Heart and the Origin of the Vertebrate Heart.}

Not only does the vertebrate heart differ from that of the invertebrate, in that it is branchial while the latter is systemic, but also it is unique in its mode of formation in the embryo. In the Appendiculata the heart is formed as a single organ in the mid-dorsal line by the growth of the two lateral plates of mesoblast dorsalwards, the heart being formed where they meet. In Mammalia and Aves, the heart and ventral aorta commence as a pair of longitudinal veins, one on each side of the commencing notochord.

If the embryo be removed from the yolk, the surface of the embryo covering these two venous trunks can be spoken of as the ventral surface of the embryo at that stage, and indeed we find that in the present day there is an increasing tendency to speak of this surface as the ventral surface of the embryo. Thus, Mitsukuri, in his studies of chelonian embryos, lays great stress on the importance of surface views and when the embryo has been removed from the yolk, figures and speaks of its ventral surface. So, also, Locy and Neal find that the best method of seeing the early segments of the embryo is to remove the embryo from the yolk, and examine what they speak of as a ventral view. At the period, then, before the formation of the throat, we may say that on the ventral surface of the embryo a pair of longitudinal venous sinuses are found, one on each side of the midventral line, which are in the same position with respect to the midaxis of the embryo as are the longitudinal venous sinuses in Limulus.

The next step is the formation of the throat by the extension of the layers of the embryo laterally to meet in the mid-line and so form the pharynx, with the consequence that a new ventral surface is formed; these two veins, as is well known, travel round also, and, meeting together in the new mid-ventral line, form the subintestinal vein, the heart, and the ventral aorta.

What is true of Mammalia and Aves, has been shown by P. Mayer to be true universally among vertebrates, so that in all cases the heart and ventral aorta have arisen by the coalescence in the new mid-ventral 
line of two longitudinal venous cliannels, which were originally situated one on each side of the notochord, in what was then the ventral
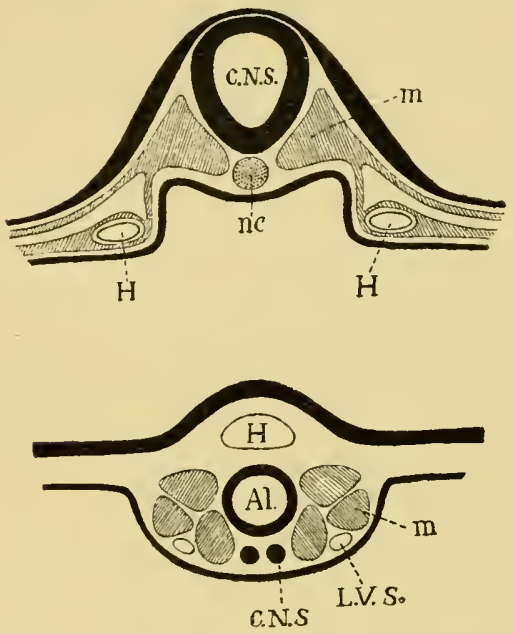

Fig. 72.-Diagram (Upper Half of Figure) of the Original Position of Veins (H) WIIICH CONE TOGETHER to Form the Heart of a Vertebrate.

C.N.S., central nervous system; $n c$., notochord; m., myotome.

The lower half of figure shows comparative position of the longitudinal venous sinus (L.V.S.) in Limulus. C.N.S., central nervous system; $A l$., alimentary canal; $H$., heart ; m., body-muscles. surface of this part of the embryo. This history is especially instructive in showing how the pharyngeal region is formed by the growing round of the lateral mesoblast, i.e. the muscular and other mesoblastic tissues of the branchial segments, and how the two longitudinal veins take part in this process. The phylogenetic interpretation of this embryological fact seems to be, that the new ventral surface of the vertebrate in this region is formed, not only by the branchial appendages, but also by the growth ventrally of that part of the original ventral surface which covered each longitudinal venous sinus.

The following out of the consecutive clues, which one after the other arise in harmonious succession as the necessary sequence of the original working hypothesis, brings even now into view the manner in which the respiratory portion of the alimentary canal arose, and gives strong hints as to the position of that part of the arthropod which gave origin to the notochord. Here I will say no more at present, for the origin of the new alimentary canal of the vertebrate and of the notochord will be more fittingly discussed as a whole, after all the other organs of the vertebrate have been compared with the corresponding organs of the arthropod.

The strong evidence that the vertebrate heart was formed from a pair of longitudinal venous sinuses on the ventral side of the central canal, carries with it the conclusion that the original single median dorsal heart of the arthropod is not represented in the vertebrate, 
for the dorsal aorta cannot by any possibility represent that heart.

Although it is not now functional the original existence of so important an organ as a dorsal heart may have left traces of its former presence; if so, such traces would be most likely to be visible in the lowest vertebrates, just as the median eyes are much more evident in them than in the higher forms. In Fig. 58 the position of the dorsal heart is shown in Limulus, and in Fig. 70 the shape and extent of this dorsal heart is shown. It extends slightly into the prosomatic region, and thins down to a point there, rums along the length of the animal and finally thins down to a point at the caudal end.

The heart is surrounded by a pericardium, from which at regular intervals a number of dorso-ventral muscles pass, to be inserted into the longitudinal venous sinus on each side. These veno-pericardial muscles are absolutely segmental with the mesosomatic segments, and are confined to that region, with the exception of two pairs in the prosomatic region. Their homologies will be discussed later.

Any trace of a heart such as we have just described must be sought for in Ammocotes between the central nervous system and the mid-line dorsally. Now, in this very position a large striking mass of tissue is found, represented in section in Fig. 73, $f$. It forms a column of similar tissue aloug the whole mid-dorsal region, except at the two extremities; it tapers away in the caudal region, and headwards grows thinner and thinner, so that no trace of it is seen anterior to the commencement of the branchial region. It resembles in its dorsal position, in its shape, and in its size a dorsal heart-tube such as is seen in Limulus and elsewhere, but it differs from such a tube in its extension headwards. The heart-tube of Limulus ceases at the anterior end of the mesosomatic region, this fat-column of Ammoceetes at the posterior end. In its structure there is not the slightest sign of anything of the nature of a heart; it is a solid mass of closely compacted cells, and the cells are all very full of fat, staining intensely black with osmic acid. Nowhere else in the whole body of Ammocotes is such a column of fat to be found. It is not skeletogenous tissue with cells of the nature of cartilagecells, as Gegenbaur thought and as Balfour has depicted (Vol. II., Fig. 315) in his 'Comparative Eubryology,' as though this tissue were a part of the vertebral column, but is simply fat-cells, such as might easily have taken the place of some other previously existing organ. 
I do not know how to decide the question which thus arises. Supposing, for the sake of argument, that this column of fat-cells has really taken the place of the original dorsal heart, what criterion would there be as to this? The heart ex hypothesi having ceased to

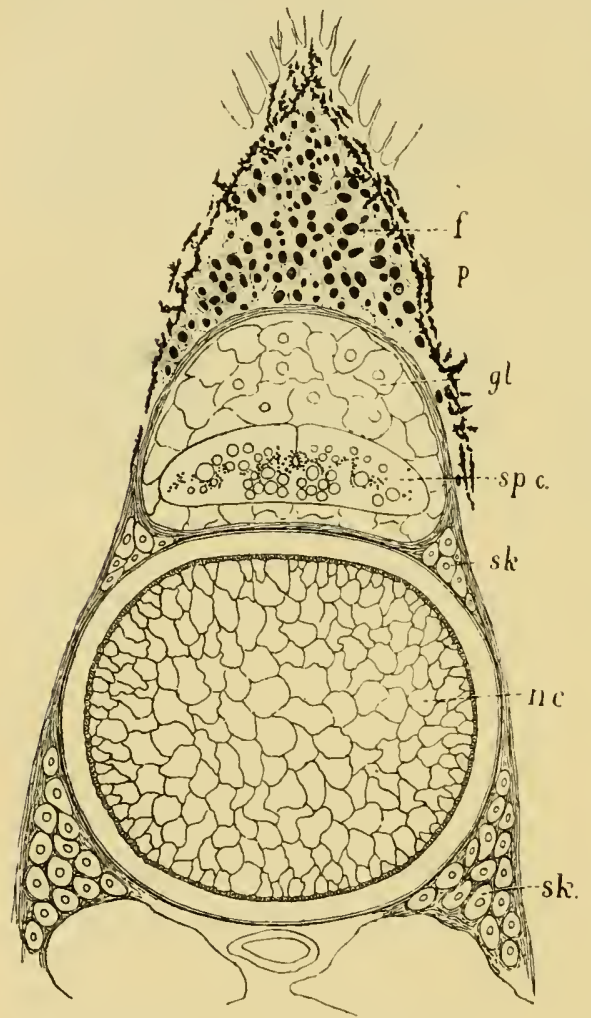

Fig. 73.-ShCtion throvgh the Notochord (nc.), the Spinal Canal and the FatCOLUMN $(f$. $)$, OF AmMOCETES, DRAWN From an Osmic Preparation.

$s p . c$. spinal cord; $g l$, glandular tissue filling the spinal canal; sti., Gegenbaur's skeletogenous cells; $p$., pigment.

function, the muscular tissue would not remain, and the space would be filled up, presumably with some form of connective tissue. As likely as not, the connective tissue might take the form of fatty tissue, the storage of fat being a physiological necessity to an animal, while at the same time no special organ has been developed for such a purpose, but fat is being laid down in all manner of places in the body.

This dorsal fat-column, as it is seen in Ammoccetes, is not found in the higher vertebrates, so that it possesses, at all events, the significance of being a peculiarity of ancient times before the vertebrate skelctal column was formed.

I mention it here in connection with my view as to the origin of vertebrates, because there it is, in the very place where the dorsal heart ought to have been. For my own part, I should not have expected that a muscular organ such as the heart would leave any trace of itself if it disappeared, so that its absence in the dorsal region of the vertebrate does not seem to me in the slightest degree to invalidate my theory. 


\section{SUMMARY.}

From the close similarity of structure and position between the branchial skeleton of Limulus and of Ammocoetes, as giren in the preceding chapter, it logically follows that the branchiæ of Ammocoetes must be homologous with the branchire of Limulus. But the respiratory apparatus of Limulus consists of branchial appendages. It follows, therefore, that the branchire of Ammocortes. and consequently of the rertebrates, must have been derived from branchial appendages, and as they are internal, not external, such branchial appendages must have been of the nature of 'sunk-in' branchial appendages. Such internal appendages are characteristic of the scorpion tribe, and of, perhaps. the majority of the Palæostraca, for no external respiratory appendages hare been discorered in any of the sea-scorpions.

In the rertebrates - and it is especially well shown in Ammocoetes-a double segmentation exists in the head-region, a body or somatic segmentation, and a branchial or splanchnic segmentation, respectively expressed by the terms mesomeric and branchiomeric segmentations. The nerves which supply the latter segments form a rery well-marked group (Charles Bell's system of lateral or respiratory nerves) which do not conform to the system of spinal nerres, for they do not arise from separate motor and sensory roots, hut are mixed nerres from the rery beginning.

The system of cranial segmental nerves is older than the spinal system, and cannot, therefore, be derived from it, but can be arranged as a system supplying two segments, somatic and splanchnic, which differ in the following way: Each somatic segment is supplied by two roots, motor and sensory respectirely, as in the spinal cord segments, while each splanchuic segment possesses only one root, which is mixed in function.

The peculiarities of the grouping of the cranial segmental nerres, which have hitherto been unexplained, immediately receive a straightforward and satisfactory explanation if the splanchnic or branchiomeric segments owe their origin to a system of appendages after the style of those of Limulus.

In Limulus and all the Arthropoda, the segmentation is double, being composed of (1) somatic or body-segments, constituting the mesomeric seguentation; (2) appendage-segments, which, seeing that they carry the branchir, constitute a branchiomeric segmentation. Similarly to the cranial region of the rertebrate. the nerres which supply the somatic segments arise from separate sensory and motor roots, while the single nerve which supplies each appendage contains all the fibres for the appendage, both motor and sensory.

It follows from this that the branchial segments supplied by the ragus and glossopharyngeal nerves ought to have arisen from appendages bearing branchia.

Although the evidence of snch appendages has entirely disappeared in the higher vertebrates, together with the disappearance of branchire, and is not strikingly apparent in the higher gill-bearing fishes, yet in Ammocotes, so great is the difference here from all other fishes, it is natural to describe the pharyngeal or respiratory chamber as a chamber into which a symmetrical series of respiratory appendages, the so-called diaphragms, are dependent. Each of these appendages possesses its own mixed nerre, glossopharyngeal or vagus, 
its own cartilage, its own set of risceral muscles, its own sense-organs, just as do the respiratory appendages of Limulus.

The branchial mnit in the rertebrate is not the gill-ponch, but the branchial bar or appendage between the pouches. Embryology shows how each such appendage grows inwards. how a coelomic cavity is formed in it, similarly to the ingrowing of the branchial appendage in scorpions.

We do not know how the palæostracan sea-scorpions breathed: they resemble the scorpion of the present day somewhat in form, but they are in many respects closely allied to Limulns. The present-day scorpion is a land animal, and the muscles by which he hreathes are dorso-rentral somatic muscles, while those of Limulus are the appendage-muscles.

The old sea-scorpions rery probably used their appendage-mnscles after the Limulns fashion, being water-breathers, even although their respiratory appendages were no Ionger free but sunk in below the surface of the body. The probability that such was the case is increased after consideration of the method of breatling in Ammocetes, for the respiratory muscles of the latter animal are directly comparable with the muscles of the respiratory appendages of Limulus, and are not somatic. Eren the gills themselves of Ammocotes are built up in the same fashion as are those of Limulus and the scorpions. The conception of the branchial unit as a gill-bearing appendage, not a gill-pouch, immediately explains the formation of the vertebrate heart. which is so strikingly different from that of all invertebrate hearts, in that it originates as a branchial and not as a systemic heart, and is formed by the coalescence of two longitudinal reins.

The origin of these two longitudinal reins is immediately apparent if the rertebrate arose from a palrostracan. for in Limulus and the whole scorpion tribe, in which the heart is a systemic heart, the branchia are supplied with blood from two large longitudinal venous sinuses. situated on each side of the middle line of the animal in an exactly corresponding position to that of the two Iongitudinal reins. which come together to form the heart and rentral aorta of the rertebrate. The consideration of the respiratory apparatus and of its bloodsupply in the rertebrate still further points to the origin of vertebrates from the Palæostraca. 


\section{CHAPTER V}

\section{THE EVIDENCE OF THE THYROID GLAND}

The ralue of the appendage-nnit in non-branchial segments.-The double nature of the hyoid segment.-Its branchial part.-Its thyroid part.-The double nature of the opercular appendage.-Its branchial part.-Its genital part. - Unique character of the thyroid gland of Ammocoetes-Its structure.Its openings.-The nature of the thyroid segment.-The uterus of the scorpion.-Its glands.-Comparison with the thyroid gland of Ammocoetes. -Cephalic genital glands of Limulus.-Interpretation of glandular tissue filling up the brain-case of Ammocoetes.-Function of thyroid gland.Relation of thyroid gland to sexual functions.-Summary.

I HAVE now given my reasons why I consider that the glossopharyngeal and vagus nerves were originally the nerves belonging to a series of mesosomatic branchial appendages, each of which is still traceable in the respiratory chamber of Ammocretes, and gives the type-form from which to search for other serially homologous, although it may be specially moditied, segments.

As long as the branchial unit consisted of the gill-pouch the segments of the head-region were always referred to such units, hence we find Dohrn and Marshall picturing to themselves the ancestor of vertebrates as possessing a series of branchial pouches right up to the anterior end of the body. Marshall speaks of olfactory organs as branchial sense-organs; Dohrn of the mouth as formed by the coalescence of gill-slits, of the trigeminal nerve as supplying modified branchial segments, etc.; thus a picture of an animal is formed such as never lived on this earth, or could be reasonably imagined to have lived on it. Yet Dohrn's conceptions of the segmentation were sound, his interpretation only was in fault, because he was obliged to express his segments in terms of the gill-pouch unit. Once abandon that point of view and take as the unit a branchial appendage, then immediately we see that in the region in front of the branchiæ we may still have seginents 
homologous to the branchial segments, originally characterized by the presence of appendages, but that such appendages need never have carried branchiæ. The new mouth may have been formed by such appendages, which would express Dohrn's suggestion of its formation by coalesced gill-slits; the olfactory organ may have been the sense-organ belonging to an antennal appendage, which would be what Marshall really meant in calling it a branchial sense-organ.

\section{The Facial Nerve and the Foremost Respiratory Segalfnt.}

This simple alteration of the branchiomeric unit from a gill-ponch to an appendage, which may or may not bear branchix, immediately sheds a flood of light on the segmentation of the head-region, and brings to harmony the chaos previously existing. Let us, then, follow out its further teachings. Next anteriorly to the glossopharyngeal and vagus nerves comes the facial nerve; a nerve which supplies the hyoid segment, or, rather, according to van Wijhe the two hyoid segments, for embryologically there is evidence of two segments. As already mentioned, the facial nerve is usually included in the trigeminal or pro-otic group of nerves, the opisthotic group being confined to the glossopharyngeal and vagus. This inclusion of the facial nerve into the pro-otic group of nerves forms one of the main reasons why this group has been supposed to have originally supplied gill-pouch segments, for the hyoid segment is clearly associated with branchix.

When, however, we examine Ammocotes ( $c f$. Figs. 63 and 64) it is clear that the foremost of the segments forming the respiratory chamber, which must be classed with the rest of the mesosomatic or opisthotic segments, is that supplied by the facial nerves.

An examination of this respiratory chamber shows elearly that there are six pairs of branchial appendages or diaphragms, which are all exactly similar to each other. These are those already considered, the foremost of which are supplied by the IXth or glossopharyngeal nerves. Immediately anterior to this glossopharyngeal segment is seen in the figures the segment supplied by the VIIth or facial nerves. It is so much like the segments belonging to the glossopharyngeal and vagus nerves as to make it certain that we are dealing here with a branchial segment, composed of a pair of branchial appendages similar to those in the other cases, except that the 


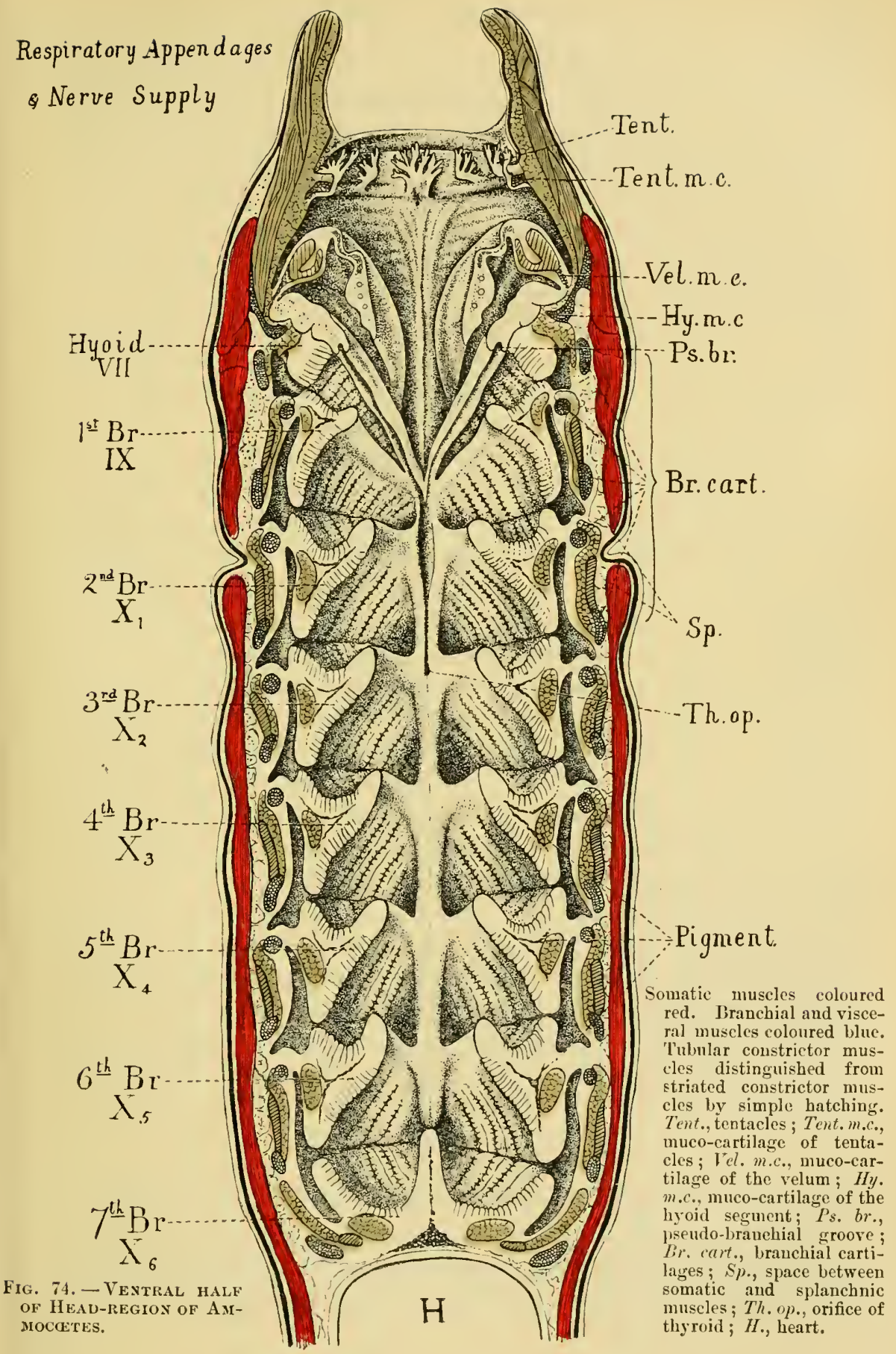


cartilaginous bar is here replaced by a bar of muco-cartilage and the branchix are confined to the posterior part of each appendage. The anterior portion is, as is scen in Fig. 74, largely occupied by blood-spaces, but in addition carries the ciliated groove (ps. br.) called by Dohrn 'psendo-branchiale Rinne.' This groove leads directly into the thyroid gland, which is a large bilateral organ situated in the middle line, as seen in Fig. 80 and Fig. 85. As shown by Miss Alcock, the facial nerve supplies this thyroid gland, as well as the posterior hyoid branchial segment, and, as pointed out by Dohrn, there is every reason to consider this thyroid gland as indicative of a separate segment, especially when van Wijhe's statement that the hyoid segment is in reality double is taken into account.

The eviclence, then, of Ammocoetes points directly to this conclusion: The facial nerves represent the foremost of the mesosomatic group of nerves, and supply two segments, which have amalgamated with each other. The most posterior of these, the hyoid segment, is a branchial segment of the same character as those supplied by the vagus and glossopharyngeal nerves; represents, therefore, the foremost pair of branchial appendages. The anterior or thyroid segment, on the other hand, differs from the rest in that, instead of branchiæ, it carries the thyroid gland with its two ciliated grooves. If this segment, which is the foremost of the mesosomatic segments, also indicates a pair of appendages which carry the thyroid gland instead of branchiæ, then it follows that this pair of appendages has joined together in the mid-line ventrally and thus formed a single median organ-the thyroid gland. If, then, we find that the foremost of the mesosomatic appendages in the Palæostraca was really composed of two pairs of appendages, of which the most posterior carried branchiæ, while the anterior pair had amalgamated in the mid-line ventrally, and carried some special organ instead of branchice, then the accumulation of coincidences is becoming so strong as to amount to proof of the correctness of our line of investigation.

\section{Tine First Mesosomatic Segment in Limulus and its Allies.}

What, then, is the nature of the foremost pair of mesosomatic appendages in Limulus. They differ from the rest of the mesosomatic appendages in that they do not carry branchix, and instead of being 
separate are joined together in the mid-line ventrally to form a single terminal plate-like appendage known as the operculum. On its posterior surface the operculum carries the genital duct on each side.

So also in the scorpion group, the operculum is always found aud always carries the genital ducts.

A survey of the nature of the opercular appendage demonstrates the existence of three different types-

1. That of Limulus, in which the operculum is free, and carries only the terminations of the genital ducts. In this type the duct on each sile opens to the exterior separately (Fig. 75).

2. The type of Scorpio, Androctonus, Buthus, etc., in which the

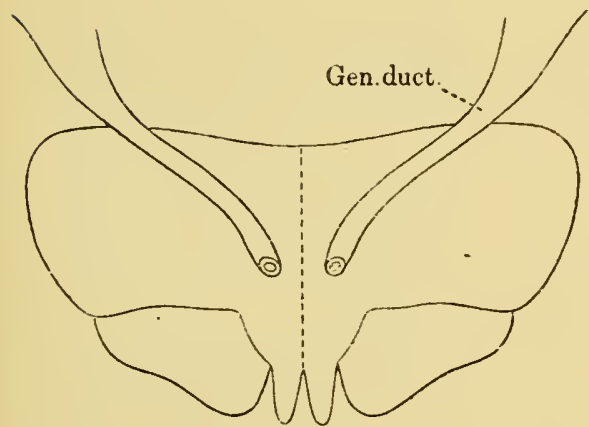

Fig. 75.-Operculum of Limulus to Show the two separate Gental Ducts.

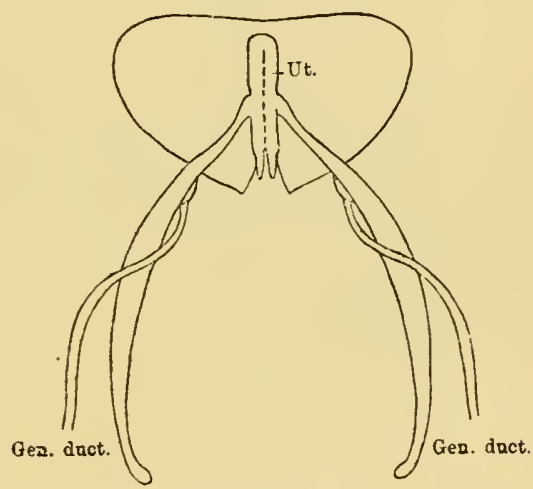

Frg. 76. - Operculum of Male Scorpion.

$\tau t$., terminal chamber, or uterus.

operculum is not free, but forms part of the ventral surface of the body-wall, but, like Limulus, carries only the terminations of the genital ducts. In this type the duct on each side terminates in a common chamber (vagina or uterus), which communicates with the exterior by a single external median opening. This common chamber, or uterus (Ut.), extends the whole breadth of the operculum (as seen in Fig. 76), and is limited to that segment.

3. The type of Thelyphonus, Hypoctonus, Phrynus, and other members of the Pedipalpi, in which the operculum forms a part of the ventral surface of the body wall, but no longer covers only the termination of the genital apparatus. It realiy consists of two parts, a median anterior, which covers the terminal genital apparatus, 
and a lateral posterior, which covers the first pair of gills, or lungbooks, as they are called. In this type (Fig. 77) the genital ducts terminate in a common chamber or uterus, the nature of which will be further considered.

As las been pointed out by Blanchard, the terminal genital organs of the scorpions and the Pedipalpi vary considerably in the different genera, especially the male genital organs. The general type of structure is the same, and consists in both male and female of vasa deferentia, which come together to form a common chamber

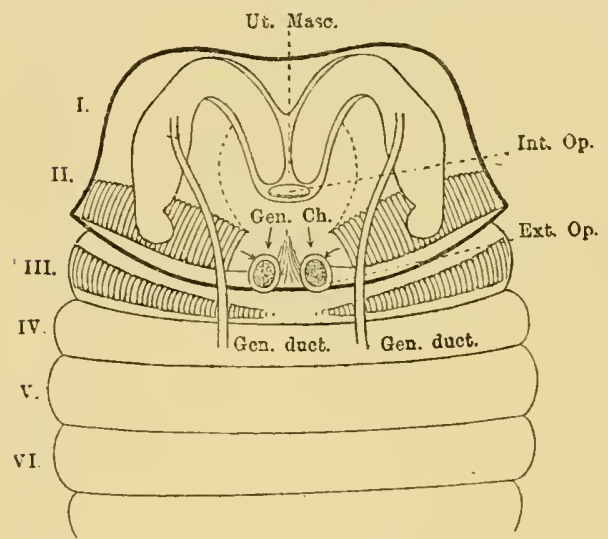

Fig. 77.-Operculum and Following Segments of Male Thelyphonus.

Opercular segment is marked out by thick black line. Ut. Masc., uterus masculinus; Int. Op., internal opening of uterus in to genital chamber; Ext. Op., common external opening to genital chamber (Gen. Ch.) and pulmonary chamber.

before the actual opening to the exterior. This comnon chamber has been called in the female scorpion the vagina, or in Thelyphonus the uterus. I shall use the latter term, in accordance with Tarnani's work, and the corresponding chamber in the male will be the uterus masculinus.

A considerable discussion has taken place about the method of action of the external genital organs in the members of the scorpion tribe, into which it is hardly necessary to enter here. The evidence points to the conclusion that in all these forms the opermum covers a median single chamber or uterus, into which the genital ducts open on each side, the main channels of emission being provided with a massive chitinous internal framework. We may feel certain that in the old extinct sea-scorpions, Eurypterus, etc., a similar arrangement existed, and that therefore in them also the median portion of the operculum covered a median chamber or uterus composed of the amalgamation of the terminations of the two genital ducts, which were originally separate, as in Limulus.

The observations of Schmidt, Zittel, and others show that the 
operculum in the old extinct sea-scorpions, Eurypterus, Pterygotus, etc., belonged to the type of Thelyphouus, rather than to that of Limulus or Scorpio. In Fig. 78 I give a picture from Schmidt of the ventral aspect of Eurypterus, and by the side of it a picture of the isolated operculum. Schmidt considers that there were five branchiæbearing segments constituting the mesosoma, the foremost of which formed the operculum. Such operculum is often found isolated, and is clearly composed of two lateral appendages fused together in the middle line, of such a nature as to form a median elongated tongue, which lies between and separates the first three pairs of branchial segments. This median tongue, together with the anterior and median portion of the operculum, concealed, in all probability, according to Schmidt, the terminal parts of the genital organs, just as the median part of the operculum in Phrynus and Thelyphonus conceals the complicated terminal portions of the genital organs. The posterior part of the operculum, like that of Phrynus and Thelyphonus, carried the first pair of branchiæ, so Schmidt thinks from the evidence of markings on some specimens.

Apparently an opercular appendage of this kind is in reality the result of a fusion of the genital

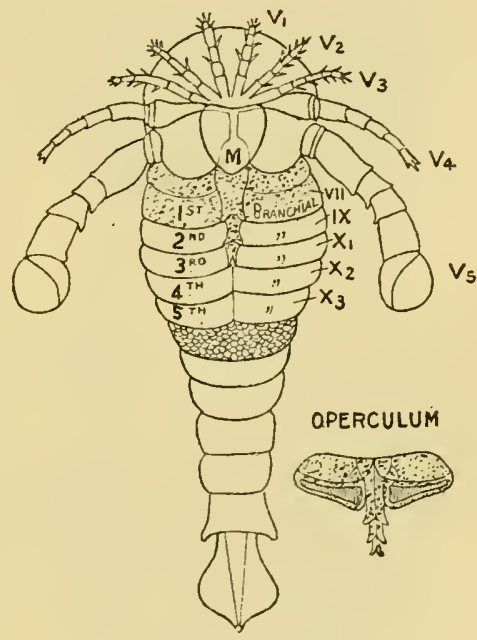

FIG. 78.-Eurypterus.

The segments and appendages on the right are numbered in correspondence with the cranial system of lateral nerve-roots as found in vertebrates. $M r$., metastoma. The surface ornamentation is represented on the first segment posterior to the branchial segments. The opercular appendage is marked out by dots. operculum with the first branchial appendage in forms such as the scorpion; for, in order that the tergal plates may correspond in number with the sternal in Eurypterus, etc., it is necessary to consider that the operculum is composed of two sternites joined together. Similarly in Thelyphonus, Phrynus, etc., this numerical correspondence is only observed if the operculum is looked upon as double.

A restoration of the mesosomatic region of Eurypterus, viewed 
from the internal surface, might be represented by Fig. 79, in which the thick line represents the outline of the opercular segment, and the fainter lines the succeeding

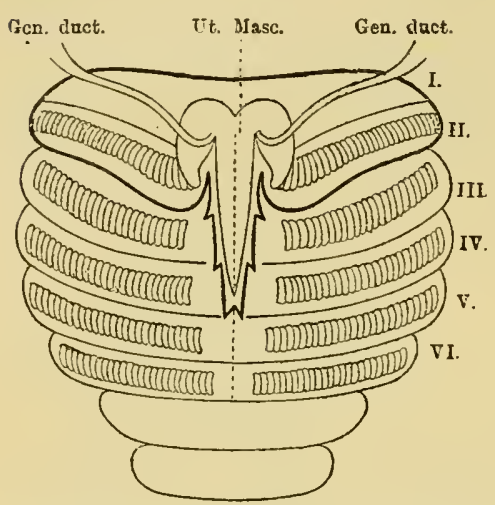

Fig. 79.-Diagran to indicate the probable Nature of the Mesosomatic Segients of Eurypterus.

The opercular segment is marked out by the thick black line. The segments $I I$.-VI. bear branchire, and segment $I$. is supposed in the male to carry the uterus masculinus (Ut. Masc.) and the genital ducts. branchial segments. The middle and anterior part of the opercular segment carried the terminations of the genital organs; these I have represented, in accordance with our knowledge of the nature of these organs in the present-day scorpions, as a median elongated uterus, bilaterally formed, from which the genital ducts passed, probably as in Limulus, towards a mass of generative gland in the cephalic region, and not as in Scorpio or Thelyphonus, tailwards to the abdominal region.

It is possible that in Holm's representation of Eurypterus, Fig. 104 , the genital duct on each side is indicated.

\section{The Throoid Gland of Ammocetes.}

If we compare this mesosomatic region of Eurypterus with that of Ammocoetes, the resemblance is most striking, and gives a meaning to the facial nerve which is in absolute accordance with the interpretation already given of the glossopharyngeal and vagus nerves. In both cases the foremost respiratory or mesosomatic segment is double, the posterior lateral part alone bearing the branchise, while the median and anterior part bore in the one animal the uterus and genital ducts, in the other the thyroid gland and ciliated grooves. We are driven, therefore, to the conclusion that this extraordinary and unique organ, the so-called thyroid gland of Ammocotes, which exists only in the larval condition and is got rid of as soon as the adult sexual organs are formed, shows the very form and position of the uterus of this invertebrate ancestor of Ammocoetes. What, then, is the nature of the thyroid gland in Ammoccetes ? 
Throughout the vertebrate kingdom it is possible to compare the thyroid gland of one group of animals with that of another without coming across any very marked difference of structure right down to and including Petromyzon. When, howerer, we examine Ammocates, we find that the thyroid has suddenly become an organ of much more complicated structure, covering a much larger space, and bearing no resemblance to the thyroid glands of the ligher forms. At transformaticn the thyroid of Ammocetes is largely destroyed, and what remains of the gland in Petromyzon becomes limited to a few follicles resembling those of other fishes. The structure and position of this gland in Ammocetes is so well known that it is unnecessary to describe it in detail. For the purpose, however, of making my points clear, I give in Fig. 80 the position and appearance of the thyroid gland $(T h$.$) when the skin and under-$ lying laminated layer has been removed by the action of hypochlorite of soda. On the one side the rentral somatic muscles have been removed to show the branchial cartilaginons basketwork.

The series of transverse sections in Fig. 81 represents the nature of the organ at different levels in front of and behind the opening into the respiratory chamber; and in Fig. 82 I have sketched the appearance of the whole gland, viewed so as to show its opening into the respiratory chamber and its posterior curled-up termination.

The series of transverse sections (1-6, Fig. 81) show that we are dealing here with a central glandular chamber, C (Fig. S1 (i) and Fig. 82), which opens by the thyroid duct $(T h, 0$.) into the pharyugeal 

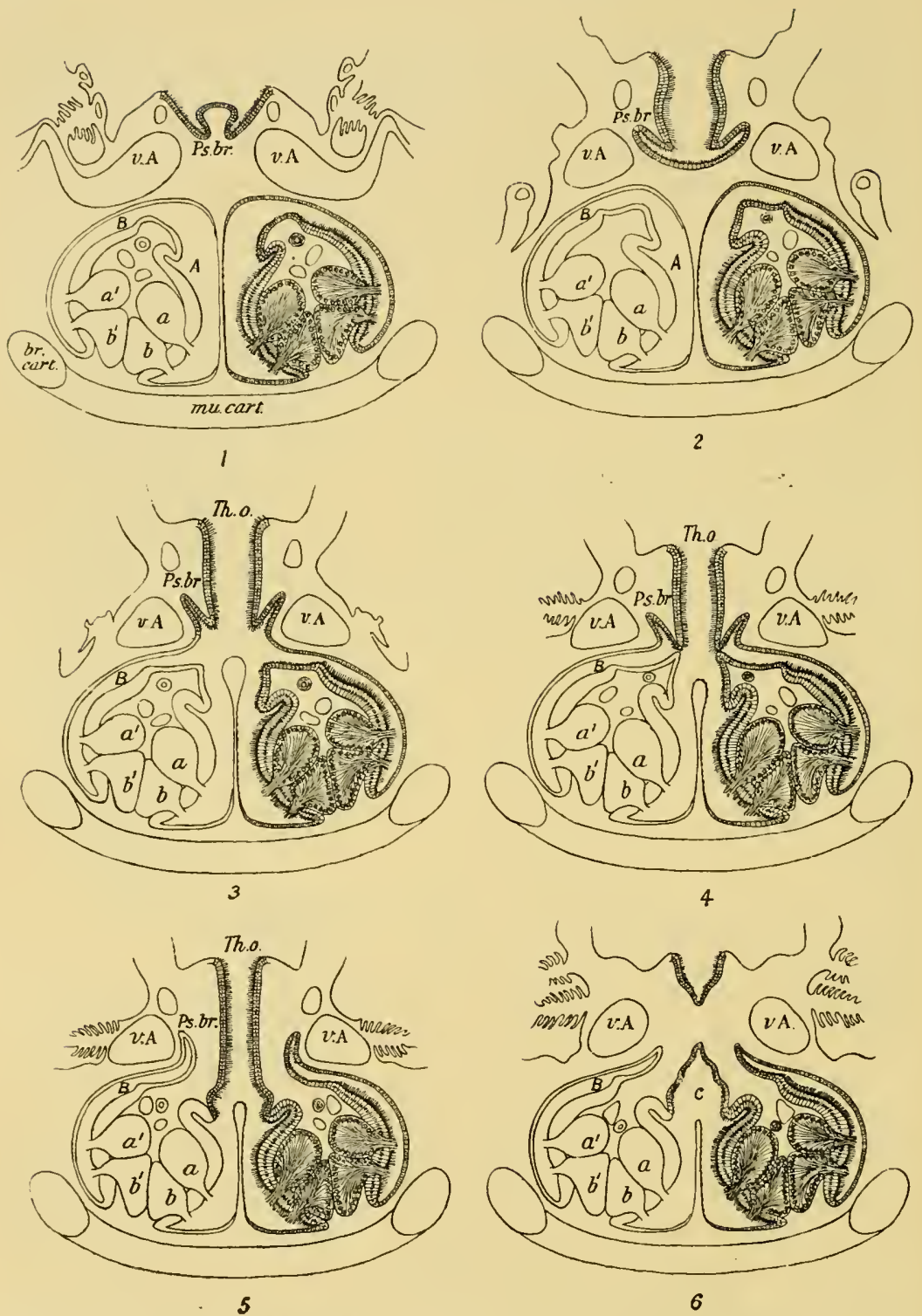

Fig. 81.-Samples from a Complete Series of Transverse Sections throdgh the Thyroid Gland of ammocentes.

Sections 1 and 2 are anterior to the thyroid opening, Th.o.; sections 3,4 , and 5 are throngh the thyroid opening; and section 6 is posterior to the thyroid opening before the commencement of the curled portion. 
chamber, and is curled upon itself in its more posterior part. This central chamber divides, anteriorly to the thyroid orifice, into two portions, A, A' (Fig. 82), giving origin to two tubes, $B, B^{\prime}$, which lie close alongside of, and extend further back than, the posterior limit of the curled portion of the central chamber, C. The structure of the central chamber, $\mathrm{C}$, and, therefore, of the separate coils, is given in both Schneider's and Dohrn's pictures, and is represented in Fig. 81 (6), which shows the peculiar arrangement and character of the glandular cells typical of this organ, and also the nature of the central cavity, with the arrangement of the ciliated epithelium. The structure of each of the lateral tubes, $B$, is different from that of the central chamber, in that only half the central chamber is present in them, as is seen by the comparison of the tube $\mathrm{B}$ with the tube $\mathrm{C}$ in Fig. 81 (5 and 6), so that we may look upon the central chamber, $\mathrm{C}$, as formed of two tubes, similar in structure to the tubes $\mathrm{B}$, which have come together to form a single chamber by the partial absorption of their walls, the remains of the wall being still visible as the septum, which partially divicles the chamber, C, into halves.

In the walls of each of these tubes is situated a continuous glandular line, the structure of the glandular elements being specially characterized by the length of the cells, by the large spherical nucleus situated at the very base of each cell, and by the way in which the cells form a wedge-shaped group, the thin points of all the wedgeshaped cells coming together so as to form a continuous line along the chamber wall. This free termination of the cells of the gland in the lumen of the chamber constitutes the whole method for the secretion of the grland; there is no duct, no alveolus, nothing but this free termination of the cells.

Moreover, sections through the portion $\mathrm{A}, \mathrm{A}^{\prime}$ (Fig. 82) show that here, as in the central chamber, $\mathrm{C}$, four of these glandular lines open into a common chamber, but they are not the same four as in the case of the central chamber, for if we name these glandular lines on the left side $a b, a^{\prime} b^{\prime}$ (Fig. 81), and on the right side $c d, c^{\prime} d^{\prime}$, then the central chamber has opening into it the glands $a b, c d$, while the chambers of $\mathrm{A}$ and $\mathrm{A}^{\prime}$ have opening into them respectively $a \cdot b, a^{\prime} b^{\prime}$, and $c \cdot d, c^{\prime} d^{\prime}$. Further, the same series of sections shows that the glands $a$ and $b$ are continuous with the glands $a^{\prime}$ and $b^{\prime}$ respectively across the apex of $A$, and similarly on the other side, so that the two glandular rows $a b$ are continuous with the two glandular rows $a^{\prime} b^{\prime}$, and we see that the 
cavity of the portion $A$ or $A^{\prime}$ is formed by the bending over of the tube or horn, B or $\mathrm{B}^{\prime}$, with the partial absorption of the septum so formed between the tube and its bent-over part. If, then, we meoil the emrled-np part of $\mathrm{C}$, and separate the portion, $\mathrm{B}$, on each side from the chamber, $\mathrm{C}$, we see that the so-ealled thyroid of Ammocretes may be represented as in Fig. 8., i.e. it consists of a long, common chamber, C,

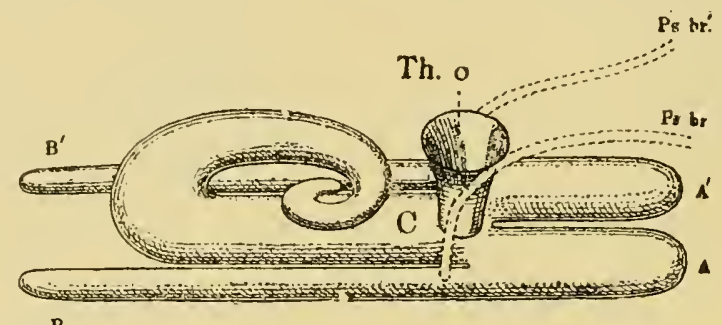

Fig. 82.-Diagramiatic Representation of the so-Called Thyroid Gland of AMMOCETES.

$C$, central chamber; $A, A^{\prime}$, anterior extremity; $B, B^{\prime}$, posterior extremity; $T h$. 0 , thyroid opening into respiratory chamber; $P s . b r ., P s . b r^{\prime}$, ciliated grooves, Tohrn's pseudo-branchial grooves.

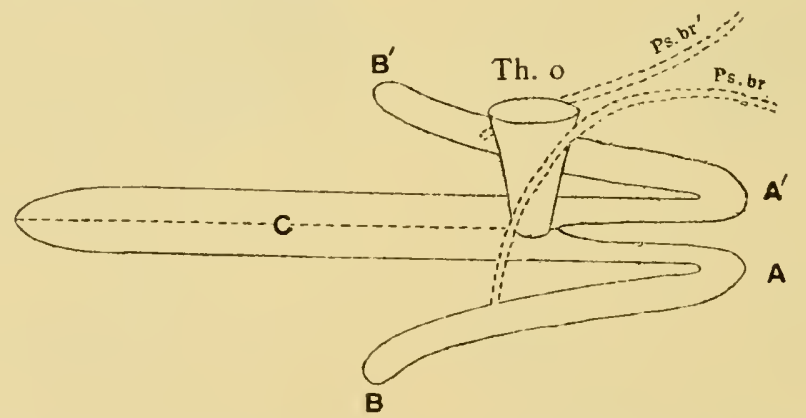

Fig. 83.-Thirroid Gland as it wolld appear if the Central Chamber were Uncurled and the Two Horns, $B, B^{\prime}$, separated from tile Central Chamber.

which, for reasons apparent afterwards, I will eall the palceo-hysteron, which opens, by means of a large orifice, into the respiratory or pharyngeal chamber. The anterior end of this chamber terminates in two tubes, or horns, B, B', the structure of which shows that the median chamber, $\mathrm{C}$, is the result of the amalgamation of two such tubes, and consequently in this chamber, or palaro-hysteron, the glandular lines are symmetrieally situated on each side.

Any explanation, then, of the thyroid gland of Ammoecetes, must 
take into account the clear evidence that it is composed of two tubes, which have in part fused together to form an elongated central chamber, in part remain as horns to that chamber, and that in its walls there exist lines of gland-cells of a striking and characteristic nature.

Further, this central chamber, with its horns, is not a closed chamber, but is in communication with the pharyngeal or respiratory chamber by three ways. In the first place, the central chamber, as is well known, opens into the respiratory chamber by a funnel-shaped opening-the so-called thyroid duct ( $T h .0$.$) . In the second place,$ there exist two ciliated grooves ( $P s . b r$. $P s .7 r^{\prime}$.), the pseudo-branchial grooves of Dohrn, which have direct communication with the thyroid chamber. The manner in which these grooves communicate with the thyroid chamber has never, to my knowledge, been described previously to my description in the Journal of Physiology and Anatomy; it is very instructive, for, as I have there shown, each groove enters iuto the corresponding lateral horn, so that, in reality, there are three openings into the thyroid chamber or palæo-hysteron-a median opening into the central chamber, and a separate opening into each lateral horn.

The system of ciliated grooves on the inner ventral surface of the respiratory chamber of Ammoecetes was originally described by Schneider as consisting of a single median groove, which extends from the opening of the thyroid to the posterior extremity of the branchial chamber, and a pair of grooves, or semi-canals, which, starting from the region of the thyroid orifice, run headwards and diverge from each other, becoming more and more lateral, and more and more dorsal, till they come together in the mid-dorsal pharyngeal line below the auditory capsules. The latter are the pseudo-branchial grooves of Dohru, of which I have already spoken. Schneider looked upon the whole of this system as a single system, for he speaks of " a ciliated groove, which extends from the orifice of the stomach (i.e. anterior intestine) to the orifice of the thyroid, then divides into two, and runs forward right and left of the median ridge, etc." Dohrn rightly separates the median ciliated groove posterior to the thyroid orifice (seen in Fig. 81 (6)) from the paired psendobranchial grooves; the former is a shallow depression which opens into the rin of the thyroid orifice, while the latter has a much more intimate connection with the thyroid gland itself. 
A series of sections, such as is given in Fig. 81, shows the relation of this pair of eiliated grooves to the thyroid better than any elaborate description. In the first place, it is clear that they remain separate up to their termination - they do not join in the middle line to open into the thyroid duct; in the second place, they are separate from the thyroid orifice-they do not terminate at the rim of the orifice, as is the case with the median groove just mentioned, but continue on each side on the wall of the thyroid duct (Fig. 81 (2)), gradually moving further and further away from the actual opening of the duct into the pharyngeal chamber. During the whole of their course on the wall of the funnel-shaped duct they retain the character of grooves, and are therefore open to the lumen of the duct. The direction of the groove (Ps. br.) shifts as it passes deeper and deeper towards the thyroid, until at last, as seen in Fig. 81 (3 and 4), it is continuous with the narrow diverticulum of the turned-down single part of the thyroid (B), or turned-down horn, as I have called it. In other words, the median chamber opens into the pharyngeal or respiratory chamber by a single large, funnel-shaped opening, and, in addition, the two ciliated grooves terminate in the lateral horns on each side, and only indirectly into the central chamber, owing to their being semi-canals, and not complete canals. If they were originally canals, and not grooves, then the thyroid of Ammocoetes would be derived from an organ composed of a large, common glandular chamber, which opened into the respiratory chamber by means of an extensive median orifice, and possessed anteriorly two horns, from each of which a canal or duct passed headwards to terminate somewhere in the region of the auditory capsule.

Dohrn has pointed out that a somewhat similar structure and topographical arrangement is found in Amphioxus and the Tunicata, the gland-cells being here arranged along the hypobranchial groove to form the endostyle and not shut off to form a closed organ, as in the thyroid of Ammocoetes. Dohrn concludes, in my opinion rightly, that the endostyle in the Tunicata and in Amphioxus represents the remnants of the more elaborate organ in Ammocotes, and that, therefore, in order to explain the meaning of these organs in the former animals, we must first find out their meaning in Ammocœetes. Dohrn, however, goes further than this; for just as he considers Amphioxus and the Tunicata to have arisen by degeneration from an Ammoccetes-like form, so he consider's Ammocotes to have arisen 
from a degenerated Selachian; therefore, in order to be logical, he ought to show that the thyroid of Ammocœtes is an intermediate down. ward step between the thyroid of Selachians and that of Amphioxus and the Tunicates. Here, it seems to me, his argument utterly breaks down; it is so clear that the thyroid of Petromyzon links on to that of the higher fishes, and that the Ammocotes thyroid is so immeasurably more complicated and elaborate a structure than is that of Petromyzon, as to make it impossible to believe that the Ammoccetes thyroid has been derived by a process of degeneration from that of the Selachian. On the contrary, the manner in which it is eaten up at transformation and absolutely disappears in its original form is, like the other instances mentioned, strong evidence that we are dealing here with an ancestral organ, which is confined to the larval form, and disappears when the change to the higher adult condition takes place. Dohrn's evidence, then, points strongly to the conchusion that the starting-point of the thyroid gland in the vertebrate series is to be found in the thyroid of Ammocetes, which has given rise, on the one hand, to the endostyle of Amphioxus and the Tunicata, and on the other, to the thyroid gland of Petromyzon and the rest of the Vertebrata.

The evidence which I have just given of the intimate connection of the two pseudo-branchial grooves with the thyroid chamber shows, to my mind, clearly that Dohrn is right in supposing that morphologically these two grooves and the thyroid must be considered together. His explanation is that the whole system represents a modified pair of branchial segments distinct from those belonging to the VIIth and IXth nerves. The cavity of the thyroid and the psendo-branchial grooves are, therefore, according to him, the remains of the gill-pouches of this fused pair of branchial segments, which no longer open to the surface, and the glandular tissue of the thyroid is derived from the modified gill-epithelium. This view of Dohrn's, which he has urged most strongly in various papers, is, I think, right in so far as the separateness of the thyroid segment is concerned, but is not right, and is not proven, in so far as concerns the view that the thyroid gland is a modified pair of gills.

We may distinctly, on my view, look upon the thyroid segment, with its ciliated grooves and its covering plate of muco-cartilage, as a distinct paired segment, homologous with the branchial segments, without any necessity of deriving the thyroid gland from a pair of gills, 
The evidence that such a median segment has been interpolated rentrally between the foremost pairs of branchial segments is remarkably clear, for the limits ventrally of the branchial segments are marked out on each side by the ventral border of the cartilaginous basket-work; and it is well known, as seen in Fig. 80, that whereas this cartilaginous framework on the two sides meets together in the middle ventral line in the posterior branchial region, it diverges in the anterior region so as to form a tongue-shaped space between

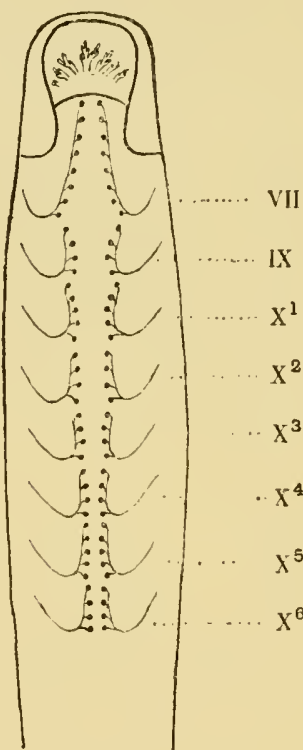

A

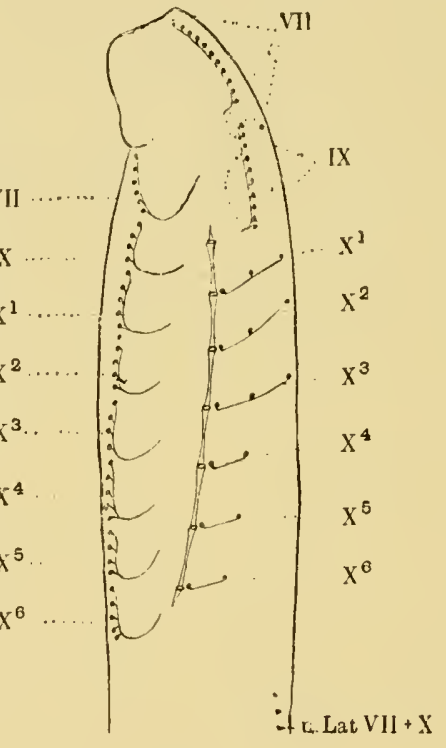

$\mathrm{B}$

Fig. 84.-Diagram of (A) Tremtral Surface axd (B) Lateral Surface of Ammocetes, showing the arrangenent of the Erithelial Pits on the Braxchial Region, and their innervation by TII., the Facial, d. $_{\text {, }}$, the Glossopharyngeal, aNd $\mathrm{X}^{\mathrm{T}}-\mathrm{X}^{\mathrm{ri}}$, the Vages Nerves.

the branchial segments on the two sides. This space is covered over with a plate of muco-cartilage which bears on its inner surface the thyroid gland.

In addition to this evidence that we are dealing here with a rentral tongue-like segment belonging to the facial nerve which is interpolated between the foremost branchial segments, we find the most striking fact that at trausformation the whole of this mucocartilaginous plate clisappears, the remarkable thyroid gland of the 
Ammoccetes is eaten up, and nothing is left except a small, totally different glandular mass; and now the cartilaginous basket-work meets together in the middle line in this region as well as in the more posterior region. In other words, the striking characteristic

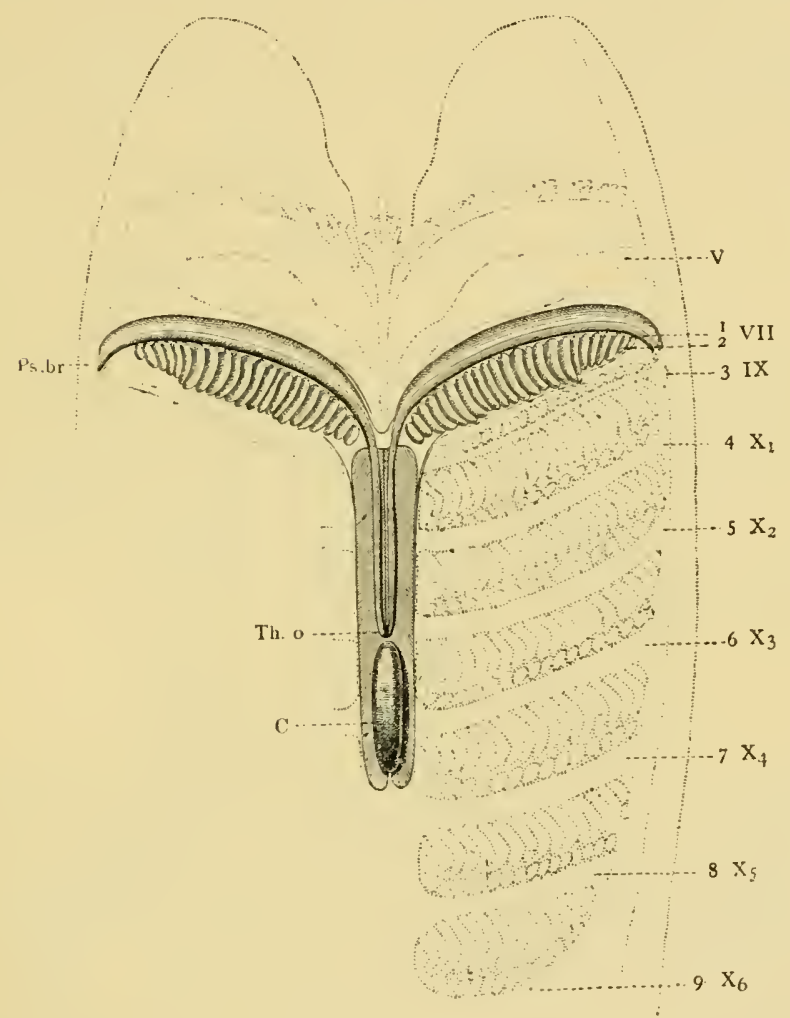

Fig. 85.-Facial Segment of Amocetes marked out by Shading.

VII. 1, thyroid part of segment; VII. 2, hyoid or branchial part; 3-9, succeeding branchial segments belonging to IXth and Xth nerves; $V$, the velar folds; Ps. br., Dohrn's pseudo-branchial groove; Th. o., thyroid opening; $C$, curled portion of thyroid.

of transformation here is the destruction of this interpolated segment, and the resulting necessary drawing together ventrally of the branchial segments on each sile.

Moreover, another most instructive piece of evidence pointing in the same direction is afforded by the behaviour of the ventral epithelial 
pits, as determined by Miss Alcock. Although there is no indication on the ventral surface of the skin of any difference between the anterior and posterior portions of the respiratory region, yet when the ventral rows of the epithelial pits supplied by each branchial nerve are mapped out, we see how the most anterior ones diverge more and more from the mid-ventral line, following out exactly the limits of the underlying muco-cartilaginous thyroid plate (Fig. 84).

The whole evidence strongly learls to the conclusion that the thyroid portion of the facial segment was inserted as a median tongue between the foremost branchial segments on each side, and that, therefore, the whole facial segment, consisting as it does of a thyroid part and a hyoid or branchial part, may be represented as in Fig. 85, which is obtained by splitting an Ammocotes longitudinally along the mid-dorsal line, so as to open ont the pharyngeal chamber and expose the whole internal surface. The facial segment is marked out by shading lines, the glosso-pharyngeal and vagus segments and the last of the trigeminal segments being indicated faintly. The position of the thyroid gland is indicated by oblique lines, $\mathrm{C}$ being the curled portion.

\section{The Uterus of the Scorpion Group.}

Seeing how striking is the arrangement and the structure of the glandular tissue of this thyroid, how large the organ is and how absolutely it is confined to Ammocœetes, disappearing entirely as such at transformation, we may feel perfectly certain that a corresponding, probably.very similar, organ existed in the invertebrate ancestor of the vertebrate; for the transformation process consists essentially of the discarding of invertebrate characteristics and the putting on of more vertebrate characters; also, so elaborate an organ cannot possibly have been evolved as a larval adaptation during the life of Ammocœes. We may therefore assert with considerable confidence that the thyroid gland was the palco-hysteron, and was derived from the uterus of the ancient palicostracan forms. If, then, it be found that a glandular organ of this very peculiar structure and arrangement is characteristic of the uterus of any living member of the scorpion group, then the confidence of this assertion is greatly increased.

In Limulus, as already stated, the genital ducts open separately 
on each side of the operculum, and do not combine to form a uterus; I have examined them and was unable to find any glandular structure at all resembling that of the thyroid gland of Ammoccetes. I then turned my attention to the organs of the scorpion, in which the two ducts have fused to form a single uterus.

I there found that both in the male and in the female the genital

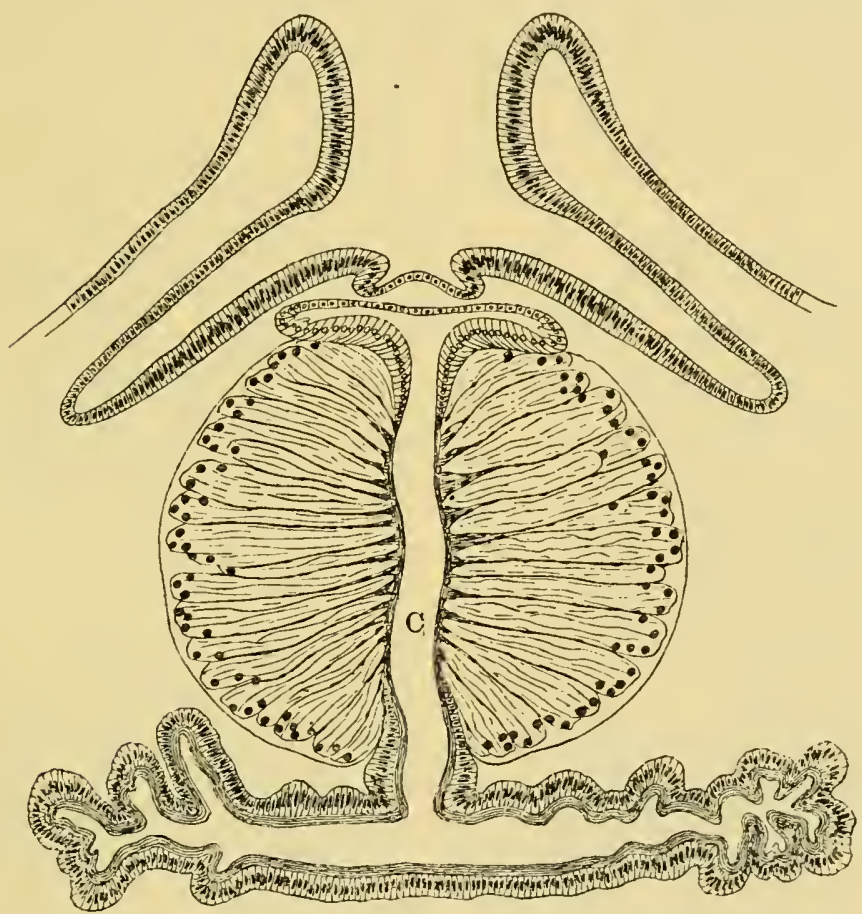

Fig. 86.-Section throvgh the Terminal Chanber or Uterus of the Male Scorpion.

$C$, cavity of chamber. A portion of the epithelial lining of the channels of emission is drawn above the section of the uterus.

ducts on each side terminate in a common chamber or uterus, which underlies the whole length of the operculum, and opens to the exterior in the middle line, as shown in Fig. 76 . In transverse section, this uterus has the appearance shown in Fig. 86, i.e. it is a large tube, evidently expansible, lined with a chitinous layer and epithelial cells belonging to the chitinogenous layer, except in two symmetrical places, where the uniformity of the uterine wall is 
interrupted by two large, remarkable glandular structures. The structure of these glands is better shown by means of sagittal sections. They are composed of very long, wedge-shaped cells, each of which possesses a large, round nucleus at the basal end of the cell (Fig. 87). These cells are arranged in bundles of about eight to ten, which are separated from each other by connective tissue, the apex of cach conical bundle being directed into the cavity of the uterus; where this brush-like termination of the cells reaches the surface, the chitinous layer is absent, so that this layer is, on surface view, seen

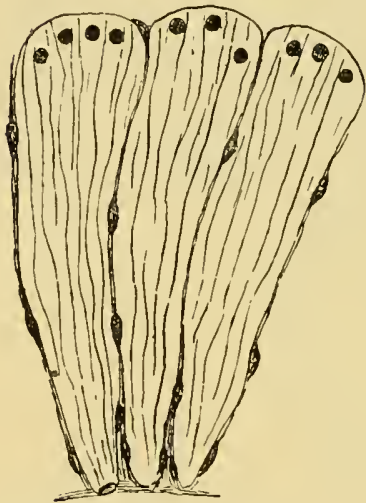

Fig. 87.-Longitudinal SecTION THROUGH THREE OF the Cones of tile Uterine Glands of the Scorion.

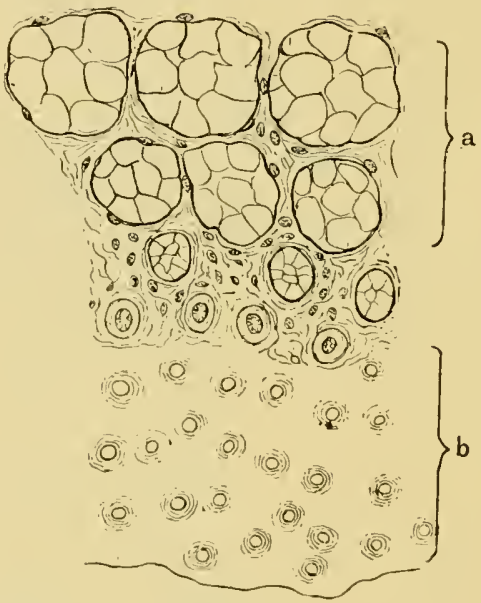

Fig. 88.-Sagittal Section throvgh the Uterine Gland of Scompion, SHOWING THE INTELINAL Chitinous Surface (b) and the Glandular Cones $(a)$ CUT THROUgh at various Distances from the Internal SurFACE.

(Fig. $88(b)$ ) to be pitted with round holes over that part of the internal surface of the uterus where these glands are situated. Each of these holes represents the termination of one of these cone-shaped wedges of cells. If the section is cut across at right angles to the axis of these cones, then its appearance is represented in Fig. 88 ( $(1)$, and shows well the arrangement of the blocks of cells, separated from each other by connective tissue. When the section passes through the basal part of the cones, and only in that case, then the nuclei of the cells appear, often in considerable numbers in one section, as 
is seen in Fig. 89 . In Fig. 88 the section shows at $b$ the holes in the chitin in which the cones terminate, and then a series of layers of sections through the cones further and further away from their apices.

These conical groups of long cells, representel in Fig. 87, form on each side of the uterus a gland, which is continuous along its whole length, and thus forms a line of secreting surface on each side, just as in the corresponding arrangement of the glandular structures in the thyroid of Ammoccetes. This uterus and glandular ar-

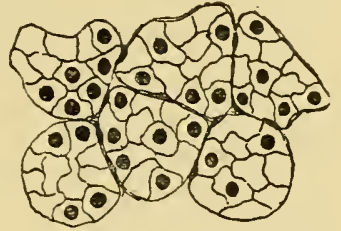

Fig. 89.-Transterse SecTION THROUGH THE BASAL PART OF THE UteriNe GLANDS OF the Scorpion. rangement is found in both sexes; the gland is, however, more developed in the male than in the female scorpion.

The resemblance between the structure of the thyroid of Ammocates and the nterus of the scorpion is most striking, except in two respects, viz. the nature of the lining of the non-glandular part of the cavity - in the one case ciliated, in the other chitinous-and the place of exit of the cavity, the thyroil of Ammocretes opening into
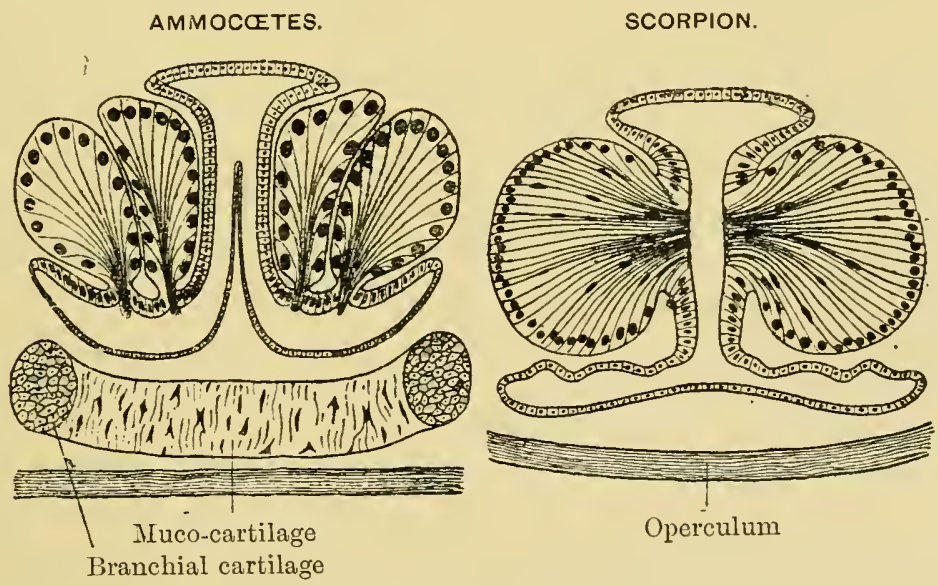

Fig. 90.-Section of Central Chamber of Thyroid of Ammoceetes and Section of Uterus of Scorpion.

the respiratory chamber, while the uterus of Scorpio opens direct to the exterior.

With respect to the first difference, the same difficulty is met 
with in the comparison of the ciliated lining of the tube in the central nervons system of vertebrates with the chitinous lining of the intestine in the arthropod. Such a difference does not seem to me either unlikely or unreasonable, seeing that cilia are found instead of chitin in the intestine of the primitive arthropod Peripatus. Also the worm-like ancestors of the arthropods almost certainly possessed a ciliated intestine. Finally, the researches of Hardy and McDougall on the intestine of Daphnia point directly to the presence of a ciliated rather than a chitinous epithelial lining of the intestine in this animal-all evidence pointing to the probability that in the ancient arthropod forms, derived as they were from the annelids, the intestine was originally ciliated and not chitinous. It is from such forms that I suppose vertebrates to lave sprung, and not from forms like the living king-crabs, scorpions, Apus, Branchipus, etc. I only use them as illustrations, because they are the only living representatives of the great archaic group, from which the Crustacea, Arachnida, and Vertebrata all took origin.

The second difference is more important, and is at first sight fatal to any comparison between the two organs. How is it possible to compare the uterus of the scorpion, which opens on the surface by an extcrnal genital opening, with the thyroid of Ammocotes, which opens by an internal opening into the respiratory chamber? However close may be the histological resemblance of structure in the two cases, surely such a difference is too great to be accounted for.

It is, however, to be remembered that the operculum of Scorpio covers only the terminal genital apparatus, and does not, therefore, resemble the operculum of the presumed ancestor of Ammocoetes, which, as already argued, must have resembled the operculum of Thelyphonus with its conjoint branchial and genital apparatus, rather than that of Scorpio. Before, therefore, making too sure of the insuperable character of this difficulty, we must examine the uterus of the Pedipalpi, and see the nature of its opening.

The nature of the terminal genital organs in Thelyphonus has been described to some extent by Blanchard, and more recently by Tarnani. The ducts of the generative organs terminate, according to the latter observer, in the large uterus, which is found both in the male and female; he describes the walls of the uterus in the female as formed of elongated glandular epithelium, with a stronglydeveloped porous, chitinized intima. In the male, he says that the 
epithelium of the uterus masculimus and its processes is extraordinarily elongated, the chitin covering being thick. In these animals, then, the common chamber or uterus into which the genital ducts empty, which, like the corresponding chamber in the scorpion, occupies the middle region of the operculum, is a large and conspicuous organ. Further, and this is a most striking fact, the uterus masculinus does not open direct to the exterior, but into the genital cavity, "which lies above the uterus, so that the latter is situated between the lower wall of the genital cavity and the outer integument." The opening, therefore, of the uterus is not external but internal, into the large intemal space known as the genital cavity. The arrangement is shown in Fig. 91, taken from Tarnani's paper, which represents a diagrammatic sagittal section through the exit of the male genital duct. Yet another most striking fact is described by Tarnani. This genital cavity is continuous with the pulmonary or gill cavities on each side, so that instead of a single opening for the genital products and one on each side for each gill-pouch, as would

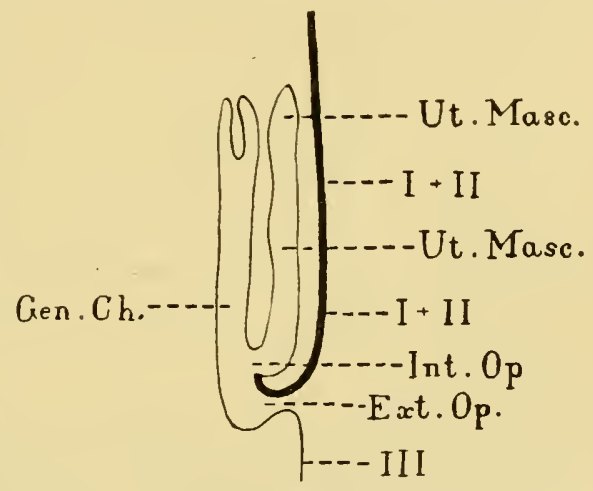

Fig. 91.-Sagittal Miedian Diagramiatic Section throdgh the Operculum OF the Male Thelyphonus. (From Tarnani.)

The thick line is the operculum, composed of two segments, I. and II. Ut. Masc., uterus masculinus; Gen. Ch., genital chamber; Int. Op., internal opening; Ext. Op., external opening common to the genital and respiratory organs. be the case if the arrangement

was of the same kind as in the scorpion, there is a single large chamber, the genital chamber, common to both respiratory and genital organs.

This genital chamber, according to Tarnani, opens to the exterior by a single median opening between the operculum and the succeeding segment; similarly, a communication from side to side exists between the second pair of gill-pouches. I have been able to examine Hypoctonus formosus and Thclyphonus caudatus, and in both cases, in both male and female, the opening to the exterior of the common chamber for respiration and for the genital products was 
not a single opening, as described by Tarnani in Thelyphonus asperutus, but on each side of the middle line, a round orifice closed by a lid, like the nest of the trapdoor spider, led into the common genital chamber (Gen. Ch.) into which both uterus and gills opened. In Fig. $77 \mathrm{l}$ have endeavoured to represent the arrangement of the genital and respiratory organs in the male Thelyphonus according to Tarnani's and my own observations.

If we may take Thelyphonns as a sample of the arrangement in those scorpions in which the operculum was fused with the first branchial appendage, among which must be included the old sea-scorpions, then it is most significant that their uterus should open internally into a cavity which was continuous with the respiratory cavity. Thus not only the structure of the gland, but also the arrangement of the internal opening into the respiratory, or, as it became later, the pharyngeal cavity, is in accordance with the suggestion that the thyroid of Ammocretes represents the uterus of the extinct Eurypterus-like ancestor.

Into this nterus the products of the generative organs were poured by means of the vasa deferentia, so that there was not a single median opening or duct in connection with it, but also two side openings, the termiuations of the vasa defcrentia. These are described by Tamani in Thelyphonus as opening into the two horns of the nterus, which thus shows its bilateral character, although the body of the organ is median and single; these ducts then pass within the hody of the animal, dorsal to the uterus, towards the testes or ovaries as the case may be, organs which are situated in these animals, as in other scorpions, in the abdomen, so that the direction of the ducts from the generative glands to the uterus is headwards. If, however, we examine the condition of affairs in Limnlus, we find that the main mass of the generative material is cephalic, forming with the liver that dense glandnlar mass which is packed round the supraresophageal and prosomatic ganglia, and round the stomach and muscles of the head-region. From this cephalic region the duct passes ont on each side at the junction of the prosomatic and mesosomatic carapace to open separately on the posterior surface of the operculum, near the middle line, as is indicated in Fig. 75.

We have, therefore, two distinct possible positions for the genital ducts among the group of extinct scorpion-like animals, the one from the cephalic region to the operculum, and the other from the abdominal region to the operculum. 


\section{'The Generative Glands of Limulus and its Alles.}

The whole argument, so far, has in every case ended with the conclusion that the original scorpion-like form with which I have been comparing Ammocetes resembled in many respects Limulus rather than the present-day scorpions, and therefore in the case also of the generative organs, with which the thyroid gland or palieohysteron was in connection, it is more probable that they were cephalic in position rather than abdominal. If this were so, then the duct on each side, starting from the median ventral uterus, would take a lateral and dorsal course to reach the huge mass of generative gland lying within the prosomatic carapace, just as I have represented in the figure of Eurypterus (Fig. 79), a course which would take much the same direction as the ciliated grouve in Ammocutes.

We ought, therefore, on this supposition, to expect to find the remains of the invertebrate generative tissue, the ducts of which terminated in the thyroid, in the head-region, and not in the abdomen.

Upon removal of the prosomatic carapace of Limulus, a large brownish glandular-looking mass is seen, in which, if it happens to be a female, masses of ova are very conspicuous. This mass is composed of two separate glands, the generative glauds and the hepaticopancreatic glands-the so-called liver-and surrounds closely the central nervous system and the alimentary canal. From the generative glands proceed the genital ducts to terminate on the posterior surface of the operculum. From the liver ducts pass to the pyloric end of the cephalic stomach, and carry the fluid by means of which the food is digested, for, in all these animals, the active digesting juices are formed in the so-called liver, and not in the cells of the stomach or intestine.

It is a very striking fact that the brain of Ammocetes is much too small for the brain-case, and that the space between brain and brain-case is filled up with a very peculiar glandular-looking tissue, which is found in Ammoceetes and not elsewhere. Further, it is also striking that in the brain of Ammocoetes there should still exist the remains of a tube extending from the $I V^{r}$ th ventricle to the surface at the conus post-commissurulis, which can actually be traced right into this tissue on the outside of the brain (see Fig. 13, a-e, I'l. XXVI, in my paper in the Quarterly Joumal of IFicroscopical Science). 
This, in my opinion, is the last remnant of one of the old liver-ducts which extended from the original stomach and intestine into the cephalic liver-mass. This glandular-looking material is shown surrounding the pineal eye and its nerve, in Fig. 31, also in Fig. 22, and separately in Fig. 92. It is composed of large cells, with a badly staining nucleus, closely packed together with lines of pigment here and there between the cells; this pigment is especially congregated at the spot where the so-called liver-duct loses itself in this tissue. The protoplasm in these large cells does not stain well, and with osmic acid gives no sign of fat, so that

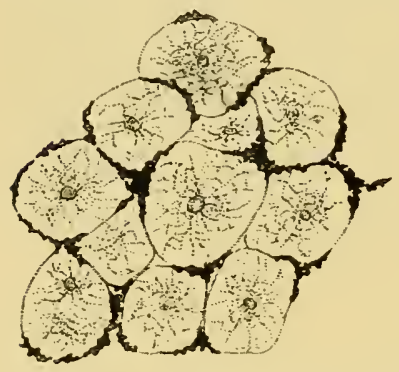

Fig. 92.-Drawing of the Tissue which surrounds the Brain of Ammocoetes. Ahlborn's description of this tissue as a peculiar arachnoideal fat-tissue is not true; peculiar it certainly is, but fatty it is not.

This tissue has been largely described as a peculiar kind of connective tissue, which is there as packing material, for the purpose of steadying a brain too small for its case. On the face of it such an explanation is unscientific; certainly for all those who really believe in evolution, it is out of the question to suppose that a brain-case has been laid down in the first instance too large for the brain, in order to provide room for a subsequent inerease of brain; just as it is out of the question to suppose that the nervous system was laid down originally as an epithelial tube in order to provide for the further development of the nervous system by the conversion of more and more of that tube into nervous matter. Yet this latter proposition has been seriously put forward by professed believers in evolution and in natural selection.

This tissue bears no resemblance whatever to any form of connective tissue, either fatty or otherwise. By every test this tissue tells as plainly as possible that it is a vestige of some former organ, presumably glanclular, which existed in that position; that it is not there as packing material because the brain liappened to be too small for its ease, but that, on the contrary, the brain is too small for its ease, because the case, when it was formel, included this organ as well as the brain; in other words, this tissne 
is there because it is the remuant of the great glandular mass which so closely surrounds the brain and alimentary canal in animals such as Limulus. In my paper in the Quarterly Journal of Mieroscopical Scionce, in which I was comparing the tube of the vertebrate nervous system with the alimentary canal of the invertelsrate, I spoke of this tissue as being the remnant of the invertebrate liver. At the same time the whole point of my argument was that the glandular material surrounding the brain of Limulus was made up of two glands--liver and generative gland-so that this tissue might be the remnant of either one or the other, or both. All I desired, at that time, was to point out the glandular appearance of this so-called packing tissue, which surrounded the brain-region of Ammocoetes, in connection with the fact that the brain and alimentary canal of Limulus were closely surrounded with a glandular mass composed partly of liver, partly of the generative gland. At present, I think these large cells found round the brain in Ammocoetes are much more likely to be the remnant of the generative gland than of the liver; the size of the cells and their arrangement recalls Owen's picture of the generative gland in Limulus, and seeing how important all generative glands are in their capacity of internal secreting glands, apart entirely from the extrusion of the ripe generative products, and how unimportant is an hepato-pancreas when the alimentary canal is closed, it is much more likely that of the two glands the former would persist longer than the latter. It may be that all that is left of the old hepatopancreas consists of the pigment so markedly found in between these cells, especially at the place where the old liver-duct reaches the surface of the brain; just as the only remnant of the two pineal eyes in the higher vertebrates is the remains of the pigment, known as braiu-sand, which still exists in the pineal gland of even the highest vertebrate. This, however, is a mere speculation of no importance. What is important is the recognition of this tissue round the brain as the remuant of the glandular mass round the brain of animals such as Limulus. Still further confirmation of the truth of this comparison will be given when the origin of the auditory organ comes up for discussion.

I conclude, therefore, from the evidence of Ammocœtes, that the generative glands in the ancestral form were sitnated largely in the cephalic region, and suggest that the course and direction of the ciliated pseudo-branchial grooves on each side indicate the direction of the 
original opereular duets by which the generative products were conveyed to the nterine chamber, i.e. to the chamber of the thyroid gland, and thence to the common genital and respiratory cavity, and so to the exterior.

It is easy to picture the sequence of events. First, the generative glands, chiefly confined to the cephalic region, communicating with the exterior by separate ducts on the inner surface of the opereulum as in Limulus. Then, in comnection with the viviparons habit, these two oviducts fused together to form a single ehamber, covered by the operculum, which opened out to the exterior by a single opening as in Scorpio: or, in forms such as Eurypterus, in which the opereulum had amalgamated with the first lranchial appendage and possessed a long, tongue-like ventral projection, the amalgamated duets formed a long nterine chamber which opened internally into the genital chamber-a chamber which, as in Thelyphonus, was common with that of the two gill-chambers, while at the same time the genital duets from the cephalic generative material opened into two uterine horns which arose from the anterior part of the uterus, as in Thelyphonus.

Such an arrangement would lead direetly to the condition found in Anmocotes, if the generative material around the brain lost its function, owing to a new exit for generative produets being formed in the posterior part of the body. The connection of the genital duet with this eephalic gland being then elosed and cut off by the braincase, the position of the oviduets would still be shown by the ciliated grooves opening into the folded-down thyroid tube, i.c. the foldeddown horns of the uterus; the uterus itself would remain as the main body of the thyroid and still open by a eonspicuous orifice into the common respiratory clamber. Next, in the degeneration process, we may suppose that not only the oviduets opened ont to form the eiliated groove, but that the uterine chamber itself also opened out, and thus formed the endostyle of Amphioxus and of the Tunieata.

It might seem at first sight improbable that a closed tube should beeome an open groove, although the reverse phenomenon is common enough; the difficulty, however, is clearly not considered great, for it is precisely what Dohrn imagines to have taken place in the eonversion of the thyroid of Ammocotes into the endostyle of Amphioxus and the Tunicata; it is only earrying on the same idea a stage further to see in the open, eiliated groove of Ammocates the remains of the elosed genital duct of Limulus and its allies. 
Such is the eonclusion to whieh the study of the thyroid gland in Ammoerctes seems to me to lead, and one eannot help wontering why such an unused and rudimentary organ should have remained after its original function had gone. Is it possible to find out its funetion in Ammocnetes?

\section{The Function of the Thyrotd Gland in Ammocetes.}

The thyroid gland has been supposed to secrete mneus into the respiratory chamber for the purpose of entangling the particles of food, and so aiding in digestion. I see no sign of any such function; neither by the thionin method, nor by any other test, have Miss Aleock and myself ever been able to see any trace of mucous secretion in the thyroid, and, incleed, the thyroid duct is always remarkably free from any sign of any secretion whatever. Not only is there no evidenee of any mucous seeretion in the thyroid of the fully developed Ammocretes, but also no necessity for such seeretion from Dohrn's point of view, for so eopious a supply of mueus is poured ont by the glands of the branchiæ, along the whole pharyngeal tract, especially from the cells of the foremost or hyoid gills, as to mix up with the food as thoroughly as can possibly be needed. Further, too, the ciliaterl pharyngeal bands described by Sichneider are amply sufficient to move this mixed mass along in the way required by Dohrn. Finally, the evidence given by Miss Alcock is absolutely against the view that the thyroid takes any part in the process of digestion, while, on the other hand, her evidence directly favours the view that these glandular branchial mucus-secreting cells play a most important part in the digestive process.

In Fig. 93, $\mathrm{A}$ is a representation of the respiratory tissue of a normal gill; $\mathrm{B}$ is the corresponding portion of the first or hyoid gill, in which, as is seen, the whole of the respiratory epithelium is converted into gland-tissue of the nature of mueous cells.

To sum up, the evidence is elear and conchusive that the Ammoeates possesses in its pharyngeal chamber muens-secreting glands, which take an aetive part in the digestive process, which do not in the least resemble either in structure or arrangement the remarkable cells of the thyroid gland, and that the experimental evidence that the latter eells either secrete mucus or take any part in digestion is so far absolutely negative. It is, of course, possible, that they 
may contain mucin in the younger developmental stages, and therefore possible that they might at that stage secrete it; they certainly, howerer, show no sign of doing so in their more adult condition, and cannot be compared in the very faintest ilegree to the glantular cells of the pharyngeal region. It is also perfectly possible for gland-cells belonging to a retrograde organ to become mucus-secreting, and so to

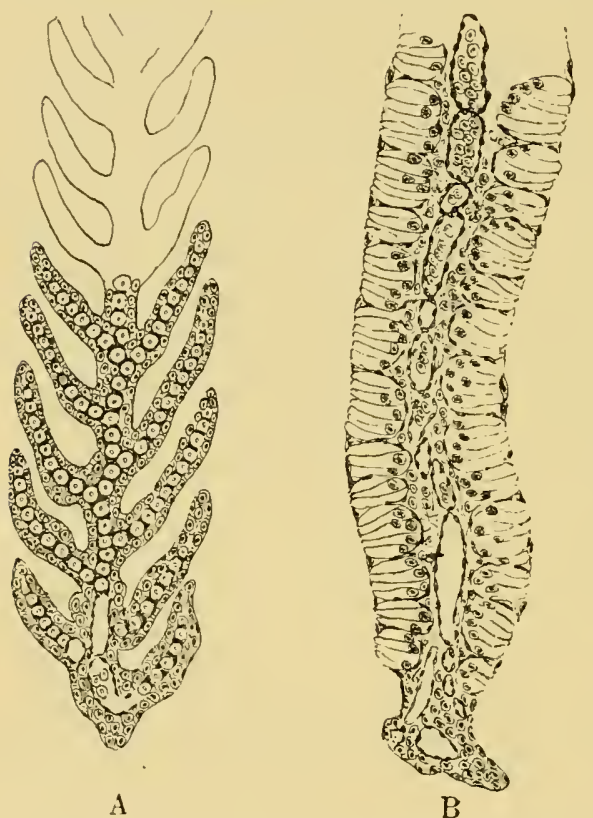

Fig. 93.-A, Portion of a Gill of AmyoCETES With ORDINARY Respiratory Epithelium; B, Corresponding Portion of the Finst on Hyoid GiLt. give rise to the cells of Amphioxus and the Tunicata.

If, then, these cells were not retained for digestive purposes, what was their function? To answer this question we must first know the function of the corresponding gland-cells in the uterus of the scorpion, which undoubtedly secreted into the cavity of the uterus and took some part in connection with the generative act, and certainly not with digestion. What the function of these cells is or in what way they act I am unable at present to say. I can only suppose that the reason why the thyroid gland has persisted throughout the vertebrate kingdom, after the generative tissues had found a new outlet for their products in the body-cavity of the posterior region, is because it possessed some important function in addition to that connected with the exit of the products of the generative organs; a function which was essential to the well-being, or even to the life of the animal. We do not know its function in the scorpion, or the nature of its secretion in that animal. We know only that physiology at the present day has demonstrated clearly that the actual external secretion of a gland may be by no means its most important function ; in addition, glands possess what is called an internal secretion, viz. a 
secretion into the blood and lymph, and this latter secretion may be of the most vital importance. Now, the striking fact forces itself prominently forward, that the thyroid gland of the higher vertebrates is the most conspicuous example of the importance of such internal secretion. Here, although ductless, we have a gland which cannot be removed without fatal consequences. Here, in the importance of its internal secretion, we have a reason for the continued existence of this organ; an organ which remains much the same throughout the Vertebrata down to and including Petromyzon, but, as is seen at transformation, is all that remains of the more elaborate, more extensive organ of Ammocotes. Surely we may argue that it is this second function which has led to the persistence of the thyroil, and that its original form, without its original function, is seen in Ammocretes, because that is a larval form, and not a fully-developed animal. As soon as the generative organs of Petromyzon are developed at transformation, all trace of its connection with a genital duct vanishes, and presumably its internal secretory function alone remains.

Yet, strange to say, a mysterious connection continues to exist between the thyroid gland and the generative organs, even up to the highest vertebrate. That the thyroid gland, situated as it is in the neck, should have any sympathy with sexual functions if it was originally a gland concerned with digestion is, to say the least of it, extremely unlikely, but, on the contrary, likely enough if it originated from a glandular organ in connection with the sexual organs of the palieostracan ancestor of the vertebrate.

Freund has shown, and shown conclusively, that there is an intimate connection between the condition of the thyroid gland and the state of the sexual organs, not only in human beings, but also in numerous animals, such as dogs, sheep, goats, pigs, and deer. He points out that the swelling of the gland, which occurs in consequence of sexual excitement (a fact mentioned both in folk-lore tales and in poetical literature), and also the swelling at the time of puberty, may both lead to a true goitrous enlargement; that most of the permanent goitres commence during a menstrual period; that during pregnancy swelling of the thyroid is almost universal, and may become so extreme as to threaten suffocation, or even cause death; that the period of puberty and the climacteric period are the two maximal periods for the onset of goitre, and that exophthalmic goitre especially is associated with a special discase connected with the uterus. 


\section{Sumary.}

Step by step in the preceding chapters the evidence is accumnlating in farour of the origin of rertebrates from a member of the palasstracan gromp. In a contimuously complete and harmonions manner the evidence has throughout been most convincing when the rertebrate chosen for the purpose of my arguments las been Ammocotes.

So many fixed points have been firmly established as to enable us to proceed further with very great confidence, in the full expectation of being able ultimately to lomologize the Vertehrata with the Palrostraca eren to minute details.

Perhaps the most striking and unexpected result of such a comparison is the discovery that the thyroid gland is derived from the nterus of the palrestracan ancestor. Yet so elear is the evidence that it is difficult to see low the loomology can be denied.

In the one animal (Palrestraca) the foremost pair of mesosomatic appendages forms the operculum. which always bears the terminal generative organs and is fused in the middle line. In many forms, essentially in Eurypterns and the ancient sea-scorpions, the operenlum was composed of two segments fused together: an anterior one which carried the nterus, and a posterior one which carried the first pair of branchire.

In the other animal (Ammocotes) the foremost segments of the mesosomatic or respiratory region, immediately in front of the glossopharyngeal segments. are supplied by the facial nerre, and are markedly different from those supplied by the vagus and glossopharyngeal. for the facial supplies two segments fused together: the anterior one, the thyroid segment, carrying the thyroid gland, the posterior one, the hyoid segment, carrying the first pair of branchia.

Just as in Eurypterus the fused segment, carrying the uterus on its internal surface, forms a long median tongme which separates the most anterior branchial segments on each side, so also the fused segment carrying the thyroid forms in Ammocotes a long median tongne, which separates the most anterior branchial segments on each side.

Finally, and this is the most conchnsive evidence of all, this thyroid gland of Ammocoetes is totally unlike that of any of the higher vertebrates, and. indeed, of the adult form Petromyzon itself, but it forms an elaborate complicated organ, which is directly comparable with the nterns and genital dncts of animals such as scorpions. Not only is such a comparison valid with respect to its shape, but also with respect to its structure, which is absolutely unique among vertehrates. and very different to that of any other rertebrate gland. but resembles in a striking manner a glandnlar structure found in the uterus. both of male and female scorpions.

The generative glands in Limulus, tugether with the liver-glands, form a large glandular mass, sitnated in the head-region closely surrounding the central nerrous system, so that the genital ducts pass from the head-region tailwards to the operenlnm. In the scorpion they lie in the abdominal region, so that their ducts pass headwards to the opereulnm.

Probably in the Palrestraca the generative mass was situated in the cephalie region as in Limuhs, and it is probable that the remnant of it still exists in 
Ammocotes in the shape of the peculiar large cells packed together. with pigment masses in between them, which form such a characteristic feature of the glandular-looking material. which fills up the space between the cranial walls and the central nerrous system.

Finally, the relationship which has been known from time immemorial to exist between the sexual organs and the thyroid in man and other animals. and has hitherto been a mystery without any explanation, may possibly be the last reminiscence of a time when the thyroid glands were the nterine glands of the paleostracan ancestor.

The consideration of the facial nerve, and the segments it supplies, still further points to the origin of the Vertebrata from the Palrestraca. 


\section{CHAPTER VI}

\section{THE EVIDENCE OF THE OLFACTORY APPARATUS}

Fishes divided into Amphirhinæ and Monorhinæ.-Nasal tube of the lamprey. - Its termination at the infundibulum.-The olfactory organs of the scorpion group.-The camerostome.-Its formation as a tube.-Its derivation from a pair of antemr.- Its termination at the true mouth.-Comparison with the olfactory tube of Ammocotes.-Origin of the nasal tube of Ammocotes from the tube of the hypophysis.-Direct comparison of the hypopliysial tube with the olfactory tube of the scorpion group-Summary.

IN the last chapter I finished the evidence given by the consideration of the mesosomatic or opisthotic nerves, and the segments they supplied. The evidence is strongly in accordance with that of previous chapters, and not only confirms the conclusion that vertebrates arose from some member of the Palæostraca, but helps still further to delimit the nature of that member. It is almost startling to see how the hypothesis put forward in the second chapter, suggested by the consideration of the nature of the vertebrate central nervous system and of the geological record, has received stronger and stronger confirmation from the consideration of the vertebrate optic apparatus, the vertebrate skeleton, the respiratory apparatus, and, finally, the thyroid gland. All fit naturally into a harmonious whole, and give a feeling of confidence that a similar harmony will be found upon consideration of the rest of the vertebrate organs.

Following naturally upon the segments supplied by the opisthotic (mesosomatic) cranial nerves, we ought to consider now the segments supplied by the pro-otic (prosomatic) cranial nerves, i.e. the segments belonging to the trigeminal nerve-group in the vertebrate, and in the invertebrate the segments of the prosoma with their characteristic appendages. There are, however, in all vertebrates in this foremost cranial region, in addition to the optic nerves, two other well-marked nerves of special sense, the olfactory and the anditory. Of these, the former are in the same class as the optic nerves, for they arise 
in the vertebrate from the supra-infundibular nerve-mass, and in the invertebrate from the supra-cesophageal ganglia. The latter arise in the vertebrate from the infra-infundibular nerve-mass, and, as the name implies, are situated in the region where the pro-otic nerves are contiguous to the opisthotic, i.c. at the junction of the prosomatic and mesosomatic nerve-regions.

The chapter dealing with the evidence given by the olfactory nerves and the olfactory apparatus ought logically to have followed immediately upon the one dealing with the optic apparatus, seeing that both these special sense-nerves belong to the supra-infundibular segments in the vertebrate and to the supra-csophageal in the invertebrate.

I did not deal with them in that logical sequence because it was necessary for their understanding to introduce first the conception of modified appendages as important factors in any consideration of vertebrate segments; a conception which followed naturally after the evidence afforded by the skeleton in Chapter III., and by the branchial segments in Chapter IV. So, too, now, although the discussion of the prosomatic segmentation ought logically to follow immediately on that of the mesosomatic segmentation, I have determined to devote this chapter to the evidence of the olfactory organs, because the arguments as to the segments belonging to the trigeminal nervegroup are so much easier to understand if the position of the olfactory apparatus is first made clear.

In all vertebrates the nose is double and opens into the pharynx, until we descend to the fishes, where the whole group Pisces has been divided into two subsidiary groups, Monorhinæ and Amphirhine, according as they possess a median unpaired olfactory opening, or a paired opening. The Monorhinæ include only the Cyclostomata-the lampreys and hag-fishes.

In the lampreys the single olfactory tube ends blindly, while in the hag-fishes it opens into the pharynx. In the lamprey, both in Petromyzon and Ammocoetes, the opening of this nasal tube is a conspicuous object on the dorsal surface of the head in front of the transparent spot which indicates the position of the right median eye. It is especially significant, as showing the primitive nature of this median olfactory passage, that a perfectly similar opening in the 
same position is always found in the dorsal head-shields of all the Cephalaspide and Tremataspide, as will be explained more fully in Chapter X.

All the evidence points to the conclusion that the olfactory apparatus of the vertebrate originated as a single median tube, containing the special olfactory sense-epithelinm, which, although median and single, was innervated by the olfactory nerve of each side. The external opening of this tube in the lamprey is dorsal. How does it terminate ventrally?

The ventral termination of this tube is most instructive and suggestive. It terminates blindly at the very spot where the infundibular tube terminates blindly and the notochord ends. After transformation, when the Ammocnete becomes the Petromyzon, the tube still ends blindly, and does not open into the pharynx as in Myxine; it, however, no longer terminates at the infundibulum, but extends beyond it towards the pharynx.

This position of the nasal tube suggests that it may originally have opened into the tube of the central nervous system by way of the infundibular tube. This suggestion is greatly enhanced in value by the fact that in the larval Amphioxus the tube of the central nervous system is open to the exterior, its opening being known as the anterior neuropore, and this anterior neuropore is situated at the base of a pit, known as the olfactory pit hecause it is supposed to represent the olfactory organ of other fishes.

Following the same lines of argument as in previous chapters, this suggestion indicates that the special olfactory organs of the invertebrate ancestor of the vertebrates consisted of a single median olfactory tube or passage, which led directly into the cesophagus and was imnervated, though single and median, by a pair of olfactory nerves which arose from the supra-resophageal ganglia. Let us see what is the nature of the olfactory organs among arthroporls, and whether such a suggestion possesses any probability.

\section{The Olfactory Organs of the Scorpion Group.}

At first sight the answer appears to be distinctly adverse, for it is well known that in all the Insecta, Crustacea, and the large majority of Arthropoda, the first pair of antenux, often called the antennules, are olfactory in function, and these are free-moving, bilaterally 
situated, independent appendages. Still, even here there is the striking fact that the nerves of these olfactory organs always arise from the supra-cesophageal ganglia, although those to the second pair of antennie arise from the infra-cesophageal ganglia, just as the olfactory nerves of the vertebrate arise from the supra-infundibular brain-mass. Not only is there this similarity of position, but also a similarity of structure in the olfactive lobes of the brain itself of so striking a character as to cause Bellonci to sum up his investigations as follows:-

"The structure and connections of the olfactive lobes present the same fundamental plan in the higher arthropods and in the vertebrates. In the one, as in the other, the olfactory fibres form, with the connecting fibres of the olfactory lobes, a fine meshwork, which, consisting as it does of separate groups, may each one be called an olfactory glomerulus."

He attributes this remarkable resemblance to, a physiological necessity that similarity of function necessitates similarity of structure, for he considers it out of the question to suppose any near relationship between arthropods and vertebrates.

Truly an interesting remark, with the one fallacy that relationship is out of the question.

The evidence so far has consistently pointed to some member of the palieostracan groul as the ancestor of the vertebrates-a group which had affinities both to the crustaceans and the arachnids; indeed, many of its members resembled scorpions much more than they resemble crustaceans. The olfactory organs of the scorpions and their allies are, therefore, more likely than any others to give a clue to the position of the desired olfactory organs. In these animals and their allies paired olfactory antennæ are not present, either in the living land-forms or the extinct sea-scorpions, for all the antennæ-like, frequently chelate, appendages seen in Pterygotus, etc. (Fig. 8), represent the chelicere, and correspond, therefore, to the second pair of antenne in the crustaceans.

What, then, represents the olfactory antenne in the scorpions? The answer to this question has been given by Croneberg, and very striking it is. The two olfactory antenne of the crustacean have combined together to form a hollow tube at the base of which the mouth of the animal is situated, so that the food passes along this olfactory passage before it reaches the mouth. This organ is often called after Latreille, the camerostome, sometimes the rostrum; it is natually median in position and appears, therefore, to be an unpaired organ; its paired 
character is, of course, evident enough, for it is innervated by a pair of nerves, and these nerves, as ought to be the case, arise from the supracesophageal ganglia. In Galeodes it is a conspicuously paired anteunælike organ (Fig. 94).

Croneberg has also shown that this rostrum, or camerostome, arises embryologically as a pair of appentages similar to the other append-

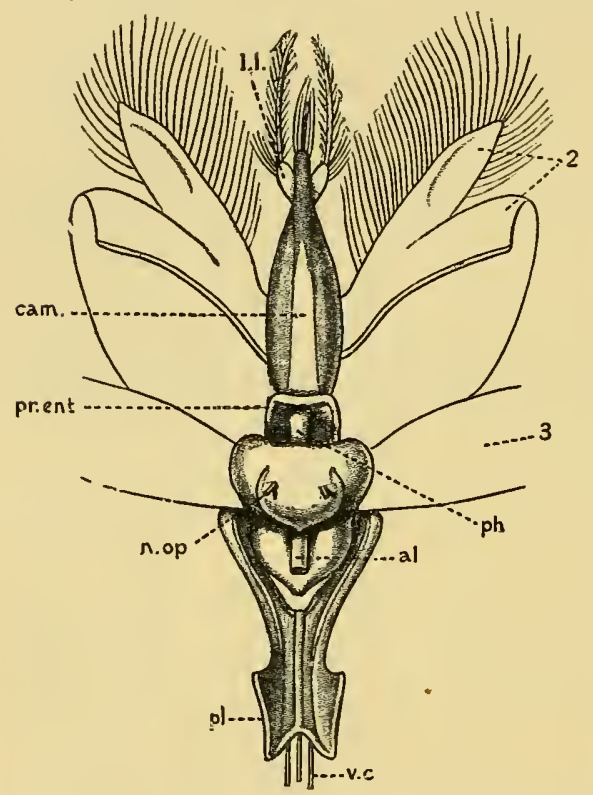

Fig. 94.-Dorsal View of Brain and Canerostome OF GALEODES.

cam., camerostome; $p r$. ent., pre-oral entosclerite; l.l., dependent portion of camerostome; $p h .$, pharynx; al., alimentary canal; $n$. op., median optic nerves; $p l$., plastron; v.c., ventral nerve chain; 2,3 , second and third appendages. ages. This last observation of Croneberg has been confirmed by Brauer in 1894, who describes the origin of the upper lip, as he calls it, in very similar terms, without, however, referring to Croneberg's paper. Croneberg further shows that this foremost pair of antennæ not only forms the so-called upper lip or camerostome, but also a lower lip, for from the basal part of the camerostome there projects on each side of the pharynx a dependent accessory portion, which in some cases fuses in the middle line, and forms, as it were, a lower lip. The entosclerite belonging to this dependent portion is apparently the post-oral entosclerite of Lankester and Miss Beck.

At the base of the tubular passage formed by this modified first pair of antennæ the true mouth is found opening directly into the dilated pharynx, the muscles of which enable the act of suction to be carried out. The narrow cesophagus leads out from the pharynx and is completely surrounded by the supra- and infra-cosophageal nerve masses.

Huxley also describes the mouth of the scorpion in precisely the same position ( $c f . o$, Fig. 96). 
In order to convey to my readers the antennæ-like character of the cannerostome in Galeodes (Fig. 101), and its position, I give a figure (Fig. 94) of the organ from its dorsal aspect, after removal of the cheliceræ and their muscles. A side view of the same organ is given in Fig. 95 to show the feathered termination of the camerostome, and the position of the dependent accessory portion (l.l.) (Croneberg's 'untere Anhang') with its single long antenna-like feather. In both figures the alimentary canal $(a l$.) is seen issuing from the conjoined supra- and infra-cesophageal mass.

As is seen in the figures, the bilateral character of the rostrum, as Croncberg calls it, is apparent not only in its feathered extremity but also in its chitinous covering, the softer median dorsal part (left

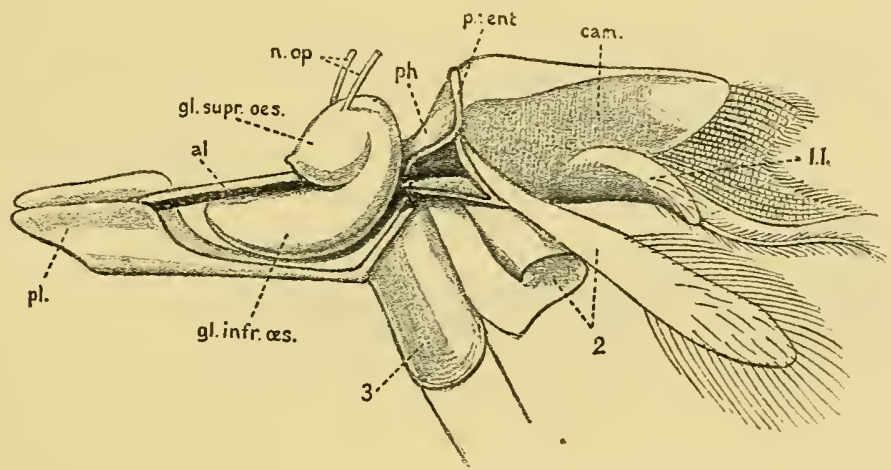

Fig. 95.--Lateral View of Brain and Canerostome of Galeodes.

gl. supr. œs., supra-œsophageal ganglion; gl. infr. ces., infra-cesophageal ganglion. The rest of the lettering same as in Fig. 94 .

white in figure) being bounded by two lateral plates of hard chitin, which meet in the iniddle line near the extremity of the organ. In all the members of the scorpion group, as is clearly shown in Croneberg's figures, the rostrum or' camerostome is built up on the same plan as in Galeodes, though the antenna-like character may not be so evident.

When we consider that the first pair of antennæ in the crustaceans are olfactory in function, Croneberg's observations amount to this-

In the arachnids and their allies the first pair of antemnæ form a pre-oral passage or tube, olfactory in function; the snall mouth, which opens directly into the pharynx, being situated at the end of this olfactory passage. 
Cronebery's olservations and conclusions are distinctly of very great importance in bringing the arachnids into line with the crustaceans, and it is therefore most surprising that they are absolntely ignored by Lankester and Miss Beck in their paper published in 1883, in which Latreille only is mentioned with respect to this organ, and his term "camerostome," or upper lip, is used throughont, in accordance with the terminology in Lankester's previous paper. That this organ is not only a movable lip or tongue, but essentially a sense-organ, almost certainly of smell and taste, as follows from Croneberg's conclusions, is shown by the series of sections whieh I have made through a number of young Thelyphonus (Fig. 102).

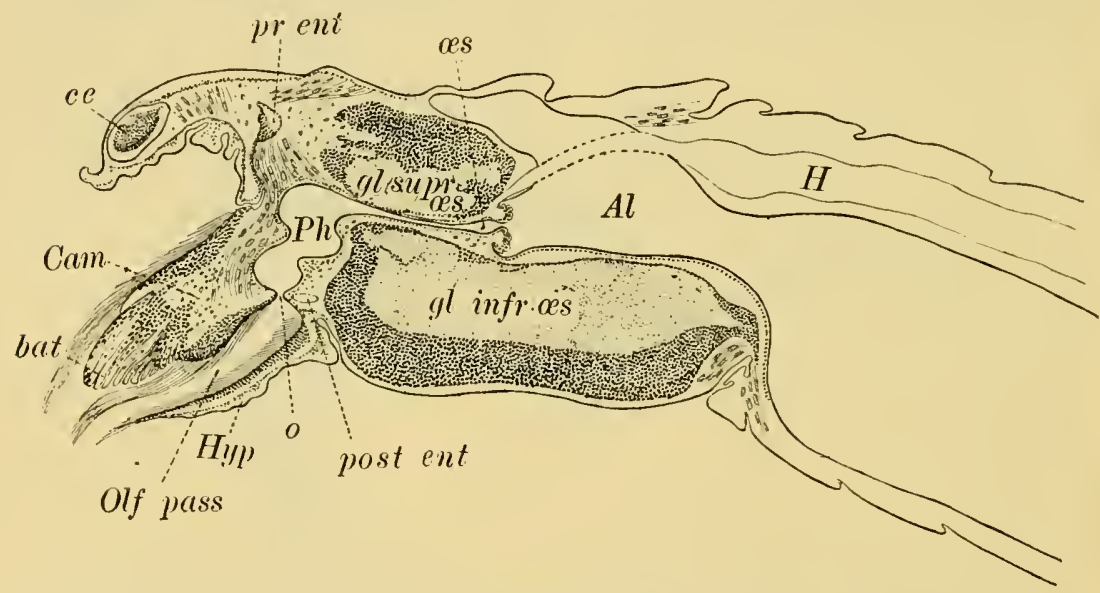

Fig. 96.-Miedian Sagittal Section throvgh a Young Thelyphones.

I give in Fig. 96 a sagittal nedian section throngh the head-end of the animal, which shows clearly the nature of Croneberg's conception. At the front end of the body is seen the median eye (cc.), 0 is the mouth, Ph. the pharyux, ces. the narrow cesophagus, compressed between the supra-œesophageal (supr. ces.) and infra-cesophageal (infr. css.) brain mass, which opens into the large alimentary canal (Al.); Olf. pass. is the olfactory passage to the mouth, lined with thick-set, very fine hairs, which spring from the hypostome (Hyp.) as well as from the large conspicuous camerostome $(\mathrm{Cam}$.), which limits this tube anteriorly. The space between the camerostome and the median eye is filled up by the massive chelicerce, which are not shown in this section, as they begin to appear in the 
sections on each side of the median one. The muscles of the pharynx and the muscles of the camerostome are attached to the pre-oral entosclerite ( $m$ r. cnt.). The post-oral entosclerite is shown in section as post. ent. The dorsal blood-ressel, or heart, is indicated at $I$.

In Fig. 97 I give a transverse section through another specimen of the same litter, to show the nature of this olfactory tube when cut across. Both sections show most clearly that we are dealing here with an elaborate sense-organ, the surface of which is partly covered with very fine long hairs, partly, as is secn in the figure, is composed of long, separate, closely-set sense-rods (bat.), well protected by the long hairs which project on every side in front of them, which recall to mind Bellonci's figure of the 'batomnets olfactives' on the antennæ of Sphæroma. Finally, we have the observation of Blanchard quoted by Huxley, to the effect that this camerostome is innervated by nerves from the supra-œesophageal ganglia which are clearly bilateral, seeing that they arise from the ganglion on each side and then unite to pass into the camerostome ; in other words, paired olfactory nerves from the supra-œsophageal ganglia.

These facts demonstrate with wonderful clearness that in one group of the Arthropoda the olfactory antenne have been so modified as to form an olfactory tube or passage, which leals directly into the mouth and so to the osophagus of the animal, and, strikingly cnough, this group, the Arachnida, is the very one to which the scorpions belong.

If for any cause the month o in Fig. 96 were to be closed, then the olfactory tube (olf. pass.) might still remain, owing to its importance as the organ of smell, and the olfactory tube would terminate blindly at the very spot where the corresponding tube does terminate in the vertebrate, according to the theory put forward in this book.

\section{The Olfactori Tube of Amocetes.}

In all cases where there is similarity of topographical position in the organs of the vertebrate and arthropod we may expect also to find similarity of structure. At first sight it would appear as though such similarity fails us here, for a cross-section of the olfactory tube in Petromyzon represents an elaborate organ such as is shown in Fig. 98 , very different in appearance to the section across the olfactory passage of a young Thelyphonus given in Fig. 97. 


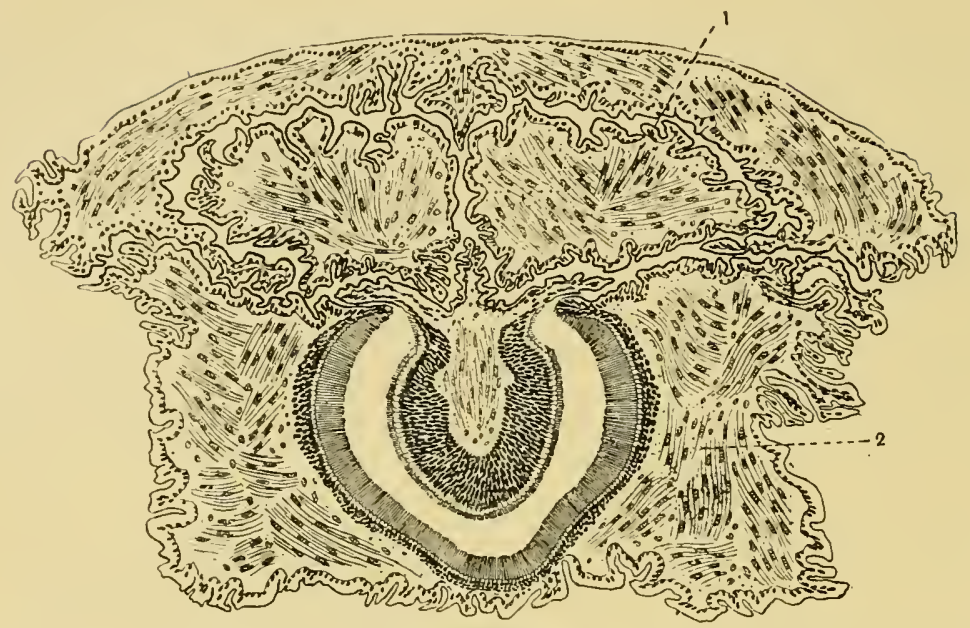

Fig, 97.-Transterse Sfction throvgh the Olfactom Passage of a Young THELYPHONUS.

1 and 2, sections of first and second appendages.

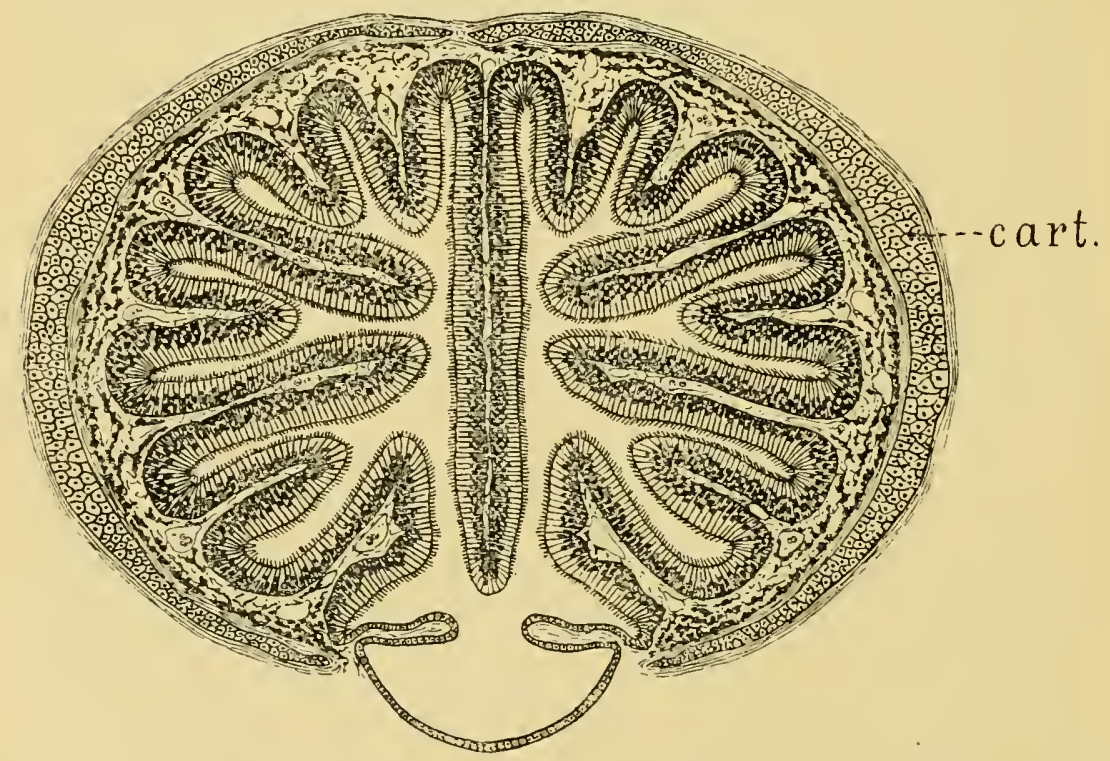

Fig. 98.-Transverse Section throlgh the Olfactory Passage of Petronyzon. cart., nasal cartilage. 
As is seen, it is difficult to see any connection between these folds of olfactory epithelium and the simple tube of the scorpion. But in the nose, as in all other parts of the head-region of the lamprey, remarkable changes take place at transformation, and examination of the same tube in Ammocotes demonstrates that the elaborate structure of the adult olfactory organ is actually derived from a much simpler form of organ, represented in Fig. 99. Here, in Ammocetes, the section is no longer strikingly different from that of the Thelyphonus organ, but, instead, most strikingly similar to it. Thus, again, it is shown that this larval form of the lamprey gives

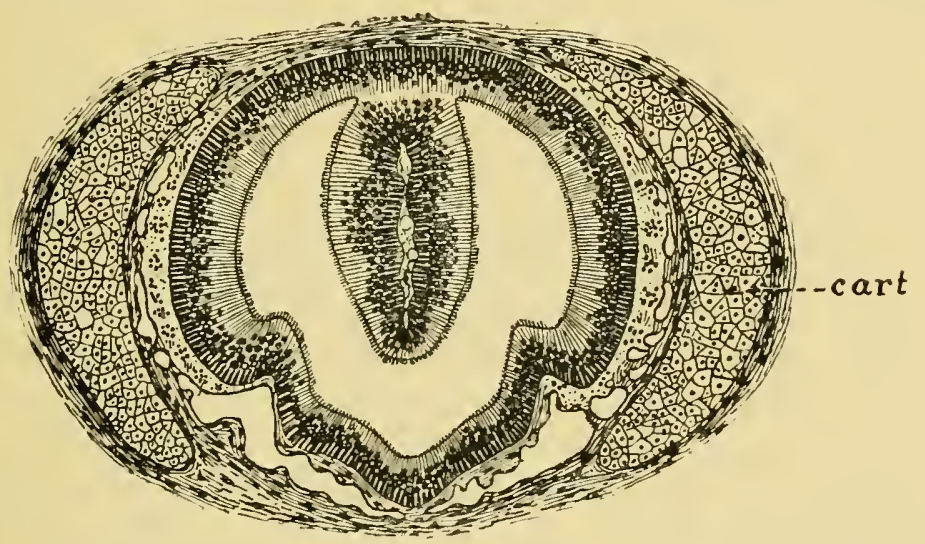

Fig. 99.-Transverse Section through the Olfactory Passage of Ammocetes. cart., nasal cartilage.

more valuable information as to vertebrate ancestry than all the rest of the vertebrates put together.

Still, even now the similarity between the two organs is not complete, for the tube in the lamprey opens on to the exterior on the dorsal surface of the head, while in the scorpion tribe it is situated ventrally, being the passage to the mouth and alimentary canal. In accordance with this there is no sign of any opening on the dorsal carapace of any of the extinct sea-scorpions or of the living landscorpions, such as is so universally found in the cephalaspids, tremataspids, and lampreys. Here is a cliscrepancy of an apparently serious character, yet so wonderfully does the development of the individual recapitulate the development of the race, that this very discrepancy becomes converted into a triumphant vindication of the 
correctness of the theory advocated in this book, as soon as we turn our attention to the development of this nasal tube in the lamprey.

We must always remember not only the great importance of a larval stage for the unriddling of problems of ancestry, but also the great advantage of being able to follow more favourably any clues as to past history afforded by the development of the larva itself, owing to the greater slowness in the development of the larva than of the embryo. Such a clue is especially well marked in the course of development of Ammocœtes according to Kupfer's researches, for he finds that when the young Ammocoetes is from 5 to $7 \mathrm{~mm}$. in length, some time after it has left the egg, when it is living a free larval life, a remarkable series of changes takes place with considerable rapidity, so that we may regard the transformation which takes place at this stage, as in some degree comparable with the great transformation which occurs when the Ammocœtes becomes a Petromyzon.

All the evidence emphasizes the fact that the latter transformation indicates the passage from a lower into a higher form of vertebrate, and is to be interpreted phylogenetically as an indication of the passage from the Cephalaspidian towards the Dipnoan style of fish. If, then, the former transformation is of the same character, it would indicate the passage from the Palieostracan to the Cephalaspid.

What is the nature of this transformation process as described by Kupffer?

It is characterized by two most important events. In the first place, up to this time the oral chamber has been cut off from the respiratory chamber by a septum-the rehum-so that no food could pass from the mouth to the alimentary canal. At this stage the septum is broken through, the oral chamber commmicates with the respiratory chamber, and the velar folds of the more adult Ammocotes are left as the remains of the original septum. The other striking change is the growth of the upper lip, by which the orifice of the nasal tube is transferred from a ventral to a dorsal position. Fig. 100, taken from Kupfer's paper, represents a sagittal section through an Ammocotes $4 \mathrm{~mm}$. long; l.l. is the lower lip, u.l. the upper lip, and, as is seen, the short oral chamber is closed by the septum, $r e l$. Opening ventrally is a tube called the tube of the hypophysis, $H y$., which extends close up to the termination of the infundibulum. On the anterior surface of this tube is the projection called by Kupfier the olfactory plakode. At this stage the npper lip grows witl great 
rapidity and thickens considerably, thus forcing the opening of the hypophysial tube more and more dorsalwards, until at last, in the fullgrown Ammocotes, it becomes the dorsal opening of the nasal tube, as already described. Here, then, in the hypophysial tube we have the original position of the olfactory tube of the vertebrate ancestor, and it is significant, as showing the importance of this organ, to find that such a hypophysial tube is characteristic of the embryological development of every vertebrate, whatever may be the ultimate form of the external nasal orifices.

The single median position of the olfactory organ in the Cyclostomata, in contradistinction to its paired character in the rest of the

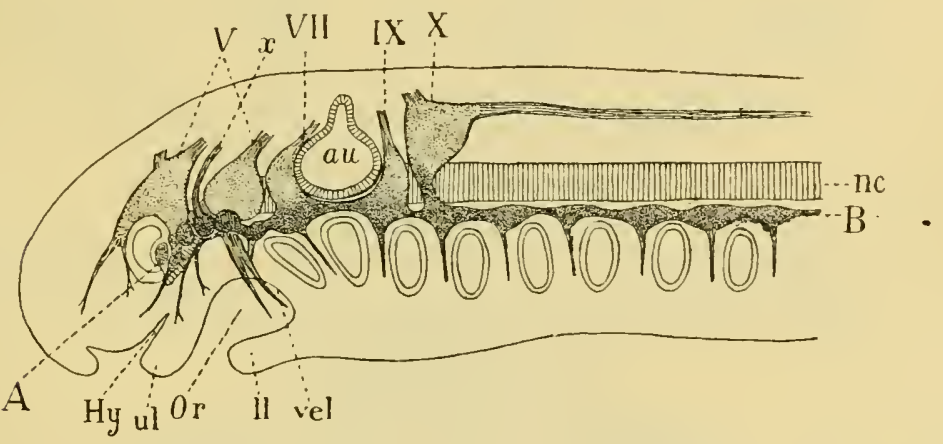

Fig. 100.-Ganglia of the Cranial Nerves of an Ammocetes, 4 ma. in length, projected on to the Median Plane. (After Kupfier.)

$A-B$, the line of epibranchial ganglia; au., auditory capsule; nc., notochord; Hy., tube of hypophysis ; Or., oral cavity ; u.l., upper lip ; l.l. lower lip; vel., septum between oral and respiratory cavities; $\mathrm{I}$., VII., $I X$., X., cranial nerves; $x$., nerve with four epibranchial ganglia.

rertebrates, has always been a stumbling-block in the way of those who desired to consider the Cyclostomata as degenerated Selachians, for the origin of the olfactory protuberance, as a single median plakode, seemed to indicate that the nose arose as a single organ and not as a paired organ.

On the other hand, the two olfactory nerves of Ammoccetes compare absolutely with the olfactory norves of other vertebrates, and force one to the conclusion that this median organ of Ammocoetes arose from a pair of bilateral urgans, which have fused in the middle line.

The comparison of this olfactory organ with the camerostome 


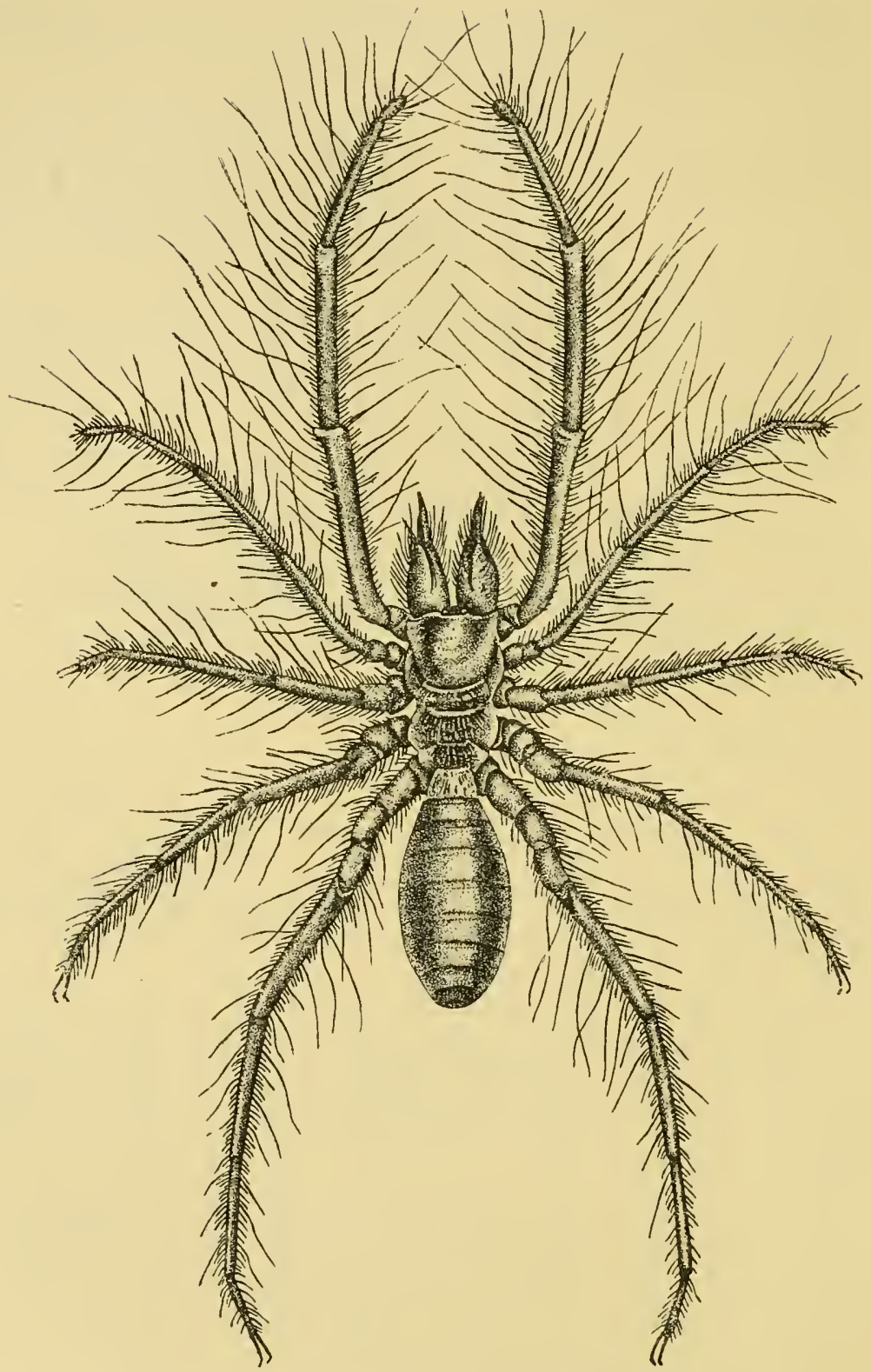

Fic, 101.-Galeodes. (From the Royal Natural History.) 
gives a satisfactory reason for its appearance in the lowest rertebrates as an unpaired median organ; equally so, the history of the camerostome itself supplies the reason why the olfactory nerves are double, why the organ is in reality a paired organ and not a single

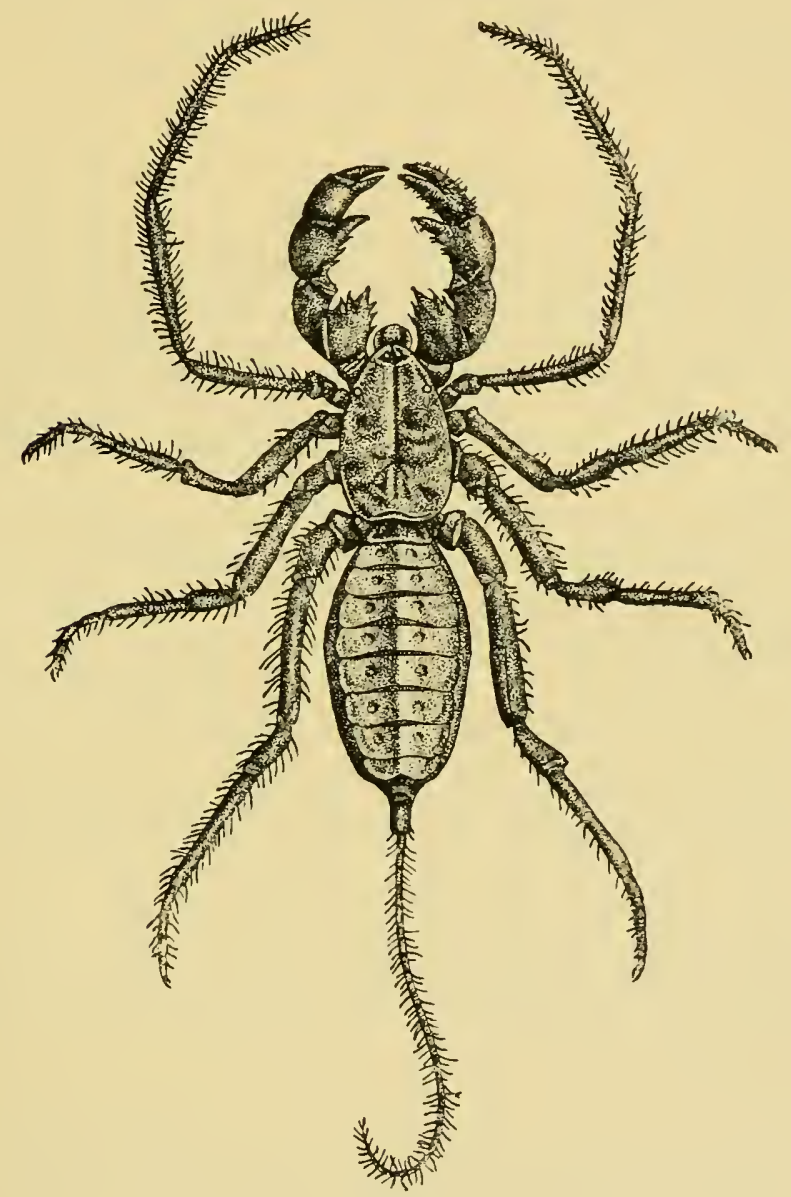

FIG. 102.-Thelyphonus. (From the Royal Natural History.)

median one. Thus, in a sense, the grouping of the fishes into Monorhinæ and Amphirhinæ has not much meaning, seeing that the olfactory organ is in all cases double.

The evidence of the olfactory organs in the vertebrate not only confirms, in a most striking manner, the theory of the origin of the 
vertebrate from the Palæostracan, but points indubitably to an origin from a scor]ion-like rather than a crustacean-like stock. To complete the evidence, it ought to be shown that the ancient sea-scorpions did possess an olfactory passage similar to the modern land-scorpions. The evidence on this question will come best in the next chapter, where I propose to deal with the prosomatic appendages of the Palieostracan group.

\section{SUMMARY.}

The vertebrate olfactory apparatus commences as a single median tube which terminates dorsally in the lamprey. and is supplied by the two olfactory nerves which arise from the supra-infundibular portion of the brain. It is a long, tapering tube which passes ventrally and terminates blindly at the infundibulum in Ammocotes. The dorsal position of the nasal opening is not the original one, but is brought abont by the growth of the npper lip. The nasal tube originally opened rentrally, and was at that period of derelopment known as the tube of the hypophysis.

The evidence of Ammocotes thus goes to show that the olfactory apparatus started as an olfactory tube on the rentral side of the animal, which led directly up to, and probably into. the ossopliagus of the original alimentary canal of the palrostracan ancestor.

Strikingly enough, although in the crustaceans the first pair of antenna form the olfactory organs, no such free antenne are found in the arachnids, but they have amalgamated to form a tube or olfactory passage, which leads directly into the month and cosophagus of the animal.

This olfactory passage is very conspicuous in all members of the scorpion group, and, like the olfactory tube of the rertebrate, is innervated by a pair of nerves, which resemble those supplying the first pair of antennæ in crustaceans as to their origin from the supra-cesophageal ganglia.

This nasal passage. or tube of the hypoplyssis, corresponds in structure and in position most closely with the olfactory tube of the scorpion group, the only difference being that in the latter case it opens directly into the osophagns. while in the former, owing to the closure of the old mouth, it camnot open into the infundibulum.

The evidence of the olfactory apparatus, combined with that of the optic apparatus, is most interesting. for, whereas the former points indubitably to an ancestor having scorpion-like affinities, the structure of the lateral eyes points distinctly to crustacean, as well as arachuid, affinities.

Taking the two together the evidence is extraordinarily strong that the rertebrate arose from a member of the palreostracan group with marked scorpion-like affinities. 


\section{CHAPTER VII}

THE PROSOMATIC SEGMENTS OF LIMULUS AND ITS ALLIES

Comparison of the trigeminal with the prosomatic region.--The prosomatic appendages of the Gigantostraca.-Their number and nature.--Endognaths and ectognath.-The metastoma.--The coxal glands.-Prosomatic region of Eurypterus compared with that of Ammocotes.-Prosomatic segmentation shown by muscular markings on carapace.-Eridence of colomic carities in Limulus.-Summary.

The derivation of the olfactory organs of the vertebrate from the olfactory antennæ of the arthropod in the last chapter is confirmatory proof of the soundness of the proposition put forward in Chapter IV., that the segmentation in the cranial region of the vertebrate was derived from that of the prosomatic and mesosomatic regions of the palrostracan ancestor. Such a segmentation implies a definite series of body-segments, corresponding to the mesomeric seginentation of the vertebrate, and a definite series of appendages corresponding to the splanchnic segmentation of the vertebrate.

Of the foremost segments belonging to the supra-cesophageal region characterized by the presence of the median eyes, of the lateral eyes, and of the olfactory organs, a wonderfully exact replica has been shown to exist in the pineal eyes, the lateral eyes, and the olfactory organ of the vertebrate, belonging, as they all do, to the supra-infundibular region.

Of the infra-cesophageal segments belonging to the prosoma and mesosoma respectively, the correspondence between the mesosomatic segments carrying the branchial appendages and the uterus, with those in the vertebrate carrying the branchix and the thyroid gland respectively, has been fully proved in previous chapters.

There remain, then, only the segments of the prosomatic region to be considered, a region which, both in the vertebrate and invertebrate, is never respiratory in function but always masticatory, such 
mastication being performed in Limulus and its allies by the muscles which move the foot-jaws or gnathites, which are portions of the prosomatic appendages specially modified for that purpose, and in the vertebrates by the masticatory muscles, which are always innervated by the trigeminal or Vth cranial nerve. This comparison implies that the motor part of the trigeminal nerve originally supplied the prosomatic appendages.

The investigations of van Wijhe and of all observers since the publication of his paper prove that in this trigeminal region, as in the vagus region, a double segmentation exists, of which the ventral or splanchnic segments, corresponding to the appendages in the invertebrate, are supplied by the trigeminal nerves, while the dorsal or somatic segments, corresponding to the somatic segments in the invertebrate, are supplied by the IIIrd or oculomotor and the IVth or trochlear nerves-nerves which supply muscles moving the lateral eyes.

In accordance, then, with the evidence afforded by the nerves of the branchial segments, it follows that the muscles supplied by the motor part of the trigeminal ought originally to have moved the appendages belonging to a series of prosomatic segments. On the other hand, the eye-muscles ought to have belonger to the body-part of the prosomatic segments, and must therefore have been grouped originally in a segmental series correspouding to the prosomatic appendages.

The evidence for and against this conchusion will be the subject of consideration in this and the succeeding chapters. At the outset it is evident that any such comparison necessitates an accurate knowledge of the number of the prosomatic segments in the Gigantostraca and of the nature of the corresponding appendages.

In all this group of animals, the evidence as to the number of segments in either the prosomatic or mesosomatic regions is given by -

1. The number of appendages.

2. The segmental arrangement of the muscles of the prosoma or mesosoma respectively.

3. The segmental arrangement of the colomic or head-cavities.

4. The divisions of the central nervous system, or neuromeres, together with their outgoing segmental nerves.

It follows, therefore, that if from any cause the appendages are not apparent, as is the case in many fossil remains, or have divindled 
away and become insignificant, we still have the muscular, ccelomic, and nervous arrangements left to us as evidence of segmentation in these animals, just as in vertebrates.

In this prosomatic region, we find in Limulus the same tripartite division of the nerves as in the mesosomatic region, so that the nerves to each segment may be classed as (1) appendage-nerve; (2) sensory or dorsal somatic nerve, supplying the prosomatic carapace; (3) motor or ventral somatic nerve, supplying the muscles of the prosoma, and containing possibly some sensory fibres. The main difference between these two regions in Limulus consists in the closer aggregation of the prosomatic nerves, corresponding to the concentration of the separate ganglia of origin in the prosomatic region of the brain.

The number of prosomatic segments in Limulus is not evident by examination of the prosomatic carapace, so that the most reliable guide to the segmentation of this region is given by the appendages, of which one pair corresponds to each prosomatic segment.

The number of sucl segments, according to present opinion, is seven, viz. :-

(1) The foremost segment, which bears the cheliceræ.

$(2,3,4,5,6)$ The next five segments, which carry the paired locomotor appendages; and

(7) The last segment, to which belongs a sinall abortive pair of appendages, known by the name of the chilaria, situated between the last pair of locomotor appendages and the operculum or first pair of mesosomatic appendages. These appendages are numbered from 1-7 in the accompanying drawing (Fig. 103).

Of these seven pairs of appendages, the significance of the first and the last has been matter of dispute. With respect to the first pair, or the cheliceræ, the question has arisen whether their nerves belong to the infra-aesophageal group, or are in reality supraresophageal.

It is instructive to observe the nature and the anterior position of this pair of appendages in the allied sea-scorpions, especially in Pterygotus, where the only chelate organs are found in these long, antennælike cheliceræ. In Slimonia and in Stylonurus they are supposed by Woodward to be represented by the small non-chelate antemne seen in Fig. 8, B and C (p. 27), taken from Woodward. If such is the case, then these figures show that a pair of appendages is missing in each 
of these forms, for they possess only five free prosomatic appendages instead of six, as in Limulus and in Pterygotus. Similarly, Woodward only allowed five appendages for Pterygotus, so that his restorations were throughout consistent. Schmidt, in P'terygotus osiliensis has shown that the true number was six, not five, as seen in his restoration given in Fig. $8, \mathrm{~A}$ (p. 27).

With respect to Eurypterus, Schmidt figures an exceedingly

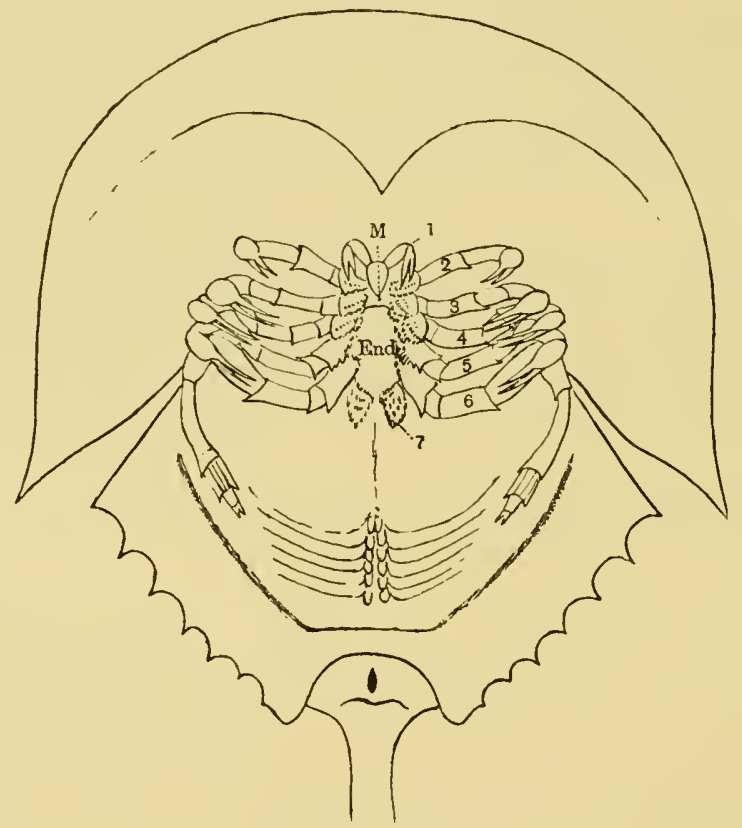

Frg. 103.-Ventral Surface of Linulus. (Taken from Kishinouse.)

The guathic bases of the appendages have been separated from those of the other side to show the promesosternite or endostoma (End.).

minute pair of antennæ between the coxal joints of the first pair of appendages, thus making six pairs of appendages. Gerhard Holm, however, in his recent beautiful preparations from Schmidt's specimens and others collected at Rootzikiill, has proved most conclusively that the chelicere of Eurypterus were of the same kind as those of Limulus. I reproduce his figure (Fig. 104) showing the small chelate chelicere (1) overhanging the mouth orifice, just as in Limulus or in Scorpio. 
So, also, since Woodward's monograph, Laurie has discovered in Slimonia acuminata a small median pair of chelate appendages exactly corresponding to the chelicere of Limulus, or of Eurypterus, or of Scorpio. We may, therefore, take it for granted that such was also the case in Stylonurus, and that the foremost pair of prosomatic appendages in all these extinct sea-scorpions were in the same position and of the same character as the chelicere of the scorpions.

In the living scorpion and in Limulus the nerves to this pair of

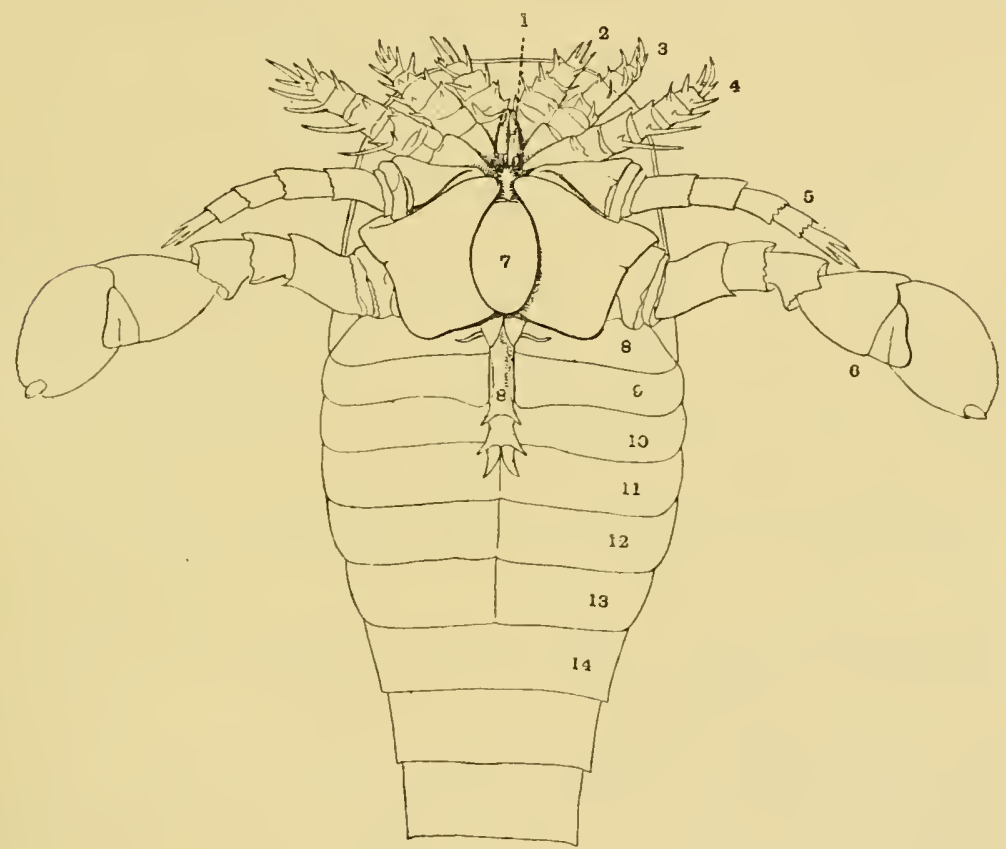

Fig. 104.-Furypterus Fischeri. (From Howm.)

appendages unclouhtedly arise from the foremost prosomatic ganglia, and the reason why they appear to belong to the supra-cosophageal brain-mass has been made clear by Brauer's investigations on the embryology of Scorpio; for he has shown that the cheliceral ganglia shift from the ventral to the dorsal side of the osophagus during development, thus becoming pseudo-supra-cesophageal, though in reality belonging to the infra-cesophageal ganglia. This cheliceral pair of appendages is, in all probability, homologous with the second pair of antenne in the crustacea. 
I conclude, then, that the chelicerre must truly be inclurled in the prosomatic group, but that they stand in a somewhat different category to the rest of the prosomatic appendages, inasmuch as they take up a very median anterior and somewhat dorsal position, and their ganglia of origin are also exceptional in position.

Next for consileration come the chilaria ( 7 in Fig. 103), which Lankester did not consider to belong to appendages at all, but to be a peculiar pair of sternites. Yet their very appearance, with their spinons hairs corresponding to those of the other gnathites and their separate nerve-supply, all point distinctly to their being a modified pair of appendages, and, indeed, the matter has been placed beyond doubt by the observations of Kishinonye, who has found embryologically that they arise in the same way as the rest of the prosomatic appendages, and belong to a distinet prosomatic segment, viz. the seventh segment. In accordance with this, Brauer has found that in the scorpion there is in the embryo a segment, whose appendages degenerate, which is situated between the segment bearing the last pair of thoracic appendages and the genital operculum-a segment, therefore, comparable in position to the chilarial segment of Limulus.

Coming now to the five locomotor appendages, we find that they resemble each other to a considerable extent in most cases, with, however, certain striking differences. Thus in Limulus they are chelate, with their basal joints formed as gnathites, except in the case of the fifth appendage, in which the extremity is modified for the purpose of digging in the sand. In Pterygotus, Slimonia, Eurypterus, the first four of these appendages are very similar, and are called by Huxley and Woodward endognaths; in all cases they possess a basal part or sterno-coxal process, which acts as a gnathite or foot-jaw, and a non-chclate tactile part, which possesses no prehensile power, and in most cases could have had no appreciable share in locomotion, called by Huxley and Woodward the palpus. These small palps were probably retractile, and capable of being withdrawn entirely under the hood. The fifth appendage is nsually different, being a large swimming organ in Pterygotus, Eurypterus, and Slimonia (Figs. 8 and 104), and is known as the ectognath.

Finally, in Drepanopterus Bembycoides, as stated by Laurie, all five locomotor appendages are built $u$ p after the same fashion, the last one not being formed as a paddle-shaped organ or elongated as 
in Stylonurus, but all five possess no special locomotor or prehensile power. According to Laurie this is a specially primitive form of the group.

It is significant to notice from this sketch that with the absence of special prehensile terminations such as chele, or the absence of special locomotor functions such as walking or swimming, these appendages tend to dwindle and become insignificant, taking up the position of mere feelers round the mouth, and at the same time are concentrated and pressed closely together, so that their appendagenerves must also be close together.

This sketch therefore shows us that-

Of the six foremost prosomatic appendages, the cheliceræe and the four endognaths were, at the time when the vertebrates first appeared, in very many cases dwindling away; the latter especially no longer functioned as locomotor appendages, but were becoming more and more mere palps or tentacles situated round the mouth, which conld by no possibility afford any help to locomotion.

On the contrary, the sixth pair of appendages - the ectognathsremained powerful, being modified in many cases into large oar-like limbs by which the animal propelled itself through the water.

It is a striking coincidence that those ancient fishes, Ptericthys and Bothriolepis, should have possessed a pair of large oar-like appendages.

At this time, then, in strong contrast to the endognaths, the ectognaths, or sixth pair of appendages, remained strong and vigorous. What about the seventh pair, the chilaria of Limulus?

Of all the prosomatic appendages these are the most interesting from the point of view of my theory, for whereas in the scorpion of the present day they have dwindled away and left no trace except in the embryo, in the sea-scorpions of old, far from dwindling, they had developed and become a much more important organ than the chilaria of Limulus.

In all these animals a peculiarly striking and unique structure is found in this region known by the name of the metastoma, or lip-plate (Figs. 8 and $104(7)$ ); it is universally considered to be formed by the fusion of the two chilarial appendages.

All observers are agreed that this lip-plate was freely movable. Nieskowski considers that the movement of the metastoma was entirely in a vertical direction, whereby the cleft which is seen 
between the basal joints of all the pairs of locomotor appendages could be closed from behind. Woolward says it no doult represents the labium, and served more effectually to enclose the posterior part of the buccal orifice, being found exteriorly to the toothed edges of the ectognaths or maxillipedes. Schmidt agrees with Nieskowski, and
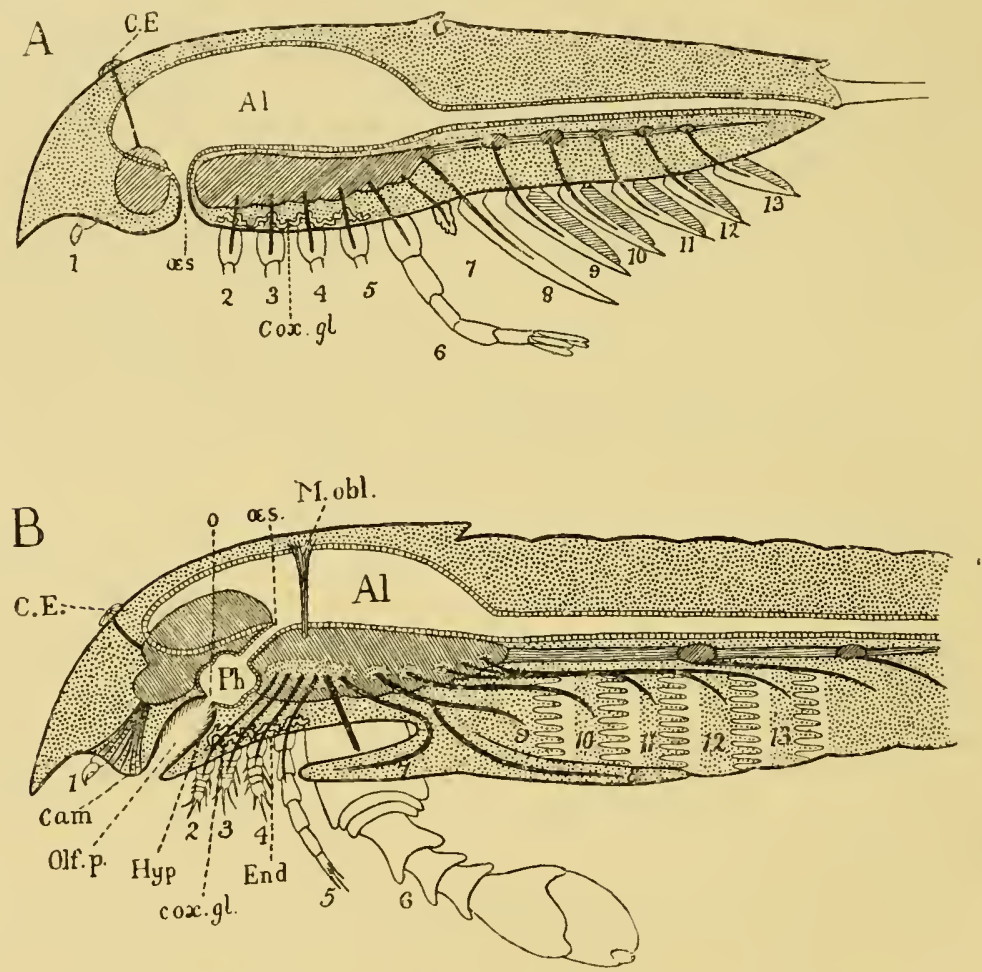

Fig. 105.--Diagram of Sagittal Median Section through A, Limulus, B, EURYPTERUS.

looks on the mestasoma as forming a lower lip within which the bases of the ectognaths worked.

Quite recently Gerhard Holm has worked over again the very unmerous specimens of Eurypterus Fischeri, which are obtainable at Rootzikiill, and has thrown new light on the relation of the metastoma to the mouth-parts. His preparations show clearly that the true lower lip of Eurypterus was not the metastoma, for when the metastoma is removed another plate (End., Fig. 105, B) situated 
internally to it is disclosed, which, in his view, corresponds to the sternite between the bases of the pro-somatic appendages in Limulus, i.e. to the sternite called by Lankester, the pro-mesosternite (End., Fig. 103). This inner plate formed with the metastoma ((7) Fig. 105) and the ectognaths (6) a chamber closed posteriorly, within which the bases of the ectognaths worked. In other words, the removal of the metastoma discloses in Eurypterus the true anterior rentral surface of the animal which corresponds to that of Limulus, or of the scorpion gronp, with its pro-mesosternite and laterally attachel gnathites or sterno-coxal processes. To this inner plate or pro-mesosternite Holm gives the name of endostonu.

To the anterior edge of the endostoma a thinner membrane is attached which passes inwards in the direction of the throat, and forms, therefore, the lower lip' (Hyp., Fig. 105, B) of the passage of the mouth $(o l f \cdot p$.$) . This membrane bears upon its surface a tuft of$ hairs, which lie thought were probably olfactory in function. Consequently, in his preliminary communication, he lescribes this lower lil as forming, in all probability, an olfactory organ; in his full communication he repudiates this suggestion, because he thinks it unlikely that such an organ woukl be situated within the mouth. I feel sure that if Holm had referred to Cronelierg's paper, and seen how the true mouth in all the scorpion group is situated at the base of an olfactory passage, he would have recognized that his first suggestion is in striking accordance with the nature of the entrance to the month in other scorpions.

That Emypterus also possessed a camerostome ( $\mathrm{ccm}$.) seems to follow of necessity from its evident affinities both with Limulus and the scorpions. We see, in fact, that the month of these old seascorpions was formed after the fashion of Limulus, surrounded by masticatory organs in the shape of foot-jaws, and yet foreshadowed that of the scorpion, so that an ideal sagittal section of one of these old paleostracan forms would be obtained by the combination of actual sagittal sections through Limulus and a member of the scorpion group, with, at the same time, a due recognition of Iolm's researches. Such a section is represented in Fig. 105, B, in which I have drawn the central nervous system and its nerves, the median eyes (C.E.), the olfactory organs ( $(\mathrm{am}$.), the pharynx ( $P h$.$) , cesopliagus (ces.), and$ alimentary canal $(A l$.), but have not tried to indicate the lateral eyes. I have represented the prosomatic appendages by numbers (1- 7 ), and 
the foremost mesosomatic segments by numbers (8-13). I have placed the four endognaths and the nerves going to them close together, and made them small, mere tentacles, in recognition of the character of these appendages in Eurypterus, and have indicated the position aud size of the large ectognath, with its separate nerve, by (6). If among the ancient Eurypterus-like forms, which were living at the time when vertebrates first appeared, there were some in which the ectognaths also har dwindled to a pair of tentacles, then such animals would possess a prosomatic chamber formed by a metastoma or accessory lip, within which were situated five pairs of short tactile appendages or tentacles. If the vertebrate were derived from such an animal, then the trigeminal nerve, as the representative of these prosomatic appendage-nerves, ought to be found to supply the muscles of this accessory lip and of these five pairs of tentacles in the lowest vertebrate.

This prosomatic or oral chamber, as it might be called, was limited posteriorly by the fused metastoma (7) and operculum (8), so that if in the same imaginary animal one imagines that the gill-chanbers, instead of being separate, are united to form one large respiratory chamber, then, in such an animal, a prosonatic oral chamber, in which the prosomatic appendages worked, would be separated from a mesosomatie respiratory chamber by a septum composed of the conjoined basal portions of the mesosonatic opereulum and the prosomatic metastoma, as indicated in the diagram. In this septum the nerves to the last prosomatic appendage (equivalent to the last part of the trigeminal in the vertebrate) and to the first mesosomatic (equivalent to the thyroid part of the facial) wonld rum, as shown in the figure, close together in the first part of their course, and wonld separate when the ventral surface was reached, to pass headwarts and tailwarls respectively.

\section{Tire Coxal Giands.}

One more characteristic of these appendages requires mention, and that is the excretory glands situated at the base of the four endognatlis known as the coxal glands. These glands are the main excretory organs in Limulus and the scorpions, and extend into the basal segments or coxa of the four endognaths, not into those of the ectognatlıs or the chilaria (or metastoma). Hence their name, coxal 
glands; and, seeing the importance of the excretory function, it is likely enough that they would remain, even when the appendages themselves had dwindled away. With the concentration and dwindling of the endognaths these coxal glands would also be concentrated, so that in the diagram (Fig. 105) they would rightly be grouped together in the position indicated $(c 0 x . g l$.$) .$

Such a diagram indicates the position of all the important organs of the head-region except the special organs for taste and hearing. These, for the sake of convenience, I propose to take separately, in order at this stage of my argument not to overburden the simplicity of the comparison I desire to make with too much unavoidable detail.

\section{The Prosomatic Region of Anmocgtes.}

Let us now compare this diagram with that of the eorresponding region in Ammocnetes and see whether or no any points of similarity exist.

With respect to this region, as in so many other instances already mentioned, Ammocretes occupies an almost unique position among vertebrates, for the region supplied by the trigeminal nerve-the prosomatic region - consists of a large oral chamber which was separated from the respiratory chamber in the very young stage by a septum which is subsequently broken through, and so the two chambers communicate.

This chamber is bounded by the lower lip ventrally, the upper lip and trabecular region dorsally, and the remains of the septum or velum laterally and posteriorly. It contains a number of tentacles arrangerl in pairs within the cliamber so as to form a sieve-like fringe inside the circular mouth; of these, the ventral pair are large, fused together, and attached to the lower lip.

All the muscles belonging to this oral chamber are of the risceral type, and are innervated by the trigeminal nerve. In accordance with the evidence obtained up to this point this means that such an oral chamber was formed by the prosomatic appendages of the invertebrate ancestor, similarly to the oral chamber just figured for Eurypterus.

This chamber in the full-grown Ammocœetes is not only open to the respiratory chamber, but is bounded by the large upper lip (U.L., Fig. 106, D). On the dorsal surface of this region, in front of the 
pineal eye (C.E.), is the most conspicuous opening of the olfactory tube $(N a$.), which olfactory tube passes from the dorsal region to the ventral side to terminate blindly at the very spot where the infundibulum comes to the surface of the brain. Here, also, is situated that extraordinary glandular organ known as the pituitary borly (Pit.). A sagittal section, then, in diagram form, of the position of parts in the full-grown Ammocretes, would he represented as in Fig. 106, D.

But, as argued out in the last chapter, the diagram of the adult Ammocotes must be compared with that of a cephalaspidian fish; the diagram of the palrostracan must be eompared with the larval condition of Ammocoetes. In other words, Fig. 106, S, must be compared with Fig. 106, C, which represents a seetion through the larval Ammoccetes as it would appear if it reached the adult condition without any forward growth of the upper lip or any hreaking throngh of the septum between the oral and respiratory chambers. The striking similarity hetween this diagram and that of Eurylterus beeomes inmediately manifest even to the smallest details. The only difference between the two, except, of course, the notochord, consists in the closure of the mouth opening (o), in Fig. 106, B, by which the olfactory passage (olf. $p$.) of the scorpion becomes converted into the bypophysial tube $\left(H_{y}\right)$. Fig. 106 , C, and later into the nasal tube ( $N_{u}$.), Fig. 106, D, of the full-grown Ammocoetes. That single closure of the old month is absolutely all that is required to convert the Enrypterus diagram into the Ammocretes diagranl.

Such a comparison immediately explains in the simplest manner a number of anatomical peculiarities which have hitherto been among the great mysteries of the rertebrate organization. For not only do the median eyes (C.E.) correspond in position in the two diagrams, and the infundibular tube $(\operatorname{Inf}$. .) and the rentricles of the brain (C.C.) corresponil to the cesophagus (ces.) and the cephalic stomach $(A l$.$) , as already fully discussed; but even in the very place where the$ narrow nesophagus opened into the wider chamber of the pharynx $(P h$.$) , there, in all the lower vertebrates, the narrow infundibular tube$ opens into the wider chamber of the membranous saccus rasculosus (sac. vase.). This is the last portion of the membranous part of the tube of the central nervous system which has not received explanation in the previous chapters, and now it is seen how simple its explanation is, 

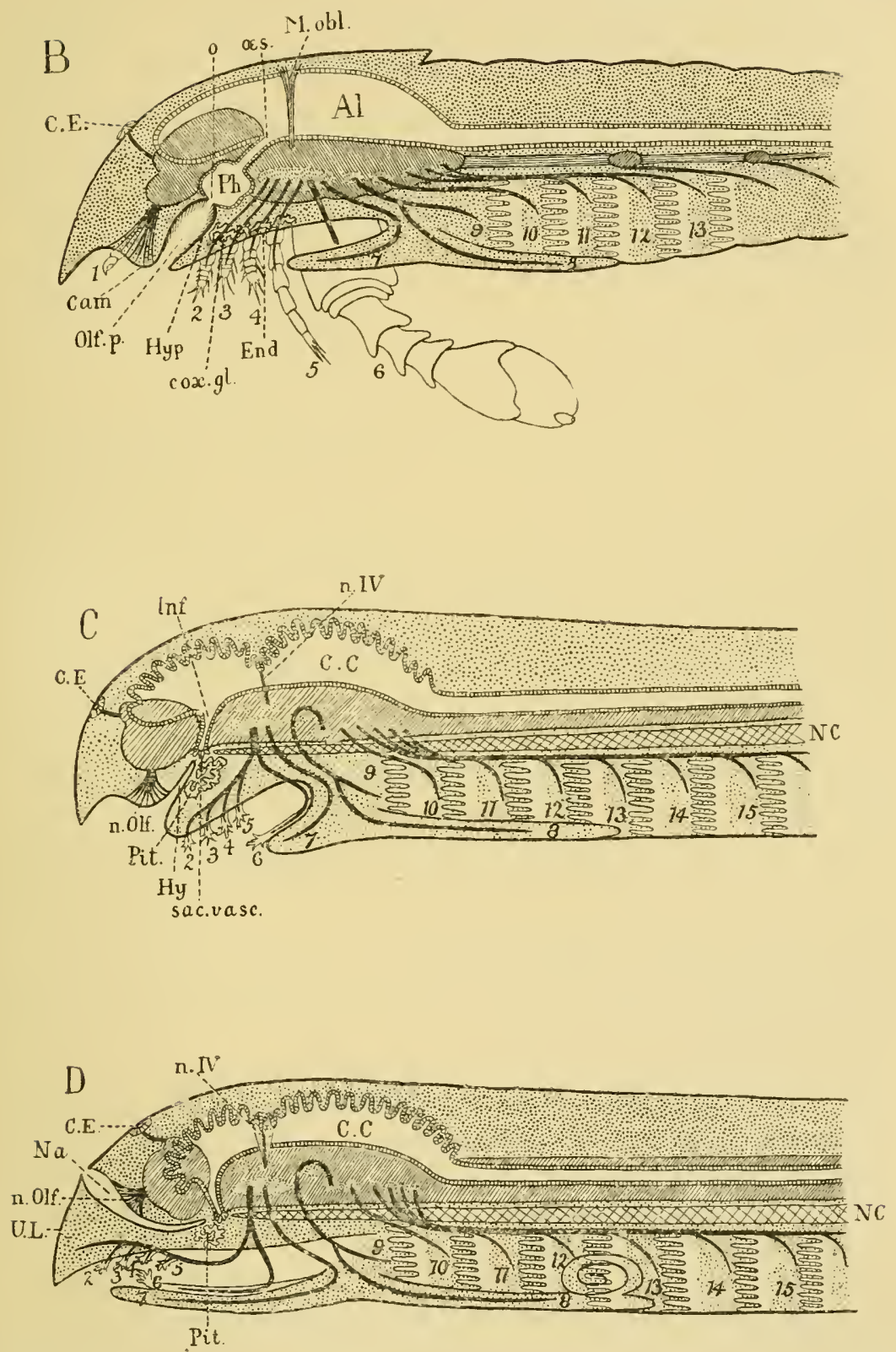

Fil, 106.-Diagran of Sagittal Median Section throvgil B, Eviriteres; C, Lamal Anhocetes; D, Fill-grown Amocetes. 
how natural its presence-it represents the old pharyngeal chamber of the palieostracan ancestor.

Next among the mysteries requiring explanation is the pituitary body, that strange glandular organ always found so closely attached to the brain in the infundibular region that when it is detached in taking out the brain it leaves the infundibular canal patent right into the IIIrd rentricle. A comparison of the two diagrams indicates that such a glandular organ (I'it.), Fig. 106, C, was there because the coxal excretory glands (cox. gl.), Fig. 106, B, were in a similar position in the palcostracan ancestor-that, indeed, the pituitary body is the desceudant of the coxal glands.

Finally, the diagrams not only indicate how the mesosomatic appendage-nerves supplying in the one case the operculum and the respiratory appendages correspond to the respiratory group of nerves, VII., IX., X., supplying in the other case the thyroid, hyoid, and branchial segments, but also that a similar correspondence exists between the prosomatic appendage-nerves in the one case and the trigeminal nerve in the other; a correspondence which supplies the reason why in the vertebrate a septum originally existed between an oral and respiratory chamber.

Such a comparison, then, leads directly to the suggestion that the trigeminal nerve originally supplied the prosomatic appendages, such appendages being: 1. The metastoma, which has becume in Anmocoetes the lower lip supplied by the velar or mandibular branch of the trigeminal nerve $(7) ; 2$. The ectognath, which has become the large merlian ventral tentacle, called by Rathke the tongue, supulied by the tongue nerve $(6) ; 3$. The endognaths, which have been reduced to tentacles and are supplied by the tentacular brauch of the trigeminal nerve $(2,3,4,5)$.

I have purposely put these two diagrams of the larval Ammocutes and of Eurypterus before the minds of my readers at this early stage of my argument, so as to make what follows more understandable. I propose now to consider fully each one of these suggestive comprarisons, and to see whether or no they are in accordance with the results of inodern research.

In the first instance, the cliagrams suggest that the trigeminal nerve originally supplied the prosomatic appendages of the palcostracan ancestor, while the eye-muscle nerves supplied the bodymuscles of the prosoma. 
As these appendages did not carry any vital organs such as branchiæ, but were mainly locomotor and masticatory in function, it follows that their disappearance as such would be much more complete than that of the mesosomatic branchial appendages. Most probably, then, in the higher rertebrates no trace of such appendages might be left; consequently the segmentation due to their presence would be very obscure, so that in this region the very reverse of what is found in the region of the vagus nerve would be the rule. There branchiomeric segmentation is especially evident, owing to the persistence of the branchial part of the branchial appendages; here, owing to the disappearance of the appendages, the segmentation is no longer branchiomeric, but essentially mesomeric in consequence of the persistence of the somatic eye-muscles.

In addition to the evidence of the appendages themselves, the number of prosomatic segments is well marked out in all the members of the scorpion group by the divisions of the central nervous system into well-defined neuromeres in accordance with the appendages, a segmentation the reminiscence of which may still persist after the appendages themselves have dwindled or disappeared. In accordance with this possibility we see that one of the most recent discoveries in farour of a number of segments in the headregion of the rertelurate is the discovery in the early embryo of a number of partial divisions in the brain-mass, forming a system of cephalic neuromeres which may well be the rudiments of the welldefined cephalic neuromeres of animals such as the scorpion.

\section{The Evidence of the Prosonatic Musculature.}

Eren if the appendages as such become obscure, yet their muscles might remain and show evidence of their presence. The most persistent of all the appendage-muscles are the basal muscles which pass from coxa to carapace and are known by the name of tergo-coxal muscles. They are large, well marked, segmentally arranged muscles, dorso-ventral in direction, and, owing to their connecting the limb with the carapace, are likely to be retained eren if the appendage dwindles away.

The muscular system of Linulus and Scorpio has been investigated by Benham and Miss Beck under Lankester's direction, and the conclusions to which Lankester comes are these- 
The simple musculature of the primitive animal from which both Limulus and the scorpions arose consisted of-

1. A series of paired longitndinal dorsal muscles passing from tergite to tergite of each snccessive segment.

2. A similar series of paired longitudinal ventral muscles.

3. A pair of dorso-rentral muscles passing from tergite to sternite in each segment.

4. A set of dorso-ventral museles moving the coxa of each limb in its socket.

5. A pair of veno-pericardial muscles in each segment.

Of these groups of muscles, any one of which would indicate the mumber of segments, Groups 1 and 2 do not extent into the prosomatic region, and Group 5 extends only as far as the lreart extends in the case of both Limulus and the Scorpion group; so that we may safely conclude that in the Palcostraca the evidence of somatic segmentation in the prosomatic region would be given, as far as the musculature is concerned, by the dorso-ventral somatic muscles (Group 3), and of segmentation due to the appendages by the dorso-rentral appendage musculature (Group, 4).

Therefore, if, as the evidence so far indicates, the vertebrate has arisen from a palæostracan stock, we should expect to find that the musculature of the somatic segments in the region of the trigeminal nerve did not resemble the segmental muscles of the spinal region, was not, therefore, the eontinuation of the longitudinal musculature of the body, but was dorso-ventral in position, and that the musculature of the splanchic segments resembled that of the vagus region, where, as pointed ont in Chapter IV., the respiratory museles arose from the dorso-ventral muscles of the mesosomatic appendages. This is, of course, exactly what is found for the muscles which move the lateral eyes of the vertebrate; these muscles, innervated by the IIIrd, IVth, and VIth nerves, afford one of the main evidences of segmentation in this region, are always grouped in line with the somatic muscles of spinal segments, and yet cannot be classed as longitudinal muscles. They are dorso-ventral in direction, and yet belong to the somatic system; they are exactly what one ought to find if they represent Group 3-the dorso-ventral body-museles of the prosomatic segments of the invertebrate ancestor.

The interpretation of these muscles will be given immediately; at present I want to pass in review all the different kinds of evidence 
of segmentation in this region afforded by the examination of the invertebrate, whether living or fossil, so as to see what elues are left if the evidenee of appendages fails us. I will take in the first instance the evidence of segmentation afforded by the presence of the musculature of Group 4, even when, as in the ease of many fossils, no appendages have yet been found. In such animals as Mygale and Phrynus the prosomatic carapace is seen to be marked ont into a series of elevations and depressions, and upon removing the carapace we see that these elevations eorrespond with and are due to the large tergo-coxal museles of the appendages; so that if sueh earapace alone were found fossilized we could say with certainty : this animal possessed prosomatic appendages the number of which ean be gnessed with more or less certainty ly these indieations of segments on the earapace.

In those forms, then, which are only known to ns in the fossil condition, in which no prosomatie appendages have been found, but which possess, more or less elearly, radial markings on the prosomatie carapaee resembling those of Phrynus or Mygale, such radial markings may be interpreted as due to the presence of prosomatie appendages, which are either entirely concealed by the prosomatic earapace or dorsal head-plate, or were of such a nature as not to have been capalile of fossilization.

The group of animals in question forms the great gromp of animals, chiefly extinet, elassified by $\mathrm{H}$. Woodward nucler the order of Merostomata. They are divided by him into the sub-order of Eurypteride, which includes-(1) Pterygotus, (2) Slimonia, (3) Stylonurus, (4) Eurypterus, (5) Adelophthalmus, (6) Bunodes, (7) Arthropleura, (8) Hemiaspis, (9) Exapinurus, (10) Psendoniseus; and the sub-order Xiphosura, which inchudes-(1) Belinurus, (2) Prestwichia, (3) Limulus.

The evidenee of the Xiphosura and of the Hemiaspide conclusively shows, in Woodward's opinion, that the Merostomata are elosely related to the Trilobita, and the Hemiaspidxe espeeially are supposed to be intermediate between the trilobites and the king-eralss. They are characterized, as also Belinurus and Prestwichia, by the alssenee of any prosomatic appendages, so that in these eases, as is seen in Fig. 12 (p. 30), representing Bunodes lunulu, found in the Enrypterus layer at Rootziküll, we have an animal somewhat resembling Limulus in which the prosomatic appentages have either dwindled away and are 


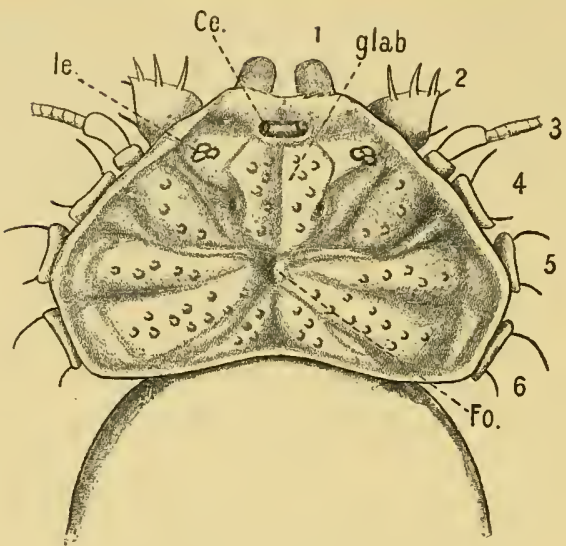

FIG. 107.-1'hrynus Margine-Maculata.

Ce., median eyes; le., lateral eyes; glab., median plate over brain; Fu., forea.

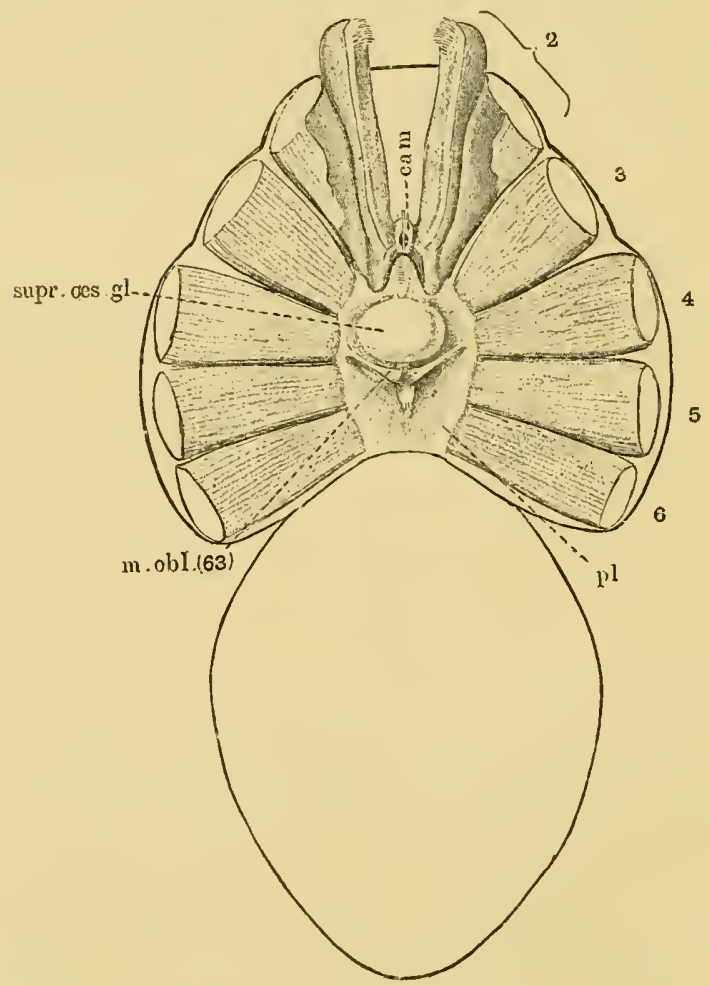

Fig. 108.-Phrymus sp. (?). Carap'ace henoted. cam., camerostome; $p l .$, plastron. 
completely hidden by the prosomatic carapace, or becane so suft as not to be preserved in the fossilized condition. The appearance of the prosomatic carapace is, to $\mathrm{my}_{\mathrm{y}}$ mind, suggestive of the presence of such appendages, for it is marked out radially, as is seen in the figme, in a mamer resembling somewhat the markings on the prosomatic carapace of Mygale or Phrymus; the latter markings, as already mentionel, are due to the aponeuroses between the tergo-coxal muscles of the prosomatic appendagres which lie underueath and are attached to the carapace.

A very similar radial marking is shown by Woodward in his picture of Hcmiaspis limuloides, reproduced in Fig. 109, found in the Lower Lndlow beds at Leintwardine. This sprecies has yielded the most perfect specimens of the genus Hemiaspis, which is recognized as differing from Bunodes by the possession of a telson.

It is striking to find that sinilar indications of segnents have been found on the dorsal surface of the head-region

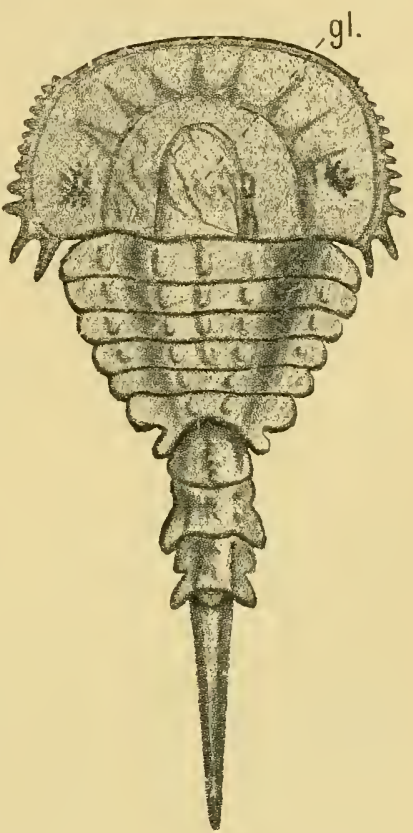

Fig.109.-Hemiaspis limuloides.

(From WOODWARD.)

gl., glabellum. in many of the most ancient extinct fishes, as will be fully discussed later on.

\section{The Eviuence of Celonic Cavities.}

In the head-region of the vertebrate, morphologists depend largely upon the embryonic divisions of the mesoderm for the estimation of the number of segments, and, therefore, upon the number of celomic cavities in this region, the walls of which give origin to the striated muscles of the head, so that the question of the number of segments depends very largely upon the origin of the museles from the walls of these head-cavities. It is therefore interesting to examine whether a similar criterion of segmentation holds good in such a segmented 
animal as Limulus, or in the members of the scorpion group, in which the number of segments are known definitely by the presence of the appendages. In Limulus we know, from the observations of Kishinouye, that a series of colomic cavities are formed embryologically in the varions segments of the mesosona and prosoma, in a manner exceedingly similar to their mode of formation in the liead-region of the rertebrate, and he has shown that in the mesosoma a separate colomic cavity exists for each segment, so that just as the dorso-rentral somatic muscles are regularly segmentally arranged in this region, so are the cuelomic carities, and we should be right in our estimation of the number of segments in this region ly the consideration of the numerical correspondence of these cavities with the mesomatic appendages. Similarly, in the vertebrate, we find every reason to believe that a single, separate head-cavity corresponds to each of the branchial segments in the opisthotic region, and therefore we should estimate rightly the number of segments by the division of the mesoderm in this region.

In the prosomatic region of Limulns, the dorso-rentral muscles are not arranged with such alsolute segmental regularity as in the mesosomatic region, and Kishinouye's observations show that the calomic cavities in this region do not correspond absolutely with the number of prosomatic appendages. His words are:-

A pair of ccelomic cavities appears in every segment except the segments of the 2nd, 3rd, and 4th appendages, in which culomic cavities do not appear at all. At least eleven pairs of these cavities are produced. The eleventh pair belongs to the seventh abdominal segment.

The first pair of coelomic eavities is common to the cephatic lobe and the segment of the first appendage (i.e. the chelicerce).

The second colomic cavity belongs to the segment of the fifth appendage. It is well developed.

The ventral portion of the second ectomic cavity remains as the coxal gland.

Consequently, if we were to estimate the number of segments in this region by the number of calomic cavities we should not judge rightly, for we should find only four cavities and seven appendages, as is seen in the following table:- 
LIMULUS.

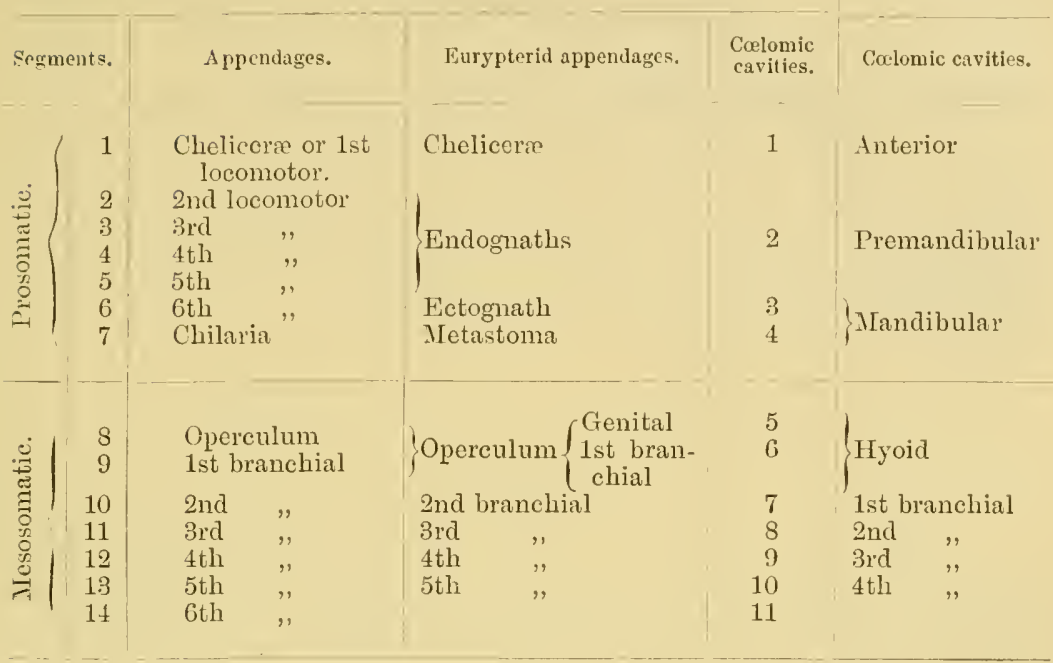

The second cavity would in reality represent four segments belonging to the 2ud, 3rd, 4th, 5th locomotor appendages, i.e. the very four segments which in the Eurypteride are concentrated together to form the endognaths, and we should be justifierl in putting this interpretation on it, because, according to Kishinouye, its ventral portion forms the coxal gland, and, according to Lankester, the coxal gland sends prolongations into the coxa of the 2nd, 3rd, 4th, 5 th locomotor appendages. Similarly in the vertebrate, we find three hearl-cavities in the region which corresponds, on my theory, to the prosomatic region of Limulus, (1) the anterior cavity discovered by Miss Platt, (2) the premandibular eavity, and (3) the mandibular cavity, which, if they corresponded with the prosomatic crelomic cavities of Limulus, would represent not three segments but seven segments, as follows:-the anterior cavity would correspond to the first erelomic cavity, i.e. the cavity of the cheliceral segments in both Limulus and the Eurypteridie; the premandibular, to the second enelomic carity, representing, therefore, the 2 nd, $3 \mathrm{rd}, 4$ th, 5 th prosomatic segments in Limulus and the endognathal segments in the Eurypteridx; and the mandibular to the srd and 4 th colomic cavities, representing the last locomotor and ehilarial segments in Limulus, i.c. the ectognathal and metastomal segments in the Eurypteridi. 
It is worthy of note that, in respect to their cnelomic cavities, as in the position and origin of their nerves in the central nervous system, the first pair of appendages, the cheliceræ, retain a unique position, differing from the rest of the prosomatic appendages.

In the table I have shown how the vertebrate crelomic cavities may be compared with those of Limulus. The next question to consider is the evidence obtained by morphologists and anatomists as to the number of segments supplied by the trigeminal nerve-group; this question will be considered in the next chapter.

\section{Sumart.}

In Chapters IV. and V. I have dealt with the opisthotic segments of the rertelurate. including therein the segments snpplied by the facial nerve, and shown that they correspond to the mesosomatic segments of the palaostracan; conseqnently the facial (VII.), glossopharyugeal (IX.), and ragns (X.) nerves originally supplierl the branchial and opereular appendlages.

In this chapter the consideration of the pro-otic segments is commencerl. that is. the segments supplied by the trigeminal $(V$.$) and the eye-muscle nerves$ (III.. IV.. VI.). I have considered the VIth nerve with the rest of the eremuscle nerves for convenience sake, though in reality it belongs to the same segment as the facial. Of these, that part of the trigeminal which innervates the muscles of mastication corresponds to the splanchnic segments, while the eye-muscle nerves belong to the corresponding somatic segments; but the pro-otic segments of the vertebrate onght to correspond to the prosomatic segments of the invertebrate, just as the opisthotic correspond to the mesosomatic. Therefore the motor part of the trigeminal onglht to supply muscles which originally moved the prosomatic appendages, while the eye-muscles onght to have belonged to the somatic part of the same segments.

The first question considered is the number of segments which ought to be fonnd in this region. In Limulns the Eurypteride. and the scorpions there are seren prosomatic segment; which carry (1) the chelicera, $(2,3,4,5)$ the forr first locomotor appendages - the endognatlis, (ii) the large special appendage-the ectognath and (7) the appendages. which in Limulus are known as the chilaria, and are small and insigniticant, but in Enrypterns and other forms grow forwards. fnse together. and form a single median lip to an accessory oral chamber, which lip is known as the metastoma. Of these appendages the (-helicere and endognaths tend to dwindle away and become mere tentacles. while the large swimming ectognath and metastoma remain strong and rigorons.

In this, the prosomatic region, the somatic segmentation is not characterized by the presence of the longitudinal muscle segments, for they do not extend into this head-region, but only by the presence of the segmental somatic ventro- 
dorsal muscles. Among the muscles of the appendages the system of large tergo-coxal muscles is especially apparent.

From these considerations it follows that the number of segments in this region in the rertebrate ought to he seren; that the musculature supplierl by the trigeminal nerve ought to represent seren rentral or splanchnic segments. of which only the last two are likely to be conspicnous; and that the musculature supplied by the eye-muscle nerres ought to be dorso-rentral in direction, which it is. and represent seren dorsal or somatic segments.

A further peculiarity of this region, both in Limulus and the scorpions, is found in the excretory organs which are known by the name of coxal glands. becanse they extend into the basal joint. or coxa. of certain of the prosomatic limbs. The appendages so characterized are always the four endognaths. and it follows that if these four endognaths lose their locomotor power, become redncer in size, and concentrated together to form mere tentacles, then of necessity the coxal glands will be concentrated together. and tend to form a glandular mass in the region of the mouth; in fact, take up a position corresponding to that of the pituitary body in rertebrates.

Taking all these facts into consideration, it is possible to construct a drawing. of a sagittal section through the head-region of Eurypterus, which will represent, with considerable probability, the arrangement of parts in that animal. 'This can be compared with the corresponding' section through the head of Ammocoetes.

Now, as pointed out in the last chapter, the early stage of Ammocoetes is remarkably different from the more advanced stage; at that time the septum between the oral and respiratory chambers has not yet broken throngh, and the olfactory or nasal tube. known at this stage as the tube of the hypophysis, is directed ventrally, not dorsally.

The comparison of the diagram of Eurypterus with that of the early stage of Ammocotes is remarkably close, and immediately suggests not only that the single nose of the former is derired from the corresponding organ in the palæostracan, but that the pituitary body is derived from the concentrated coxal glands, and the lower lip from the metastoma. The further working out of these homologies will be discussed in the next chapter.

In addition to the evidence of segmentation afforded by the appendages, there are in this region, in Limulus and the scorpion group, three other criteria of segmentation arailable to us, if from any cause the evidence of appendages fails us. These are-

1. The number of nemromeres are marked ont in this region of the brain more or less plainly, especially in the young animal. just as they are also in the embryo of the vertebrate.

2. The segmentation is represented here, just as in the mesosomatic region. by two sets of muscle-segments ; the one somatic, consisting of the segmentally arranged dorso-rentral muscles, the continuation of the group already discussed in comnection with the mesosomatic segmentation. and the other appendicular. characterized by the tergo-coxal muscles. These latter segmental muscles are especially raluable, for in such forms as Mygale, Phrynus, etc., their presence is indicated externally by markings on the prosomatic carapace, and thus corresponding markings found on fossil carapaces or on dorsal head-shields can be 
interpreted. These two sets of muscle-segments correspond in the rertebrate to the somatic and splanchnic segmentations.

3. In the rertelnate the segmentation in this region is indicated by the colomic or head-cavities, which are carities former in the mesoderm of the embryo, the walls of which give origin to the striated muscles of the hear. In Limulus corresponding colomic eavities are fonnd, which are directly comparable with those found in the rertebrate. 


\title{
CHAPTER VIII
}

\author{
THE SEGMENTS BELONGING TO THE TRIGEMIMAL \\ NERVE-GROUP
}

The prosomatic segments of the vertebrate.-Number of segments belonging to the trigeminal nerve-group.-History of cranial segments.-Eye-muscles and their nerves. - Comparison with the dorso-ventral somatic muscles of the scorpion.-Explanation of the oculomotor nerve and its group of muscles. -Explanation of the trochlearis nerve and its dorsal crossing.-Explanation of the abducens nerve--Number of segments supplied by the trigeminal nerres.-Evidence of their motor nuclei.-Evidence of their sensory ganglia.-Summary.

From the evidence given in the last chapter, combined with that given in Chapter IV., the probability of the theory that the trigeminal group of nerves of the vertebrate have been derived from the prosomatic group of nerves of the invertebrate can be put to the test by the answers to the following morphologieal and anatomical questions :-

1. Do we find in the vertebrate two segmentations in this region corresponding to the two segmentations in the branchial region, i.e. a somatic or dorsal series of segments, and a splanchnic or ventral series of segments? The latter would not be branchial, but rather of the nature of free tactile appendages; so that it is useless to look for or talk about gill-slits, although such appendages, being serially homologous with the branchial mesosomatic appendages, would readily give rise to the conception of branchial segments.

2. Is there morphological evidence that the trigeminal nerve is not the nerve belonging to a single segment, or even to two segments, but is really a concentration of at least six, probably seven, segmental nerres?

3. Is there morphological evidence that the oculomotor and trochlear nerves, which on all sides are regarded as belonging to the trigeminal segments, are not single nerves corresponding each 
to a single segment, but are the somatic motor roots belonging to the same segments as those to which the trigeminal supplies the splanchnic roots?

4. Do the mesoderm segments, which give origin to the eyemuscles, and therefore do the head-cavities of this region, correspond with the trigeminal segments? Considering the concentration of parts in this region and the difficulty ahready presented by the want of numerical agreement between the prosomatic appendages and the prosomatic colomic cavities in Limulus, it may very probably be difficult to determine the actual number of the mesoderm segments.

5. Is there anatomical evidence that the ganglion of origin of the motor part of the trigeminal nerve is not a single ganglion, but a representative of many, probalsly seven?

6. Is there anatomical evidence that the ganglia of origin of the oculomotor and trochlear nerves represent many ganglia?

7. Is there any evidence that the organs originally supplied by the motor part of the trigeminal nerve are directly comparable with prosomatic appendages?

It is agreed on all sides that in this region of the head there is distinct evidence of double segmentation, the dorsal mesoderm segments giving origin to the eye-muscles, and the ventral segments to the musculature innervated by the trigeminal nerve. Originally, according to the scheme of van Wijhe, two segments only were recognized, the dorsal parts of which were innervated by the IIIrd and IVth nerves respectively. Since his paper, the tendency has been to increase the number of segments in this region, as is seen in the following sketch, taken from liabl, of the history of cranial segmentation.

\section{History of Cranial Segmentation.}

The first attempt to deal with this question was made by Goethe and Oken. They considered that the cranial skeleton was composed of a series of vertebrie, but as early as 1842 Vogt pointed out that only the occipital segments could be reduced to vertebræ. In 1869, Huxley showed that vertebræ were insufficient to explain the cranial segmentation, and that the nerves must be specially considcred. The olfactory and optic nerves he regarded as parts of the brain, not true segmental nerves; the rest of the cranial nerves 
were segmental, with special reference to branchial arches and clefts, the facial, glossopharyngeal, and separate vagus branches supplying the walls of the various branchial pouches. In a similar manner, the supra- and infra-maxillary branches of the trigeminal were arranged on each side of the mouth, and the inner and outer twigs of the first (ophthalmic) branch of the trigeminal on each side of the orbito-nasal cleft, the trabecular and the supra-maxillary arches being those on each side of this cleft. Thus Huxley considered that there was evidence of a series of pairs of ventral arches belonging to the skull, viz. the trabecular and maxillary in front of the mouth, the mandibular, hyoid, and branchial arches behind, and that the Vth, VIIth, IXth, and Xth nerves were segmental in relation to these arches and clefts. Gegenbaur, in 1871 and 1872, considered that the branchial arches represented the lower arches of cranial vertebræ, and therefore corresponded to lower arches in the spinal region, i.e. the skull was composed of as many vertebre as there are branchial arches. These vertebre were confined to the notochordal part of the skull, the prechordal part having arisen secondarily from the vertebral part, while the number of vertebrx are at least nine, possibly more. The nerves which conld be homologized with spinal nerves were, he thought, divisible into two great groups-(1) the trigeminal group, which included the eye-muscle nerves, the facial, and its dorsal branch, the auditory; (2) the vagus group, which included the glossopharyngeal and vagus.

Such was the outcome of the purely comparative anatomical work of Huxley and Gegenbaur-work that has profoundly influenced all the views of segmentation up to the present day.

Now came the investigations of the embryologists, of whom I will take, in the first instance, Balfour, whose observations on the embryology of the Selachians led him to the conclusion that besides the evidence of segmentation to be found in the cranial nerves and in the branchial clefts, further evidence was afforded by the existence of head-cavities, the walls of which formed muscles just as they do in the spinal region. He came to the conclusion that the first headcavity belonged to one or more pre-oral segments, of which the nerves were the oculomotor, trochlearis, and possibly abducens; while there were seven post-oral segments, each with its head-cavity and its visceral arch, of which the trigeminal, facial, glossopharyngeal, and the four parts of the vagus were the respective nerves. 
Marshall, in 1882, considered that the eranial segments were all originally respiratory, and that all the segmental nerves are arranged uniformly with respect to a series of gill-clefts which have become modified anteriorly and have been lost, to a certain extent, posteriorly. He included the olfactory nerves among the segmental nerves, and looked upon the olfactory pit, the orbito-nasal lacrymal duct, the mouth, and the spiracle as all modified gill-slits, so that he reekoned three pre-oral and oral segments belonging to the Ist, IIIrd, $I V$ th, and Vth nerves, and eight post-oral segments belonging respectively to the VIIth and VIth nerves, and to the IXth nerve, and six segments belonging to the Xth nerve. He pointed out that muscles supplied by the oculomotor nerve develop from the outer wall of the first head-cavity; not, however, the obliquus superior and rectus externus, the latter originating probably from the walls of the third cavily.

In the same year, 1882 , came van Wijhe's well-known paper, in which he showed that the mesoderm of the heal in the selachian divided into two sets of segments, dorsal and ventral; that the dorsal segments were continuous with the body-somites, and that the ventral segments formed the lateral plates of mesoblast between each of the visceral and branchial pouches. He concluded that the dorsal somites were originally nine in number, that each was supplied with a ventral nerve-root, in the same way as the somites in the trunk, and that to each one a visceral pouch corresponded, whose walls were supplied by the corresponding dorsal nerve-root; of these nine segments, the ventral nerve-roots of the first three segments were respectively the oculomotor, trochlearis, and abducens nerves. The next three segments possessed no definable ventral root or muscles, and the seventh, eighth, and ninth segments possessed as ventral roots the hypoglossal nerve, with its muscular supply. The corresponding dorsal nerve-roots were the trigeminal, facial, anditory, glossopharyngeal and vagus nerves, the difference between cranial and spinal clorsil roots being that the former contain motor fibres.

Ahlborn, in 1884, drew a sharp distinction between the segments of the mesoderm and those of the endoderm. The former segmentation he called mesomeric, the latter branehiomeric. He considered the two segmentations to be independent, and concluded that the branchiomeric was secondary to the mesomeric, and therefore not of 
segmental value. As to the segments of the mesorlerm in the hearl, the three hindmost or occipital in Petromyzontide remain permanently, and correspond to the three last segments in the selachian hearl. of the anterior mesoderm segments, he considered that there were originally six, and that there are six typical eye-muscles in all Craniota, which have been compressed into three segments, as in Selachia.

Froriep (1885) showed in sheep-embryos and in chicks that the hypoglossal nerve belongs to three proto-vertebræ posterior to the vagus region, which were true spinal segments. He therefore modified Gegenbaur's conceptions to this extent: that portion of the skull designated by Gegenbaur as vertebral must be divided into two parts - a hind or occipital region, which is clearly composed of modified vertebre and is the region of the hypoglossal nerves, and a front region, extending from the oculomotor to the accessorius nerves, which is characterized segmentally by the formation of branchial arches, but in which there is no evidence that proto-vertebræ were ever formed. He therefore divides the head-skeleton into three parts-

1. Gegenbaur's evertebral part-the region of the olfactory and optic nerves-which cannot be referred to any metameric segmentation.

2. The pseudo-vertebral, pre-spinal, or branchial part, clearly shown to be segmented from the consideration of the nerves and branchial arches, but not referable to proto-vertebrec-the region of the trigeminal and vagus nerves.

3. The vertebral spinal part-the region of the hypoglossal nerves.

He further showed that the ganglia of the specially branchial nerves, the facial, glossopharyngeal, and vagus, are at one stage in connection with the epidermis, so that these parts of the epidermis represent sense-organs which do not develop; these organs probably belonged to the lateral line system. As the connection takes place at the dorsal edge of the gill-slits, they may also be called rudimentary branchial sense-organs.

Since this paper of Froriep's, it has been generally recognized, and Gegenbaur has accepted Froriep's view, that the three hindmost metameres, which distinctly show the characteristics of vertebre, leelong to the spinal and not to the cranial region, so that the metameric segmentation of the cranial region proper has hecome 
more and more associated with the branchial segmentation. Froriep's discovery of the rudimentary branclial sense-organs as a factor in the segmentation question has led Beard to the conclusion that the olfactory and auditory organs represent in a permanent form two of these rudimentary branchial sense-organs. He therefore includes both the olfactory and anditory nerves in his list of cranial segmental nerves, and makes eleven cranial branchial segments in front of the spinal segments represented by the hypoglossal.

A still larger number of cranial segments is supposed to exist, according to the researches of Dohrn and Killian, in the embryos of Torpclo ocellata. The former, holding to the view that vertebrates arose from annelids, considered that the head was formed of a series of metameres, to each one of which a mesoderm-segment, a gill-arch, a gill-cleft, a segmental nerve and vessel belonged. He found in the front head-region of a Torpedo embryo, corresponding to van Wijhe's first four somites, no less than twelve to fifteen mesoderm segments, and concluded, therefore, that the eye-muscle nerves, especially the oculomotor, represented many segmental nerves, and were not the nerves of single segments; so, also, that the inferior maxillary part of the trigeminal and the hyoid nerve of the facial are probably not single nerves, but a fusion of several. Killian comes to much the same conclusion as Dohrn, for he finds seventcen to eighteen separate mesoderm segments in the head, of which twelve belong to the trigeminal and facial region.

Since Rabl's paper, a number of papers have appeared, especially from America, dealing with yet another criterion of the original segmentation of the head, viz. a scries of divisions of the central nervous system itself, which are seen at a very early stage of development, and are called neuromeres; the divisions in the cranial region being known as encephalomeres, and those of the spinal region as myomeres. Locy's paper has especially brought these divisions into prominence as a factor in the question of segmentation. They are essentially segments of the epiblast and not of the mesoblast; they are conspicuous in very early stages, and appear to be in relation with the cranial nerves, according to Locy. He recognizes in Squalus acanthias, in front of the spino-occipital region, fourteen pairs of such encephalomeres and a median unsegmented termination, which may represent one more pair fused in the middle line, making at least fifteen. He distributes these fifteen segments as follows: 
fore-brain three and unsegmented termination, mid-brain two, and hind-brain nine.

Again, Kupfer, in his recent papers on the embryology of Ammocœtes, asserts that especial information as to the number of primitive segments is afforded by the appearance in the carly stages of a series of epibranchial ganglia in comnection with the cranial nerves, which remain permanently in the case of the vagus nerves, but clisappear in the case of pro-otic nerves. He considers that the evilence points to the number of segments in the mid-and hind-brain region as being primitively fifteen, viz. six segments belonging to the trigeminal and abducens group, three segments belonging respectively to the facial, auditory, and glossopharyngeal, and six to the vagus.

From this sketch we see that the modern tendency is to make six segments at least ont of the region of the trigeminal nerves rather than two. In this region, as already mentioned, the evidence of segmentation is based more clearly on the somatic than on the splanchnic segments. We ought, therefore, in the first place, to consider the teaching of the eye-muscles and their nerves and the calomic cavities in connection with them, and see whether the hypothesis that such muscles represent the original dorso-ventral somatic muscles of the paleostracan ancestor is in harmony with and explains the facts of modern research.

\section{Eve-Muscles AND theik Nerves.}

The only universally recognized somatic nerves belonging to these segments which exist in the adult are the nerves to the eye-muscles, of which, according to van Wijhe, the oculomotor is the norve of the 1st segment, the trochlearis of the $2 \mathrm{nd}$, and the abducens of the 3rd; while the nerves and muscles belonging to the 4th and 5th segments, i.e. the 2nd facial and glossopharyngeal segments respectively, show only the merest rudiments, and do not exist in the adult. One significant fact appears in this statement of van Wijhe, and is accepted by all those who follow him, viz. that the oculomotor nerve has equal segmental value with the trochlearis and the abducens, although it supplies a number of muscles, each of which, on the face of it, has the same anatomical value as the superior oblique or external rectus. Dohrn alone, as far as I know, as already pointed out, insists upon the multiple character of the oculomotor nerve. 
As far as the anatomist is concerned, the evidence is becoming clevrer and clearer that the nucleus of the IIIrd nerve is a composite ganglion composed of a number of nuelei, each similar to that of the trochlearis, so that if the trochlearis nucleus is a segmental motor nucleus, then the oculomotor nucleus is a combined nucleus belonging to at least four segmental nerves, each of which has the same value as that of the trochlearis.

The investigations of a number of anatomists, among whom may be mentioned Gurlden, Obersteiner, Edinger, Kölliker, Gehuchten, all lead directly to the conclusion that this oculomotor nucleus is composed of a number of separate nuclei, of which the most anterior as also the Edinger-Westphal nucleus contains small cells, while the others contain large cells. Thus Edinger divides the origin of the oculomotor nerve into a small-celled anterior part and a larger posterior part, of which the cells are larger and distinctly arranged in three groups-(1) dorsal, (2) ventral, and (3) median. Between the anterior and posterior groups lies the Edinger-Westphal nucleus, which is small-celled; naturally, the large-celled group is that which gives origin to the motor nerves of the eye-muscles, the small-celled being possibly concerned with the motor nerves of the pupillary and ciliary muscles. I may mention that Köliker considers that the anterior lateral nucleus has nothing to do with the oculomotor nerve, but is a group of cells in which the fibres of the posterior longitudinal bundle and of the deep part of the posterior commissure terminate.

These conelusions of Edinger are the outcome of work done in his laboratory by Perlia, who says that in new-born animals the nucleus of origin of the oculomotor nerve is made up of a number of gromps quite distinct from each other, each group being of the same character as that of the trochlearis. He finds the same arrangement in various mammals and birds. Further, he finds that some of the fibres arise from the nucleus of the opposite side, thus crossing, as in the trochlearis; these crossing fibres belong to the most posterior of the dorsal group of nuclei, i.e. to the nerve to the inferior oblique muscle.

The evidence, therefore, points to the conclusion that the oculomotor nucleus is a multiple nucleus, each part of which gives origin to one of the nerves of one of the eye-muscles.

Edinger says that sueh an array of clinical observations exists, 
and of facts derived from post-mortem dissections, that one may venture to designate the portion of the nucleus from which the innervation of each indivilual ocnlar muscle comes. He gives Starr's table, the latest of these numerons attempts, begun by Pick. According to Starr, the nuclei of the nerves to the individual miscles are arranged from before backward, thus-

m. sphineter iridis.
m. levator palpebre.
m. rectus superior.
m. oblinus inferior.

m. ciliaris.

m. rectus internus.

m. reetus inferior.

Further, the evidence of the well-known physiological experiments of Hensen and Völckers that the terminal branches of the oculomotor nerve arise from a series of segments of the nueleus, arranged more or less one behind the other in a longitudinal row, leads them to the conclusion that the nuclei of origin are arranged as follows, proceeding from head to tail :-

Nearest brain.

1. m. ciliaris.

2. m. sphincter iritis.

3. m. rectus internus.

4. m. reetus superior.

5. m. levretor palpebrec.

6. m. rectus inferior.

Most posterior. $\quad 7$. m. obliquus inferior.

It is instructive to compare this arrangement of Hensen and Völckers with the arrangement of the origin of these museles from the premandibular eavity as given by Miss Platt.

Thus she states that the most posterior part of the premandibular cavity is cut off so as to form a separate eavity, resembling, except in position, the anterior cavity; this separate, most posterior part gives origin to the inferior oblique muscle. She then goes on to describe how the dorsal wall of the remainder of the premandibular cavity beeomes thickened, to form posteriorly the rudiment of the inferior rectus and anteriorly the rudiments of the superior and internal recti, a slight depression in the wall of the cavity separating these rudiments. The internal rectus is the more median of the two anterior muscles. In other words, her evidence points not only to a fusion of somites to form the premandibular cavity, but also to the arrangement of these somites as follows, from head to tail: (1) internal rectus, (2) superior rectus, (3) inferior rectus, (4) inferior 
oblique-an order precisely the same as that of Hensen and Völckers, and of Starr.

I conclude, from the agreement between the anatomical, physiological, and morphological evidence, that the IIIrd and IVth nerves contain the motor somatic nerves belonging to the same segments as the motor trigeminal, in other words, to the prosomatic segments, so that the eyc-muscles, innervated by III. and IV., represent segmental muscles belonging to the prosoma. Further, I conclude that originally there were seven prosomatic scgments, the first of which is represented by the anterior cavity described by Miss Platt, and does not form any permanent muscles; that the next four belong to the premandibular cavity, and the muscles formed are the superior rectus, internal rectus, inferior rectus, and inferior oblique; and that the last two belong to the mandibular cavity, the muscles formed being Miss Platt's mandibular muscle and the superior oblique. It is, to say the least of it, a striking coincidence that such an arrangement of the ccelomic cavities as here given should be so closely mimicked by the arrangement in the prosomatic region of Limulus as already mentioned; it suggests inevitably that the head-cavities of the vertebrate are nothing more than the prosomatic and mesosomatic segmental crelomic cavities, as found in animals such as Limulns. In the table on $\mathrm{p} .253$, I have inserted the segments in the vertebrate for comparison with those of Limulus.

Before we can come to any conclusion as to the original position of these eyc-muscles, it is necessary to consider the VIth nerve and the external rectus muscle. This nerve and this muscle belong to van Wijhe's 4th segment. The muscle is, therefore, the somatic segmental muscle belonging to the same segment as the facial and is, in fact, a segmental muscle belonging not to the prosoma, but to the mesosoma. Neal comes to the conclusion that the existing abducens is the only root which remains permanent among a whole series of corresponding ventral roots belonging to the opisthotic segments, and further points out that the external rectus was originally an opisthotic muscle which has taken up a pro-otic position, or, translating this statement into the language of Limulus, etc., it is a mesosomatic muscle which has taken up a prosomatic position.

There is, however, another muscle-the Retractor aculi-belonging to the same group which is innervated by the VIth nerve. Quite recently Elgeworth has shown that in birds and reptiles this muscle 
belongs to the hyoid segment; so that in this respect also the hyoid segment proclaims its double nature.

With respect to the external rectus muscle, Miss Platt has shown that the mandibular muscle is formed close alongside the external rectus, so that the two are in close relationship as long as the former exists.

Further, as already mentioned, the eye-muscles in Ammocretes must be considered by themselves; they do not belong in structure or position to the longitudinal somatic muscles innervated by the spinal nerves; their structure is not the same as that of the tubular constrictor or branchial muscles, but resembles that structure somewhat; their position is dorso-ventral rather than longitudinal; they may be looked upon as a primitive type of somatic muscles segmentally arranged, the direction of which was dorso-ventral.

Anderson also has shown that the time of medullation of the nerves supplying these muscles is much earlier than that of the nerves belonging to the somatic trunk-muscles, their medullation taking place at the same time as that of the motor nerves supplying the striated visceral muscles; and Sherrington has observed that these muscles do not possess muscle-spindles, while all somatic trunk-muscles do. Both these observations are strong confirmation of the view that the eye-muscles must be classified in a different category to the ordinary somatic trunk muscle group.

What, then, is the interpretation of these various embryological and anatomical facts?

Remembering thetripartite division of each segmental nerve-group in Limulus into (1) dorsal or sensory somatic nerve, (2) appendagenerve, and (3) ventral somatic nerve, I venture to suggest that the three nerves-the oculomotorius, the trochlearis, and the abduccns -represent the ventral somatic nerves of the prosorna, and partly also of the mesosoma; that they are nerves, therefore, which may have originally contained sensory fibres, and which still contain the sensory fibres of the eye-muscles themselves, as stated by Sherrington. According to this suggestion, the eye-muscles are the sole survivors of the segmental dorso-rentral somatic muscles, so characteristic of the group from which I imagine the vertebrates to have sprung. In the mesosomatic region the dorso-ventral muscles which were retained were those of the appendages and not of the mesosoma itself, because the presumed ancestor breathed after the fashion of the waterbreathing Limulus, by means of the dorso-ventral muscles of its 
branchial appendages, and not after the fashion of the air-breathing scorpion, by means of the dorso-ventral muscles of the mesosoma. The only mesosomatic dorso-ventral muscles which were retained were those of the foremost mesosomatic segments, i.e. those supplied by the VIth nerve, which were preserved owing to their having taken on a prosomatic position and become utilized to assist in the movements of the lateral eyes.

Let us turn now to the consideration of the corresponding musculature in Limulus and in the scorpion group. These muscles constitute the markedly segmental museles to which I have given the name 'dorso-ventral somatic muscles.' They are most markedly segmental in the mesosomatic region, both in Limulus and in Scorpio, each mesosomatic segment possessing a single pair of these vertical mesosomatic muscles, as Benham calls them ( $c f$. Fig. $58(D v$.$) ). In$ the prosomatic region the corresponding muscles are not so clearly defined in Limulus; they are apparently attached to the plastron forming the group of plastro-tergal muscles. From Benham's description it is sufficiently evident that they formed originally a single pair to each prosomatic segment.

In Scorpio, according to Miss Beck, the dorso-ventral prosomatic muscles are situated near the middle line on each side and form the following well-marked series of pairs of muscles, shown in Fig. 110, A, taken from her paper, and thus described by her:-

1. The dorso-cheliceral-sternal muscle (61) is the most anterior of the dorso-ventral muscles. It is very small, and is attached to the carapace near the median line anteriorly to the central eyes.

2. The median dorso-preoral-entosclerite muscle (62) is a large muscle, between which and its fellow of the opposite side the eyes are sitnated. It is attached dorsally to the carapace and ventrally to the pre-oral entosclerite.

3. The anterior dorso-plastron muscle (63) is attached dorsally to the carapace in the middle line, being joined to its fellow of the opposite side. They separate, and are attached ventrally to the plastron. Through the arch thus formed the alimentary canal and the dorsal vessel pass.

4. The median dorso-plastron muscle (64) is attached dorsally to the posterior part of the carapace. It runs forward on the anterior surface of the posterior flap of the plastron to the body of the plastron, to which it is attached. 


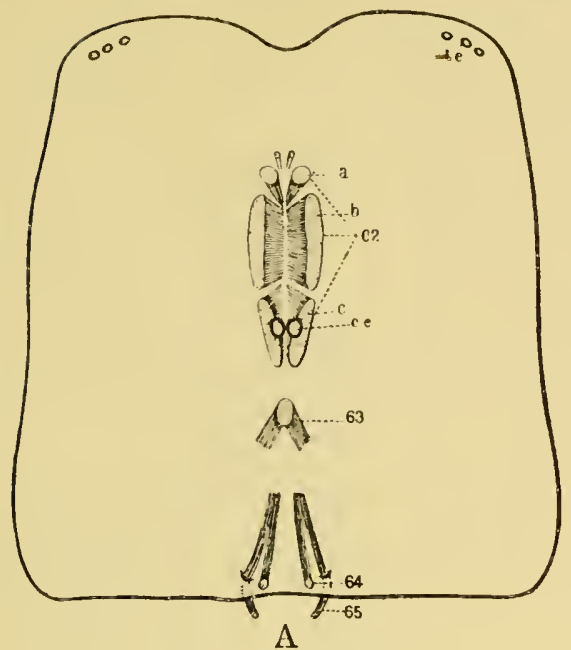

A.

Dorso - ventral Mescles on Carapace of Scorpion. (From Miss Beck.)

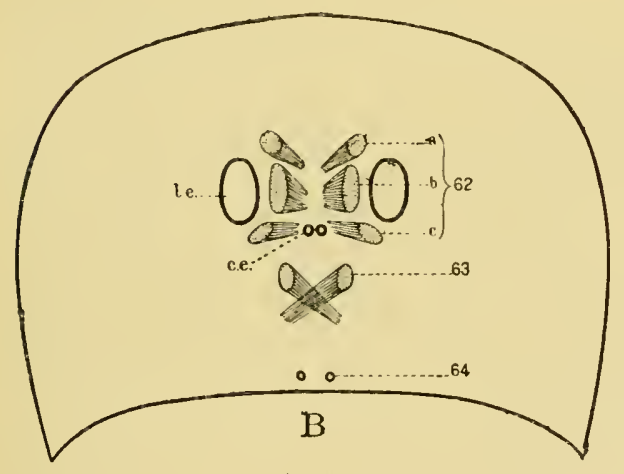

P.

Similar Mugcles on Carapace of Eurypterus.

C.

Similar Muscles on HeadShield of a Cephalaspid.

l.e., lateral eyes; c.e., central eyes; Fro., narial opening.

62-65 refer to Miss Beck's catalogue of the scorpion muscles.

FIG. 110. 
To these may be added, owing to its attachment to the plastron,

5. The posterior dorso-plastron muscle (65). This is the first of the dorso-ventral muscles attached to the mesosomatic tergites, being attached to the tergite of the first segment of the mesosoma.

This muscle is of interest, in connection with the prosomatic dorso-ventral muscles, because it is attached to the plastron, and runs a course in close contact with the muscle (64), the two muscles being attached dorsally close together, on each side of the middle line, the one at the very posterior edge of the prosomatic carapace, and the other at the very anterior edge of the mesosomatic carapace.

Taking these muscles separately into consideration, it may be remarked with respect to (61) that the cheliceral segment in its paired dorso-ventral muscles, as in its tergo-coxal muscles, takes up a separate position isolated from the rest of the prosomatic segments.

Next comes (62) the median dorso-preoral-entosclerite muscle, which is strikingly different from all the other dorso-ventral muscles in its large size and the extent of its attachment to the dorsal carapace, according to Miss Beck's figures. The reason of its large size is clearly seen upon dissection of the mnuscles in Buthus, for I find that, strictly speaking, it is not a single muscle, but is composed of a series of muscle-bundles, separated from each other by connective tissue. There are certainly three separate muscles included in this large muscle, which are attached in a distinct series along the pre-oral entosclerite, and present the appearance given in Fig. 110, A, at their attachment to the prosomatic carapace. Of this muscle-group the most anterior and the most posterior bundle are distinctly separate muscles; I am not, however, clear whether the mildle bundle represents one or two muscles.

This division of Miss Beck's muscle (62) into three or four muscles briugs the prosomatic region of the scorpion into line with the mesosomatic, and enables us to feel sure that a single pair of dorso-ventral somatic muscles belongs to each prosomatic segment just as to each mesosomatic, and, conversely, that each such single pair of muscles possesses segmental value in this region as inuch as in the mesosomatic.

It is very striking to see how in all the Scorpionidx, in which the two median eyes are the principal eyes, this muscle group (62) on the two sides closely surrounds these two eyes, so that with a fixed 
pre-oral entosclerite, a slight movement of the eyes, laterally or anteriorly, owing to the flexibility of the carapace, might result as the consequence of their contraction. But this cannot be the main object of these museles. The pre-oral entoselerite is firmly fixed to the camerostome, as is seen in Fig. 94, pr. ent., so that the main object of these muscles is, as Huxley has pointed out, the movement of this organ.

In order to avoid repetition of the long name given to this musele group (62) by Miss Beck, becanse of their position, and for other reasons which will appear in the sequel, I will call this group of muscles the group of recti museles. These recti muscles belong clearly to the segments posterior to the first prosomatic or eheliceral segment, and represent certainly three, probably four, of these segments, i.e. beloug to the segments corresponding to the second, third, fourth, and fifth prosomatic locomotor appendages-the endognaths of the old Eurypterids.

The next pair of museles is the pair of anterior dorso-plastron muscles (63). This muscle-pair evidently belongs to a segment posterior to the segments represented by the group already discussed, and belongs, therefore, in all probability to the same segment as the sixth pair of prosomatic appendages-the ectognaths of the old Eurypterids. This can be settled by considering either the nervesupply or the embryological development. In the Eurypteridie it seems most highly probable that the dorso-ventral museles of each balf of the segments helonging to the endognaths should be compressed together and separate from the dorso-ventral muscle belonging to the ectognathal segment, on account of the evident concentration and small size of the endognathal segments in contradistinction to the separateness and large size of the ectognathal segment.

The striking peculiarity of this muscle-pair, which distinguishes it from all other muscles in the scorpion, is the common attachment of the muscles of the two sides in the mid-clorsal line, so that the pair of museles forms an arch through which the alimentary canal and dorsal blood-vessel pass.

The same dorso-ventral muscles are present in Phrynus, and in this animal the fibres of this pair of muscles (63) actually interlace before the attachment to the prosomatic carapace, so that the attachment of the musele on each side overpasses the mid-ilorsal line, and a true crussing oecurs. In Fig. 108 the position of this pair of 
muscles is shown just posteriorly to the brain-mass. This muscle I will call the oblique muscle.

Finally we come to the muscles (64) and (65), the median and posterior dorso-plastron muscles, which run close together. Both muscles are attached to the plastron, and, therefore, to that extent belong to the prosomatic region; they are attached dorsally close to the junction of the prosoma and mesosoma. This position of the first mesosomatic dorso-ventral muscle belonging to the opercular segment may be compared with the position of the first mesosomatic dorso-ventral muscle in Limulus which has become attached to the prosomatic carapace; in both cases we see an indication that the foremost pair of mesosomatic dorso-ventral somatic muscles tend to take up a prosomatic position.

As to the pair of small muscles (64), I believe that they represent the dorso-ventral muscles of the seventh prosomatic segment (if the pair of muscles (63) belongs to the segment of the sixth locomotor prosomatic appendages), i.e. they belong to the chilarial segment or metastoma.

I desire to draw especial attention to the fact that the dorsoventral muscle (64), which represents the seventh segment, always runs close alongside the dorso-ventral muscle (65), which represents the first mesosomatic or opercular segment.

The comparison, then, of these two sets of facts leads to the following conclusions :-

The foremost prosomatic or trigeminal segment stood separate and apart, being situated most anteriorly; the musculature of this segment does not develop, so that the only evidence of its presence is given by the anterior colomic cavity. This corresponds, according to my scheme, with the first or anterior colomic cavity of Limulus, and therefore represents, as far as the prosomatic appendages arc concerned, the first prosomatic appendage-pair, or the chelicere; the appendage-muscles being the muscles of the cheliceræe, and the dorso-ventral somatic muscles the pair of dorso-cheliceral sternal muscles (61) in the scorpion. Both these sets of muscles, therefore, dwindle and disappear in the vertebrate.

Then came four segments fused together to form the premandibular segment, the characteristic of which is the apparent nonformation of any permanent musculature from the ventral mesodermsegments, and the formation of the eyc-muscles innervated by the 
oculomotor nerve from the dorsal mesoderm segments. These four segments have been so fused together that van Wijhe looked upon them as a single segment, and the premandibular cavity as the cavity of a single segment. They represent, according to my scheme, the segments belonging to the endognaths, i.e. the second, third, fourth, fifth pairs of prosomatic appendages; the premandibular cavity, therefore, represents the second coelomic cavity in Limulns, which, according to Kishinouye, is the sole representative of the cœlomic cavities of the second, third, fourth, fifth prosomatic segments. The muscles derived from the ventral mesoderm-segments represent the muscles of these appendages, which therefore dwindle and disappear in the vertebrate, with the possible exception of the muscles innervated by the descending root of the trigeminal. The muscles derived from the dorsal mesoderm-segments, i.e. the eye-muscles supplied by the oculomotor nerve, represent the dorso-ventral somatic muscles of these four segments, muscles which are represented in the scorpion by the recti group of muscles, i.e. the median dorso-preoral-entosclerite muscles (62).

Then came two segments, the mandibular, in which muscles are formed both from the ventral and from the dorsal mesoderm-segments. From the former arose the main mass of muscles innervated by the motor root of the trigeminal, from the latter the superior oblique muscle and the mandibular muscle of Miss Platt, of which the former' alone survives in the adult condition. These two segments are looked upon as a single segment by van Wijhe, of which the mandibular cavity is the colomic cavity. They represent, according to my scheme, the segments belonging to the sixth pair of prosomatic appendages or ectognaths, and the seventh pair, i.e. the chilaria or metastoma.

The first part, then, of the mandibular cavity represents the third colomic cavity in Limulus and the muscles derived from the ventral mesoderm, in all probability the muscles of the tongue in the lamprey (cf. Chap. IX.), which represents the ectognaths or sixth pair of prosomatic appendages, while the muscles derived from the dorsal mesoderm, i.e. the superior oblique muscles, represent the dorso-ventral somatic muscles of this segment, muscles which are represented in the scorpion group by the pair of anterior dorsoplastron or oblique muscles (63).

The second part of the mandibular eavity represents the 4th 
celomic eavity in Limulus and the muscles derived from the ventral mesoderm, in all probability the muscles of the lower lip in the lamprey (cf. Chap. IX.), which represents the metastoma; while the muscles derived from the dorsal mesoderm, i.e. Miss Platt's pair of mandibular inuscles, represent the dorso-ventral somatic muscles of this segment, muscles which are represented in the scorpion group by the pair of median dorso-plastron muscles (64).

In connection with this last pair of muscles we find that the external rectus in the vertebrate represents the first dorso-ventral mesosomatic muscle in the scorpion, i.e. the posterior dorso-plastron muscle (65), and, as already mentioned (p. 267), that it always lies closely alongside the mandibular muscle, just as in the scorpion group muscle (65) always lies alongside muscle (64).

In the invertebrate as well as in the vertebrate this muscle is a mesosomatic muscle which has taken up a prosomatic position.

The question naturally arises, what explanation can be given of the fact that these dorso-ventral muscles attached on each side of the mid-dorsal line to the prosomatic carapace became converted into the muscles moving the eyeballs of the two lateral eyes? An explanation which must take into account not only the isolated position of the abducens nerve, but also the extraordinary course of the trochlearis. The natural and straightforward answer to this question appears to me quite satisfactory, and I therefore venture to commend it to my readers.

I have argued the case out to myself as follows: The lateral eyes must have been originally situated externally to the group of muscles innervated by the oculomotor nerve, for a sheet of muscle representing the superior internal and inferior rectus muscles conld only wrap round the internal surface of each lateral eye; i.e. the arrangement of the muscle-sheet, as in the scorpion, about two median eyes, is in the wrong position, for if those two eyes, which are the main eyes in the scorpion, were to move outwards to become two lateral eyes, then such a muscle-group would form a superior external and inferior rectus group. The evidence, however, of Eurypterus and similar forms is to the effect that the lateral eyes became big and the median eyes insignificant and degenerate. If, then, with the degeneration of the one and the increasing importance of the other, these lateral eyes came near the middle line, then the muscular group (62), which I have ealled the recti group, would naturally be pressed into their 
service, and would form an internal and not an external group of eye-muscles.

In Fig. 110, A, taken from Miss Beck's paper, I have shown the relative position of the eyes and the segmental dorso-ventral prosomatic muscles on the carapace of the scorpion. In Fig. 110, B, I have drawn the prosomatic carapace of Eurypterus Scouleri, taken from Woodward's paper, with the eyes as represented there; in this I have inserted the segmental dorso-ventral muscles as met with in the scorpion, thereby demonstrating how, with the degeneration of the median eyes and the large size of the lateral eyes, the recti muscles of the scorpion would approach the position of an internal recti group to the lateral eyes, and so give origin to the group of muscles innervated by the oculomotor nerve. In the Eurypterus these large eyes are large single eyes, not separate ocelli, as in the scorpion.

All, then, that is required is that in the first formed fishes, which still possessed the dorso-ventral muscles of their Eurypterid ancestors, the lateral eyes should be the important organs of sight, large and near the mid-dorsal line. Such, indeed, is found to be the case. In amongst the masses of Eurypterids found in the upper Silurian deposits at Oesel, as described by Rohon, numbers of the most ancient forms of fish are found belonging

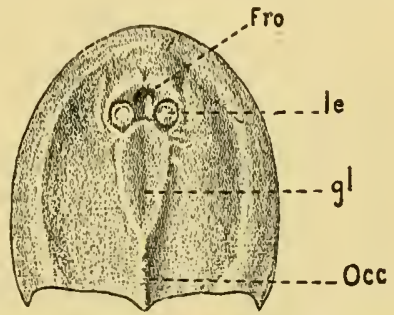

FIG. 111. - Dorsal HeadSHIELD OF Tremataspis Mickwitzi. (From Rohos.)

Fro., narial opening; l.e., lateral eyes; $g l$. , glabellum plate over brain; Occ., occipital spine. to the genera Thyestes and Tremataspis. The nature of the clorsal head-shields of these fishes is shown in Fig. 14, which represents the dorsal head-shield of Thyestes verrucosus, and Fig. 111 that of Tremataspis Mickwitzi. They show how the two lateral eyes were situated close on each side of the mid-dorsal line in these Eurypteruslike fishes, in the very position where they must have been if the eye-muscles were derived from the dorso-ventral somatic muscles of a Eurypterid ancestor.

In Lankester's words, one of the characteristics of the Osteostraci (Cephalaspis, Auchenaspis, etc.), as distinguished from the Heterostraci (Pteraspis), are the large orbits placed near the centre of the shield. The apparent exception of Thyestes mentioned by him is no 
exception, for orbits of the same character have since been discovered, as is seen in Rohon's figure (Fig. 14). In Fig. 110, C, I give an outline of the frontal part of the head-shield of a Cephalaspid, in which I have drawn the eye-muscles as in the other two figures.

Although all the members of the Osteostraci possess large lateral eyes towards the centre of the head-shield, the other gromp of ancient fishes, the Heterostraci, are characterized by the presence of lateral cyes far apart, situated on the margin of the head-shield on each side ( $c f$. Fig. 142, o, p. 350).

So, also, on the invertebrate side, the lateral eyes of Pterygotus and Slimonia are situated on the margin of the prosomatic carapace, while those of Eurypterus and Stylonurus are situated much nearer the middle line of the prosomatic carapace.

Next comes the question of the superior oblique muscle and the trochlearis nerve. Why does this nerve (n.IV. in Fig. 106, C and D) alone of all the nerves in the body take the peculiar position it always does take? The only suggestion that I know of which sounds reasonable and worth consideration is that put forward by Fürbringer, which is an elaboration of the original suggestion of Hoffmann. Hoffmann suggested in 1889 that the trochlearis nerve represented originally a nerve for a protecting organ of the pineal eye, which became secondarily a motor nerve for the lateral eye as the pineal eye degenerated. Fürbringer differs from Hoffmann in that he considers that the nerve was originally a motor nerve, and was not transformed from sensory to motor, yet thinks Hoffmann's suggestion is in the right direction.

He points out that the crossing of the trochlearis is not a crossing of fibres between two centres in the central nervous system, but may be explained by the shifting of the peripheral organ, i.e. the muscle, from one sicle to the other, and the nerve following this shift. Consequently, says Fürbringer, the course of the nerve indicates the original position of the inuscle, and therefore he imagines that the ancestor of the superior oblique muscle was a muscle the fibres of which were attached in the mid-dorsal line, and,interlaced with those of the other side, the two muscles thus forming an arch through which the nervous system with its central canal passed. Then, for the sake of getting a more efficient pull, the crossing muscle-fibres became more definitely attached to the opposite side of the middle line, and finally obtained a new attachment on the opposite side, with the 
obliteration of the inuscular arch; the nerve on each side, following the shifts of the muscle, naturally took up the position of the original muscular arch, and so formed the trochlear nerve, with its dorsal crossing. This explanation of Fürbringer's was associated by him with movements of the median pineal eyes, the length of their nerve, according to him, even yet indicating their previous mobility. This assumption is not, it seems to me, necessary. The length of the nerve is certainly no indication of mobility, for in Limulus and the scorpion group the nerve to each median eye is remarkably long, yet these eyes are immovably fixed in the carapace. All that is required is a pair of dorso-ventral muscles belonging to the segment immediately following the group of segments represented by the oculomotor nerves, the fibres of which should cross the mid-dorsal line at their attachment; for, seeing that the lateral eyes were originally so near this position, it follows that such muscles might form part of the muscular group belonging to the lateral eye without having previously moved the pineal eyes. In fact, Fürbringer's explanation requires as startingpoint that the pair of muscles which ultimately become the-superior oblique should have the exact position of the pair of dorso-ventral muscles in the scorpion, called by Miss Beck the anterior dorsoplastron muscles (63), which I have named the oblique muscles. Here, and here only, do we find an interlacement, across the middorsal line, of the fibres of attachment of the muscles on the two sides, in consequence of which this pair of muscles is described by her as forming an arch encircling the alimentary canal and dorsal vessel. If, then, as I have previously argued, the primitive plastron formed a pair of trabecula, and the nervous system grew round the alimentary canal, such an arch would encircle the tubular central nervous system of the vertebrate.

Still more striking is this pair of muscles (63) in Phrynus (Fig. 108), where we see how the arch formed by them almost tonches the posterior extremity of the supra-cesophageal brain-mass, crossing, therefore, over the beginning of the stomach region of the animal. The angle formed by the arch is much more obtuse than that formed in Scorpio, so that an actual crossing of the muscle-fibres has taken place at the point of attachment to the carapace. Also, only the part nearest the carapace is muscular, the rest forming a long tendinous prolongation of the plastron wall (the primordial cranium), as seen in the figure. 
This muscle-pair is, as it should be, the pair of dorso-ventral muscles belonging to the segment immediately following on the group of segments represented by the recti muscles, i.e. according to previous argnment, the segment belonging to the sixth pair of locomotor appendages or ectognaths; a muscle, therefore, which would arise in the vertebrate from the mandibular, and not from the premandibular cavity. A similar muscle probably existed in

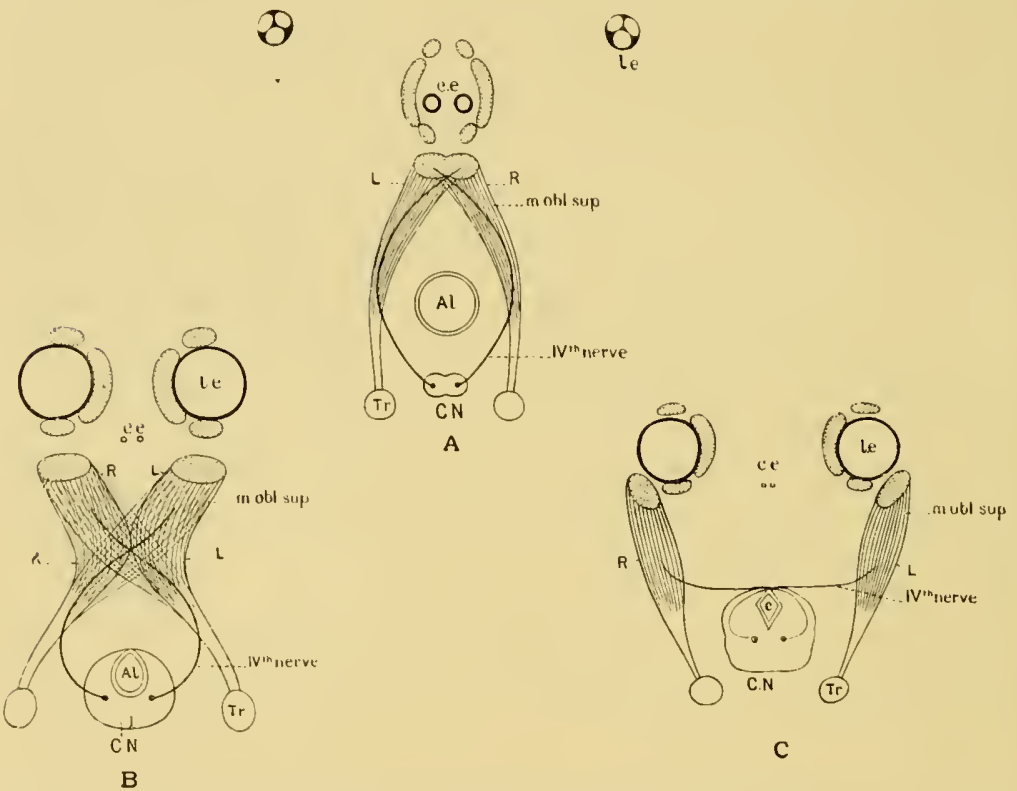

Fig. 112.-A, Diagram of Position of Oblique Muscle in Scorpion; B, Diagram of Transition Stage; C, Diagram of Superior Oblique Muscle in VerteBRATE.

l.e., lateral eyes; c.e., central eyes; C.N., central nervous system; $A l$, alimentary canal; c., aqueductus Sylvii.

Eurypterus (11.obl. in Fig. 106, B), and, as in the case of the formation of the oculomotor group, derived from the recti group of the scorpion, would form the commencement of the superior oblique muscle in Thyestes and Tremataspis.

It is instructive to notice that the original position of attachment of this muscle is naturally posterior to that of the oculomotor group of muscles, and that Fïrbringer, in his description of the eye-muscles of Petromyzon, asserts that this muscle in this primitive vertebrate 
form is not attached as in other vertebrates, but is posterior to the other muscles, so that he calls it the posterior rather than the superior oblique. The nature of the change by which the muscle known in the scorpion as the anterior dorso-plastron muscle (63) was probably converted into the superior oblique muscle of the vertebrate, is represented in the drawings Fig. 112, in which also are indicated the dwindling of the median eyes, and the progressive superiority of the lateral eyes, as well as the transformation of the recti musclegroup of the scorpion into the inuscles supplied by the oculomotor nerve of the vertebrate.

With respect to the external rectus muscle, it follows naturally that if the muscles (64) and (65) are to follow suit with the rest of the group and become attached to the lateral eyes, they must take up an external position. These two muscles, which always run together, as seen in Fig. 110, A, the one belonging to the prosoma and the other to the mesosoma, are represented by the mandibular muscle of Miss Platt and the external rectus, the former derived from the walls of the last pro-otic head-cavity, the latter from the foremost of the opisthotic head-cavities.

Such, then, is the simple explanation of the origin of the eyemuscles which follows from my theory, and we see that the successive alterations of the position of the orbit, and, therefore, of the globe of the eye with its muscles, as we pass from Thyestes to man, is the natural consequence of the growth of the frontal bone, i.e. of the brain.

\section{The Trigemal Nerves axd the Muscles supplied by thex.}

Turning now to the evidence as to the number of ventral segments, i.e. the motor and sensory supply to the prosomatic appendages afforded by the trigeminal nerve, we must, I think, come to the same conclusion as Dolırn, viz. that if there were originally seven dorsal or somatic segments in this region represented by: 1, Anterior cavity, muscle lost ; $2,3,4,5$, muscles of the premandibular cavity, sup. rectus, inf. reetus, int. rectus, inf. oblique, supplied by IIIrd nerve; 6, 7, muscles of the mandibular cavity, sup. oblique, supplied by IVth nerve and muscle lost, there must have been also seven corresponding ventral or splanchnic segments supplied by the trigeminal. At present the evidence for such segments is nothing like so strong as for the corresponding somatic ones; there are, however, certain suggestive 
facts which point distinctly in this direction in connection with both the motor and sensory parts of the trigeminal. The origin of the trigeminal motor fibres in the central nervous system is most striking. We may take it for granted that a nucleus of cells giving origin to one or more segmental motor nerves will possess a greater or less longitudinal extension in the central nervons system, according to the number of fused separate segmental centres it represents. Thus a nucleus such as that of the IVth nerve or of the facial is small and compact in comparison to the extensive conjoint nucleus of the vagus and cranial accessory.

Upon examination of the motor nucleus of the trigeminal, we find a compact or well-defined nucleus, the nucl. masticatorius, the nerves of which supply the masseter, temporal, and other muscles, so that the anatomical evidence at first sight appears to bear out van Wijhe's conclusion that the motor trigeminal supplies at most two segments. Further examination, however, shows that this is not all, for the extraordinary so-called descending root of the $V$ th must be taken into consideration in any question of the origin of the motor elements, just as the equally striking ascending root enters into the consideration of the meaning of the sensory elements of the Vth.

It is not necessary here to discuss the controversy as to whether this descending root is motor or sensory. It is universally considered at present to be motor, and is believed to supply, as Kölliker suggested, among other muscles, the m. tensor tympani and the m. tensor veli palati. It is thus described by Obersteiner-

"From the region of the mid-brain the motor root receives an important addition of thick fibres, which form the cercbral or descending root. The large, round vesicular cells from which the fibres of the descending root arise form no single compact group, but are partly single, partly arranged like little bunches of grapes, as far as the region of the anterior corpora quadrigemina. The further we go brainwards, the smaller is the number of fibres. In the region of the anterior corpora quadrigemina, the few cells of origin are found more and more median; so that the uppermost trigeminal fibres descend in curves almost from the mid-line, as is shown by the exceptional occurrence of one or more of the characteristic cells above the aqueduct. At the height of the posterior commissure one finds the last of these trigeminal cells." 
The anatomy of the $V$ th nerve reveals, then, three most striking facts :-

1. The motor nucleus of the Vth extends from the very commencement of the infra-infundibular region to nearly the commencement of the mucleus of the VIIth; in other words, the motor nucleus of the Vth extends through the whole prosomatic region, just as it must have done originally if its motor nerves supplied the muscles of the prosomatic appendages. Such an extended range of origin is indicative of the remains of an equally extended series of segmental centres or ganglia.

2. Of these centres the candalmost have alone remained large and vigorous, constituting the nucleus masticatorius, which in the fish is divided into an anterior and posterior group, thus indicating a double rather than a single nucleus; while the foremost ones have dwindled away until they are represented only by the cells of the descending root, the muscles of these segments being still represented by possibly the tensor veli palati and the other muscles innervated from these cells.

3. The headmost of these cells takes up actually a position dorsolateral to the central canal, so that the groups on each side nearly come together in the mid-dorsal line; a very unique and extraordinary position for a motor cell-group, but not improbable when we recall to mind Brauer's assertion as to the shifting of the foremost prosomatic ganglion-cells of the scorpion from the ventral to the dorsal side of the alimentary canal.

On the sensory side the evidence is also suggestive, the question here being not so much the distribution of the sensory nerves as the number of ganglia belonging to each of the cranial nerves.

With respect to this question, morphologists have come to the conclusion that there is a marked difference between spinal and cranial nerves, in that whereas the posterior root-ganglia of the spinal nerves arise from the central nervous system itself, i.e. from the neural crest, the ganglia of the cranial nerves arise partly from the neural crest, partly from the proliferation of cells on the surface of the animal; and because of the situation of these proliferating epidermal patches over the gill-clefts in the case of the vagus and glossopharyngeal nerves, they have been called by Froriep and Beard branchial sense-organs. Beard divides the cranial ganglia into two sets, one connected with the neural ridges, called the neural ganglia, 
and the other connected with the surface-cells, which he calls the lateral ganglia. This second set corresponds to Kupffer's epiluranchial ganglia. Now it is clear that in the case of the ragus nerve, where, as is well shown in Ammocœtes, the nerve is not a single segmental nerve, but is in reality made up of a number of nerves going to separate branchial segments, the indication of such segments is not given by the main vagus ganglion or neural ganglion, but by the series of lateral ganglia. So also it is argued in the case of the trigeminal, that if in addition to the ganglion-cells arising from the neural crest separate ganglion-masses are found in the course of development, in comnection with proliferating patches of the surface (plakodes, Kupffer calls them), then such isolated lateral ganglia are indications of separate segments, just as in the case of the vagus, even though the separate segments do not show themselves in the adult. So far the argument appears to me just, but the further conclusion that the presence of such plakodes shows the previous existence of bronchial sense-organs, and, therefore, that such ganglia are epibranchial ganglia, indicating the position of a lost gill-slit, is not justified by the premises. If, as I suppose, the trigeminal nerve supplied a series of non-branchial appendages serially homologous with the branchial appendages supplied by the vagus, then it is highly probable that the trigeminal should behave with respect to its sensory ganglia similarly to the vagus nerve, without having anything to do with branchiæ.

Such plakodal ganglia, then, may give valuable indication of nonbranchial segments as well as of branchial segments. The researches of Kupfer on the formation of the trigeminal ganglia in Ammocotes are the chief attempt to find out from the side of the sensory ganglia the number of segments originally belonging to the trigeminal. The nature and result of these researches is described in my previous paper (Journal of Anatomy and Physiology, vol. xxxiv.), and it will suffice here to state that he himself concludes that the trigeminal originally supplied five at least, probably six, segments. As I have stated there, the evidence as given by him seems to me to indicate eren as many as seren segments.

In the full-grown Ammocetes, as is well known, there are two distinct ganglia belonging to the trigeminal, the one the ganglion of the ramus ophthalmicus, the other the main ganglion.

According to Kupffer the larval Ammocoetes possesses three sets of ganglia, not two, for between the foremost and hindmost ganglion 
he describes a nerve (x., Fig. 113), with four epibranchial ganglia, which do not persist as separate ganglia, but either disappear or are absorbed into the two main ganglia (Fig. 113). This discovery of Kupffer's is very suggestive, for, as already stated, a transformation takes place when the Ammocotes is $5 \mathrm{~mm}$. long, so that the arrangement of the parts before that period is distinctly more indicative of the ancestral arrangement than any later one.

If we use the name plakodal ganglia to represent that part of these ganglia which was originally connected with the skin, then

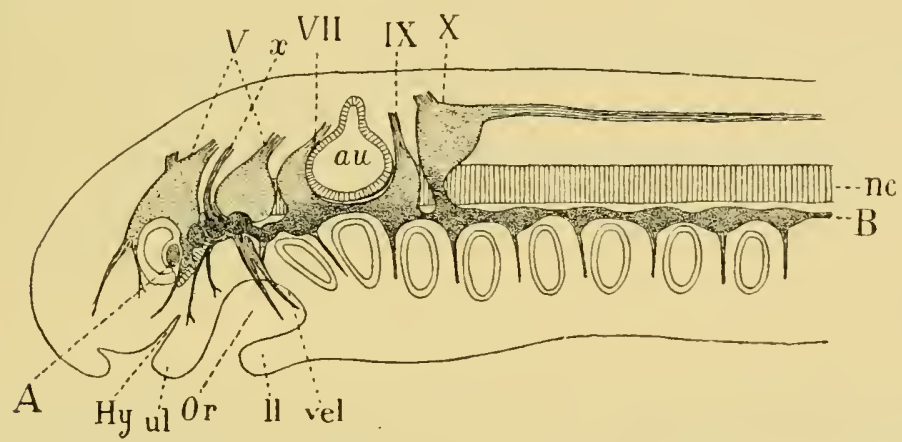

Fig. 113.-Ganglita of the Craniat Nerves of an Amoccetes, 4 min. in lengtif, projected on to the Median Plane. (After Kupffer.)

$A-B$, the line of epibranchial ganglia; au., auditory capsule; $n c$. , notochord; $H y$., tube of hypophysis ; Or., oral cavity; u.l., upper lip ; l.l. lower lip; vel., septum between oral and respiratory cavities; V., VII., $I X ., X$., cranial nerves; $x$., nerve with four epibranchial ganglia.

Kupffer's researches assert that in the larval Aminocotes there were seven such plakodal ganglia, one in front belonging to the foremost trigeminal ganglion, two behind, parts of the hindmost ganglion, and four in between, which do not exist later as separate ganglia.

In accordance with the views put forward in this book, a possible interpretation of these plakodal ganglia would be given as follows :-

Beard, who, after Froriep, drew attention to this relation of the cranial ganglia to special skin-patches, has compared them with the parapodial ganglia of annelids, i.e. ganglia in connection with annelidan appendages; whether we are here obtaining a glimpse of the far-off annelidan ancestry of both arthropods and vertebrates it would be premature at present to say. It is natural enough to expect, on iny view, to find evidence of annelidan ancestry in 
vertebrate embryology (as has been so often asserted to be the case), seeing that undoubtedly the Arthropoda are an advanced stage of Annelida; and, indeed, the way is not a long one when we consider Beecher's evidence that the Trilobita belong to the Phyllopoda, certainly a primitive crustacean group, which Pernard derives directly from the annelid group Chretopoda. If, then, these plakodal ganglia indicate the former presence of appendages, we obtain this result :The foremost ganglion on each side possesses one plakodal ganglion, and therefore indicates an anterior pair of appendages, possibly the chelicere. Then comes the peculiar nerve with four plakodal ganglia indicating on each side four appendages close together, possibly the endognaths. Then, finally, on each side, the second large ganglion with two plakodal ganglia, indicating two pairs of appendages, possibly the ectognaths and the metastoma.

\section{SUMMARY.}

The consideration of the history of the cranial segmentation shows that whereas, from the commencement of that history, the eridence for two rentral segments supplied by the trigeminal nerve is clear and unmistakable, later observers have tended more and more to increase the number of these segments, until at the present time the evidence is in farour of at least six, probably seven, as the number of segments supplied by the motor part of the trigeminal.

So, also, the original eridence for the number of dorsal or somatic segments limits the number to three, innerrated respectively by the oculomotor (III.). trochlear (IV.), and alducens (VI.) nerves, or rather two, since the last nerve belongs to the facial segment. The muscles which these three nerves supply are derired respectively from the walls of the premandibular. mandibular, and hyoid celomic cavities.

Later eridence points strongly to the conclusion that the ocnlomotor nerre and the premandibular carity represent not one segment but the fusion of four, while the mandibular carity represents two segments. In addition to these. Miss Platt has discovered a still more anterior head-eavity, which she has named the anterior cavity, so that the pro-otic segments on this reckoning are seren in number, riz. : (1) the anterior cavity, $(2,3,4,5)$ the premandibular carity, $(6,7)$ the mandibular earity. The somatic muscles belonging to these dorsal segments are the eye-muscles, which are all dorso-rentral in position, and are not the same as the longitudinal somatic muscles, but belong to a distinct dorsorentral segmental group, the only representative of which at present known in the mesosomatic region is the external rectus innervated by the VIth nerre.

These head-carities, and these muscles of the rertebrate, resemble the corresponding carities and muscles of the invertebrate to an extraordinary 
degree, so that it becomes easy to see how the dorso-rentral muscles of the prosomatic segments of the latter have become converted into the eye-musculature of the former. The most powerful proof of all that such a conversion has taken place is that a natural and simple explanation is at once giren of the extraordinary course taken by the IVth or trochlear nerve. Erer since neurology began. the course of this nerve has arrested the attention of anatomists. Why should just this one pair of nerre-roots of all those in the whole body be directed dorsalwards instead of rentralwards, and cross each other in the valve of Vieussens, each to supply a simple eye-muscle (the superior oblique) belonging to the other side? For generations anatomists have wondered and found no solution, and yet, without any straining of hypotheses, in consequence simply of the investigation of the anatomy of the corresponding pair of muscles in the scorpion group, the solution is immediately apparent.

This pair of muscles alone, of all the musculature attached to the carapace, crosses the mid-dorsal line to be attached to the other side, thus carrying its nerve with it to the other side; by a continuation of the same process the relation of the trochlear to the superior oblique muscle can be explained.

The comparison of the eye-muscles of the rertebrate with the dorso-rentral segmented muscles of the invertebrate makes the number and nature of the pro-otic segments much clearer. 


\section{CHAPTER IX}

\section{THE PROSOMATIC SEGMENTS OF AMMOCETES}

The prosomatic region in Ammocotes.-The suctorial apparatus of the adult Petromyzon.-Its origin in Ammocotes. - Its derivation from appendages. -The segment of the lower lip or metastomal segment.-The tentacular segments.-The tubular muscles.-Their segmental arrangement.-Their peculiar innervation.-Their correspondence with the system of renopericardial muscles in Limulus.-The old mouth or palæostoma.-The pituitary gland.-Its comparison with the coxal gland of Limulus.Summary.

In the last chapter it was seen not to be incompatible with both the anatomical and morphological evidence to look upon the trigeminal nerves as having originally supplied the seven prosomatic pairs of appendages of the invertebrate ancestor, the foremost of which, the cheliceræ, and the four pairs of endognaths dwindled away and became insignificant, leaving as trace of their former presence the descending root of the Vth nerve; while the two hindmost pairs, the ectognaths and the chilaria, or metastoma, remained vigorous and developed, leaving as proof of their presence the nuclcus masticatorius. Evidence in favour of this suggestion and of the nature of the dwindling process is afforded when we examine what the trigeminus does supply in Ammocoetes. In all vertebrates this nerve supplies the great muscles of mastication which, in all gnathostomatous fishes, move the jaws. The lowest fishes, the cyclostomes, possess no jaws ; they take in their food by attaching themselves to their prey and by neans of rasping teeth situated in serried rows within the circular mouth, combined with a porrerful snctorial apparatus, they suck the juices of the fish they feed upon. Not possessing jaws, they feed by suction on the living animal, a method of feeding which gives them no more claim to be classed as parasitic animals than the whole group of spiders which feed in a similar manner on living flies. 


\section{Tile Origin of the Suctorial Apparates of Petroniyon.}

This powerful suctorial apparatus is innervated entirely by the trigeminal nerve, so that here in its muscular arrangements any original segmental arrangement of the muscles of mastication might be expected to be visible. It consists of a large rod or piston, to which are attached powerful longitudinal muscles; a large muscle, the basilar muscle, which assists the piston in producing a racuum, and annular muscles around the circular lip.

Turn now to the full-grown larval form, Ammocetes, an animal in the case of Petromy:on Planeri as large as the full-grown P'etromyzon, and seek for this musculature. There is, apparently, no sign of it, no suctorial apparatus whatever, only, as already mentioned, an oral chamber bounded by the lower and upper lips and the remains of the septum between it and the respiratory chamber-the velar folds. Attached to its walls a number of tentacles are situated, which form a fringe around and within the moutl. Most extraordinary is the contrast liere between the larval and the adult stages; in the former, no sign of the suctorial apparatus, but simply tentacles and relar folds; in the latter, no sign of tentacles or of velar folts, but a massive suctorial apparatus.

In order, then, to understand the origin of the muscles of mastication, it is necessary to study the changes which occur at transformation, and thus to find out how the suctorial apparatus of the adult arises. This most important investigation has been undertaken by Miss Alcock, and owing to the kindness of Mr. Millington, of Thetford, we have been able to obtain a better series in the transformation process than lias ever been obtained before. Miss Alcock has not yet published her researches, but has allowed me to make use of some of her facts.

An enormous proliferation of muscular tissue takes place with great rapility during this transformation, which causes the disappearance of the tentacles, and gives origin to the suctorial apparatus. The starting point of this proliferation can be traced back in all cases to little groups of embryonic tissue found below the epithelial lining of the oral chamber in Ammocetes. Of these groups the most conspicuous one is situated at the base of the large median ventral tentacles. Others are situated at the base of the tentacular ridge. Further, althongh this extraordinary change takes place in the 
peripheral organ, no marked difference occurs in the arrangement of the nerves issuing from the trigeminal motor centre, no new nerves are formed to supply the new muscles, but every motor nervefibre and the motor cell from which it arises increases enormously in size, and these giant nerve-fibres thms formed split into innumerable filaments corresponding with the proliferation of themuscular elements.

The clue, then, to the origin of the suctorial apparatus and of the nature of the original organs supplied by the trigeminal is afforded in this case, as in all other similar inquiries, by the central nervous system and its outgoing nerves. Here is always the citadel, the fixed seat of government, here is 'headquarters,' from which the answers to all our inquiries must originate.

The Trigeminal Nerie of Amaoceetes.

Striking is the answer. In Fig. 114, Miss Alcock has drawn the distribution of the trigeminal nerve as traced by her through a series

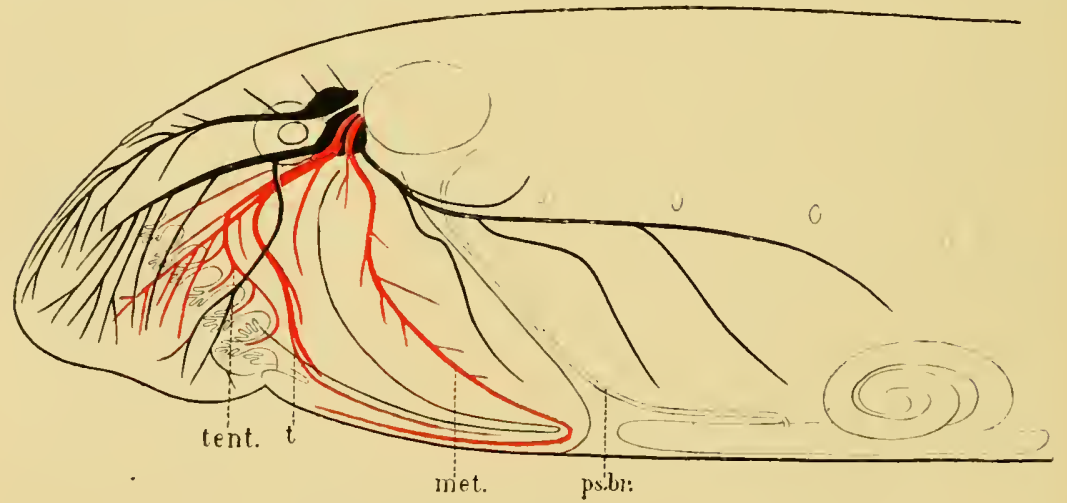

Fig. 114.-Distribution of Trigeminat Nerve in Amroceetes.

ps. $b r$., pseudo-branchial groove; met., nerve to lower lip, or metastomal nerve; $t$., nerve to tongue; tent., nerve to tentacles. The mandibular and internal maxillary nerves are coloured red; the purely sensory nerves to the external surface are coloured black.

of sections. It arises, as is well known, from two separate ganglia, of which the foremost gives rise to a pmely cutaneous nerve, the ophthalmic nerve, and the hindmost to three nerves, the most posterior of which is purely cutaneous and passes tailwards over the ventral branchial region, as shown in the figure; the other two nerves, both 
of which contain motor fibres, are called by Hatschek the mandibular and maxillary nerves. Of these the mandibular or velar nerve (met.) is a large, conspicuous nerve, which arises so separately from the rest of the trigeminal as almost to deserve the title of a separate nerve. When it leaves the large posterior ganglion, it passes into the anterior part of the velum, runs along with the tubular muscles, which it supplies, to the ventral surface as far as the junction of the lower lip with the thyroid plate, and has not been followed further by Hatschek. Miss Alcock, however, by means of serial sections, has traced it further, and shown that at this point it turus abruptly headwards to terminate in the muscles of the lower lip. If, then, as suggested, the lower lip represents the metastoma-the last pair of prosomatic appendages-then this mandibular or velar nerve represents that segmental nerve.

The other nerve-the maxillary nerve of Hatschek-which constitutes the larger part of the trigeminal, passes forwards from the ganglion, and at a point somewhere about the anterior region of the eyeball, divicles into two, an external (black in Fig. 114) and an internal (red in Fig. 114) nerve. The external branch is apparently entirely sensory, and supplies the external surfaces of the upper and lower lips. The internal branch is mainly motor, and supplies the muscles of the upper lip; it contains also the nerves of the tentacles.

The nerve to the median ventral tentacle $(t$. ) or tongue leaves the internal division of the maxillary immediately after its separation from the external; it runs ventralwards, and at the same time passes interually until it reaches a position between the muco-cartilage and the epithelium lining the cavity of the throat. It then turns, and passing posteriorly (towards the tail) to the point where the median ventral tentacle is attached to the lower lip, it supplies some rery rudimentary-looking muscles which run from the tentacle to the adjoining surface, and no doubt serve to move the tentacle from side to side. A portion of the nerve still continues to run along the sicle of the median ventral ridge, as far back as the point where the muscles of the hyoid segment pass round to the ventral side between the velum and the thyroid; in fact, this small nerve passes along the whole length of the median ventral ridge.

This description shows that the trigeminal nerve divides itself into two groups: the one representer black in the figure, which is purely cutaneous and sensory, corresponding, in the main, according 
to my theory, to the epimeral nerves of Limulus; the other coloured red, which supplies muscles belonging to the visceral or splanchnic muscle-group, and contains also the nerves to the tentacles.

This latter group, which is formed by two distinct well-defined nerves, viz, the mandibular and the internal branch of the maxillary, corresponds, according to my theory, to the amalgamated nerves of the prosomatic appendages, and is clearly divisible into three distinct nerves-

1. The lower lip-nerve or the metastomal nerve (met.).

2. The tongue-nerve $(t$.).

3. The nerve (tent.) to the upper lip and tentacles.

Of these three pairs of nerves it is suggested that the first pair were derived from the nerves to the metastomal appendage. The second pair of nerves ought, on this theory, originally to have supplied the pair of appendages immediately in front of the metastoma - that is, the pair of ectognaths, and therefore the ventral pair of tentacles, known as the tongue, would represent the last remnant of these ectognaths. Similarly, the other tentacles would represent the endognaths, and therefore the third pair of nerves would represent the fused nerves to these concentrated endognaths, which, in the Eurypterids, stand aloof from the ectognaths.

Let us consider these three propositions separately. In the first place, have we any right to attribute segmental value to the mandibular nerve? What evidence is there of segments in this region in Ammocœetes?

\section{The Segment of the Lower Lip, or Metastomal Segment.}

We have seen that in the branchial or mesosomatic region the segments corresponding to the mesosomatic appendages were mapped out by means of their supporting or skeletal structures, their segmental muscles, and their nervous arrangements, as well as by the arrangement of the branchiæ. Similarly, the segments in front of the branchial region, corresponding to the prosomatic appendages, ought to be definable by the same means, although, owing to the absence of branchiæ and the greater concentration in this region, the separate segments wonld probably not be so conspicuous.

The last segment considered was the segment belonging to the VIIth nerve corresponding to the opercular appendages of the 
Eurypterid. The segment immediately in front of this is the next for consideration, viz. that corresponding to the chilarial appendages or metastoma; and as the basal part of this pair of appendages was fused with the basal part of the operculum, the one cannot be discussed without the other; therefore, the segnent to which the lower lip belongs must be considered in connection with and not apart from the thyro-hyoid segments already dealt with.

In Chapter V., p. 188, I stated that the supporting bars of the foremost mesosomatic segments, the thyro-hyoid segments, differed from the cartilaginous bars of the branchial segments, in that they were composed of muco-cartilage. Also in addition to the mucocartilaginous skeletal bars, a ventral plate of muco-cartilage exists in Ammocœtes which covers over the thyroid gland.

Similarly in the prosomatic segments the skeletal bars are composed of muco-cartilage and the ventral plate of muco-cartilage continues forward as the plate of the lower lip. It is of special interest, in connection with the segments indicated by such supporting structures, to find that this special tissue is entirely confined to the head-region, and disappears absolutely at transformation, thus indicating the ancestral nature of the segments marked out by its presence.

This muco-cartilaginous skeleton is the key to the whole position, and requires, therefore, to be understood. It is of great importance, not only because it demonstrates the position of the segments in Ammocotes which characterized its invertebrate ancestor, but also because it possesses a structure remarkably similar to that found in the head-plates of the most ancient fishes. For the present I will confine myself to the consideration of this muco-cartilaginous skeleton as evidence of the relationship of Ammocotes to the Eurypterids, and in the next chapter will show how absolutely the same skeleton corresponds to that of the Cephalaspidæ, so that Ammocotes is really a slightly modified Cephalaspid, the larval form of which was Eurypterid in character.

In Chapter IV., Figs. 63, 64, I have given a representation of the ventral and dorsal views of an Ammocœetes cut in half horizontally. Such a section shows with great clearness the series of branchial appendages with their segmental muscles and cartilaginous bars which form the branchial segments innervated by the IXth and Xth nerves, according to my view of the branchial unit. As is seen (Fig. 64 or 115), the skeletal bar of the hyoid or opercular appendage, 


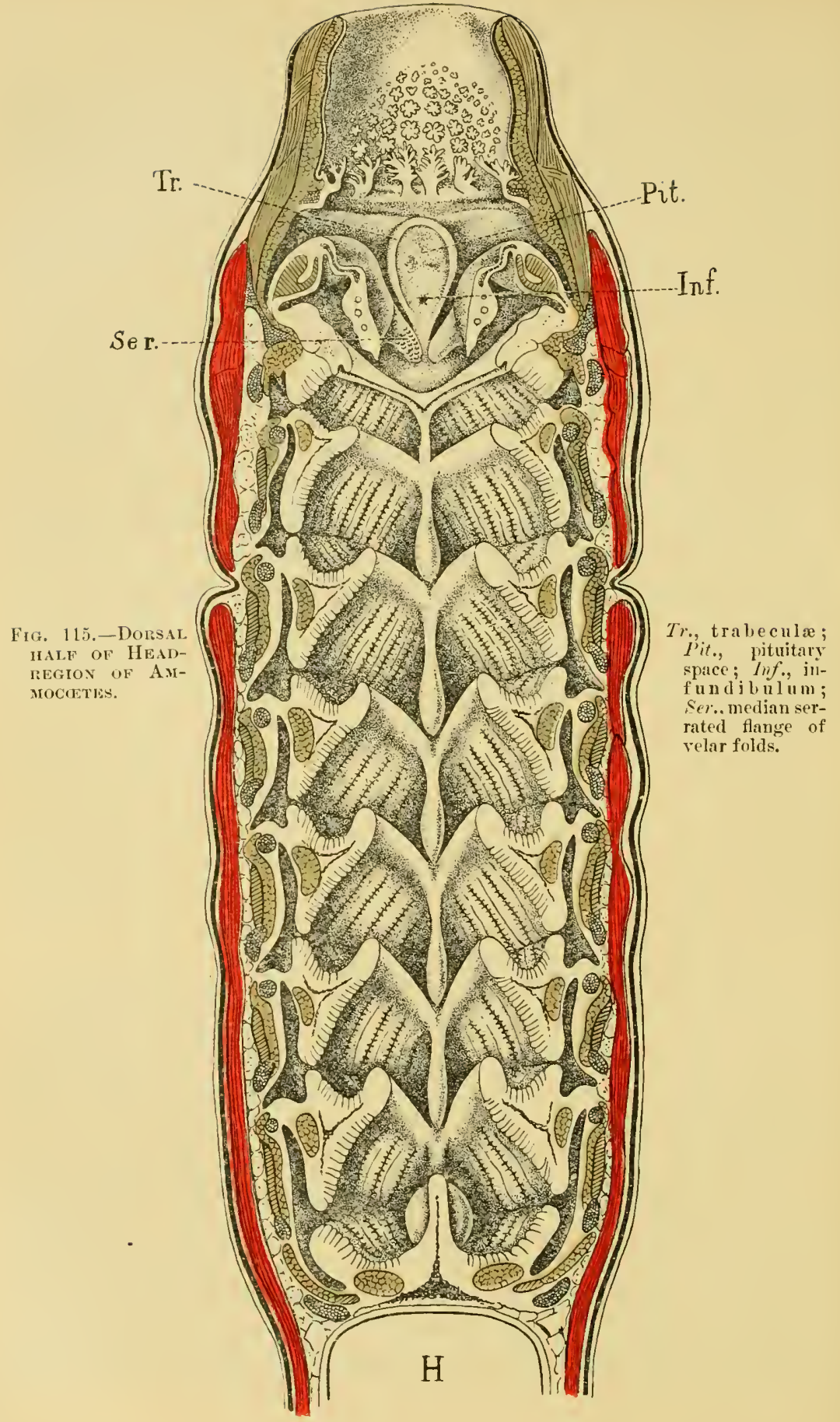


which is clearly serially homologous with the other branchial bars, is composed of muco-cartilage, and not of cartilage. If we follow this series of horizontal sections nearer to the origin of the cartilaginous

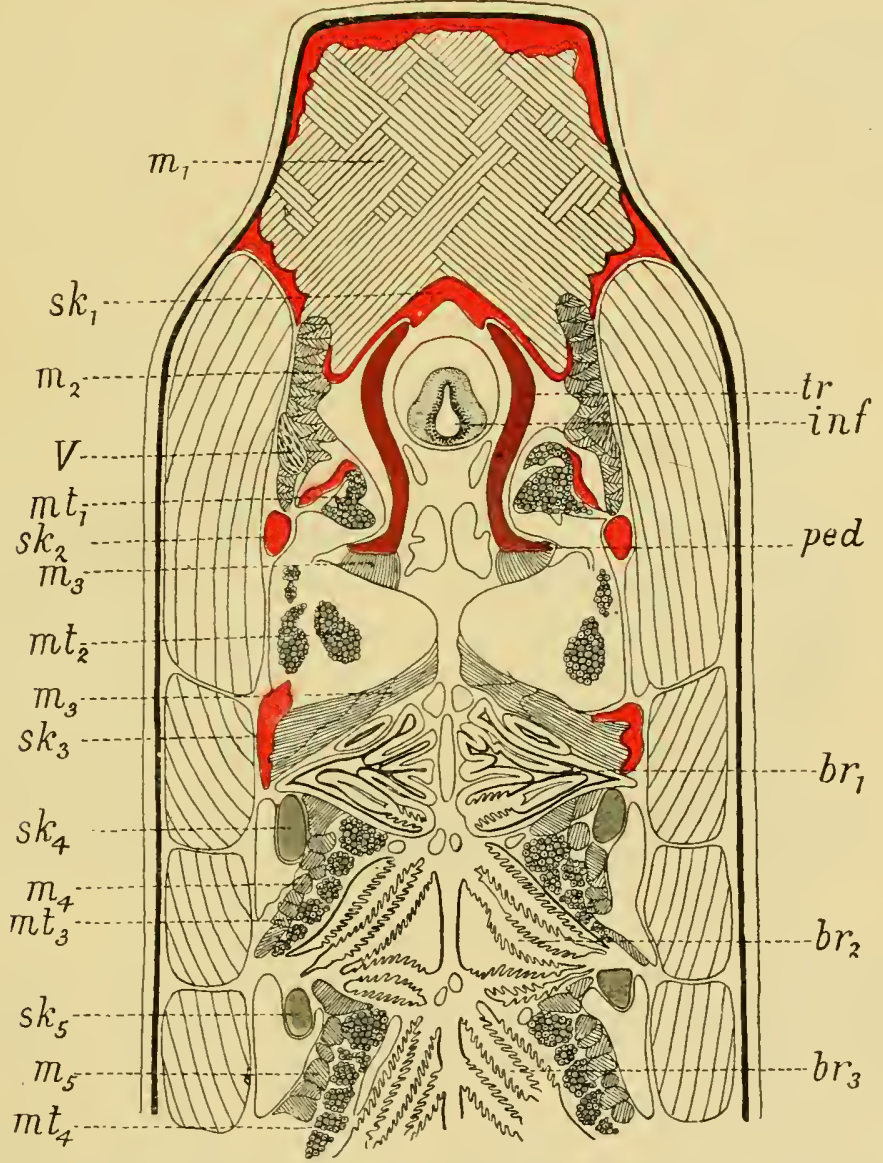

Fig. 116.-Horizontal Section throdgh the Anterior Part of Amaocetes, mmediately Ventrally to the Auditory Capsule.

$s k_{1}-s k_{5}$, skeletal bars; $m_{1}-m_{5}$, striated visceral muscles; $m t_{1}-m t_{\ddagger}$, tubular muscles; $b r_{1}-b r_{3}$, branchiæ; $t r$., trabeculæ; inf., infundibulum; ped., pedicle; $T_{\text {., tri- }}$ geminal nerve. Huco-cartilage, red; soft cartilage, blue; hard cartilage, purple.

bars from the sub-chordal cartilaginous rod on each side of the notochord, we obtain a picture, as in Fig. 116, in which each branchial segment is defined by the section of the branchial cartilaginous bar 
$\left(s k_{4}, s k_{5}\right)$, by the section of the separate branchix $\left(2 r_{2}, b r_{3}\right)$, and by the separate segmental muscles arranged round each har, these museles heing partly ordinary striated $\left(m_{4}, m_{5}\right)$, partly tulular $\left(m t_{3}, m t_{4}\right)$. The uppermost of these branchial segments shows the same arrangement; $\left(s k_{3}\right)$ is the branchial skeletal bar, which is now eomposed of mucocartilage, not cartilage; $\left(b r_{1}\right)$ is the branchice in the same situation as the others, but here composed of glandular rather than of respiratory epithelinm, while the orlinary striated branchial museles of this segment are marked as $\left(m_{3}\right)$, being separated from the tubular muscles of the segment $\left(m t_{2}\right)$, owing to the large size of the blood-space in which

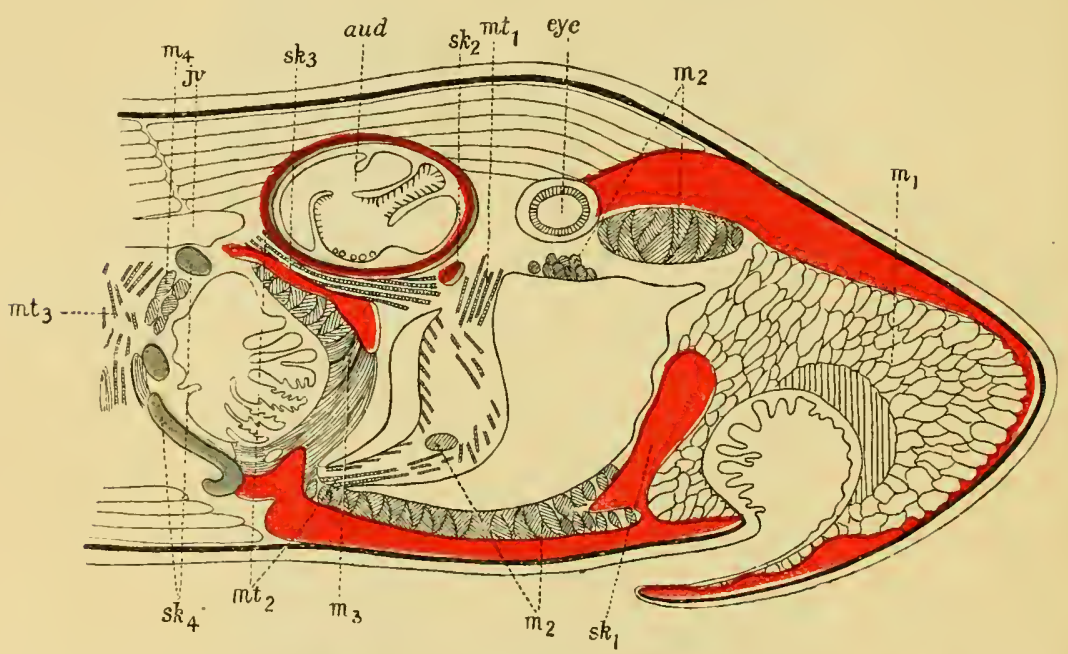

Fig. 117.-Sagittal Lateral Section through the Anterior Part of Ammoceetes.

Lettering and colouring same as in Fig. 116. aud., auditory capsule; j.v., jugular vein.

these latter muscles are lying. In front of this segment so defined we see again another well-marked skeletal bar (ski2) of muco-cartilage, evidently indicating a similar segment anterior to the hyoid segment. In eomnection with this bar there are no branchiæ, but again we see two sets of visceral muscles, the one ordinary striated, marked $\left(m_{2}\right)$, and the other tubular, marked $\left(m t_{1}\right)$. Here, then, the section indicates the existence of a segment of the same character as the posteriorly situated branchial segments but belonging to a non-branchial region - a segment which would represent a non-branchial appendage, the last, therefore, of the prosomatic appendages. Let us, then, follow 
out these two segmental mueo-eartilaginous bars and their attendant muscles, and see to what sort of segments their investigation leads.

The bar which comes first for consideration (sti3) arises immediately behind the auditory capsule from the first branchial eartilage very soon after it leaves the sub-chordal cartilaginous ligament; the soft cartilage of the sub-chordal ligament ceases abruptly in its extension aloug the notochord at the place whero the hard cartilage of the parachordal joins it, and in a sense it may be said to leave the notochord at this place and pass into the basal part of the first branchial bar. The most anterior coutiuuation of this branchial system is this muco-cartilaginous bar $\left(s k_{3}\right)$, which passes forward and rentralwards, being separated from the axial line by the auditory capsule (ef. Fig. 118, A, B, C). Its position is well seen in a sagittal section, such as Fig. 117. It follows absolutely the line of the psendo-branchial groove (ps. br., Fig. 114), and ventrally joins the plate of mucocartilage which covers the thyroid sland. It forms a thickeneel border to this plate anteriorly, just as the branchial cartilaginous bars border it posteriorly. In fact, it behaves with respect to the hyoid segment in a manner similar to the rest of the cartilaginous bars with respect to their respective segments.

It represents, although composed of muco-cartilage, the cartilaginous bar of the operculum in Limulus, which also forms the termination of the bramehial cartilaginous system, as fully explained in Chapter III. ; it may therefore be called the opercular bar.

The next bar $\left(s i_{2}\right)$ is extremely interesting, as we are now out of the branchial or mesosomatic region, and into the region correspouding to the prosoma. It starts from a cartilaginous projection made of hard eartilage, just in front of the auditory capsule, callect by Parker the 'pedicle of the pterygoill' - a projection (ped.) which defines the posterior limit of the trabeculac on each side, where they join on to the parachordals,-and winding round and below the auditory capsule, joins the opercular bar ( $f$. Fig. 118), to pass thence into and form part of the muco-cartilaginous plate of the lower lip. In the section figmed (Fig. 116), this projection of hard cartilage is not directly continuous with (sha), owing to a slight curvature in the bar; the next few sections show clearly the comnection between (ped.) and (sh.), and consequently the complete separation ly means of this bar of the hroid segment from the segment in front. In the figures, the hard 


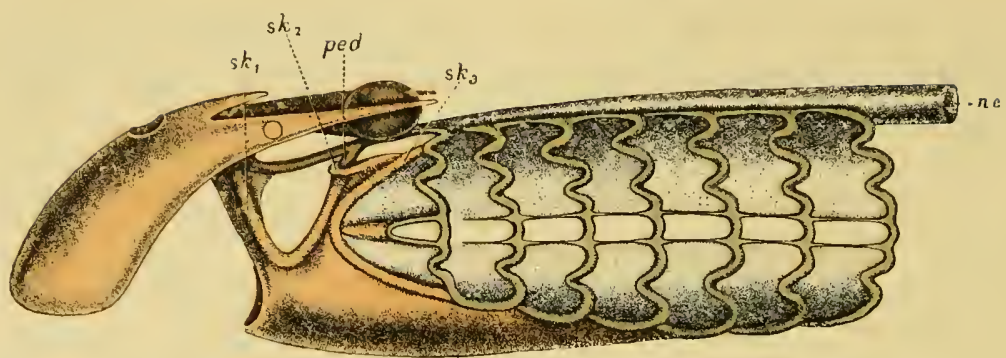

A

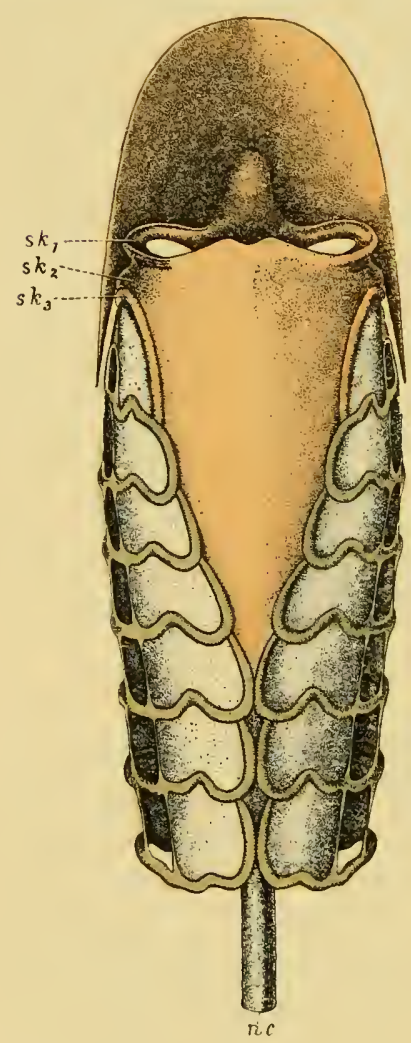

B

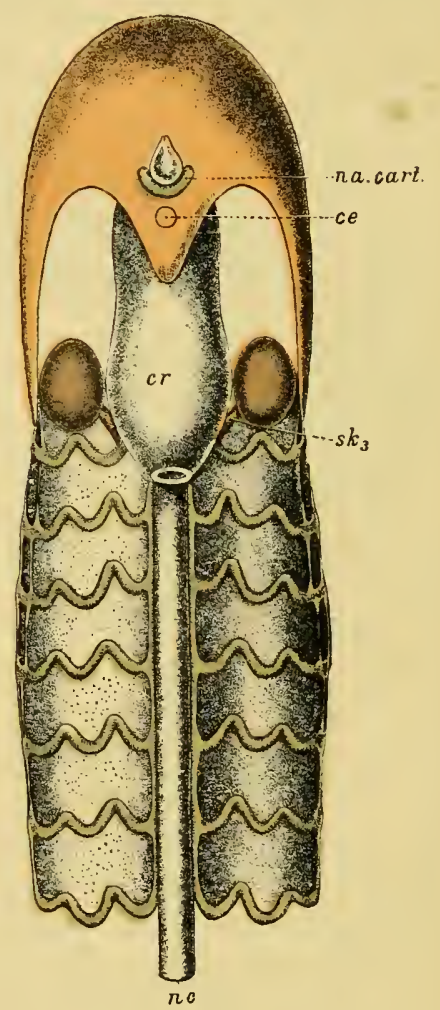

C

Fig. 118.-Skeletox of Head-Region of Ammocates. A, Lateral View; B, "Ventral View; C, Dorsal View.

Muco-cartilage, red; soft cartilage, blue; hard cartilage, furple. $s k_{1}, s k_{2}, s k_{i_{3}}$, skeletal bars; c.c., position of pineal cye; na. cart., nasal cartilage; ped., pedicle; cr., cranium; nc., notochord. 
cartilage is coloured purple, the soft cartilage blue, and the mucocartilage red, so that the position of this bar is well shown. This bar may be looked upon as bearing the same relation to the mucocartilaginous plate of the lower lip as the opereular bar does to the muco-cartilaginous plate over the thyroid; and seeing that these two plates form one continuous ventral head-shield of mueo-cartilage (Fig. 118, B), and also that this bar fuses with the opereular bar, we may conclude that the segment represented by the lower lip is closely connected with the hyoid or operenlar segments. In other words, if the lower lip arose from the metastoma, then this pair of skeletal bars might be called the metastomal bars, which formed the supporting skeleton of the last pair of prosomatic appendages and, as is likely enough, arose in connection with the posterior lateral horns of the plastron; these posterior lateral horns, like the rest of the plastron, would give rise to hard cartilage, and so form in Ammoceetes the two lateral so-called pterygoid projections.

In the branchial region the mussles which marked out each branchial segment were of two kinds-ordinary striatel visceral muscles and tubular muscles. Of these the former represented the dorso-ventral museles of the branchial appendages, while the latter formed a separate group of dorso-rentral muscles with a separate innervation which may have been originally the segmental venopericardial muscles so characteristic of Limulus and the scorpions. In Figs. 116, 117, the grouping of these muscles in each branchial segment is well shown, and it is immediately seen that the hyoid segment possesses its group of striated visceral inuscles $\left(m_{3}\right)$ supplied by the VIIth nerve in the same manner as the posterior groups, as has already been pointed out by Niss Alcock in her previous paper. Passing to the segment in front, Fig. 116 shows that the group of visceral muscles $\left(m_{2}\right)$ corresponds in relative position with respect to the metastomal bar to the hyoid museles with respect to the opereular bar or to the branchial visceral museles with respect to each branchial bar. What, then, is this muscular group? The series of sectious show that these are the dorso-ventral muscles belonging to the lower lip, which, as seen in Fig. 119 (M.), form a well-marked muscular sheet, whose fibres interlace across the midventral line of the lower lip. This group of lower lip-muscles is very suggestive, for these muscles arise, not from the trabeculæ, but from the front clorsal region of the cranium, just in front of the two lateral 
eyes. In Fig. 117 the dorsal part is seen eut across on its way to its dorsal attachment. Such an origin is reminiscent of the tergo-coxal groul' of muscles, arising, as they do, from the prinordial cranium and the tergal carapace, and suggests at once that when the chilarial

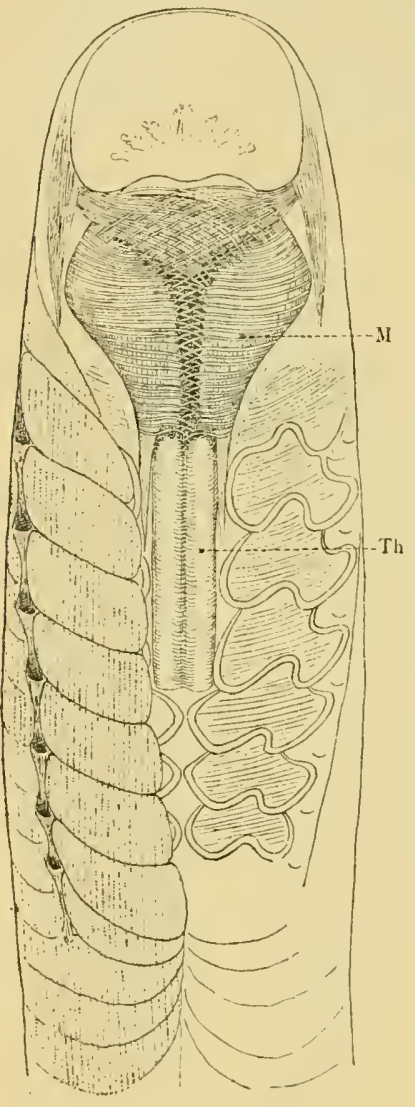

Fig. 119.-Ventral Tiew of Head-Region of AnMocetes.

Th., thyroid gland; M., lower lip, with its muscles. appendages expanded to form a metastoma, their tergo-coxal muscles formed a sheet of muscles similar to those of the lower lip of Ammocates, by which the movements of the metastoma were effected. The posterior limit of these muscles ventrally marks out the junction of the segment of the lower lip, with that of the thyroid; in other words, indicates where the metastoma had fused ventrally with the operculum (Fig. 117).

Besides the striated visceral muscles, each branchial segment possesses its own tubular unuscles, shown in Fig. $116\left(m t_{3}\right)$ and $\left(m t_{4}\right)$. As the section shows, there is clearly a group of tubular musclefibres belonging to the hyoid seginent $\left(m t_{2}\right)$, and also another group belonging to the segment in front of the hyoid $\left(m t_{1}\right)$; so that, judging from this section, each of these segments possesses its own tubular musculature just as do the branchial segments, the difference being that the tubular muscles are more separated from the striated visceral group than in the true branchial segments, owing to the size of the bloodspaces surrounding them. What, then, are these two groups of muscles? Tracing them in the series of sections, both groups are seen to belong to the system of velar muscles, forming an anterior and a posterior group respectively; and we see, further, that there is not the slightest trace of any tubular museles anterior to these inuscles of the velum.

In the living Ammoccetes the velar folds on each side can be seen 
to move synchronously with the movements of respiration, contracting at each expiration, and thus closing the slit by which the oral and respiratory ehambers eommunieate, and so forcing the waters of respiration through the gill-slits, as described by Sehneider. - Such a fact is clear evidence that these tubular muscles of the velar folds belong to the same series as the tuluular muscles of the branchial segments, so that if, as I have alrearly suggested, the latter museles were originally the veno-pericardial museles of segments corresponding to the branchial appendages, then the former would represent the veno-pericardial museles of the segments corresponding to the operenlar and metastomal appendages. What, then, are these velar folds, and how is it that the tubular muscles of these two segments lecome the velar museles? I will consider, in the first instance, the posterior group of muscles $\left(m t_{2}\right)$ in Fig. 116.

It has already been pointed out that the tubular museles of the branchial segments are dorso-ventral, but do not run with the ordinary constrictors, having separate attachments and running part of their course internally to and part externally to the ordinary constrictors. At first sight, as is usually stated, the hyoid segment does not appear to possess tubular museles at all. If, however, we follow the posterior group of velar muscles $\left(m t_{2}\right)$, we see (Fig. 117) that they pass between the auditory capsule and the opercular har $\left(s l_{3}\right)$ of muco-cartilage to reach the region of the jugular vein (j.v.) posteriorly to the auditory eapsule, so that their dorsal origin bears the same relation to the hyoid segment as the dorsal attachment of the rest of the tubular muscles to their respeetive segments. Further, these muscles run along the length of the velar fold, and are attached ventrally on each side of the thyroid gland, so that their ventral attachment also eorresponds in position, as regards the hyoid segment, with the ventral attachment of the rest of the tubular museles as regards their respective segments.

This ventral attachment is shown in Fig. 119 on each side of the thyroid, and in Fig. $120\left(\mathrm{mt}_{2}\right)$; while in Fig. 117 the fibres are seen converging to this ventral position. In other words, this large posterior musele of the velar folds is a dorso-ventral musele, and would aetually take the same position in the hyoid segment as the dorso-ventral tubular muscles in the other branchial segments, if the velum were put back into its original position as the septum terminating the branchial chamber. Conversely, the presence of these 
hyoid tubular muscles in the velum gives evidence that the opercular segment takes part in the formation of the septum, as already singgested.

Miss Alcock, in her paper, speaks of tubular muscles belonging to the hyoid segment, which are attached to the muco-cartilage. Schaffer also speaks of certain tubular muscles belonging to the velar group as piercing the muco-cartilage $(h . r . s$.$) in lis figures 24$ and 25 , i.e. the metastomal bar, near its junction with the opercular har. In my specimens there is a distinct group of tubular muscles which pierce the opercular bar of muco-cartilage at its junction with the metastomal bar, and pass into the posterior groul of velar muscles. They clearly belong to the hyoid segment, as Miss Alcock supposed, but are not attached to the muco-cartilage. It is possible that they represent a different group to those already considered, and suggest the possibility that this opercular or thyro-hyoid segment is double with respect to its original veno-pericardial muscles as well as in other respects.

The anterior group of tubular muscles ( $m t_{1}$, Figs. 116, 117) belonging to the same segment as the metastomal bar must now be taken into consideration. Very different is their origin to that of the posterior group: they arise close up against the eye, and have given rise to Kupffer's and Hatschek's misconception that the superior oblique muscle of the eye arises from a part of the velar muscnlature. Naturally, as Neal has pointed out, they have nothing to do with the eye-muscles; the superior oblique muscle is plainly in its true place entirely apart from these velar muscles, which form the foremost group of the segmental tubular muscles. They pass into the anterior part of the velar folds and run round to the ventral side just in the same way as does the posterior group. This anterior group of tubular muscles represents the veno-pericardial muscle of the segment immediately in front of the opercular, i.e. the metastomal segment, and is the foremost of these reno-pericardial muscles. Its presence shows that the velar folds, formed as they were by the breaking down of the septum, are in reality part of two segments, viz. the opereular and the metastomal, which have fused together in their basal parts, and by such fusion have caused the inter-relationship between the VIIth and Vth nerves, so apparent in the anatomy of the rertebrate cranial nerves.

A further piece of evilence that this anterior portion of the velum 
belongs to the same segment as the lower lip is the fact that in addition to the tubular muscles a single ordinary striated muscle is found in the velum which, like the muscles of the lower lip, is innervated by this same mandibular nerve.

This muscle is attached laterally to the muco-cartilage of the metastomal bar $\left(s k_{2}\right)$ at its junction with the muco-cartilage of the lower lip, and spreads out into a number of strands which are attached at intervals along the whole length of the free anterior edge of the velum. It is the only non-tubular muscle belonging to the velum, and by its contraction it draws the anterior portions of the velar folds ajart from each other, and so opens the slit between them, throngh which the food and mul must pass. Clearly from its position it does not belong to the original tergo-coxal group of muscles as do those of the lower lip; it must lave been one of the intrinsic muscles of the metastoma itself.

This anterior portion of the velar folds affords yet another striking hint of the correctness of my comparison of the lower lip segment of Ammoceetes with the chilaria of Limulus or the metastoma of Eurypterus; for the most dorsal anterior portion, which at its attachment possesses a wedge of muco-cartilage, forms a separate, well-defined, rounded basal projection marked Ser. in Fig. 115, and $B$ in the accompanying Fig. 120. This is that part of the velar folds which comes together in the middle line and closes the entrance into the respiratory chamber. The epithelial surface here is most striking and suggestive, for it is markedly serrated, being covered with a large number of closely-set projections or serræ. The serration of the surface here is of so marked a character that Langerhans considered this part of the velar folds to act as a masticating organ, grinding and rasping the food and mud which passed through the narrow slit. In fact, Langerhans supposed that this portion of the velum acted in a manner closely resembling the action of the gnathobases of the prosomatic appendages in Limulus or the Eurypteridx.

This suggestion of Langerhans is surely most significant, consilering that this somewhat separate portion of the velum, to which he assigns such a function, is in the very place where the gnathite portion of the metastomal appendages would have been situated if it were true that the lower lip and anterior portion of the velum of Ammocates were derived from the metastoma.

In addition to this marked serrated edge the whole surface of 
the anterior portion of the velum is covered over with a scale-like or tubercular pattern remarkably like the surface-ornamentation

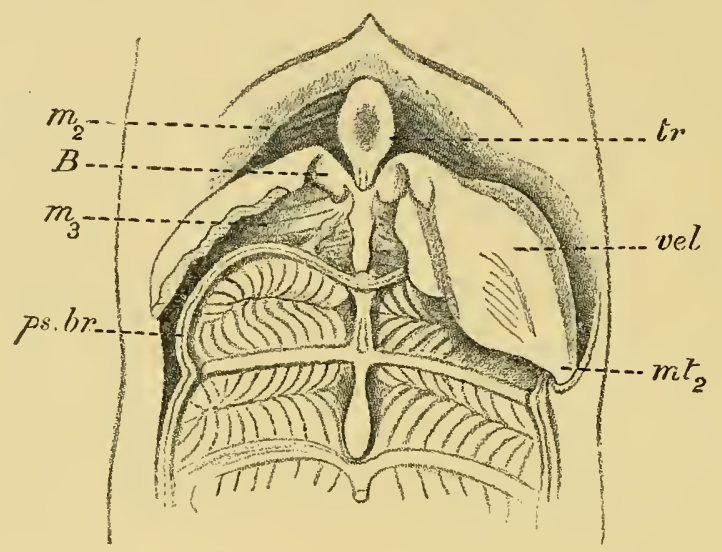

Fig. 120.-Annocetes cut open in Mid-Ventral Line to show Position of Telum; Velar folds removed on one side.

tr., trabeculæ; vel., velum; $B$., anterior gnathic portion of velum; ps. $b r$. , pseudobranchial groove; $m_{2}$, muscles of lower lip segment; $m_{3}$, muscles of thyro-hyoid segment; $m t_{2}$, insertion of tubular muscles of velum near thyroid.

seen in many of the members of the ancient group Eurypteride. In Fig. 121 I give a picture of this surface-marking of the velum. It is striking to see that just as in the case of the invertebrate this marking and these serre are formed simply by the cuticular surface of the epithelial cells; a surface which, according to Wolff, possibly

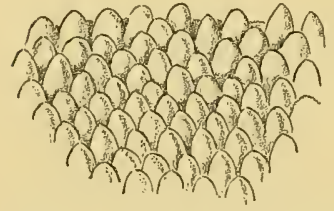

Fig. 121.--Surface View of ANTERior Surface of Velum. contains chitin. The interpretation which I would give of the velar folds is therefore as follows:-

They represent the fused basal parts of the opercular and metastomal appendages, the gnatho-bases of the latter still retaining in a reduced degree their rasping surfaces, because, owing to their position on each side of the opening into the respiratory chamber they were still able to manipulate the food as it passed by them after the closure of the old mouth.

The whole evidence points irresistibly to the conclusion that the manclibular or velar nerve of the trigeminal does supply a splanchnic 
segment which is, in all respects, comparable with the segments supplied by the facial, glossopharyngeal, and vagus nerves, except that it does not possess branchix. This simply means that the appendages which these nerves originally supplied were prosomatic, not mesosomatic, and corresponded, therefore, to the chilarial or metastomal appendages.

A comparison of the ventral surface of Slimonia, as given in Fig. 8, 1. 27, with that of Ammocotes (Fig. 119), when the thyroid gland and lower lip muscles liave been exposed to view, enables the reader to recognize at a glance the correctness of this conclusion.

\section{The Tentacular Segments and the Upper Lip.}

Anterior to this metastomal segment, Fig. 116 shows a group of visceral muscles, $m_{1}$, and yet again a muco-cartilaginous bar, $s k_{1}$, but, as already stated, no tubular muscles. These risceral muscles indicate the presence in front of the lower lip-segment of one or more segments of the nature of appendages. The muscles in question $\left(m_{1}\right)$ are the muscles of the upper lip, the skeletal elements form a pair of large bars of muco-cartilage $\left(s k_{1}\right)$, which start from the termination of the trabeculæ, and pass ventralwards to fuse with the muco-cartilaginous plate of the lower lip (Figs. 117 and 118). This large bar forms the tentacular ridge on each side, and gives small projections of nucocartilage into each tentacle. In addition to this tentacular bar, a special bar of muco-cartilage exists for the fused pair of median tentacles, the so-called tongue, which extends in the middle line along the whole length of the lower lip, being separated from the muco-cartilaginous plate of the lower lip by the muscles of the lower lip. This tongue bar of muco-cartilage joins with the muco-cartilage of the lower lip at its junction with the thyroid plate, and also with the tentacular bar just before the latter joins the muco-cartilaginous plate of the lower lip. This arrangement of the skeletal tissue suggests that the pair of tentacles known as the tongue stand in a category apart from the rest of the tentacles; a suggestion which is strongly confirmed by the separate character of its nerve-supply, as already mentioned.

For three reasons, viz. the separateness both of their nerve-supply and of their skeletal tissue, and the importance they assume at transformation, this pair of ventral tentacles must, it seems to me, be put 
into a separate category from the rest of the tentacles. On the other hand, the innervation of the rest of the tentacles by a single nerve which sends off a branch as it passes each one, together with the concentration of their skeletal elements into a single har, with projections into each tentacle, points directly to the conclusion that these tentacles must be considered as a group, and not singly.

I suggest that these tentacles are the remains of the ectognaths and endognaths; the tongue representing the two ectognaths, and the four tentacles on each side the four pairs of endognaths.

As we see, this method of interpretation attributes segmental value to the tentacles, a conclusion which is opposed to the general opinion of morphologists, who regard them as having no special morphological importance, and certainly no segmental value. On the other hand, the importance of the pair of ventral tentacles, the 'tongue' of Rathke, which lie in the mid-line of the lower lip, has been shown by Kaensche, Bujor, and others, all of whom are unanimons in asserting that at transformation they are converted into that large and important organ the piston or tongue of the adnlt Petromyzon. It is supposed that the rest of the tentacles vanish at transformation, being absorbed; they appear to me rather to take part in the formation of the sucking-disc, so that I am strongly inclined to believe that the whole of the remarkable suctorial apparatus of Petromyzon is derived from the tentacles of Ammocetes. In other words, on my view, a conversion of the prosomatic appendages into a suctorial apparatus takes place at transformation, just as is frequently the case among the Arthropoda.

It is to the arrangement of the muscles that we look for evidence of segmental value. As long as it was possible to look upon these tentacles as mere sensory feelers round the month entrance, it was natural to deny segmental value to them. Matters are now, however, totally different since Miss Alcock's discovery of the rudimentary muscles at the base of the tentacles and their development at transformation. If these muscles represent some of the appendage muscles belonging to the foremost prosomatic segments just as the ocular muscles represent the dorso-ventral somatic muscles of those same segments, then we may expect ultimately to be able to give as good evidence of segmentation in their case as $I$ have been able to give in the case of these latter muscles; for the two sets of muscles are curiously alike, seeing that the eye-muscles do not develop until 
transformation, but thronghout the Ammocotes stage remain in almost as rudimentary a condition as the tentacular muscles.

Another difficulty with respect to the tentacles is the determination of the number of them, owing to the fact that in addition to what may be called well-defined tentacles a large number of smaller tactile projections are found on the surface of the upper lip, as is seen in Fig. 115. In the very young condition, 7 or $8 \mathrm{~mm}$. in length, it is easier to make sure on this point. At this stage they may be spoken of as arranged in two groups: an anterior small group and a posterior larger group. The anterior group consists of a pair of very small tentacles and a very small median tentacle, all three situated quite clorsally in the front part of the upper lip. The posterior group, which is separate from the anterior, consists of five pairs of much larger tentacles, the most ventral pair in the mid-line ventrally on the lower lip being fused together to form the large ventral median tentacle or tongue already mentioned. This pair, according to Shipley, is markedly larger than the others. There are, therefore, five conspicuous tentacles on each side, and in front of them a smaller pair and a small median dorsal one. In the very young condition the accessory projections above-mentioned are not present, or at all events are not conspicuous, and the tentacles are also markedly larger in comparison to the size of the animal than in the older condition, where they have distinctly dwindled.

This posterior group of five conspicuous tentacles is the one which I suggest represents the four endognaths and one ectognath. What the significance of the small anterior group is, I know not. It is possible that the cheliceræ are represented here, for they are situated distinctly anterior to the other group; I know, however, of no sign of a markedly separate innervation to these most dorsal tentacles such as I should have expected to find if they represented the cheliceræ.

The muscles of the upper lip, which distinctly belong to the visceral and not to the somatic nusculature, form part of the foremost segments, and in these muscles the tentacular nerve reaches its final destination. From their innervation, then, they must have belonged to the same appendages as the tentacles supplied by the tentacular nerve, i.e. to the endognaths. What conclusion can we form as to the probable origin of the upper lip of Ammocotes? Since the oral chamber was formed by the forward growth of the metastoma, i.e. the lower lip of Ammoccetes, it follows that the upper 
lip is the continuation forwards of the original ventral surface of such an animal as Limulus or a member of the scorpion group, where there is no metastoma, and corresponds to the endostoma, as Holm calls it, of Eurypterus. This termination of the ventral surface in all these animals is made $1 \mathrm{p}$ of two parts: (1) Of sternites composing the true median ventral surface of the bocly, called by Lankester the proand meso-sternites; and (2) of the sterno-coxal processes of the foremost prosomatic appendages, called in the case of Limulus gnathites, because they are the main agents in triturating the food previously to its passage into the mouth. In Limulus, a conjoined pro-mesosternite forms the median ventral wall to which the sterno-coxal processes are attached on each side, and in Phrynus and Mygale a well-marked pro-sternite and meso-sternite are present, forming the posterior limit of the olfactory opening. In Buthus and the true scorpions the sterno-coxal processes of the $2 \mathrm{nd}$, 3rd, and 4 th prosomatic appendages take part in surrounding the olfactory tubular passage; in Thelyphomus only the processes of the 2nd pair of prosomatic appendages play such a part, the pro-sternite not being rresent ( $c f$. Fig. 97).

Seeing, then, what a large share the sterno-coxal processes of one or more of these prosomatic appendages plays in the formation of this endostoma, and seeing also that the nerve which supplies the upper lip-muscles in Ammocuetes is the same as that supplying the tentacles which are attached to the upper lip, it appears to me more probable than not that the muscles in question are the vestiges of the sterno-coxal muscles. These muscles differ markedly in their attachments from the muscles of the lower lip, for whereas the latter resemble the tergo-coxal group in their extreme dorsal attachment, the former resemble the sterno-coxal group in their attachment to what corresponds to the endostoma.

This interpretation of the meaning of the transformation process is in accordance with all the previous evidence both from the side of the palrostracan as from the side of the vertebrate, for it signifies that a dwindling process has taken place in the foremost of the original prosomatic appendages-the chelicere and the endognaths; while, on the contrary, the ectoguath and the metastoma have continued to increase in importance right into the vertebrate stage. This process is simply a continuation of what was already going on in the invertebrate stage, for whereas in Eurypterus and other cases 
the chelicere and endognaths had dwindled down to mere tentacles, the ectognath was the large swimming appendage, and the metastoma was on the upward grade from the two insignificant chilaria of Limulıs.

The transformation of these foremost appendages into a suctorial apparatus is very common annong the arthropods, as is seen in the transformation of the caterpillar into the butterfly, and it is in accordance with the evidence that the main mass of that suctorial apparatus should be formed from appendages corresponding to the ectognath and metastoma rather than from the four endognaths. In all probability the nuclcus masticatorius of the trigeminal nerve with its innervation of the great muscles of mastication is evidence of the continued development of the musculature of these two last prosomatic appendages, just as the descending root of the Vth demonstrates the further disappearance of all that belongs to the foremost prosomatic appendages. As yet, however, as far as I know, the musculature of the head-region of Petromyzon has not been brought into line with that of other vertebrates, and until that comparative study has been completed it is premature to discuss the exact position of the masticating muscles of the higher vertebrates.

The analysis of these tentacular segments belonging to the trigeminal nerve presents greater difficulties than that of any of the other cranial segments, owing to the deficiency of our knowledge of what occurs at transformation. Light is required not only on the origin of the new muscles but also on the origin of the new and elaborate cartilages which are newly formed at this time.

Miss Alcock has not yet worked out the origin of all these cartilages and muscles, so that we are not yet in a position to analyze the trigeminal supply in Petromyzon into its component appendage clements, an analysis which ought ultimately to enable us to determine from which appendage-muscles the masticating muscles in the ligher vertebrates have arisen. As far as the muscles are concerned, she gives me the following information:-

The tongue-nerve supplies in Ammocetes the rudimentary muscles which pass laterally from the base of the large ventral tentacle to the wall of the throat, and even in Ammocotes must possess some power of moving that tentacle.

At transformation these museles proliferate and develop enormously, and form the bulk of the large basilar muscle which 
surrounds the throat ventrally and laterally, and is the most bulky muscle in the suctorial apparatus.

The velar or mandibular nerve supplies in Ammocoetes the muscles of the lower lip. In Petromyzon it supplies also the longitudinal muscles of the tongue. The tongue-cartilage first develops in the region of the median ventral tentacle, and there the longitudinal tongne-muscles first begin to develop, not from the rudimentary muscles in the tongue but from those in the lower lip region.

In Ammocotes the tentacular nerve supplies the rudimentary muscles in the tentacles and the muscles of the upper lip. The latter disappear entirely at transformation, and in Petromyzon the tentacular nerve supplies the circular, pharyngeal, and annular muscles, which are derived from the rudimentary tentacular muscles.

For the convenience of my reader I append here a table showing my conception of the manner in which the endognathal and ectognathal segments of the Palæostracan are represented in Ammocœetes. It shows well the uniform manner in which all the individual segmental factors have been fused together to represent the appearance of a single segment (van Wijhe's first segment) in the case of the four endognathal segments, but have retained their individuality in the case of the ectognathal segment.

\begin{tabular}{|c|c|c|c|c|c|c|c|c|c|}
\hline \multirow{2}{*}{ 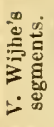 } & \multirow{2}{*}{ 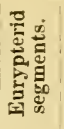 } & \multicolumn{2}{|c|}{ A ppendages. } & \multirow{2}{*}{$\begin{array}{l}\text { Appendage } \\
\text { nerves. }\end{array}$} & \multirow{2}{*}{$\begin{array}{c}\text { Skeletal } \\
\text { elements. }\end{array}$} & \multirow{2}{*}{$\begin{array}{l}\text { Somatic } \\
\text { motor } \\
\text { nerves. }\end{array}$} & \multirow{2}{*}{$\begin{array}{l}\text { Dorso- } \\
\text { ventral } \\
\text { segmental } \\
\text { muscles. }\end{array}$} & \multirow{2}{*}{$\begin{array}{l}\text { Coelomic } \\
\text { cavities. }\end{array}$} & \multirow{2}{*}{$\begin{array}{l}\text { Coxal } \\
\text { glands. }\end{array}$} \\
\hline & & E'urypterid. & Ammocoetes & & & & & & \\
\hline 1 & $\left.\begin{array}{l}2 \\
3 \\
4 \\
5\end{array}\right)$ & $\begin{array}{l}4 \text { Endo- } \\
\text { gnaths }\end{array}$ & $\begin{array}{l}4 \text { Ten- } \\
\text { tacles }\end{array}$ & $\begin{array}{l}1 \text { Ten- } \\
\text { tacular } \\
\text { to } 4 \\
\text { tentacles }\end{array}$ & $\begin{array}{l}1 \text { Ten- } \\
\text { tacular } \\
\text { bar to } 4 \\
\text { tentacles }\end{array}$ & $\begin{array}{l}1 \text { Oculo- } \\
\text { motor } \\
\text { supply- } \\
\text { ing } 4 \\
\text { muscles }\end{array}$ & $\begin{array}{l}\text { Sup. } \\
\text { inf. int. } \\
\text { rectus } \\
\text { and inf. } \\
\text { oblique }\end{array}$ & $\begin{array}{l}1 \text { Pre- } \\
\text { mandi- } \\
\text { bular } \\
\text { fusion } \\
\text { of } 4\end{array}$ & $\begin{array}{l}1 \text { Pitui- } \\
\text { tary } \\
\text { body; } \\
\text { fusiou of } \\
4 \text { coxal } \\
\text { glands. }\end{array}$ \\
\hline 2 & 6 & $\begin{array}{l}1 \text { Ecto- } \\
\text { gnath }\end{array}$ & 1 Tongue & $\begin{array}{l}1 \text { Tongue } \\
\text { nerve }\end{array}$ & 1 Tongue & $\begin{array}{l}1 \text { Troch- } \\
\text { learis } \\
\text { supply- } \\
\text { ing } 1 \\
\text { muscle }\end{array}$ & $\begin{array}{l}\text { Sup. } \\
\text { oblique }\end{array}$ & $\begin{array}{l}1 \text { Man- } \\
\text { dibular }\end{array}$ & \\
\hline
\end{tabular}




\section{The Tubular Muscles.}

The only musculature innervated by the trigeminal nerve which remains for further discussion, consists of those peculiar muscles found in the velum, known by the name of striated tubular muscles. This group of muscles has already been referred to in Chapter IV., dealing with respiration and the origin of the heart.

It is a muscular group of extraordinary interest in seeking an answer to the question of vertebrate ancestry, for, like the thyroid gland, it bears all the characteristics of a survival from a prevertebrate form, which is especially well marked in Ammoccetes. I have already suggested in this chapter that the homologues of these muscles are represented in Limulus by the veno-pericardial group of muscles. I will now procecd to deal with the evidence for this suggestion.

The structure of the muscle-fibres is peculiar and rery characteristic, so that wherever they occur they are easily recognized. Each fibre consists of a core of granular protoplasm, in the centre of which the nuclei are arranged in a single row. This core is surrounded by a margin of striated fibrillæ, as is seen in Fig. 122. Such a structure is characteristic of various

A
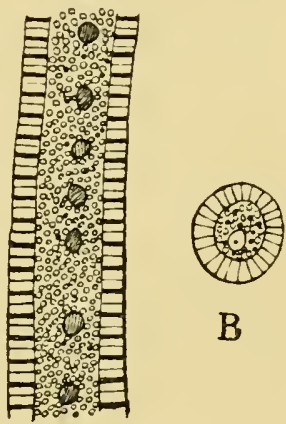

B

FIG. 122. - A TUBUAR MUSCLE-FIBRE OF AMNOCCETES.

A, portion of fibre seen longitudinally; $\mathrm{B}$, transverse section of fibre (osmic preparation); the black dots are fat-globules. forms of striated muscle found in various invertebrates, such as the muscle-fibre of mollusca. It is, as far as I know, found nowhere in the vertebrate kinglom, except in Ammoccetes. At transformation these muscles entirely disappear, becoming fattily degenerated and then absorbed.

For all these reasons they bear the stamp of a survival from a prevertebrate form. This alone would not make this tissue of any great importance, but when in addition these muscles are found to be arranged absolutely segmentally throughout the whole of the branchial region, then this tissue becomes a clue of the highest importance.

As mentioned in Chapter IV., the segmental muscles of respiration consist of the adductor muscle and the two constrictor muscles 
-the striated constrictor and the tubular constrictor. Of these muscles, both the muscles possessing ordinary striation are attached to the branchial cartilaginous skeleton, whereas the tubular constrictors have nothing to clo with the cartilaginons basket-work, but are attached ventrally in the neighbourhood of the ventral aorta.

These segmental tubular muscles are found also in the velar folds - the remains of the septum or velum which originally separated the oral from the respiratory chamber. In the branchial region they act with the other constrictors as expiratory muscles, forcing the water out of the respiratory chamber. In the living Ammoccetes, the velar folds on each side can be seen to move synchrononsly with the movements of respiration, contracting at each expiration; they thus close the slit by which the oral and respiratory chambers communicate, and therefore, in conjunction with the respiratory muscles, force the water of respiration to flow out through the gill-slits, as described by Schneider.

These tubular muscles thus form a dorso-ventral system of muscles essentially connected with respiration; they belong to each one of the respiratory segments, and are also found in the velum; anterior to this limit they are not to be found. What, then, are these tubnlar muscles in the velar folds? Miss Alcock has worked out their topography by means of serial sections, and, as already fully explained, has shown that they form exactly similar dorso-ventral groups, which belong to the two segments anterior to the purely branchial segments, i.e. to the facial or hyoid segments and the lower lip-segment of the trigeminal nerve. If the velar folds could be put back into their original position as a septum, then the hyoid or facial group of tubular muscles would take up exactly the same position as those belonging to each branchial segment.

The presence of these two so clearly segmental groups of muscles in the velum - the one belonging to the region of the trigeminal, the other to the region of the facial-is strong confirmation of my contention that this septum between the oral and respiratory chambers was caused by the fusion of the last prosomatic and the first mesosomatic appendages, represented in Limulus by the chilaria and the operculuu1.

Yet another clue to the meaning of these muscles is to be found in their imervation, which is very extraordinary and unexpected. Throughont the branchial region the striated muscles of each segment 
are strictly supplied by the nerve of that segment, and, as already described, each segment is as carefully mapped out in its innervation as it is in any arthropor appendage. One exception occurs to this orderly, symmetrical arrangement : a nerve arises in connection with the facial nerve, and passes tailwards throughout the whole of the branchial region, giving off a branch to each segment as it passes. This nerve ( $B r^{*}$. prof., Fig. 123) is known by the name of the ramus branchicelis profundus of the facial, and its extraordinary course has always aroused great curiosity in the minds of vertebrate anatomists. Miss Alcock, by the laborious method of following its course throughout a complete series of sections, finds that each of the segmental branches which is given off, passes into the tubular muscles of that segment (Fig. 124). The tubular muscles which belong to the velum,

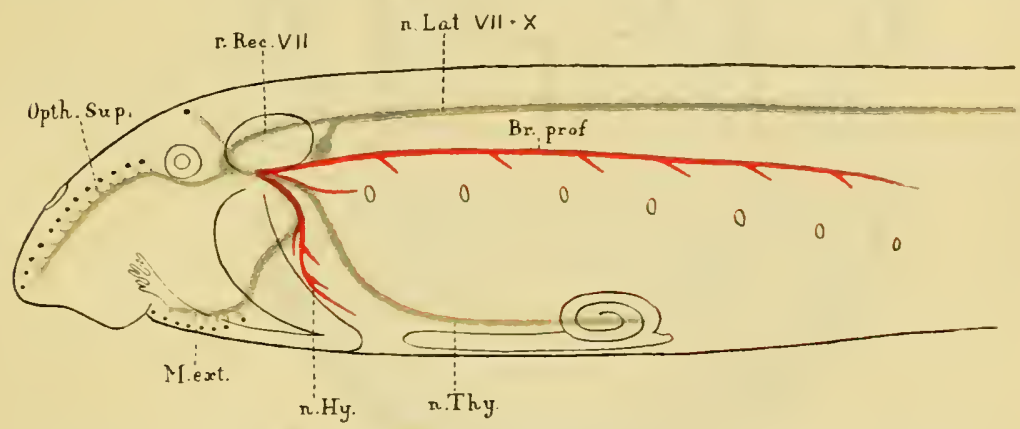

Fig. 123.-Diagray showing the Distribltion of the Facial Nerve.

Iotor branches, red; sensory branches, blue.

i.e. those belonging to the lower lip-segment and to the hyoid segments, receive their innervation from the relar or mandibular nerve, and belong, therefore, to the trigeminal, not to the facial, system.

The evidence presented by these muscles is as follows:-

In the ancestor of the vertebrate there must have existed a segmentally arranged set of dorso-ventral muscles of peculiar structure, concerned with respiration, and confined to the mesosomatic segments and to the last prosomatic segment, yet differing from the other dorso-ventral muscles of respiration in their innervation and their attachment.

Interpreting these facts with the aid of my theory of the origin of vertebrates, and remembering that the homologue of the vertebrate ventral aorta in such a palitostracan as Limulus is the longitudinal 
venous sinus, while the opercular and chilarial segments are respectively the foremost mesosomatic and the last prosomatic segments; they signify that the palieostracan ancestor must have possessed a separate set of segmental dorso-ventral muscles confined to the branchial, opercular and chilarial or metastomal segments, which, on the

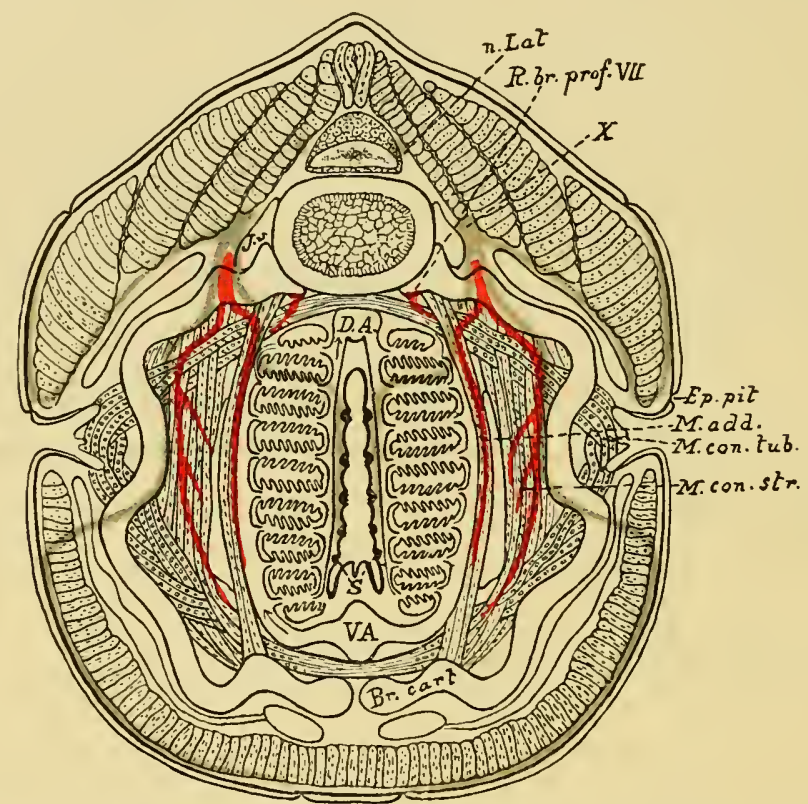

Fig. 124.-Diagram constructed from a series of Transyerse Sections throvgh a Branchial Segient; showing the arrangement and relative positions of the: Cartilage, Muscles, Nerves, and Blood-Vessels.

Nerves coloured red are the motor nerves to the branchial muscles. Nerves coloured blue are the interual sensory nerves to the diaphragms and the exterual sensory nerves to the sense-organs of the lateral line system. Br. cart., branchial cartilage; $M$. con. str., striated constrictor muscles; $M$. con. tub., tubular constrictor muscles; $M$. add., adductor muscle ; D.A., dorsal aorta ; V.A., ventral aorta; S., sense-organs on diaphragm; n. Lat., lateral line nerve; X., epibranchial ganglia of vagus; R. br.prof. VII., ramus branchialis profundus of facial; J.v., jugular vein; Ep. pit., epithelial pit.

one hand, were respiratory in function, and on the other were attached to the longitudinal venous sinus. Further, these muscles must all have received a nerve-supply from the neuromeres belonging to the chilarial and opercular segments, an unsymmetrical arrangement of nerves, on the face of it, very mlikely to occur in an arthropod. 
Is this prophecy borne out by the examination of Limulus? In the first place, these muscles were dorso-ventral and segmental, and, referring back to Chapter VII., Lankester arranges the segmental dorso-ventral muscles in three groups : (1) The dorso-ventral somatic muscles; (2) the dorso-rentral appendage muscles; and (3) the venopericardial muscles. Of these the first group is represented in the vertebrate by the muscles which move the eye, the second group by the striated constrictor and adductor muscles and the muscles for the lower lip. There is, then, the possibility of the third group for this system of tubular muscles.

Looking first at the structure of these muscles as previously described, so different are they in appearance from the ordinary muscles of Limulus, that Milne-Edwards, as already stated, called them "brides transparentes," and clid not recognize their muscular character, while Blanchard called them in the scorpion, "ligaments contractils."

Consider their attachment and their function. They are attached to the longitudinal sinus, according to Lankester's observation, in such a way that the muscle-fibres form a hollow cone filled with blood; when they contract they force this blood towards the gills, and thus act as accessory or branchial hearts. According to Blanchard, in the scorpion they contract synchronously with the heart; according to Carlson, in Limulus they contract with the respiratory muscles. In Ammoccetes, where the respiration is effected after the fashion of Limulus, not of Scorpio, the tubular muscles are respiratory in function.

Look at their limits. The veno-pericardial muscles in Limulus are limited by the extent of the heart, they do not extend beyond the anterior limit of the heart. In Fig. 70 (p. 176) two of these muscles are seen in front of the branchial region also attached to the longitudinal venous sinus, although in front of the gill-region. In Ammocectes the upper limit of the tubular muscles is the group found in the velum; this most anterior group belongs to a region in front of the branchial region - that of the trigeminal.

Moreover, the supposition that the segmental tubular muscles belong throughout to the veno-pericardial group gires an adequate reason why they do not occur in front of the velum; for, as their existence is dependent upon the longitudinal collecting sinus in Limulus and Scorpio, which is represented by the ventral aorta in 
Ammocotes, they cannot extend beyond its limits. Now, Dolirn asserts that the ventral aorta terminates in the spiracular artery, which exists only for a short time; and, in another place, speaking of this same termination of the ventral aorta, he states: "Dass je eine vorderste Arterie aus den beiden primären Aesten des Conus arteriosus hervorgeht, die erste Anlage der Thyroidea unfasst, in der Mesodermfalte des späteren Velums in die Höhe steigt um in die Aorta der betreffenden Seite einzumunden." These observations show that the vessel which in Ammocotes represents the longitudinal collecting sinus in the Merostomata does not extend further forwards than the velum, and in consequence the representatives of the venopericardial muscles cannot extend into the segments anterior to the velum. One of the extraordinary characteristics of these tubular muscles which distinguishes them from other muscles, but brings them into close relationship with the veno-pericardial group, is the manner in which the bundles of muscle-fibres are always found lying freely in a blood-space; this is clearly seen in the branchial region, but most strikingly in the velum, the interior of which, apart from its muco-cartilage, is simply a large lacunar blood-space traversed by these tubular muscles.

All these reasons point to the same conclusion: the tubular muscles in Ammocotes are the successors of the veno-pericardial system of muscles.

If this is so, then this homology ought to throw light on the extraordinary innervation of these tubular muscles by the branchialis profundus branch of the facial nerve and the velar branch of the trigeminal. We ought, in fact, to find in Limulus a nerve arising exclusively from the ganglia belonging to the chilarial and opercular segments, which, instead of being confined to those segments, traverses the whole branchial region on each sicle, and gives off a branch to each branchial segment; this branch should supply the veno-pericardial muscle of that side.

Patten and Redenbaugh have traced ont the clistribution of the peripheral nerves in Limulus, and have found that from each mesosomatic ganglion a segmental cardiac nerve arises which passes to the heart and there joins the cardiac median nerve, or rather the median heart-ganglion, for this so-called nerve is really a mass of ganglion-cells. In all the branchial segments the same plan exists, each cardiac nerve belonging to that neuromere is strictly segmental. 
Upon reaching the opercular and chilarial neuromeres an extraordinary exception is found the cardiac nerves of these two nemromeres are fused together, run dorsally, and then form a single nerve called the pericardial nerve, which runs outside the pericardium along the whole length of the mesosomatic region, and gives off a branch to each of the cardiac nerves of the branchial neuromeres as it passes them.

This observation of Patten and Redenbangh shows that the pericardial nerve of Limulus agrees with the very nerve postulated by the theory, as far as concerns its origin from the chilarial and opercular neuromeres, its remarkable course along the whole branchial region, and its segmental branches to each branchial segment.

At present the comparison goes no further; there is no evidence available to show what is the destination of these segmental branches of the pericardial nerve, and so far all evidence of their having any connection with the veno-pericardial muscles is wanting. Carlson, at my request, endeavoured in the living Limulus to see whether stimulation of the pericardial nerve caused contraction of the venopericardial muscles, but was unable to find any such effect. On the contrary, his experimental work indicated that each veno-pericardial muscle received its motor supply from the corresponcting mesosomatic ganglion. This is not absolutely conclusive, for if, as Blanchard asserts in the case of the scorpion, a close connection exists between the action of these muscles and of the heart, it is highly probable that their innervation conforms to that of the heart. Now Carlson has shown that this cardiac nerre from the opercular and chilarial neuromeres is an inhilitory nerve to the heart, while the segmental carliac nerves belonging to the branchial ganglia are the augmentor nerves of the heart.

His experiments, then, show that the motor nerves of the heart and of the veno-pericardial museles run together in the same nerves, but he says nothing of the inhibitory nerves to the latter muscles. If they exist and if they are in accordance with those to the heart, then they ought to run in the pericardial nerve, and would naturally reach the veno-pericardial muscles by the segmental branches of the pericardial nerve.

Moreover, inhibitory nerves are, in certain cases, curiously associated with sensory fibres; so that the nerve which corresponds 
to the pericardial nerve, viz. the branchialis profundus of the facial, may be an inhibitory and sensory nerve, and not motor at all. Miss Alcock's observations are purely histological; 110 physiological experiments have been made.

At present, then, it does not seem to me possible to say that Carlson's experiments have disproved any connection of the pericardial nerve with the veno-pericarlial muscles. We do not know what is the destination of its segmental branches; they may still supply the veno-pericardial muscles even if they do not cause them to contract; they certainly do not appear to pass directly into them, for they pass into the segmental carliac nerves, and can only reach the muscles in conjunction with their motor nerves. Such a course would not be improbable when it is borne in mind how, in the frog, the augmentor nerves run with the inhibitory along the whole length of the vagus nerve.

Until further evidence is giren both as to the function of the segmental branches of the pericardial nerve in the Limulus, and of the branchialis mofundus in Ammocœes, it is impossible, I think, to consider that the phylogenetic origin of these tubular muscles is as firmly established as is that of most of the other organs already considered. I must say, my own bias is strongly in favour of looking upon them as the last trace of the veno-pericardial system of muscles, a view which is distinctly strengthened by Carlson's statement that the latter system contracts synchronously with the respiratory movements, for undoubtedly in Ammocœes their function is entirely respiratory. Then again, although at present there is no evidence to connect the pericardial nerve in Limulus with this veno-pericardial system of muscles, yet it is extraordinarily significant that in such animals as Limulus and Ammoccetes, in both of which the mesosomatic or respiratory region is so markedly segmental, an intrusive nerve should, in each case, extend through the whole region, giving off branches to each segment. Still more striking is it that this nerve should arise from the foremost mesosomatic and the last prosomatic neuromeres in Limulus - the opercular and chilarial segments - precisely the same neuromeres which give origin to the corresponding nerve in Ammocotes, for according to my theory of the origin of vertebrates, the nerves which supplied the opercular and snetastomal appendages have become the facial nerve and the lower lip-branch of the trigeminal nerve. 
With the formation of the rertebrate heart from the two longitudinal venous sinuses and the abolition of the dorsal invertebrate heart, the function of these tubular muscles as branchial hearts was no longer needed, and their respiratory function alone remained. The last remnant of this is seen in Ammocotes, for the ordinary striated muscles were always more efficient for the respiratory act, and so at transformation the inferior tubular musculature was got rid of, there being no longer any need for its continned existence.

\section{The Paleostona, or Old Mouth.}

The arrangement of the oral chamber in Ammocotes is peculiar among vertebrates, and, upon my theory, is explicable by its comparison with the accessory oral chamber which apparently existed in Eurypterus. According to this explanation, the lower lip of the original vertebrate mouth was formed by the coalescence of the most posterior pair of the prosomatic appendages-the chilaria; from which it follows that the vertebrate mouth was not the original mouth, but a new structure due to such a formation of the lower lip.

It is very suggestive that the direct following out of the original working hypothesis should lead to this conclusion, for it is universally agreed by all morphologists that the present mouth is a new formation, and Dohrn has argued strongly in favour of the mouth being formed by the coalescence of a pair of gill-slits. Interpret this in the language of my theory, and inmediately we see, as already explained, gill-slits must mean in this region the spaces between appendages which did not carry gills; the mouth, therefore, was formed by the coalescence of a pair of appendages to form a lower lip just as I have pointed ont.

Where, then, must we look for the palæostoma, or original mouth ? Clearly, as already suggested, it was situated at the base of the olfactory passage, and the olfactory passage or nasal tube of Ammocoetes was originally the tube of the hypophysis, so that the following out of the theory points directly to the tube of the hypophysis as the place where the palæostoma must be looked for.

This conclusion is not only not at variance with the opinions of morphologists, but gives a straightforward, simple explanation why the palæostoma was situated in the very place where they are most inclined to locate it. Thus, if we trace the history of the question, 
we see that Dohrn's original view of the comparison of the vertebrate and the annelid led him to the conception that the vertebrate mouth was formed by the coalescence of a pair of gill-slits, and that the original month was situated somewhere on the dorsal surface and opened into the gut by way of the infundibulum and the tube of the hypophysis. This, also, was Cunninghan's view as far as the tube of the hypophysis was concerned. Beard, in 1888, holding the view that the vertebrates were derived from annelids which had lost their supra- esophageal ganglia, and that, therefore, there was no question of an osophageal tube piercing the central nervous system of the vertebrate, explained the close connection of the infundibulum with the hypophysis by the comparison of the tube of the hypophysis with

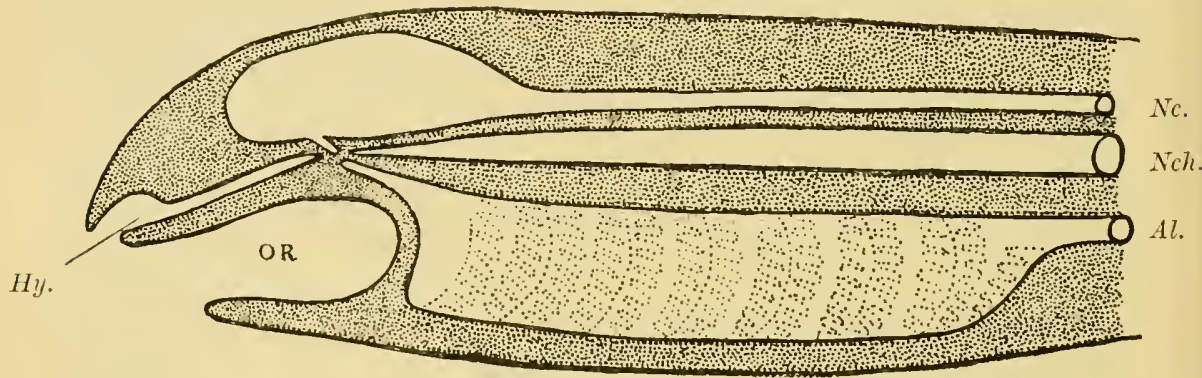

Fig. 125.-Diagram to show the Meeting of the Four Tubes in such a Vertebrate as the Lamprey.

$N c$, neural canal with its infundibular termination; $N c h$., notochord ; Al., alimentary canal with its anterior diverticulum; Hy., hypophysial or nasal tube; Or., oral chamber closed by septum.

the annelidan mouth, so that the infundibular or so-called nervous portion was a special nervous innervation for the original throat, just as Kleinenberg had shown to be the case in many annelids. Beard therefore called this opening of the hypophysial tube the old mouth, or palieostoma. Recently, in 1893, Kupffer has also put forward the view that the hypophysial opening is the paliostoma: basing this view largely upon his observations on Ammocoetes and Acipenser.

As is seen in Fig. 125, the position of this palæostoma is a very suggestive one. At this single point in Ammocretes, four separate tubes terminate; here is the end of the notochordal tube, the termination of the infundibulum, the blind end of the nasal tube or tube 
of the hypophysis, and the pre-oral elongation of the alimentary canal.

It is perfectly simple and easy for the olfactory tube to open into any one of the other three. By opening into the infundibulum it reproduces the condition of affairs seen in the scorpion; by opening into the gut it produces the actual condition of things seen in Myxine and other vertebrates; by opening into the notochordal tube it would produce a transitional condition between the other two.

The view held by Kupffer is that this nasal tube (tube of the hypophysis) opened into the anterior diverticulum of the vertebrate gut, and was for this reason the original mouth-tube; then a new mouth was formed, and this connection was closed, being subsequently reopened as in Myxine. My view is that this tube originally opened into the infundiluulum, in other words, into the original gut of the palrostracan ancestor, and was for this reason the original mouth-tube, in the same sense as the olfactory passage of the scorpion may be, and often is, called the mouth-tube. When, with the breaking through of the septum between the oral and respiratory chambers, the external opening of the oral chamber became a new mouth, the old mouth was closed but the olfactory tube still remained, owing to the importance of the sense of smell. Subsequently, as in Myxine and the higher vertebrates, it opened into the pharynx, and so formed the nose of the higher vertebrates.

It is not, to my mind, at all improbable that during the transition stage, between its connection with the old alimentary canal, as in Eurypterus or the scorpions, and its blind ending, as in Ammoceetes, the nasal tube opened into the tube of the notochord. This question will be discussed later on when the probable significance of the notochord is considered.

\section{The Pituitary Gland.}

Turning back to the comparison of Fig. 106, B, and Fig. 106, C, which represent respectively an imaginary sagittal section through an Eurypterus-like animal and through Ammoccetes at a larval stage, all the points for comparison mentioned on p. 244 have now been discussed with the exception of the suggested homology between the coxal glands of the one animal and the pituitary body of the other. 
This latter gland undoubtedly arises posteriorly to the hypophysial tube, or Rathke's pouch (as it is sometimes called), and, as already mentioned, is supposed by Kupfler to be formed from the posterior wall of this pouch. More recently, as pointed ont in Haller's paper, Nusbaum, who has investigated this matter, finds that the glandular hypophysis is not formed from the walls of Rathke's pouch, but from the tissue of the rudimentary connection or stalk between the two premandibular cavities, which becomes closely connected with the posterior wall of Rathke's pouch, and becoming cut off from the rest of the premandibular cavity on each side, becomes permanently a part of the 'Hypophysis Anlage.'

The importance of Nusbaum's investigation consists in this, that he derives the glandular hypophysis from the connecting stalk between the two premandibular cavities, and therefore from the walls of the ventral continuation of this cavity on each side.

This may be expressed as follows:-

The cœlomic cavity, known as the premandibular cavity, divides into a dorsal and a ventral part; the walls of the dorsal part give origin to the somatic muscles belonging to the oculomotor nerve, while the walls of the ventral part on each side form the connecting stalk between the two cavities, and give origin to the glandular hypophysis.

Now, as already pointed out, the premandibular cavity is homologous with the 2nd prosomatic colomic cavity of Limulus, and this 2nd prosomatic colomic cavity divides, according to Kishinouye, into a dorsal and a ventral part; and, further, the walls of this ventral part form the coxal gland. Both in the vertebrate, then, and in Limulus, we find a marked glandular tissue in a corresponding position, and the conclusion is forced upon us that the glandular hypophysis was originally the coxal gland of the invertebrate ancestor. As in all other cases already considered, when the facts of topographical anatomy, of morphology and of embryology, all combine to the same conclusion as to the derivation of the vertebrate organ from that of the invertebrate, then there must be also a structural similarity between the two. What, then, is the nature of the coxal gland in the scorpions and Limulus? Lankester's paper gives us full informatiou on this point as far as the scorpion and Limulus are concerned, and he shows that the coxal gland of Limulus differs markedly from that of Scorpio in the size of the cells and in the 
arrangement of the tubes. In Fig. $126, \mathrm{~A}$, I give a picture of a piece of the coxal gland of Limulus taken from Lankester's paper.

Turning now to the vertebrate, Bela Haller's paper gives us a number of pictures of the glandular hypophysis from various vertebrates, and he especially points out the tubular nature of the gland and its solidification in the course of development in some cases. In Fig. 126, B, I give his licture of the gland in Ammocoetes.

The striking likeness between Haller's picture and Lankester's picture is apparent on the face of it, and shows clearly that the histological structure of the glands in the two cases confirms the deductions drawn from their anatomical and morphological positions.

$A$
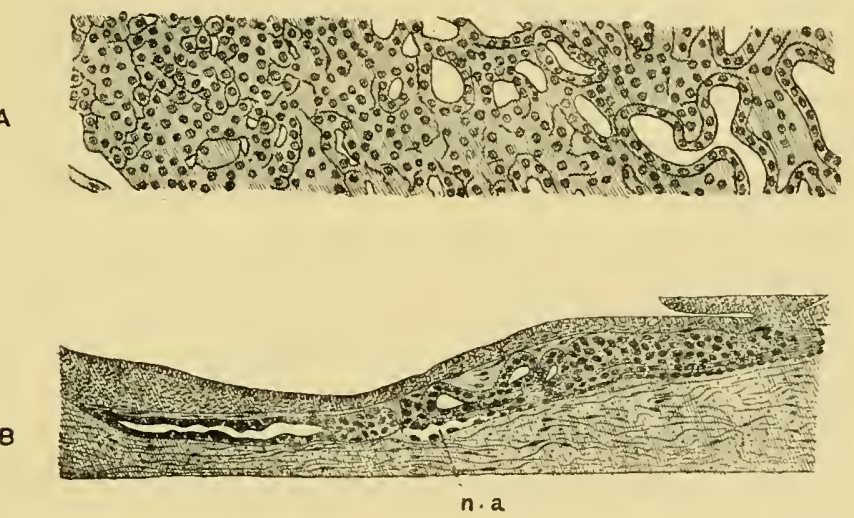

Fig. 126. - A, Section of Coxal Giand of Limulus (from Lankester); B, Section of Pituitary Body of Amiocetes (from Bela Haller!.

n.a., termination of nasal passage.

The sequence of events which gave rise to the pituitary body of the vertebrate was in all probability somewhat as follows:-

Starting with the excretory glands of the Phyllopoda, known as shell-glands, which existed almost certainly in the phyllopod Trilobite, we pass to the coxal gland of the Merostomata. Judging from Limulus, these were coextensive with the coxæ of the 2 nd, $3 \mathrm{rd}, 4$ th, and 5 th locomotor appendages. When these appendages became reduced in size and purely tactile they were compressed and concentrated round the mouth region, forming the endognaths of the Merostomata; as a necessary consequence of the concentration of the coxæ of the endognaths, the coxal gland also became concentrated, 
and took up a situation close against the pharynx, as represented in Fig. 106, B. When, then, the old mouth closed, and the pharynx became the saccus vasculosus, the coxal gland remained in close contact with the saccus rasculosus, and became the pituitary body, thus giving the reason why there is always so close a connection between the pituitary body and the infundibular region.

Whatever was the condition of the digestive tracts at the transition stage between the arthropod and the vertebrate, the original mouth-opening at the base of the olfactory tube was ultimately closed. The method of its closure was exceedingly simple and evident. The membranous cranium was in process of formation by the extension of the plastron laterally and dorsally; a slight growth of the same tissue in the region of the mouth would suffice to close it and thus separate the infundibulum from the olfactory tube. As evidence that such was the method of closure, it is instructive to see how in Ammocoetes the glandular tissue of the pituitary body is embedded in and mixed up with the tissue of this cranial wall; how the termination of the nasal tube is embedded in this same thickened mass of the cranial wall-how, in fact, both coxal gland and olfactory tube have become involved in the growth of the tissue of the plastron, by means of which the mouth was closed.

I have now passed in review the nature of the evidence which justifies a comparison between the segments supplied by the cranial nerves of the vertebrate and the prosomatic and mesosomatic segments of the palæostracan. For the convenience of my readers I have put these conclusions into tabular form (see p. 323), for all the segments as far as that supplied by the glossopharyngeal nerves. In both vertebrate and invertebrate this is a fixed position, for in the former, however variable may be the number of branchial segments which the vagus supplies, the second branchial segment is always supplied hy a separate nerve, the glossopharyngeal, and in the latter, though the number of segments bearing branchiæ varies, the minimum number of such segments (as seen in the Pedipalpi) is never less than tro.

\section{Summari.}

The general consideration of the evidence of the number of segments, and their nature in the pro-otic region of the vertebrate, as given in the last chapter, is not incompatible with the view that the trigeminal nerve originally 
THE PROSOMATIC SEGMENTS OF AMMOCETES 323

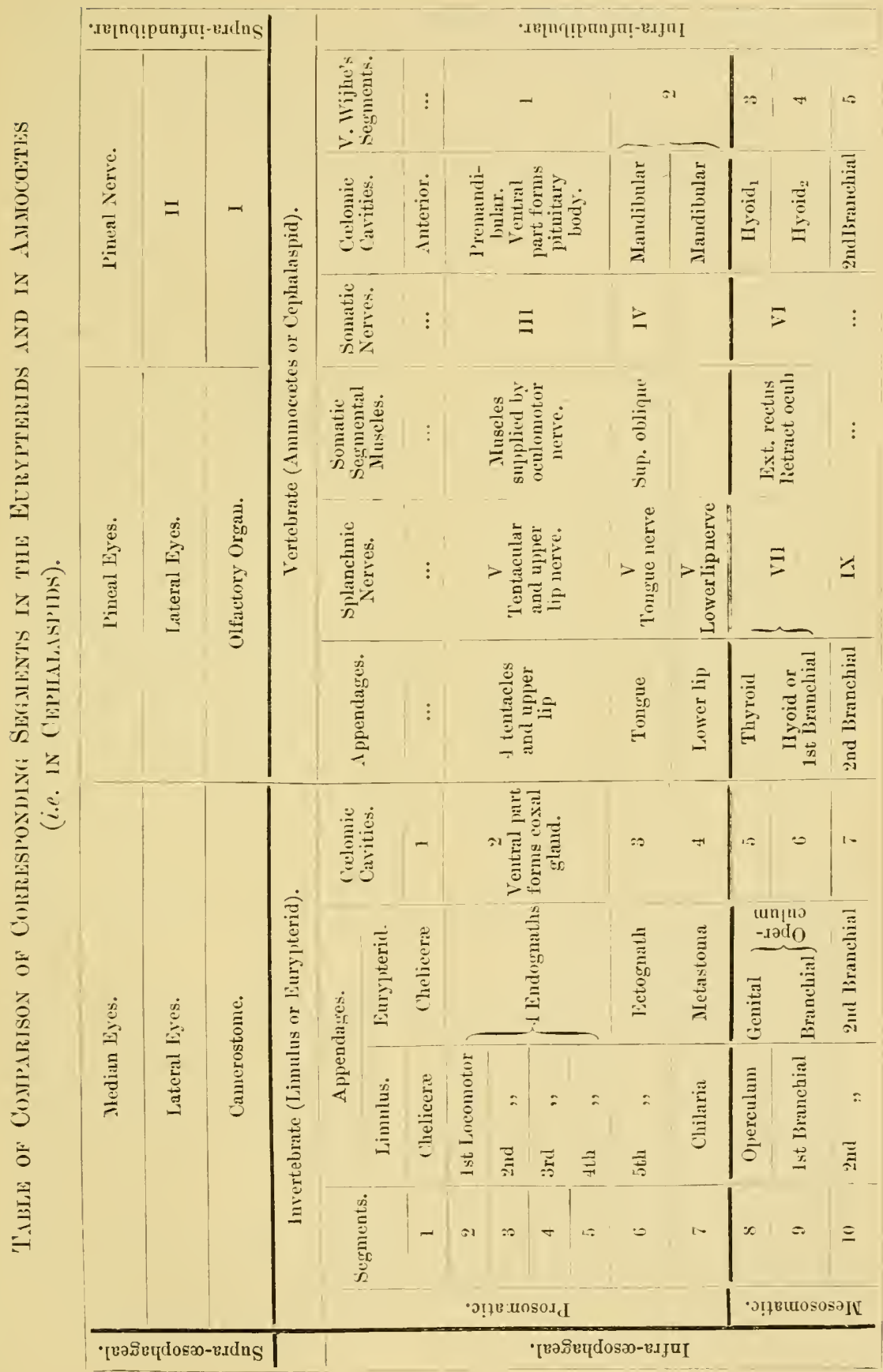


supplied seren appendages. which appendages did not carry branchia, but were originally nsed for purposes of locomotion as well as of mastication.

Such appendages clearly no longer exist in the higher vertebrates, the muscles of mastication only remaining; but in the earliest fish-forms they must hare existed. as, indeed, is seen in Ptericthys and Bothriolepis. Judging from all the previous eridence some signs of their existence may reasonably be expected still to remain in Ammocotes. Such is indeed the case.

In the adult Petromyzon the trigeminal nerve innervates specially a massive suctorial apparatus, by means of which it holds on to other fishes, or to stones in the bottom of the stream. There is here no apparent sign of appendages. Very great. however, is the difference in the oral chamber of Ammoceetes: here there is no sign of any suctorial apparatus, but instead, a system of tentacles, together with the remains of the septum or relum, which originally closed off the oral from the respiratory chamber. These tentacles are the last remnants of the original foremost prosomatic appendages of the palrostracan ancestor. Like the lateral eyes they do not derelop mil the transformation comes, but during the whole larral condition their musculature remains in an embryonic condition. and then from these embryonic muscles the whole massire musculature of the suctorial apparatus develops; a sucking apparatus derived from the moditication of appendages, as so frequently occurs in the arthropods.

The study of Ammocotes indicates that the velum and lower lip correspond to the metastoma of the Emypterid, i.e. the chilaria of Limulus, while the large rentral pair of tentacles, called the tongme. correspond to the ectognaths of the Eurypterids, and probably to the oar-like appendages of Ptericthys and Bothriolepis. From these two splanclnic segments the suctorial apparatus in the main arises; the motor supply of these two segments forms the mass of the trigeminal nerve-supply, and the nerres snpplying them, the relar nerre and the tongue-nerve, are markedly separate from the rest of the trigeminal nerre.

The rest of the tentacles present much less the sign of independent segments. In their nerres, their muco-cartilaginous skeleton, and their rudimentary muscles. they indicate a concentration and amalgamation, such as might be expected from the concentrated endognaths. The continuation of the dwindling process. already initiated in the Eurypterid, would easily result in the tentacles of Ammocotes.

The nasal tube of Ammocoetes, which originates in the hypophysial tube, corresponds absolutely in position and in its original structure, to the olfactory tube of a scorpion-like animal. From this lomology two conclusions of importance follow: (1) the old month, or palrostoma, of the rertebrate was situated at the end of this tube, therefore, at the termination of the infundibulum ; (2) the upper lip, which by its growth, brings the olfactory tube from a rentral to a dorsal position, was originally formed by the foremost sternites or endostoma. or else by the sterno-coxal processes of the second pair of prosomatic appendages of the palrostracan ancestor.

In strict accordance with the rest of the comparisons made in this region, the pituitary body shows by similarity of structure, as well as of position, that it arose from the coxal glands, which were situated at the base of the four endognaths. 
One after another, when once the clue has been found, all these mysterious organs of the rertebrate, such as the pituitary and thyroid glands, fall harmoniously into their place as the remnants of corresponding important organs in the palrestraca.

Yet another clue is afforded by the tubular muscles of Ammocotes, that strange set of non-rertebrate striated muscles, which are so markedly ar'ranged in a segmental manner, which disappear at transformation, and are never found in any of the higher rertebrates, for the limits of their distribution correspond to the reno-pericardial muscles of Limulus.

Their nerve-supply in Ammocotes is most extraordinary; for, although they are segmentally arranged throughout the whole respiratory region, which is segmentally supplied by the VIIth. IXth, and Xth nerres, and are found in front of this region only in one segment, that of the lower lip, which is supplied by the relar branch of the Vth nerve, yet they are not supplied segmentally. but only by the relar nerre and a branch of the VIIth, the ramus branchialis profundus. This latter nerve extends throughout the respiratory region, and gives off segmental branches to supply these muscles.

It is also a curions coincidence that in sucl a markedly segmented animal as Limulns, a nerre-the pericardial nerve-which arises from the nerres of the chilarial and opercular segments, should pass along the whole respiratory region and gire off branches to each mesosomatic segment. It is strange. to say the least of it, that the chilarial or metastomal and the opercular segments of Limulus should. on the theory adrocated in this book, correspond to the lower lip and hyoid segments of the rertebrate. At present the homology suggested is not complete, for there is no evidence as yet that the reno-pericardial muscles have anything to do with the pericardial nerre. 


\section{CHAPTER X}

THE RELATIONSHIP OF AMMOCETES TO THE MOST A.VIENT FISHES-THE OSTRACODERMATA

The nose of the Osteostraci-Comparison of head-shield of Ammocoetes and of Cephalaspis,-Ammocetes the only living representative of these ancient fishes,-Formation of eranium.-Closure of old month.-Rohon's primordial cranium,-Primoldial cranium of Phrymus and Galeodes,-Summary.

TuE shifting of the orifice of the olfactory passage, which led to the old month, from the ventral to the dorsal side, as seen in the transformation of the rentrally situated hypophysial tube of the young Ammoccetes, to the dorsally situated nasal tube of the full-grown Ammocetes, affords one of the most important clues in the whole of this story of the origin of vertebrates; for, if Ammocotes is the nearest living representative of the first-formed fishes, then we ought to expect to find that the dorsal head-shield of such fishes is differentiated from that of the contemporary Palicostraca by the presence of a median frontal opening anterior to the eyes. Conversely, if such median nasal orifice is found to be a marked characteristic of the group, in combination with lateral and median eyes, as in Ammocetes, then we have strong reasons for interpreting these head-shields by reference to the head of Ammocnetes.

The oldest known fishes belong to a large group of strange forms which inhabited the Silurian and Devonian seas, classed together by Smith Woodward miler the name of Ostracodermi. These are divided into three orders: (1) the Heterostraci, including one family, the Pteraspidæ, to which Pteraspis and Cyathaspis belong; (2) the Osteostraci, divisible into two families, the Cephalaspidre and Tremataspida, which inchude Cephalaspis, Eukeraspis, Auchenaspis or Thyestes, and Tremataspis; and (3) the Antiarcha, with one family, the Astrolepidæ, including Astrolepis, Pterichthys, and Bothriolepis. 
Of these, the first two orders belong to the Upper Silurian, while the third is Devonian.

\section{The Dorsal Head-Shield of the Osteostraci.}

Of the three orders above-named, the Heterostraci and Osteostraci are the oldest, and among them the Cephalaspidre have afforded the most numerous and best worked-out specimens. At Rootzikïll, in the island of CEsel, the form known as Thyestcs (Auchenaspis) vcrucosus is especially plentiful, being found thickly present in among the masses of Eurypterid remains, which give the name to the deposit. Of late years this species has been especially worked at by Rohon, and many beautiful specimens have been figured by him, so that a considerable advance has been made in our knowledge since Pander, Eichwald, Huxley, Lankester, and Schmidt studied these most interesting primitive forms.

All observers agree that the head-region of these fishes was covered by a dorsal and ventral head-shield, while the body-region was in most cases unknown, or, as in Eichwald's specimens, and in the specimens figured in Lankester and Smith Woodward's memoirs, was made up of segments which were not rertebral in eharacter, but formed an aponeurotic skeleton, being the hardened aponeuroses between the body-muscles. This body-skeleton, which possesses its exact counterpart in Ammoecetes, will be considered more fully when I discuss the origin of the spinal region of the vertebrate.

Of the two head-shields, ventral and dorsal, the latter is best known and characterizes the group. It consists of a dorsal plate, with characteristic horns, which in Thyestcs verrucosus (Fig. 128), as described by Rohon, is composed of two parts, a frontal part and an occipital part (occ.), the occipital part being composed of segments, and possessing a median ridge-the crista occipitalis. In Lankester's memoir and in Smith Woodward's catalogue, a large number of known forms are described and delineated, and we may perhaps say that in some of the forms, such as Eukcraspis pustuliforus (Fig. 127, B), the frontal part of the shield only is capable of preservation as a fossil, while in Cephalaspis (Fig. 127, A) not only the frontal part but a portion of the occipital region is preserved, the latter being small in extent when compared with the occipital region of Auchenaspis (Thyestes). Finally, in Tremataspis and Didymaspis, the whole of both frontal 
and occipital region is capable of preservation, the line of demarcation between these two regions being well marked in the latter species.
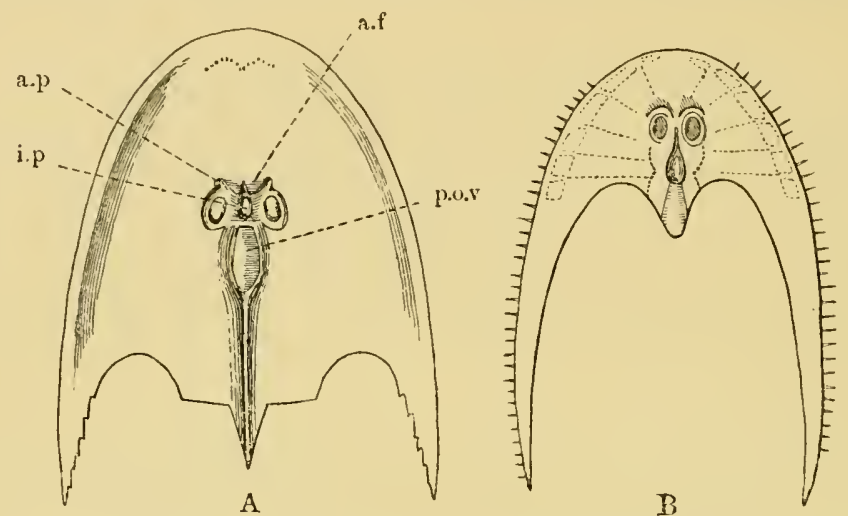

Fig. 127.-A, Dorsal Head-Shield of Cephalaspis (from Laxkester); B, Dorsal Head-Shield of Keraspis (from Lankester).

In the best preserved speeimens of all this group of fishes a frontal median orifice is always present; it appears in some specimens

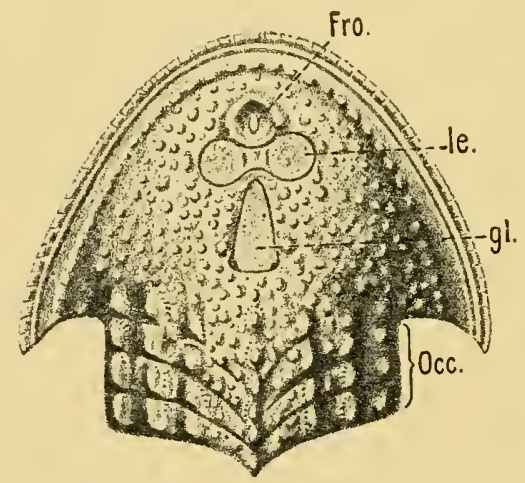

Fig. 128.--Dorsal Head-Shield of Thyestes (Auchenaspis) verrucosus. (From Rонок.)

Fro., narial opening; l.e., lateral eyes ; gl., glabellum or plate over brain; Occ., occipital region. obseurely partially divided into two parts. Perhaps the best specimen of all was obtained by Rohon at Rootziküll, and is thus described by him :-

The frontal part of the dorsal head-plate earried (Fig. 128) the two orbits for the lateral eyes (l.c.), a marker frontal organ (fro.), and a median depression $(g l$.$) , to which he gives the$ name parietal organ. The occipital part (occ.) was clearly segmented, and carried, he thinks, the branehis. I reproduce Rohon's figure of the frontal organ in Thyestes (Fig. 129); he describes it as a deeply sunk pit, divided in the middle by a slit, which leads deeper in, he supposes, towards the central nervous system. 
A similar organ was described by Schmidt in Tremataspis, and considered by him to be a median nose. Such also is the view of Jaekel, who points out that a median pineal eye exists between the two lateral eyes in this animal, as in all other of these ancient fishes, so that this frontal organ does not, as Patten thinks, represent the pineal eye. The whole of this group of fishes, then, is characterized by the following striking characteristics :-

1. Two well-marked lateral eyes near the middle line.

2. Between the lateral eyes, well-

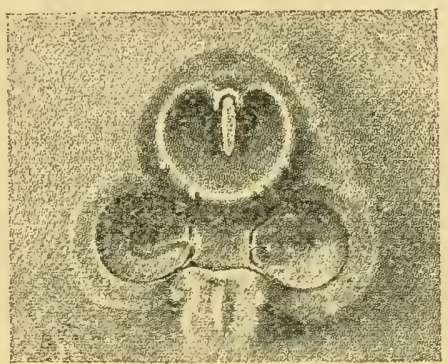

Fig. 129.-Narial Openisg and Lateral Orbits of Thyestes Terrucosus. (From Rohox.) marked median eyes, very small.

3. In front of the eye-region a median orifice, single.

In aldition, behind the eye-region a median plate is always found, frequently different in structure to the rest of the head-shield, being liarder in texture-tlie so-called post-orbital plate.

Structure of He.dD-Sineld of Cephalaspis compared with that of Amalectes.

What is the structure of this head-shield? It has been spoken of as formed of bone because it possesses cells, being thus unlike the layers of chitin, which are formed by underlying cells but are not themselves cellular. At the same time, it is recognized on all sides that it has no resemblance to bone-structure as seen in fossil remains of higher vertebrates. The latest and best figure of the structure of this so-called bone is given in Rohon's paper alrearly referred to. It is, so he describes, clearly composed of fibrillæ and star-shaped cells, arranged more or less in regular layers, with other sets of similar cells and fibrillæ arranged at right angles to the first set, or at varying angles. The groundwork of this tissue, in which these colls and fibrils are cmbedded, contained calcium salts, and so the whole tissue was preserved. In places, spaces are found in it, in the deepest layer large medullary spaces; more superficially, ramifying spaces which he considers to be vascular, and calls Haversian canals; the 
star-like cells, however, are not arranged concentrically around these spaces, as in true Haversian canals.

This structure is therefore a calcareous infiltration of a tissue with cells in it. Where is there anything like it?

As soon as I saw Rohon's picture (Fig. 130), I was astounded at its startling resemblance to the structure of muco-cartilage as is seen in Fig. 131, taken from Ammocœetes. If such muco-cartilage were infiltrated with lime salts, then the muco-cartilaginous skeleton of Ammocotes would be preserved in the fossil condition, and be comparable with that of Cephalaspis, etc.

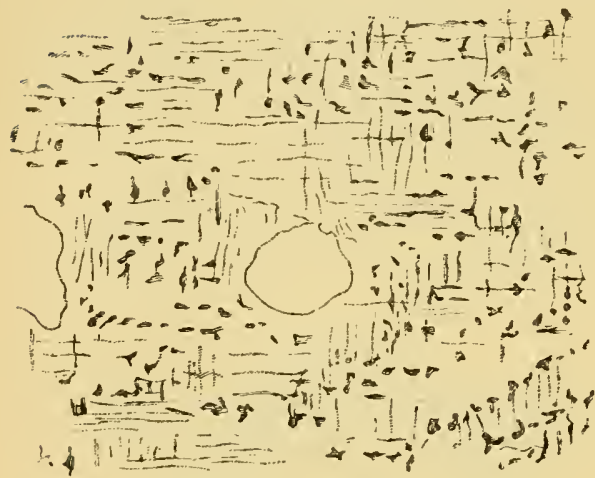

Fig, 130.- Skction of a HeadPlate of a Cephalaspid. (From RoHon.)

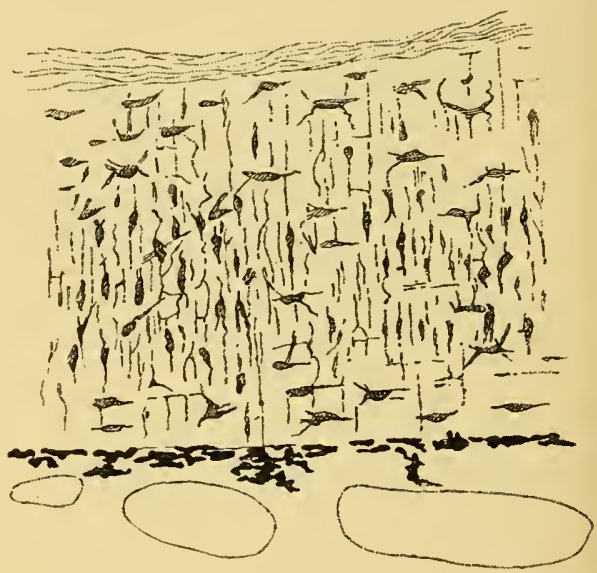

Fig. 131.-Section of MucoCartilage from Dorsal Head-Plate of Amocetes.

The whole structure is clearly remarkably like Fohon's picture of a section of the head-plate of a Cephalaspid (Fig. 130). In the latter case the matrix contains calcium salts, in the former it is composed of the peculiar homogeneous mucoid tissue which stains so characteristically with thionin. With respect to this ealcification, it is instructive to recall the calcification in the interior of the branchial cartilages of Limulus, as described in Chapter III., for this example shows how easy it is to obtain a calcification in this chondro-mucoid material. With respect to the medullary spaces and smaller spaces in this tissue, as described by Rohon, I would venture to suggest that they need not all necessarily indicate blood-vessels, for similar spaces would appear in the head-shield of Ammoccetes if its muco-cartilage alone 
were preserved. Of these, some would indicate the position of bloodvessels, such, for instance, as of the external carotid which traverses this structure; but the largest and most internal spaces, resembling Rohon's medullary spaces, would represent muscles, being filled up with bundles of the upper lip-muscles.

\section{Tie Muco-Cartilaginous Head-Shield of Amiocretes.}

The resemblance between the structure of the head-shield of Thyestes and the muco-cartilage of Ammocoetes, is most valuable, for muco-cartilage is unique, occurs in no other vertebrate, and every trace of it vanishes at transformation; it is essentially a characteristic of the larval form, and must, therefore, in accordance with all that lias gone before, be the remuant of an ancestral skeletal tissue. The whole story deduced from the study of Ammocotes would be incomplete without some idea of the meaning of this tissue. So also, as already mentioned, the skeleton of Ammoecetes is incomplete without taking this tissue into account. It is confined entirely to the head-region; no trace of it exists posteriorly to the branchial basket-work. It consists essentially of dorsal and ventral headshields, connected together by the tentacular, metastomal, and thyroid bars, as already described. The ventral shield forms the muco-cartilaginous plate of the lower lip and the plate over the thyroid gland, so that the skeleton ventrally is represented by Fig. 118, B, which shows how the cartilaginous bars of the branchial basket-work are separated from each other by this thyroid plate. At transformation, with the disappearance of this muco-cartilaginous plate, the bars come together in the middle line, as in the more posterior portion of the branchial basket-work.

The dorsal head-shield of muco-cartilage covers over the upper lip, sends a median prolongation over the median pineal eyes and a lateral prolongation on each side as far as the auditory capsules, giving the shape of the head-shield of muco-cartilage, as in Fig. $118, \mathrm{C}:$

Not only then is the structure of the head-shield of a Cephalaspid remarkably like the muco-cartilage of Ammocoetes, but also its general distribution strangely resembles that of the Ammocretes muco-cartilage.

Now, these hear-shields in the Cephalaspidie and Tremataspidat 
vary very much in shape, as is seen by the comparison of Tremataspis and Auchenaspis with Cephalaspis and Eukeraspis, and yet, undoubtedly, all these forms helong to a single group, the Osteostraci.

The conception that Ammocotes is the solitary living form allied to this group affords a clue to the meaning of this variation of shape, which appears to me to be possible, if not indeed probable. There is a certain amount of evidence given in the development of Ammocretes which indicates that the hranchial region of its ancestors was covererl with plates of muco-cartilage as well as the prosomatic region.

The evidence is as follows :-

The somatic muscles of Ammocotes form a continuous longitudinal sheet of muscles along the length of the body, which are divided up by connective tissue bands into a series of imperfect segments or myotomes. This simple muscular sheet can be dissected off along the whole of the head-region of the animal, with the exception of the most anterior part, without interfering with the attachments or arrangements of the splanchnic muscular system in the least. The reason why this separation can be so easily effected is to be found in the fact that the two sets of muscles are not attached to the same fascia. The sheet of fascia to which the somatic muscles are attached is separated from the fascia which encloses the branchial cavity by a space (cf. Figs. 63 and 64 ) filled with blood-spaces and cells containing fat, in which space is also situated the cartilaginous branchial basket-work. These branchial bars are closely comnected with the branchial sheet of fascia, and have no connection with the somatic fascia, their perichondrium forming part of the former sheet. Upon examination, this space is seen to be mainly vascular, the blood-spaces being large and frequently marked with pigment; but it also possesses a tissue of its own, recognized as fat-tissue by all observers. The peculiarity of the cells of this tissue is their arrangement; they are elongated cells arranged at right angles to the plates of fascia, just as the fibres of the muco-cartilage are largely arranged at right angles to their limiting plates of perichondrium. These cells do not necessarily contain fat; and when they do, the fat is found in the centre of each cell, and does not push the protoplasm of the cell to the periphery, as in ordinary fat cells. 
In Fig. 132, B, I give a specimen of this tissue stained by osmic acid; in Fig. 132, A, I give a drawing of ordinary muco-cartilage taken from the plate of the lower lip; and in Fig. 133, A, a modification of the muco-cartilage taken from the velum, which shows the formation of a tissue intermediate between ordinary muco-cartilage and this branchial fat-tissue.

Further, in fully-grown specimens of Ammoccetes, in the region of undoubted muco-cartilage, a fatty degeneration of the cells frequently appears, together with an increase in the blood spaces,-- the precursor, in fact, of the great change which overtakes this tissue soon afterwards, at the time of transformation, when it is invaded by hlood, and swept away, except in those places where new cartilage is formed. I conclude, then, that the tissue of this rascular space was originally mucocartilage, which has degenerated during the life of the Ammocortes. The fact that in most cases

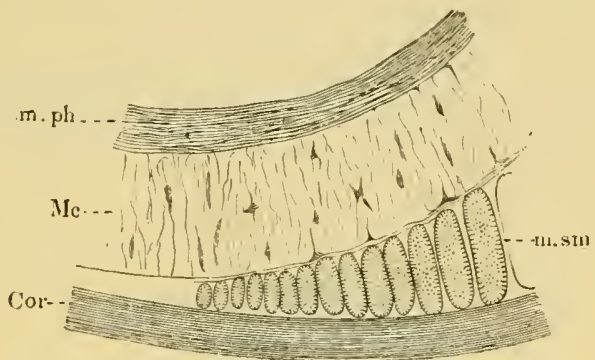

A

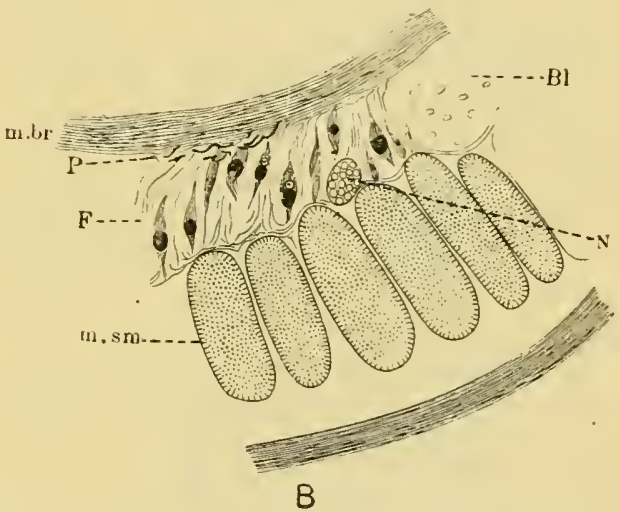

Fig, 132.-A, Mitco-cartilage of Lower Lip (Mc.) ; m.ph., muscle of lower lip; m.sm., somatic muscle; Cor., laminated layer of skin. B, Degenerated Mrco-cartilage of BrayChial Region. $F$., fat layer; $P$., pigment; $B l$., blood-space; $N$., somatic nerve; $m . b r$., branchial muscle; m.sm., somatic muscle. undoubted muco-cartilage is to be found here and there in this space, is strong confirmation of the truth of this conclusion.

If this conclusion is correct, we may expect that it would be confirmed by the embryological history of the tissue, and we ought to find that in much younger stages a lomogeneons tissue of the same nature as muco-cartilage fills up the spaces in the branclial 
region, where in the Ammocnetes only hlood and fat-containing cells are present. For this purpose Shipley kintly allowed me to exanine lis series of sections throngh the embryo at varions ages. These specimens are very instructive, especially those stained by osmic acid, which prescrves the natural thickness of this space better than other staining methods. At an age when the branchial cartilages are seen to be formed, when no fat-cells are present, a distinctive tissue (Fig. 133, B) is plainly visible in the velum and at the hase of the tentacles, in the very position where in the more advanced Ammocoetes muco-cartilage exists. Taking, then, this tissne as our guide, the specinens show that the space between the skin and the visceral muscles in which the cartilaginous basket-work lies is filled with a

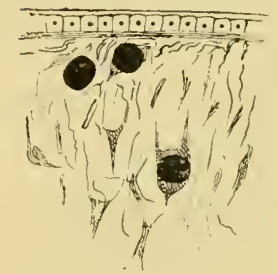

A

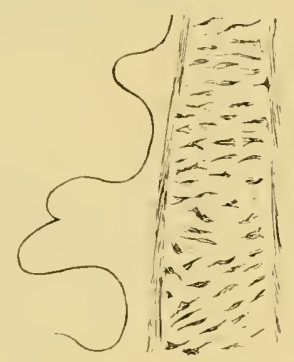

$\mathrm{B}$
Fig. 133.-A, Micco-Cartilage of Velum;

B, Embryonic Muco-Cartilagie of TentacetaR BAR, similar material. At this stage a sheet of embryonic tissue ocenpies the position where, later on, bloodspaces and fat-cells are found, and this tissue resembles that seen in the velum and other places where muco-cartilage is afterwards found.

I conclude, therefore, that originally the branchial or mesosomatic region was covered with a dorsal plate of mnco-cartilage, which carried on its under surface the dorsal part of the branchial basket-work, and sprang from the central core of skeletogenous tissne around the notochord; this plate was separated from the plate which covered this region ventrally by the lateral grove in which the gill-slits are situated. The ventral plate carried on its under surface the ventral part of the branchial basketwork, and was originally continuous with the plate over the thyroid gland.

In Fig. 134, A, B, C, the cranial skeleton of Ammocoetes is represented from the dorsal, ventral, and lateral aspects. The muco-cartilage is coloured red, the branchial or soft cartilage blue, and the hard cartilage purple. The degenerated muco-cartilage of the branchial region is represented as an uncoloured plate, on 


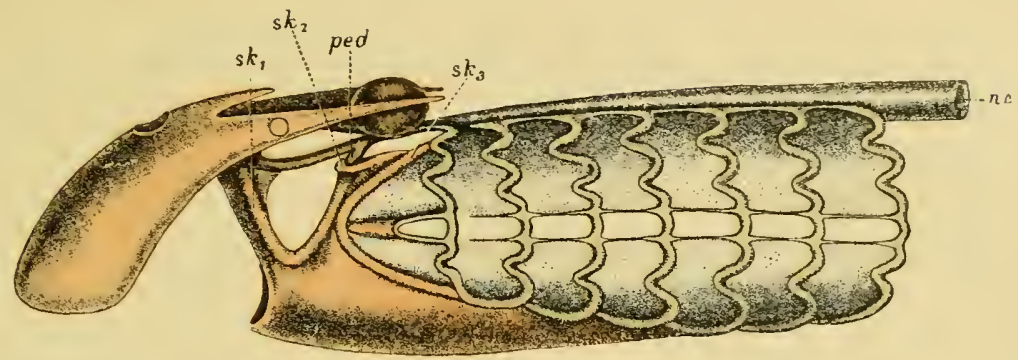

A
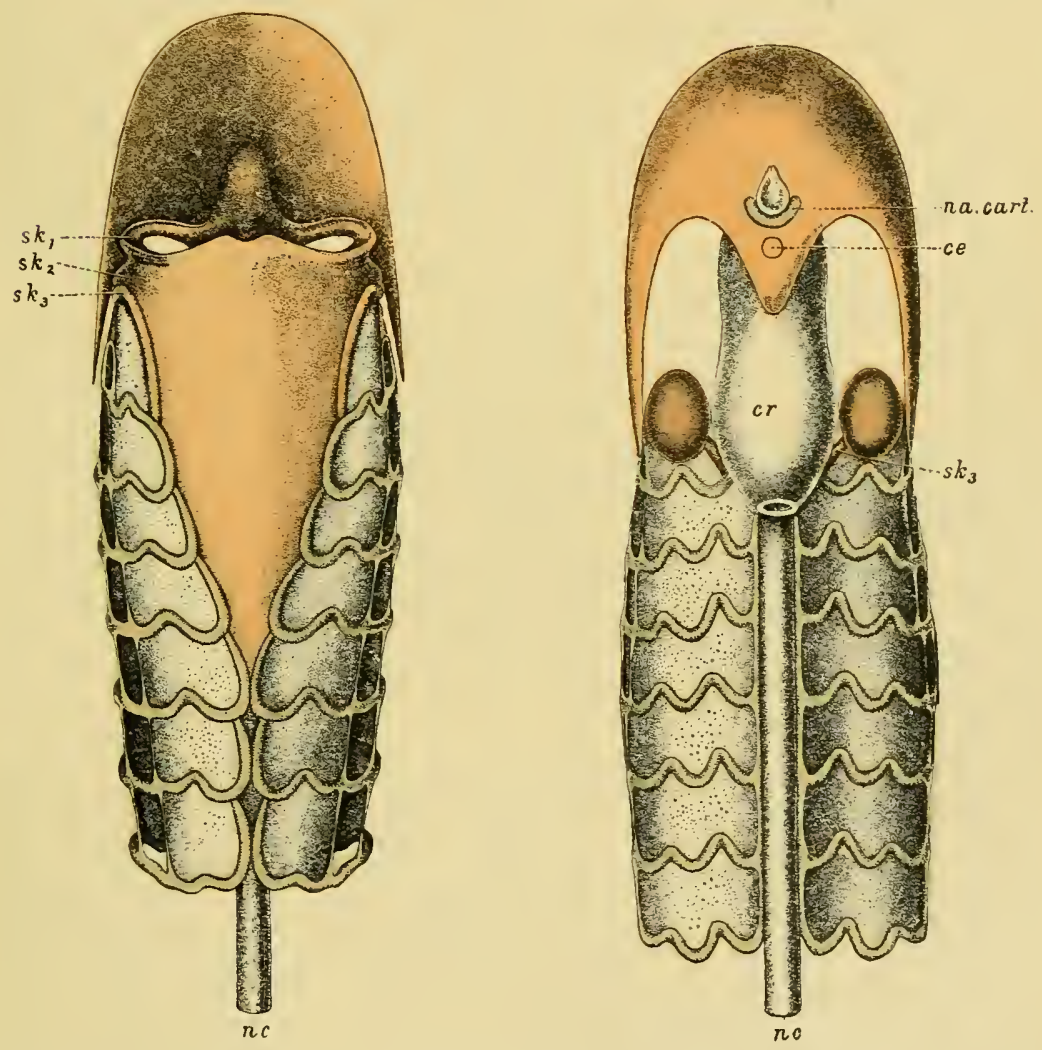

Fig. 134.-Skeleton of Head-Region of Ammocetes. A, Lateral View; B, Ventral View; C, Dorsal View.

MIueo-cartilage, red; soft cartilage, blue; hard cartilage, purple. $s k_{1}, s k_{2}, s i_{3}$, skeletal bars; c.e., position of pineal eye; na.cart., nasal cartilage ; ped., pedicle; cr., cranium; nc., notochord. 
which the branchial basket-work stands in relief. If it were restored to its original condition of muco-cartilage, it would represent a uniform plate, on the under surface of which the basket-work would be situated; and if it were calcified and made solid, the branchial basket-work would not show at all in these figures.

Is it possible to find the reason why this skeletal covering has degenerated so early before transformation, and why the thyroid plate remains intact nntil transformation? We see that all that part which has degenerated is covered over by the somatic muscles,-by, in fact, muscles which, being innervated by the foremost spinal nerves, belong naturally to the region immediately following the branchial. I suggest, therefore, that the original skeletal covering of muco-cartilage has remained intact only where it has not been invaded and covered over by somatic muscles, but has been invaded by blood and undergone the same kind of degenerative change as overtakes the great mass of this tissue at transformation wherever the somatic muscles have overgrown it.

The covering somatic muscles in the branchial region form a dorsal and ventral group, of which the latter is formed in the embryo much later than the former, the line of separation between the two groups being the lateral groove, with its row of branchial openings. This groove ends at the first branchial opening, but the ventral and dorsal somatic muscles continue further headwards. It is instructive to see that, although the lateral groove terminates, the separation between the two groups of muscles is still marked out by a ridge of muco-cartilage, represented in Fig. 134, A, which terminates anteriorly in the opercular bar.

Passing now to the prosomatic region, we find that here, too, the muco-cartilaginous external covering is divisible into a dorsal and a ventral head-plate, the ventral head-plate being the plate of the lower lip, and the dorsal head-plate the plate of muco-cartilage over the front part of the head. The staining reaction with thionin maps out this dorsal head-plate in a most beautiful manner, and shows that the whole of the upper lip-region in front of the nasal orifice is one large plate of muco-cartilage, obscured largely by the invasion of the crossing muscles of the upper lip, but left pure and uniuvaded all around the nasal orifice, and where the upper and lower lips come together. In addition to this foremost plate, a median tongue of inuco-cartilage covers over the pineal eye and fills up the 
median depression between the two median dorsal somatic nuscles. Also, two lateral cornua pass caudalwards from the main frontal mass of muco-cartilage over the lateral eyes, forming the well-known wedge which separates the dorsal and lateral portions of the dorso-lateral somatic muscle. In fact, similarly to what we find in the branchial region, the muco-cartilaginous covering can be traced with greater or less completeness only in those parts which are not covered by somatic inuscles.

In Fig. 134, A, B, C, this striking muco-cartilaginous headshield, both dorsal and ventral, is shown. Seeing that the upper lip wraps round the lower one on each side, and that this most ventral edge of the upper lip contains muco-cartilage, as is seen in Fig. 117, the dorsal head-shield of muco-cartilage ought, strictly speaking, to extend more ventrally in the drawings. I have curtailed it in order not to interfere with the representation of the lower lip and tentacular muco-cartilages.

From what has been said, it follows that the past history of the skeletal covering of the whole head-region of Ammoccetes, both frontal and occipital, can be conjectured by means of the ontogenetic history of the foremost myomeres.

Dohru and all other observers are agreed that during the development of this animal a striking forward growth of the foremost somatic nyomeres takes place, so that, as Dohrn puts it, the body-musculature has extended forwards over the gill-region, and at the same time the gill-region has extended backwards. It is therefore probable that in the ancestral form the inyotomes, immervated by the first spinal nerves, inmediately succeeded the branchial region. Judging from Ammocretes, the forward growth was at first confined to the dorsal region, and therefore invaded the dorsal head-plate, the ventral musculature being distinetly a later growth. With respect to this dorsal part of the myotomes, the first myotome is originally situated some distance behind the anditory capsule, and then grows forward towards the nasal opening; the lateral part, according to Hatschek, grows forward more quickly than the dorsal part, and splits itself above and below the eye into a dorso-lateral part, which extends "1]' to the olfactory capsule, and a ventro-lateral part (m. latermlis capitis anterior, superior, and inferior), thus giving rise to the characteristic appearance of the muco-cartilaginuus head-shield of Ammoccetes.

According, then, to the extent of the growth of these somatic 
muscles, the shape of the muco-cartilaginous head-shield will vary, and if it were calcified and then fossilized we should obtain fossil head-shields of widely differing configuration, although such fossils might be closely allied to each other. This is just what is found in this group. Let the muco-cartilage extend over the whole of the branchial region of Ammocotes, the resulting head-shield would be as in Fig. 135, A; the branchial bar's below the muco-cartilaginous shield might or might not be evident, and the line between the branchial and the trigeminal region might or might not be indicated. Snch a head-shield would closely resemble those of Didymaspis and Tremataspis respectively. Now suppose the somatic musculature to eneroach slightly on the branchial region and also

A

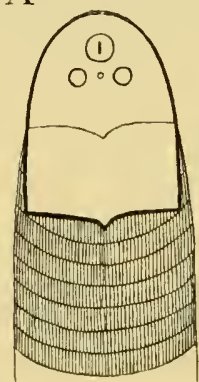

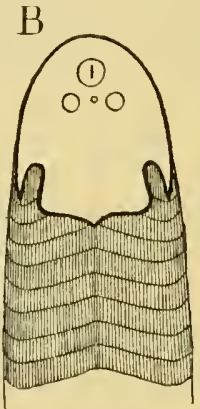
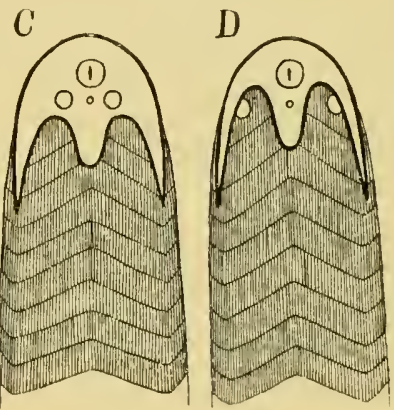

Fig. 135.-Diagrams to show the different shapes of Head-Shields due to THE FORWARD Growth OF the Somatic Musculature.

A, Didymaspis; B, Auchenaspis; C, Cephalaspis; D, Ammocotes.

laterally to the end of the anterior branchial region, then we should obtain a shape resembling that of Thyestes (Fig. 135, B). Continue the same process further, the lateral muscle always encroaching further than the median masses, until the whole or nearly the whole branchial region is invested, and we get the heal-shield of Cephalaspis (Fig. 135, C); further still, that of Keraspis, and yet still further, that of Ammocotes (Fig. 135, D).

So close is this similarity, from the comparative point of view, between the clorsal head-shield of the Osteostraci and the dorsal cephalic region of Ammocotes that it justifies us in taking Ammocretes as the nearest living rejuesentative of such tyles; it is justifiable, therefore, to interpret by means of Ammocoetes the position of other organs in these forms. First and foremost is the hard plate 
known as the post-orbital plate, so invariably found. In Fig. 13t, C, I have inserted (cr.) the position of the nembranous cranium of Ammocoetes, and it is immediately evident that the primordial cranium of the Osteostraci must occupy the exact position indicated by this median hard plate. For this very reason this median plate would be harder than the rest in order to afford a better protection to the brain underneath. This plate, because of its position, may well receive the same name as the similar plate in the trilobite and various palæostracans and be called the glabellum.

\section{Evidence of Segmestation in the Head-Shield-Formation of Cranium.}

We may thus conceive the position of the nose, lateral eyes, median eyes, and cranium in these old fishes. In addition, other indications of a segmentation in this head-region have heen found. The most striking of all the specimens hitherto discovered are some of Thycstes verrucosus, discovered by Rohon, in which the dorsal shield has been removed, and so we are able to see what that dorsal shield covered.

In Fig. 136, I reproduce his drawing of one of his specimens from the dorsal and lateral aspects. These drawings show that the frontal part of the shield covered a markedly segmented part of the animal; five distinet segments are visible apart from the median most anterior region. This segmented region is entirely confined to the prosomatic region, i.e. to the region innervated by the trigeminal nerve. An indication of similar markings is given in Lankester's figure of Eukeraspis pustulifer'ts (see Fig. 127, B), and, indeed, evilence of a segmentation under the antero-lateral border of the head-shield is recognized at the present time, not only in the Cephalaspidie, but also in the Pteraspidæ, as was pointed out to me by Smith Woodward in the specimens at the British Museum. Also, in C'yathaspis, Jaekel las drawn attention to markings of a similar segmental nature (Fig. 137).

There seems, then, little doubt but that these primitive fishes possessed something in this region which was of a segmental character, and indicated at least five segments, probably more.

I iohon entitles his discovery ' the segmentation of the primordial crauium.' It would, I think, be better to call it the segmentation of 
the anterior region of the head, for that is in reality what his figures show, not the segmentation of the primordial eranium, which, to juclge from Ammoeutes, was eonfined to the region of the glabellum.

What is the interpretation of this appearance?

Any segnentation in the head-region must be indieative of segments belonging to the trigeminal or prosomatic region, or of segments belonging to the vagus or mesosomatic region. Many palicontologists,
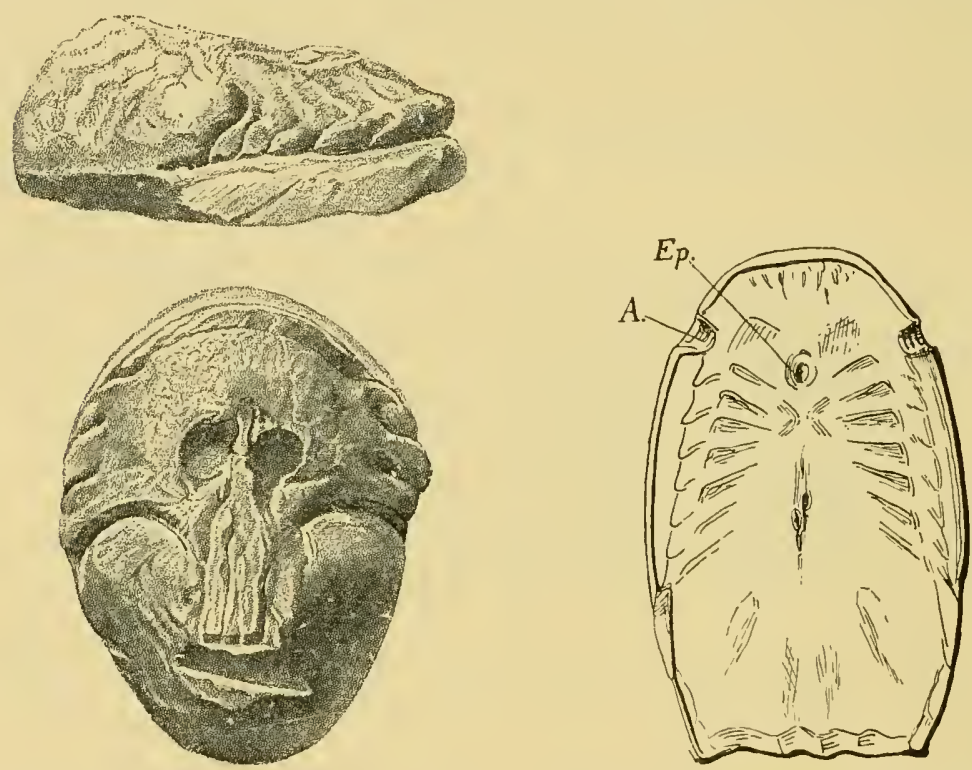

Fig. 136.-Lateral and Dorsal Vifiws of the Frontal and Occipital Regions OF THE HEAD-SHILLD OF THYESTES.AFTER Removal of tile Outer Surface. (From ROHON.)

Fic. 137.-Under Surface of HeadShield of Crathaspis. (From JAEKEL.)

A., lateral eyes; $E_{p}$., median eyes.

looking upon segmentation as indicative of gills and gill-slits, have attempted to interpret sueh markiugs as branehial segments, regardless of their position. As the figures show, they extend in front of the eyes and reach round to the front middle line, a position which is simply impossible for gills, but points direetly to a segmentation connected with the trigeminal nerve. Comparison with $A$ mmocutes makes it plain enough that the markings in pnestion are prosomatie in position, and that the gill-region must be sought for in the place 
where Schmirlt and Rolnon locaterl it in Thyestes, viz. the so-called occipital region.

This discovery of Rohon's is, in my opinion, of immense importance, for it indicates that, in these early fishes, the prosomatic segmentation, associated with the trigeminal nerve, was much more wellmarked than in any fishes living in the present day. Why shonld it he more well-marked? Tuming to the palieostracan, it is very suggestive to compare the markings on their prosomatic earapace with these markings. Again and again we find indications of segmentation in these fossils sinilar to those seen in the ancient fishes. Thus in Fig. 1:38 I have put side by sirle the palirostracan Bunodes and the fish Thyjestes, both life size. In the latter I have indicated Rohon's segments; in the former the markings usually seen.

From the evidence of I'hrynus, Mygale, etc., as alrearly pointed out, such markings in the palrostracan fossils would inclicate the position of the tergo-coxal muscles of the prosomatic appendages, even though such appendages have not yet heen discovered, and it is significant that in all these cases there is a distinct indication of a median plate or

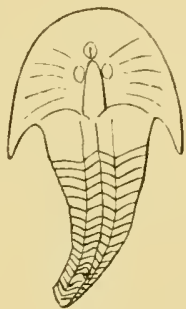

A

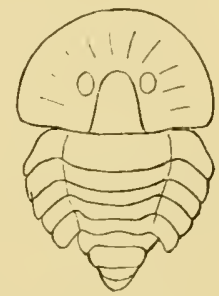

B

Fig. 138.--A, Outline of Thyestes Terrucosus with RoIrox's SegMENTS INDiCated ; B, OUtLiNe of Bunodes Lunula with Lateral Eyes inserted.

Both figures natural size. glabellum in addition to the segmental markings. Especially instructive is the eviltence of Phryuns, as is seen by a comparison of Figs. 107 and 108, which shows clearly that this median plate (glab.) covered the brain-region, a lrain-region which is isolated and protected from the tergo-eoxal muscles liy the growth dorsalwards of the flanges of the plastron. In this way an incipient cranium of a membranous character is formerl, which helps to give attachment to these tergo-coxal muscles. As such cranium is derived directly from the plastron, it is natural that it shonld ultimately become cartilaginous, just as occurs when Ammoccetes becomes Petromyzon and the cartilaginous cranimm of the latter arises from the membranous cranium of the former. In Galeodes also the growth dorsalwards of the lateral flanges of the plastron to form an incipient cranium in which the brain lies is very apparent. 
I venture, then, to suggest that in the Osteostraci the median hard plate or glabellum protected a brain which was enclosed in a membranous cranium, very probably not yet complete in the dorsal region-certainly not complete if the median pincal eyes so universally found in these ancient fishes were functional-a cranium derived from the basal trabeculæ, in precisely the same manner as we see it already in its commencement in Phrynus and other scorpions. With the completion of this cranium and its conversion into cartilage, and subsequently into bone, an efficient protection was afforded to the most vital part of the animal, and thus the hard head-shield of the Palieostraca and of the earliest fishes was gradually supplanted by the protecting bony cranium of the higher vertebrates.

Step by step it is easy to follow in the mind's eye the evolution of the vertebrate cranium, and because it was evolved direct from the plastron, the impossibility of resolving it into segments is at once manifest; for although the plastron was probably originally segmented, as Schimkéwitsch thinks, all sign of such segmentation had in all probability ceased, before ever the vertehrates first made their appearance on the earth.

It follows further, from the comparison here made, that those antero-lateral markings indicative of segments, found so frequently in these primitive fishes, must he interpreted as due not to gills but to aponemroses, due to the presence of muscles which moved prosomatic appendages, muscles which arose from the dorsal region in very much the same position as do the muscles of the lower lip in Ammocetes; the latter, as already argued, represent the tergo-coxal muscles of the last pair of prosomatic appendages-the chilaria or metastoma. Such an interpretation of these markings signifies that the first-formed fishes must have possessed prosomatic appendages of a more definite character than the tentacles of Ammocnetes, something intermediate between those of the palieostracan and Ammoccetes.

For my part I should not be in the least surprised were I to hear that something of the nature of appendages in this region had been found, especially in view of the well-known existence of the pair of appendages in the members of the Asterolepidæ-large, oar-like appendages which may well represent the ectognaths. 


\section{The Remationship of the Ostracoderis.}

Of the three groups of fishes--the Heterostraci, the Osteostraci, and the Antiarcha-the last is Devonian, and therefore the latest in time of the three, while the earliest is the first group, as both Pteraspis and Cyathaspis have been found in lower levels of the Silurian age than any of the Osteostraci, and, indeed, Cyathaspis has been discovered in Sweden in the lower Silurian. This, the earliest of all groups of fishes, is confined to two forms onlyPteraspis and Cyathaspis,-for Scaphaspis is now recognized to be the ventral shield of Pteraspis.

Hitherto a strong tendency has existed in the minds both of the comparative anatomist and the palieontologist to look on the elasmobranchs as the earliest fishes, and to force, therefore, these strange forms of fish into the elasmobranch ranks. For this purpose the same device is often used as has been utilized in order to account for the existence of the Cyclostomata, viz. that of degeneration. The evidence I have put forwarl is very strongly in favour of a connection between the cyclostomes and the cephalaspids, and agrees therefore with all the rest of the evidence that the jawless fishes are more ancient than those which bore jaws - the Gnathostomata.

This is no new view. It was urged by Cope, who classified the Heterostraci, Osteostraci, and Antiarcha under one big group-the Agnatha-from which subsequently the Gnathostomata arose. Cope's arguments have not prevailed up to the present time, as is seen in the writings of Traquair, one of the chief authorities on the subject in Great Britain. He is still an advocate of the elasmobranch origin of all these earliest fishes, and clains that the latest discoveries of the Silurian deposits (Thelodus Pagri) and other memlers of the Cololepidæ confirm this view of the question.

This view may be summed up somewhat as follows:-

Cartilaginous jaws would not fossilize, and the Ostracorlerms may have possessed them.

They may have degenerated from elasmobranchs just as the cyclostomes are supposed to have degenerated.

Seeing that bone succeeds cartilage, the presence of bony shiclds in Cephalaspis, etc., indicates that their precursors were cartilaginous, presumably elasmobranch fishes.

Of these arguments the strongest is based on the supposed bony 
covering of the Ostenstraci, with the consequent supposition that their ancestors possessed a cartilaginous covering This argument is entirely upset, if, as I have pointed out, the structure of the cephalaspid slield is that of muco-cartilage and not of hone. If these plates are a calcified muco-cartilage, then the whole argument for their ancestry from animals with a cartilaginous skeleton falls to the ground, fur muco-cartilage is the precursor not only of hone, hut also of cartilage itself.

The evidence, then, points strongly in farour of Cope's view that the most primitive fishes were Agnatha, after the fashion of cyclostomes, as is also believed by Smith Woodwarl, Bashford Dean, and Jaekel.

Among living animals, as I have shomn, the Limulus is the sole survivor of the palieostracan type, and Ammocrites alone gives a clue to the nature of the cephalaspirl, i.e the osteostracan fish. Older than the latter is the heternstracan, Pteraspis, and Cyathaspis. Is it possible from their structure to obtain any clue as to the actual passage from the palipostracan to the vertebrate?

Here again, as in the case of the Osteostraci, a relationship to the elasmobranch has been supposed, for the following reasons:--

The latest discoveries in the Filurian and Devonian deposits have brought to light strange forms such as Thelodus anıl Drepanaspis, of which the latter from the Devonian must, according to Traquair, he included in the Heterostraci. It possessed, as seen in Fig. 139, large plates, after the fashion of Pteraspis, and also many smaller ones.

The former, from the upper Silurian, helongs to the Crololepida, and was covered over with shagreen composed of small scutes, after the fashion of an elasmolnancl. Traquair suggests that Thelodus arose from the original elasmolnanch stock; that hy the fusion of scutes such a form as Drepanaspis occurred, and, with still further fusion, Pteraspis.

There are always two ways of looking at a question, and it seems to me possilule and more prohalile to turn the matter round and to argue that the original condition of the surface-covering was that of large plates, as in Pteraspis. Iyy the subsequent splitting up of such plates, Drepanaspis was formed, and later on, by further splitting, the elasmolranch, Thelodus being a stage on the way to the formation of an elasmobranch, and not a backward stage from the elasmobranch towards Pteraspis. 
This method of looking at the problem seems to me to be more in consonance with the facts than the reverse; for, as pointed out by Jaekel, the fishes with large plates are the oldest, and in Cyathaspis, the very oldest of all, the size of the plates is most conspicuons; he considers, therefore, this preeonceived view that large plates are formed by the fusion of small ones must give way to the opposite helief.

So also Rohon, as quoted by Traquair, who, in his first paper accepted Lankester's view that the ridges of the pteraspidian shield
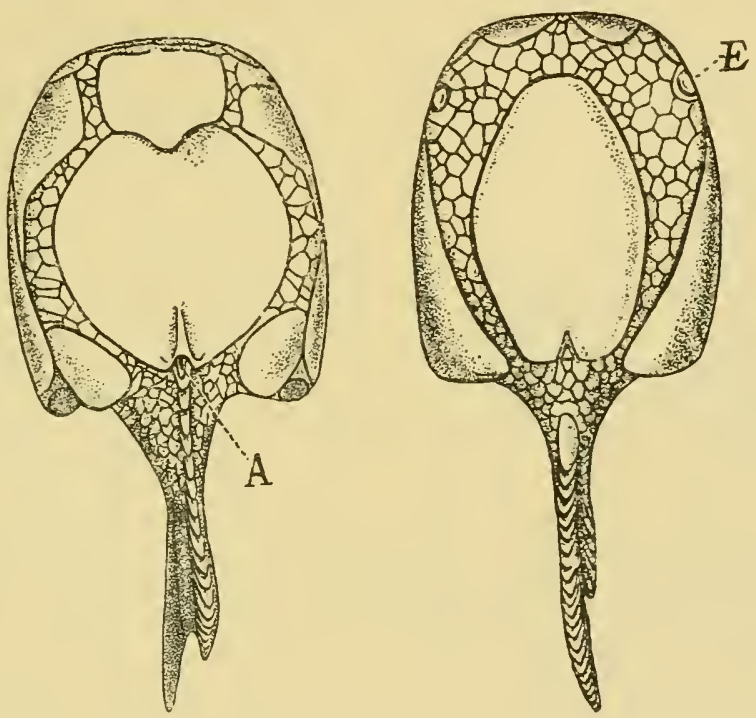

Fig. 139.-Drepanaspis. Ventral and Dorsal Aspects. (After Lankester.) $A$., anus; $E$., lateral eyes.

were formed lyy the fusion of a linear arrangement of numbers of placoid scales, suggests in his second paper that these ridges may have been the most primitive condition of the dermal skeleton of the vertebrate, ont of which, hy differentiation, the dermal denticles (placoid seales) of the selachian, as well as their modifications in the ganoids, teleosteans, and amphibians, have arisen.

One thing is agreed upon on all siles; no sign of bone-corpuseles is to be found in this dermal covering of Pteraspis. In the deeper layers are large spaces, the so-called pulp-cavities leading into narrow canaliculi, the so-callerl dentine canals. The structure is 
looked npon as similar to that of the pulp and dentine canals of many fish-scales.

On the other land, this dermal covering of Pteraspis has been compared by Patten with the arrangement of the chitinous structure of certain parts of the external covering of Limulus, a comparison which to my mind presents a great difficulty. The chitin-layers in Limulus are external to the epilermal cells, heing formed by them; the layers in Pteraspis which look like chitin must have been internal to the epidermal layer; for each rascular canal which passes from a pulp-cavity on its way to be distributed into the dentine canals of the ridge gives off short side branches, which open directly into the groove between the rilges. If these canals were filled with blood they could not possibly open directly into the open grooves between the ridges; these openings must, therefore, have been covered over with an epithelial layer which covered over the surface of the animal, and consequently the chitin-like structure must have been internal to the epiclemis, and not external, as on Patten's view. The comparison of this structure with the dentine of fish-scales signifies the same thing, for in the latter the epidermis is external to the dentine-plates, the hard skeletal structure is in the position of the cutis, not of the cuticle.

The position appears to me to be this : the dermal cranial skeleton of vertebrates, whether it takes the form of a bony skull or of the clorsal plates of a cephalaspid or a pteraspicl is, in all cases, not cuticular, i.e. is not an external formation of the epidermal cells, but is formed in tissue of the nature of connective tissue mnderlying the epidermis. On the contrary, the hard part of the head-carapace of the palæostracan is an external formation of the epidernal cells.

If, then, this tissue of Pteraspis is not to be looked upon as chitin, how can we imagine its formation? It is certainly not bone, for there are no bone-corpuscles; it is a very regular laminated structure resembling in appearance chitin rather than anything else.

As in all cases of difficulty, turn to Ammocnetes and let us see what clue there is to be found there. The skin of Ammocoetes is peculiar among vertebrates in many respects. It consists of a number of epidermal cells, as in Fig. 140, the varying function of which need not he considered here, covered orer with a cuticular layer which is extraordinarily thick for the cuticle of a vertebrate skin; this cuticular layer is perforated with fine canaliculi, through which the 
secretion of the underlying cells passes, as is seen in Fig. 140, A and B. This cuticle corresponds to the chitinous covering of the arthropod, and like it is perforated with canaliculi, and, according to Iwoff, possibly contains chitin. The epidermal cells rest on a thick layer of most striking appearance (Fig. 141), for it resembles, in an extraordinary degree, when examined superficially, a layer of chitin ; it is called the laminated Iayer, and is characterized by the extreme regularity of the laminæ. This appearance is due, as the observations of Miss Alcock show, to alternate layers of connective tissne fibres arranged at right angles to each other, each fibre running a straight course and possessing its own nucleus. Althongh the fibres in each layer are packed close together, they are sufficiently apart to form with the fibres of the alternate layers a meshwork rather than a homogeneous structure, and thus the surface view of this layer shows a regular network of very fine spaces through which nervefibres and fluid pass. This layer is easily dissolved in a solution of hypochlorite of soda, a fluid which dissolves chitin. Any one looking at Ammoenetes woulil say that the only

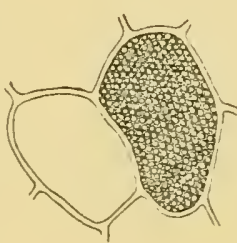

A

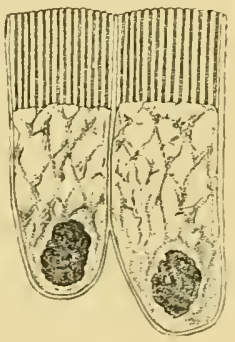

B

Fig. 140.-Epithelial Cells of AmoCoftes to SHOW the Canaliculi in the Thick Cuticle (B). A, Transterse Section throtgh the Cuticle. part of its skin which resembles chitin -is this laminated layer, and therefore the only part of its skin which would afford an inrlication of the nature of the skeleton of Pteraspis is this laminated layer, which belongs to the cutis, and not to the cuticle. Yet another significant peculiarity of this layer is its entire disappearance at transformation. Miss Alcock, in a research not yet published, has shown that this layer is completely broken up and absorbed at transformation; the cutis of Petromyzon is formed entirely anew, and no longer presents any regular laminated character, but resembles rather the sub-epidernal connective tissue layer of the skin of higher rertebrates. This laminated layer, then, just like the muco-cartilage, shows, by its complete disappearance at transformation, its ancestral character.

Very suggestive is the arrangement of the different skeletal 
tissues in the hearl-region of Ammocretes. Fig. 141 represents a seetion throngh the head near the pineal eye. Most internally is $a$, a section of the membranous craninm, then comes $b$, the mucocartilaginous skeleton, then $c$, the laminaterl layer, and finally $\|$, the external entiele. If in Ammocretes we possess an epitome of the history of the vertebrate, how would these layers be represented in

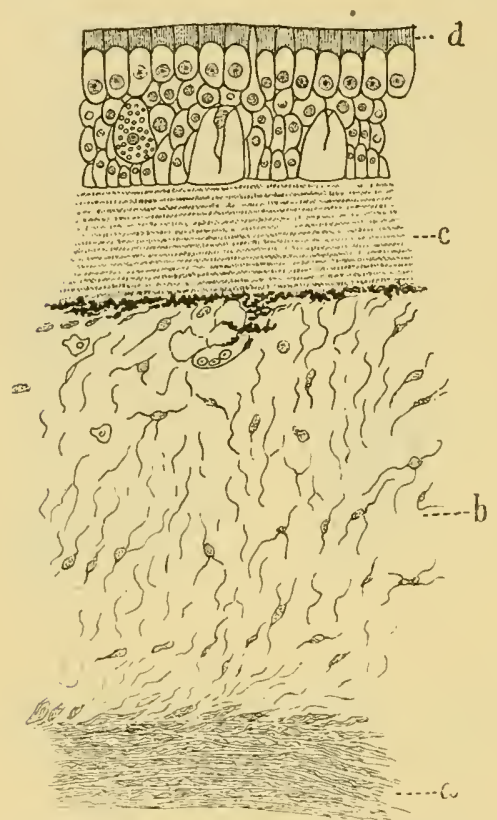

Fig. 141.-Section of Shin and UnderLying Tissces in this fikad-Rikgion of Ammocates.

$a$, cranial wall; $b$, muco-cartilage; $c$, laminated layer; $d$, external cuticular layer. the past ages, supposing they conld be fossilized?

The most internal layer a, liy the formation of cartilage and then hone, represents the great mass of vertebrate fossils; the next layer 7 , by a process of calcifieation, as previonsly argued, represents the head-shield of the Osteostracan fishes; while the entieular layer $d$, no longer thin, is the remnant of the Palacostracan heal-carapace. Between these two layers, $b$ and $d$, lies the laminated layer $c$. Intermediate to the Palcestracan and the Osteostracan eomes the Heterostracan, with its peculiar head-shield-a hear-shield whose origin is more easily conceivable as arising from something of the rature of the laminated layer than from any other structure represented in Ammoccetes.

My present suggestion, then, is this: the transition from the skeletal covering of the Palæostraean to that of the highest vertebrates was brought about by the ealcification of successive layers from without inwards, all of which still remain in Ammoeretes and show how the external ehitinous eovering of the arthropod was gradually replaced by the deep-lying internal bony cranium of the higher vertelurates.

In Ammocrites the layer which represents the eovering of the 
l'alieostracan lias alrearly almost disappeared. At transformation the layers representing the stage arrived at lyy the Heterostracan and the Osteostracan disappear; but the stage rejresenting the higher vertebrates, far from disappearing, by the formation of cartilage reaches a higher stage and prepares the way for the ultimate stage of all-the formation of the bony cranium.

So much for the evidence as to the uature of the structure of the head-shield of the Pteraspidx.

It suggests that these fishes were covered anteriorly with armoured plates derived from the cutis layer of the skin, a layer which was specially thickened and very vascular, apparently, to enable respiration to be very largely, if not entirely, effected by the surface of the body. It is difficult to understand how the sea-scorpions breathed, and it is easy to see how the formation of ventral and dorsal plates enclosing the mesosomatic appendages may at the outset have hindered the action of the branchiae. The respiratory chamber, according to iny view, had at first the double fuuction of respiration and digestion. A new digestive apparatus was the pressing need at the time ; it would, therefore, be of distinct advantage to remove, as much as possible, the burden of respiration from this incipient alimentary canal.

What can be said as to the shape of these ancient forms of fishes? Certain parts of them are absolutely known, other parts are gruesswork. They are known to have possessed a dorsal shield, a ventral shield formerly looked upon as belonging to a separate species, ealled Scapliaspis, and a spine attached to the dorsal shield. The rest of their configuration, as given in Smith Woodward's restoration (Fig. 142) is gnesswork; the fish-like body with its scales, the heterocercal tail, is based on the most insufficient evidence of something of the nature of scales having being found near the heal-plates.

The dorsal shield is elaracterized by a pair of lateral eyes situated on the edge of the shield, not as in Cephalaspis near the middle line. In the middle line, where the rostrum meets the large dorsal plate, median eyes were situated. But the slightest sign of any median single nasal opening, such as is so characteristic of the head-shield of the Osteostraci and of Ammocotes has never been discovered. The olfactory organ must have been situated on the rentral sicle as in the larval stage of Ammocutes, or in the Palacostraca. Many of these head-shields are remarkably well preserved, 
amel it is diffienlt to believe that an olfactory opening would not be seen if any such had existed, as it does in Thyestes.

The difficulty of interpreting these types is the difficulty of understanding their method of locomotion; that is largely the reason why the spine lias been placed as if projecting from the back, and a fishlike body with a heterocereal tail-fin added. If, on the contrary; the
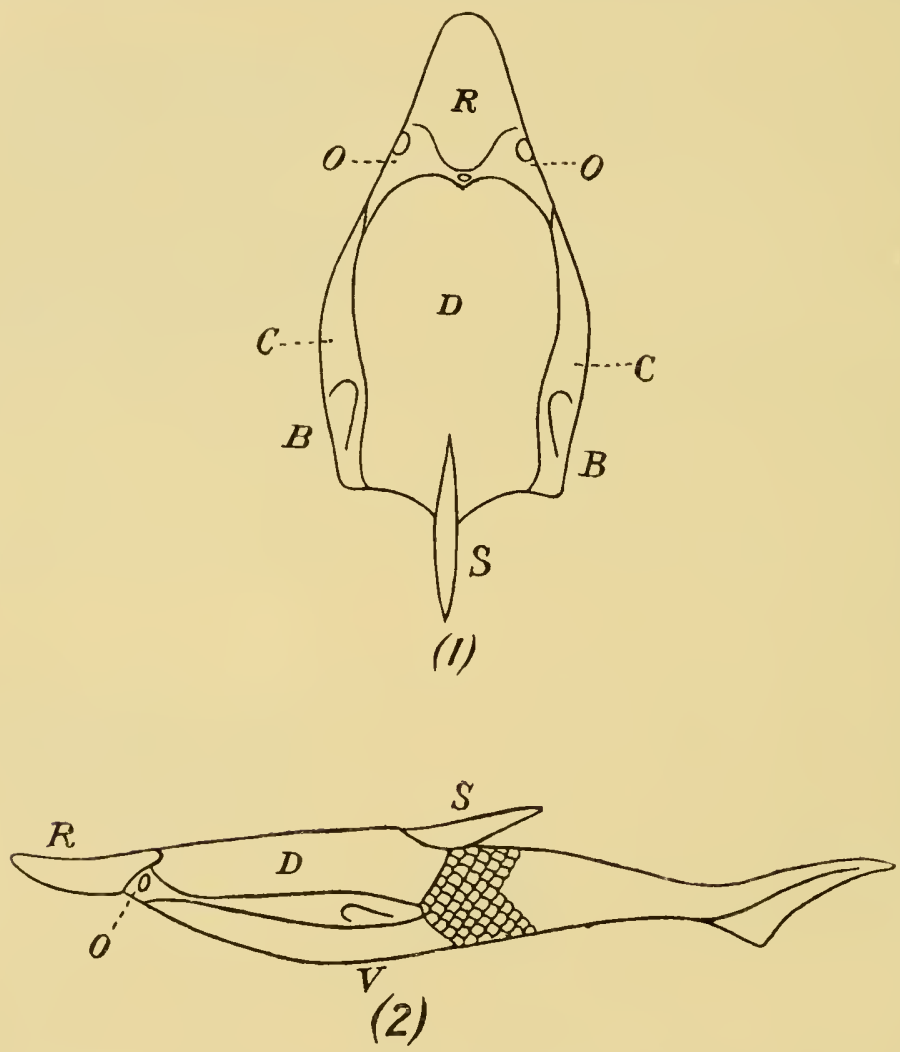

Fig. 142.-Restoration of Pteraspis. (After Simth Woodward.)

spine is a terminal tail-spine, then, as far as the fossilized remains indicate, the animal consisted of a dorsal shield, a ventral shield, and a tail-spine, to which must be added two apparently lateral pieces and a few scales. If the animal clicl not possess a flexible body with a tail-fin, but terminated in a rigid spike after the fashion of a Limulus-like animal, then it must have moved by means of 
appendages. At present we have not sufficient evidence to decicle this question.

That the animal crawled about in the mud by means of free appendages is by no means an impossible view, seeing how difficult it is to find the remains of appendages in the fossils of this far-back time, even when we are sure that they existed. Thus, for many generations, the appendages of trilobites, which ocenr in such countless numbers, and in such great variety of form, were absolutely unknown, until at last, in consequence of a fortunate infiltration by pyrites, they were found by Beecher preserved down to the minutest detail. Even to this day no trace of appendages has been found in such forms as Hemiaspis, Bunodes, Belinurus, Prestwichia.

The whole question of the evidence of any prosomatic appendages in these ancient fishes is one of very great interest, and of late year's has been investigated by Patten. It has long been known that forms such as Pterichthys and Bothriolepis possessed two large, jointed locomotor appendages, and Patten has lately obtained better specimens of Bothriolepis than have ever been found before, which show not only the general configuration of the fish, but also the presence of mandibles or gnathites in the nonth-region resembling those of an arthropod. These mandibles had been seen hefore (Smith Woodward), but Patten's specimens are more perfect than any previously described, and cause him to conclude that these ancient fish were of the nature of arthropods rather than of vertebrates.

Patten has also been able to obtain some excellent specimens of the nuder surface of the head of Tremataspis, which, as evident in Fig. 143, show the presence of a series of holes, ranging on each side from the month-opening, in a semicircular fashion towards the middle line. He considers that these openings indicate the attachments of appendages, in opposition to other observers, such as Jaekel, who look upon them as gill-slits. To my mind, they are not in the right position for gill-slits; they are certainly in a prosomatic rather than in a mesosomatic position, and I should not be at all surprised if further research justified Patten's position. So convinced is he of the presence of appendages in all these old forms, that he considers them to be arthropods rather than vertebrates, although, at the same time, he looks upon them as indicating the origin of vertebrates from arthropods. Here, perhaps, it is adrisable to say a few worls on l'atten's attitude towards this question. 
Two years after I had put forward my theory of the derivation of vertebrates from arthropods, Patten published, in the Quarlerly Jonrnul of Microscopicul. Sricnec, simultaneously with my paper in that jourual, a paper entitled "The Origin of Vertebrates from Arachnids." In this paper he made no reference to my former publications, but he made it clear that there was an absolutely fundamental difference between our treatment of the problem; for he took the old view that of necessity there must be a reversal of

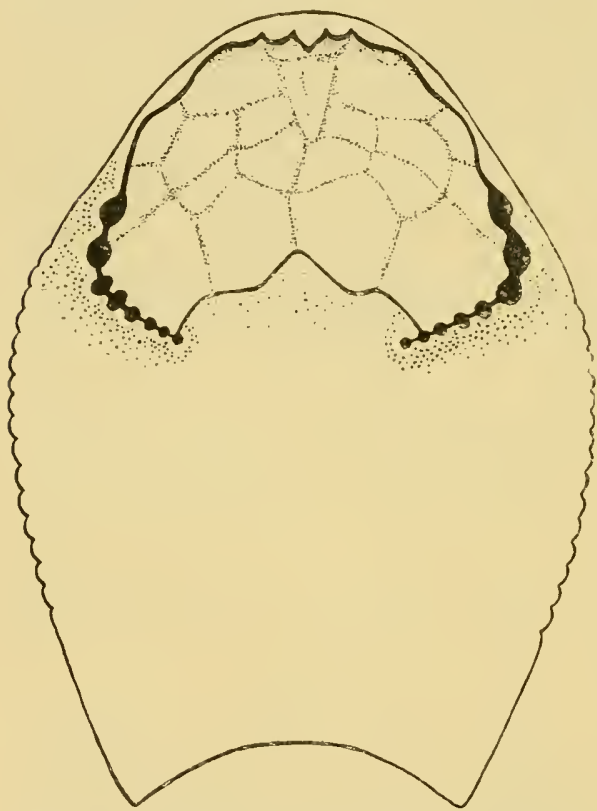

Fig. 143.-Under-Surface of Head-Region in Tremataspis. (Aftor Patten.) surfaces in order that the internal organs should be in the same relative positions in the vertebrate and in the invertebrate. He simply, therefore, substituted Arachnid for Annelid in the old theory. Because of this necessity for the reversal of surfaces he disearded the terms dorsal and rentral as indicative of the surfaces of an animal, and substituted hemal and neural, thereby hopelessly confusing the issue and making it often very difficult to understand his meaning.

He still holds to his original opinion, and I am still waiting to find out when the reversal of surfaces took place, for his investigations lead him, as must naturally be the case, to compare the dorsal (or, as he would call it, the hiemal) surface of Bothriolepis, of the Cephalaspidie, and of the Pteraspidæ with the dorsal surface of the I'alæostraca.

All these ancient fishes are, according to him, still in the arthropod stage, have not yet turned over, though in a pecnliarly unscientific manner he argnes elaborately that they must have swum on their back rather than on their front, and so indicated the coming reversal. Because they were arthropods they cannot have had a 
frontal nose-organ; therefore, Patten looks upon the nose and the two lateral eyes of the Osteostraci as a complex median eye, regardless of the fact that the median eyes already existed.

Every atom of evidence Patten has bronght forward, every new fact he has discovered, confirms my position and makes his still more hopelessly confused. Keep the animal the right side uppermost, and the evidence of the rocks confirms the transition from the Palæostracan to the Cyclostome; reverse the surfaces, and the attempt to derive the vertebrate from the palæostracan becomes so confused and hopelessly muddled as to throw discredit on any theory of the origin of vertebrates from arthropods. For my own part, I fully expect that appendages will be found not only in the Cephalaspidæ but also in the Pteraspidæ, and I hope Patten will continue his researches with increasing success. I feel sure, however, his task will be much simplified if he abandons his present position and views the question from my standpoint. .

\section{Summary.}

The shifting of the nasal tube from a rentral to a dorsal position, as seen in Ammocetes, is perhaps, the most important of all clues in convection with the comparison of Ammocotes to the Palaostracan on the one hand, and to the Cephalaspid on the other; for, whereas the exact counterpart of the opening of such a tube is always found on the dorsal head-shield in all members of the latter group. nothing of the kind is ever found on the dorsal carapace of the former group.

The reason for this difference is made immediately evident in the development of Ammocoetes itself, for the olfactory tube originates as a rentral tubethe tube of the hypophysis - in exactly the same position as the olfactory tube of the Paleostracan, and later on in its derelopment takes up a dorsal position.

In fact, Ammocotes in its development indicates how the Palrostracan head-shield became transformed into that of the Ceplialaspid.

In another most important character Ammocotes indicates its relationship to the Cephalaspidie, for it possesses an external skeleton or hear-shield composed of muco-cartilage, which is the exact counterpart of the so-called bony headshield of the latter group; and still more strikingly the structure of the cephalaspidian head-shield is remarkably like that of muco-cartilage. In the one case, by the deposition of calcium salts, a hard external skeleton, capable of being preserved as a fossil, has been formed; in the other, by the absence of the calcium salts, a soft chondro-mucoid matrix, in which the characteristic cells and fibrils are embedded, distinguishes the tissue.

The recognition that the head-shields of these most primitive fishes were not composed of bone, but of muco-cartilage, the precursor of both cartilage and bone, immediately clears up in the most satisfactory manner the whole 
question of their derivation from elasmobranch fishes ; for the main argument in favour of the latter derivation is the exceedingly strong one that bone succeeds cartilage-not vice versi -therefore, these forms, since their head-shield is bony, must have arisen from some other fishes with a cartilaginons skeleton, most probably of an elasmobranch nature. Seeing, however, that the structure of their shields resembles muco-cartilage much more closely than bone, and that Ammocotes forms a head-slield of muco-cartilage closely resembling theirs, there is no longer any necessity to derive the jawless fishes from the gnatho. stomatous; but, on the contrary, we may look with certainty upon the Agnatha as the most primitive group from which the others have been derived.

The history of the rocks slows that the group of fishes, Pteraspis and Cyathaspis, are older than the Cephalaspidr-come, therefore, phylogenetically between the Palreostraca and the latter group. In this gronp the headshields are of a very different character, without any sign of any structure comparable with that of bone, and although they possessed both lateral and median eyes, there is never in any case any trace of a dorsal nasal orifice. Their olfactory passage, like that of the Palrostraca, must hare been rentral.

The remarkable comparison which exists between the head-shields of Ammocotes and Cephalaspis, enables us to locate the position of the brain and craninm of the latter with considerable accnracy, and so to compare the segmental markings found in many of these fossils with the corresponding markings, found either in fossil Palrestraca or on the head-carapaces of living scorpions and spiders, such as Phrynus and Mygale. In all cases the cranial region was covered with a median plate, often especially hard, which corresponded to the glabellum of the trilobite; the growtl of the cranium can be traced from its beginnings as the mpturned lateral flanges of the plastron to the membranous cranium of Ammocotes.

From such a comparison it follows that the segments, found in the anterolateral region of the head-shield, were not segments of the cranimm, but of parts beyond the region of the cranium, and from their position must have been segments supplied by the trigeminal nerve, and not by the ragus group; segments, therefore, which dir not indicate gills and gill-slits, but muscles, innervated by the trigeminal nerve; muscles which, as indicated by the corresponding markings on the carapace of Phryuus, Mygale, etc, were the tergocoxal muscles of the prosomatic appendages.

The discovery of the nature of these appendages in the Pteraspida and Cephalaspidre, as well as in the Asterolepidre (Pterichthys and Bothriolepis), is a problem of the future, though in the latter, not only have the well-known oar-like appendages been long since discovered. but Patten has recently found specimens of Bothriolepis which throw light on the anterior masticating gnathite-like appendages which these ancient forms possessed. 


\section{CHAPTER XI}

\section{THE EVIDENCE OF THE AUDITORY APIARATUS AND \\ THE ORGANS OF THE LATERAL LINE}

Lateral line organs.-Function of this group of organs.-Poriferous senseorgans on the appendages in Limulus.-Branchial sense-organs.-Prosomatic sense organs.-Flabellum.-Its structure and position.-Sense-organs of mandibles.-Auditory organs of insects and arachnids.-Poriferous chordotonal organs. - Balancers of Diptera.-Resemblance to organs of flabellum.-Racquet-organs of Galeodes.-Pectens of scorpions.-Large size of nerve to all these special sense-organs.-Origin of parachordals and auditory capsule.--Reason why VIIth nerve passes in and out of capsule.Evidence of Animocotes,-Intrusion of glaudular mass round brain into anditory capsule.-Intrusion of generative and hepatic mass round brain into base of flabellum.-Summary.

Wirfx speaking of the tripartite arrangement of the cranial nerves, an arrangement which gave the clue to the meaning of the cranial segments, I spoke of the trigeminal as supplying the sensory nerves to the skin in the head-region, and I compared this dorsal system of afferent nerves to the system of epimeral nerves in Limulus which supply the prosomatic and mesosomatic carapaces of Limulus with sensory fibres. I compared the ventral system of eye-muscle nerves with the system of nerves supplying the segmental dorso-ventral somatic muscles of the prosomatic region, and I compared the lateral system of mixed nerves with the nerves supplying the prosomatic and mesosomatic appendages of Limulus. I compared, also, the optic nerves and the olfactory nerves with the corresponding nerves in the same invertebrate group. My readers will see at once that one well-marked group of nerves - the auditory and lateral line systemhas been entirely omitted up to the present, it has not even heen mentioned in the scheme of the cranial segments; I have purposely reserved its consideration until now, because the organs these nerves supply, though situated in the skin, are of such a special character 
as to form a eategory by themselves. These nerves cannot he elassed among the afierent nerves of the skin any more than the nerves of the optic and olfactory apparatus; they require separate consideration. A very extensive literature has grown up on the subject of this system of lateral line sense-organs and their innervation, the outerme of which is decisively in favour of this system heing classed with the sense-organs supplied by the anditory nerve, so that in enteavoming to understand the position of the auditory nerve, we must always bear in mind that any theory as to its origin must apply to the system of lateral line nerves as well.

Now, although the auditory apparatus is common to all vertebrates, the lateral line system is not found in any land-dwelling animals; it belongs essentially to the fishes, and is, therefore, an old system so far as concerns the vertebrate group. Its sense-organs are arranged along the lateral line of the fish, and, in addition, on the head-region in three well-marked lines known as the supraorbital, infra-orbital, and mandibular line systems. These senseorgans lie in the skin in a system of canals, and are innervated by a special nervous system different to that innervating adjacent skinareas. The great peculiarity of their innervation consists in the fact that their nerves all belong to the branchial system of nerves; no fibres arise in connection with the trigeminal, but all of them in connection with the facial, glossopharyngeal and vagus nerves. In other words, although organs in the skin, their nerve-supply belongs to the lateral nervous system which supplies splanchnic and not somatic segments, a system which, according to the theory advanced in this book, originated in the nerves supplying appendages. The conchusion, therefore, is that in order to obtain some clue as to the origin of the sense-organs of this system in the assumed palæostracan ancestor, we must examine the mesosomatic appendages and see whether they possess any special sense-organs of similar function.

Further, considering that the auditory organ is to be regarded as a specially developed member of this system, we must especially look for an exceptionally developed organ in the region supplied by the anditory nerve.

The question of the origin of this system of lateral line senseorgans possesses a special interest for all those who attempt to obtain a solution of the origin of vertebrates, for the uphollers of the view that the vertebrates have descended from annelids have always 
found its strongest support in the similarity of two sets of segmental organs found in annelids and vertebrates. On the one hand, great stress was laid rpon the similarity of the segmental excretory organs in the two groups of animals, as will be discussed later; on the other, of the similarity of the segmentally arranged lateral sense-organs.

These lateral sense-organs of the annelids have been specially described by Eisig in the Capitellidx, and, according to Lang, "there are many reasons for considering these lateral organs to be homologous with the dorsal cirri of the ventral parapodia of other Polychreta, and in the family of the Glyeeridre we can follow, almost step by step, the transformation of the cirri into lateral organs." Eisig describes them in the thoracic prebranchial region as slightly different from those in the abdominal branchial region; in the latter region, the rentral prapodia are gill-bearing, so that these lateral orgaus are in the branchial region closely connected with the branchice, just as is also the case in the rertebrates. It is but a small step from the gill-bearing ventral parapodia of the annelid to the gill-bearing appendages of the phyllopod-like protostracan; so that if we assume that this is the correct line along which to search for the origin of the vertelsate auditory apparatus, then, on my theory of the origin of the vertebrates from a group resembling the Protostraca, it follows that special sense-organs must have existed either on or in close connection with the lranchial and prebranchial appendages of the protostracan ancestor of the vertebrates, which would form an intermediate link between the lateral organs of the annelids and the lateral and aulitory organs of the vertebrates.

Further, these special sense-organs could not have leen mere tactile hairs, but must hare possessed some special function, and their structure must have been compatible with that function. Can we obtain any clear conception of the original function of this whole system of sense-organs?

A large amount of experimental work has been done to determine the function of the lateral line organs in fishes, and they have leen thought at one time or another to be supplementary organs for equilibration, organs for estimating pressure, etc. The latest experimental work done by Parker points directly to their being organs for estimating slow vibrations in water in contradistinction to the quicker vilnations constituting somd. He concludes that surface wave-movements, whether produced by air moving on the water or 
solid bodies falling into the water, are accompanied by disturbances which are stimuli for the lateral line organs.

One of these segmental organs has become especially important and exists thronghout the whole vertelrate group, whether the animal lives on land or in water-this is the anditory organ. Thronghout, the anditory organ has a double function-the function of hearing and the function of equilibration. If, then, this is, as is generally supposed, a specialized member of the group, it follows that the less specialized members must possess the commencement of both these functions, just as the experimental evidence suggests.

In our search, then, for the origin of the auditory organ of vertebrates, we inust look for special organs for the estimation of vibrations and for the maintenance of the equilibrim of the animal, situated on the appendages, especially the branchial or mesosomatic appendages; and, further, we must specially look for an exceptional development of such segmental organs at the junction of the prosomatic and mesosomatic regions.

Throughout this book the evidence which I have put forward has in all cases pointed to the same conclusion, viz. that the vertebrate arose by way of the Cephalaspidie from some arthropod, either belonging to, or closely allied to, the group called Palæostraca, of which the only living representative is Limulns. If, then, my argument so far is sound, the appendages of Limulus, both prosomatic and mesosomatic, ought to possess special sense-organs which are concerned in equilibration or the appreciation of the depth of the water, or in some modification of such function, and among these we might expect to find that somewhere at the junction of the prosoma and mesosoma such sense-organs were specially developed to form the beginning of the auditory organ.

Now, it is a striking fact that the appendages of Limulus do possess special sense-organs of a remarkable character, which are clearly not simply tactile. Thus Gegenbaur, as already stated, has drawn attention to the remarkable branchial sense-organs of Limulus; and Patten has pointed ont that special organs, which he considers to be gustatory in function, are present on the mandibles of the prosomatic appendages. I myself, as mentioned in my address to the British Issociation at Liverpool in 1896, searched for some special sense organ at the junction of the prosoma and nesosoma, and was rewarded by finding that that extraordinary adjunct to the 
last locomotor appendage, known as the flabellum, was an elaborate sense-organ. I now propose to show that all these special senseorgans are constructed on a somewhat similar plan; that the structure of the lranchial sense-organs suggests that they are organs for the estimation of water pressures; that among air-breathing arthropods sense-organs, built up on a somewhat similar plan, are universally found, and are considered to be of the nature of auditory and equililration organs; and, what is especially of importance, in view of the fact that the most prominent members of the Palæostraca were the sea-seorpions, that the remarkable sense-organs of the scorpions known as the pectens belong apparently to the same group.

\section{The Poriferous Sense-Organs of the Appendages in Linulus.}

On all the branchial appendages in Limulus, special seuse-organs are found of a most conspicuous character. They form in the living animal bluish convex eircular patches, the situation of which on the appendages is shown in Fig. 58. These organs are not found on the non-branchial operculum. Gegenbaur, who was the first to describe them, has pointed out how the surface of the organ is elosely set with chitinous goblets shaped as seen in Fig. 14t, A, which do not necessarily project free on the surface, but are extruded on the slightest pressure. Each goblet fits into a socket in the chitinous covering, and is apparently easily protruded by variations of pressure from within. The whole surface of the organ on the appendage is slightly bulged in the living condition, and the chitin is markedly softer here than in the surrounding part of the limb. Each of these organs is survounded by a thick protection of strongly branching spines. On the surface of the organ itself no spines are found, only these goblets, so that the surface-riew presents an appearance as in Fig. 144, B. Each goblet possesses a central pore, which is the termination of a rery fine, very tortuous, very brittle chitinous tubule (ch.t.), which passes from the goblet through the layers of the chitin into the subjacent tissue. The goblets vary considerably in size, a few very large ones being scattered here and there. The fine chitinous tubule is especially conspicuous in connection with these largest goblets. In the smaller ones there is the same appearance of a pore and a commencing tube, but I have not been able to trace the tube through the chitinous layers, as in the case of the larger goblets. 
Gegenbaur, in his picture, draws a straight tubule passing from every goblet among the fine canaliculi of the chitin. He says they are difficult to see, except in the case of the larger goblets. The tubule from the larger goblets is most conspienous, and is in my sections always tortnous, never straight, as represented by Gegenbaur. A special branch of the appendage-nerve passes to these organs, and

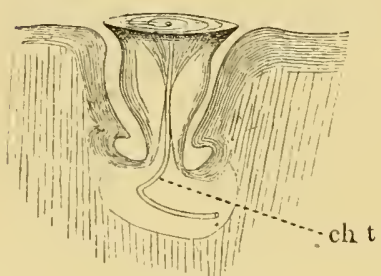

A

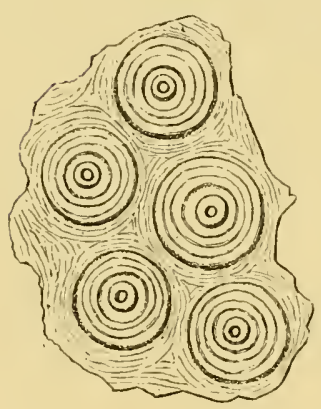

$\dot{B}$

Fig. 144.-A, A Goblet from one of the Branchial SenseOrgans of Limulus (ch.t., chitinous tubule); $\mathrm{B}$, SURFace View of a Portion of a BranChial Sexse-Organ.

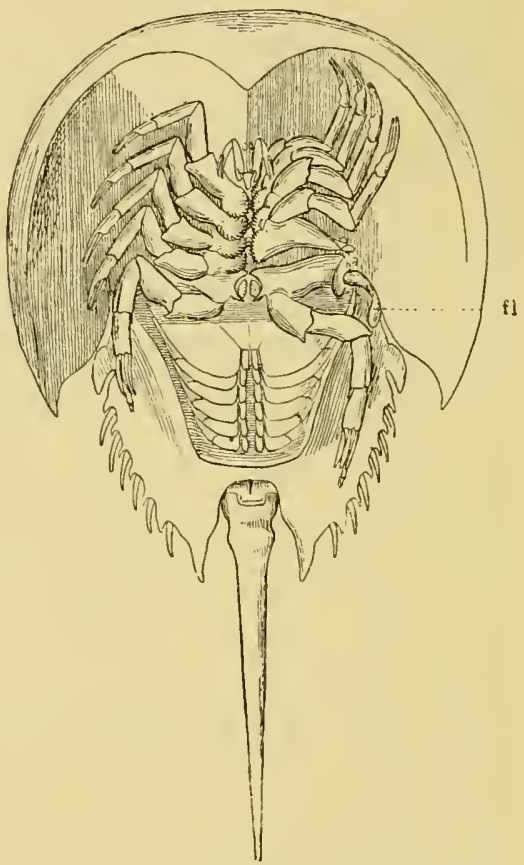

Fig. 145.-The Endognaths of Linulus PUSHED OUT OF THE WAY ON OXE SIDE IN ORDER TO SHOW THE POSITION OF the Flabelium $(f$. $)$ projecting toWARdS the CRaCK between the Prosonatic and Mesosonatic Carapaces.

upon the fine branches of this nerve groups of ganglion-cells are seen, very similar in appearance to the groups described by Patten on the terminal branches of the nerves which supply the mandibular organs. At present I can see no mechanism by which the goblets are extruded or returned into place. In the case of the Capitellide, Eisig describes retractor muscles by means of which the lateral sense-organs are 
brought below the level of the surface, and he imagines that the protrusion is effected by hydraulic means, by the aid of the vascular system. In the branchial sense-organs of Limulus there are no retractor muscles, and it seems to me that both retraction and protrusion must be brought about by alterations of pressure in the vascular fluids. Certainly the eavity of the organ is very vascular. If this be so, it seems likely enough that such an organ should be a very delicate organ for estimating changes in the pressure of the external medium, for the position of the goblets would depend on the relation between the pressure of the fluid inside the organ and that on the surface of the appendage. Whether the chitinous tubule contains a nerve-terminal or not I am unable to decide from $m y$ specimens, but, judging from Patten's description of the similar chitinous tubules belonging to the mandibular organs, it is most highly probable that these tubules also contain a fine terminal nerve-fibre.

These organs, then, represent segmental branchial sense-organs, of which it can be said their structure suggests that they may be pressure-organs; but the experimental evidence is at present wanting.

Passing now from the branchial to the prosomatic region, the first thing that struck me was the presence of that most conspicuous projection at the base of the last locomotor appendage, which is usually called the flabellum, and has been described by Lankester as an exopodite of this appendage. It is jointed on to the most basal portion of the limb ( $c f$. Fig. 155), and projects dorsally from the limb into the open slit between the prosumatic and mesosomatic carapace, as is seen in Fig. $145(f l$.). Of its two surfaces, the undermost is very convex and the uppermost nearly flat from sicle to side, the whole organ being bent, so that when the animal is lying half buried in sand, entirely covered over by the prosomatic and mesosomatic carapaces except along this slit between the two, the upper flat or slightly convex surface of the flabellum is exposed to any movement of water through this slit, and owing to its possessing a joint, the direction of the whole organ can be altered to a limited extent. The whole of this flat upper surface is one large sense-urgan of a striking character, thus forming a great contrast to the convex under surface, which is remarkably free from tactile spines or special sense-organs.

The nerve going to the flabellum is very large, almost as large as the nerve to the rest. of the appendage, and the very large majority 
of the nerve-fibres turn towarls the flat, uppermost side, where the sense-organ is situated. Between the nerve-fibres $(n$.) and the chitinous surface eontaining the special sense-tubes masses of eells $(g l$.) are seen, as in Fig. 146, apparently nerve-eells, which form a liroad border between the nerve-fibres and the pigmented chitinogenous
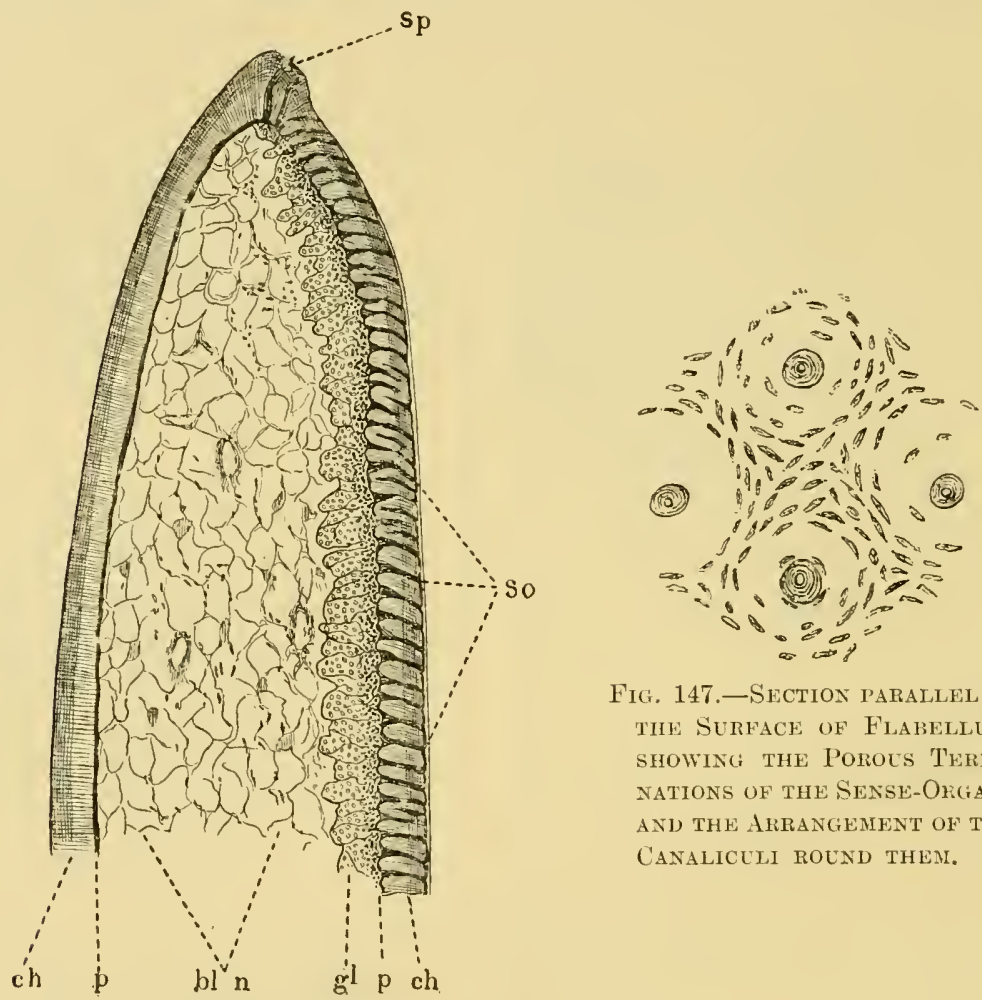

Fig. 147.-Section Parallel to tile Surface of Flabellum, SHOWING the Porols ThrmiNATIONS OF THE SENSE-OHiaAs AND THE ARRANGEMENT OF THE CaNaliceli ROUNd THEM.

Fig. 146.-Section throegh Flabellum.

$c h$, chitinous layers; s.o., sense-organs; $s p$., spike-organ; $p$. , pigment layer; $g l$., ganglion cell layer; $b l$. and $n$., blood-spaces and nerves.

layer $(p$.$) . On the opposite side, nothing of the sort intervenes$ between the pigmented layer and the blood-spaces and nerve-fibres which constitute the central mass of the flabellum.

At present I am inclined to look upon this mass of cells as constituting a large ganglion, which extends over the whole length and brealth of the upper surface of the flabellum. At the same 
time, my preparations are not sufficiently clear to cmable me to trace out the connections of these cells, especially their connections with the special senseorgans.

In Fig. 148 I give a magnified representation of a section through three of these flabellar senseorgans. As is seen, the section divides itself into four zones: (1) the chitinous layer (ch.); (2) the layer of pigment ( $p$.) and hypodermal cells; (3) the layer of ganglioncells ( $g l$.$) ; and (4) the$ layer of nerve-fibres $(n$.) and blood-spaces (bl.). The chitinous layer is composed of the usual three zones of the Liinulus surface - externally (Fig. 148), a thin homogeneous layer, followed by a thick layer of chitin (3), in which the fine vertical tubules or canaliculi are well marked; the external portion (2) of this layel is differentiaterl from the rest by the presence of well-marked horizontal layers in addition to the canaliculi.

In this chitinous layer the special sense-organs

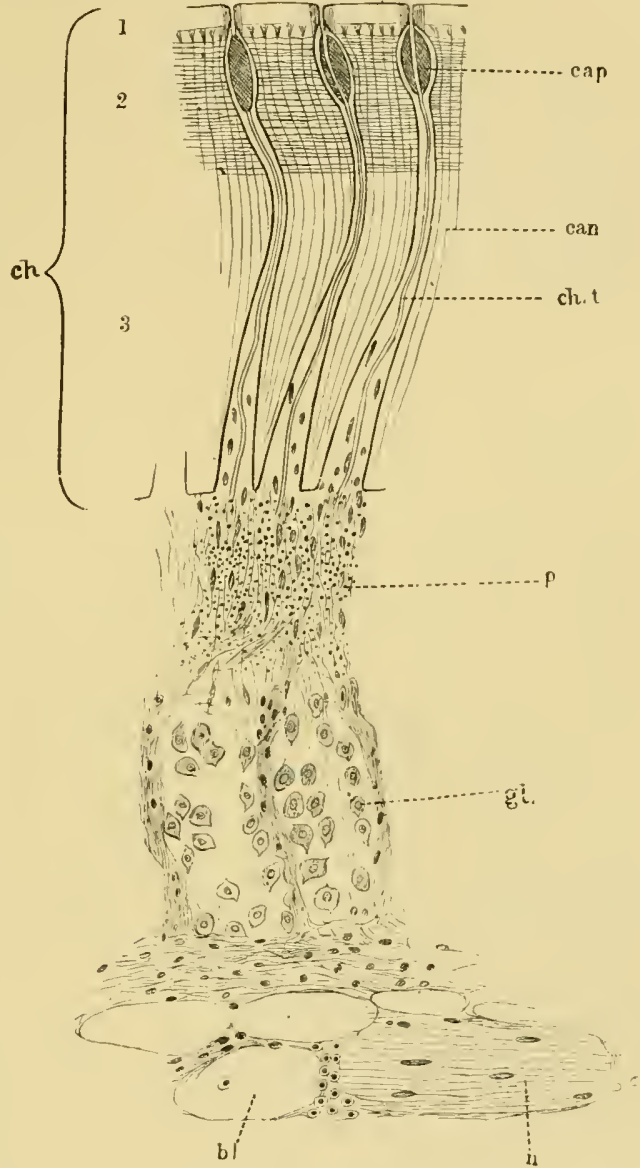

Fig. 148, - Section throtgh three SexseOrgaxs of Flabellum.

$u l$., blood-spaces; $n$., nerve; gl., layer of ganglioncells; $p$., pigment layer; ch, $1,2,3$, the three lavers of ehitin; ch.t., ehitinous tubule in large tube of sense-organ ; cap., capitellum or swollen extremity of large tube; can., very fine porous canals or canaliculi of chitin.

are found. They consist of a large tube which passes through all the layers of the chitin except the thin lomogeneous most external layer. 
This tube is conical in shape, its.base, which rests on the pigmented layer, being so large and the organs so crowded together that a section of the chitin across the base of the tulues gives the alyearance of a honeycomb, the septa of which is all that remains of the chitin. This large tube narrows down to a thin elongated neck as it passes throngh the chitin, and then, at its termination, bulges out again into an oval swelling (cap.) situated always beneath the homogeneous most external layer of chitin. Within this tube a fine chitinous tubule (ch.t.) is situated similar to that seen in the branchial senseorgans; it lies apparently free in the tube, not straight, but sinnous, and it passes right through all the chitinous layers to open at the surface as a 1,ore; in the last part of its course, where it passes through the most external layer (1) of chitin, it lies always at right angles to the surface.

If the flabellum be stained with methylene blue and acid fuchsin, then all the canaliculi in the chitin show up as fine red lines, and present the appearance given in Fig. 148, and it is seen that each of the terminations of the tubules is surromnded in the homogeneous layer of chitin by a thick-set cireular patch of canalieuli which pass to the very surface of the chitiu, while the canaliculi in other parts terminate at the commencement of the homogeneous layer and do not reach the surface. Further, the contents of the oval swelling, and, indeed, of the tube as a whole, are stained blue, the chitinous tubule being either unstained or slightly pink in colour. We see, then, that the chitinous tubule alone reaches the surface, while the large tube, which contains the tubule, terminates in an oval swelling, which often presents a folded or wrinkled appearance, as in Fig. 149 (see also Patten's Fig. 1, Plate I.). This terminal bulging of the tube is reminiscent of the bulging in the chitimous tubes of the lyriform organs of the Arachnida, as described by Gaubert, and of the poriferous chordotonal organs in insects, as described by Graber (see Fig. 150). This terminal swelling is filled with a homogeneous refringent mass staining blue with methylene blue, in which I have seen no trace of a nucleus; through this the clitinous tubule makes its way without any sign of bulging on its part. Patten, in his description of the sense-organs on the mandibles of Limulus, which are cvidently the same in structure as those on the flabellum, refers to this homogeneous mass as a cuagulum. I doubt whether this is an allequate description; it apuears to me to stain rather more 
readily than a blood-coagulum, yet in the sense of being structureless it resembles a coagulum.

The enormous number of these organs crowded together over the whole flat surface of the flabellum produces a very striking appearance when riewed on the surface. Such a riew presents an appearance resembling that of the surface-riew of the branchial senseorgans; in both cases the surface is covered with a great number of closely set circular plaques, in the centre of each of which is seen a well-narkerl pore. The circular plaques in the case of the flabellum are much smaller than those of the branchial sense-organs, and clearly are not protrusible as in the latter organs, the appearance as of a plaque being due to the ring of thickly-set canaliculi round the central tubule, as already described. When stained with methylene 1,lue, the surface view of the flabellum under a low power presents an appearance of innumerable circular blue masses, from each of which springs a fine bent hair, terminating in a pore at the surface. The blue masses are the homogeneous substance (crp.) of the bulgings seen through the transparent external layer of chitin, and the hairs are the terminal part of the chitinous tubules. Patten has represented their appearance in the mandibles in his Fig. 2, Plate I.

The large tubes in the chitin alter in shape according to their position. Those in the middle of the sensory surface of the flabellum, in their course through the chitinous layers, are hardly bent at all; as they approach the two lateral edges of this surface, their long thin neck becomes bent more and more, the bending always being directed towards the middle of the surface (see Fig. 146); in this way the chitinous tubules increase more $\mathrm{ol}^{2}$ less regularly in length from the centre of the organ to the periphery. The large basal part of the conical tube contains, besiles the chitinous tubule, a number of nuclei which are confined to this part of the tube; some of these nuclei look like those belonging to nerve-fibres, others are apparently the nuclei of the chitinogenous membrane lining the tube. I have never seen any sign of nerve-cells in the tube itself.

The only other kind of sense-organ I have found in connection with these sense-organs are a few spike-like projections, the appearance of which is given in Fig. 149. I have always seen these in the position given in Fig. 146 (sp.), i.e. at the junction of the surface which contains the sense-organs and the surface which is free from them. They are, so far as I have seen, not very numerous; I have 
not, however, attempted to examine the whole sense-organ for the purpose of estimating their number and arrangement.

As is seen in Fig. 149, they possess a fine tubule of the same character as that of the neighbouring sense-organs, which apparently terminates at the apex of the projecting spike. They appear to belong to the same group as the other poriferous sense-organs, and are of special interest, because in their appearance they form a link letween the latter and the poriferous sense-organs which characterize the pecten of the scorpion ( $c f$. Fig. 152, C).

Such, then, is the structure of this remarkable sense-organ of the flabellum, as far as I have been alle to work it ont with the materials

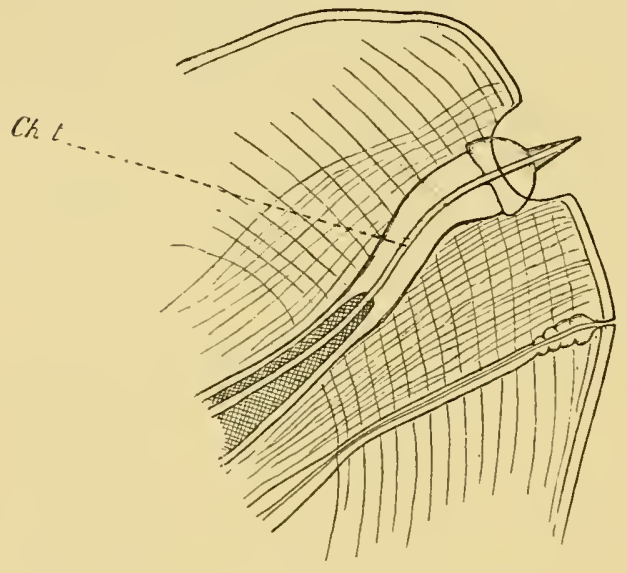

Fig. 149.-Spike-Organ of Flabellum. ch.t., chitinous tubule. at my disposal. It is evident that the flabellar organs, apart from the spike-organs, are of the same lind as those described by Patten on the mandibles and chele of Limulus, and therefore it is most probable that the nerve-terminals in the chitinous tubules, and the origin of the latter, are similar in the two sets of organs.

These organs, as Patten has described them, are situated in lines on the

spines of the mandibles of the prosomatic locomotor appendages, and are grouped closely together to form a compact sense.organ on the surface of the inner mandible (Lankester's epicoxite) (i.m. in Fig. 155), so that a surface-view of the organ here gives the characteristic appearance of these poriferous sensc-patches. Precisely similar organs are found on the chilaria, which are, in function at all events, simply isolated mandibles, to use Patten's terminology.

On the digging appendage (ectognath), as the comparison of Fig. 155, A and C, shows, the mandibular spines are almost nonexistent, and the inner mandible or epicoxite is not present, so that 
the special sense-organ of this appendage is represented solely by the flabellum.

This sketch of the special sense-organs of Limulus shows that all the appendages of Limulus possess special sense-organs, with the exception of the operculum. All these sense-organs are formed on the same plan, in that they possess a fine chitinous tubule passing through the layers of chitin into the underlying hypodermal and nervous tissues, which terminates on the surface in a pore. The surface of the chitin where these pores are situated is perfectly smooth, although, in the case of the branchial sense-organs, the goblet-shaped masses of chitin, each of which contains a pore, are able to be pressed out beyond the level of the surface.

As to their functions, we unfortunately do not know much that is definite. Patten considers that he has evidence of a gustatory function in the case of the mandibular organs, and suggests also a temperature-sense in the case of some of these organs. The large organ of the flabellum and the branchial organs he has not taken into consideration. The situation of these organs puts the suggestion of any gustatory function, as far as they are concerned, out of the question; and I do not think it proballe that such large specialized organs would exist only for the estimation of temperature, when one sees how, in the higher animals, the temperature-nerves and the nerves of common sensation are universally distributed over the body. As already stated, the structure of the branchial organs seems to me to point to organs for estimating varying pressures more than anything else, and I am strongly inclined to look upon the whole set of organs as the derivatives of the lateral sense-organs of annelids, such as are described by Eisig in the Capitellida. This is Patten's opinion with respect to the mandibular organs; and from what I have shown, these organs cannot be separated in type of structure from those of the flabellum and the branchial sense-organs.

In our search, then, for the origin of the vertebrate auditory organ in Limulus and its allies, we see so far the following indications :-

1. The auditory organ of the vertebrate is regarded as a special organ belonging to a segmentally arranged set of lateral sense-organs, whose original function was co-orlination and equilibration.

2. Such a set of segmentally arranged lateral sense-organs is found in annelids in connection with the dorsal cirri of the ventral parapodia. 
3. If, as has been supposed, there is a genetic connection between (1) and (2) and if, as I suppose, the vertebrates did not arise from the annelicls directly, but from a protostracan group, then it follows that the lateral sense-organs, one of which gave rise to the auditory organ, must have been situated on the protostracan appendages.

4. In Limulus, which is the sole surviving representative of the palieostracan group, such special sense-organs are found on both the prosomatic and mesosomatic appendages, and therefore may be expected to give a direct clue to the origin of the vertebrate auditory organ.

5. Both from its position, its size, and its specialization, the flabellum, i.e. an organ corresponding to the flabellum, must be looked upon as more likely to give a direct clue to the origin of the auditory organ than the sense-organs of the branchial appendages, or the so-called gustatory organs of the mandibles.

\section{The Audtory Organs of Arachidids and Insects.}

The difficulty of the investigating these organs consists in the fact that so little is known about them in those Arthropoda which live in the water; the only instance of any organ apparently of the nature of an auditory organ, is the pair of so-called auditory sacs at the base of the antenne in various decapods. We are in a slightly better position when we turn to the land-living arthropods; here the presence of stridulating organs in so many instances carries with it the necessity of an organ for appreciating sound. It has now been shown that such stridulating organs are not confined to the Insecta, but are present also in the scorpion group, and I myself have added to their number by the discovery of a distinct stridulating apparatus in various members of the Phrynidie. We may then take it for granted that arachnids as well as insects hear. Where is the auditory organ?

Many observers believe that certain surface-organs found universally among the spiders, to which Gaubert has given the name of lyriform organs, are auditory in function. His investigations show that they are universally present on the limbs and pro-meso-sternite of all spiclers; that they are present siugly, not in groups, on the limbs of Thelyphonus, and that a group of them exists on the second segment of cach limb in the members of the Phrynus tribe. In the latter case this organ is the most elaborate of all described by him. 
It is especially noticeable that they do not exist in Galeodes or in the scorpions, but in the former special sense-organs are found in the shape of the so-called 'racquet-organs,' on the basal segments of the most posterior pair of appendages, and also, according to Gaubert, on the extremity of the palps and the first pair of feet, while in the latter they occur in the shape of the pectens.

This observation of Gaubert suggests that the place of the lyriform organs in other arachnids is taken in. Galeodes by the racquet-organs, and in the scorpions by the pectens. Bertkau, Schimkéwitsch, and Wagner, as quoted by Gaubert, all suggest that the lyriform organs of the arachnids belong to the same group of sense-organs as the porous chordotonal organs of the Insecta, senseorgans which have been found in every group of Insecta, and are generally regarded as anditory organs. Gaubert does not agree with this, and considers the lyriform organs to be concerned with the temperature-sense rather than with andition.

The chordotonal organs of insects have been specially studied by Graber. He divides them into two groups, the poriferous and the non-poriferous, the former being characterized by the presence of pores on the surface arranged in gromps or lines. These poriferous chordotonal organs are remarkably constant in position, being found only at the base of the wings on the subcostal ridge, in marked contrast to the other group of chordotonal organs which are found chiefly on the appendages in various regions. The striking character of this fixity of position of these organs and the universality of their presence in the whole group, led Graber to the conclusion that in these poriferous chordotonal organs we are studying a form of auditory apparatus which characterized the ancestor of the insectgroup. These organs are always well developed on the hind wings, and in the large group of Diptera the anditory apparatus has usurped the whole of the function of the wing; for the balancers or 'halteres,' as they are called, are the sole representatives of the hind wings, and they are usually considered to be of the nature of auditory organs. It is instructive to find that such an auditory organ serves not only for the purpose of audition, but also as an organ of equilibration; thus Lowne gives the evidence of various observers, and confirms it himself, that removal of the balancers destroys the power of orderly flight in the animal.

A striking peculiarity of these organs in the Insecta, as described 
by Graber, is the bulging of the porous canal near its termination (Fig. 150, C). This bulging is filled with a homogeneous, highly refractive material, from which, according to Lowne, a chordotonal thread passes, to be connected with a ganglion-cell and nerve. This sphere of refractive material he calls the 'capitellum' of the chordotonal thread. The presence of this material produces in a surface view an appearance as of a halo around the terminal plaque with its central pore; Graber has attempted to represent this by the white area round the central area (in Fig. 150, B). A very similar appearance is presented by the surface view of the flabellum in those parts where the tube runs straight to the surface, so that the

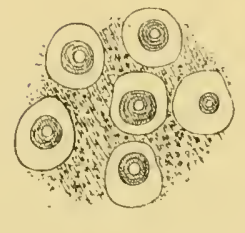

B

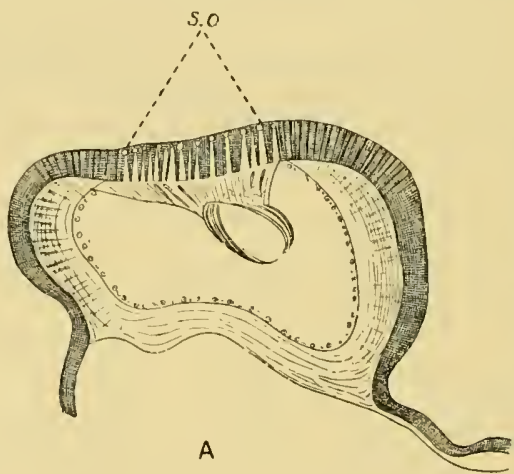

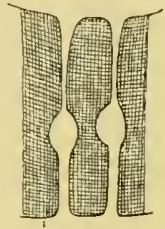

C

Fig. 150 (from Grabliz).-A, Section of Subcostal Nervure of Hind Wing of Drtiscus to show patch of Poriferous Organs (s.o.). B, Surface View of Porifkrous Organs; the White Space round each Organ indicates the deeper lying Refringent Body which fllls the bulging of the Canal Seen in Transverse Section in C.

refractive material which fills the oval bulging shines through the overlying chitin and appears to surround the terminal plaque with a translucent halo.

Such a peeuliarity must have a very definite meaning, and suggests that the canals in the flabellum of Limulus and in the hind wings of insects belong to the sane class of organ, the chitinous tubule with its nerve-terminal in the former corresponding to the chordotonal thread in the latter. One wonders whether this sphere of refractive material or 'eapitellum' (to use Lowne's phraseology) is so universally present in order to act as a damper upon the vibrations of the chordotonal thread in the one case and of the 
ehitinous tubule in the other, just as the membrona tectorice and the otoliths act in the ease of the vertebrate ear.

Patten says that the only organs which seem to him to be comparable with the gustatory porous organs of Limulus are the sense-organs in the extremities of the palps and of the first pair of legs of Galeodes, as described by Gaubert. I imagine that he was thinking only of arachuids, for the comparison of his drawings with those of Graber show what a strong family resemblance exists between the poriferous sense-organs of Limulus and those of the insects. On the course of the terminal nerve-fibres, between the nerve-cell and their entrance into the porous chitinous canal, Graber describes the existence of rods or seolophores. On the course of the terminal fibres in the Limulus organ, between the nerve-cells and their entrance into the porous chitinous canal, Patten describes a spindle-shaped swelling, containing a number of rort-like thickenings among the fibrils in the spindle, which present an appearance reminiscent of the rods described lyy Graber.

It appears as though a type of sense-organ, charactcrized by the presence of pores on the surface and a fine chitinous canal which opens at these pores, was largely distributed among the Arthropoda. According to Graber, this kind of organ represents a primitive type of sense-organ, which was probably concerned with audition and equilibration, and he expresses surprise that similar organs have not been discovered among the Crustacea. It is, therefore, a matter of great interest to find that so ancient a type of animal as Limulus, closely allied to the primitive elustacean stock, does possess poriferous sense-organs upon its appendages which are directly comparable with these poriferous ehordotonal organs of the Insecta.

\section{The Pectens of Scorpions.}

Among special sense-organs such as those with which I am now dealing, the pectens of scorpions and the 'racquet-organs' of Galeodes must, in all probability, be classed. I have given my reasons for this conclusion in my former paper. ${ }^{1}$ At present such reasons are based entirely upon the structure of the organs; experimental

1 "The Origin of Vertebrates, deduced from the Study of Ammocotes." Part X., "The Origin of the Auditory Organ : the Meaning of the VIIIth Cranial Nerve." Journ. Anat, and Physiol., vol, 36, 1902. 
eviclence as to their function is entirely wanting. With respect to the pectens of the scorpion (Fig. 151), it has been snggested that they are of the nature of copulatory organs, a suggestion which may be dismissed without hesitation, for they are not constructed after the fashion of elaspers, but are simply elaborate sense-organs, and, as

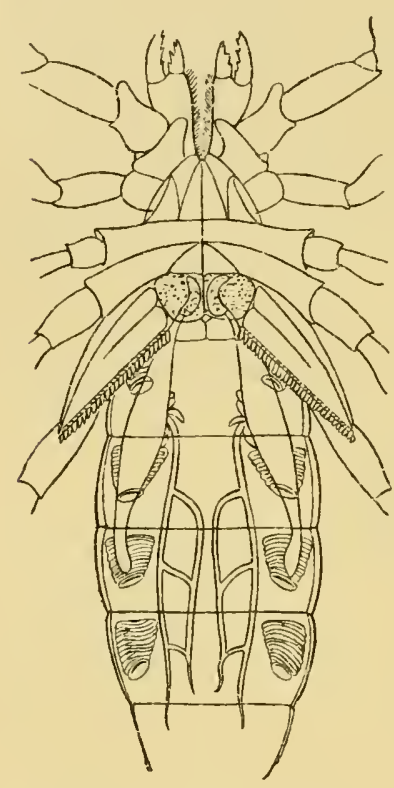

Fig. 151.-Under Suliface of Scorpion (Androctonus).

The opereulum is marked out with dots, and on each side of it is seen one of the peotens. such, are found equally in male or female. The only observer who has hitherto specially studied the structure of the sense-organs in the pecten is, as far as I know, Gaubert, and he deseribes their strueture together with that of the senseorgans of the racquets of Galeodes, in connection with the lyriform organs of arachnids, as though he recognized a family resemblance between the three sets of organs.

The pecten of the scorpions is an elaborate sense-organ, or rather group of sense-organs, the special organ being developed on each tooth of the comb; its surface, which is frequently flattened, being direeted backwards and inwards, when the axis of the peeten is horizontal at right angles to the length of the body. The surface view of this part of the tooth resembles that of the branchial organs or of the flabellum in Limulus, in that it is thickly eovered with cireular patches, in the centre of which an ill-defined appearance as of a fine pore is seen. In Fig. 152, B, I give a sketch of the surface view of a jart of the organ.

Transverse sections of a tooth of the comb of Scorpio Europecus present the appearance given in Fig. 152, A, and show that each of these circular patches is the surface-view of a goblet-shaped chitinous organ, Fig. 152, C, from the centre of which a short, somewhat cylindrical chitinous spike projects. Within this spike, and rumning through the goblet into the subjacent tissne, is a fine tubule. The series of goblets gives rise to the appearance of the circular plaques on the surface-view, while the spike with its tubule 
is the canse of the ill-defined appearance of the central pore, just as the terminal pore is much less conspicuous on surface-view in the spike-organs of the flabellum than in the purely poriferous organs, no part of which projects beyond the level of the chitinous surface.

The fine tubule is soon lost in the thickened but soft modification of the chitinous layer (ch.) which is characteristic of the sense-organ; at all events, I have not succeeded in tracing it through this layer with any more success than in the corresponding case of the tubules

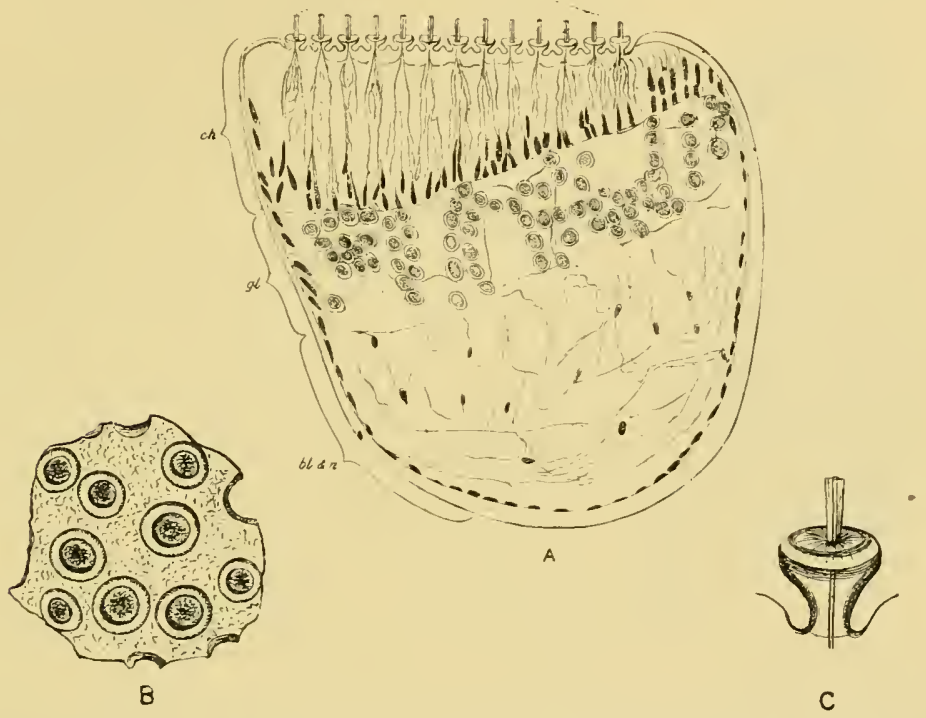

Fig. 152.-A, Section throtgh Tooth of Pecten of Scorpion; B, Serface View of Sense-Organs; C, Goblet of Sfanse-Organ hore migilly magnified.

$b l$. and $\imath$., region of blood-spaces and nerves; gl., ganglion-cell layer; ch., modified chitinous layer; s.o., sense-organ.

belonging to the smaller goblets of the branchial sense-organ of Limulus already described.

It the base of the modified chitinous layer a series of cells is seen, many, if not all, of which belong to the chitinogenous layer. Next to these is the marked layer of ganglion-cells $(g l$.), similar to those seen in the flabellum of Limulus. The rest of the space in the section of the tooth is filled up with nerves $(n$.) and blood-spaces $(b l$.) just as in the section, Fig. 146, of the flabellum of Limulus.

Gaubert does not appenr to have seen the goblets at all clearly; 
he deseribes them simply as conical eminences, and states that they "recouvrent un pore analogue a celui des poils mais plus petit; il est rempli par le protoplasma de la couche hypodermique." From the ganglion, according to him, nervous prolongations pass, which traverse the chitinogenous layer and terminate at the base of the conical eminences. Each of these prolongations "présente sur son trajet, mais un peu plus près du ganglion que de sa terminaison périphérique, une cellule nerveuse fusiforme $(g$.$) offrant,$ eomme celles du ganglion, un gros noyau." He illustrates his

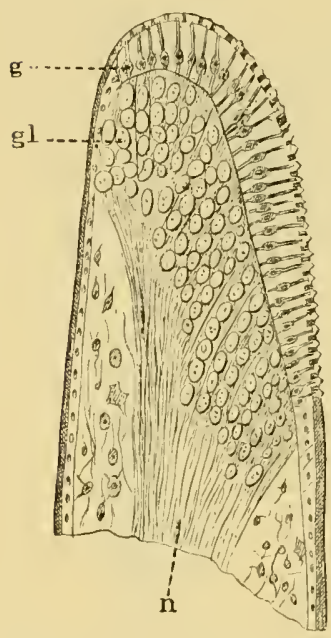

Fig. 153 (from GaUbert). - SECTION OF A TOOTH of Pectein of Scorpion. n., nerve; $g l$, ganglion. (lescription with the following, Fig. 15:?, taken from his paper.

I have not been able to obtain any evidence of a fusiform nerve-cell on the course of the terminal nerve-fibres as depicted by him; fusiform cells there are in plenty, as depicted in my drawing, but none with a large nucleus resembling those of the main ganglion. In no case, either in the flabellum or in the branchial organs of Limulus, or in the peeten-organs, have I ever seen a ganglioneell within the chitin-layer; all the nuelei seen there resemble those of the cells of the hypodermis or else the elongatel nuelei characteristie of the presence of nerve-fibres. Gaubert's drawing is a striking one, and I have looked through my speeimens to see whether there was anything similar, but have hitherto failed to obtain any definite evidence of anything of the kind.

I feel, myself, that an exhaustive examination of the structure and function of the pecten of scorpions ought to be undertaken. At present I ean only draw the attention of my readers to the similarity of the arrangement of parts, and of the nature of the end-organs, in the sense-organs of the flabellum of Limulns and of the peeten of the seorpion. In both eases the special nerve-fibres terminate in a massive ganglion, situated just below the chitinogenous layer. In both cases the terminal fibres from these ganglion-eells pass through the modified chitinous layer to supply end-organs of a striking character; and although the end-organ of the pecten of the scorpion does 
not closely resemble the majority of the end-organs of the flabelhum, yet it does resemble, on the one hand, the isolaterl poriferous spikes found on the flabellum (Fig. 149) and, on the other, the poriferous goblets found on the sense-patches of the branchial appenrlages of Limulus (Fig. 144, A), so that a combination of these two end-organs would give an appearance very closely resembling that of the pecten of the scorpion.

Finally, the special so-called 'racquet-organs' of Galendes, which are found on the most hasal segments of the last pair of prosomatic appendlages, onght also to be considered here. Gaubert has descriherl their structure, and shown how the nerve-trunk in the handle of the racquet splits up into a great number of separate bunlles, which spread out fan-shaped to the free erlge of the racquet; each of these separate bundles supplies a special sense-organ, which terminates as a conical eminence on the floor of a leep groove, running round the whole free elge of the racquet. This groove is almost converter into a canal, owing to the projection of its two sides. (iaubert imagines that the sense-organs are pushed forward out of the groove to the exterior by the turgescence of the whole organ; each of the nerve-fibres forming a bundle is, according to Gaubert, connected with a nerve-cell before it reaches its termination.

This sketch of the special sense-organs on the appendages of Limulus, of the scorpions, of Galeodes, and other arachnids, and their comparison with the porous chordotonal organs of insects, affords reason for the belief that we are dealing here with a common group of organs, which, although their nature is not definitely known, have largely been accredited with the functions of equilibration and audition, a group of organs among which the origin of the auditory organ of vertebrates must be songht for, upon any theory of the origin of vertebrates from arthropods.

Whenever in any animal these organs are concentrated together to form a special organ, it is invariably found that the nerve going to this organ is very large, out of all proportion to the size of the organ, and also that the nerve possesses, close to its termination in the organ, large masses of nerve-cells. Thus, althongh the whole hind wing in the blow-fly has been reduced to the insignificant balancers or 'halteres,' yet, as Lowne states, the nerves to them are the largest in the boty.

The pectinal nerve in the scorpion is remarkable for its size, and 
so, also, is the nerve to the flabellum in Limulus, while the large size of the anditory nerve in the vertebrate, in distinction to the size of the auditory apparatus, has always aroused the attention of anatomists.

Throughont this book my attention has been especially directed to both Limulus and the scorpion group in endeavouring to picture to myself the ancestor of the earliest vertebrates, because the Furypteridie possessed such marked scorpion-like characteristics; so that in considering the origin of a special sense-organ, sncl as the vertebrate aurlitory organ near the junction of the prosoma and mesosoma, it seems to me that the presence of such marked special sense-organs as the flabellum on the one hand and the pecten on the other, must both be taken into account, even although the former is an adjunct to a prosomatic appendage, while the latter represents, according to present ideas, the whole of a mesosomatic appendage.

From the point of view that the VIIIth nerve represents a segment immediately posterior to that of the VIIth, it is evident that an organ in the situation of the pecten, immediately posterior to the operculum, i.e. according to my view, posterior to the segment originally represented by the VIIth nerve, is more correctly situated than an organ like the flabellum, which belongs to a segment anterior to the operenlum.

On the other hand, from the point of view of the relationship between the scorpions and the king-crabs, it is a possibly debatable question whether the pecten really belongs to a segment posterior to the operculum. The position of any nerve in a series depends upon its position of origin in the central nervous system, rather than upon the position of its peripheral organ. Now, Patten gives two figures of the brain of the scorpion built up from serial sections. In both he shows that the main portion of the pectinal nerve arises from a swelling, to which he gives the name ganglion nodosum. This swelling arises on each side in close connection with the origin of the most posterior prosomatic appendage-nerve, according to his drawings, and posteriorly to such origin he figures a small nerve which he says supplies the distal parts of the sexual organs. This nerve is the only nerve which can be called the opercular nerve, and apparently arises posteriorly to the main part of the pectinal nerve. If this is so, it would indicate that the pectens arose from sense-organs which were originally, like the flabella, pre-opereular in position, but have shifted to a post-opercular position. 
The Ortgin of the Parariondals and Auntory Camtigaginous Capsule.

In addition to what I have already said, there is another reason why a special sense-organ such as the pecten is suggestive of the origin of the vertebrate anditory organ, in that such a suggestion gives a clue to the possible origin of the parachordals and anditory eartilaginous capsules.

In the lower vertebrates the auditory organ is characterized by being surrounded with a cartilaginous capsule which springs from a special part of the axial eartilaginous skeleton on each side, known as the pair of parachordals. The latter, in Ammocoetes, form a pair of cartilaginous bars, which unite the trabecular bars with the branchial cartilaginous basket-work. They are recognized throughout the Vertebrata as distinet from the trabecular bars, thus forming a separate paired cartilaginous element between the trabecula and the branchial cartilaginous system, which of itself indicates a position for the anditory capsule between the prosomatic trabeculæ and the mesosomatic branchial eartilaginous system.

The auditory capsule and parachordals when formed are made of the same kind of cartilage as the trabeeule, i.e. of hard cartilage, and are therefore formed from a gelatin-containing tissue, and not from muco-cartilage. Judging from the origin already ascribed to the trabecula, viz. their formation from the great prosomatic entochondrite or plastron, this would indicate that a second entochondrite existed in the ancestor of the vertebrate in the region of the junction of the prosoma and mesosoma, which was especially connected with the sense-organ to which the auditory organ owes its origin. This pair of entochondrites becoming eartilaginous would give origin to the parachordals, and subsequently to the auditory eapsules, their position being such that the nerve to the operculum would be surrounded at its origin by the growth of eartilage.

On this line of argument it is very signifieant to find that the seorpions do possess a seeond pair of entoehondrites, viz. the supra-pectinal entochondrites, situated between the nerve-cord and the peetens, so that if the ancestor of the Cephalaspid was sufficiently scorpion-like to have possessed a second pair of entochondrites and at the sanne time a pair of special sense-organs of the nature either of 
the pectens or flabella, then the origin of the anditory apparatus would present no difficulty.

It is also easy to see that the formation of the parachordals from entochondrites homologous with the supra-pectinal entochondrites, wonld give a reason why the VIIth or opercular nerve is involved with the VIIIth in the formation of the auditory capsule, especially if the special sense-organ which gave origin to the anditory organ was originally a pre-opercular sense-organ such as the flabellum, which subsequently took up a post-operenlar position like that of the pecten.

\section{The Evidence of Ammoctetes.}

As to the anditory apparatus itself, we see that the elaborate organ for hearing-the cochlea-has been evolved in the vertebrate phylum itself. In the lowest vertebrates the anditory apparatus tends more and more to resolve itself into a simple epithelial sac, the walls of which in places bear auditory hairs projecting into the sac, and in part form otoliths. Such a simple sac forms the early stage of the anditory vesicle in Ammocetes, according to Shipley; subsequently, by a series of foldings and growings together, the chambers of the ear of the adult Petromyzon, as figured and described by Retzius, are formed. Further, we see that throughout the Vertebrata this sac was originally open to the exterior, the anditory vesicle being first an open pit, which forms a vesicle by the approximating of its sides, the last part to close being known as the recessus labyrinthicus; in many cases, as in elasmobranchs, this part remains open, or communicates with the exterior by means of the ductus culolymphaticus.

Judging, therefore, from the embryological evidence, it would appear that the auditory organ originated as a special seuse-organ, formed by modified epithelial cells of the surface, which epithelial surface becoming invaginated, came to line a closer auditory vesiclo under the surface. This special sense-organ was innervated from a large ganglionic mass of nerve-cells, situated close against the peripheral sense-cells, the axis-cylinder processes of which formed the sensory roots of the nerve.

Yet another peculiarity of striking significance is seen in comnection with the auditory organ of Ammocnetes. The opening of the cartilaginons capsule towards the brain is a large one (Fig. 154), ancl 
admits the passage not only of the auditory and facial nerves, but also of a portion of the peculiar tissue which surrounds the brain. The large cells of this tissue, with their feebly staining nuclei and the pigment between them, make them quite unmistakable; and, as I have alreacly stated, nowhere else in the whole of Ammoenetes is such a tissue found. When I first noticed these cells within the auditory capsule, it seemed to me almost impossible that my interpretation of them as the remnant of the gencrative and hepatic tissue which surrounds the brain of animals such as Limulus could be true, for it seemed too unlikely that a part of the generative system could

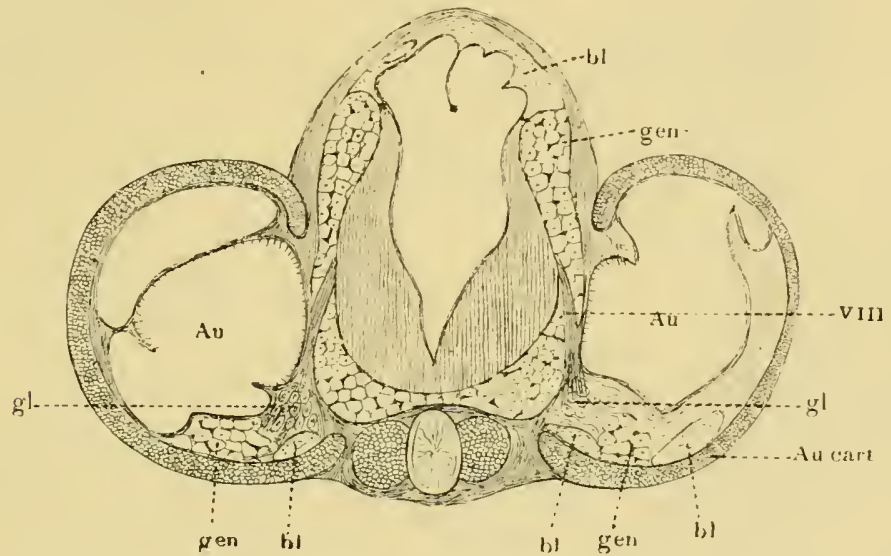

Fig. 154.-Transterse Section throtgh Auditory Capsules and Brain of AMMOCETES.

A u., anditory organ; TIII, auditory nerve; $g l$, ganglion cells of VIIIth nerve; Au. cart., cartilaginous auditory capsule; gen., cells of old generative tissue round brain and in auditory capsule; bl., blood-ressels.

ever have become included in the auditory capsule. Still, they are undonbtedly there; and, as already argued with respect to the substance rouml the brain, they must represent some pre-existing tissue which was functional in the ancestor of Ammocretes. If my interpretation is right, this tissue must be generative and hepatic tissue, and its presence in the anditory capsule immediately becomes a most important piece of evidence, for it proves that the auditory organ must have been originally so situated that a portion of the generative and hepatic mass surrounding the cephalic region of the nervous system followed the auditory nerve to the peripheral sense-organ. 
Here there was a test of the truth of my theory ranking second only to the test of the median eyes; the strongest possible evidence of the truth of any theory is given when by its aid new and unexpected facts are brought to light. The theory sail that in the group of animals from which the vertehrates arose, a special sense-organ of the nature of an auditory organ must have existed on the base of one of the appendages situated at the junction of the prosoma and mesosoma, and that into this basal part of the appendage a portion of the ceplaalic mass of generative and hepatic material must have marle its way in close contiguity to the nerve of the special organ.

The only living example which nearly approaches the ancient extinct forms from which, accorling to the theory, the vertebrates arose, is Limulus, and, as has already been shown, in this animal, in the very position postulated by the theory, a large special senseorgan-the flabellum-exists, which, as alrearly stated, may well have given rise to a sense-organ concerned with equilibration and andition. If, further, it be found that a diverticulum of the generative and hepatic material does accompany the nerve of the flabellum in the basal part of the appendage, then the evidence becomes very strong that the auditory organ of Ammocoetes, i.e. of the ancient Cephalaspids, was derived from an organ homologous with the flabellum; that, therefore, the material round the brain of Ammocotes was originally generative and hepatic material; that, in fact, the whole theory is true, for all the parts of it hang together so closely that, if one portion is accepted, all the rest must follow. As pointed ont in my address at Liverpool, and at the meeting of the Philosophical Society at Cambrilge, it is a most striking fact that a mass of the generative and hepatic tissue does accompany the flabellar nerve into the basal part of this appendage. Into no other appendage of Limulus is there the slightest sign of any intrusion of the generative and hepatic masses; nowhere, except in the auditory capsule, is there any sign of the peculiar large-celled tissne which surrounds the hrain and upper part of the spinal cord of Ammocoetes. The actual position of the flabellum on the basal part of the ectognath is shown in Fig. 155, A, and in Fig. 155, B, I have removed the chitin, to show the generative and hepatic tissue (gen.) lying beneath.

The reason why, to all appearance, the generative and hepatic mass penctrates into the hasal part of this appendage only is apparent 
when we see (as Patten and Redenbangh have pointed ont) to what part of the appendage the flabellum in reality belongs.

Patten and liedenbaugh, in their description of the prosonatic appendages of Limulus, describe the segments of the limbs as (1) the

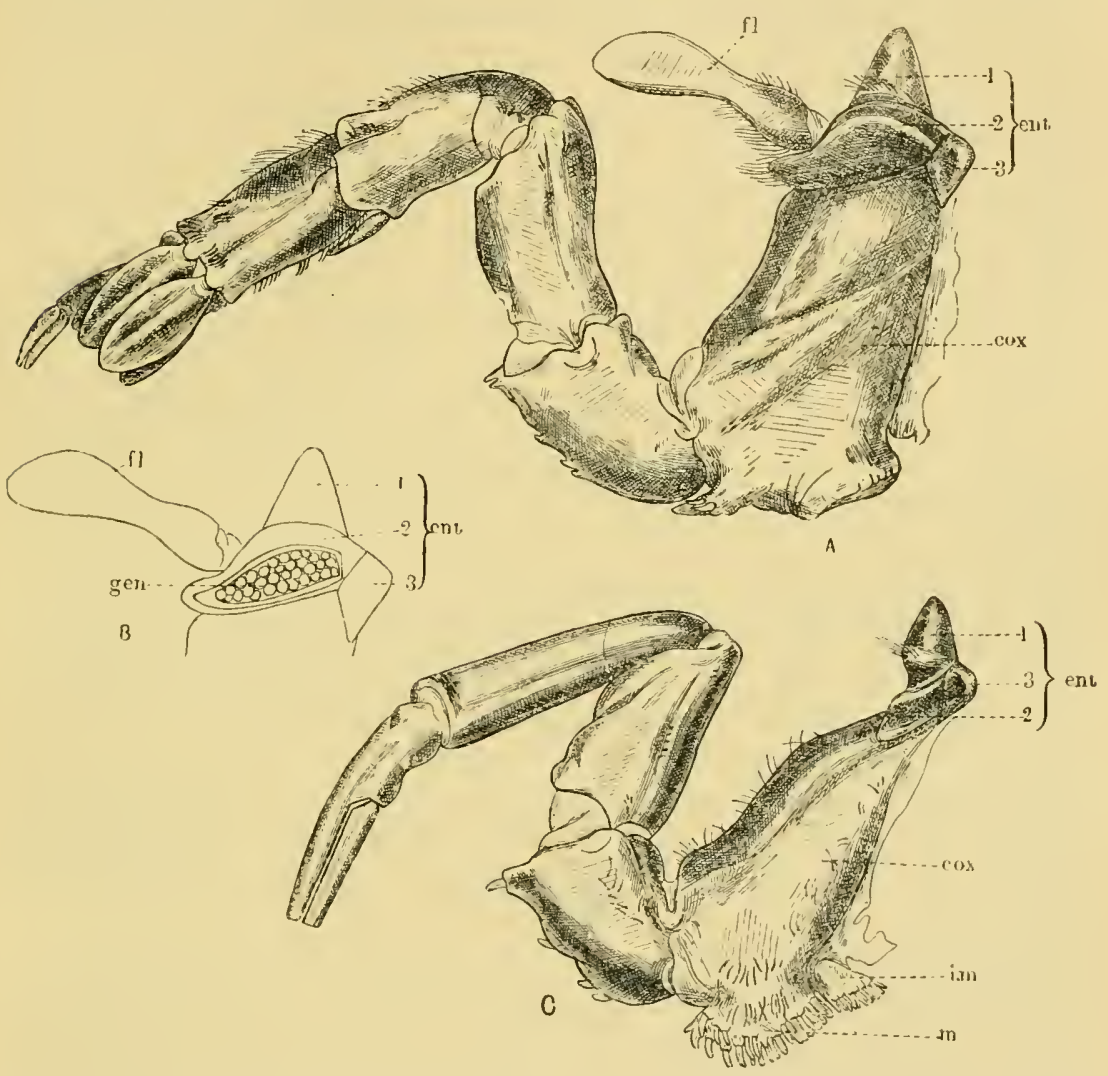

Fig. 155.-A, The Digging Appendage on Ectognath of Limulus; B, The Midule Protuberance (2) of the Entocoxite opened, to show the Generative and Hepatic Tissue (gen.) within it; C, One ol the Prosoiatic Loconotor Appexdages on EndogNaths of Linulus, for conpanisos WITH A.

$f l$, flabellum; cox., coxopodite; ent., entocoxite; $m$. , mandible; i.m., inner mandible or epicoxite.

dactylopodite, (2) the propodite, (3) the mero- and carpo-podites, (4) the ischiopolite, (5) the hasipodite, and (6) the coxopodite (cox. in Fig. 155). Still more basal than the coxopoclite is situated the entocoxite (cnt. in Fig. 155), which is composed of three sclerites 
or sensory knobs, to use Patten's description. The middle one of these three sclerites enlarges greatly in the digging appendage, and grows over the coxopodite to form the base from which the flabellum springs. Thus, as they have pointed out, the flabellum does not belong to the coxopodite of the appendage, but to the middle sensory knob of the entocoxite. Upon opening the prosomatic carapace, it is seen that the cephalic generative and hepatic masses press closely against the internal surface of the prosomatic carapace and also of the entocoxite, so that any enlargement of one of the sensory knolss of the entocoxite would necessarily be filled with a protrusion of the generative and hepatic masses. This is the reason why the generative and hepatic material apparently passes into the basal segment of the ectognath, and not into that of the endognaths; it does not really pass into the coxopodite of the appendage, but into an enlarged portion of the entocoxite, which can hardly be considered as truly helonging to the appendage. Kishinouye has stated that a knob arises in the emluryo at the base of each of the prosomatic locomotor appendages, lut that this knol, develops only in the last or digging appendage (ectognath) forming the flabellum. Doulutless the median sclerites of the entocoxites of the endognaths represent Kishinonye's undeveloped knols.

I conclude, therefore, that the flabellum, together with its basal part, is an adjunct to the appendage rather than a part of it, and might, therefore, easily remain as a separate and well-developed entity, even although the appendage itself dwindled down to a mere tentacle.

The evidence appears to me very strong that the flabellum of Limulus and the pecten of scorpions are the most likely organs to give a clne to the origin of the auditory apparatus of vertebrates. At present both the Eurypterids and Cephalaspids lave left us in the lurch; in the former there is no sign of either flabellum or pecten; in the latter, no sign of any auditory capsule beyond Rohon's discovery of two small apertures situated dorsally on each side of the middle line in Tremataspis, which he considers to be the termination of the ductus cndolymphaticus on each side. In both cases it is probable, one might almost say certain, that any such special sense-organ, if present, was not situated externally, but was sunk below the surface as in Ammocœtes.

The method by which such a sense-organ, situated externally on 
the surface of the animal, comes phylogenetically to form the lining wall of an internally situated membranous capsule is given by the ontogeny of this eapsule, whieh shows step by step how the senseorgan sinks in and forms a capsule, and finally is entirely removed from the surface except as regards the ductus cndolymplucticus.

\section{Sumuari.}

The special apparatus for hearing is of a very different character from that for vision or for smell, for its nerve belongs to the infra-infundibular group of nerves, and not to the supra-infundibular, as do those of the other two special senses. Of the fire special senses the norres for toneh, taste, and hearing, all belong to the infra-infundibular segmental nerve-gromps. The invertebrate origin, then. of the vertebrate anditory nerve must be sought for in the infraœsophageal segmental group of nerres. and not in the supra-œesophageal.

The organs supplied by the auditory nerve are only partly for the purpose of hearing; there is always present also an apparatus - the semicireular canals -coneerned with equilibration and co-ordination of movements. Such equilibration organs are not contined to the anditory nerve. but in the water-living rertebrates are arranged segmentally along the body, forming the organs of the lateral line in fishes; the anditory organ is bnt one of these lateral line organs. which has been specially dereloped.

These lateral line organs lave been compared to similar segmental organs found in comnection with the appendages in worms, especially the respiratory appendages. In accordance with this suggestion we see that they are all innervated from the region of the respiratory nerves the ragus, glossopharyngeal, and facial-nerves which originally supplied the respiratory inpendages of the palieostracau ancestor.

The logical conclusion is that the appendages of the Palieostraca possessed special sense-organs concerned with the perception of special ribrations. especially in the mesosomatic or respiratory region, and that somewhere at the junction of the prosoma and mesosoma. one of these sense-organs was specially developed to form the origin of the vertebrate anditory apparatus.

Impressed by this reasoning I made search for some specially striking sense-organ at the base of one of the appendagres of Limulus, at the junction of the prosoma and mesosoma, and was immediately rewarded by the discovery of the extraordinary nature of the flabellum, which revealed itself as an elaborate sense-organ supplied with a nerve ont of all proportion to its size. Up to this time no one had the slightest conception that this flabellum was a special sense-organ; the diseovery of its nature was entirely due to the logical following ont of the theory of the origin of rertebrates described in this book.

The structure of this large sense-organ is comparable with that of the sense-organs of the pectens of the scorpion, and of many other organs found on the appendages of various members of the seorpion group, of arachnids and 
other air-breathing arthropods. Many of these organs, such as the lyriform organs of arachnids, and the 'halteres' or balancers of the Diptera. are usually rogarded as anditory and equilibration organs.

On all the mesosomatic appendages of Limulus very remarkable sense-organs are found, apparently for estimating pressures, which. when the appendages sank into the body to form with their basal parts the hranchial diaphragms of Ammocotes, could easily be conceived as remaining at the surface, and so giring rise to the lateral line organs.

Further confirmation of the riew that an organ. such as the flabellum, nunst be looked upon as the originator of the rertebrate auditory organ, is afforded by the extraordinary coincidence that in Limulus a direrticulum of the generative and hepatic mass accompanies the flabellar nerve into the basal part of the digging appendage, while in Ammocoetes, accompanying the auditory nerre into the anditory capsule, there is seen a mass of cells belonging to that peculiar tissue which tills up the space between the brain and the cranial walls. and has already. on other grounds, been homologized with the generative and hepatic masses which fill up the encephalic region of Limulus.

For all these reasons special sense-organs, such as are found in the flabellum of Limulus and in the pectens of scorpions, may be looked upon as giving origin to the vertebrate anditory apparatus. In such case it is highly probable that the parachordals, with the auditory capsules attached, arose from a second entochondrite of the same nature as the plastron; a probability which is increased by the fact that the scorpion does possess a second entochondrite. which, owing to its special relations to the pecten, is known as the supra-pectinal entochondrite. 


\section{C'HAPTER XII}

\section{THE REGION OF THE SPINAL CORD}

Difference between cranial and spinal regions.-Absence of lateral root.Meristic variation.-Segmentation of coelom. - Segmental excretory organs. -Development of nephric organs : pronephric, mesonephric, metanepliric. -Excretory organs of Amphioxus.-Solenocytes.-Excretory orcans of Branchipus and of Peripatus, appendicular and somatic.-- Comparison of coelom of Peripatus and of vertebrate.-Pronephric organs compared to coxal glands.- Origin of rertebrate body-cavity (metacole).-Segmental duct.-Summary of formation of exeretory organs.--Origin of somatic trunk-musculature.-Atrial carity of Amphioxus.-Pleural folds.-Ventral growth of pleural folds and somatic musculature.-Pleural folds of Cephalaspidar and of Trilobita.-Significance of the ductless glands.-Alteration in structure of excretory organs which have lost their dnct in rertebrates and in invertebrates.-Formation of lymphatic glands.-Segmental coxal glands of arthropods and of vertebrates.-Origin of adrenals, pituitary body, thymus, tonsils, thyroid, and othex ductless glands.-Summary.

THE consideration of the anditory nerve and the anditory apparatus terminates the comparison between the cranial nerves of the vertebrate and the prosomatic and mesosomatic nerves of the arthropod, and leaves us now free to pass on to the consideration of the vertebrate spinal nerves and the organs they supply. Before doing so, it is advisable to pass in review the conclusions already attained.

Starting with the working hypothesis that the central nervous system of the vertebrate has arisen from the ccntral nervous system of the arthropod, but has involved and enclosed the alimentary canal of the latter in the process, so that there has been no reversal of surfaces in the derivation of the one form from the other, we have been enabled to compare closely all the organs of the hearl-region in the two groups of animals, and in no single case have we been compelled to make any startling or improbable assumptions. The simple following out of this clue has led in every case in the most natural 
manner to the interpretation of all the organs in the heal-region of the vertebrate from the corresponding organs of the arthropod.

That it is possible to bring together all the striking resemblances between organs in the two classes of animals, such as I have done in preceding chapters, las been ascribed to a perverted ingennity on my part-a suggestion which is flattering to my imaginative powers, but has no foundation of fact. There has been absolutely no ingennity on my part; all I have done is to compare organs and their nervesupply, as they actually exist in the two groups of animals, on the supposition that there has been no turning over on to the back, no reversal of dorsal and ventral surfaces. The comparison is there for all to read; it is all so simple, so self-evident that, given the one clue, the only ingennity required is on the part of those who fail to see it.

The great distinction that has arisen between the two head-regions is the disappearance of appendages as such, never, however, of important organs on those appendages. If the olfactory organs of the one group were originally situated on antennules, the olfactory organs still remain, although the antenuules as such have disappeared. The coxal excretory organs at the base of the endognaths remain and become the pituitary body. A special sense-organ, such as the flabellum of Limulus or the pecten of scorpion, remains and gives rise to the auditory organ. A special glandnlar organ, the uterus in the base of the operculum, remains, and gives rise to the thyroid gland. The branchiæe and sense-organs on the mesosomatic appendages remain, and even the very muscles to a large extent. As will be seen later, the excretory organs at the base of the metasomatic appendages remain. It is merely the appendage as such which vanishes either by dwindling away, or by so great an alteration as no longer to be recognizable as an appenclage.

This dwindling process was already in full swing before the vertebrate stage; it is only a continuation of a previons tendency, as is seen in the dwindling of the prosonatic appendages in the Merostomata and the inclusion of the branchice within the body of the scorpion. Already among the Paleostraca, swimming had largely taken the place of crnwling. The whole gradual transformation from the arthropod to the vertebrate is associated with a transformation from a crawling to a swimming animal-with the concomitant loss of locomotor appendages as such, and the alteration of the shape of 
the animal into the lithe fish-like form. The consideration of the manner in which this latter change was brought about, takes us out of the cranial into the spinal region.

If we take Limulus as the only living type of the Palieostraca, we are struck with the fact that the animal consists to all intents and purposes of prosomatic and mesosomatic regions only; the metasoma consisting of the segments posterior to the mesosoma is very insignificant, so that the large mass of the animal consists of what has become the head-region in the vertebrate; the spinal region, which has become in the higher vertebrates by far the largest region of the body, can harlly be said to exist in such an animal as Limulus. As to the Eurypterids and others, similar remarks may be made, though not to the same extent, for in them a distinct metasoma does exist.

In this book I have considered up to the present the cranial region as a system of segments, and shown how such segments are comparable, one by one, with the corresponding segments in the prosoma and mesosoma of the presumed arthropod ancestor.

In the spinal region such direct comparison is not possible, as is evident on the face of it; for even among vertebrates themselves the spinal segments are not comparable one by one, so great is the variation, so unsettled is the number of segments in this region. This meristic variation, as Bateson calls it, is the great distinctive character of the spinal region, which distinguishes it from the cranial region with its fixed number of nerves, and its substantive rather than meristic variation. At the borderland, between the two regions, we see how the one type merges into the other; how difficult it is to fix the segmental position of the spino-occipital nerves; how much more variable in number are the segments supplied by the vagus nerves than those anterior to them.

This meristic variation is a sign of instability, of want of fixedness in the type, and is evidence, as already pointed out, that the spinal region is newer than the cranial. This instability in the number of spinal segments does not necessarily imply a variability in the number of segments of the metasoma of the invertebrate ancestor; it may simply be an expression of adaptability in the vertebrate phylum itself, according to the requirements necessitated by the conversion of a crawling into a swimming animal, and the subsequent conversion of the swimming into a terrestrial or flying animal. 
However many may have been the original number of segments belonging to the spinal region, one thing is certain - the segmental character of this region is remarkably clearly shown, not only by the presence of the segmental spinal nerves, but also by the marked segmentation of the mesoblastic structures. The question, therefore, that requires elucidation above all others is the origin of the spinal mesoblastic segments, i.e. of the colomic cavities of the trunk-region, and the structures derived from their walls.

Proceeding on the same lines as in the case of the cranial segments, it is necessary in the first instance to inquire of the vertebrate itself as to the scope of the problem in this region. In addition to the variability in the number of segments so characteristic of the spinal region, the complete absence in each spinal segment of a lateral root affords another marked difference between the two regions. Here, except, of course, at the junction of the spinal and cranial regions, each segmental nerve arises from two roots only, dorsal and ventral, and these roots are separately sensory and motor, and not mixed in function as was the lateral root of each cranial segment. Now, these lateral roots were originally the nerves sup'plying the prosomatic and mesosomatic appendages with motor as well as sensory fibres. The absence, therefore, of lateral roots in the spinal region implies that in the vertebrate none of the musculature belonging to the metasomatic appendages has remained. Consequently, as far as muscles are concerned, the clue to the origin of the spinal segments must be sought for in the segmentation of the body-muscles.

Here, in contradistinction to the cranial region, the segmentation is most marked, for the somatic spinal musculature of all vertebrates can be traced back to a simple sheet of longitudinal ventral and dorsal muscles, such as are seen in all fishes. This sheet is split into segments or myotomes by transverse connective tissue septa or myo-commata; each myotome corresponding to one spinal segment.

In addition to the evidence of segmentation afforded by the bodymusculature in all the higher vertebrates, similar evidence is given by the segmental arrangement of parts of the supporting tissue to form vertebræ. Such segments have received the name of sclerotomes, and each sclerotome corresponds to one spinal segment.

Yet another marked peculiarity of this region is the segmental arrangement of the excretory organs. Just as our body-musculature 
has arisen from the uniformly segmented simple longitudinal musculature of the lowest fish, so, as we pass down the vertebrate phylum, we find more and more of a uniform segmental arrangement in the excretory organs.

The origin of all these three separate segmentations may, in accordance with the phraseology of the day, be included in the one term-the origin of the spinal mesoblastic segments-i.e. of the calomic cavities of the trunk-region and the structures derived from their walls.

\section{The Origis of the Seghental Excretori Organs.}

Of these three clues to the past history of the spinal region, the segmentation manifested by the presence of vertebra is the least important, for in Ammoccetes there is no sign of vertebræ, and their indications only appear at transformation. Especially interesting is the segmentation due to the excretory organs, for the evidence distinctly shows that such excretory organs have steadily shifted more and more posteriorly during the evolntion of the vertebrate.

In Limulus the excretory organs are in the prosomatic regionthe coxal glands; these become in the vertebrate the pituitary body.

In Amphioxus the excretory organs are in the mesosomatic region, segmentally arranged with the gills.

In vertebrates the excretory organs are in the metasomatic region posterior to the gills, and are segmentally arranged in this region. Their investigation has demonstrated the existence of three distinct stages in these organs: 1. A series of segmental excretory organs in segments immediately following the branchial segments. This is the oldest of the three sets, and to these organs the name of the pronephros is given. 2. A second series which extends more posteriorly than the first, overlaps them to an extent which is not yet settled, and takes their place; to them is given the name of the mosonephros. 3. A third series continuous with the mesonephric is situated in segments still more posterior, supplants the mesonephros and forms the kidneys of all the higher vertebrates. This forms the metanephros.

These three sets of exeretory organs are not exactly alike in their origin, in that the pronephrie tubules are formed from a different portion of the ecelomic walls to that from which the meso- and 
metanephric tubules are formed, and the former alone gives origin to a duct, which forms the basis for the generative and urinary ducts, and is called the segmental duct. The mesonephric tubules, called also the Wolffian body, open iuto this duct.

In order to make the embryology of these excretory organs quite clear, I will make use of van Wijhe's phraseology and also of his illustrations. He terms the whole calomic cavity the proccelom, which is divisible into a ventral unsegmented part, the body-cavity or metacelom, and a dorsal segmented part, the somite. This latter part again is divided into a dorsal part-the epimere-and a part connecting the dorsal part with the body-cavity, to which therefore he gives the name of mesomere.

The cavity of the epimere disappears, and its walls form the muscle and cutis plates of the body. The part which forms the muscles is known as the myotome, which separates off from the mesomere, leaving the latter as a blind sac-the mesocolom-communicating by a narrow passage with the body cavity or metacelom. At the same time, from the mesomere is formed the sclerotome, which gives rise to the skeletal tissues of the vertebre, etc., so that van Wijhe's epimere and mesomere together correspond to the original term, protovertebra, or somite of Balfour; and when the myotome and sclerotome lave separated off, there is still left the intermediate cell-mass of Balfour and Sedgwick, i.c. the sac-like mesocoele of van Wijhe, the walls of which give origin to the mesonephrotome or mesonephros. Further, according to van Wijhe, the dorsal part of the unsegmented metaccelom is itself segmented, but not, as in the case of the mesocule, with respect to both splanchnopleuric and somatopleuric walls. The segmentation is manifest only on the somatopleuric side, and consists of a distinct series of hollow somatopleuric outgrowths, called by lim hypomeres, which give rise to the pronephros and the segmental duct.

V an Wijhe considers that the whole metacolom was originally segmented, because in the lower vertebrates the segmentation reaches further ventral-wards, so that in Selachia the body-cavity is almost truly segmental. Also in the gill-region of Amphioxus the cavities which are homologons with the body-cavity arise segmentally.

As is well known, Balfour and Semper were led, from their embryological researches, to compare the nephric organs of vertebrates with those of annelids, and, indeed, the nature of the vertebrate segmental excretory organs has always been the fact which has kept 


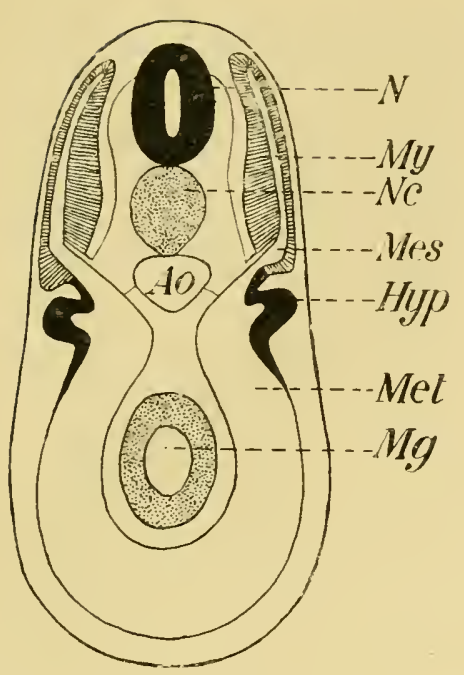

A

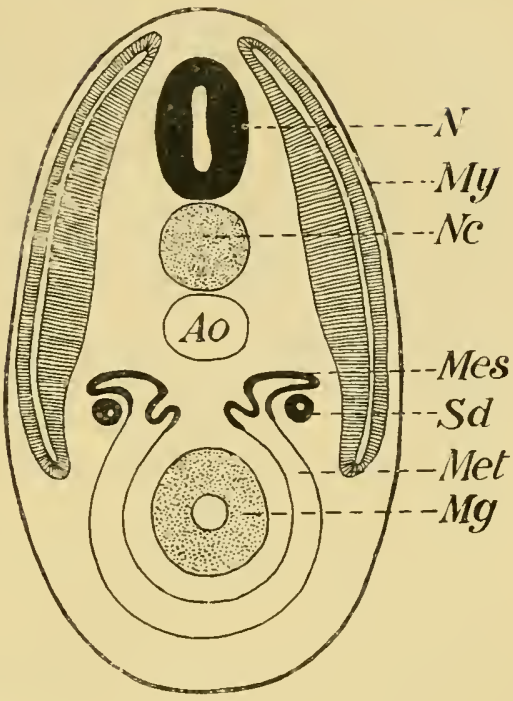

B

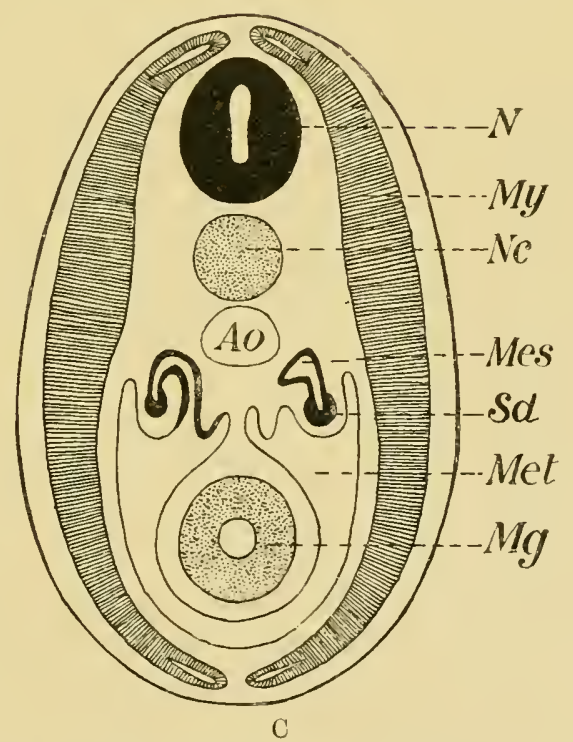

Fig. 156.-Diagrans to illestrate the Develophent of the Vertebrate Celour. (After vas Wijhe.)

N., central nervous system; $N_{c}$., notochord; Ao., aorta; $M I g$., midgut. A, My., myocœle; Mes., mesocœle; Mct., metacœle; Hyp., hypomere (pronephric). B and C, $M y$., myotome; $M$ Ies., mesonephros; S.d., segmental duct (pronephric) ; Met., body cavity. 
alive the belief in the origin of vertebrates from a segmented annelid. These segmental organs thus compared were the mesonephric tubules, and doubts arose, especially in the mind of Gegenbaur, as to the validity of such a comparison, because the mesonephric tubules did not open to the exterior, but into a duct-the segmental duct-which was an unsegmented structure opening into the cloaca; also because the segmental duct, which was the excretory duct of the pronephros, was formed first, and the mesonephric tubules only opened into it after it was fully formed. Further, the pronephros was said to arise from an outbulging of the somatopleuric mesoblast, which extended over a limited number of metameres, and was not segmental, but continuous. Gegenbaur and others therefore argued that the original prevertebrate excretory organ was the pronephros and its luct, not the mesonephros, from which they concluded that the vertebrate must have been derived from an unsegmented type of animal, and not from the segmented annelid type.

Such a view, however, has no further reason for acceptance, as it was based on wrong premises, for Riuckert has shown that the pronephros does arise as a series of segmental nephric tubules, and is not unsegmented. He also has pointed out that in Torpedo the anterior part of the pronephric duct shows indications of being segmented, a statement fully borne out by the researches of Maas on Myxine, who gives the clearest evidence that in this animal the anterior part of the pronephric duct is formed by the fusion of a series of separate ducts, each of which in all probability once opened out separately to the exterior.

Riückert therefore concludes that Balfour and Semper were right in deriving the segmental organs of vertebrates from those of annelids, but that the amnelid organs are represented in the vertebrate, not by the mesonephric tubules, but by the pronephric tubules and their ducts, which originally opened separately to the exterior. By the fusion of such tubules the anterior part of the segmental duct was formed, while its posterior part either arose by a later conogenetic lengthening, or is the only remuant of a series of pronephric tubules which originally extended the whole length of the body, as suggested also by Maas and Boveri. Riiickert therefore supposed that the mesonephric tubules were a secondary set of nephric organs, which were not necessarily directly clerived from the annelid nephric organs. 
At present, then, Riickert's view is the one most generally accepted-the original annelid nephric organs are represented by the pronephric tubules and the pronephric duct, not by the mesonephric tubules, which are a later formation. This latter statement would hold good if the mesonephric tubules were found entirely in segments posterior to those containing the pronephric tubules; such, however, is said not to be the case, for the two sets of organs are said to overlap in some cases; even when they exist in the same segments, the former are said always to be formed from a more dorsal part of the coelom than the pronephros, always to be a later formation, and never to give any indication of communicating with the exterior except by way of the pronephric duct.

The recent observations of Braner on the excretory organs of the Gymnophiona throw great doubt on the existence of mesonephric and pronephric tubules in the same segment. He criticizes the observations on which such statements are based, and concludes that, as in Hypogeophis, the nephrotome which is cut off after the separation of the sclero-myotome gives origin to the pronephros in the more anterior regions, just as it gives origin to the mesonephros in the more posterior regions. In fact, the observations of van Wijhe and others do not in reality show that two excretory organs may be formed in one segment, the one mesonephric from the remains of the mesomere and the other pronephric from the hypomere, but rather that in such cases there is only one organ-the pronephros-part of which is formed from the mesomere and part from the hypomere. Brauer goes further than this, and doubts the validity of any distinction between pronephros and mesonephros, on the ground of the former arising from a more ventral part of the procelom than the latter; for, as he says, it is only possible to speak of one part of the somite as being more ventral than another part when both parts are in the same segment; so that if pronephric and mesonephric organs are never in the same segment, we cannot say with certainty that the former arises more ventrally than the latter.

These observations of Braner strongly confirm Sedgwick's original statement that the pronephric and mesonephric organs are homodynamous organs, in that they are both derived from the original serially situated nephric organs, the differences between them being of a subordinate nature and not sufficient to force us to believe that the mesonephros is an organ of quite different origin to the 
pronephros. So, also, Price, from his investigations of the exeretory organs of Bdellostoma, considers that in this animal both pronephros and mesonephros are derived from a common embryonic kidney, to which he gives the name holonephros.

Brauer also is among those who conclude that the vertebrate excretory organs were derived from those of annelids; he thinks that the original ancestor possessed a series of similar organs over the whole pronephric and mesonephric regions, and that the anterior pronephric organs, which alone form the segmental duet, became modified for a larval existence-that their peeuliarities were adaptive rather than ancestral. This last view seems to me very far-fetched, without any sufficient basis for its acceptance. According to the much more probable and reasonable view, the pronephros represents the oldest and original excretory organs, while the mesonephros is a later formation. Brauer's evidence seems to me to signify that the pronephros, mesonephros, and metanephros are all serially homologous, and that the pronephros bears much the same relation to the mesonephros that the mesonephros does to the metanephros. The great distinetion of the pronephros is that it, and it alone, forms the segmental duct.

We may sum up the conclusions at which we have now arrived as follows:-

1. The pronephric tubules and the pronephric duct are the oldest part of the excretory system, and are distinetly in evidence for a few segments only in the most anterior part of the trunk-region immediately following the branchial region. They differ also from the mesonephric tubules by not being so clearly segmental with the myotomes.

2. The mesonephric tubules belong to segments posterior to those of the pronephros, are strictly segmental with the myotomes, and open into the pronejhric duet.

3. All observer's are agreed that the two sets of excretory organs resemble each other in very many respects, as though they arose from the same series of primitive organs, and, according to Seclgwick and Braiter, no distinction of any importance does exist between the two sets of organs. Other observers, however, consider that the pronephrie organs, in part at all events, arise from a part of the nephroecele more ventral than that which gives origin to the mesonephric organs, and that this difference in position of origin, combined 
with the formation of the segmental duct, does constitute a true morphological distinction between the two sets of organs.

4. All the recent observers are in agreement that the vertebrate excretory organs strongly indicate a derivation from, the segmental organs of annelids.

The very strongest support has been given to this last conclusion by the recent discoreries of Boveri and Goodrich upon the excretory organs of Amphioxus. According to Boveri, the nephric tubules of Amphioxus open into the dorsal ccelom by one or more funnels. Around each funnel are situated groups of peculiar cells, called by lim 'Fadenzellen,' each of which sends a long process across the opening of the funnel. Goodrich has examined these 'Fadenzellen,' and found that they are typical pipe-cells, or solenocytes, such as he has described in the nephridial organs of various nembers of the annelid group Polychæta. Also, just as in the Polychrta, the ciliated nephric tubule has no internal funnel-shaped opening into the colom, but terminates in these groups of solenocytes. "Each solenoeyte consists of a cell-body and nuclens situated at the distal free extremity of a delicate tube; the proximal end of the tube pierces the wall of the nephridial canal and opens into its lumen. A single long flagellum arising from the cells works in the tube and projects in to the canal."

The exceedingly close resemblance between the organs of Amphioxus and those of Phyllodoce, as given in his paper, is most striking, and, as he says, leads to the conclusion that the excretory organs of Amphioxus are essentially identical with the nephridia of certain polychæte worms.

It is to me most interesting to find that the very group of annelids, the Polychrta, which possess solenocytes so remarkably resembling those of the excretory organs of Amphioxus, are the highest and most developed of all the Annelida. I have argued throughont that the law of evolution consists in the origination of successive forms from the dominant group then alive, dominance signifying the highest type of brain-power achieved up to that time. The highest type among Annelida is found in the Chretopoda; from them, therefore, the original arthropod type must have sprung. This original group of Arthropola gave rise to the two groups of Crustacea and Arachnida, in my opinion also to the Vertebrata, and, as already mentioned, it is convenient to grive it a generalized 
name, the Protostraca, from which subsequently the Palaostraca arose.

The similarity between the excretory organs of Amphioxus and those of Phyllodoce suggests that the protostracan ancestor of the vertebrates arose from the highest group of the Chretopoda-the Polychæta. The evidence which I have already given points, however, strongly to the conclusion that the vertebrate did not arise from members of the Protostraca near to the polychrete stock, but rather from members in which the arthropod characters had already become well developed-members, therefore, which were nearer the Trilobita than the Polychæta. Such early arthropods would very probably have retained in part excretory organs of the same character as those found in the original polychrete stock, and thus account for the presence of solenocytes in the excretory organs of Amphioxus.

In connection with such a possibility, I should like to draw attention to the observations of Claus and Spangenberg on the excretory organs of Branchipus-that primitive phyllopod, which is recognized as the nearest approach to the trilobites at present living. According to Claus, an excretory apparatus exists in the neighbourhood of each nerve-ganglion, and Spangenberg finds a perfectly similar organ in the basal segment of each appendage-a system, therefore, of excretory organs as segmentally arranged as those of Peripatus. Clans considers that although these organs formed an excretory system, it is not possible to compare then with the annelid segmental organs, because he thought the cells in question arose from ectoderm. Now, the striking point in the description of the excretory cells in these organs, as described both by Claus and Spangenberg, is that they closely resemble the pipe-cells or solenocytes of Goodrich; each cell possesses a long tube-like projection, which opens on the surface. They appear distinctly to belong to the category of flame-cells, and resemble solenocytes more than anything else. According to Goodrich, the solenocyte is probably an ectodermal cell, so that even if it prove to be the case, as Claus thought, that these pipe-cells of Branchipus are ectodermal, they would still claim to be derived from the segmental organs of annelids, especially of the Polychxta, being, to use Goodrich's nomenclature, true nephridial organs, as opposed to coelomostomes.

These observations of Claus and Spangeuberg suggest not only that the primitive arthropod of the trilobite type possessed segmental 
organs in every segment directly derived from those of a polychrete ancestor, but also that such organs were partly somatic and partly appendicular in position. Such a suggestion is in strict accord with the observations of Sedgwick on the excretory organs of the most primitive arthropod known, viz. Peripatus, where also the excretory organs, which are true segmental organs, are partly somatic and partly appendicular. Further, the excretory organs of the Scorpion and Limulus group are again partly somatic and partly appendicular, receiving the name of coxal glands, because there is a ventral projection of the gland into the coxa of the corresponding appendage.

Judging from all the evilence available, it is probable that when the arthropod stock arose from the annelids, simultaneously with the formation of appendages, the segmental somatic nephric organs of the latter extended ventrally into the appendage, and thus formed a segmental set of excretory organs, which were partly somatic, partly appendicular in position, and might therefore be called coxal glands.

As already stated, all investigators of the origin of the vertebrate excretory organs are unanimous in considering them to be derived from segmental organs of the annelid type. I naturally agree with them, but, in accordance with my theory, would substitute the words "primitive arthropod" for the word "annelid," for all the evidence I have accumulated in the preceding chapters points directly to that conclusion. Further, the most primitive of the three sets of vertebrate segmental organs-the pronephros, mesonephros, and metanephros-is undoubtedly the pronephros; consequently the pronephric tubules are those which I consider to be more directly derived from the coxal glands of the primitive arthropod ancestor. Such a derivation appears to me to afford an explanation of the difficulties connected with the origin of the pronephros and mesonephros respectively, which is more satisfactory than that given by the direct derivation from the annelid.

The only living animal which we know of as at all approaching the most primitive arthropod type is, as pointed out by Korschelt and Heider, Peripatus ; and Peripatus, as is well known, possesses a true colom and true calomic excretory organs in all the segments of the body. Sedgwick shows that at first a true colom, as typical as that of the annelids, is formed in each segment of the body, and that then this colom (which represents in the vertebrate van Wijhe's pro-cœlom) 
splits into a dorsal and a rentral part. In the anterior segments of the body the dorsal part disappears (presumably its walls give origin to the mesoblast from which the dorsal body-muscles arise), while the ventral part remains and forms a nephrocole, giving origin to the excretory organs of the adult. According to von Kennel, the cavity lecomes divided into three spaces, which for a time are in communication-a lateral (I.), a median (II.), and a dorso-median (III.). The dorso-median portion becomes partitioned off, and this, as well as the greater part of the lateral portion, which lies principally in the foot, is used up in providing elements for the formation of the body-and appendage-muscles respectively and the connective tissue.

In Fig. 157 I reproduce von Kennel's diagram of a section across a Peripatus embryo, in which I. represents the lateral appendicular part of the colom, II. the ventral somatic part, and III. the dorsal part which separates off from the ventral and lateral parts, and, as its walls give origin largely to the body-muscles, may be called the inyocale. The muscles of the appendages are formed from the ventral part of the original procolom, just as I have argued is the case with the muscles of the splanchnic segmentation in vertebrates.

Sedgwick states that the ventral part of the colom extends into the base of each appendage, and there forms the end-sac of each nephric tubule, into which the nephric fumnel opens, thus forming a coxal gland; this end-sac or vesicle in the appendage is called by him the internal vesicle $(i . x$.), because later another vesicle is formed from the ventral cœlom in the body itself, close against the nerve-cord on each side, which he calls the external vesicle (c.v.). (Cf. Fig. 158, taken from Sedgwick.) This second vesicle is, according to him, formed later in the development from the nephric tubule of the internal vesicle, so that it discharges its contents to the exterior by the same opening as the original tubule. Of course, as he points out, the whole system of internal and external vesicles and nephric tubules are all simply derivatives of the original ventral part of the colom or nephrocele.

Here, then, in Peripatus, and presumably, therefore, in members of the Protostraca, we see that the original segmental organs of the annelid have become a series of nephric organs, which extended into the base of the appendages, and may therefore be called coxal glands; also it is clear, from Sedgwick's description, that if the appendages 
disappeared, the nephric organs would still remain, not as coxal glands, hit as purely somatic excretory glands. They would still be homologous with the annelid segmental organs, or with the coxal glands, but would arise in toto from a part of the ventral colom or nephrocale, more dorsal than the former appendicular part, because the appendages and their enclosed colom are always situated rentrally to the body. Again, according to Sedgwick, the nephric tubules are

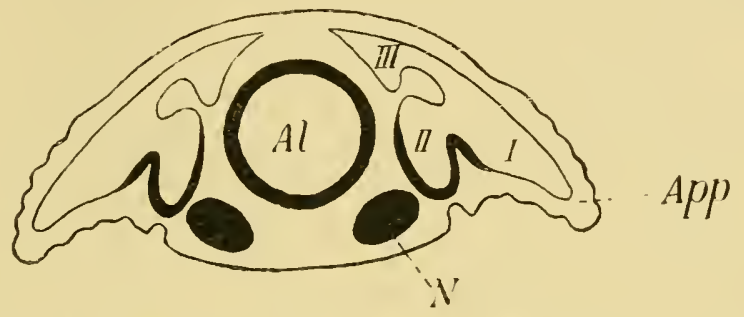

Fig. 157.-Traxsterse Section of Peripatus Embryo. (After von Kennel.) Al., alimentary canal; $N$., nerve-cord; $A p p$., appendage; $I, I I, I I I$, the three divisions (lateral, median, and dorso-median) of the cœlom.

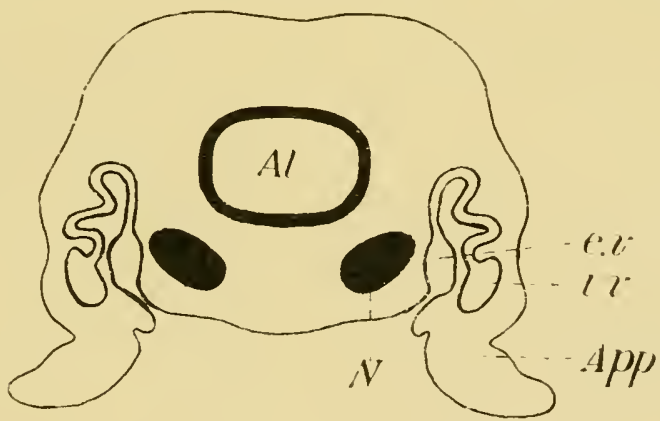

Fig. 158.-Section of Peripatus. (After Sedgiwick.)

Al., alimentary canal; N., nerve-cord; App., appendage; i.v., internal, and e.v., external vesicles of the segmented excretory tubule (coxal gland).

connected with two colomic vesicles, the one in the appendage the internal vesicle, and the other, the so-called bladder, or the external vesicle, in the body itself, close against the nerve-cord. Sedgwick appears to consider that either of these vesicles may form the endsac of a nephric tubule, for he discusses the question whether the single vesicle, which in each case gives origin to the nephridia of the first three legs, corresponds to the internal or external vesicle. $\mathrm{He}$ 
lecides, it is true, in favour of the internal vesicle, and therefore considers the excretory organ to be appendicular, i.e. a coxal gland, in these segments as well as in those more posterior. Still, the very discussion shows that in his opinion, at all events, the external vesicle might represent the end-sac of the tubule, in the absence of the internal or appendicular vesicle.

Such an arrangement as Sedgwick describes in Peripatus is the very condition required to give rise to the pronephric and mesonephric tubules, as deduced by me from the consideration of the vertebrate, and harmonizes and clears up the controversy about the mesonephros and pronephros in the most satisfactory manner. Both pronephros and mesonephros are seen to be derivatives of the original amnelid segmental organs, not directly from an annelid, but by way of an arthropodan ancestor; the difference between the two is simply that the pronephric orgaus were coxal glands, and indicate, therefore, the presence of the original metasomatic appendages, while the mesonephric organs were homologous organs, formed in segments of later origin which had lost their appendages. For this reason the pronephros is said to be formed, in part at least, from a portion of the colom situated more ventrally than the purely somatic part which gives rise to the mesonephros. For this reason Sedgwick, Braner, etc., can say that the mesonephros is strictly homodynamons with the pronephros; while equally Riickert, Semon, and van Wijhe can say it is not homodynamous, in so far that the two organs are not derived strictly from absolutely homologous parts of the colom. For this reason Semon can speak of the mesonephros as a dorsal lerivative of the pronephros, just as Sedgwick says that the external or somatic vesicle of Peripatus is a derivative of the appendicular nephric organ. For this reason the pronephros, or rather a part of it, is always derived from the somatopleuric layer, for, as is clear from Miss Sheldon's drawing, the part of the colom in Peripatus which dips into the appendage is derived from the somatopleuric layer alone.

Such a coelom as that of Peripatus, Fig. 157, would represent the origin of the vertebrate cœlom, and would therefore represent the proceclom of van Wijhe. In strict accordance with this, we see that it separates into a dorsal part, the walls of which give origin to the somatic muscles, or at all events to the great longitudinal dorsal muscles of the animal, and a ventral part, which forms a nephrocele, 
dips into the appendage, and gives origin to the muscles of the appendage. In the vertebrate, after the somatic dorsal part or myoccele has separated off, a ventral part is left, which forms a nephroccele in the trunk-region, and gives origin to the splanchnic striated muscles in the cranial region, i.e. to the muscles which, according to my theory, were once appendicular muscles. This ventral nephroccelic part is divisible in the trunk into a segmented part, which forms the excretory organs proper, and an unsegmented part, the metaccele or true body-cavity of the vertebrate.

This comparison of the procelom of the vertebrate and arthropod signifies that the vertebrate metacœle was directly derived by ventral downgrowth from the arthropod nephrocole, so that if, as I suppose, the vertebrate nervous system represents the conjoined nervous system and alimentary canal of the arthropod, then the vertebrate metacole, or body-cavity, must have been originally confined to the region on each side of the central nervous system, and from this position have spread ventrally, to enclose ultimately the new-formed vertebrate gut. This means that the body-cavity (metaccle) of the vertebrate is not the same as the body-cavity of the annelid, but corresponds to a ventral extension of the nephrocele, or ventral part of such body-cavity.

Such a phylogenetic history is most probable, because it explains most naturally and simply the facts of the development of the vertebrate body-cavity; for the mesoblast always originates in the neighbourhood of the notochord and central nervous system, and the lumen of the body-cavity always appears first in that region, and then extends laterally and ventrally on each side until it reaches the most ventral surface of the embryo, thus forming a ventral mesentery, which ultimately disappears, and the body-cavity surrounds the gut, except for the dorsal mesentery. Thus Shipley, in his description of the formation of the mesoblastic plates which line the body-cavity in Ammoccetes, describes them as commencing in two bands of mesoblast situated on each side, close against the commencing nervous system :-

"These two bands are separated dorsally by the juxtaposition of the dorsal wall of the mesenteron and the epiblast, and ventrally by the hypoblastic yolk-cells which are in contact with the epiblast over two-thirds of the embryo. Subsequently, but at a much later date, the mesoblast is completed ventrally by the downgrowth on 
each sirle of these mesohlastic plates. The subsequent downward growth is brought about by the cells proliferating along the free ventral edge of the mesoblast, these cells then growing ventral wards, pushing their way between the yoke-cells and epiblast.".

The derivation of the vertebrate pronephric segmental organs from the metasomatic coxal glands of a primitive arthropod would mean, if the segmental organs of Peripatus be taken as the type, that such glands opened to the exterior on every segment, either at the base of the appendage or on the appendage itself. It is taken for granted by most observers that the pronephric segmental organs once opened to the exterior on each segment, and then, from some cause or other, ceased to do so, and the separate ducts, by a process of fusion, came to form a single segmental duct, which opened into the cloaca. Many observers have been led to the conclusion that the pronephric duct is epiblastic in origin, although from its position in the adult, it appears far removed from all epiblastic formations. However, at no time in the developmental history is there any clear evidence of actual fusion of any part of the pronephric organ with the epidermis, and the latest observer, Braner, is strongly of opinion that there is never sufficiently close contact with the epidermis to warrant the statement that the epiblastic cells take part in the formation of the duct. All that can be said is, that the formation of the duct takes place at a time when the pronephric diverticnlum is in close propinquity to the epidermis, before the ventral downgrowth of the myotome has taken place.

The formation of the anterior portion of the pronephric duct is, according to Maas in Myxine, and Wheeler in Petromyzon, undoubtedly brought about by the fusion of a number of pronephric tubules, which, according to Maas, are clearly seen in the youngest specimens as separate segmental tubes; each of these tubules is supplied by a capillary network from a segmental branch of the aorta, as in the tubules of Amphioxus according to Boveri, and does not possess a glomerulus.

The posterior part of the duct into which the mesonephric tubules enter possesses also a capillary network, which Maas considers to represent the original capillary network of a series of pronephric tubules, the only remnant of which is the duct into which the mesonephric tubules open. He therefore argnes that the pronephric duct indicates a series of pronephric tubules, which originally extended 
along the whole length of the body, and were supplanted by the mesonephric tubules, which also belonged to the same segments.

I also think that the paired appendages which have left the pronephric tubules as signs of their past existence, existed originally, in the invertebrate stage, on every segment of the body. But I do not consider that such a statement is at all equivalent to saying that such pairs of tubules must have existed upon every one of the segments existing at the present day ; for it seems to me that Ruickert is much more likely to be right when he says that in Selachians the duct clearly does grow back, and is not formed throughout in situ; so that he gives a double explanation of the formation of the duct-a palingenetic anterior part formed by the fusion of the extremities of the original excretory tubules, to which a posterior cœenogenetic lengthening has been added.

It does not seem to me at all necessary that the immediatc invertebrate ancestor of the vertebrate should have possessed excretory organs which opened out separately to the exterior on each segment; a fusion may already have taken place in the invertebrate stage, and so a single duct have been acquired for a number of organs. Such a suggestion has been made by Rïckert, because of the fact discovered by Cunningham and E. Meyer, that the segmental organs of Lrenice conclitegu are on each side connected together by a single strong longitudinal canal. I would, however, go further than this and say, that even although the nephric organs of the polychæte ancestor opened out on every segment, and although the primitive arthropodan ancestor derived from such polychrete possessed coxal glands which opened out either on to or at the base of each appendage, similarly to those of Peripatus, yet the immediate arthropodan ancestor, with its palæostracan affinities, may already have possessed metasomatic coxal glands, all of which opened into a single duct, with a single opening to the exterior.

Judging from Limulus, such was very probably the case, for Patten and Hazen have shown (1) that the coxal glands of Limulus are segmental organs belonging to the prosomatic segments; (2) that the organs belonging to the cheliceral and ectognathal segments are not developed; (3) that the four glands belonging to the endoguaths become connected together by a stolon, which communicates with a single nephric duct, opening to the exterior on the basal segment of the 5th prosomatic appendage (the last endognath). At 
no time is there any evidence of any separate openings or any fusion with the ectoderm, such as might indicate separate openings of these prosomatic coxal segmental organs. Thus we see that in Limulus, which is presumably much nearer the annelid condition than the vertebrate, all evidence of separate nephric ducts opening to the exterior on each prosomatic segment has entirely disappeared, just as is the case in the metasomatic coxal glands (i.e. the pronephros) of the vertebrate. What is seen in the prosomatic region of Limulus, and doubtless also of the Eurypterids, may very probably have occurred in the metasomatic region of the immediate invertebrate ancestors of the vertebrate, and so account for the single pronephric duct belonging to a uumber of pronephric organs.

The interpretation of these various embryological investigations may be summed up as follows :-

1. The ancestor of the vertebrates possessed a pair of appendages on each segment; into the base of each of these appendages the segmental excretory organ sent a diverticulum, thus forming a coxal gland.

2. Such coxal glands, even in the invertebrate stage, may have discharged into a common duct which opened to the exterior most posteriorly.

3. Then, from some cause, the appendages were rendered useless, and dwindled away, leaving only the pronephric organs to indicate their former presence. At the end of this stage the animal possessed vertebrate characteristics.

4. For the purpose of increasing mobility, of forming an efficient swimming instead of a crawling animal, the body-segments increased in number, always, as is invariably the case, by the formation of new ones between those already formed and the cloacal region, and so of necessity caused an elongation of the pronephric duct. Into this there now opened the ducts of the segmental organs formed by recapitulation, those, therefore, belonging to the body-segments-mesonephrichaving nothing to do with appendages, for the latter had alrealy ceased to exist functionally, and would not, therefore, be repeated with each meristic repetition.

This, so to speak, passive lengthening of the pronephric duct in consequence of the lengthening of the early vertebrate body by the addition of metameres, each of which contained only mesonephric and $n o$ pronephric tubules, is, to my mind, an example of a principle 
which has played an important part in the formation of the vertebrate, riz. that the meristic variation by which the spinal region of even the lowest of existing vertebrates has been formed, has largely taken place in the rertebrate phylum itself, and that such changes must be eliminated before we can picture to ourselves the pre-vertebrate condition. As an example, I may mention the remarkable repetition of similar segments pictured by Bashford Dean in Bdellostoma. Such repetition leads to passive lengthening of such parts as are already formed but are not meristically repeated: such are the notochord, the vertebrate intestine, the canal of the spinal cord, and possibly the lateral line nerve. The fuller discussion of this point means the discussion of the formation of the vertebrate alimentary canal; I will therefore leave it until I come to that part of $\mathrm{my}$ subject, and only say here that the evidence seems to me to point to the conclusion that at the time when the vertebrate was formed, the respiratory and cloacal regions were very close together, the whole of the metasoma being represented by the region of the pronephros alone.

Here, as always, the evidence of Ammoccetes tends to give definiteness to our conceptions, for Wheeler points ont that up to a length of $7 \mathrm{~mm}$. the pronephros only is formed; there is no sigu of the more posteriorly formed mesonephros. Now we know, as pointed out in Chapter VI., p. 228, this is the time of Kupffer's larval stage of Ammocoetes. This is the period during which the invertebrate stage is indicated in the ontogeny, so that, in accordance with all that has gone before, this means that the metasoma of the invertebrate ancestor was confined to the region of the pronephros.

Again, take Shipley's account of the development of I'etromyzon. He says-

"The alimentary canal behind the branchial region may be divided into three sections. Langerhans has termed these the stomach, midgut, and hindgut, but as the most anterior of these is the narrowest part of the whole intestine, it would, perhaps, be better to call it cesophagus. This part of the alimentary canal lies entirely in front of the yolk, and is, with the anterior region, which subsequently bears the gills, raised from the rest of the egg when the head is folded off. It is supported by a dorsal mesentery, on each side of which lies the heacl-kidney (pronephros)."

Further on he says- 
"The hindgut is smaller than the midgut; its anterior limit is marked by the termination of the spiral valve, which does not extend into this region. The two segmental ducts open into it just where it turns ventrally to open to the exterior by a median ventral anus. Its lumen is from an early stage lined with cells which have lost their yolk, and it is in wide communication with the exterior from the first. This condition seems to be, as Scott suggests, connected with the openings of the ducts of the pronephros, for this gland is completed and seems capable of functioning long before any food could find its way through the midgut, or, indeed, hefore the stomodieum has opened."

Is there no significance in this statement of Shipley? Even if it be possible to find some special reason why the branchial and cloacal parts of the gut are freed from yolk and lined with serviceable epithelium a long time before the midgut, why should a bit of the midgut, which Shipley calls the cesophagus, which is connected with the region of the pronephros and not of the branchix, differ so markedly from the rest of the midgut? Surely the reason is that the branchial region of the gut, the pronephric region of the gut, and the cloacal region of the gut, belong to a different and earlier phase in the phylogenetic history of the Ammoceetes than does the midgut between the pronephric and cloacal regions. This observation of Shipley fits in with and emphasizes the view that the original animal from which the vertebrate arose consisted of a cephalic and branchial region, followed by a pronephric and cloacal region; the whole intermediate part of the gut, which forms the midgut, with its large lumen and spiral valve, and belongs to the mesonephric region, being a later formation brought about by the necessity of increasing the length of the body.

The Origin of the Sollatic Trunk-Musculature axd the Formation of at Atrial Caviti.

Next comes the question, why was the pronephros not repeated in the meristic repetition that took place during the early vertebrate stage? What, in fact, cansed the disappearance of the metasomatic appendages, and the formation of the smooth body-surface of the fish?

The embryological evidence given by van Wijhe and others of the manner in which the original superficially situated pronephros is 
removel from the surface and caused to assume the deeper position, as seen in the later embryo, is perfectly clear and uniform in all the vertebrate groups. The diagrams at the end of van Wijhe's paper, which I reproduce here, illustrate the process which takes place. At first the myotome (Fig. 159, A) is confined to the dorsal region on each side of the spinal cord and notochord. Then (Fig. 159, B) it separates from the rest of the somite and commences to extend ventrally, thus covering over the pronephros and its duct, until finally (Fig. 159, C) it reaches the mid-rentral line on each side, and the foundations of the great somatic body-muscles are finally laid.

In order, therefore, to understand how the obliteration of the appendages took place, we must first find out what is the prast history of the myotomes. Why are they confined at first to the dorsal region of the body, and extend afterwards to the ventral region, forcing by their growth an organ that was originally external in situation to become internal?

In the original discussion at Cambridge, I was accused of violating the important principle that in phylogeny we must look at the most elementary of the animals whose ancestors we seek, and was told that the lowest vertebrate was Amphioxus, not Ammocoetes; that therefore any argument as to the origin of vertebrates must proceed from the consideration of the former and not the latter animal. My reply was then, and is still, that I was considering the cranial region in the first place, and that therefore it was necessary to take the lowest vertebrate which possessed cranial nerres and sense-organs of a distinctly vertebrate character, a criterion evidently not possessed by Amphioxus. Such argument does not apply to the spinal region, so that, now that I lave left the cranial region and am considering the spinal, I entirely agree with iny critics that Amplioxus is likely to afford valuable help, and ought to be taken into consideration as well as Ammocetes. The distinction between the value of the spinal (including respiratory) and cranial regions of Amphioxus for drawing phylogenetic conclusions is recognized by Boreri, who says that, in his opinion, "Amphioxus shows simplicity and undifferentiation rather than degeneration. If truly Amphioxus is somewhat degenerated, then it is so in its prehensile and masticatory apparatus, its sense organs, and perhaps its locomotor organs, owing to its method of living."

Hatschek describes in Amphioxus how the culom splits into a 


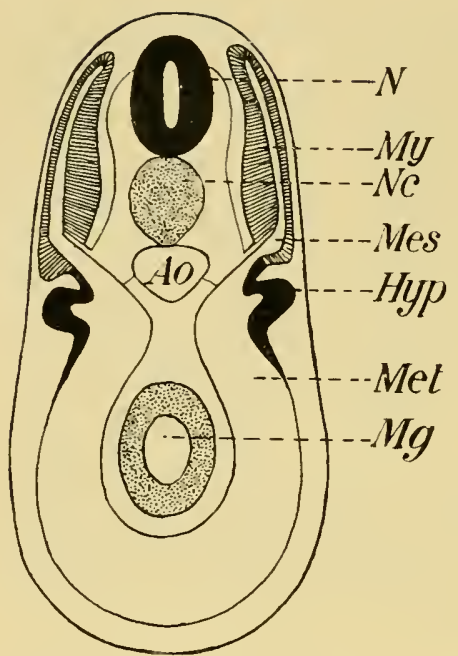

A

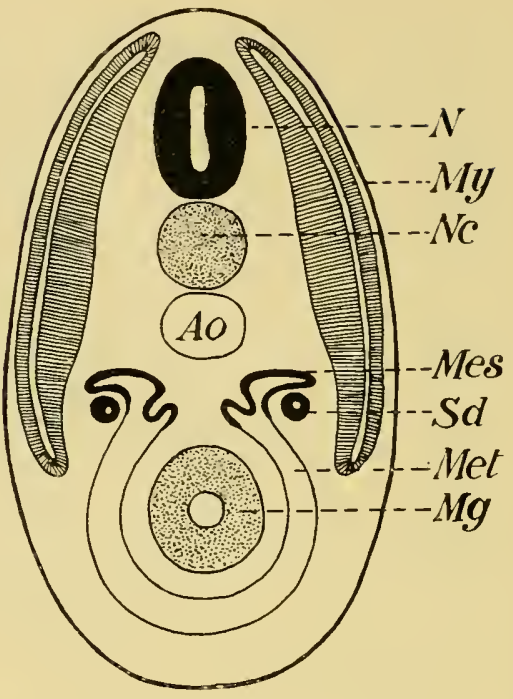

B

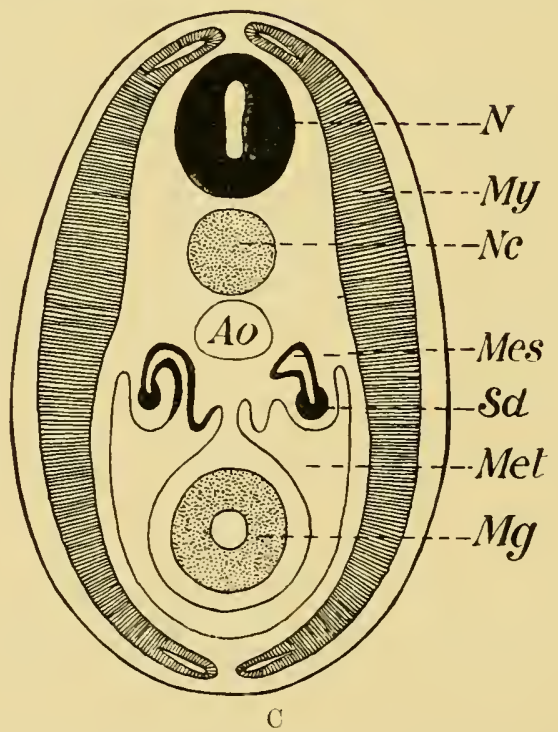

Fig, 159.--Diagrams to illustrate the Developient of the Vertebrate Celom. (After tain WiJHe.)

$N$., central nervous system; $N c$, notochord; Ao., aorta; $M I g$., midgut. A, $M I_{y}$., myocœle; Mes., mesocœle; Met., metacœle; Hyp., hypomere (pronephric). B and C, My., myotome; Mes., mesonephros; s'.d., segmental duct (proncphric); Met., body-cavity. 
dorsal segmented portion, the protovertebra, and a ventral unsegmented portion, the lateral plates. He describes in the dorsal part the formation of myotome and sclerotome, as in the Craniota. Also, he describes how the myotome is at first confined to the dorsal region in the neighbourhood of the spinal cord and notochord, and subsequently extends ventrally, until, just as in Ammocutes, the body is enveloped in a sheet of somatic segmented muscles, the wellknown myomeres.

The conclusion to be drawn from this is inevitable. Any explanation of the origin of the somatic muscles in Ammocoetes must also be an explanation of the somatic muscles in Amphioxus, and conversely; so that if in this respect Amphioxus is the more primitive and simpler, then the condition in Ammocetes must be looked upon as derived from a more primitive condition, similar to that found in Amphioxus. Now, it is well know that a most important distinction exists between Amphioxus and Ammocetes in the topographical relation of the ventral portion of this muscle-sheet, for in the former it is separated from the gut and the body-carity by the atrial space, while in the latter there is no such space. Fürlringer therefore concludes, as I have already mentioned, that this space has become obliterated in the Craniota, but that it must be taken into consideration in any attempt at formulating the nature of the ancestors of the vertebrate.

Kowalewsky described this atrial space as formed by the rentral downgrowth of pleural folds on each side of the body, which met in the mid-ventral line and enclosed the branchial portion of the gut. According to this explanation, the whole rentral portion of the somatic musculature of the adult Amphioxus belongs to the extension of the pleural folds, the original body-musculature being confined to the dorsal region. This is expressed roughly on the external surface of Amphioxus by the direction of the comnective tissue septa between the nyotomes ( $c f$. Fig. 162, B). These septa, as is well known, bend at an angle, the apex of which points towards the heacl. The prart dorsal to the bend represents the part of the muscle belonging to the original body; the part ventral to the bend is the pleural part, and represents the extension into the pleural folds.

Lankester and Willey have attempted to grive another explanation of the formation of the atrial cavity ; they look upon it as originating from a ventral groove, which becomes a canal by the meeting of two 
outgrowths from the metapleure on each side. This canal then extends dorsalwards on each side, and so forms the atrial cavity; the metapleure still remains in the adult; the somatic museles in the epipleure of the aclult are the original body-museles, and not extensions into an epipleuric fold, for there is no such fold.

This explanation is a possible eoneeption for the post-branchial portion of the atrinm, but is impossible for the lranchial region; for; as Macbride points out, as must necessarily be the ease, the point of origin of the atrial wall is, in all stages of development, situated at the end of the gill-slit. It shifts in position with the position of the gill-slit, but there ean be no backwards extension of the eavity. Macbride therefore agrees with Kowalewsky that the atrial cavity is formed by the simultaneous ventral extension of pleural folds, and of the branchial part of the original pharynx. Thus, in his summing up, he states: "In the larva practically the whole sides and dorsal portion of the pharynx represent merely the hyper-pharyngeal groove and the adjacent epithelium of the pharynx of the adult, the whole of the branchial epithelium of the adult being represented by a very narrow strip of the ventral wall of the pharynx of the larva. The subsequent disproportionate growth of this part of the pharynx of the larva, and of the adjacent portion of the atrial eavity, has given the impression that the atrial eavity grew upwards and displaced other structures, which is not the case."

Further, van Wijhe states that the atrium extends beyond the atriopore right up to the anus, just as must have been the ease if the pleural folds originally existed along the whole length of the body. His words are: "Allerdings hat sieh das Atrium beim Amphioxus lancolatus eigenthümlich ausgebildet, indem sich dasselbe dureh den ganzen Rumpf bis an den Anus, d.h. bis an die Wurzel des Sehwanzes ausdelunt."

We get, therefore, this conception of the origin of the somatic musculature of the rertebrate. The invertebrate ancestor possessed on each side, along the whole length of its body, a lateral fold or pleuron which was segmented with the body, and eapable of movement with the body, because the dorsal longitudinal somatic muscles extended segmentally into each segment of the pleuron. By the ventral extension of these pleural folds, not only was the smooth body-surface of the vertebrate attained, but also the original appendages obliterated as such, leaving only as signs of their existence the 
branchia, the pronephric tubules, and the sense-organs of the lateral line system.

Such an explanation signifies that the somatic trunk-musculature of the vertebrate was derived from the dorsal longitudinal musculature of the body of the arthropod, and not from the ventral longitudinal museulature, and that therefore in the primitive arthropod stage the equivalent of the myotome of the rertebrate did not give origin to the ventral longitudinal muscles of the invertebrate ancestor. Now, as I have said, von Kemnel states that in the proccelom of Peripatus a dorsal part (III. in Fig. 157) is cut off which gives origin to the dorsal body-musculature, while the ventral part which remains (I. and II. in Fig. 157) gives origin in its appendicular portion (I.) to the muscles of the appendage, and presumably in its ventral somatic portion (II.) to the ventral longitudinal muscles of the body. This dorsal cut-off part might be called the myotome, in the same sense as the corresponding part of the frocolom in the vertebrate is called the myotome. In both cases the muscles derived from it form only a part of the voluntary musculature of the animal, and in botlı cases the muscles in question are the dorsal longitudinal muscles of the body, to which must be added the dorso-ventral bodymuscles. Now, the whole of my theory of the origin of vertebrates arose from the investigation of the structure of the cranial nerves, which led to the conception that their grouping is not, like the spinal, a dual grouping of motor and sensory elements, but a dual grouling to supply two sets of segments, characterized especially by the different embryological origin of their musculature. The one set I called the somatic segmentation, because the muscles belonging to it were the great longitudinal body-muscles; the other I called the splanchnic segmentation, because its muscles were those connected with the branchial and visceral arches. According to my theory, this latter segmentation was due to the segmentation of the appendages in the invertebrate ancestor; and in previous chapters, dealing as they do with the cranial region, attention was especially directed to the way in which the position of the striated splanchnic musculature could be explained by a transformation of the prosomatic and mesosomatic appendages. Now, I am dealing with the metasomatic region, in which it is true the appendages take a very subordinate llace, but still something corresponding to the splanchnic segments of the cranial region might fairly be expected to exist, and I therefore 
desire to emphasize what appears to me to be the fact, that the musculature, which in the region of the trunk would correspond to that derived from the ventral segmentation of the mesoblast in the region of the head, may have arisen not only from the musculature of the appendages, but also from the ventral longitudinal musculature of the body of the invertebrate ancestor, for it seems probable that this latter musculature had nothing to do with the origin of the great longitudinal muscles of the vertebrate body, either dorsal or ventral.

The way in which I imagine the obliteration of the atrial cavity to have taken place is indicated in Fig. $160, \mathrm{~B}$, which is a modification of a section across a trilobite-like animal as represented in Fig. 160, A. As is seen, the pleural folds on each side have nearly met the bulged-out ventral body-surface. A continuation of the same process would give Fig. 160, C, which is, to all intents and purposes, the same as Fig. 159, C, taken from van Wijhe, and shows how the segmental duct is left in the remains of the atrial cavity. The lining walls of the atrial cavity are represented very black, in order to indicate the presence of pigment, as indeed is seen in the corresponding position in Ammocotes. In these diagrams I have rejresented the median ventral surface as a large bulged-ont bag, without indicating any structures in it except the ventral extension of the proculom to form the metaccelom. At Iresent I will leave the space between the central nerrous system and the ventral mesentery blank, as in the diagrams; in my next chapter I will discuss the possible method of formation within this blank space of the notochord and midgut. Boveri considers that the obliteration of the atrial cavity in the higher vertebrates is not complete, but that its presence is still visible in the shape of the pronephric duct. The evidence of Maas and others that the duct is formed by the fusion of the pronephric tubules is, it seems to me, conclusive against Boveri's view; but yet, as may be seen from my diagrammatic figures, the very place where one would expect to find the last remnant of the atrial cavity is exactly where the pronephric duct is situated. For my own part I should expect to find evidence of a former cxistence of an atrial cavity rather in the pigment round the pronephros and its duct than in the duct itself.

The conception that Amphioxus shows us how to account for the great envelope of somatic muscles which wraps round the vertebrate body, in that the ancestor of the vertebrate possessed on each side of 


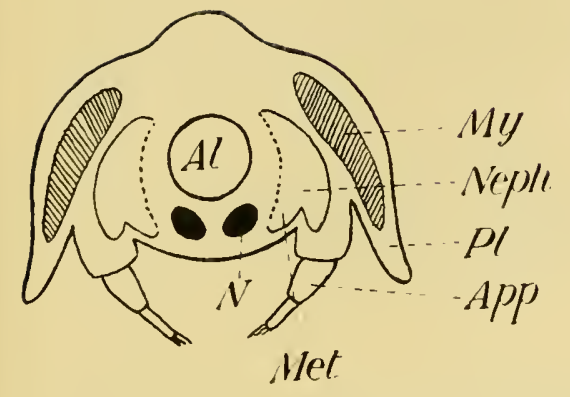

A

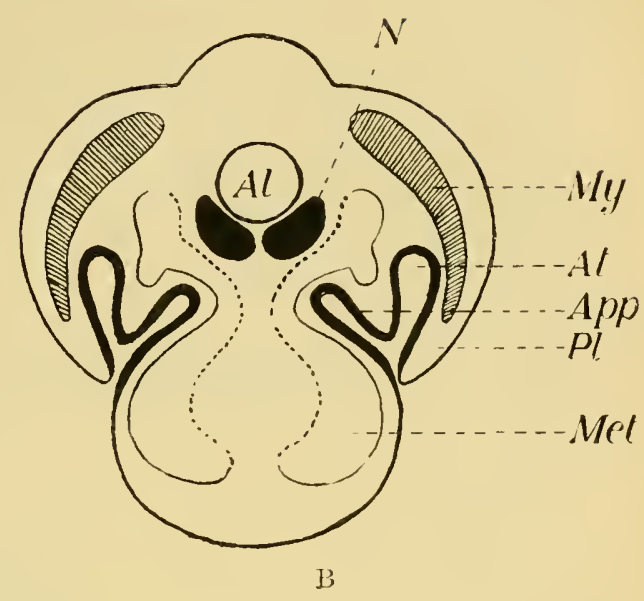

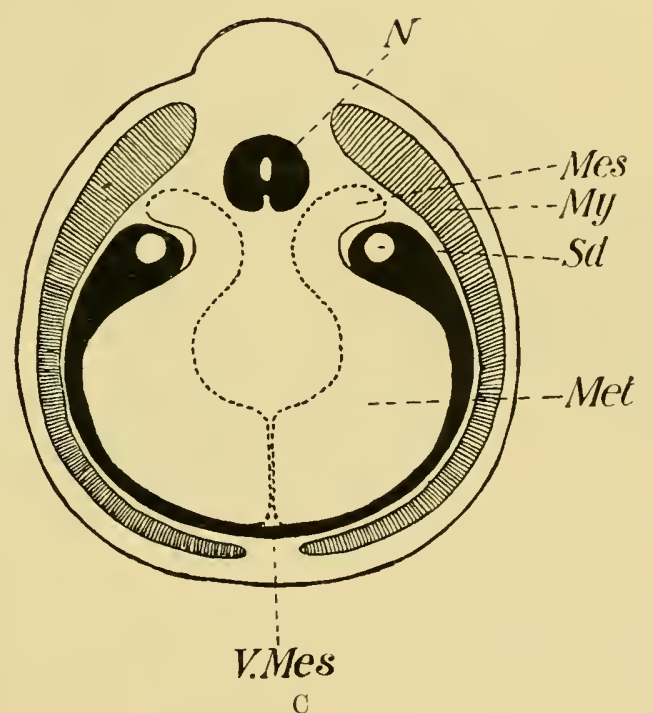

Fig. 160.-A, Diagrail of Section tirbough a Trilobite-like Aximal; B, Diagram to illustrate Suggested Obliteration of Appendages and The Formation of an Atrial Cavity by the Ventral Extension of the Pleural Folds; C, Diagram to illustrate the Completion of the Vertebrate Trpe bi the Meeting of the Pleural Folds in the Mid-ventral LiNe and the Obliteration of tife Atrial Cavity.

$A l$., alimentary canal; $N$. nervous system; $M y .$, myotome; Pl., pleuron; App., appendage; Neph., nephroccle; Met., metaccle; S.d., segmental duct; At., atrial chamber; T.Mes., ventral mesentery; Mes., mesonephros. The dotted line represents the splanchnopleuric mesoblast in all figures. 
the body a segmented pleuron, is exactly in accordance with the theory of the origin of vertebrates deduced from the study of Ammocotes, as already set forth in previous chapters. For we see that one of the striking characteristics of such forms as Bunodes, Hemiaspis, etc, is the presence of segmented pleural flaps on each side of the main part of the body; and if we pass further back to the great group of trilobites, we find in the most manifold form, and in various degrees of extent, the most markedly segmented pleural folds. In fact, the hypothetical figure (Fig. 160, A) which I have deduced from the embryological evidence, might very well represent a cross-section of a trilobite, provided only that each appendage of the trilobite possessed an excretory coxal gland.

The earliest fishes, then, ought to have possessed segmented pleural folds, which were moved by somatic muscles, and enveloped the body after the fashion of Ammocœtes and Amphioxus, and I cannot help thinking that Cephalaspis shows, in this respect also, its relation to Ammocretes. It is well known that some of the fossil representatives of the Cephalaspids show exceedingly clearly that these animals possessed a very well-segmented body, and it is equally recognized that this skeleton is a calcareous, not a bony skeleton, and does not represent vertebre, etc. It is generally called an aponeurotic skeleton, meaning thereby that what is preserved represents not dermal plates alone, or a vertebrate skeleton, but the calcified septa or aponeuroses between a number of muscle-segments or myomeres, precisely of the same kind as the septa between the myomeres in Ammocetes. The termination of such septa on the surface would give rise to the appearance of dermal plates or scutes, or the septa may even have been attached to something of the nature of dermal plates. The same kind of picture would be represented if these connective tissue dissepiments of Ammocotes were calcified, and the animal then fossilized. In agreement with this interpretation of the spinal skeleton of Cephalaspis, it may be noted that again and again, in parts of these dissepiments, $I$ have found in old specimens of Ammoccetes nodules of cartilage formed, and at transformation it is in this very tissue that the spinal cartilages are formed.

Now, the specimens of Cephalaspis all show, as seen in Fig. 161, that the skeletal septa cover the body regularly, and then along one line are bent away from the body to form, as it were, a fringe, or 
rather a free pleuron, which has been easily pushed at an angle to the body-skcleton in the process of fossilization. Patten thinks that this fringed appearance is evidence of a number of segmental appendages which were jointed to the corresponding body-segments, and in the best specimen at the Sonth Kensington Natural History Museum he thinks such joints are clearly visible. He concludes, therefore,

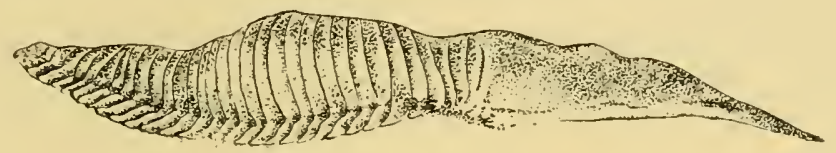

A

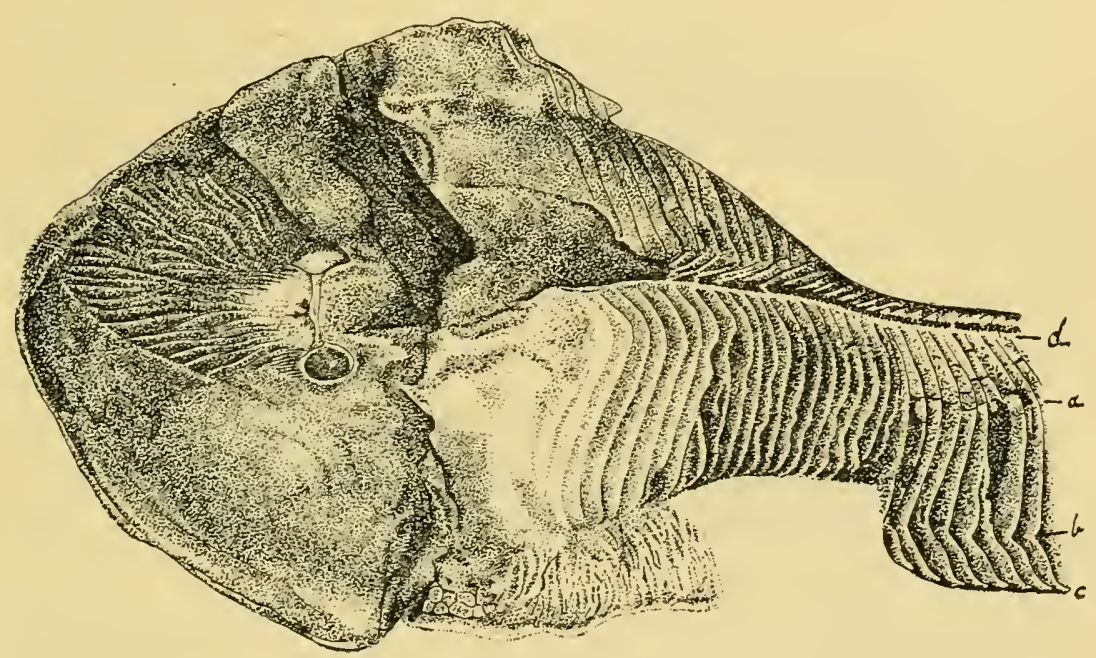

$\mathrm{B}$

Fig. 161.-A, Facsinile of Woodward's Drawing of a Specimen of Cephalaspis Murchisoni, as Seex fron the Side. The Cephalic ShIeld is oN the Right and Caudal to it the Pleural Fringes are well shown; B, Another Specimen of Cephalaspis Murchisoni taken from the SAME block of Stone, showing the Dermoseptal Skeleton and in one place the Pleural Frivges, $b c$.

that the cephalaspids were arthropods, and not vertebrates. I have also carefully examined this specimen, and do not consider that what is seen resembles the joint of an arthropod appendage; the appearance is rather such as would be produced if the line of attachment of Patten's appendages to the body were the place where the pleural body folds became free from the body, and so with any pressure a 
hending or fracture of the calcified plates would take place along this line. There is, undoubtedly, an appearance of finish at the termination of these skeletal fringes, as though they terminated in a definitely shaped spear-like point, just as is seen in the trilobite pleurre. This, again, to my mind, is rather evidence of pleural fringes than of true appendages.

As already argued, I look upon Ammoccetes as the only living fish at all resembling the cephalaspids; it is therefore instructive to compare the arrangement of this spinal dermo-septal skeleton of Cephalaspis with that of the septa between the myomeres in the
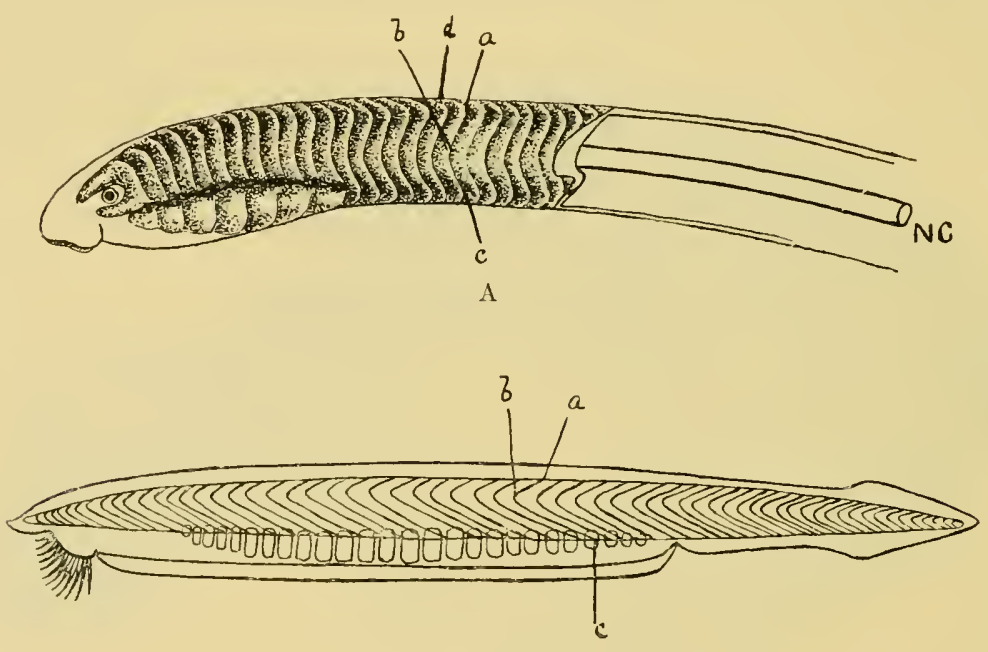

$\mathrm{B}$

Fig. 162.-A, Arrangemext of Septa in Ammocetes (NC., position of notochord); B, Arrangement of Septa in Amphioxus.

trunk-region of Ammocetes and Amphioxus. Such a skeleton in Ammocetes would be represented by a series of plates overlapping each other, arranged as in Fig. 162, A, and in Amplioxus as in Fig. 162, B. I have lettered the corresponding parts of the two structures by similar letters, $a, b, c$. Ammocotes differs in confignration from Amphioxus in that it possesses an extra dorsal $(\alpha, d)$ and an extra ventral bend. Ammoccetes is a much rounder animal than Amphioxus, and both the dorsal and ventral bends are on the extreme ventral and lorsal surfaces-surfaces which can hardly be said to exist in Amphioxus. The part, then, of such an aponeurotic skeleton 
in Ammoceetes which I imagine corresponds to $b, c$ in Amphioxus, and therefore would represent the pleural fold, is the part ventral to the bend at $b$. In both the animals this bend corresponds to the position of the notochord NC.

The skeleton of Cephalaspis compares more directly with that of Ammocetes than that of Amphioxus, for there is the same extra dorsal bend (Fig. 161, $a, d$ ) as in Ammocoetes; the lateral part of the skeleton again gives an angle $a, b, c$; the part from $b$ to $c$ would therefore represent the pleural fold. I picture to myself the sequence of events somewhat as follows:-

First, a protostracan ancestor, which, like Peripatus, possessed appendages on every segment into which celonic diverticula passed, forming a system of coxal glands; such glands, being derived from the segmental organs of the Chrtopoda, discharged originally to the exterior by separate openings on each segment. It is, however, possible, and I think probable, that a fusion of these separate ducts had already taken place in the protostracan stage, so that there was only one external opening for the whole of these metasomatic coxal glands, just as there is only one exterual opening for the corresponding prosomatic coxal glands of Limulus. Then, by the ventral growth of pleural body-folds, such appendages became enclosed and useless, and the coxal glands of the post-branchial segments, with their segmental or pronephric duct, were all that remained as evidence of such appendages. This dwindling of the metasomatic appendages was accompanied by the getting-rid of free appendages generally, in the manner already set forth, with the result that a smooth fish-like body-surface was formed; then the necessity of increasing mobility brought about elongation by the addition of segments between those last formed and the cloacal region. Each of such new-formed segments was appendageless, so that its segmental organ was not a coxal gland, but entirely somatic in position, and formed, therefore, a mesonephric tubule, not a pronephric one. Such glands could no longer excrete to the exterior, owing to the enclosing shell of the pleural folds; but the pronephric duct was there, already formed, and so these nephric tubules opened into that, instead of, as in the case of the branchial slits, forcing their way through the pleural walls when the atrium became closed. 


\section{The Meaning or tile Ductless Glands.}

If it is a right conception that the excretory organs of the protostracan gronp, which gave origin to the vertebrates as well as to the crustaceans and arachnids, were of the nature of coxal glands, then it follows that such coxal glands must have existed originally on every segment, because they themselves were derived from the segmental organs of the aumelids; it is therefore worth while making an attempt to trace the fate of such segmental organs in the vertebrate as well as in the crustacean and arachnid.

Such an attempt is possible, it seems to me, because there exists throughout the animal kingdom striking evidence that excretory organs which no longer excrete to the exterior do not disappear, but still perform excretory functions of a different character. Their cells still take 1 p effete or injurious substances, and instead of excreting to the exterior, excrete into the blood, forming either ductless glauds of special character, or glands of the nature of lymphatic glands.

The problem presented to us is as follows:-

The excretory organs of both arthropods and vertebrates arose from those of amnelids, and were therefore originally present in every segment of the borly. In most arthropods and vertebrates they are present only in certain regions; in the former case, as the coxal glancls of the prosomatic or hearl-region; in the latter, as the nepluric glands of the metasomatic or trunk-region, and, in the case of Amphioxns, of the mesosomatic or branchial region.

In the original arthropod, judging from Peripatus, they were present, as in the annelid, in all the segments of the body, and formed coxal glands. Therefore, in the ancestors of the living Crustacea and Arachnida, coxal glands must have existed in all the segments of the body, and we ought to be able to find the vestiges of them in the mesosomatic or branchial and metasomatic or abdominal regions of the body.

Similarly, in the vertebrates, derived, as has been shown, not from the annelids, but from an arthropod stock, evidence of the previous existence of coxal glands ought to be manifested in the prosomatic or trigeminal region, in the mesosomatic or branchial region, as well as in the metasomatic or post-branchial region.

How does an excretory organ change its character when it ceases 
to excrete to the exterior? What should we look for in our search after the lost coxal glands?

The answer to these questions is most plainly given in the case of the pronephros, especially in Myxine, where Maas has been able to follow out the whole process of the conversion of nephric tubules into a tissue resembling that of a lympli-gland.

He states, in the first place, that the pronephros possesses a capillary network, which extends over the pronephric duct, while the tubules of the mesonephros possess not only this capillary network, equivalent to the capillaries over the convoluted tubules in the higher vertebrates, but also a true glomerulus, in that the nephrie segmental arteriole forms a coil (Knauel), and pushes in the wall of the mesonephric tubule. He describes the pronephros of large adult indivicluals as consisting of-

1. Tubules with funnels which open into the pericardial colom.

2. A large capillary network (the glomus) at the distal end.

3. A peculiar tissue (the 'strittige Gewebe' of the Semon-Spengel controversy), which Spengel considers to be composed of the altered epithelium of pronephric tubules, while Semon looks on it as an amalgamation of glomeruli.

Maas is entirely on the side of Spengel, and shows that this peculiar tissue is actually formed by modified pronephric tubules, which become more and more lymphatic in character.

He says: "The pronephros consists of a number of nephrie tubules, placed separately one behind the other, which were originally segmental in character, each one of which is supplied by a capillary network from a segmental branch of the aorta. The tubules begin with many mouths (dorso-lateral and medial-ventral) in the pericardial cavity; on their other blind end they have lost their original external opening, and there, in the cranial portion of the head-kidney, hefore they have joined together to form a collecting duct, they, together with the vascular network, are transformed into a peculiar adrenal-like tissue. The most posterior of the segmental capillary nets retain their original character, and are concentrated into the separate capillary mass known as the glomus."

Later on he says: "Further, the separate head-kilney is more and more removed in structure from an excretory organ in the ordinary sense. One cannot, however, speak of it as an organ becoming rudimentary; this is proved not only by the progressive transformation 
of its intemal tissue into a tissue of a very definite character, but also by the cilia in its canals, and the steady increase in the number of its funnels. It appears, therefore, to be the conversion of an excretory organ into an organ for the transference of fluid out of the coelom into a special tissue, i.e. into its blood-sinus; in other words, into an organ which must be classed as belonging to the lymph-system."

In exact correspondence with this transformation of a nephric tubule into a ductless gland of the nature of a lymphatic gland, is the formation of the head-kidney in the Teleostea. Thus, Weldon points out that, though the observations of Balfour left it highly probable that the "lymplatic" tissue described by him was really a result of the transformation of part of the embryonic kidney, he did not investigate the details of its development. This was afterwards done by Emery, with the following results: "In those Teleostea which he has studied, Profesșor Emery finds that at an early stage the kidney consists entirely of a single pronephric fumel, opening into the pericardium, and connected with the segmental duct, which already opens to the exterior. Behind this funnel, the segmental duct is surrounded by a blastema, derived from the intermediate cell-mass, which afterwards arranges itself more or less completely into a series of solid cords, attaching themselves to the duct. These develop a lumen, and become normal segmental tubules, but it is, if I may be allowed the expression, a matter of chance how much of the blastema becomes so transformed into kidney tubules, and how much is left as the 'lymphatic' tissue of Balfour, this 'lymphatic' tissue remaining either in the pronephros only, or in both pro- and neso-nephrus."

If we turn now to the invertebrates, we see also how close a connection exists between lymphatic and phagocytic organs and excretory organs. The chief merit for this discovery is due to Kowalewsky, who, taking a hint from Heidenlaain's work on the kidney, in which he showed how easy it was to find out the nature of different parts of the mammalian excretory organ by the injection of different sulbstances, such as a solution of ammoniated carmine, or of indigocarmine, has injected into a large number of different invertebrates various colouring matters, or litmus, or bacilli, and thus shown the existence, not only of known excretory organs, but also of others, lymphatic or lymphoid in nature, not hitherto suspected.

In all cases he finds that a phagocytic action with respect to solid 
bodies is a property of the lencocytes, and that these leucocytes which are found in the ccelomic spaces of the Annelida, etc., are apparently derived from the epithelium of such spaces. Also by the proliferation of such epithelium in places, o.g. the septal glands of the terrestrial Oligochæta, segmental glandular masses of such tissue are formed which take up the colouring matter, or the bacilli. In the limicolous Oligochæta such septal glands are not found, but at the commencement of the nephridial organ, immediately following upon the funnel, a remarkable modification of the nephridial wall takes place to form a large cellular cavernous mass, the so-called filter, which in Enaxes is full of leucocytes; the cells are only definable by their nuclei, and look like and act in the same way as the free leucocytes outside this nephridial appendage. As G. Schneider points out, the whole arrangement is very like that described by Kowalewsky in the leeches Clepsine and Nephelis, where, also immediately succeeding the fumnel of the nephridial organ, a large accessory organ is found, which is part of the nephridium, and is called the nephridial capsule. This is the organ par excellence which takes up the solid carminegrains and bacilli, and apparently, from Kowalewsky's description, contains leucocytes in large numbers. We see, then, that in such invertebrates, just as in the vertebrate, modifications of the true excretory organ may give rise to phagocytic glands of the nature of lymphatic glands. Further, these researches of Kowalewsky suggest in the very strongest manner that whenever by such means new, hitherto unsuspected glands are discovered, such glands must belong to the excretory system, i.c. must be derived from ccelomic epithelium, even when all evidence of any colom has disappeared. Kowalewsky himself was evidently so impressed with the same feeling that he heads one of his papers "The Excretory Organs of the Pantopoda," although the organs in question had been discovered by him by this method, and appeared as ductless glands with no external opening.

To my mind these observations of Kowalewsky are of exceeding interest, for it is immediately clear that if the segmental organs of the annelids, which must have existed on all the segments of the forefathers of the Crustacea and Arachnida (the Protostraca), have left any sign of their existence in living crustaceans and arachnids, then such indication would most likely take the form of lymphatic glands in the places where the excretory organs ought to have been.

Now, as alreadly pointed out in Peripatus, such segmental organs 
were formed by the ventral part of the colom, and dipped originally into each appendage. We know also that each segment of an arachnid embryo possesses a cœlomic cavity in its ventral part which extends into the appendage on each side; this cavity afterwards disappears, and is said to leave no trace in the adult of any excretory coxal gland derived from its walls. If, however, it is found that in the very position where such organ ought to have been formed a segmentally arranged ductless gland is situated, the existence of which is shown by its taking up carmine, etc., then it seems to me that in all probability such gland is the modification of the original coxal gland.

This is what Kowalewsky has done. Thus he states that Metschnikoff had fed Mysis with carmine-grains, and found tubules at the base of the thoracic feet coloured red with earmine. He himself used an allied species, Parapodopsis cornutum, and found here also that the carmine was taken up by tubules situated in the basal segments of the feet. In Nebalia, feeding experiments with alizarin blue and carmine stained the antennal glands, and showed the existence of glands at the base of the eight thoracic feet. These glands resemble the foot-glands of Mysis, Parapodopsis, and Paliemon, and lie in the space through which the blood passes from the thoracic feet, i.c. from the gills, to the heart. In Squilla also, in addition to the shell-glands, speeial glands were discovered on the branchial feet on the path of the blood to the heart. These glands form continuous masses of cells which constitute large eompact glands at the base of the branchial feet. Single cells of the same sort are found along the whole course of the branchial venous canal, right up to the pericardium.

These observations show that the Crustacea possess not only true excretory organs in the shape of coxal glands, i.e. antennary glands, shell-glands, etc., in the eephalic region, but also a series of segmental glands situated at the base of the appendages, especially of the respiratory appendlages: a system, that is to say, of coxal glands which have lost their excretory function, through having lost their external opening, but have not in consequence disappeared, but still remain in situ, and still retain an important excretory function, liaving become lymphatie glands containing leucocytes. Such glands are especially found in the branchial appendages, and are called branchial glands by Cuénot, who describes them for all Decapoda.

Further, it is significant that the same method reveals the 
existence in Pantopoda of a donble set of glands of similar character, one set in the basal segments of the appendage, and the other in the adjacent part of the body.

In scorpions also, Kowalewsky has shown that the remarkable lymphatic organ situated along the whole length of the nerve-cord in the abdominal region takes up carmine grains and bacilli; an organ which in Androctonus does not form one continuous gland, but a number of separate, apparently irregularly grouped, glandular bodies.

In addition to this median lymphatic gland, Kowalewsky has discovered in the scorpion a pair of lateral glands, to which he gives the name of lymphoid glands, which communicate with the thoracic body-cavity (i.e. the pseudocnele), are phagocytic, and, according to him, give origin to lencocytes by the proliferation of their lining cells, thus, as he remarks, reminding us of the nephridial capsules of Clepsine. These glands are so elosely related in position to the coxal glands on each side that he has often thought that the lumen of the gland communicated with that of the coxal gland; he, however, has persuaded liimself that there is no true communication between the two glands. Neither of these organs appears to be segmental, and until we know how they are developed it is not possible to say whether they represent fused segmental organs or not.

The evidence, then, is very strong that in the Crustacea and Arachnida the original segmental excretory organs do not disaplear, but remain as ductless glands, of the nature of lymphatic glands, which supply leucocytes to the system.

Further, the evidence shows that the nephric organs, or parts of the colom in close connection with these organs, may be transformed into ductless glands, which do not necessarily contain free leucocytes as do lymph-glands, but yet are of such great importance as excretory organs that their removal profoundly modifies the condition of the animal. Such a gland is the so-called adrenal or suprarenal body, disease of which is a feature of Addison's disease; a gland which forms and presumably passes into the blood a substance of remarkable power in causing contraction of blood-vessels, a substance which has lately been prepared in crystalline form by Jokichi Takamine, and called by him " adrenalin "; a gland, therefore, of very distinctly peculiar properties, which cannot be regarded as rudimentary, but is of vital importance for the due maintenance of the healthy state.

In the Elasmobranchs two separate glandular organs have been 
called suprarenal; a segmental series of paired organs, each of which possesses a branch from the aorta and a sympathetic ganglion, and an unpaired series in close connection with the kidneys, to which Balfour gave the name of interrenal glands. Of these two sets of glands, Swale Vincent has shown that the extract of the interrenals has no marked physiological effect, in this respect resembling the extract of the cortical part of the mammalian gland, while the extract of the paired segmental organs of the Elasmobranch produces the same remarkable rise of blood-pressure as the extract of the medullary portion of the mammalian gland.

The development also of these two sets of glands is asserted to be different. Balfour considered that the suprarenals were derived from sympathetic ganglion-cells, but left the origin of the interrenals donbtful. Weldon showed that the cortical part of the suprarenals in the lizard was derived from the wall of the glomerulus of a number of mesonephrie tubules. In Pristiurus, he stated that the mesoblastic rudiment described by Balfour as giving origin to the interrenals is derived from a diverticulum of each segmental tubule, close to the narrowing of its funnel-shaped opening into the bodycavity. With respect to the paired suprarenals he was unable to speak positively, but doubted whether they were derived entirely from sympathetic ganglia.

Weldon sums up the results of his observations by saying: "That all vertebrates except Amphioxus have a portion of the kidney modified for some unknown purpose not connected with excretion; that in Cyclostomes the pronephros alone is so modified, in Teleostei the pro- and part of the meso-nephros; while in the Elasmobranchs and the higher vertebrates the mesonephros alone gives rise to this organ, which has also in these forms acquired a secondary connection with certain of the sympathetic ganglia."

Since Weldon's paper, a large amount of literature on the origin of the adrenals has appeared, a summary of which, up to 1891, is given by Hans Tabl in his paper, and a further summary by Aichel in his paper published in 1900 . The result of the investigations up to this latter paper may be summer up by saying that the adrenals, using this term to include all these organs of whatever kind, are in all cases, partly at all events, derived from some part of the walls of either the mesonephric or pronephric excretory organs, but that in addition a separate origin from the sympathetic nervous system must 
be ascribed to the medullary part of the organ and to the separate paired organs in the Elasmobranchs, which are equivalent to the medullary part in other cases.

The evilence, then, of the transformation of the known vertebrate excretory organs-the pronephros and the mesonephros-leads to the conclusion that in our search for the missing coxal glands of the meso-and pro-somatic regions, we must look for either lymphatic glands, or ductless glands of distinct importance to the body. I have already considered the question in the prosomatic region, ancl have given my reasons why the pituitary gland must be looked upon as the descendant of the arthropod coxal gland. In this ease also the resulting ductless gland is still of functional importance, for disease of it is associated with acromegaly. If, as is possible, it is homologous with the Ascidian hypophysial gland, then it is confirmatory evidence that this latter is said by Julin to be an altered nephridial organ.

Finally, I come to the mesosomatic or branchial region; and here, strikingly enough, we find a perfectly segmental glandular organ of mysterious origin-the thymus gland--segmental with the branchire, not necessarily with the myotomes, belonging, therefore, to the appendicular system; and since the branchix represent, according to my theory, the basal part of the appendage, such segmental glands would be in the position of coxal glands. Here, then, in the thymus may be the missing mesosomatic coxal glands.

What, then, is the thymus?

The answer to this question has been given recently by Beard, who strongly confirms Kölliker's original view that the thymus is a gland for the manufacture of leucocytes, and that such leucocytes are directly derived from the epithelial cells of the thymus. Kölliker also further pointed out that the bloor of the embryo is for a certain period destitute of leucocytes. Beard confirms this last statement, and says that up to a certain stage (varying from 10 to $16 \mathrm{~mm}$. in length of the embryo) the embryos of Raja batis have no leucocytes in the blood or elsewhere. $U_{p}$ to this period the thymus-placode is well formed, and the first leucocytes can be seen to be formed in it from its epithelial cells; then such formation takes place with great rapidity, and soon an enormous discharge of lencocytes occurs from the thymus into the tissue-spaces and blood. He therefore concludes that all lymphoid tissues in the borly arise originally from the thymus gland, i.e. from leucocytes discharged from the thymus. 
The segmental branchial glands, known by the name of thymus, are, according to this view, the original lymphatic glands of the vertelsate; and it is to be noted that, in fishes and in Amphibia, lymphatic glands, such as we know them in the higher mammals, do not exist; they are characteristic of the higher stages of vertebrate evolution. In the lower vertebrates, the only glandular masses apart from the cell-lining of the body-cavity itself, which give rise to leucocyte-forming tissue, are these segmental branchial glands, or possibly also the modified post-branchial segmental glands, known as the head-kidney in Teleostea, etc.

The importance ascribed by Beard to the thymus in the formation of leucocytes in the lowest vertebrates would be considerably reduced in value if the branchial region of Ammocotes possessed neither thymus glands nor anything equivalent to them. Such, however, is not the ease. Schaffer has shown that in the young Ammocretes masses of lymphatic glandular tissue are found segmentally arranged in the neighbourhood of each gill-slit-tissue which soon becomes converted into a swarming mass of lencocytes, and shows by its staining, ete., how different it is from a blood-space. The presence of this thymus leucocyte-forming tissue, as described by Schaffer, is confirmed by Beard, and I myself have seen the same thing in my youngest specimen of Ammocoetes.

Further, the very methods by which Kowalewsky has brought to light the segmental lymph-glands of the branchial region of the Crustacea, etc., are the same as those by which Weiss discovered the branchial nephric glands in Amphioxus-excretory organs which Boveri considers to represent the pronephros of the Craniota. In this supposition Boveri is right, in so far that both pronephros and the tubules in Amphioxus belong to the same system of excretory organs; but I entirely agree with van Wijhe that the region in Amphioxus is wrong. The tubules in Amphioxus ought to be represented in the branchial region of the Craniota, not in the postbranchial region; van Wijhe therefore suggests that further researches may homologize them with the thymus gland in the Craniota, not with the pronephrós. This suggestion of ran Wijhe appear's to me a remarkably good one, especially in view of the position of the thymus glands in Ammocotes and the nephric branchial glands in Amphioxus. If, as I have pointed out, the atrial cavity of Amphioxus has been closed in Ammocotes by the apposition of 
the pleural fold with the branchial body-surface, then the remains of the position of the atrial chamber must exist in Ammocoetes as that extraordinary space between the somatic muscles and the branchial basket-work filled with blood-spaces and modified muco-cartilage. It is in this very space, close against the gill-slits, that the thymus glands of Ammoeretes are found, in the very place where the nephric tubules of Amphioxus would be found if its atrial eavity were closed completely. Instead, therefore, of considering with Boveri that the branchial nephric tubules of Amphioxus still exist in the Craniota as the pronephros, and that the atrial chamber has narrowed down to the pronephric duct, I would agree with van Wijhe that the pronephros is post-branchial, and suggest that by the complete closure of the atrial space in the branchial region the branchial nephric tubules have lost all external opening, and consequently, as in all other cases, have changer into lymphatic tissue and become the segmental thymus glands.

As van Wijhe himself remarks, the time is hardly ripe for making any positive statement about the relationship between the thymus gland and branchial excretory organs. There is at present not sufficient consensus of opinion to enahle us to speak with any certainty on the subjeet, yet there is so much suggestiveness in the various statements of different authors as to make it worth while to consider the question briefly.

On the one hand, thymus, tonsils, parathyroids, epithelial cellnests, and parathymus, are all stated to be derivatives of the epithelium lining the gill-slits, and Naurer wonld draw a distinction between the organs derived from the dorsal side of the gill-cleft and those derived from the ventral side-the former being thymus, the latter forming the epithelial cell-nests, i.e. parathyroids. The thymus in Ammocates, according to Schaffer, lies both ventral and clorsal to the gill-eleft; Maurer thinks that only the dorsal part corresponds to the thymus, the ventral part corresponding to the parathyroids, ete. Structurally, the thymus, parathyroids, and the epithelial cell-nests are remarkably similar, so that the evidence appears to point to the conclusion that, in the neighbourhood of the gill-slits, segmentally arranged organs of a lymphatic character are situated, which give origin to the thymus, parathyroids, tonsils, etc. Now, among these organs, i.e. among those ventrally situated, Mamer places the carotid gland, so that, if he is right, the origin of the carotid gland 
might be expected to help in the elucidation of the origin of the thymus.

The origin of the carotid gland has been investigated recently by Kohn, who finds that it is associated with the sympathetic nervous system in the same way as the suprarenals. He desires, in fact, to make a separate category for such nerve-glands, or paraganglia, as he calls them, and considers them all to be derivatives of the sympathetic nervous system, and to have nothing to do with excretory organs. The carotid gland is, according to him, the foremost of the stuprarenal masses in the Elasmobranchs, viz. the so-called axillary heart.

In my opinion, nests of sympathetic ganglion-cells necessarily mean the supply of efferent fibres to some organ, for all such ganglia are efferent, and also, if they are found in the organ, wonld have been brought into it by way of the blood-vessels supplying the organ, so that Aichel's statement of the origin of the suprarenals in the Elasmobranchs seems to me much more probable than a derivation from nerve-cells. If, then, it prove that Aichel is right as to the origin of the suprarenals, and Kohn is right in elassifying the carotid gland with the suprarenals, then Mamrer's statements would bring the parathyroids, thymus, etc., into line with the adrenals, and suggest that they represent the segmented glandular excretory organs of the branchial region, into which, just as in the interrenals of Elasmobranchs, or the cortical part of the adrenals of the higher vertebrates, there has been no invasion of sympathetic ganglion-cells.

Wheeler makes a most suggestive remark in his paper on Petromyzon: he thinks he has obtained evidence of serial homologues of the pronephric tubules in the branchial region of Ammoccetes, but has not been able up to the present to follow them out. If what he thinks to be serial homologues of the pronephric tubules in the branchial region shonld prove to be the origin of the thymus glands of Schaffer, then van Wijhe's suggestion that the thymus represents the cxcretory organs of the branchial region would gain enormously in probability. Until some such further investigation has been undertaken, I can only say that it seems to me most likely that the thymus, etc., represent the lymphatic branchial glands of the Crustacea, and therefore represent the missing coxal glands of the branchial region.

This, however, is not all, for the appendages of the mesosomatic region, as I have shown, do not all bear branchiæ; the foremost or 
opercular appendage carries the thyroid gland. Again, the basal part of the appendage is all that is left; the thyroid gland is in position a coxal gland. It ought, therefore, to represent the coxal gland of this appendage, just as the thymus, tonsils, etc., represent the coxal glands of the rest of the mesosomatic appendages. In the thyroid gland we again see a ductless gland of immense importance to the economy, not a useless organ, but one, like the other modified coxal glands, whose removal involves far-reaching vital consequences. Such a gland, on my theory, was in the arthropod a part of the external genital ducts which opened on the basal joint of the operculum. What, then, is the opinion of morphologists as to the meaning of these external genital ducts?

In a note to Gulland's paper on the coxal glands of Limulus, Lankester states that the conversion of an externally-opening tubular gland (coxal gland) into a ductless gland is the same kind of thing as the history of the development of the suprarenal from a modified portion of mesonephros, as given by Weldon. Further, that in other arthropods with glands of a tubular character opening to the exterior at the base of the appendages, we also have coxal nephridia, such as the shell-glands of the Entomostraca, green glands of Crustacea (antennary coxal gland); and further on he writes: "When once the notion is admitted that ducts opening at the base of limbs in the Arthropoda are possibly and even probably modified nephridia, we immediately conceive the hypothesis that the genital ducts of the Arthropoda are modified nephridia."

So, also, Korschelt and Heider, in their general summing up on the Arthropoda, say: "In Peripatus, where the nephridia appear, as in the Annelida, in all the trunk-segments, a considerable portion of the primitive segments is directly utilized for the formation of the nephridia. In the other groups, the whole question of the rise of the organs known as nephridia is still undecided, but it may be mentioned as very proballe that the salivary and anal glands of l'eripatus, the antennal and shell-glands of the Crustacea, the coxal glands of Limulus and the Arachnida, as well as the efferent genital ducts, are derived from nephridia, and in any case are mesodermal in origin."

The necessary corollary to this exceedingly probable argument is that glandular structures such as the uterine glands of the scorpion already described, which are found in connection with these terminal 
genital ducts, may be classed as modified nephridial glands, and that therefore the thyroid gland of Ammoccetes, which, on the theory of this book, arose in comnection with the opercular genital ducts of the pakeostracan ancestor, represents the coxal glands of this fused pair of appendages. Such a gland, although its function in connection with the genital organs had long disappeared, still, in virtue of its original excretory function, persisted, and even in the higher vertebrates, after it had lost all semblance of its former structure and become a ductless gland of an apparently rudimentary nature, still, by its excretory function, demonstrates its vital importance even to the highest vertebrate.

By this simple explanation we see how these hitherto mysterious ductless glands, pituitary, thymus, tonsils, thyroid, are all accounted for, are all members of a common stock-coxal glands-which originally, as in Peripatus, excreted at the base of the prosomatic and mesosomatic appendages, and are still retained becanse of the importance of their excretory function, althongh ductless owing to the modification of their original appendages.

Finally, there is yet another organ in the vertebrate which follows the same law of the conversion of an excretory organ into a lymphatic organ when its connection with the exterior is obliterated, and that is the vertebrate body-cavity itself. According to the scheme here put forth, the body-cavity of the vertebrate arose by the fusion of a ventral prolongation of the original nephroccele on each side; prolongations which accompanied the formation of the new ventral midgut, and by their fusion formed originally a pair of cavities along the whole length of the abdomen, being separated from each other by the ventral mesentery of the gut. Subsequently, by the ventral fusion of these two cavities, the body-cavity of the adult vertebrate was formed.

This is simply a statement of the known method of formation of the body-cavity in the embryo, and its phylogenetic explanation is that the body-cavity of the vertebrate must be looked upon as a ventral prolongation of the original ancestral body-cavity. Embryology clearly teaches that the original body-cavity or somite was confined to the region of the notochord and central nervous system, and there, just as in Peripatus, was divisible into a dorsal part, giving origin to the inyocole, and a ventral part, forming the nephrocule. From this original nephrocele are formed the pronephric excretory organs, the mesonephric excretory organs, and the body-cavity. 
That the vertebrate body-cavity was originally a nephroccele is grenerally accepted, and its excretory function is shown by the fact that it communicates with the exterior in all the lower vertebrates, either through abdominal pores or by way of nephridial funnels. Bles has shown how largely these two methors of communicating with the exterior mutually exclude each other. In the higher vertebrates both channels become closed, except in the case of the Fallopian tubes, and thus, so to speak, the body-cavity becomes a ductless gland, still, however, with an excretory function, but now, as in all other cases, forming a part of the lymphatic rather than of the true excretory system.

\section{SEMMART.}

The consideration of the formation of the rertebrate cranial region, as set forth in previous chapters, indicates that the ancestor of the vertebrates was not an arachnid purely or a crustacean purely. but possessed partly crustacean and partly arachnid characters. In order to express this conclusion. I have used the term Protostraca. invented by Korschelt and Heider. to indicate a primitive arthropod g'roup. from which both arachnids and crustaceans may be supposed to have arisen, and have therefore stated that the rertebrate did not arise directly from the annelids. but from the Protostraca. Such an origin signifies that the origin of the excretory organs of the vertebrate must not be looked for in the segmental organs of the annelid, but rather in such modified annelid organs as wonld naturally exist in a primitive arthropod gronp. The natnre of such organs may be inferred, owing to the fortunate circumstance that so primitive an arthropod as Peripatns still exists, and we may conchule that the protostracan ancestor possessed in erery segment a pair of appendages and a pair of colomic carities. which extended into the base of these appendages. The rentral portion of each of these colomic cavities separated off from the dorsal and formed a nephrocoele. giving origin to a segmental excretory organ, which. seeing that its end-resicle was in the base of the appendage, and seeing also the nature of the known arachnid and crustaceañ excretory organs, may fitly be termed a coxal gr]and. This, then, is the working hypothesis to explain the difficulties connected with the origin of the pronephros and mesonephros - that the original segmental organs were coxal glands, and therefore indicated the presence of appendages. This hypothesis learls to the following conchsions:-

1. The coxal glands belonging to the post-branchial appendages of the invertebrate ancentor are represented by the pronephric tubules. and existed. over the whole metasomatic region.

2. Such grlands discharged into a common duct-the pronephric duct--which opened into the cloacal region, either in the protostracan stage, when the metasomatic appendages were still in existence, just as the coxal glands of the prosomatic region in Limulus discharge into a common duct, or else the pronephric duct was formed when the appendages were obliterated. 
3. 'The metasomatic appendages distuppeared owing to their enclosme by pleural folds. which, meeting in the mid-ventral line. not only cansed the obliteration of the appendages, and gave a smooth fish-like body-surface to the animal, but also cansed the formation of an atrial cavity.

4. Into these plemal folds the dorsal longitudinal muscles of the body extended, and ultimately reached to the rentral surface, thus forming the somatic muscles of the vertebrate horly.

5. When the plemial folds had met in the mid-rentral line the animal had became a rertebrate, and was dependent for its locomotion on the movements of these somatic muscles, and not on the movements of appendages. Consequently, elongation of the trunk-region took place, for the purpose of increasing mobility. by the formation of new metameres.

6. Each of such metameres possessed its own segmental excretory organ, formed in the same way as the previons pronephric organs, but, as there were no appendages in these new-former segments, the excretory organs took on the characters of a mesonephros, not a pronephros, and opened into the pronephric dnet, because the direct way to the exterior was blocked by the enveloping pleural folds.

7. The group of annelids from which the protostracan ancestor of the vertebrates arose was the highest annelidin group, viz. the Polychata. as shown hy the nature of the exeretory organs in Amphioxus.

8. The coxal glands of the protostracan ancestor existed on all the segments, and were, therefore, divisible into three groups, prosomatic, mesosomatic, and metasomatic: these three groups of coxal glands still exist in the rertebrate as ductless glands.

9. The prosomatic coxal glands form the pituitary body.

11. The mesosonatic coxal grlands form the thymis, thyroid. parathyroids. tonsils, etc.

11. The metasomatic coxal glands form the alrenals.

12. The procoelom of the vertebrate is the procolom of the protostracan ancestor, which splits into a dorsal part. the myocole, and a ventral part, the nephrocole. This latter part not only forms the pronephros and mesonephros: but also by a rentral extension gives origin to the walls of the rertebrate borlycavity or metacoele.

13. This rentral extension of the original nephrocole at first excreted to the exterior, through abdominal pores, or through peritoneal fummels. When such paths to the exterior became closed, it also became a dnctless grland, belonging to the lymplatic system. 


\section{CHAPTEI XIII}

\section{THE NOTOCHORD AND ALIMENTARY CANAL}

Relationship between notochord and gut.-Position of misegmented tube of notochord.-Origin of notochord from a median groove.-Its function as an accessory digestive tube.--Formation of notochordal tissue in invertebrates from closed portions of the digestive tube--Digestive power of the skin of Ammocotes. - Formation of new gut in Ammocotes at transformation.-Innervation of the rertebrate gut.-The three outflows of efferent nerves belonging to the organic system.-The original close contiguity of the respiratory chamber to the cloaca.-The elongation of the gut.Conclusion.

Is the previous chapters all the important organs of the arthropod have been found in the vertebrate in their appropriate place, of similar structure, and innervated from corresponding parts of the central nervous system. Such comparison is possible only as long as the ventral and dorsal surfaces of the vertebrate correspond with the respective surfaces of the arthropod, and no reversal is assumed. This method of comparative anatomy is the surest and most certain guide to the relationship between two animals, and when the facts obtained by the anatomical method are so strikingly confirmatory of the palæontological evilence, the combined evidence becomes so strong as to amount almost to a certainty that vertebrates did arise from arthropods in the manner mapped out in previous chapters, and not from a hypothetical group of animals, such as is postulated in the theory of their origin from forms like Balanoglossus.

The latter theory derives the alimentary canal of the vertebrate from that of the invertebrate, and finds in the latter the commencement of the notochord. In the comparison which I have made the alimentary canal of the invertebrate ancestor has become the tube of the central nervous system of the vertebrate, and there is no sign of a notochord whatever. All the organs of the arthropod have aheady been allocated; where the notochord is situated in the 
vertebrate there is nothing but a gap in the invertebrate, but the position of that gap can be settled with great accuracy from the previous comparison of organs in the two groups. So, also, the alimentary canal of the vertebrate is from the very nature of the case a new organ, yet, as has been shown in Chapter V., the comparison of the respiratory organs in the two groups gives a strong suggestion of the manner in which such a canal was formed.

\section{The Origin of the Notochord.}

The time has now come to endeavour to frame a plausible theory of the method of formation of the notochord and the new alimentary canal, and thus to complete the diagram on p.413. The comparative method is no longer available, for these structures are both unrepresented as such in the arthropod; any suggested explanation, therefore, must be more tentative, and cannot give the same feeling of certainty as is the case with all the organs already considered. Our only chance of finding out the past history of the notochord lies in the embryological method, in the hope that, according to the "law of recapitulation,' the ancestral history may be repeated in the ontogeny with sufficient clearness to enable some conclusion to be drawn.

At the outset, one point comes out clearly-the close relationship between the notochord and the vertebrate gut; they are both derived from the same layer, both parts of the same structure. On this point all embryologists are agreed; it is expressed in such statements as, "the notochord, as well as the alimentary canal, is formed from hypoblast"; "the notochord arises as a thickening in the dorsal wall of the alimentary canal." The two structures are so closely connected together that they must be considered together. If we can conjecture the origin of the one, we may be sure that we have the clue to the origin of the other. The two together form the one new organ which distinguishes the vertebrate from the arthropod, the only thing left which requires explanation for the completion of this strange history.

What, then, is the notochord? What are its characteristics? In the highest vertebrates it is conspicuous only in the embryo; with the development of the axial skeleton it is more and more squeezed out of existence, until in the adnlt it is no longer visible. By the 'law of recapitulation' this developmental history implies that, as we descend the vertebrate phylum, the notochord ought to be more and 
more conspicuous, more and more permanent during the life of the animal. Such is, indeed, found to be the case, until at last, in the lowest vertebrates, such as the lamprey, and in forms like Amphioxus, the notochord persists throughout the life of the animal as a large important axial supporting rod.

This rod has a number of striking characteristics which distinguish it from all other structures, and are the only means of guessing its proballe origin. Its position in the body is always the same in all vertebrates and is very significant, for it lies just ventrally to the central nervous system, along nearly the whole length of the animal, not quite the whole length, for it invariably terminates close to the place where the infundibulum comes to the surface of the brain; it is, in fact, always confined to the infra-infundibular and spinal cord part of the central nervous system. Interpreting this into the language of the arthropod, it means that a rod was formed just ventrally to the nervous system, which extended the whole length of the infracesophageal and ventral chain of ganglia, and terminated at the orifice of the mouth. Moreover, this rod was unsegrmented, for the notochord is devoid of segmentation.

At the anterior end the rod tapers to a point, as in Fig. 166. In its middle part it is very large and conspicuous, cylindrical in shape; its interior is filled with a peculiar vacuolated tissue, different to any other known vertebrate tissue, which has therefore received the name of notochordal tissue. Outside this is a thick sheath formed of many layers, of which the external one gives the staining reactions of elastin, and is called the external elastic layer. Between this sheath and the notochordal tissue a thin layer of lining cells, of normal appearance, is conspicuous in Ammoceetes. These cells secrete the layers of the sheath, and have originally, by proliferation, given rise to the notochordal tissue. In the notochord of Ammoccetes there is no sign of either nerves, blood-vessels, or muscles.

The centre of the notochord presents the appearance of a slight slit, as though it had originated from a tube, and that is the opinion now generally held, for its mode of formation in the embryo is as that of a tube formed from an open groove, as will be explained immediately.

We may, then, conceive of the notochord as originally a tube lying in the mid-line just ventraily to the central nervous system, and extending from the original mouth to the end of the body. Translate this into the language of the arthropod and it denotes a tube on the 
mid-ventral surface of the body, which extended from mouth to anus. Such a tube might be formed from the mid-rentral surface as follows :-

In Fig. 163, A, the lining of the ventral surface between two appendages is represented flat, in B is shown how the formation of a solid rod may arise from the bulging of that ventral surface, and in $C^{\prime}$ how a groove on that surface may lead to the formation of a tube between the two appendages. The difference between a notochordal rod formed as in B from that in C would be shown in the sheath, for in B the sheath would be formed from the cuticle of the lining cells, and in $\mathrm{C}$ from the basement membrane. The structure of the sheath is in accordanee with the embryological evidence that the notocliord is formed as a tube from a groove, as in $\mathrm{C}$, and not as a solid rod as in B, for it possesses a well-marked elastin layer, and elastin has never yet been found as a constituent of any euticular secretion, but invariably in connection with basement-membranes.

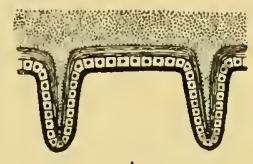

A

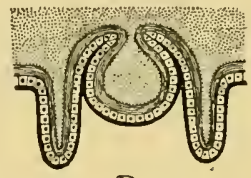

B

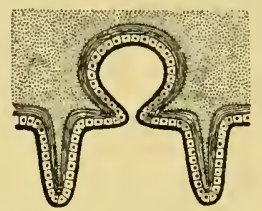

C

Fig. 163.-Diagram of two possible nethods of the Formation of a Notochord.

The position, then, of the notochord and its method of formation suggests that the mid-ventral surface of the arthropod ancestor of the vertebrate formed a deep groove between the bases of all the prosomatic, mesosomatic, and metasomatic appendages, which was subsequently converted into a tube extending along the whole of the body between mouth and anus, and finally, by the proliferation of its lining cells and their conversion into notochordal tissue, became the notochordal rod of the vertebrate.

As already frequently stated, Apus and Branchipus are the two living arthropods which most nearly resemble the extinct trilobites. The beatiful specimens of Triarthrus (Fig. 165) found by Beecher give an idea of the under surface of the trilobite such as has never been obtained before, and demonstrate how closely the condition of things found in Apus (Fig. 164) was similar to that occurring in the trilobites. In both cases the mid-ventral surface of the animal formed a deep groove which extended the whole length of the 
animal; on each sicle of this groove in Apus are closely set the gnatho-bases of the appendages, in such a manner that the groove can he easily converted into a canal by the movements of these bases -a canal which, owing to the great number of the appendages and their closeness to each other, can be completely and efficiently closed.

All those who have seen Apus in the living state assert that this canal so formed is actually used by the animal for feeding purposes. By the movements of the gnatho-bases food is passed up from the

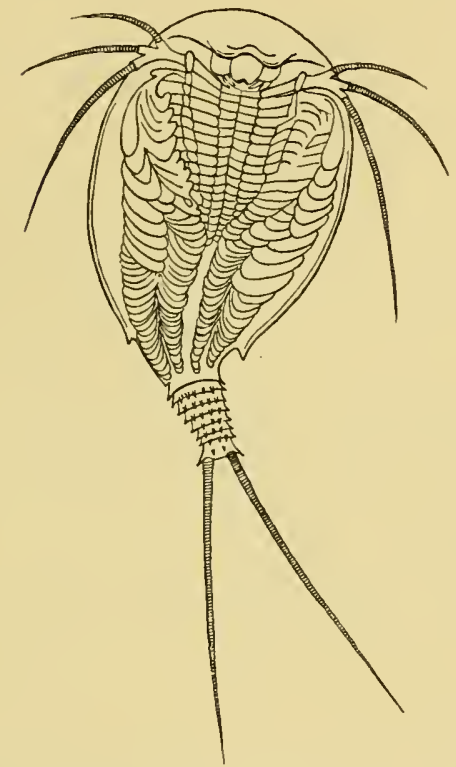

Fig, 164. - Under-Surface of Apus. (After Brona.)

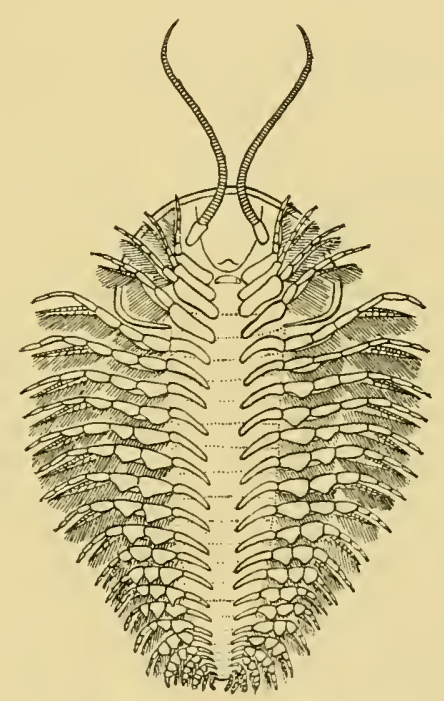

Fig, 165.-Under-SURFace OF a Trilobite (Triarthrus). (From BEECHER.)

hind end of the animal along the whole length of this ventral canal to the mouth, where it is taken in and swallowed. In this way Apus has been seen to swallow its own eggs.

In the trilobites there is a similar deep channel formed by the mid-ventral surface, similar gnatho-bases, and closely set appendages, and the membrane of this ventral groove was extremely thin.

Here, then, in the very group of animals which were the progenitors of the presumed palrostracan ancestor of the vertebrate-a group which is characterized by its extensive prevalence and its 
enormous variety of form during the great trilobite era-the formation of a mid-ventral canal out of this deep ventral groove is seen to be not only easy to imagine, but most probable, provided that a necessity arose for such a conversion.

For what purpose might such a tube have been formed? I would suggest that it might have acted as an accessory food-channel, which was of sufficient value at the time to give some advantage in the struggle for existence to those members of the group who were thus able to supplement their intake of food, but at the same time was so inefficient that it was quickly superseded by the new alimentary canal, and thus losing its temporary function, became solid, and was utilized to form an axial supporting rod.

There is a very considerable amount of evidence in favour of the view that the notochord was originally a digestive tube; in fact, as far as I know, this conclusion is universally accepted. The evidence is based essentially upon its development and upon its structure. It is formed in the vertebrate from the same layer as the alimentary canal, i.e. the lyypoblast, and in Amphioxus it commences as a groove in the clorsal wall of the future alimentary canal; this groove then closes to form the tube of the notochord, and separates from the alimentary canal. Embryologically, then, the notochord is looked upon as a tube formed directly from the alimentary canal.

As regards its structure, its tissue is, as already stated, something sui generis. Notochordal tissue has no resemblance to bone or cartilage, or any of the usual supporting tissues. Such a tissue is not, however, entirely confined to the notochord of the vertebrates, but tissue closely resembling it has been found not only in Amphioxus and the Tunicata, but in certain other invertebrates, in the Enteropneusta (Balanoglossus, etc.), in Cephalodiscus, and in Actinotrocha. In all these latter cases, such a tissue is invariably found in disused portions of the alimentary canal; a diverticulum of the alimentary canal becomes closed, vacuolation of its lining cells takes place, and a tissue resembling notochordal tissue is formed.

Owing to the notochord being invariably so striking and mysterious a feature of the lowest vertebrates, the ter'm vertebrate, which is inappropriate in the members of the group which do not yet possess vertebre, has been largely superseded by the term chordate, with the result of attributing an undue preponderance to this tissue in any system of classification. Hence, wherever any animal has been found 
with a tissue resembling that of the notochord, enthusiasts have immediately jumped to the conclusion that a relationship must exist between it and the chordate animals; and, accordingly, they have classified such animals as follows: Amphioxus belongs to the group Cephalorhorla because the notochord projects beyond the central nervous system; the Tunicata are called Urochorda because it is confined to the tail; the Enteropneusta, Hemichorra, because this tissue is confined to a small diverticulum of the gut, and, finally, Diplochorda has been suggested for Actinotrocha and Phoronis because two separate portions of the gut are transformed in this way.

This exaggerated importance given to any tissue resembling in structure that of the notochord is believed in by many of those who profess to be our teachers on this subject, the very men who can deliberately shut their eyes to the plain reading of the story of the pineal eyes, and say, "In our opinion this pineal organ was not an eye at all."

The only legitimate inference to be drawn from the similarity of structure between the notochord and these degenerated gut-diverticula, is that the structure of the notochord may have arisen in the same way, and that therefore the notochord may once have functioned as a gut. With cessation of its function its cells became vacuolated, as in these other cases, and its lumen became filled with notochorkal tissue. This evidence strongly confirms the suggestion that the notochord was once a digestive tube, but by no means signifies that such tissue, wherever found, indicates the presence of a notochord.

In order to resemble a notochord, this tissue must possess not only a definite structure but a definite position, and this position is a remarkably striking and suggestive one. The notochordal tube is unsegmented, although the vertebrate is markedly segmented. But in all segmented animals the only unsegmented tube which extends the whole length of the body, from mouth to anus, is invariably the gut. In the vertebrate there are three such tubes: (1) the gut itself, (2) the central canal of the nervous system, and (:3) the notochordal tube.

The first is the present gut, the second the gut of the invertebrate ancestor, and the third the tube in question.

These three unsegmented tubes, extending along the whole length 
of the segmented animal, constitute the great peculiarity of the vertebrate group; it is not the unsegmented notochord alone which requires explanation, but the presence of three such tubes in the same animal. Any one of them might be the unsegmented gut of the segmented animal. The most rentral tube is the actual gut of the present vertebrate; the most dorsal-the neural canal-was, according to my view, the original gut of the invertebrate ancestor; the middle one-the notochordal tube-was, in all probability, also once a gut, formed at the time when the exigencies of the situation marle it difficult for food to pass along the original gut.

Yet another circumstance in favour of this suggestion is the very

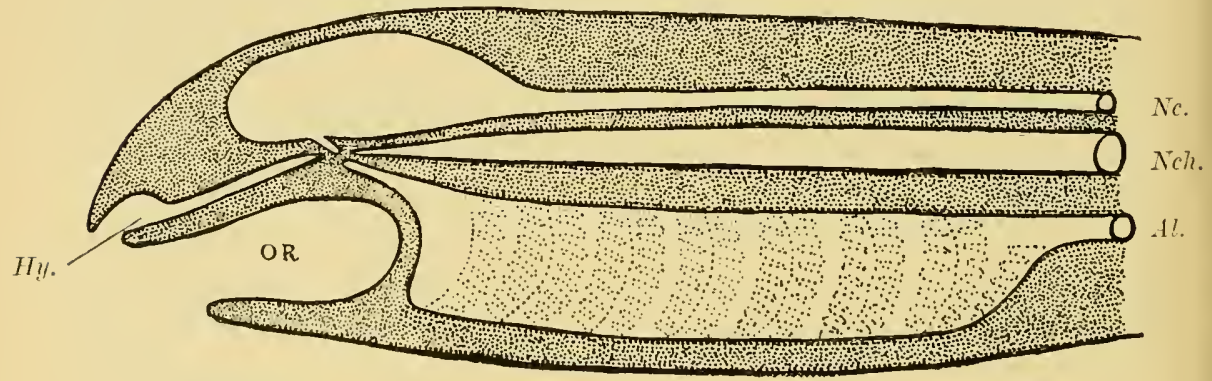

Fic, 166,-Diagram to show the MLeeting of the Four Tubes in sech a Vertebrate as the Lampres.

Ne., neural canal with its infundibular termination ; Nch., notochord ; $A l$., alimentary canal with its anterior diverticulum ; Hy., hypophysial or nasal tube; Or., oral chamber closed by septum.

striking position of the anterior termination of the notochord. It terminates at the point of convergence of three structures:-

(1) The tube of the hypophysis or nasal tube.

(2) The infundibulum or old month-termination.

(3) The notochordal tube.

To these may be added, according to Kupffer, in the embryonic stage, the anterior diverticulum of the gut (Fig. 166).

This is a very signifieant point. Here originally, in the invertebrate stage, the olfactory passage opened into the old mouth and asophagus. Here, finally, in the completed vertebrate the same olfactory passage opens in to the new pharynx. In the stage between the two it may well have opened into an intermediate gut, the notochordal tube, its separation from which would leave the end of the 
notochord blind, just as it had alrearly left the end of the infundibulum blind.

The whole evidence points to the derivation of the notoehord from a ventral groove on the surface of the animal, which closed to form a tube capable of acting as an accessory gut at the critical period before the new gut was fully formed. The essentials of a gut tube are absorption and digestion of food; is it likely that a tube formed as I have suggested would be efficient for such purposes?

As far as absorption is concerned, no difficulty would arise. The gut of the arthropod is lined with a thin layer of chitin, which is traversed, like all other chitinous surfaces, by fine canaliculi. Through these canaliculi, absorption of fluid material takes place, from the gut to the body. Similar canaliculi occur in the chitin covering the animal externally, so that, if such external surface formed a tube, and food in the right condition for absorption passed along it, absorption could easily take place through the chitinous surface. The evidence of Apus proves that food does pass along such a tube in the open condition, and in the trilobites the chitinous surface lining a similar groove was apparently very thin, a condition still more favourable to such an absorption process.

At first sight the second essential of a gut-tube-the power of digestion-appears to present an insuperable difficulty to this method of forming an accessory gut-tube, for it necessitates the formation of a secretion capable of digesting proteid material by the external cells of the body, whereas until recently it was supposed that such a function was confined to cells belonging to the so-called hypoblastic layer. Experiments were made now years ago of turning a Hydra inside out so that its interual layer should become external, and vice versî, and they were said to have been successful. Such an animal could go on living and absorbing and digesting food, although its epiblastic surface was now its digestive interual surface. More recent observations have shown that these experiments were fallacious. At night-time, when the observer was not looking, the hydra reinverted itself, so that again its original digestive surface was inside and it lived and prospered as before.

Another piece of evidence of somerhat similar kind, which has not as yet been diseredited, is seen in the Tunicata. In many of these, new individuals are formed from the parent by a process of budding, and it has been proved that frequently the gut of the new 
individnal thus budded off arises not from the gut or hypoblastic layer of the parent, but from the surface or epiblastic layer. Such gut so formed possesses as efficient digestive powers as the gut of the parent.

The most remarkable evidence of all has been afforled by Miss Alcock's experiments. She examined the different tissues of Ammocetes for the express purpose of finding out their power of digesting fibrin, with the result that the most active cells were those of the liver. Next in activity came the extract of the lining cells of the respiratory chamber and of the skin. The intestine itself when freed from the liver-secretion had very little digestive power; extracts of muscle, nervous system, and thyroid gland had no power whatever, but the extract of the skin-cells possessed in powerful digesting action.

Furthermore, it is not necessary to make an extract of the skin in order to obtain this digestive fluid, for under the influence of chloroform the skin of Ammocotes secretes copiously, and this fluid thus secreted was found to possess strong digestive powers. So, also, Miss Alcock has demonstrated the power of digesting fibrin in a similar secretion of the epithelial cells lining the carapace of the crayfish. In both cases a very plausible reason for the presence of a digestive ferment in a skin-secretion is found in the necessity of preventing the growth of parasites, fungoid, or otherwise, especially in those parts where the animal cannot keep itself clean by 'preening.' 'Thus in a crayfish, in which the osophageal commissures had been cut, fungus was found to grow on the ventral side, but not on the dorsal carapace. The animal was accustomed to keep its ventral surface clean by preening; owing to the paralysis it could not do so, and consequently the fungus grew there. In the lamprey I found that wherever there was a removal of the surface-epithelium, from whatever canse, that spot was immediately covered with a fungoid growth, although in the intact lamprey the skin was invariably smooth and clean.

I imagine, then, that this digestive potrer of the skin arose as a protective mechanism against parasitic attacks; it is self-evident how a tube formed of such material must ab initio act as a digestive tube.

In yet another respect this skin secretion of Ammocoetes is most instrnctive. The surface of Ammocoetes is absolutely smooth, no scales 
of any kind exist; this smoothness is due to the presence of a very well-defined cuticular layer secreted by the underlying epithelial cells. This cuticle is very much thicker than is usually found in vertebrates, and, strangely enough, has been thought to contain chitin. Whether it really contains chitin or not I am unable to say, but it certainly resembles a chitinous layer in one respect; it is perforated by innumerable very fine tubes or canaliculi, along which, by appropriate staining, it is easy to see the secretion of the underlying cell pass to the exterior (Fig. 140). This marked digestive power of the skin of Ammococtes, together with the easy passage of the secretion through the thin cuticular layer, renders it almost certain that a tube formed from the deep ventral groove of the trilobite would, from the very first, act as a digestive as well as an absorbent tube; in other words, the notochord as soon as formed was able to act as an accessory digestive tube.

This suggested origin of the notochord from a groove along the millventral surface of the body not only indicates a starting-point from a markedly segmented portion of the body, but also points to its formation at a stage previous to the formation of the operculum by the fusion of the two foremost mesosomatic appendages-indicates therefore its formation at a stage more nearly allied to the trilobite than to the sea-scorpion. The chance of ever finding any direct evidence of such a chordate trilobite stage appears to me exceedingly improbable, and I greatly fear that this conception of the mode of formation of the notochord can never be put to direct proof, but must always remain guesswork.

On the other haud, evidence of a kind in favour of its origin from a segmented part of the body does exist, and that evilence has this special value, that it is found only in that most primitive animal, Amphioxus.

This evilence is as follows:-

At fairly regular intervals, the sheath of the notochord is interrupted on each sile of the mid-dorsal line by a series of holes, which penetrate the whole thickness of the sheath. This dorsal part is pressed closely against the spinal cord, and through these holes fibres appear to pass from the spinal cord to the interior of the notochord. So greatly do these fibres present the appearance of rentral roots to the notochord, that Miss Platt looks upon them as paired motor roots to the notochord, or at all events as once having been such motor 
roots. Lwoff and Rolph both describe a direct communication between the spinal cord and the notochord by means of fibres passing throngh these holes, without however looking upon this connection as a nervous one. Joseph alone asserts that no absolute connection exists, for the internal elastic layer of the notochord, according to him, is not interrupterl at these holes, and forms, therefore, a barrier between the fibres from the spinal cord and those from the interior of the notochord. Still, whatever is the ultimate verdict as to these fibres, the suggestive fact remains of the spaces in the notochordal sheath and of the corresponding projecting root-like fibres from the spinal cord. The whole appearance gives the impression of some former connection, or rather series of connections, between the spinal cort and the notochord, such as would have occurred if nerves had once passel into the notochord. On the other hand, such nerves were not arranged segmentally with the myotomes, for, according to Joseph, in the middle of the animal ten to twelve such holes occur in one body-segment. In Apus the appenclages are more numerous than the body-segments, so that it is not necessary for a segmental arrangement to coineide with that of the body-segments.

\section{The Origin of the Alinentary Casai.}

In close connection with the notochord is the alimentary canal. Any explanation of the one must be of assistance in explaining the other.

According to the prevalent embryological teaching, the body is formed of three layers, epiblast, hypoblast, and mesoblast, and the gastrea theory of the origin of all Metazoa implies of necessity that the formation of every individual commences with the formation of the gut. For this reason the alimentary canal must in every case be regarded as the earliest formed organ, however late in the development it may attain its finished appearance. Hence the notochord is spoken of as developed from the mid-dorsal wall of the alimentary canal. It is possible to look at the question the other way round, and suppose that the organ whose development is finished first is older than the one still in process of making. In this case it would be more right to say a ventral extension of the tissue, which gives rise to the notochord, takes place and forms the alinentary canal. It is, to my mind, perfectly possible, and indeed probable, that 
the formation of the vertebrate alimentary canal was a repetition of the same process which had already led to the formation of the notochordal tube. The formation of the anterior part of the alimentary canal in Ammocotes at the time of transformation strongly suggests the marked similarity of the two processes.

Of all the startling surprises which occur at transformation, this formation of a new anterior gut is the most startling. From the oral chamber of Petromyzon two tubes start: the one leads into the gill-chambers, is known as the bronchus, and is entirely concerned with respiration; the other leads without a break from the month to the anus, has no connection with respiration, and is the alimentary canal of the animal. Any one looking at Petromyzon would say that its alimentary canal was absolutely non-respiratory in character. Before transformation, this kind of alimentary canal commences at the end of the respiratory chamber; from here to the anus it is of the same character as in Petromyzon, but in Ammocates the nonrespiratory anterior part simply does not exist: the whole anterior chamber is both respiratory and affords passage to food. This part of the alimentary canal of the adult is formed anew. We see, then, here the formation of a part of the alimentary canal taking place, not in an embryo full of yolk, but in a free-living, independent, grown-up larval form in which all yolk has long since disappeared : a condition absolutely unique in the vertebrate kingdom, but one which more than any other may be expected to give a clue to the method of formation of a vertebrate gut.

The formation of this new gut can be easily followed at transformation, and was originally described by Schneider. His statement has been confirmed by Nestler, and its absolute truth has been demonstrated to me again and again by Miss Alcock, in her specimens illustrative of the transformation process. First, in the mid-dorsal line of the respiratory chamber a distinct groove is formed, the edges of which come together and form a solid rod. 'This solid rod blocks the opening of the respiratory chamber into the mid-gut, so that during this period of the transformation no food can pass out of the pharyngeal chamber. A lumen then begins to appear in this solid rod at the posterior end, which steadily advances monthwards until it opens into the oral chamber and thus forms an open tube connecting the mouth with the gut.

Here, then, is the foundation of a new gut on very similar lines 
to that of the notochord, by the conversion of a groove into a tube. Still more suggestive is it to find that the tube so formed has no appearance whatever of segmentation; it is as unsegmented as the rest of the gut, although, as is seen in Fig. 62, the dorsal wall of the respiratory chamber from which it arose is as markedly segmented as any part of the animal. Here under our very eyes, in the course of a few days or weeks, an object-lesson in the process of the manufacture of an alimentary canal is carried out and completed, and the teaching of that lesson is that a gut-tube may be formed in the same way as the notochordal tube, by the conversion of a grooved surface into a canal, and that gnt-tube so formed, like the notochord, loses all sign of segmentation, even althongh the original grooved surface was markedly segmented.

The suggestion then is, that the new gut may have been formed by a repetition of the same process which had already given origin to the notochord.

Such a method of formation is not, in my opinion, opposed to the evidence given by embryology, but in accorlance with it; the discussion of this point will come best in the next chapter, which treats of the embryological evidence as a whole, and will therefore be left till then.

\section{The Evidence given by the Indergation of the Verteblate Almentary Canal.}

Throughout this investigation the one fixed landmark to which all other comparisons must be referred, is the central nervous system, and the innervation of every organ has given the clue to the meaning of that organ. So also it must be with the new alimentary canal; by its innervation we ought to obtain some insight into the manner of its origination. In any organ the nerves which are specially of value in determining its inmervation, are of necessity the efferent or motor nerves, for the limits of their distribution in the organ are much more easily determined than those of the afferent or sensory nerves. The question therefore of primary importance in encleavouring to determine the nature of the origin of the alimentary canal from its innervation is the determination of the efferent supply to the musculature of its walls.

Already in previous chapters a commencement has been made in 
this direction; thus the musculature of the oral chamber has been derived directly from the musculature of the prosomatic appendarges; the muscles which move the eyes from the prosomatic and mesosomatic dorso-rentral somatic muscles; the longitudinal body-muscles from the dorsal longitudinal somatic muscles of the arthropod; the muscles of respiration from the dorso-rentral muscles of the mesosomatic appendages.

In all these cases we have been dealing with striated musculature and consequently with only the motor nerres of the muscle; but the gut posterior to the pharyngeal or respiratory chamber contains unstriped instead of striped muscle, and is innervated by two sets of nerves, those which cause contraction and are motor, and those which cause relaxation and are inhilitory. It is by no means certain that these two sets of nerves possess equal value from a morphological point of view. The meaning of an inhibitory nerve is at present difficult to understand, and in this instance, is rendered still more doubtful owing to the presence of Auerbach's plexus along the whole length of the intestine - an elaborate system of nerve-cells and nervefibres situated between the layers of longitudinal and circnlar muscles surrounding the gut-walls, which has been shown by the recent experiments of Magnus, to constitute a special enteric nervous system.

One of the strangest facts kuown about the system of inhibitory nerves is their marked tendency to leave the central nervous system at a different level to the corresponding motor nerves, as is well known in the case of the heart, where the inhibitory nerve-the vagus-arises from the medulla oblongata, while the motor nerve-the augmentor or accelerator-leaves the spinal cord in the upper thoracic region. It is very difficult to obtain any idea of the origin of such a peculiarity; I know of only one suggestive fact, which concerns the innervation of the muscles which open and close the chela of the crayfish, lobster, etc. These muscles are antagonistic to each other, and both possess inlibitory as well as motor nerves. The central nervous system arrangements are of such a character that the contraction of the one muscle is accompanied by the inhibition of its opposer, and the nerves which inhibit the contraction of the one, leave the central nervous system with the nerves which cause the other to contract. Thus the inhibitory and motor nerves of either the abductor (opener) or adductor (closer) muscles of the crayfish claw do not leave the central nervous system together, but in separate nerves. 
If now for some cause the one set of muscles either disappeared, or were so altered as no longer to present any appearance of antagonism, then there would be left a single set of muscles, the inhibitory and motor nerves of which would leave the central nervous system at different levels, and the older such systems might be, the greater would be the modification in the shape and arrangements of parts in the animal, so that the two sets of fibres might ultimately arise from very different levels.

As mentioned in the introductory chapter, the whole of this investigation into the origin of vertebrates arose from my work on the system of efferent nerves which innervate the vascular and visceral systems. One of the main points of that investigation was the proof that such nerves did not leave the central nervous system uniformly along the whole length of it, but in three great ontflows, cranial, thoracico-lumbar, and sacral; there being two marked gaps separating the three outflows, caused by the interpolation of the plexuses for the imnervation of the anterior and posterior limbs respectively. All these nerves are characterized by the presence of ganglion-cells in their course to the periphery, they are, therefore, clistinguished from ordinary motor nerves to striated muscle in that their impulses pass through a ganglion-cell before they reach the muscle.

The ganglia of the large middle thoracico-lumbar outflow constitute the ganglia of the sympathetic system.

The functions of the nerves constituting these three outflows are very different, as I pointed out in my original papers. Since then a large amount of further information has been obtained by various observers, especially Langley and Anderson, which enable the following statements to be made:-

All the nerves which cause contraction of the unstriped muscles of the skin, whether pilomotor or not, all the nerves which cause secretion of sweat glands wherever situated, all the nerves which cause contraction or augmentation of the action of muscles belonging to the vascular system, all the nerves which are motor to the muscles belonging to all organs derived from the Wolffian and Mïllerian ducts, c.g. the uterus, ureters, urethra, arise from the thoracicolumbar outflow, never from the cranial or sacral outflows. It is essentially an efferent skin-system.

On the other hand, the latter two sets of nerves are concerned 
with the supply of motor nerves to the alimentary canal; they form essentially an efferent gut-system in contradistinction to the sympathetic or skin-system.

A marked distinction exists between these cranial and sacral nerves. The vagus never supplies the large intestine, the sacral nerves never supply the small intestine. Associated with the large intestine is the bladder, the whole system arising from the original cloacal region; the vagus never supplies the bladder, its motor nerves belong to the sacral outflow. The motor nerves to the ureters, to the urethra, and to the trigonal portion of the bladder between the ureters and the urethra, do not arise from the sacral outflow, but from the thoracico-lumbar. These muscles belong really to the muscles in connection with the Müllerian and Wolffian ducts and skin, not to the cloacal region.

The motor innervation then of the alimentary canal reveals this striking and suggestive state of affairs. The motor innervation of the whole of the small intestine arises from the cranial region, and is immediately followed by an innervation from the sacral region for the whole of the muscles of the cloaca. It thus indicates a hearlregion and a tail-region in close contiguity, the whole of the spinal cord region between these two extremes being apparently unrepresented. Not, however, quite unrepresented, for Elliott has shown recently that the ileo-colic valve at the junction of the small and large intestine is in reality an ileo-colic sphincter muscle, and that this muscle receives its motor nerves neither from the vagus nor from the sacral nerves, but from the thoracico-lumbar outflow or sympathetic system. This may mean one of two things, either that a band of fibres belonging to the skin-system has been adder to the gut-muscnlature, for the purpose of forming a sphincter at this spot, or that the region between the vagus territory and the cloaca is represented by this small band of muscle. The second explanation seems to me the more probable of the two. Between the mesosomatic region represented by the vagus, and the cloacal region, there existed a small metasomatic region, represented by the pronephros, with its segmental duct, as already liscussed in Chapter XII. That part of the new alimentary canal which belonged to this region is the short piece indicated by the ileo-colic sphincter, and innervated, therefore, from the same region as the organs derived from the segmental duct. Such innervation seems to me to suggest that originally the 
vertebrate consisted, as far as its gut was concerned, of a prosonatic and mesosomatic (branchial) region, close behind which came the cloaca and anus. Between the two there was a short metasomatic region (possibly pronephric), so that the respiratory chamber did not open clirectly into the cloaca.

Such an interpretation is, I think, borne out by the study of the most ancient forms of fish. In Bothriolepis, according to Patten, and in Drepanaspis, according to Traquair, the cloacal region and anus follow immediately upon the posterior end of the head-shield, i.e. immediately after that region which presumably contained the branchiæe. Similarly, on the invertebrate side, all those forms which resembled Limulus must have possessed a very short region between the branchial and cloacal parts of the body. The original cloacal part of the vertebrate gut may well have been the original cloaca of the arthropod, into which its intestine emptied itself, especially when we see the tendency of the scorpion group of animals to form an accessory cloacal pouch known as the stercoral pouch or pocket.

Again, it is striking to see how, in certain of the scorpion group, e.f. Thelyphonus and Phrynus, there is a caudal massing of the central nerve-cells as well as a cephalic massing, so that their central nervous system is composed of a cephalic and caudal brain. These two brains are connected together by commissures extending the whole length of the body, in which I have been unable to find any sign of ganglion-cells. What this caudal brain innervates I do not know; it is, I think, a matter worth further investigation, especially as there are many indications in the vertebrate that the lumbo-sacral region of the cord possesses higher functions than the thoracic region.

The method of formation of the alimentary canal as indicated by its innervation is as follows :-

In front an oral chamber, formed, as already pointed out, by the modification of the prosomatic appendages, followed by a respiratory chamber, the muscles and branchiæ of which were the muscles and branchiæ of the mesosomatic appendages. This mesosomatic, or branchial, part was in close contiguity to the cloaca and anus, being separated from it only by a short tube formed in the metasomatic or pronephric region.

I imagine that this connection was originally in the form of an 
open groove, as already explained for both notochord and the anterior part of the gut itself in Ammocotes; an open groove formed from the mid-ventral surface of the body, on each side of which were the remnants of the pronephric appendages. By the closure of this groove ventrally, and the growing round of the pleural folds, as already suggested, the remains of the pronephric appendages are indicated by the segmental duct and the form of the vertebrate body is attained.

Even in the branchial region the same kind of thing must, I think, have occurred. The grooved ventral surface became a tube, on each side of which were lying in regular order the in-sunk branchial appendages, the whole being subsequently covered by the pleural folds to form an atrial chamber. A tube thus formed from the grooved ventral surface would carry with it to the new ventral surface the longitudinal venous sinuses, and thus form, in the way already suggested, the heart and ventral aorta. Posterior to the heart in the pronephric region, the same process would give rise to the sub-intestinal vein.

The evidence of comparative anatomy bears out most conclusively the suggestion that in the original vertebrate the gut was mainly a respiratory chamber. In man and all mammals the oral chamber opens into a small pharynx, followed by the cesophagus, stomach and small intestine. Of this whole length, a very small part is taken up by the pharynx, in which, in the embryo, the branchial arches are found, showing that this represents the original respiratory part of the gut. In the ordinary fish this branchial part is much more conspicuous, occupies a large proportion of the gut, and in the lowest fishes, such as Ammoccetes and Amphioxus, the branchial region extends over a large portion of the animal, while the intestine proper is a straight tube, the length of which is insignificant in comparison with its length in the higher vertebrates.

Such a tube was able to act as a digestive tube, owing, as already pointed out, to the digestive powers of the skin-epithelium, and I imagine at first the respiratory chamber, seeing that it composed very nearly the whole of the gut, was at the same time the main digestive chamber; even in Ammocoetes its digestive power is superior to that of the intestine itself.

Just posterior to the branchial part a diverticulum of the gut was formed at an early stage, as seen in Amphioxus, and provided the 
commencement of the liver. This simple liver-diverticulum became the tubular liver of Ammocoetes, and formed, curiously enough, not a glandular organ of the same character as the liver of the higher vertebrates, but a liepato-pancreas, like the so-called liver of the arthropods, which also is a special diverticulum of the gut, or rather the main true gut of the animal. In both cases the liver is the chief agent in digestion, for in Ammocotes the liver-extract is very much more powerful in the digestion of proteids than the extract of any olher organ tried by Miss Alcock. Subsequently in the vertebrate the gastric and pancreatic glands arise and relieve the liver of the burden of proteid digestion.

It is, to my mind, somewhat significant that the liver on its first formation in the vertebrate should have arisen as a digestive organ of the same character as the so-called liver in the arthropods; whether it originally belonged to any separate segment is in our present state of knowledge difficult to say.

\section{Conclusion.}

In conclusion, I will endeavour to illustrate crudely the way in which, on my theory, the notochord and vertebrate gut may have been formed, the agencies at work being in the main two, viz. the dwindling of appendages as mere organs of locomotion, and the conversion of a ventral groove into a tube.

I imagine that, among the Protostraca, forms were found somewhat resembling trilobites with markedly polychetan affinities; which, like Apus, possessed a deep ventral groove from one end of the body to the other, and also pleural fringes, as in many trilobites. This might be called the Trilobite stage (Fig. 167, A).

This groove became converted into a tube and so gave rise to the notochord, while the appendages were still free and the pleure had not met to form a new ventral surface. This might be called the Chordate Trilobite stage (Fig. 167, B).

Then, passing from the protostracan to the palieostracan stage, the oral and respiratory chambers were formed, not communicating with each other, in the manner described in previous chapters, a ventral groove in the metasomatic region being the only connection between respiratory chamber and cloaca. This might be called the Chordate Palieostracan stage (Fig. 167, C). 


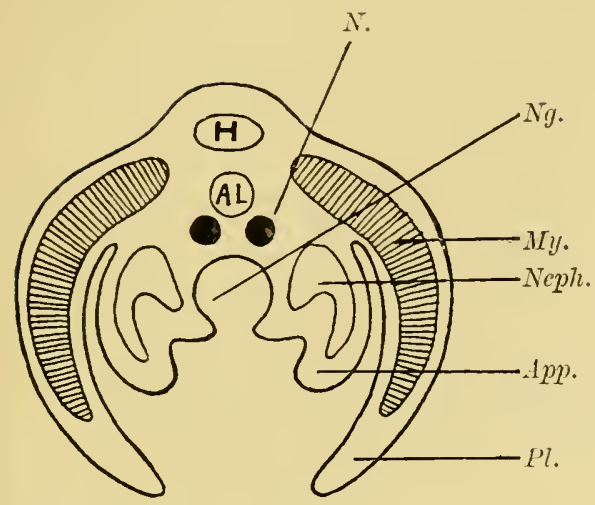

A

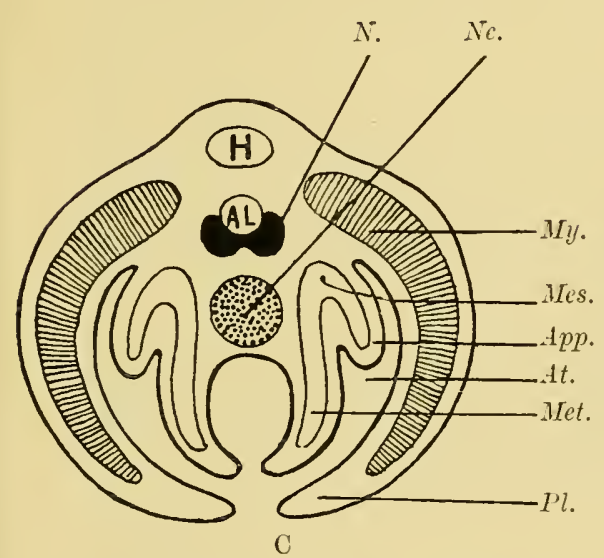

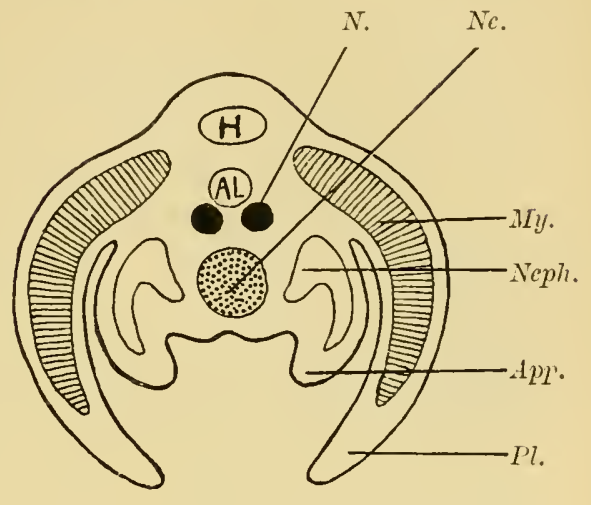

B

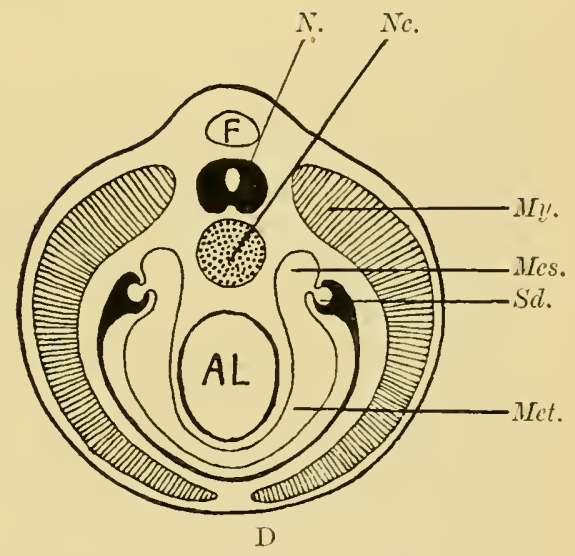

Fig. 167.-A, Diagrair of Section through a Trilobite-like Axinal; B, Diagran to illustrate the Suggested Forjation of the Notochord from a Vextral Groove; C, Diagray to illustrate the Suggested Formation of the Post-Branchial Gut bi the contixuation of the same process of Ventral Groove-Formatios, combined with Obliteration of Appendages and Growth of Pleural Folds; D, Diagrai to illestrate: the Completion of the Vertebrate Type by the Neetisg of the Pleural Folds in the MID-Ventral Line With the Obliteration of the Atrial Cavity and the CoNversiox of the Textral Groove ixto the closed Alimentary Canal.

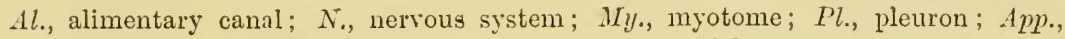
appendage; Neph., nephrocele; Met., metacœle; Sd., segmental duct; Mes., mesonephros; $\mathcal{A}$., atrial chamber; $N$ s., notcchord; $H$., heart; $F_{\text {. }}$, fat body ; $\mathrm{Ng}$., notochordal groove. (These diagrams are intended to complete the diagrams on p. 413, which, as stated there, were purposely left incomplete.) 
Finally, with the conversion of this groove into a tube, the opening of the oral into the respiratory chamber, and the formation of an atrium by the ventralwards growth of the pleural folds, the formation of a Vertebrate was completed (Fig. 167, D).

In my own mind I picture to myself an animal which possessed enrypterid and trilobite characters combined, in which a notochordal tube had been formed in the way suggested, and a respiratory chamber which communicated with the cloaca by means of a grooved channel along the mid-ventral line of the inetasomatic portion of the bocly. On each side of this channel were the remaius of the metasomatic appendages (pronephric). The whole was enveloped in the pleural folds, which probably at this time dicl not yet meet in the middle line to form a new ventral surface. This respiratory chamber, owing to the digestive power of the epilermis, assisted in the process of alimentation to such an extent as to supersede the temporary notochordal tube, with the effect of bringing about the conversion of the metasomatic groove into a closed canal, and so the formation of an alimentary tube continuous with the respiratory chamber. The amalgamation of the pleural folds ventrally completed the process, and so formed an animal resembling the Cephalaspidx, Ammoccetes, or Amphioxus.

I have endeavoured in this chapter to make some suggestions upon the origin of the notochord and of the vertebrate gut in accordance with my theory of the origin of vertebrates. I feel, however, strongly that these suggestions are much more speculative than those put forward in the previous chapters, and of necessity cannot give the same feeling of soundness as those based directly upon comparative anatomy and histology. Still, the fact remains that the origin of the notochord is at present absolutely unknown, and that my speculation that it may have originated as an accessory digestive tube is at all events in accordance with the most widely spreal opinion that it arises in close connection with an alimentary canal. 


\section{CHAPTER XIV}

\section{THE PRINCIPLES OF EMBRYOLOGY}

The law of recapitulation.-Vindication of this law by the theory advanced in this book.-The germ-layer theory.-Its present position.-A physiological not a morphological conception.-New fundamental law required.Composition of adult body.-Nemo-epithelial syncytium and free-living cells.-Meaning of the blastula.-Derivation of the Metazoa from the Protozoa. Importance of the central nervous system for Ontogeny as well as for Phylogeny.-Derivation of free-living cells from germ-cells.-Meaning of coelom.-Formation of neural canal.-Gastrula of Amphioxus and of Lucifer.-Summary.

Is a discussion upon this theory of mine, which took place at Cambridge on November 25 and December 2, 1895, it was said that such a theory was absolutely and definitely put out of court, because it contravened the principles of embryology, was opposed, therefore, to our surest guide in such matters; and the law was laid down with great assurance that no claim for genetic relationship between two groups of animals can be allowed which is based upon topographical and structural coincidences revealed by the study of the anatomy of two adult animals, however numerous and striking they may be, if there are fundamental differences in the embryology of the members of these two groups.

According to my theory the old gut of the arthropod still exists in the vertebrate as the tubular lining of the central nervous system, and the vertebrate has formed a new gut. According to the principles of embryology as held up to the present, in all animals above the Protozoa, the different structures of the body arise from three definite embryonic layers, the epiblast, nesoblast, and hypoblast, and in all cases the gut arises from the hypoblastic layer. In the vertebrate the gut also arises from the hypoblast, while the neural canal is epiblastic. My theory, then, makes the impossible assertion that what was hypoblast in the arthropod has become epiblast in the vertebrate, and what was epiblast in the arthropod has become liypoblast in the rertebrate. Such a conception is supposed to be so 
absolutely impossible that it only requires to be stated to be dismissed as an absurdity.

Against this opinion I claim boldly that my theory is not only not contrary to the principles of embryology, but is mainly based upon the teachings of embryology. I wish here not to be misunderstood. The great value of the study of embryology for questions of the sequence of the evolution of animals is to be found in what is known as the Law of Recapitulation, which asserts that every animal gives some indication in the stages of its individual development of its ancestral history. Naturally enough it camnot pass through all the stages of its past history with equal clearness, for what has taken millions of years to be evolved has to be compressed into an evolution lasting only a few months or weeks, or even less.

When in the highest vertebrate a vestigial organ, such as the pineal gland, can be traced back without leaving the vertebrate kingdom to a distinct median eye, such as is found in the lamprey, that rudimentary organ is eridence of an organ which was functional in the earliest rertebrates or their immediate ancestors. So it is generally with well defined vestigial organs found in the adult animal; they always indicate an organ which was functional in the near ancestor.

Passing from the adult to the embryo we still find the same law. Here, also, vestigial organs are met with, which may leave no trace in the adult, but indicate organs which were functional in the near ancestor. Thus, but for embryology, we should have no certainty that the air-breathing vertebrates had been derived from waterbreathing fishes; the indication is not given by any close resemblance between the formation of the embryos in their earliest stages, but lyy the formation of vestigial gill-arches even in the embryos of the highest mammal.

For all questions of evolution the presence of restigial organs in the embryo is the important consideration, for they give an indication of near ancestry; the early formation of the embryo concerus a much more remote ancestral period, all vestigial organs of which may well have been lost and obscured by conogenetic ehanges. Let us, then, consider the two things--the restigial organs and the early formation of the embryo-separately, and see how far my opponents are justified in their statement that my theory contravenes the principles of embryology. 
First, I will take the teachings of vestigial organs and the arrangement of organs found in the vertebrate embryo. Here it is inpossible to say that my theory is contrary to the teaching of embryology, for as the previous chapters have shown again and again, the argument is based very largely upon the facts of embryology. In the first place, the comparison which I have chiefly mate is a comparison between the larval form of a very low vertebrate and the arthropod group, a comparison which exists only for the larval form, and not for the adult. The whole theory, then, is based upon a developmental stage of the vertebrate, and not upon the anatomy of the adult.

Throughont the whole history it seems to me perfeetly marvellous how eompletely the law of recapitulation is vindicated by my theory of the origin of the vertebrate. The theory asserts that the clue to the origin of vertebrates is to be found in the tubular nature of the central nervous system of the vertebrate; in that the vertebrate central nervous system is in reality formed of two things: (1) a central nerrons system of the arthropod type, and (2) an epithelial tube in the position of the alimentary canal of the arthropod.

Is it possible for embryology to recapitulate such a phylogenetic history more clearly than is here the case? In order to avoicl all possibility of our mistaking the clne, the nerve-tube in the embryo always opens into the anus at its posterior end, while in the larval Amphioxus it is actually still open to the exterior at the anterior end. The separateness of the tube from the nervous system at its first origin is shown especially well in the frog, where, as Assheton has pointed out, owing to the pigment in the eells of the external layer of epithelium, a pigmented tube is formed, on the outside of which the nervous tissue is lying, and step by step the gradual intermingling of the nerve-cells and the pigmented lining cells can be followed out.

Consider the shape of the nerve-tube when first formed in the vertebrate. At the cephalic end a simple bulged-out tube with two simple anterior diverticula, which passes into a narrow straight spinal tube; from this large cephalic bulging a narrow diverticulum, the infundibulum, passes to the ventral surface of the forming brain. This tube is the embryological expression of the simple dilated cephalic stomach, with its ventral cesophagus and two anterior diverticula, which opens into the straight intestine of the arthropod. Nay, more, by its very shape, and the invariable presence of two anterior 
diverticula, it points not only to an arthropod ancestry, but to a descent from a particular group of primitive arthropods. Then comes the formation of the cerebral vesicles, and the formation of the optic cup, telling us as plainly as can be how the iuvasion of nervous material over this simple cephalic stomach and its diverticula has altered the shape of the original tube, and more and more enclosed it with nervous elements.

So, too, in the spinal cord region. When the tube is first formed, it is a large tube, the latero-ventral part of which presents two marked bulgings; connecting these two bulgings is the anterior commissure. These two lateral bulgings, with their transverse commissure, represent, with marked ficlelity, the ventral ganglionmasses of the arthropod with their transverse commissure, and occupy the same position with respect to the spinal tube, as the ganglionmasses do with respect to the intestine in the arthropod. Then the further development shows how, by the subsequent growth of the nervous material, the calibre of the tube is diminished in size, and the spinal cord is formed.

Again, I say, is it possible to conceive that embryology should indicate the nature of the origin of the vertebrate nervous system more clearly than it does?

It is the same with all the other organs. Take, for instance, the skeletal tissues. The study of the vertebrate embryo asserts that the cartilaginous skeleton arose as simple branchial bars and a simple cranio-facial skeleton, and also that the parenchymatous variety of cartilage represents the embryonic form. Word for word, the early embryonic stage of the vertebrate skeleton closely resembles the stage reached in the arthropod, as shown by Limulus, and again records, unmistakably, the past history of the vertebrate.

So, too, with the whole of the prosomatic region; the situation of the old mouth, the manner in which the nose of the cephalaspidian fishes arose from the palieostracan, are all shown with vivid clearness by Kupffer's investigations of the early stage of Ammocotes, while at the same time the closure of the oral cavity by the septum shows how the oral chamber was originally bounded by the operculum. Nay, further, the very formation of this chamber embryologically was brought about by the forward growth of the lower lip, just as it must have been if the chilaria grew forward to form the metastoma.

So, too, the study of the embryo teaches that the branchice arise as 
ingrowths, that the heart arises as two longitudinal veins, just as the theory supposes from the facts provided by Limulus and the scorpions. No indication of the origin of the thyroid gland is given by the study of its structure in any adult vertebrate, but in the larval form of the lamprey there is still preserved for us a most graphic record of its past history.

The close comparisons which it is possible to make between the eye-muscles of the vertebrate and the recti muscles of the scorpion group on the one hand, and between the pituitary and coxal glands on the other, are based upon, or at all events are strikingly confirmed by, the study of the colomic cavities and the origin of these museles in the two groups. In fact the embryological evidence of the double segmentation in the head and the whole nature of the cranial segments is one of the main foundation-stones on which the whole of my theory rests.

So it is throughout. Turn to the exeretory organs - it is not the kidney of the adult animal which leads direct to the excretory organs of the primitive arthropod, but the early embryonic origin of that kidney.

So far from having put forward a theory which runs comter to the principles of embryology, I claim to have rindicated the great Law of liecapitulation which is the foundation-stone of embryological principles. My theory is largely based upon embryological facts, and its strength consists in the manner in which it links together into one harmonious whole, the facts of Embryology, Palieontology, Anatomy, and Physiology. Why, then, is it possible to assert that my theory disregards the principles of embryology, when, as we have seen, embryology is proclaiming as loudly as possible how the vertebrate arose? In my opinion, it is because the embryologists have to a large extent gone wrong in their fundamental principles, and have attached more weight to these faulty fundamental principles than to the obrious facts which, looked at thoughtfully, could not have failed to suggest a doubt as to the correctness of these 'principles.'

The current laws of embryology upon which such weight is laid are based on the homology of the germinal layers in all Metazoa, and state that in all cases after segmentation is finished a blastula is formed, from which there arises a gastrula, formed of an internal layer, the hypoblast, and an external layer, the epiblast; subsequently 
between these arises a third layer, the mesoblast. These layers are strictly morphological conceptions, and are stated to be homologous in all cases, so that the hypoblast of one animal must be homologous to the hypoblast of another. In order, therefore, to compare two aduIt animals for the purpose of finding kinship between them, it is necessary to find whether parts such as the gut, which in both cases have the same function, arise from the same germinal layer in the embryo. We can, in fact, have no certainty of kinship, even although the two animals are built up as far as the adult state is concerned on a remarkably similar plan, unless we can study their respective embryos and find out what parts arise from the hypoblast and what from the epiblast. The homology of the germinal layers constitutes in all cases of disputed relationship the court of final appeal. A new gut, therefore, in any animal can only be formed from hypoblast, and any theory, such as that advocated in this book, which deals with the formation of a new gut, and does not form that gnt from pre-existing hypoblast, must of necessity be wrong and needs no further consideration.

Such is the result of current conceptions-conceptions which to be valid must be based 11pon an absolutely clear morphological definition of the formation of the germinal layers, a definition not based on their subsequent history and function, but determined solely by the uniformity of the manner of their origin.

What, then, is a germinal layer? How can we identify it when it first arises? What is the morphological criterion by which hypoblast can be distinguished from epilulast, or mesoblast from either?

This is the question put by Braem, in an admirable series of articles in the Biologisehes Centralblatt, and is one that must be answered by every worker who bases his views of the process of evolution upon embryological investigation. As Braem points out, the germinal layers are definable either from a morphological or physiological standpoint. In the one case they must arise throughout on the same plan, and whatever be their fate in the adult, they must form at an early stage structures strictly homologous in all animals. In the other case the criterion is lased on function, and the hypoblast, for instance, is that layer which is found afterwards to form the definitive alimentary canal. There is no louger any morphological homology ; such layers are analogous ; they may be, but are not necessarily, homologous. Iraem gives a sketch of the history of the views held on 
the germinal layers, and shows how they were originally a purely physiological conception, and how gradually such conception changed into a morphological one, with the result that what had up to that time been looked upon as analogous structures became strictly homologous and of fundamental importance in deciding the position of any animal in the whole animal series.

This change of opinion was especially due to the lively imagination of Haeckel, who taught that the germinal layers of all Metazoa must be strictly homologous, because they were all clerived from a common ancestral stock, represented by a hypothetical animal to which he gave the name Gastrina; an animal which was formed by the simple invagination of a part of the blastula, thus giving rise to the original hypoblast and epiblast, and he taught that throughout the animal kingdom the germinal layers were formed by such an invagination of a part of the blastula to form a simple gastrula. If further investigation had borne out Haeckel's idea, if therefore the hypoblast was in all cases formed as the invagination of a part of a single-layered blastula, then indeed the dogma of the homology of the germinal layers would be on so firm a foundation that no speculation which ran comnter to it could be expected to receive acceptance; but that is just what has not taken place. The formation of the gastrula by simple invagination of the single-layered blastula is the exception, not the rule, and, as pointed out by Braəm, is significantly absent in the earliest Metazoa; in those very places where, on the Gastrea theory, it ought to be most conspicuous.

Braem discusses the question most ably, and shows again and again that in every case the true criterion upon which it is decided whether certain cells are hypoblastic or not is not morphological but physiological. The decision does not rest upon the answer to the question, Are these cells in reality the invaginated cells of a singlecelled blastula? but to the question, Do these cells ultimately form the definitive alinentary canal? The decision is always based on the function of the cells, not on their morphological position. Not only in Braem's paper, but elsewhere, we see that in recent years the physiological criterion is becoming more and more accepted by morphologists. Thus Graham Kerr, in his paper on the development of Lepidosiren, says: "It seems to me quite impossible to define a layer as hypoblastic except by asking one or other of the two questions: (1) Does it form the lining of an archenteric cavity? and (2) 
Does it become a certain part of the definitive epithelial lining of the gut?"

The appearance of Braem's paper was followed by a criticism from the pen of Samassa, who agrees largely with Braem, but thinks that he presses the physiological argument too far. He considers that morphological laws must exist for the individual development as well as for the phylogenetic, and finishes his article with the following sentence, a sentence in which it appears to me he expresses what is fast becoming the prevailing view : "Mit dem Satz, den man mitunter lesen kann: 'es muss doch auch für die Ontogenie allgemeine Gesetze geben' kam leicht Missbranch getrieben werden; diese allgemeinen Gesetze giebt es wohl, aber sie liegen nicht anf flacher Hand und bis zu ihrer Erkenntnis hat es noch gute Wege; das eine kann man aber wohl heute schon sagen, die Keimblätterlehre gehört zu diesen allgemeinen Gesetzen nicht."

I conclude, then, that we onght to go back to a time previous to that of Haeckel and ask ourselves seriously the question, When we lay stress on the germinal layers and speak of this or that organ arising from this or that germinal layer, are we thereby adding anything to the knowledge that we already possess from the study of the anatomy and physiology of the adult body? If by hypoblast we only mean the internal surface or alimentary canal and its glands, etc., and by epiblast we mean the external surface or skin and its glands, etc., while mesoblast indicates the middle structures between the other two, then I fail to see what advantages we obtain by using Greek terms to express in the embryo what we express in English in the adult.

The evidence given by Braem, and it could be strengthened considerably, is conclusive against the morphological importance of the theory of the germinal layers, and transfers the fundamental importance of the early embryonic formation, from that of a three-layered embryo to that of a single-layered embryo-the blastula-from which, in various ways, the adult animal has arisen.

The derivation of both arthropod and vertebrate from such a single-layered animal is perfectly conceivable, even though the gut of the latter is not homologous with the gut of the former. We have seen that the teachings of embryology, as far as its later stages are concerned, afford one of the main supports upon which this theory rests. What, therefore, is required to complete the story is the way 
in which these later stages arise from the blastula stage; here, as in all cases, the ontogenetic laws must be in harmony with the phylogenetic; of the latter the most important is the steady development of the central nervous system for the upward progress of the animal race. The study of comparative anatomy indicates the central nervous system, not the gut, as the keystone of the edifice. So, also, it must be with ontogeny; here also the central factor in the formation of the adult from the blastula ought to be the formation of the central nervous system, not that of the gut.

Such, it appears to me, is the case, as may be seen from the following considerations.

The study of the development of any animal can be treated in two ways: either we can trace back from the adult to the very beginning in the orum, or we can trace forward from the fertilized egg to the adult. Both methods ought to lead to the same result; the difference is, that in the first case we are passing from the more known to the less known, and are expressing the nnknown in terms of the known. In the second case we are passing from the less known to the more known, and are expressing the known in speculative terms, invented to explain the unknown. What has just been said with respect to the germinal layers means that, however much we may study the embryo and try to express the adult in terms of it, we finally come back to the first way of looking at the question, and, starting with the adult, trace the continuity of function back to the first formation of cells having a separate function.

Let us, then, apply this thronghont, and see what are the logical results of tracing back the various organs and tissues from the adult to the embryo.

The adult body is built up of different kinds of tissues, which fall naturally, from the standpoint of physiology, into groups. Such groups are, in the first place-

1. All those tissues which are connected with the central nervous system, including in that group the nervous system itself.

2. All those tissues which have no connection with the nervous system.

In the second group the physiologist places all germinal cells, all blood-and lymph-corpuscles, all plasma-cells and connective tissue and its derivatives-in fact, all free-living cells, whether in a free state or in a quiescent, so to speak encysted, condition, such as is 
found in connective tissne. In the first group the physiologist recognizes that the central nervous system is connected with all muscular tissnes, whether striped or unstriped, somatic or splanchnic, and that such connection is of an intimate character. Further, all epithelial cells, either of the onter or inner surfaces, whether forming special sense-organs and glands, such as the digestive and sweat-glands, or not, are connected with the nervous system. Besides these structures, there is another set of organs as to which we cannot speak definitely at present, which must be considered separately, viz. all the cells, together with their derived organs, which line the body-spaces. Whatever may be the ultimate decision as to this gronp of cells, it must fall into one or other of the two main groups.

The members of these two groups are so interwoven with one another that either, if taken alone, wonld still give the form of the body, so that, in a certain sense, we can speak of the body as formed of two syncytia, separate from each other, but interlaced, of which the one forms a contimous whole by means of cells connected together ly a fluid medinm or by solid threads formed in such fluid medinm, while the other does not form a syncytinm in the sense that any cell of one kind may be connected with any cell of another kind, but a syncytium of which all the different elements are connected together only throngh the medium of the nervous system.

If we choose to speak of the body as made up of two syncytia in this way, we must at the same time recognize the fundamental difference in character between them. In the one case the elements are connected together only by what may be called non-living material; there is no direct metabolic activity caused by the action of one cell over a more distant cell in consequence of such connection, it is not a true syncytium; in the second case there is a living connection, the metabolism of one part is directly influenced by the activity of another, and the whole utility of the system depends upon such functional connection.

The tissues composing this second syncytium may be spoken of as the master-tissnes of the body, and we may express this conception of the building np of the hody of the higher Metazoa by saying that it is composed of a syncytial host formed of the master-tissues, which contains within its meshes a system of free-living cells, none of which have any connection with the nervons system. This syncytial 
host is in the adult composed of a number of double elements, a nerve-cell element, and an epithelial element, such as muscle-cell, gland-cell, etc., conneeted together by nerves; and if such connection is always present as we pass from the adult to the embryo, if there is no period when, for example, the neural element exists alone free from the muscle-cell, no period when the two can be seen to come together and join, then it follows that when the single-layered blastula stage is reached, muscle-cell and nerve-cell must have fused together to form a neuro-museular cell. Similarly with all the other neuroepithelial organs; however far apart their two components may be in the adult, they must come together and fuse in the embryo to form a neuro-epithelial element.

The close connection between muscle and nerre which has always been recognized by physiologists, together with the origin of muscle from a myo-epithelial cell in Hydra and other Coelenterata, led the older physiologists to accept thoronghly Hensen's views of the neuro. epithelial origin of all tissues connected with the central nerrous system. Of late years this conception has been largely given up owing to the statement of His that the nervous system arises from a number of neuroblasts, whieh are entirely separate cells, and have at first no connection with muscle-cells or any peripheral epithelial cells, but subsequently, by the outgrowing of an axial fibre, find their way to the musele, ete., and connect with it. I do not think that His' statement by itself would have induced any physiologist to give up the eonception of the intimate connection of muscle and nerve, if the work of Golgi, Ramón y Cajal, and others had not brought into prominence the neurone theory, i.e. that each element of the central nervous system is an independent element, without real connection with any other element and capable of influencing other cells by contact only. These two statements, emanating as they did from embryological and anatomical studies respectively, have done much to put into the background Hensen's conceptions of the syncytial nature of the motor, neural, and sensory elements, which make up the master-tissues of the body, and have led to the view that all the elements of the body are alike, in so far as they are formed of separate cells each leading an independent existence, without any real intimate connection with each other.

The further progress of investigation is, it seems to me, bringing us back to the older conception, for not only has the neuroblast theory 
proved very difficult for pliysiologists to accept, but also Graham Kerr, in his latest papers on the development of Lepidosiren, has shown that there is continuity between the nerve-cell and the musclecell from the very first separation of the two sets of elements; in fact, Hensen is right and His wrong in their respective interpretation of the earliest stages of the connection between muscle and nerve. So also, it seems to me, the intimate connection between the metabolism of the gland-cell, as seen in the submaxillary gland, and the integrity of its nervous connection implies that the connection between nerre-cell and gland-cell is of the same order as that between nerve-cell and muscle-cell. Graham Kerr also states in his paper that from the very commencement there is, he believes, continuity between nerve-cell and epithelial cell, but so far he has not obtained sufficiently clear evidence to enable him to speak positively on this point.

Further, according to the researches of Anderson, the cells of the superior cervical ganglion in a new-born animal will continue to grow healthily as long as they remain connected with the periphery, even though entirely separated from the central nervous system by section of the cervical sympathetic nerve, and conversely, when separated from the periphery, will atropliy, even though still connected with the central nervous system. So, also, on the sensury side, Anderson has shown that the ganglion-cells of the posterior root-ganglion will grow and remain liealthy after separation of the posterior roots in a new-born animal, but will atrophy if the peripheral nerve is cut, even though they are still in connection with the central nervous system. Further, although section of a posterior root in the new-born animal does not affect the development of the nerve-cells in the spinal gauglion, and of the nerve-fibres connecting the posterior root-ganglion with the periphery, it does hinder the development of that part of the posterior root connected with the spinal ganglion.

These experiments of Anderson are of enormous importance, and force us, it seems to me, to the same conclusion as that to which he has already arrived. His words are (p. 511): "I suggest, therefore, that the section of peripheral nerves checked the development of motor and seusory neurones, not because it blocked the passage of efferent impulses in the first case and the reception of stimuli from the periphery in the second, but for the same rcason in both cases, 
vi\%. that the lesion disturbed the ehemico-physical equilibrium of an anatomically continuous (neuro-muscular or neuro-epithelial) chain of cells, by separating the non-nervous from the nervous, and that the changes occurring in denervated muscle, which I shall describe later (and possibly those in denervated skin), are in part due to the reciprocal chemico-physical disturbance effected in these tissues by their separation from the nervous tissues; also that the section of the posterior roots checked the development of those portions of them still attached to the spinal ganglia, because the chemicophysical equilibrium in those processes is maintained not only by the spinal ganglion-cells, but also by the intra-spinal cells with which these processes are anatomically continuous."

What is seen so strikingly in the new-born animal can be seen also in the adult, and in Anderson's paper references are given to the papers of Lugaro and others which lead to the same conclusion.

These experiments seem to me distinctly to prove that the connection between the elements of the peripheral organ and the proximate neurone is more than one of contact.

We can, however, go further than this, for, apart from the observations of Apathy, there is direct physiological evidence that the vitality of other neurones besides the terminal neurones is dependent upon their connection with the peripheral organ, even thongh their only connection with the periphery is by way of the terminal neurone. Thus, as is seen from Anderson's experiments, section of the cervical sympathetic nerve in a very young animal causes atrophy of many of the cells in the corresponding intermediolateral tract, cells which I supposed gave origin to all the vasoconstrictor, pilomotor, and sweat-gland nerves. A still more striking experiment given by Anderson is the effect of the removal of the periphery upon the medullation of those efferent fibres which arise from these same spinal cells, for, as he has shown, section of the nerves from the superior cervical ganglion to the periphery in a very young animal delays the medullation in the fibres of the cervical sympathetic-that is, in preganglionic fibres which are not directly connected with the periphery but with the terminal nemrones in the superior cervical ganglion. So also on the afferent side a sufficiently extensive removal of sensory field will cause atrophy of the colls of Clarke's column, so that, just as in the case of the primary neurones, 
the secondary neurones show by their degenerative changes the importance of their comnection with the peripheral organs.

In this way I can conceive the formation of a series of both efferent and afferent relays in the nervous system by proliferation of the original neural moiety of the neuro-epithelial elements, every one of which is dependent upon its connection with the peripheral epithelial elements for its due vitality, the whole system being a scheme for co-ordination of a larger and larger number of peripheral elements. Thus the cells of the vasomotor centre are in connection with the whole system of segmental vaso-constrictor centres in the lateral horns of the thoracic region of the cord, so that to cause atrophy of these cells a very extensive removal of the vascular system would be required. Each of the segmental centres in the cord supplies a number of sympathetic segments, the connection with all of which would have to be ent in order to ensure complete removal of the connection of each of its cells with the periphery, and finally each of the cells in the sympathetic gauglia supplies a number of peripheral elements, all of which must be removed to ensure complete severance.

Thus, if we take any arbitrary number, such as 4, to represent the number of peripheral organ-elements with which each terminal neurone is connected, and suppose that each neurone has proliferated into sets of 4 , then a cell of the third order, such as a cell of the vasomotor centre, would require the removal of 64 peripheral elements to cause its complete separation from the periphery, one of the second order (a cell of the thoracic lateral horn) 16 elements, one of the first order (a cell of a sympathetic ganglion) 4 elements.

Such intimate inter-relationship between the neurones, both afferent and efferent, and their corresponding peripheral organs does not imply that all nerve-cells are necessarily as closely dependent upon some connection with the periphery, for just as the proliferation of epithelial or muscle-cells forms an epithelial or muscular sheet, the elements of which are so loosely, if at all, connected together that their metabolism is in 110 way dependent upon such connection, so also a similar proliferation of the neural elements may form connections between nerve-cell and nerve-cell of a similarly loose nature.

It is this kind of proliferation which, in my opinion, would bind together the separate relays of efferent and afferent neurones, and 
so give origin to reflex actions at different levels. Such neurones would not be in the direct chain of either the afferent or efferent neurones, and so not directly connected with the periphery, and could therefore be removed without affecting the vitality of either the efferent or afferent chain of neurones. In other words, the vitality of the cells on the efferent side ought not to be dependent on the integrity of the reflex arc. With regard to the development of the anterior roots, Anderson has shown that this is the case, for section of all the posterior roots conveying afferent impulses from the lower limb in a new-born animal does not hinder the normal development of the anterior roots supplying that limb. Also Mott, who originally thought that section of all the posterior roots to a limb caused atrophy of the corresponding anterior roots, has now come to the same conclusion as other observers, and can find no degeneration on the efferent side due to removal of afferent impulses.

Again, the process of regeneration after section of a nerve is not in favour of the neuroblast theory. There is no evidence that the cut end of a nerve can grow down and attach itself to a muscular or epithelial element without the assistance of a nerve tube down which to grow. When the cut nerves connected with the periphery degenerate, that applies only to the axis-cylinder and the medullary sheath, not to the neurilemma; the connective tissue elements remain alive and form a tube into which the growing axon finds its way, and so is conducted to the end-plate or endorgan of the peripheral structure.

Possibly, as suggested by Mott and Halliburton, the products of degeneration of the axis-cylinder and medullary sheath stimulate these connective tissue sheath-cells into active proliferation, and so bring about the great multiplication of cells arranged as cellchains, which are so often erroneously spoken of as forming the young nerves. These sheath-cells are then supposed to re-form and secrete a pabulum which is important for the process of regeneration of the down-growing axis-cylinder and medullary sheath. Without such pabulum regeneration does not take place, as is seen in the central nervous system, where the sheath of Schwann is absent.

Again, it is becoming more and more doubtful whether the peripheral terminations of nerves are ever really free. As far as efferent nerves are concerned the nervous element may entirely 
preciominate over the museular or glandular, as in the formation of the eleetric organs of the Torpedo and Malapterurus, but still the final effect is produced by the alteration of the musele or gland-cell. On the afferent side especially free nerve-terminations are largely recognized, or, as in Barker's book, nerves are spoken of as arising in connective tissue. Thus the numerous kinds of special sense-organs, such as Pacinian bodies, tendon-organs, genital corpuscles, etc., are all referred to by Barker under the heading of "sensory nerve beginnings in mesoblastic tissues." Yet the type of these organs has been known for a long time in the shape of Grandry's corpuscles or the tactile corpuscles in the duck's bill, where it has been proved that the nerve terminates in special large taetile cells derived from the surface-epithelium.

So also with all the others, further investigation tends to put them all in the same category, all special sensory organs originating from a localized pateh of surface-epithelium. Thus Anderson has shown me in his specimens how the young Pacinian body is composed of rows of epithelial cells, into each of which a twig from the nerve passes. He has also shown me how, in the case of the tendon-organ, each nerve-fibre passes towards the attachment of the tendon and then bends back to supply the tendon-organ, thus indicating, as he suggests, how the nest of epithelial cells has wandered inwards from the surface to form the tendon-organ. Again, Meissner's corpuscles and Herbst's corpuscles are evidently referable to the same elass as those of Grandry and Pacini.

Yet another instance of the same kind is to be found in the chromatophores of the frog and other animals which are under the influence of the central nervous system and yet have been supposed by various observers to be pigmented connective tissue cells. The most recent work of Leo Loeb and others has conclusively shown that snch cells are invariably derived from the surface-epithelium.

Finally, in fishes we find the special sense-organs of the lateral line and other accessory sensory organs, all of which are indisputably formed from modified surface epithelial cells.

The whole of this evilence seems to me directly against Barker's classification of sensory nerve-beginnings in mesoblastic tissues; in none of these cases are we really dealing with free nervous tissue alone, the starting point is always a neuro-epithelial conple.

We may then, I would suggest, look upon the adult as formed of 
a neural syncytium, which we may call the host, which carries with it in its meshes a number of free cells not connected with the nervous system. If, then, we confine our attention to the host and trace back this neural syncytium to its beginnings in the cmbryo, we see that, from the very nature of the neuro-epithelial couple, each epithelial moicty must approach nearer and nearer to its neural moiety, until at last it merges with it; the original neuro-epithelial cell results, and we must obtain, as far as the host is concerned, a single-layered blastula as the origin of all Metazoa. It follows, further, that there must always be continuity of growth in the formation of the host, i.e. in the formation of the neuro-epithelial syncytium; that therefore cells which have been previously free cannot settle down and take part in its fornation, as, for instance, in the case of the formation of any part of the gut-epithelium or of muscle-cells from free-living cells.

Further, since the neural moiety is the one element common to all the different factors which constitute the host, it follows that the convergence of each epithelial moiety to the neural moiety, as we pass from the adult to the embryo, is a convergence of all outlying parts to the neural moiety, i.e. to the central nervous system, if there is a concentrated nervous system. Conversely, in the commencing embryo the place from which the spreading ont of cells takes place, i.e. from which growth proceeds, must be the position of the central nervous system, if the nervous system is concentratel. If the nervous system is diffuse, and forms a general sub-epithclial layer, then the growth of the embryo would take place over the whole surface of the blastula.

Turning now to the consideration of the second group of tissues, those that are not connected with the central nervous system, we find that they include among them such special cells as the germinal cells, free cells of markedly phagocytic nature, and cells which were originally free and phagocytic, but have settled down to form a supporting framework of connective tissue, and are known as plasmacells. In the embryo we find also in many cases free cells in the yolk, forming more or less of a layer, which function as phagocytes and prepare the pabulum for the fixed cells of the growing embryo; these cells are known by the name of vitellophags, and in meroblastic vertebrate eggs form somewhat of a layer known by the name of periblast. Such cells must be included in the seconl group, and, 
indeed, have been said again and again to give origin to the freeliving blond-corpuseles of the adult. In other cases they are said to disintegrate after their work is done.

In the adult the free-living lymphoeytes and hæmocytes reproduce themselves from already existing free-living cells, but as we pass back to the embryo there comes a time, comparatively late in the history of the embryo, when such free-living cells are not found in the fluids of the body, and they are said to arise from the proliferation and setting free of cells which form a lining epithelium. Such formation of leucocytes has been especially described in connection with the lining epithelium of the crrlomic cavities, as stated in Chapter XII., so that anatomists look npon the origin of these free cells as being largely from the colomic epithelium, or mesothelium, as Minot ealls it.

Then, again, the free cells which form the germinal cells can be traeed back to a germinal epithelium, which also is part of the colom. Thus the suggestion arises that in the embryo a cellular lining is formed to a colomic cavity (mesothelium) composed of cells which have no communication with the nervous system, and are capable of a separate existence as free individuals, either in the form of germinal cells or of lymphocytes, hæmocytes, and plasma-cells, so that these latter free cells may be considered as living an independent existence in the body, and ministering to it in the same sense as the germ-cells live an independent existence in the body. Again, the function of this mesothelium apart from the germ-cell is essentially excretory and phagocytic. It is the cells of the excretory organs as well as the lymphocytes which pick up carmine-grains when injected. It is the cells of the modified excretory organs, as mentioned in Chapter XII., which, according to Kowalewsky and others, give origin to the free leucocytes.

We see, then, that the conception of a syncytial neuro-epithelial host holding in its meshes a number of free cells leads directly to the questions: What is the colom? To which category does its lining membrane belong? and further, also, What is the origin of these free cells?

The Metazoa have been divided into two great groups-those which possess a colom (the Coelomata; Lankester's Colomoenela) and those which do not (Crelenterata; Lankester's Enteroccela). As an example of the latter we may take Hydra, beeause it is a very 
primitive form, and because its derelopment has been carefully worked out recently by Braner.

In Hydra we find a dermal layer of cells and an imner layer of cells separated by a gelatinous mass known as mesogloea; in this mass between the dermal and inner layers seattered cells are found, the interstitial cells. Now, according to Braner the position of the germ in Hydra is the interstitial cell-layer. One cell of the ovarium becomes the egg-cell, the others have their substance changed into yolk-grains, forming the so-called pseudo-cells, and as such afford pabulum to the growing egg-cell. Thus we see that in between the dermal and gastral layer of cells a third layer of cells is found, composed of free living germ-cells, some of which, by the formation of yolk-granules, become degraded into pabulum for their more favoured kinsfolk. These interstitial cells are said to arise from the dermal layer, or ectoderm, but clearly, as in other cases, germ-cells constitute a class by themselves and cannot be spoken of as originating from ectoderm-cells or from hypoderm-cells.

So also in Porifera, Minchin states: "In addition to the collared cells of the gastral layer, and the various cell-elements of the dermal layer, the body-wall contains numerous wandering cells or amcebocytes, which occur everywhere among the cells and tissues. Though lodged principally in the dermal layer, they are not to be regarded as belonging to it, but as constituting a distinct class of cells by themselves. They are concerned proliably with the functions of nutrition and excretion, and from them arise the genital products." Further (p. 31): "At certain seasons some of these cells become germ-cells; hence the wandering cells and the reproductive cells may be included together under the general term archreocytes." Also (p. 51): "The mesoglcea is the first portion to appear as a structureless layer between the dermal and gastral epithelia, and is probably a secretion of the former."

He also points out that in these, the very lowest of the Metazoa, the separate origin of these archrocytes can be traced back to a very early period of embryonic life. Thus in Clathrina blanca the ovum undergoes a regular and total cleavage, resulting in the formation of a hollow ciliated blastula of oval form. At one point, the future posterior pole of the larva, are a pair of very large granular cells with vesicular nuclei, which represent undifferentiated blastomeres and are destined to give rise to the archieocytes, and, therefore, also to the 
sexual cells of the adult. Thus, as he says, from the very earliest period a distinction is made between the "tissue-forming" cells (my syncytial host) and the archeocytes.

We see, then, that the origin of all these free-living cells can be traced back to the very earliest of the Metazoa. Here between the dermal and gastral layers a gelatinous material, the mesoglena is secreted by these layers. This material is non-living, non-cellular. In it live free cells which may either be germ-cells, amœbocytes, or 'collencytes' (connective tissue cells). If this mesoglca were a fluid secretion, then we should have a tissue of the nature of blood or lymph; if it were solid, then we should have the foundation of connective tissue, cartilage, and bone.

From this primitive tissue it is easy to see how the special elements of the vascular, lymphatic, and skeletal tissues gradually arose, the matrix heing provided by the cells of the syncytial host and the cellular elements by the archrocytes. In fact, we have no right to speak of these lowest members of the Metazoa as not being triploblastic, as possessing nothing corresponding to mesoblast, for in these free cells in the mesoglnea we have the origin of the mesenchyme of the higher groups. Thus Lankester, talking of mesenchyme, says: "I think we are bound to bring into consideration here the existence in many Crelentera of a tissue resembling the mesenchyme of Colomocœla. In Scyphomedusce, in Ctenophora, and in Anthozoa, branched fixed and wandering cells are found in the mesoglcea which seem to be the same thing as a good deal of what is distinguished as mesenchyme in Crelomocoela. These appear to be derived from both the primitive layers; some produce spicules, others fibrous substance, others again seem to be amœbocytes with various functions. It appears to be probable that, though it may be necessary to distinguish other elements in it, the mesenchyme of Cœlomocœla is largely constituted by cells, which are the mother-cells of the skeletotrophic group of tissues, and are lestined to form connective tissues, blood-vessels, and blood."

Thus we see that the earliest Metazon were composed of a dermal and gastral epithelium, with a sub-epithelial nervous system connecting the parts together, which formed, as it were, a host, carrying around free living cells of varying function, all of which may be looked on as derived from archrocytes, i.e. germ-cells. From these the coelomators animals arose, and here also we find, according to 
present-day opinion, that the celom arose in the first place in the very closest connection with the germ-cells or gonads. Thus Lankester, in his review of the history of the colom, states:-

"The numerous embryological and anatomical researches of the past twenty years seem to me to definitely establish the conclusion that the cœlom is primarily the cavity, from the walls of which the gonad cells (ova or spermata) develop, or which forms around those cells. We may suppose the first colom to have originated by a closing or shutting off of that portion of the general archenteron of Enterocola (Crelentera), in which the gonads developed as in Aurelia or as in C'tenophora. Or we may suppose that groups of gonarl mother cells, having proliferated from the endoderm, took up a position between it and the ectoderm, and there acquired a vesicular arrangement, the cells surrounding the carity in which liquid accumulated.

"The cœlom is thus essentially and primarily (as first clearly formulated by Hatschek) the perigonadial cavity or gonocœl, and the lining cells of gonadial chambers are coelomic epithelium. In some few groups of Ccelomocrela the cœloms have remained small and limited to the character of gonocols. This seems to be the case in the Nemertina, the Planarians, and other Platyhelmia. In some Planarians they are limited in number, and of individually large size ; in others they are numerous."

When Lankester says that "the lining cells of gonadial chambers are coelomic epithelium," that is equivalent to saying that the lining cells of the coelom form an epithelium which was originally gonadial, provided that, as seems to me most probable, his second suggestion, of the ccelom being formed from gonarlial mother-cells which have taken up an intermediate position between endoderm and ectoderm and there acquired a vesicular arrangement, is the true one. It does not seem to me possible to conceive of the gonads arising from cells of the epiblast or of the hypoblast, in the sense that such cells are differentiated cells belonging to a layer with a definite meaning. When we consider that the gonad gives origin to the whole of a new individual, that in the protozoan ancestors of the Metazoa their ultimate aim and object was the formation of gonads, it seems a wrong conception to speak of the gonads as formed from cells belonging either to the gut-wall or to the external epithelium. The gonads must stand in a category by themselves; they represent a whole, 
while the other cells represent only a part; they camnot therefore be derived from the latter. They may, and indeed clo, give rise to cells of a subordinate character, but they cannot rightly be spoken of as derived from such cells. The very fact mentioned by Lankester, that in the lorest colomatous Metazoa, the Platyhelminthes, the culoms are limited to the character of simple gonoccels, strongly points to the conclusion that ali the colomic cells were originally of the nature of gonadial cells, and therefore free-living and independent of the rest of the cells of the body. Whether the germ-cells appear, as in Hydra, to be derived from the ectoblast, or, as is nsually stated, from the endoblast, in neither case ought they to be classed with the internal or external epithelium; they are germ-cells, and the epithelium which they form is neither epiblastic nor hypoblastic, but germinal, forming originally a simple gonoccele, afterwards, in the higher forms, the colom with its cells of various function. Thus, to quote again from Lankester, "The cœlomic fluid and the colomic epithelium, as well as the floating corpuscles derived from that epithelium, acquire special properties and importance over and above the original functions subservient to the maturation of the gonadial cells ... the most important developments of the colom are in connection with the establishment of an exit for the generative products through the body-wall to the onter world, and further in the specialization of parts of its lining epithelium for renal excretory functions."

Such exits led very early to the formation of colomoducts, which are true outgrowths of the culom itself (p. 14): "The ccelomoducts and the gonoccels of which they are a part, frequently acquire a renal excretory function, and may retain both the function of genital concluits and of renal organs, or may, where several pairs are present (metamerized $01^{\circ}$ segmented animals), subserve the one function in some segments of the body, and the other function in other segments."

The origin of the colom and its derivatives from a germinal membrane, as suggested by Lankester, appears to me most probable, and, if true, it carries with it conclusions of far-reaching importance, for it necessitates that all the cells which line true colomic cavities, and their derivatives, belong to the category of free-living cells, and are not connected with the nervous system. The cells in question are essentially those which line serous cavities and those which form excretory glands such as the kidneys. In the latter organ we onght especially to be able to obtain a clear answer to this question, for is 
it not a gland which secretes into a duct and might therefore be expected to be innervated in the same way as other secretory glands? Althongh there is a strong mima fucic presumption in favour of the existence of renal secretory nerves, yet according to the universal opinion of physiologists no evidence in favour of such nerves has litherto been found; all the phenomena of excretion of urine consequent on nerve stimulation are explicable by the action of nerves on the renal ressels, not on the renal cells. Not only is the physiological evidence negative up to the present time, but also, I think, the histological. On the one hand, letzius has failed to find nerve-connections with kidney-cells; on the other, Berkley has obtained such evidence with the Golgi method, but failed entirely with methylene blue. I do not myself think that the evidence of the Golgi method alone is sufficient without corroboration by other methods, and, in any case, Berkley's evidence does not show the nerve-fibres terminating in the kidney-cells, in the same way as can be shown by modern methods to exist in the case of epithelial cells of the surface, etc. Quite recently another paper on this subject has appeared by Smiruow, who appears to have obtained better results than those given by Berkley.

Apart from these physiological and histological considerations, this question is also dependent upon the nature of the development of the excretory organs, for, according to Lankester, all excretory organs may be divided into the two elasses of nephridial organs and crelomostomes, of which the former are largely derived from epiblast. We should, therefore, expect to find secretory nerres to nephridial organs, though possibly not to calomostomes. The kidneys of the Mammalia are supposed to be true colomostones, although, according to Goodrich's researches, the excretory organs in Amphioxus are solenocytes, i.e. true nephridia.

As to the lining epithelium of the peritoneal, pleural, and pericardial cavities-i.e. the mesothelium-there is no definite evidence that these cells are providecl with nerves. Such surfaces are remarkably insensitive in the healthy condition, and the pain in such cavities is essentially a pressure phenomenon and referable to special sense-organs, such as Pacinian bodies, ete., rather than to the mesothelium itself.

These sense-organs are identical in structure with those in the skin, and, as Anderson has shown, the nerves of these organs 
medullate at the same time as those in the skin, and both obtain their medullary sheaths earlier than any other nerves, whether afferent or efferent. However difficult it may be to explain this fact, only one conclusion seems to me possible-these Pacinian bodies, like the skin Pacinians, originate from a nest of surface epithelial cells, a conclusion which is extremely probable on my theory of the origin of vertebrates, but not, as far as I can see, on any other.

At the present moment the weight of evidence is, to my mind, in favour of the lining endothelium of the colomic cavities being composed of free cells, unconnected with the nervous system rather than the reverse, but I must confess that the question is undecided. If it be true that the coelomic lining is partly enterocolic and partly gonocolie, as Lankester teaches, then it would be natural that its cells should be in connection with the nervous system, to some extent at all events. This view is, however, based on very slender foundations. If the mesothelium is composed of celis capable of becoming free, it cannot give rise to the skeletal muscles, and it cannot therefore be right to speak of the skeletal muscles as derived from the lining cells of a part of the primary colom. The phylogenetic history of the musculature of the different animals points strongly to its intimate connection with and derivation from surface epithelial cells rather than from cœlomic mesothelial cells. Thus in the coelenterates, as seen in Hydra, the muscular layer arises directly from a modification of the surface epithelial cells; and right up to the annelids, even to the highest form in the Polychata, we still see it stated that the musculature, both circular' and longitudinal, arises from the ectoderm. In the Oligochreta and Hirudinea, according to Bergh, there are five rows of teloblasts on each side, of which four are ectodermic and give rise to the nerveganglia and the circular muscles, while one is mesoblastic and forms the nephridial organs and the longitudinal muscles. (The latter statement is, according to Bergh, well known, and is not particularly shown by him. These longitudinal muscle-bands always lie close against the nervous system at their first formation, and may well have been derived in connection with it.)

It is apparently only in the Vertebrata that the lining cells of the colomic eavity are definitely stated to give origin to the body-musculature, and taking into account on the one hand the eviclence of Graham Kerr as to the intimate connection between nerve-cell and 
muscle-cell from the very beginning, and on the other the manner in which all the skeletal muscles of the adult are lined with a lymphatic enclothelinm, I am strongly inclined to believe that at the closing up of the myocole, when the myomere separates from the mesomere, the lining cells remain scattered in among the forming musele-cells and form the ultimate lymphatic tissue of the muscles. If this is really so, then the evidence in favour of the mesothelium being composed of free cells not connected with the nervous system would be much strengthenel, for, on the one hand, an intimate relation exists between the connective tissue cells and the endothelium of the roots of the lymphatie ressels, a relation which, according to Virehow, has rendered it impossible to draw any sharp line of distinction between the two ; and, on the other, the lymphatic endothelium merges into the lining cells of the great serous cavities of the body.

It is impossible to conceive of an animal possessing a nervous system which is not in connection with sensory and muscular tissues; an isolated nerve-cell is a meaningless possession; but it is equally natural to conceive of a germ-cell being isolated, eapable of living an independent existence. Such a difference between the two kinds of tissues must have existed from the very commencement of the Metazoa, so that we must, it seems to me, imagine that in the formation of the Metazoa from the Protozoa the whole of the body of the latter did not break up into a mass of separate gonads, each capable of becoming a free-living protozoan similar to its parent, but that a portion proliferated into a inultinucleated syncytium while the remainder formed the free-living gonads. This multinucleated syncytium, or host, as it might be called, would still continue to exist for the purpose of carrying further afield the immortal gonads, which need no longer be all shed at one time.

In such an animal as Volvox globator we have an indication of the very kind of animal postulated as connecting the single-celled Protozoa and the multi-cellular Metazoa, for it consists of a manycelled ease which forms a hollow sphere, each of the cells being provided with flagella for the purpose of locomotion of the sphere, cxcept a certain number which are not flagellaterl; the latter leave the case to swim freely in the fluil contained within the sphere, and forming spermaries aud ovaries, conjugate, maturate, and then are set free by the rupture of the encircling locomotor host. 
This conception of the predecessors of the Metazoa being composed of a mortal host, holding within itself the immortal sexual prodnets, leads naturally to the idea of the separate development of the host from that of the germ-cells ab initio, so that the study of the development of the Metazoa means the study of two separate constituents of the metazoan individual - on the one hand, the elaboration of the elements forming the syneytial host, on the other, of those derived from the free-living independent germcells. The elaboration of the host means the differentiation of the protoplasm into epithelial, muscular, and nervous elements, by means of which the gonads were carried further afield and their nourishment as well as that of the host ensured.

The rite of the nervous system as the middleman between internal and external muscular and epithelial surfaces was, I imagine, initiated from the very earliest time. The further evolution of the host consisted in a greater and greater differentiation and elaboration of this nenro-epithelial syncytium, with the result of a steadily increasing concentration and departmental centralization of the main factor of the syncytium; in other words, it led to the origin and elaboration of a central nervous system. In the interstices of this syncytium the gonads were placed, and at first, doubtless, the life of the host ended when all the germ-cells had been set free. 'Reproduce and die' was, I imagine, the law of the Metazoa at its earliest origin, and throughout the ages, during all the changes of evolution, the reminiscence of such law still manifests itself even up to the highest forms as yet reached. With the differentiation of the syncytial host there came also differentiation of the free-living gronads, so that only some of them attained to the perfection of independent existence, capable of continuing the species; while others became subordinate to the first and provided them with pabulnm, manufacturing within themselves yolk-spherules, and thus in the shape of yolk-cells ministered to the developing egg-cell. Thus arose a germinal epithelium of which only a few of the elements passed out of the host as perfect individuals, the remainder being ntilized for the nutrition of these few. Such yolk-cells of the germinal epithelium would still, however, retain their character as free cells totally independent of the syncytial host, and, situated as they were between the internal and external epithelium, capable of amceboid movement, would uaturally have their phagocytic action 
utilized either as yolk-cells for the providing of pabulum to the eggrcell, or as excretory cells for the removal and rendering harmless of deleterious products of all kinds. Thus the free cells of the body would become differentiated into the three classes of germ-cells, yolk-celis, and excretory cells.

Further, the mass of gonads, which originally occupied so large a space within the interior of the host, necessarily, as the tissues of the host differentiated more and more, took up less and less space in proportion to the whole bulk of the host and formed a germinal mass of cells between the outer and inner epithelial layers. This germinal mass formed an epithelium, some of the members of which acted as scavengers for the inner and outer layers of the host, with the result that fluid accumulated between the two parts of the germinal epithelium in connection respectively with the external and internal epithelial surfaces of the host, and thus led to the formation of a gonoccele, which, by obtaining an external opening, a colomostome, gave origin to the coelom.

Again, with the longer life of the host, the setting free of the gonads no longer necessitating the destruction of the host, and also the gonads themselves requiring a longer and longer time to be fed up to maturity, the bulk and complexity of the whole organism increased and special supporting structures became a necessity. The host itself could and did provide these to a certain extent by secretions from its epithelial elements, but the intermediate supports were provided by the system of phagocytic cells utilizing the fluids of the body, at first in the shape of plasma-cells able to move from place to place, then settling down to form a connective tissue framework, and, later on, cartilage and bone.

So also were gradually evolved the whole of the endothelial structures; the lymph-cells, blood-cells, etc., all having their origin from the free cells of the body, which themselves originated in the extension of a germinal epithelium. Just as in a bee-hive the egrg-cells may form the fully developed sexual animal, whether drone or queen bee, or the asexual host of workers, so in the borly of the Metazoa the free cells may form either male or female germ-cells spermatozoa, or ova, or a host of workers, scavengers, repairers, foodproviders, all useful to the community, all showing their common origin by their absolute independence of the nerrous system.

Two points of great importance follow from this method of looking 
at the problem. First, the evolution of the animal kingdom means essentially the evolution of the host, for that is what forms the individual; secondly, as the host is composed of a syncytium, the common factor of whose elements is the neural moiety, it follows that the tissue of central importance for the evolution of the host must be, as indeed it is, the nervous system. Further, seeing that the growth of the individual means the orderly spreading out of the epithelial moiety away from the neural moiety, it follows that the germ-band or germ-area from which growth starts must be in the position of the nervous system. If then, the nerrous system in the animal is a concentrated one, then the growth will emanate from the position of such nervous system. If, on the other hand, the nervous system is diffused, then the growth will also be diffused.

In this book I have throughout argued that the ancestors of vertebrates belonged to a great group of animals which gave origin also to Limulus and scorpion-like animals; it is therefore instructive to see what is the nature of the development of such animals. For this purpose I will take the development of the scorpion, as given by Brauer, for he has worked out its development with great thoroughness and care. His papers show that the segmentation is discoidal, and results in an oval blastodermic area lying on a large mass of yolk. Very early there separates out in this area genital cells and yolkcells, which latter move freely into the yolk and prepare it into a fluid pabulum for the nutrition of the eells of the embryonic shield or germ-band. These free yolk-cells do not take part in the formation of the germinal layers, nor does the endoderm when formed give origin to free yolk-cells.

The cells of the germ-band form a small eompact area, in which by continual mitosis the cells become more than one-layered, and soon it is found that those cells which lie close agaiust the fluid pabulum form a continuous layer and absorb the nutritious material for themselves and the rest of the embryo. While this area is thus increasing in thickness by continuous development, the group of genital cells remains always apart, increasing in number, but being always in a state of isolation from the cells of the rest of the growing area. Thus from the very first Brauer's observations on the development of the scorpion point to the formation of a syneytial host containing separate genital cells. The continuous layer of cells against the fluid pabulum, which is already functioning as a gut, and may 
therefore be called hypoblast, spreads continuously over the yolk, as also does the surface epithelial layer, or epiblast. Such spreading is always a continuous one for both surfaces, so that the yolk is gradually enclosed by a continuous orderly growth from the germband, and not by the settling down of free cells in the yolk here and there to form the gut-lining. This steady orderly development proceeds owing to the nourishment afforded by the activity of the free cells or vitellophags and the absorbing power of the hypoblast, a steady growth round the yolk which results in the formation of the gut-tube, the outer covering and all the muscular and excretory organs. Where, then, is this starting-point, this germ-band from which the whole embryo grows? It forms the mid ventral area of the adult animal, it corresponds exactly to the position of the central nervous system. The whole phenomenon of embryonic growth in the scorpion is exactly what must take place on the argument deduced from the study of the adult that the animal arises as a neuro-epithelial syncytium, and we see that that layer of cells which is situated next to the food-material forms the alimentary tube. It is not a question whether such layer is ventral or dorsal to the neural cells, but whether it is contiguous to or removed from the food-material.

Take, again, a meroblastic vertebrate egg as of the bird. Again we find free cells passing into the yolk to act as vitellophags, the so-called periblast cells; again we see that the embryo starts from a germband or embryonic shield, and spreads from there continuously and steadily; again we see that the layer of cells which lies against the yolk absorbs the fluid pabulum for the growing cells; again we see that the area from which the whole process of growth starts is that of the central nervous system, and again we see that those cells which are contiguous to the food form the commencing gut, and are therefore called hypoblast, though in this case they are ventral not dorsal to the neural layer.

The comparison of these two processes shows that there is one common factor, one thing comparable in the two, one thing that is homologous and is the essential in the formation of that part of the animal which $I$ have called the host, and that is the central nervous system. Whether the epithelial layer which lies ventrally to it or the one that is dorsal forms the gut depends upon the position of the food-mass. Where the food is, there will be the absorbing layer. 
Where the food is not, there will be no gut formation, whatever may have been the previous history of that layer. If, then, we suppose, as I do, that the vertebrate arose from a seorpion-like animal without any reversal of dorsal and ventral surfaces, and that the central nervous system remained the same in the two animals, then the comparison of the development of the two embryos shows that the one would be derived from the other if the yolk-mass shifted from the dorsal to the ventral side of the nervous system. This would leave the dorsal epithelial layer of the original syncytium free from pabulum; it would no longer form the definite gut, but it would still tend to form itself in the same manner as before, would still grow from a ventrally situated germ-band dorsalvasds to form a tube, would recapitulate its past history, and show how the atimentary canal of the arthropod became the neural eanal of the vertebrate. Although this alimentary eanal is formed in the same way as before, it is no longer recognized as homologous with the scorpion's alimentary canal, but because it no longer absorbs pabulum, and does not therefore form the definite gut, it is called an epiblastic tube, and, in the words of Ray Lankester, has no developmental importance.

All the arthropods are built up on the same type, and in all the development may in its broad outlines be referred to the type just mentioned. So also with the vertebrate group; in both cases the position of the central nervous system determines the starting area of embryonic growth. In both cases the absorbing layer shows the position of the definite gut. A concentrated nervous system of this type is common to all the segmented animals from the annelids to the vertebrates, and in all cases the germ-band which indicates the first formation of the embryo is in the position of this nervous system.

As far as the embryo is concerned, there is no great difficulty in the conception that the yolk-mass may have shifted from one side to the other in passing from the arthropod to the vertebrate, for in the arthropod the embryo at first is surrounded by yolk and then passes to the periphery of the egg. If it is permissible to speak of a dorsal and ventral surface to an egg, and we may imagine the egg held with such dorsal surface uppermost, then the yolk would be situated ventrally to the embryo, as in the vertebrate, if the protoplasmic cells of the embryo rose from their central position to the surface through the yolk, while if they sank through the yolk, the yolk would be situated dorsally to the embryo, as in the arthropod. 
In cases where there is no yolk, or very little, as in Lucifer and Amphioxus respectively, the embryo is compelled to feed itself at a very early age; such embryos form a free-swimming pelagic ciliated blastula, the invagination of which, for the purpose of collecting food material out of the open sea, is the simplest method of obtaining nutriment. Here, as in other cases, it is the physiological necessity which determines the method of formation of the gut, and such similarity of appearance as exists between the gastrula of Lucifer and that of Amphioxus, by no means implies that the gut of the adult Lucifer is homologous with the gut of Amphioxus.

I have compared two meroblastic eggs of the two classes respectively, because the scorpion's egg is meroblastic. I imagine that no real difficulty arises with respect to holoblastic eggs, for the experiments of O. Hertwig and Samassa show that by centrifugalizing, stimulating, and breaking down of large spheres the holoblastic amphibian egg may be converted into a meroblastic one, and then development will proceed regularly, i.e. in this case also the growth proceeds from the animal pole; the large cells of the vegetal pole, like the yolk-cells of the meroblastic egg, manufacture pabulum for the growing syncytial host.

\section{Suminary.}

Any attempt to discover how rertebrates arose from invertebrates must be based upon the study of Comparative Anatomy, of Palreontology, and of Embryology. The arguments and evidence put forward in the precerling chapters show most clearly how the theory of the origin of rertebrates from palrestracans is supported by the geological eridence, by the anatomical evidence, and by the embryological evidence. Of the three the latter is the strongest and most conclusire, if it be taken to include the evidence given by the larval stage of the lamprey.

The stronghold of embryology for questions of this sort is the Law of Recapitulation, which asserts that the history of the race is recapitulated to a greater or less extent in the development of the individual. In the previous chapters such recapitulation has been shown for all the organs of the rertebrate boly. In this respect, then, embryology has proved of the greatest ralue in confirming the evidence of relationship between the palrestracan and the vertebrate, given by anatomical and geological study.

There is. howerer, another side to embryology, which claims that the tissues of all the Metazoa are built up on the same plan ; that in all cases in the rery early stage of the embryo three layers are formed, the epiblast. mesoblast, and hypoblast; that in all animals above the Protozoa these three layers are 
homologous, the epiblast in all cases forming the external or skin-layer. the hypoblast the internal or gont-layer.

Such a theory, therefore, as is adrocated in this book, which turns the gut of the arthropod into the neural canal of the vertebrate, and makes a new gut for the vertebrate from the exterual surface must be wrong, as it flatly contradicts the fundamental germ-layer theory.

Of recent years grave doubts have been thrown upon the validity of this theory, doubts which have increased in force year by year as more and more facts have been discovered which are not in agreement with the theory. So much is it now discredited that any criticism against my theory, which is based upon it, weighs nothing in the balance against the positive eridence of recapitulation already stated. If the germ-layer theory is no longer credited, npon what fundamental laws is embryology based?

In this chapter I have rentured to suggest a reply to this question, based on the uniformity of the laws of growth throughout the existence of the individual.

In the adult animal the body is composed of two kinds of tissues, those which are comnected with or at all events are under the control of the nervous system. and those which are capable of leading a free life independent of the nerrous system. These two kinds of tissnes can be traced back from the adnit to the embryo, and it is the task of embryology to find out how these two kinds of tissue originate.

The following ont of this line of thonght leads to the conception that, throughout the Metazoa, the body is composed of a host which consists of the master-tissues of the body, and takes the form of a nemro-epithelial syncytium. within the meshes of which free living independent organisms or cells live. so to speak, a symbiotic existence.

The evidence points to the origin of all these free cells from germ-cells, and thus leads to the conception that the blastula stage of every embryo represents two kinds of cells, the one which will form the mortal host being the locomotor neuro-epithelial cell, the other the independent immortal symbiotic germ-cell. Such conception leads directly to the conclusion that the blastula stage of erery member of the Metazoa is the embryonic representation of a Protozoan ancestor of the Metazoa; an ancestor. whose nature nay be illustrated by sucl a living form as Volvox globator, which, like a blastula. is composed of a layer of cells forming a hollow sphere. These cells partly bear cilia, aud so form a locomotor lost, partly are of a different character, and form male and female grerm-cells. The latter leave the surface of the sphere, pass as free individuals into its fluid contents, form spermaries and ovaries, and then by the rupture of the mortal locomotor host pass out into the external medium, as free swimming young Volvox.

It is of interest to note that such members of the Protozoa are among the most highly dereloped of the members of this great group.

From such a begimuing arose in orderly evolution. on the one hand. all the nemro-muscular and neuro-epithelial structures of the body-the so-called mastertissues; on the other, the germ-cells, the blood-corpuseles, lympli-corpuscles plasma and excretory cells, connective tissue cells, cartilage and bone-cells, etc., all of them independent of the central nervous system. all traceable to a modification of the original germ-cells. 
Such a riew of the processes of embryology brings embryology into harmony with comparative anatomy and phylogeny, for it makes the central nervous system and not the alimentary canal the most important factor in the derelopment of the host.

The growth of the individual, whether arthropod or vertebrate, spreads from the position of the central nerrous system, regardless of whether that position is a rentral or dorsal one with respect to the yolk-mass. Where the pabulum is, there is the definite gut, the lining walls of which are called in the embryo, hypoblast; but when the pabulum is no longer there, althorgh a tube is formed in the same manner as the alimentary canal of the arthropod, it is now called an epiblastic tube, and is known as the neural tube of the rertebrate.

This is the great fallacy of the germ-layer theory, a fallacy which consists of an argument in a vicious circle: thus the alimentary canal is homologous in all of the Metazoa, becanse it is formed of hypoblast, but there is no definition of hypoblast, except that it is always that layer which forms the definitive alimentary canal.

When, after the process of segmentation has been completed, a free swimming blastula results, unprovided with any store of pabulum in the shape of yolk, then the same physiological necessity canses such a form to obtain its nutriment from the surrounding medium. The simplest way to do this is by a process of invagination, in consequence of which food particles are swept into the invaginated part and then absorbed. For this reason in such cases true gastrula are formed, as in the case of Amphioxus among the rertebrates, and Lucifer among the crustaceans; such a formation does not in the least imply that the gut of the arthropod is homologous with that of the rertebrate. The resemblance between the two is not a morphological one, but due to the same physiological necessity. They are analogous formations, not homologous.

The muscular tissues are foumd to be formed in close connection with the nervous tissues, and in rery many cases are described as formed from epiblast, so that there are strong reasons for placing them in a special category of the so-called mesoblastic tissues. If they be separated out, then it seems to me, the rest of the mesoblast would consist of the free-living cells of the borly, which are not connected with the central nerrous system. In watching, then, the formation of mesoblast, defined in this way. we are watching the separation ont from the master-tissues of the body of the independent skeletal and excretory cells. 


\section{CHAPTER X V}

\section{FINAL REMARKS}

Problems requiring investigation-

Giant nerre-cells and giant-fibres; their comparison in fishes and in arthropods ; hlood-and lymph-corpuscles; nature of the skin; origin of system of unstriped muscles; origin of the sympathetic nerrous system ; biological test of relationship.

Criticism of Balanoglossus theory.-Theory of parallel development.-Importance of the theory adrocated in this book for all problems of Erolution.

Tre discussion in the last chapter on the "Principles of Embryology" completes the evidence which I am able to offer up to the present time in favour of my theory of the "Origin of Vertebrates." There are various questions which $I$ have left untouched, but still are well worth discussion, and may be mentioned here. The first of these is the significance of the giant nerve-cells and giant nerve-fibres so characteristic of the brain-region of the lower vertebrates. In most fishes two very large cells are most conspicuous objects in any transverse section of the medulla oblongata at the level of entrance of the auditory nerves. Each of these cells gives off a number of processes, some of which pass in the direction of the auditory nerves and one very large axis-cylinder process which forms a giant-fibre, known by the name of a Mauthnerian fibre. Each Mauthnerian fibre crosses the middle line soon after its origin from the giant-cell, and passes down the spinal cord on the opposite side right to the tail. Here, near the end of the spinal cord, it breaks up into smaller fibres, which are believed by Fritsch and others to pass out directly into the ventral roots to supply the muscles of the tail. Thus Bela Haller says: "The Mauthnerian fibres are known to give origin to certain fibres which supply the ventral roots of the last thrce spinal nerves, so that their terminal branches serve, in all probability, for the innervation of the muscles of the tail-fin." They do not occur in the eel, according to Haller, or in Silurus, according to Kölliker. 
Their absence in those fishes, in which a well-rleveloper tail-fin is also absent, increases the probability of the truth of Fritsch's original conclusion that these giant-fibres are associated axis-cylinclers for certain definite co-ordinated movements of the fish, especially for the lateral movement of the tail.

In Ammocotes, instead of two Mauthnerian fibres, a number of giant-fibres are found. They are called Müllerian fibres, and arise from giant-cells which are divisible into two groups. The first group consists of three pairs situated headwards of the level of exit of the trigeminal nerves. Two of these lie in front of the level of exit of the oculomotor nerves, and one pair is situated at the same level as the origin of the oculomotor nerres. The second group consists of a number of cells on each side at the level of the entrance of the fibres of the auditory nerves.

The Müllerian filbres largely decussate, as described by Ahlborn, and then become the most anterior portion of the white matter of the spinal cord, forming a group of about eight fibres on each side (Fig. 73). A few fibres are also found laterally, and slightly dorsally, to the grey matter. These giant-fibres pass down the spinal cord right to the anal region; their ultimate destination is unknowll. Mayer considers that in the first part of their course they correspond to those tracts of fibres known as the "posterior longitudinal bundles" in other vertebrates. I imagine, therefore, that the spinal part of their course represents the two antero-lateral descending tracts. The secoud group of giant-cells, which appears to have some connection with the auditory nerves, may represent "Deiter's nucleus." The whole system is probably the central nervous part of a co-ordination mechanism, which arises entirely in the pro-otic or prosomatic region of the brain-the great co-ordinating and equilibrating region per excellence.

If we turn now to the arthropor it is a striking coincidence that in the crayfish and in the lobster the work of Retzius, of Celesia, of Allen, and of many others demonstrates the existence of an equilibration-mechanism for the swimming movements of the tailmuscles, which is carried out by means of giant-fibres. These giantfibres are the axis-cylinder processes of giant-cells, situated exclusively in the brain-region, and they run through the whole ventral ganglionic chain in order to supply the muscles of the tail. In the rentral nerve-cord of the crayfish, according to Retzius, two specially large 
giant-fibres exist, each of which breaks up, at the last abdominal ganglion, into smaller fibres, which pass directly ont with the nerves to the tail-fin. Allen has shown that, in addition to these two specially large giant-fibres, there are a number of others, some of which, similarly to the Müllerian fibres of Ammocoetes, cross the middle line, while some do not. Each of these arises from a large nerve-cell and passes to one or other of the last pair of abdominal ganglia. The latter fibres, he says, send off collaterals, while the two specially large giant-fibres do not. The cells which give origin to all these large, long fibres are situated in or in front of the prosomatic region of the brain, similarly to the giant-cells, which give rise to the corresponding Müllerian fibres of Ammocotes. I do not know how far this system is represented in Limulus or Scorpio.

It is, to my mind, improbable that the Mauthnerian fibres pass out directly as motor fibres to the muscles of the tail-fin; it is more likely that they are conducting paths between the equilibrationmechanism in connection with the VIIIth nerve and the spinal centres for the movements of the tail. Similarly, with respect to the arthropod, it is difficult to believe that the motor fibres for the tail-muscles arise in the brain-region. In either case, the striking coincidence remains that the movements of the tail-end of the body are regulated by means of giant-fibres which arise from giant-cells in the head-region of the body in both the Arthropoda and the lowest members of the Vertebrata.

The meaning of this system of giant-cells and giant-fibres in both classes of animals is well worthy of further investigation.

Another important piece of comparative work which ought to help in the elucidation of this problem is the comparison of the blondand lymph-corpuscles of the vertebrate with those of the invertebrate groups. As yet, I have not myself made any observations in this direction, and feel that it is inadvisable to discuss the results of others until I know more about the facts from personal observation.

The large and important question of the manner of formation of the vertebrate skin has only been considered to a slight extent. A much more thorough investigation requires to be made into the nature of the skin of the oldest fishes in comparison with the skin of Ammoccetes on the one side, and of Limulus and the Palrestraca on the other.

The muscular system requires further investigation, not so much 
the different systems of the striated voluntary musculature-for these have been for the most part compared in the two groups of animals in previous chapters - as the involuntary unstriped muscnlature, about which no word has been said. The origin of the different systems of unstriped muscles in the vertebrate is bound up with the origin of the sympathetic system and its relation to the cranial and sacral visceral systems. The reason wlyy I have not included in this book the consideration of the sympathetic nervous system is on account of the difficulty in finding any such system in Ammocates. Also, so far as I know, the distribution of unstriped muscle in Ammocotes has not been worked out.

One clue has arisen quite recently which is of great importance, and must be worked ont in the future, vi\% the extraordinary connection which exists between the action of the sympathetic nervons system and the action of adrenalin. This substance, which is obtained from the medullary part of the adrenal or suprarenal glands, when injected into an animal produces the same effects as stimulation of the nerves, which belong to the lumbo-thoracic ontflow of visceral nerves, i.e. the system known as the sympathetic nervous system, which is distinct from both the cranial and sacral outflows of visceral nerves. The similarity of its action to stimulation of nerves is entirely confined to the nerves of this sympathetic system, and never resembles that of either the cranial or sacral visceral nerves.

Another most striking fact which confirms the great importance of this connection between the adrenals and the sympathetic nervous system from the point of view of the evolution of the latter system is that the extract of the adrenals always produces the same effect as that of stimulation of the nerves of the sympathetic system: whatever may be the animal from which the extract is obtained. Thus adrenalin obtained from the elasmobranch fishes will produce in the highest mammal all the effects known to occur upon stimulation of the nerves of its sympathetic system.

Further, the cells, which are always associated with the presence of this peculiar substance-adrenalin-stain in a characteristic manner in the presence of chromic salts. In Ammoccetes patches of cells which stain in this manner have been described in connection with blood-vessels in certain parts, so that, although I know of no definite evidence of the existence of cell-groups in Ammocœetes corresponding to the ganglia of the sympathetic system in other vertebrates, it is 
possible that further investigation into the nature and connection of these "chromaffine" cells may afford a clue to the origin of the sympathetic nervous system. At present it is premature to discuss the question further.

Finally, another test as to the kinship of two animals of different species must be considered more fully than I have been able to do $u p$ to the present time. This test is of a totally different nature to any put forth in previous pages. It is known as the "biological test" of relationship, and is the outcome of pathological rather than of physiological or anatomical research. It is possible that this test may prove the most valuable of all. At present we do not know sufficiently its limitations and its sources of error, especially in the case of cold-blooded animals, to be able to look upon it as decisive in a problem of the kind considered in this book.

The nature of this test is as follows: It has been found that the serum of the blood of another animal, when injected in sufficient quantity into a rabbit, will cause such a change in the serum of that rabbit's blood that when it is added to the serum of the other animal a copious precipitate is formed, although the serum of normal rabbit's blood when mixed with that of another animal will cause no precipitate whatever. This extraordinary production of a precipitate in the one case and not in the other indicates the production of some new substance in the rabbit's serum in consequence of the introduction of the foreign serum into the rabbit, which brings about a precipitate when the rabbit's serum containing it is mixed with the serum originally injected. The barbarous name "antibody" has been used to express this supposed substance in accordance with the meaning of such a word as "antitoxin," which has been a long time in use in connection with preventive remedies against pathogenic bacteria. Now, it is found that the rabbit's serum containing a particular "antibody" will cause a precipitate only when added to the serum of the blood of the animal from which the "antibody" was produced or to the serum of the blood of a nearly related animal.

Further, if that animal is closely related a precipitate will be formed nearly as copious as with the original serum, if more distantly related a cloudiness will occur rather than a precipitate, and if the relationship is still more distant the mixture of the two sera will remain absolutely clear. Thus this test demonstrates the close relationship of man to the anthropoid apes and his more distant 
relationship to monkeys in general. By this method very evident blood-relationships have been demonstrated, especially between nembers of the Mammalia.

I therefore started upon an investigation into the possibility of proving relationship in this way between Limulus and Ammoccetes, with the kind assistance of Mr. Graham Smith. I must confess I was nut sanguine of success, as I thought the distance between Limulus and Ammocetes was too great. Dr. Lee, of New York, kindly provided me with most excellent serum of Limulus, and the first experiments showed that the anti-serum of Limulus gave a most powerful precipitate with its own serum. Graham Smith then tried this anti-serum of Limulus with the serum of Ammocotes, and to his surprise, and mine, he obtained a distinct cloudiness, indicative of a relationship between the two animals. This, however, is not considered sufficient, the reverse experiment must also succeed. I therefore, with Graham Smith, obtained a considerable amount of blood from the adult lampreys at Brandon, and produced an antiserum of Petromyzon, which gave some precipitate with its own serum, but not a very powerful one. This anti-serum tried with Limulus gave no result whatever, but at the same time it gave no result with serum from Ammocœetes, so that the experiment not only showed that Petromyzon was not related to Limulus, but also was not related to its own larval form, which is absurd.

Considerable difficulties were encountered in preparing the Petromyzon anti-serum owing to the extreme toxic character of the lamprey's serum to the rabbit; in this respect it resembled that of the eel. It is possible that the failure of the lamprey's anti-serum was due to the necessity of heating the serum sufficiently to do away with its toxicity before injecting it into the rabbit. At this poiut the experiments have been at present left. It will require a long and careful investigation before it is possible to speak decisively one way or the other. At present the experiment is positive to a certain extent, and also negative; but the latter proves too much, for it proves that the larva is not related to the adult.

Some day I hope this "biological test" will be of use for determining the relationships of the Tunicata, the Enteropueusta, Amphioxus, etc., as well as of Limulus and Ammoccetes.

The origin of Vertebrates from a Palæostracan stock, as put forward in this book, gives 110 inclication of the systematic position 
of the Tunicata or Enteropneusta. Neither the Tunicata nor Amphioxus can by any possibility be on the direct line of ascent from the invertebrate to the vertelrate. They must both be looked upon as persistent failures, relies of the time when the great ehange to the vertebrate took place. The Enteropneusta are on a different footing; in their case any evidence of affinity with vertebrates is very much more doubtful.

The observer Spengel, who has made the most exhaustive study of these strange forms, rejects in toto any connection with vertebrates, and considers them rather as aberrant annelids. The so-called evidence of the tubular central nervous system is worth nothing. There is not the slightest sign of any tubular nervous system in the least resembling that of the vertebrate. It is simply that in one place of the collar-region the piece of skin containing the dorsal nerve of the animal, owing to the formation of the collar, is folded, and thus forms just at this region a short tube. My theory explains in a natural manner every portion of the elaborate and complicated tube of the vertebrate central nervous system. In the Balanoglossus theory the evolution of the vertebrate tube in all its details from this collar-fold is simple guesswork, without any reasonable standpoint. Similarly, the small closed diverticulum of the gut in Balanoglossus, which is dignified with the name of " notochord," has no right to the name. As I have already said, it may help to understand why the notochord has such a peculiar structure, but it gives no help to understanding the peculiar position of the notochord. The only really striking resemblance is between the gill-slits of Amphioxus and of the Enteropneusta. In this comparison there is a very great difficulty, very similar to that of the original attempts to derive vertebrates from annelids-the gill-slits open ventrally in the one animal and dorsally in the other. In both animals an atrial cavity exists which is formed by pleural folds, and in these pleural folds the gonads are situated so that the similarity of the two branchial chambers seems at first sight very complete. In the Enteropuensta, however, there are certain forms-Ptychodera-in which these pleural folds have not met in the mid-line in this branchial region, and in these it is plainly visible that these folds, with their gonads, spring from the ventral mid-line and arch over the dorsal region of the body. Equally clearly Amphioxus shows that its pleural folds, with the gonads, spring from the dorsal sicle of the animal, 
and grow ventralwards until they fuse in the ventral mid-line (cf. Fig. 168).

As far, then, as this one single striking similarity between Amphioxus and the Enteropneusta is concerned it necessitates the reversal of dorsal and ventral surfaces to bring the two branchial chambers into harmony.

In a mud-dwelling animal, like Balanoglossus, which possesses no appendages, no special sense-organs, it seems likely enough that ventral and dorsal may be terms of no particular meaning, and consequently what is called ventral in Balanoglossus may correspond to what is dorsal in Amphioxus; in this way the branchial regions of the
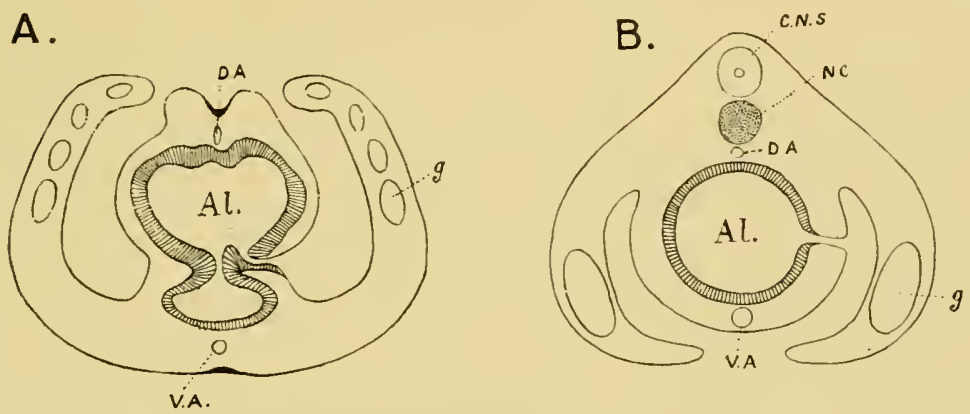

Fig. 168.--Diagran illustrating the Position of the Pleural Folds axd Goxads in Ptychodera (A) and Amphroxts (B) respectively.

Al., alimentary canal ; D.A., dorsal ressel; T.A., ventral vessel; g., gunads; NC., notochord; C.N.S., central nervous system.

two animals may be elosely compared. Such comparison, however, immediately upsets the whole argument of the vertebrate nature of Balanoglossus based on the relative position of the central nervous system and gut, for now that part of its nervous system which is looked upon as the central nervous system in Balanoglossus is ventral to the gut, just as in a worm-like animal, and not dorsal to it as in a vertebrate.

There is absolutely no possibility whatever of making such a detailed comparison between Balanoglossus and any vertebrate, as I have done between a particular kind of arthropod and Ammocotes. In the latter case not only the topographical anatomy of the organs in the two animals is the same, but the comparison is valid even to microscopical structure. In the former ease the origin of almost all 
the vertebrate organs is absolutely hypothetical, no clue is given in Balanoglossus, not even to the segmented nature of the vertebrate. The same holds good with the evidence from Embryology and from Palæontology. I have pointed out how strongly the evidence in both cases confirms that of Comparative Anatomy. In neither case is the strength of the evidence for Balanoglossus in the slightest degree comparable. In Embryology an attempt has been made to compare the origin of the colom in Amphioxus and in Balanoglossus. In Palæontology there is nothing, only an assumption that in the Cambrian and Lower Silurian times a whole series of animals were evolved between Balanoglossus and the earliest armoured fishes, which have left no trace, although they were able to hold their own against the dominant Palæostracan race. The strangeness of this conception is that, when they do appear, they are fully armoured, as in Pteraspis and Cephalaspis, and it is extremely lard luck for the believers in the Balanoglossus theory that no intermediate less armoured forms have been found, especially in consideration of the fact that the theory of the origin from the Palsestracan does not require such intermediate forms, but finds that those already discovered exactly fulfil its requirements.

One difficulty in the way of accepting the theory which I have advocated is perhaps the existence of the Tunicata. I cannot see that they show any affinities to the Arthropoda, and yet they are looked upon as allied to the Vertebrata. I can only conclude that both they and Amphioxus arose late, after the vertebrate stock had become well established, so that in their legenerated condition they give indications of their vertebrate ancestry and not of their more remote arthropod ancestry.

In conclusion, the way in which vertebrates arose on the earth as suggested in this book carries with it many important far-reaching conclusions with respect to the whole problem of Evolution.

When the study of Embryology began, great hopes were entertained that by its means it would be possible to discover the pedigree of every group of animals, and for this end all the stages of development in all groups of animals were sought for and, as far as possible, studied. It was soon found, however, that the interpretation of what was seen was so difficult, as to give rise to all manner of views, depending upon the iliosyncracy of the observer. At his will he decided whether any appearance was ccenogenetic or palingenetic, 
with the result that, in the minds of many, embryology has failed to afford the desired clue.

At the same time, the geological record was looked upon as too imperfect to afford any real help; it was said, and is said, that the Cambrian and pre-Cambrian periods were so immense, and the animals discovered in the lower Silurian so highly organized, as to compel us to ascribe the origination of all the present-dlay groups to this immense early period, the animals of which have left no trace of their existence as fossils.

In consequence of, or at all events following upon, the supposed failure of embryology and of geology to solve the problem of the sequence of evolution of animal life, a new theory has arisen, which goes very near to the denial of evolution altogether. This is the theory of parallel development. It discards the old picture of a genealogical tree with main branches arising at different heights, these again branching and branching into smaller and smaller twigs, and substitutes instead the picture of the ribs of a fan, every rib running independently of every other, each group represented by a rib reaching its highest development on the circumference of the fan and coming nearer and nearer to a common point at the handle of the fan. This point of convergence, where all the groups ultimately meet, is so far back a.s to reach"to the lowest living organisms.

This, in my opinion, unscientific and inconceivable suggestion has arisen largely in consequence of a conception which has become firmly fixed in the minds of very many writers on this subject-the conception that in the evolution of every group, the higher members of the group are the most specialized in the peculiarities of that group, and it is impossible to obtain a new group with different peculiarities from such specialized members. If, then, a higher group is to arise from a lower, it must arise from the generalized nembers of that lower group, in other words, from the lowest members or those nearly akin to the next lower group.

Similarly, the highest members of this latter group are too specialized, and again we must go to the more generalized members of the group. In this way each separate specialized group is put.on one side, and so the conception of parallel development comes into being.

The evidence given in this book dealing with the origin of vertebrates strikes at the foundations of this belief, for it presents an 
image of the sequence of evolution of animal forms in orderly up ward progress, caused by the struggle for existence among the members of the race dominant at the time, which brought about the origin of the next higher group not from the lowest members of the dominant group, but from some one of the higher members of that group.

The great factor in evolution has been throughout the growth of the central nervous system; from that group of animals which possessed the highest nervous system evolved up to that time the next higher group must have arisen.

In this way we can trace withont a break, always following out the same law, the evolution of man from the mammal, the mammal from the reptile, the reptile from the amphibian, the amphibian from the fish, the fish from the arthropod, the arthropod from the annelid, and we may be hopeful that the same law will enable us to arrange in orderly sequence all the groups in the animal kingdom.

This very same law of the paramount importance of the development of the central nervous system for all upward progress will, I firmly believe, lead to the establishment of a new and more fruitful embryology, the leading feature of which will be, as suggested in the last chapter, not the attempt to derive from the blastula three germlayers common to all animals, but rather two sets of organs-those which are governed by the nervous system and those which are notand thus by means of the development of the central nervous system obtain from embryology surer indications of relationship than are given at present.

The great law of recapitulation, which asserts that the past history of the race is indicated more or less in the development of each individual, a law which of late years has fallen somewhat into disrepute, owing especially to the difficulty of interpreting the embryological history of the vertebrate, is triumphantly vindicated by the theory put forward in this book. Each separate vertebrate organ, une after the other, as shown in the last chapter, indicates in its development the manner in which it arose from the corresponding organ of the arthropod. There is no failure in the evidence of embryology, the failure is in the interpretation thereof.

So, too, my theory vindicates the geological method. There is no failure here; on the contrary, the record of the rocks proclaims with startling clearness not only the sequence of evolution in the 
vertebrate kingdom itself, but the origin of the vertebrate from the most highly-developed invertebrate race.

The study of the comparative anatomy of organs down to the finest details has always been a most important aid in finding out relationship between animals or groups of animals. My theory endorses this view to the uttermost, and especially indicates the study of the central nervous system and its ontgoing nerves as that comparative study which is most likely to afford valuable results.

As for the individual, so for the nation; as for the nation, so for the race; the law of evolution teaches that in all cases brain-power wins. Throughout, from the dawn of animal life up to the present day, the evidence given in this book suggests that the same law has always held. In all cases, upward progress is associated with a development of the central nervous system.

The law for the whole animal kingdom is the same as for the individual. "success in this world depends upon brains." 



\section{BIBLIOGRAPHY AND INDEX OF AUTHORS}

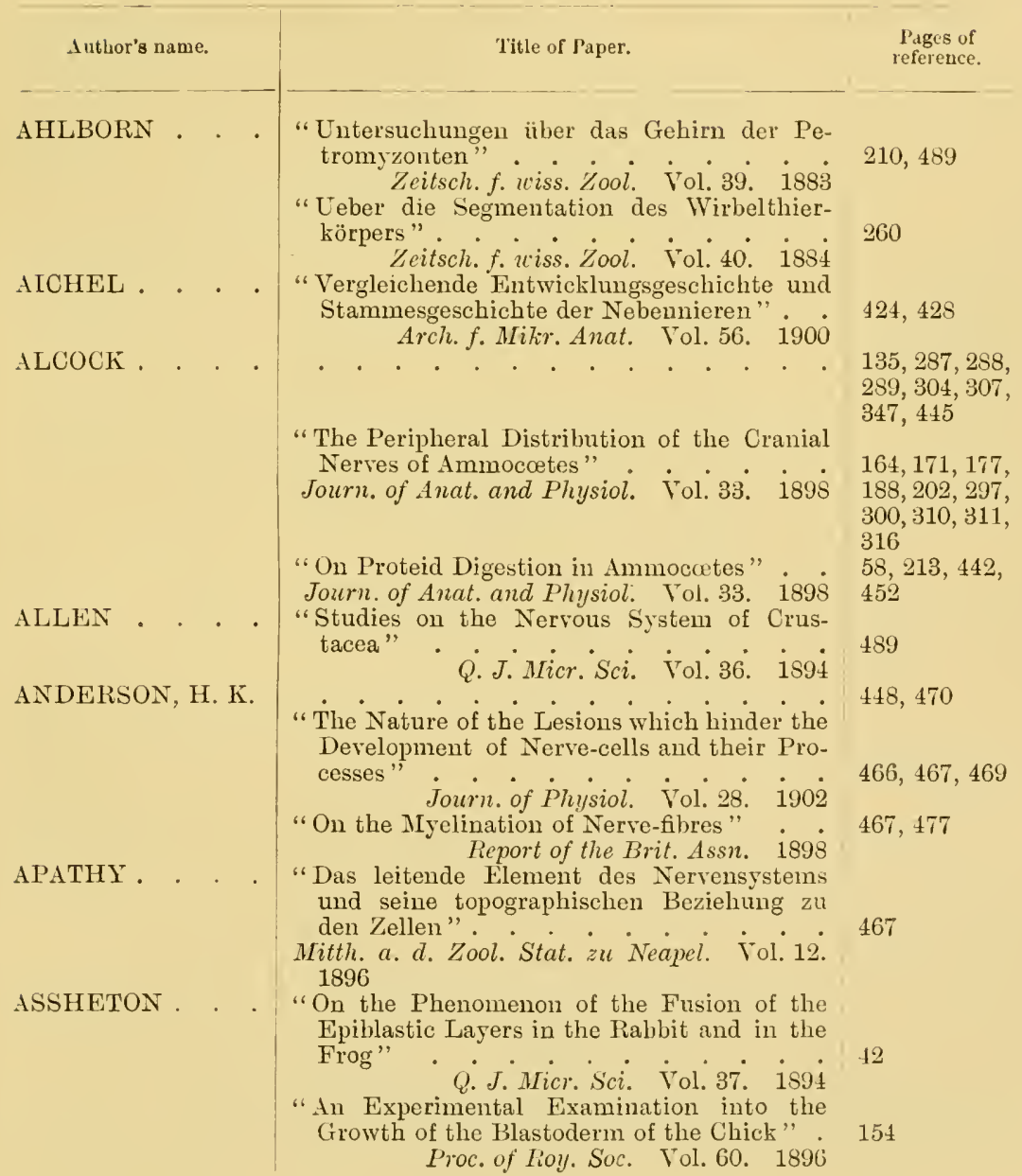




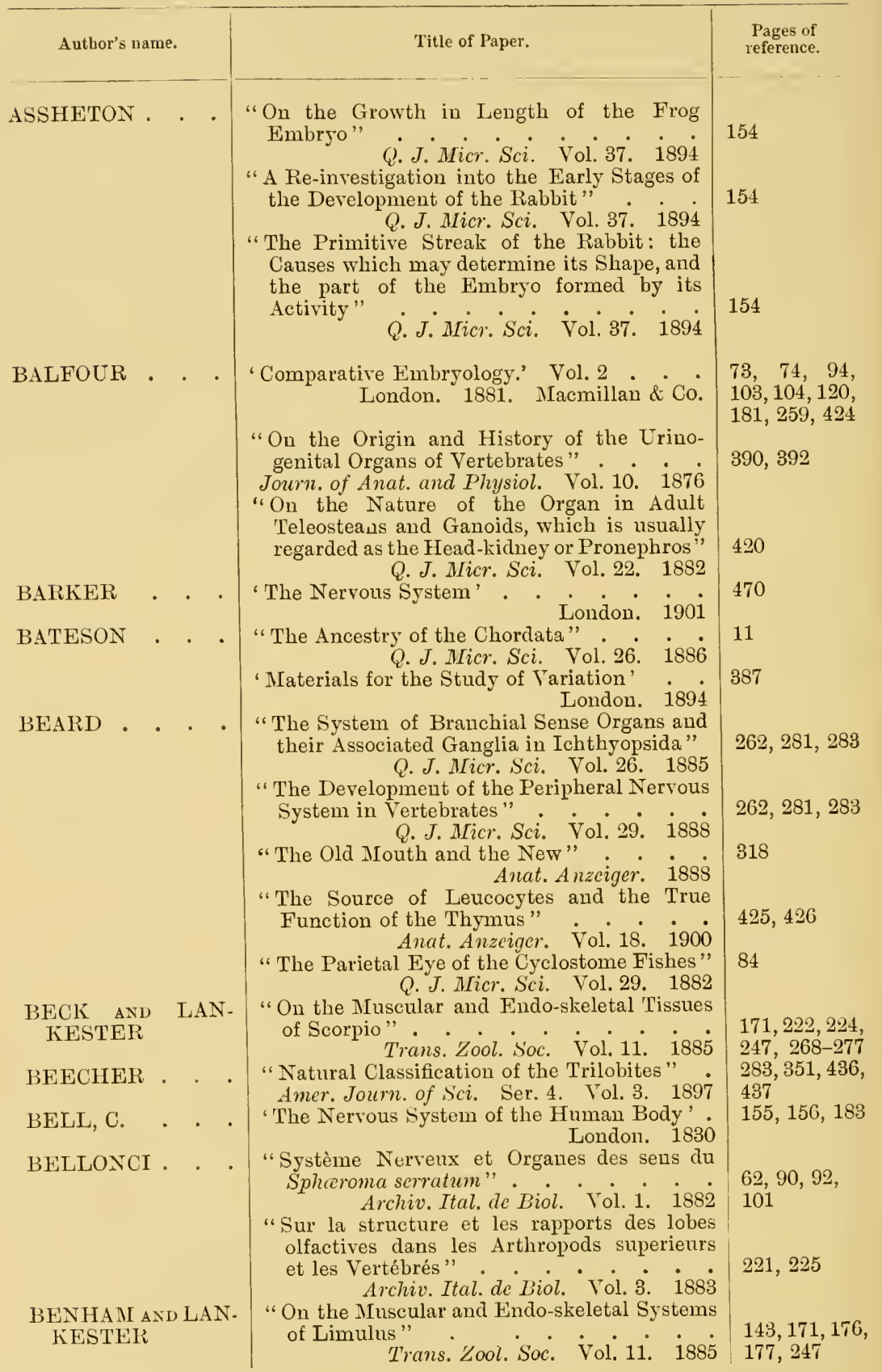




Author's name.
BERGER . . .
BERGH . . . .
BERKLEI . . .
BERNARD . .
BERTKAU . .
BIEDERIANN .
BLANCHARD . .
BLES . . .
BOBRETSKY . .
BOURNE AND LAN-
KESTER . . .

BRAEM . . . .
BRAUER. . . .

\section{BÜTSCHLI . . .}

BUJOR

CARLSON $: \cdot:$
CELESIA $: \cdot$

CLAUS
"Untersuchungen über den Bau des Gehirns und der Retina der Arthropoden" . $187 \dot{8}$

"Arbeit. a. d. Zool. Instit. Wien. Vol. 1. 1878 liden" . . . . . . . . . . Zeitsch. f. wiss. Żool. Vol, so. 1890 "The Intrinsic Nerves of the Kidney" . . 477

Bulletin of the Johns Hopkins Hospital. Vol. 4 'The Apodidæ : a NIorphological Study' : Nature Serics. 1892

"Beiträge zur Kenntniss der Sinnesorgane der Spinnen, 1. Die Augen der Spinnen" Archiv. f. mikr. Anat. Vol. 27. 1886 "Electro-physiology" . . . . . . . 20 Translated by F. A. Welby. London. 1896 Quoted by Huxley . . . . . . . . 225 'L'Organisation du Règne Animal. Arachnides' Paris. 1852

"The Correlated Distribution of Abdominal Pores and Nephrostomes in Fishes" Journ. of Anat. and Physiol. Vol. 32. 1898

'Development of Astacus and Palæmon' .

See Lankester and Bourne.

Kiew. 1873

"Die Nieren Canälchen des Amphioxus" . Zool. Jahrbuch. Vol. 5. 1892

"Was ist ein Keimblatt" . Biol. Centralblatt. Vol. 15. 1895

"Beiträge zur Kenntniss der Entwicklungsgeschichte des Skorpions" Zcit.f. wiss. Zool. Part I. Tol. 57. $189 \dot{4}^{\circ}$ Part II. Vol. 59. 1895

"Beiträge zur Kemutniss der Entwicklung und Anatomie der Gymnophionen." III. "Die Entwicklung der Excretionsorgane". Zool. Jahrbuch. Vol. 16, 1902

"Ueber die Entwicklung von Hydra" is. Zeit. f. wiss. Zool. Vol. 52. 1891

"Notiz zur Morphologie des Auges der MIuscheln" •. • •

Festschrift des Natur-hist-med. Tereins zu Heidelberg. 1886

"Contribution a l'étude de la métamorphose de l'Ammoccetes branchialis en Petromyzon Planeri". Revue Biologique à Nord dc la F̈rance. Vol. 3. 1891

'Differenziamento della proprietà inibitoria e dei funzioni coordinatrici nella catena gangliare dei crustacei decapodi' ' ' 1897 "Untersuchungen ïber den Organismus und Entwicklung von Branchipus und Artemia " Arbeit a.d. Zool. Institut. Wien. Vol. 6. 1886
Pages of reference.

88-92, 97, 100,101 478 284 369 $109,177,190$, $206,313,315$ 431 74

$392,395,402$, $407,412,426$, 427 $460,461,462$

$62,167,222$, 237, 281, 482

$393,394,400$, 402

473

114

135,304

$177,315,316$

489

$90-92,97,100$ 396 


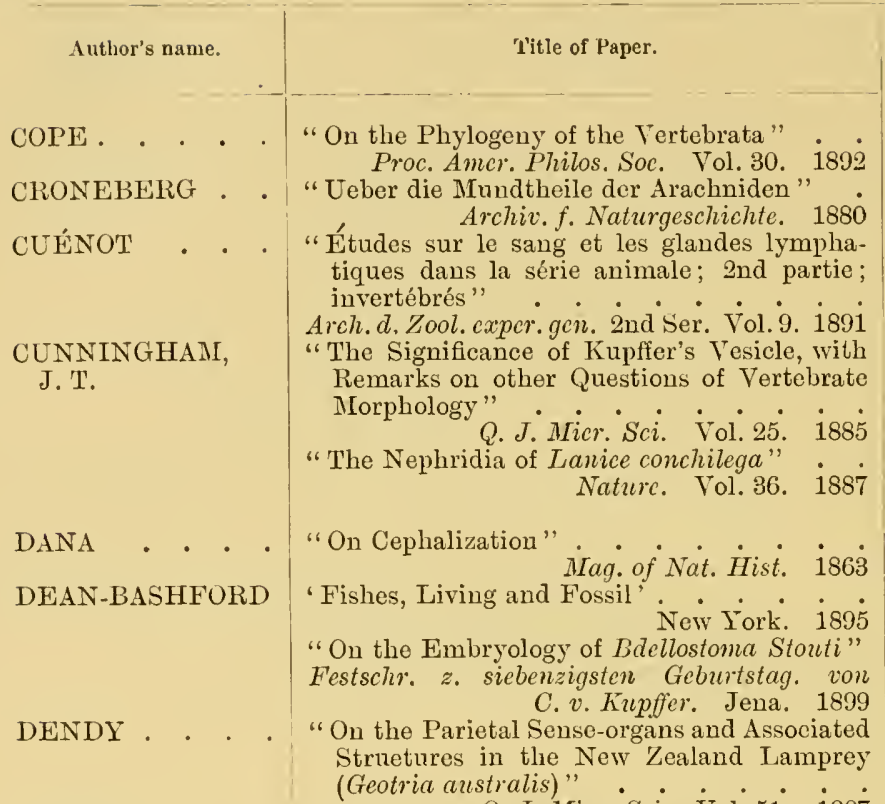

Q. J. Micr. Sci. Vol. 51. 1907 DIETL . • . "Die Organisation des Arthropoden Gehirus" DOHRN . . . 'Der Ursprung der Wirbelthiere und das Princip des Functions Wechsels' . . . Leipzig. 1875

Studien zur Urgeschichte des Wirbelthiere Körpers. VIII. "Die Thyroidea bei $\mathrm{Pe}$ tromyzon, Amphioxus, und 'Tunicaten" Mitth. Zool. Stat. z. Neapel. Vol. 6.1886

"Nene Grundlagen zur Beurtheilung der Metamerie des Kopfes" Mitth. Zcol. Stat. $z$. Neapel. 'Vol. 9. $189 \dot{0}$ Studien zur Urgeschichte des Wirbelthiere Körpers. XIII. "Ueber Nerven und Gefässe bei Ammocœetes und Petromyzon Plancri". Mitth. Zool. Stat. z. Neapel. Vol. 8. 1888 DREVERILAN . "Ueber Pteraspis dunensis" . . . . Zeitschr. d. Deutsch. Geol. Gesellschaft. Vol. 56. 1904

EDGEWORTH . . "The Development of the Head-muscles in Gallus domesticus, and the Morphology of the Head-muscles in the Sauropsida " . Q. J. Micr. Sci. Yol. 51. 1907

EDINGER . . 'Anatomy of Central Nervous System in Mau and in Vertebrates'.

Translated by Hall. 1899

Pages of refertnce.

343

$221-224,241$

422

80,82

101

$14,60,185$ $186,317,318$

$188,195-198$,

$199,212,213$

$262,263,279$

$167,314,337$

29,30

266

17,264

v. EICHWALD .

"Die Thior-und Pflanzenreste des alten rothen Sandsteins und Bergkalks im Nowgorodschen Gouvernement" . . . . . . Bull. Sci. de l'Acad. Impér. d. S't. Pctersbourg. 1840 
A uthor's name.

EISIG

ELLIOTT

EMERY . . . .

FOSTER, ML. . . FREUND . : :

FRITSCH, G. . .

FRORIEP . . .

FÜRBRINGER, M.

GAUBERT

GEGENBAUR .

r. GEHUCHTEN .

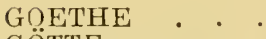

GÖTTE : : :

GOLGI GOODRICH
Title of Paper.

"Die Seiten-organe und becherförmigen Organe der Capitelliden" . • •. . Mitth.a.d. Zool. Stat. z. Neapel. Vol, 1. 1879 "Capitelliden" . . . . . . . . .

Faun. $u$. Flor. d. Golfes v. Neapel. Vol.16. 1887

"On the Innervation of the Ileo-colic Sphincter". . . . . . . . . . Jouin. of Lhysiol. Vol.31. $190 \dot{1}$

Quoted by Weldon . . . . . . .

Text-book of Physiology . . . "Die Beziehungen der Schilddrüise zu den weiblichen Geschlechtsorganen" . .

Deutsch. Zeitsch. f. Chirugie. Vol. 18. 1883

'Untersuchungen ïber den feineren Bar des Fischgehirns"

Berliu. 1878

"Ueber Anlagen fou Simnesorganen am Facialis, Glossopharyngeus und Vagus, über die genetische Stellung des Vagus zum Hypoglossus, und tiber die Herkunft der Zungenmusculatur" . . . . . . . . . Arch.f. Anat.u.Pinsiol; Anat. Abtheil. $1835^{\circ}$

'Ueber die Spino-occipetalen Nerren der Selachier und Holocephalen' . . is .
Fest-schrift für Carl Gegenbaur. 1897

'Recherches sur les organes des sens et sur les systèmes tegumentaire, glandulaire et musculaire des appendices des arachnides' Paris. 1892

"Anatomische Untersuchung eines Limulus" Abhandl. d. Naturforsch. Gesellsch. z. Halle. Tol. 4. 1858

"Ueber die Skeletgewebe der Cyclostomen" . Jen. Zeitschrift. Vol. 5. 1870

Untersuchungen zur rergleichende Anatomie der Wirbelthiere III. Heft. 'Das Kopfskelet der Selachiern' . ' Leipzig. 1872

'Grundriss der rergleichenden Anatomie' . Leipzig. $187 \dot{8}$

"De l'origine du pathétique et de la racine supérieure du trijumeau" . • • · *

Acad. d. Sci. Belg. Bulletin. 3rd Ser. Tol. 29. 1895

'Entwickluugsgeschichte der Unke' ' : Leipzig. 1875

"On the Structure of the Excretory Organs

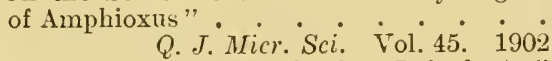

"On the Nephridia of the Polychota." Parts I., II., III. . • • • Q. J. Micr. Ści. Vols. 40,41, 43

"On the Excretory Organs of Amphioxus"
Proc. Poy. Soc. Tol. 69. 1902
261, 262, 281, 283

276-278, 409

364, 368-375

$20,358-360$

181

$151,259,261$

392

264

258

$101,102,114$

$72,465,477$

$395,396,477$

477 


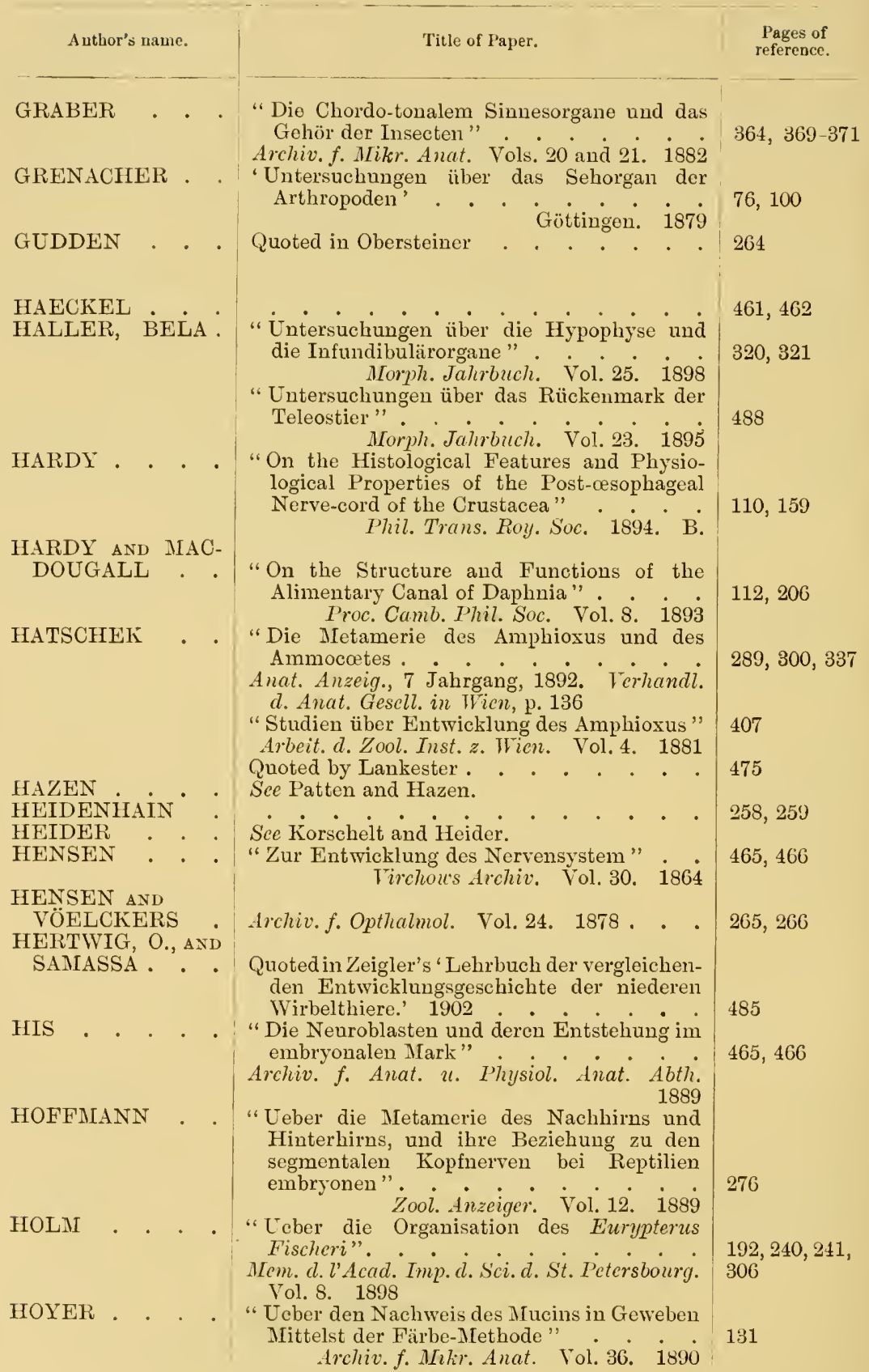




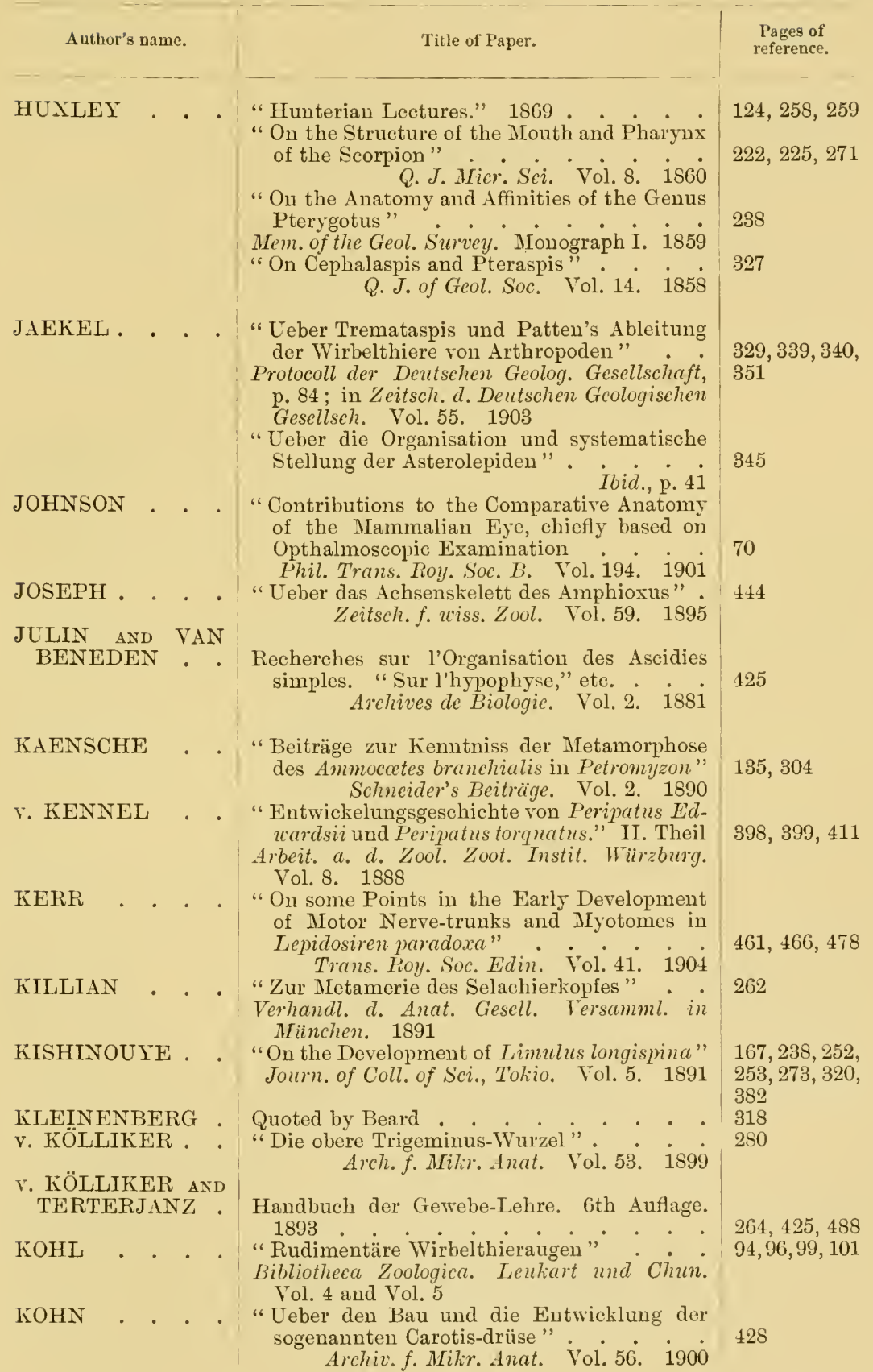




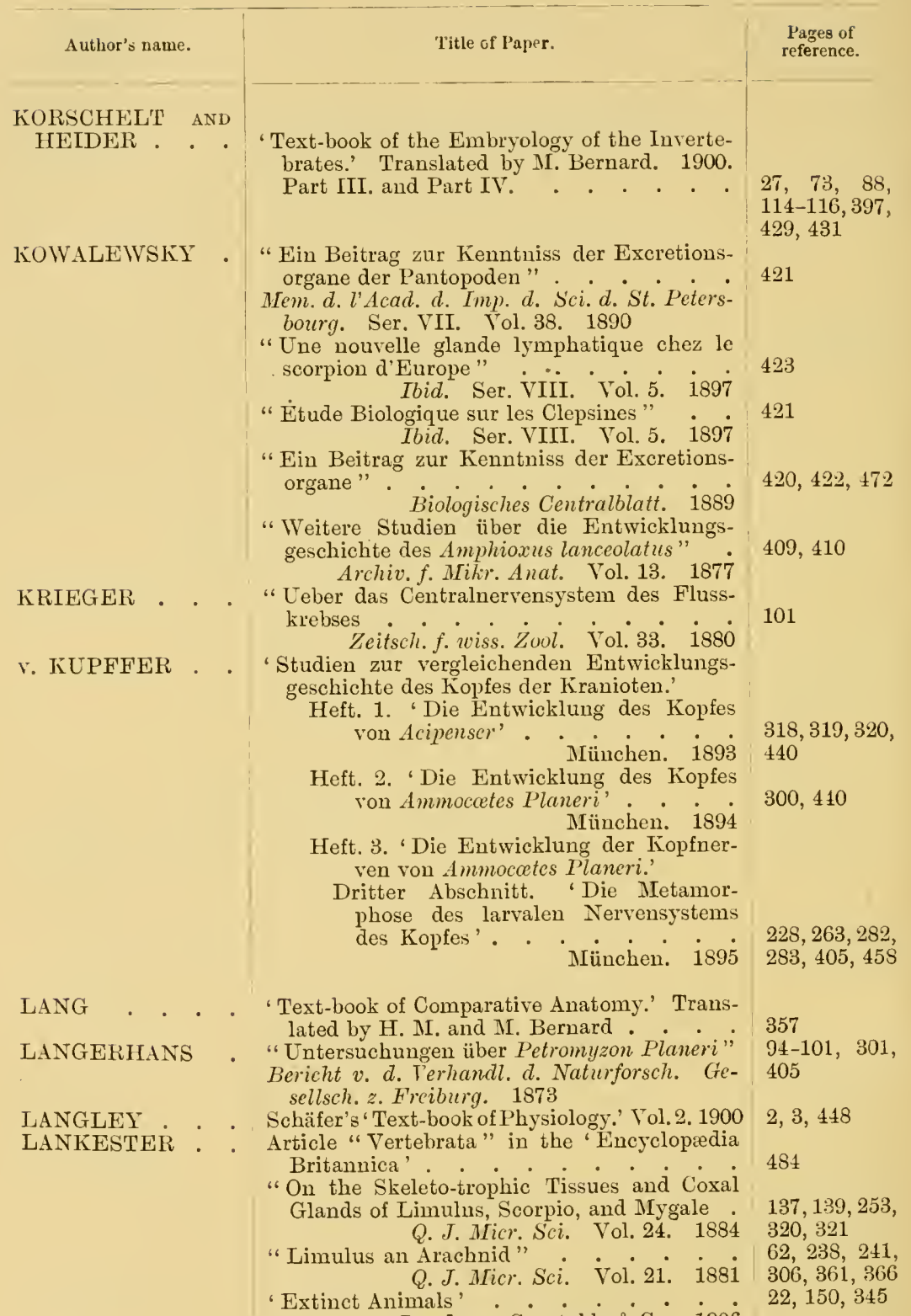

London. Constable \& Co. 1906 Lankester.

Part II. "The Entero-cola and the Colomoccela . . . . . . . 


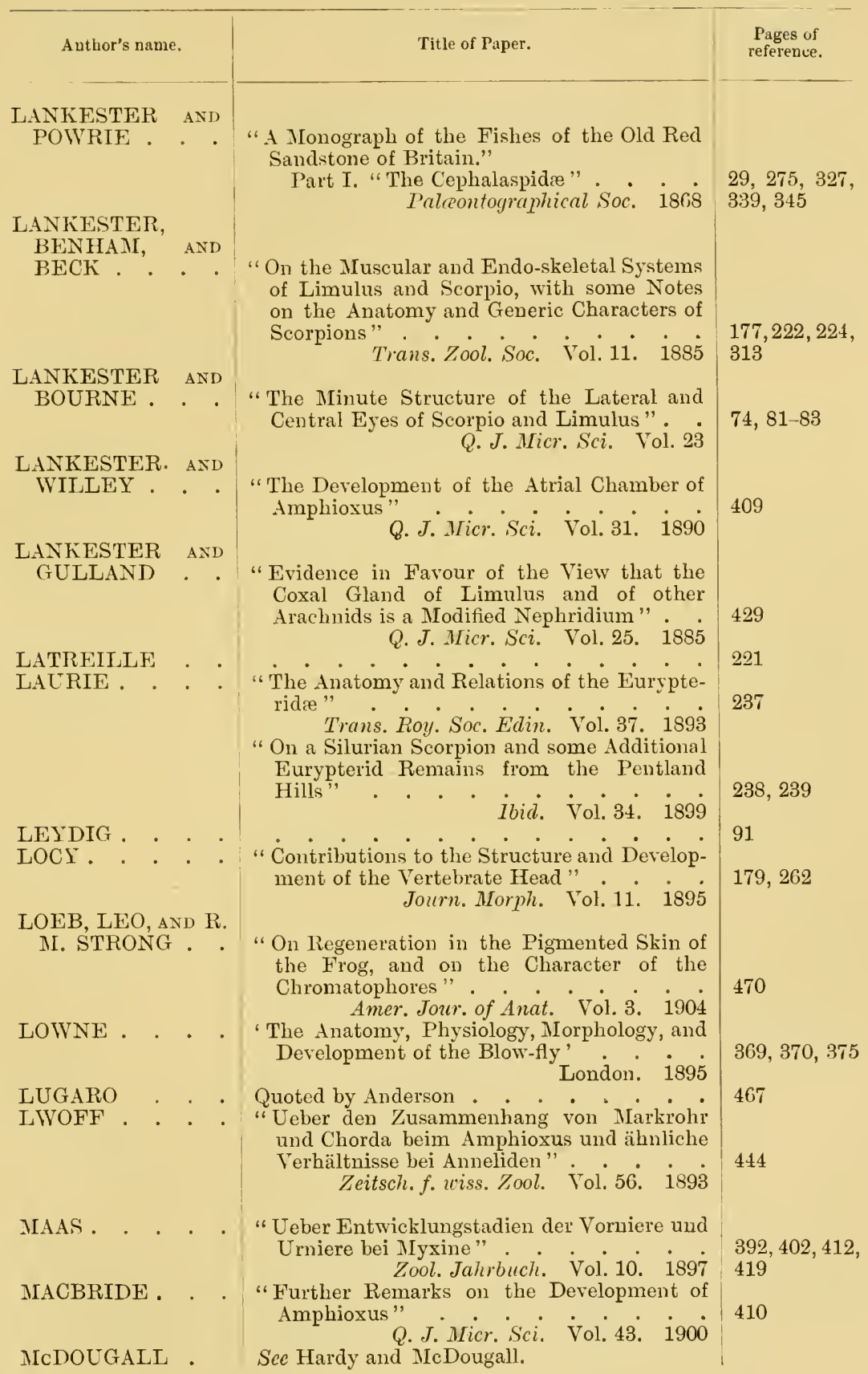




MACLEOD . . $\mid \begin{gathered}\text { Title of Paper. } \\ \text { MAGNor's name. }\end{gathered}$

MARK

MARSHALL '

MASTERMAN . .

MAURER . ·
MAYER, F. .
MAYER, P. .
METSCHNIKOW .
MEYER . . .

MILNE-EDWARDS

MINCHIN . . .

MITSUKURI

MOTT . .
MLOTT AND HALLI-
BURTON . · ·
MÜLLER, J. . .

MÜLLER, W. . .

NEAL

NESTLER
"On the Head-cavities and Associated Nerves of Elasmobranchs"

Q.J. Micr. Sci. Vol. 21. issi

"The Segmental Value of the Cranial Nerves"

Journ. of Anat. and Physiol. Vol. 16. 1882

"On the Diplochorda" . . . . . . . Q. J. Micr. Sci. Vol. $43 . \dot{1900}$

"Die Schilddrüse, Thymus und andere Schlundspaltenderivate bei den Eidechse". Morpỉ. Jahrbuch. Vol. 27. 1899

"Das Centralnervensystem von Ammocœetes" Anat. Anzeig. Vol. 13. 1897

"Ueber die Entwicklung des Herzens und der grossen Gefässstämme bei den Selachiern".

Mitth. a. d. Zool. Stat.z. Neapel. Vol. 7. 1887

Quoted by Kowalewsky . . . . . . .

"Studien über den Körperbau der Anneliden "

Mitth. a. d. Zool. Stat. z. Neapel. Vol.7. 1887

"Anatomie des Limules" . . . . . .

Annales des Sciences Naturelles. Ser. 5. Vol. 17. 1872

A treatise on Zoology. Edited by Ray Lankester. Part II. "The Porifera and Ccelenterata". . . . . . . . . . .

"On the Fate of the Blastopore, the Relations of the Primitive Streak, and the Formation of the Posterior End of the Embryo in Chelonia," etc. . . . . . . . . Journ. Coll. Sci. 'Tokyo. Vol. 10. 1896 "Croonian Lectures of the Roy. Coll. of Physicians," 1900 .

"On the Chemistry of Nerve-degeneration" . Phil. Trans. Roy. Soc. B. Vol. 194. $190 \mathrm{i}$

"Viergleichende Anatomie der Myxinoiden" " Abhandl.d. Kgl. Akad. d. Wiss. Berlin. $183 \dot{4}$

"Ueber die Stammes Entwickelung des Sehorgans der Wirbelthiere" . ‘. • ismi Festgabe C. Ludwig. Leipzig. 1874

"The Segmentation of the Nerrous System in Squalus acanthias"

Bull. of Mus. Comp. Zool. Harvard. Vol. 31 . 1898

"Beiträge zur Anatomie und Entwicklungsgeschichte von Petromyzon Planeri" Archiv. f. Naturgesch. Jahrgang, 56 . Vol. I. 1890
Pages of

reference.

169,174

447

115

185,186

260

16

$427,42 S$

489

422

403

$157,159,176$

177,313

473

179

469

1

126

$96-100,105$, 108

$179,266,300$

$168,171,175$, 445 


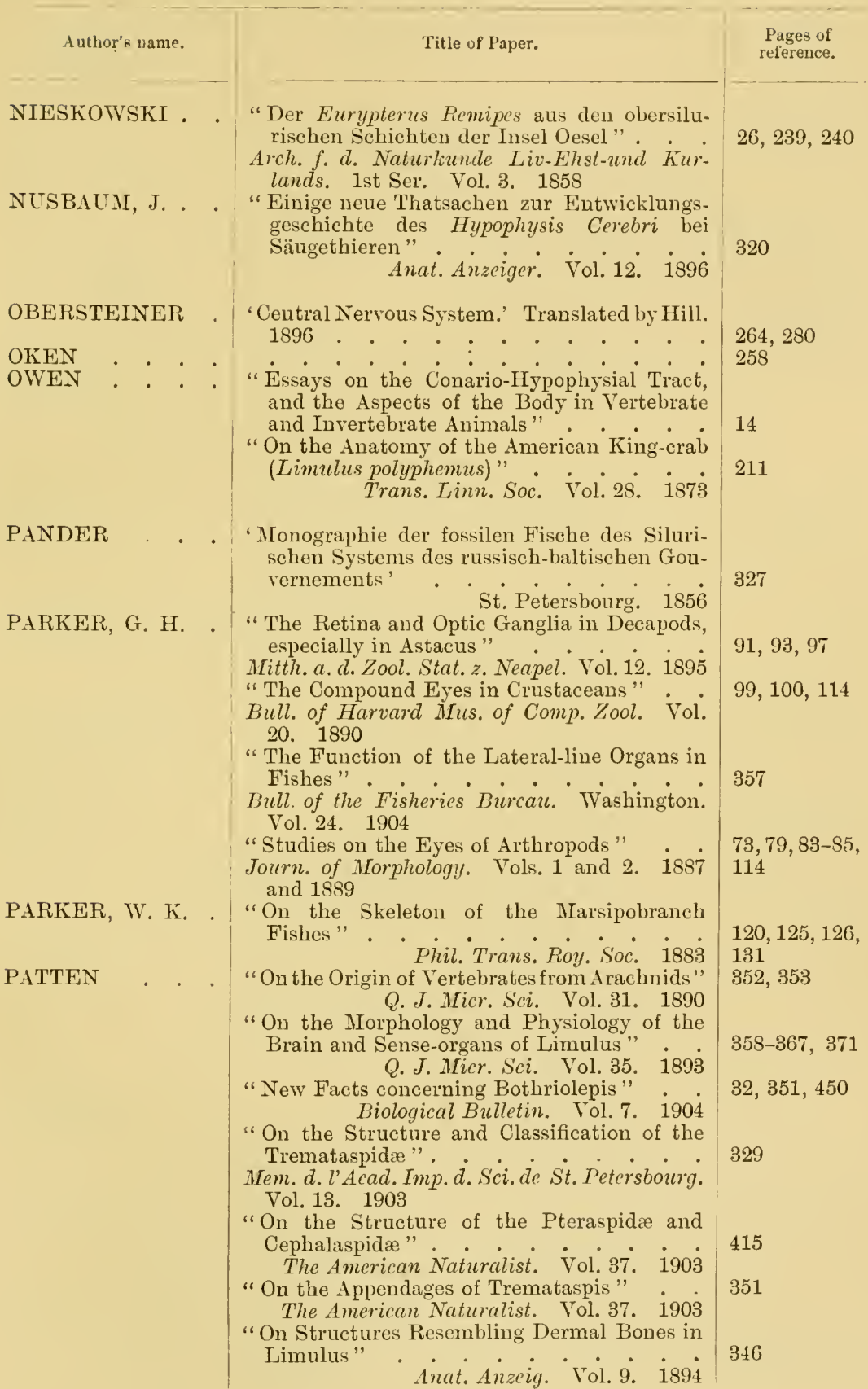




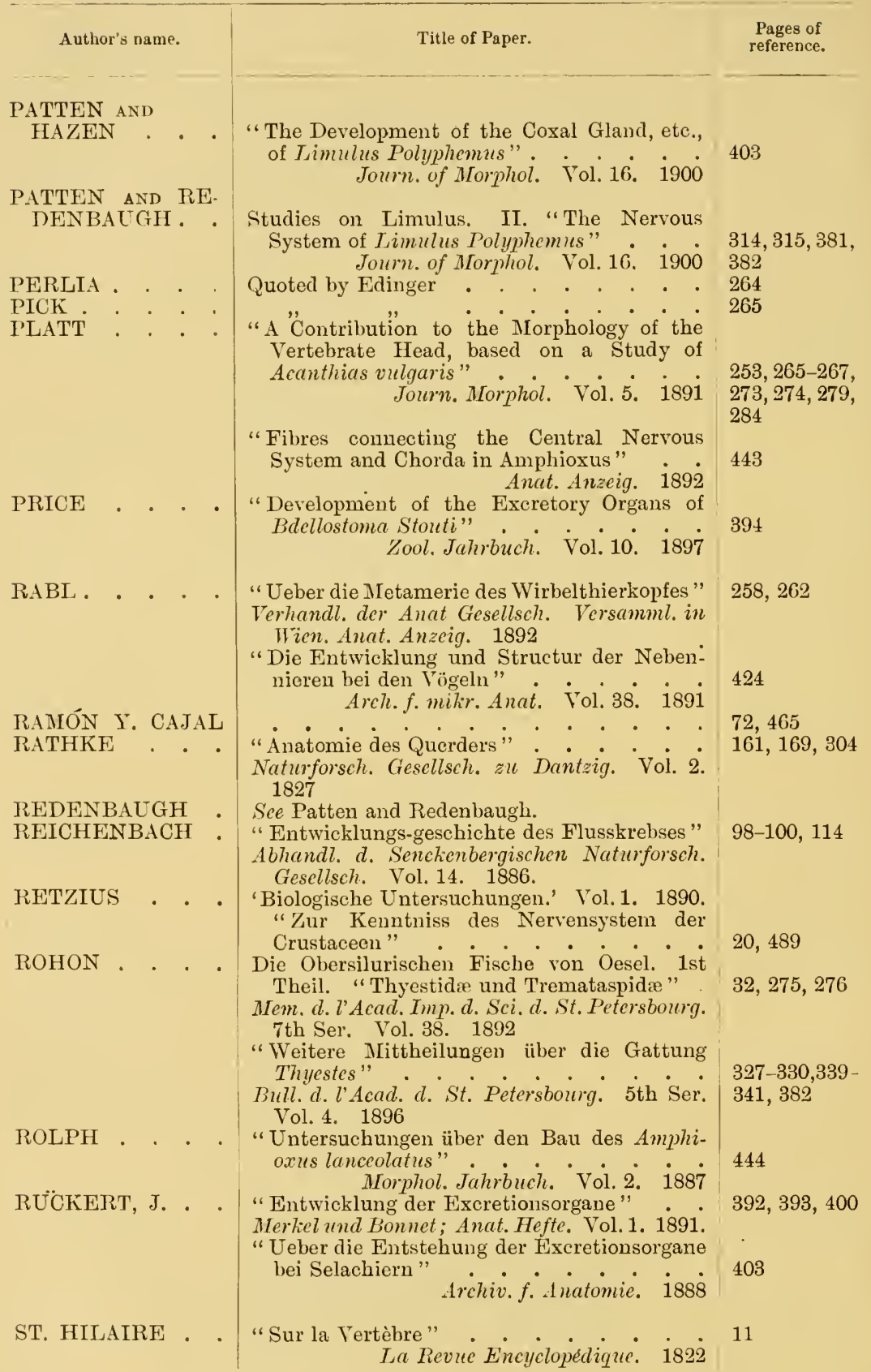


Author's name.

SAMASSA

SCHAFFER

SCHIMKËWITSCH

SCHMIDT

SCHMIEDEBERG.

SCHNEIDER, A. .

SCHNEIDER, G. .

SCOTT

SEDGWICK .

SEMON

SEMPER

SHELDON 。
Title of Paper.

"Bemerkungen über die Methode der Vergleichenden Entwicklungsgeschichte" . . . Biol. Centralblatt. Vol. 18. 1898

"Ueber das Knorpelige Skelett von Ammo-

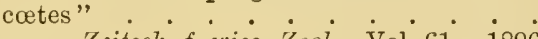
Zeitsch.f. wiss. Zool. Vol. 61 . 1896

"Ueber die Thymusanlage bei Petromyzon Planeri". •. • • • • .

Sitzungsber. d. K. Akad d. Wiss. in Wien. Vol. 103.1894

"Sur la structure et sur la signification de l'Endosternite des Arachnides" . . . . Zool. Anzeig. 1893

"Anatomie de l'Epeire" ' $\dot{\mathrm{V}} \dot{0}^{\circ} \mathrm{j}^{\circ}$ issi Ann. d. Sci. Nat. Vol. 17. 1884

"Die Crustaceen-fauna der Eurypteren. schichten von Rootzikiill auf Oesel" . .

Mem. d'Acad. Imp. d. Sci. d. St. Petersbourg. Vol. 31. 1883

"Ueber die chemische Zusammensetzung des Knorpels". . . . . . . . Arch. f. exper. Pathol. und Pharmat. Vol 28. 1891

'Beiträge zur Anatomie und Entwicklungsgeschichte der Wirbelthiere'

Berlin. 1879

" Ueber phagocytäre Organe und Chloragogenzellen der Oligochæta"

Zeitsch.f. uiss. Zool. Vol. 61. $1896^{\circ}$

"Notes on the Development of Petromyzon" Joum. of MLorphol. Vol. 1. 1887

"A Monograph of the Development of Peripatus capensis" . . . . . . . .

Studies from the Morphological Laboratory, Cambridge. Vol, 4. 1888

"Development of the Kiduey in its Relation to the Wolffian Body in the Chick"

Q. J. Micr. Sci. Vol. 20. 1880

"Early Development of the Wolffian Duct and Anterior Wolffian Tubules in the Chick; with some Remarks on the Vertebrate Excretory System" . . . . . . Q. J. Micr. Sci. V́ol. 21. is8i

"Das Excretionssystem der Myxinoiden" . Festschrift $f$. Gegenbaur. Leipzig. 1897

"Die Stammesverwandschaft der Wirbelthiere und Wirbellosen" . . . . . .

Arbeit. a. d. Zool. Zoot. Inst. Wiirzburg. Vol. 2. 1875

"Das Urinogenitalsystem der Plagiostomen und seine Bedeutung für die übrigen Wirbelthiere". . . . . "Vol.

Ibid. Vol. 2. $187 \dot{5}$

"On the Development of Peripatus NovaZealandie".... .. . . .

Studies from the Morphological Laboratory, Cambridge. Vol. 4. 1889
Pages of

reference.

462

126-135

426-428

143-145, 342

369

$190,191,236$,

$240,329,341$

$128,130,172$,

$195,197,213$, 310,445

421

$42,78,111$,

112,406

397-400

390

$393,394,400$

400,419

390,392

390,392

400 


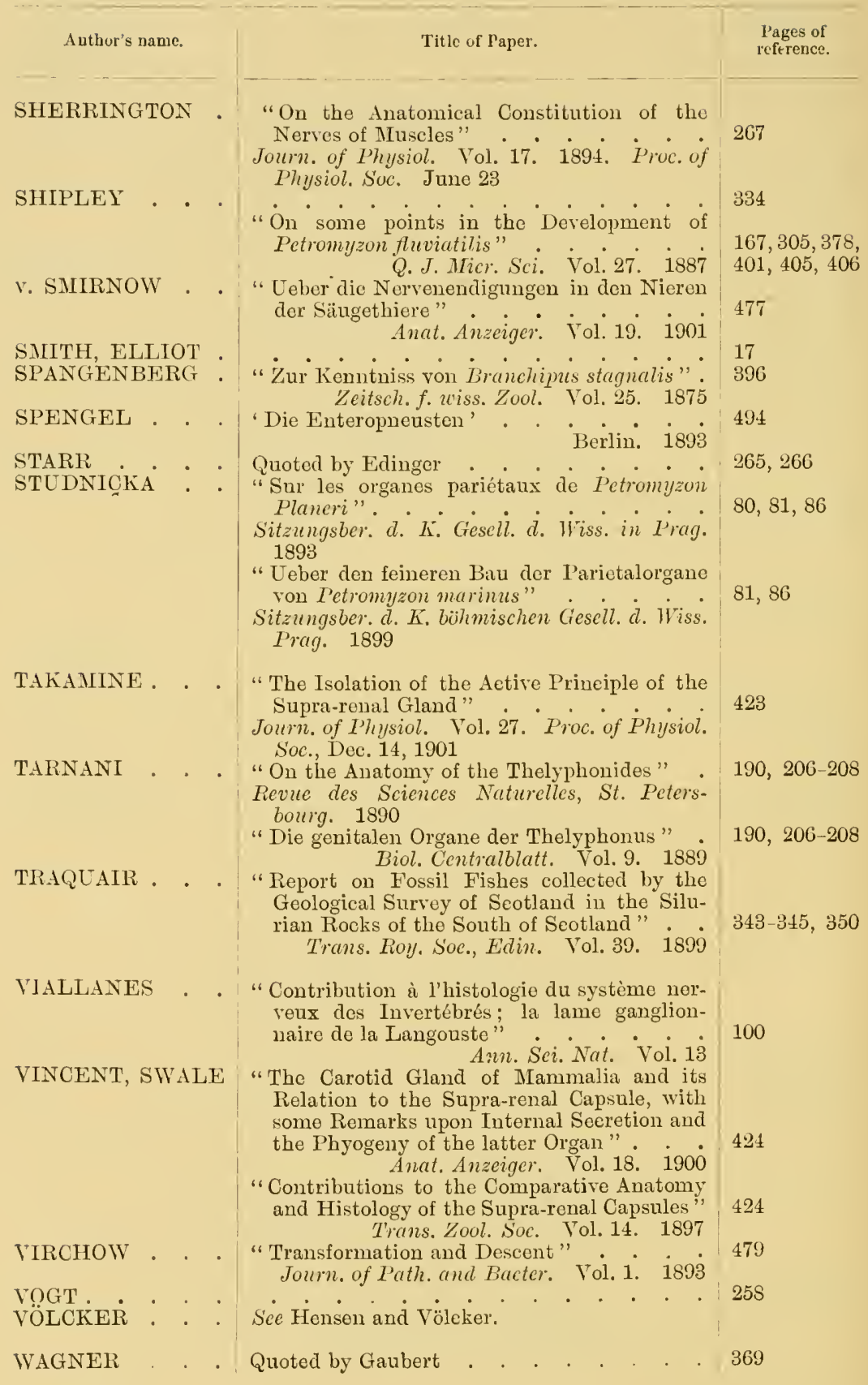




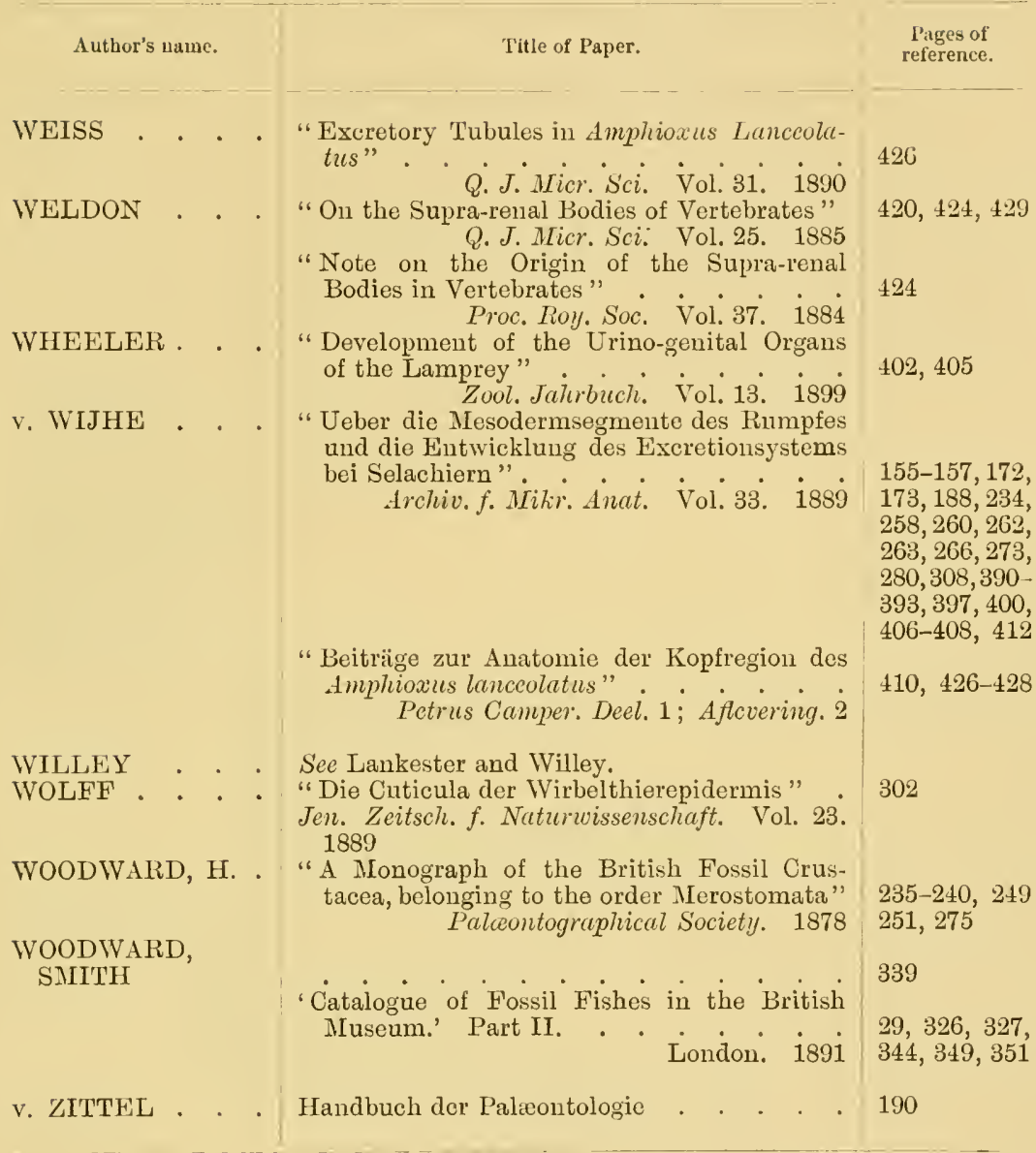





\section{GENERAL INDEX}

[The numbers in dark type refer to illustrations]

Acricrus larva, eye of, 78, 83

Acromegaly, 425

Actinotrocha, $43 \mathrm{~s}$

Addison's disease, 423

Adelopthalmus, 249

Adrenalin, 423, 491

Adrenals, 42:3, 491

Agnathostomatous fishes, 29, 343

Alimentary canal, 433

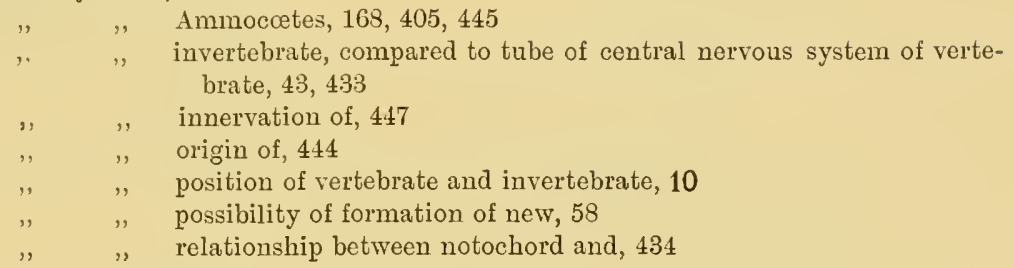

Ammoccetes, 168, 405, 445

Ammocœetes, 32, 245

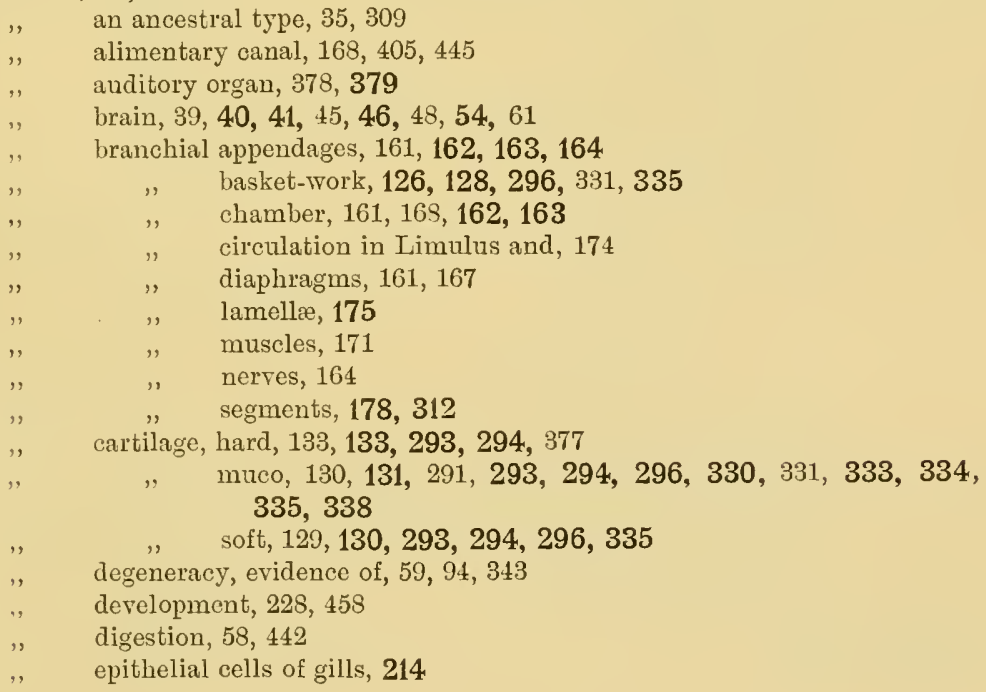


Ammocœtes, epithelial cells of skin, 347

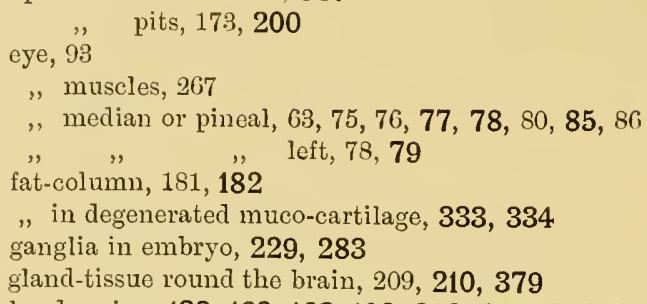

Amphibia, 23, 345 
Amphioxus, 33, 407

\begin{tabular}{|c|c|}
\hline & atrial \\
\hline & branchial nephric glands, 426 \\
\hline , & endostyle, 198,212 \\
\hline , & excretory orgaus, $389,395,477$ \\
\hline , & neuropore, 220,457 \\
\hline " & notochord, $435,436,443$ \\
\hline , & pleural folds, 495 \\
\hline & septa between myomeres, $\mathbf{4 1 6}$ \\
\hline & somatic muscles, 409 \\
\hline & yolk, 485 \\
\hline
\end{tabular}

Androctonus, 53, 54, 372, 423

Annelids, lateral sense-organs, 357, 367

, nephric organs, 390

,. origin of Arthropods from, 395

, parapodal ganglia, 283

Anthozoa, 474

", phagosytic glands, 421

Antiarclia, 29, 326, 343

Antibody, 492

Antitoxin, 492

Anus, 43,457

Aponeuroses, 327, 342, 414

Apparatus, auditory, 355

, dioptric, 83

,. respiratory, 148

, suctorial, of Petromyzon, 287

Appendages, branchial, of Ammocœetes, 161, 162, 163, 164

$\begin{array}{lll}, \quad & \text { Limulus, } 164 \\ , & , \quad \text { internal, } 149\end{array}$

" derivation of suctorial apparatus of Petromyzon from, 290

, disappearance of, in transformation of Arthropod into Vertebrate, 386, 413

" evidence of, in prosomatic region of ancient fishes, 342

" muscles, in Limulus and Scorpion, 247

., prosomatic, of Gigantostraca, 234

,. Trilobites, 351

Apus, 28, 137, 436, 437

Arachnids, eyes, 75,87

" diverticula of stomach, 109

" lyriform organs, 364,368

". segmental excretory organs, 423

Archreocytes, 473

Artemia, $v$. Branchipus

Arthropleura, 249

Arthropoda, arrangement of organs, 10

evolution, 11

., excretory organs, 396,418

" eyes, 75,89

," giant-fibres, 489

,. musculature, 411

" olfactory organs, 220 
Arthropoda, resemblance to ancient fishes, 29

Astacus, brain, 54

" digestive ferment in cells lining the carapace, 442

" optic chiasma, 101

" optic stalk, 91

" retina, 98

Asterolepis, 326, 342

Atrium, 410

Auchenaspis (Thyestes), 30, 31, 75, 275, 326, 327, 328, 338

Auditory apparatus, 355

Auerbach, plexus of, 447

Aurelia, 475

Autonomic nerves, 3

Balanoglossus, 12, 12, 433, 438, 494

Bdellostoma, 394, 405

Belinurus, 24, 249, 351

Bird, rhomboidal sinus, 46

Bladder, 449

"swim, 148

Blastula, 459, 471, 473

Blood, 463, 472, 474

" circulation, in Ammocetes and Limulus, 174

"s secretion of ductless glands into, 418

Bothriolepis, 29, 32, 239, 326, 351, 450

Bone, 344, 474, 481

Brain, Ammocotes and Arthropod, 54, 61

", and brain-case of Ammocœtes, 40, 41, 46, 209

", caudal, of Thelyphonus, 450

" epithelial lining of, 38

" roof, 39

," Sphæroma serratum, 62, 90

, Thelyphonus, 56

, ventricles, 4

"vesicles, 48

Branchial basket-work of Ammocœtes, 126, 128, 296, 331, 335

Branchipus, 28

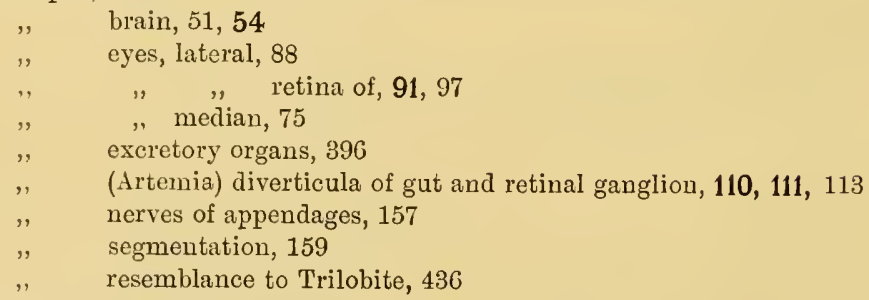

Bunodes, 24, 30, 249, 341, 351, 414

Bundle of IIeynert, 48, 77

Bundles, posterior longitudinal, 489

Buthus, muscles, 270

Calcification in aponeuroses of Cephalaspis, 414 
Calcification in cartilage, 140,330

successive layers of the skin, 348

Camerostome, 221, 222, 223, 224, 241, 271

Canal, alimentary, formation of vertebrate, 53, 433, 446

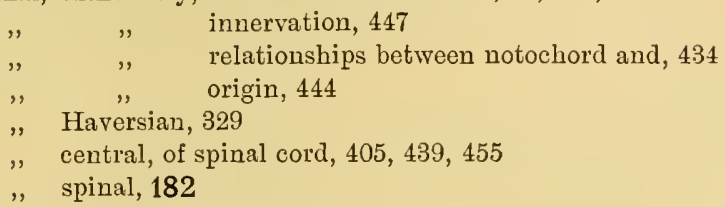

Capsule, auditory, 377,379

Cartilage Ammocotes, muco, 127, 130, 131, 200, 291, 303, 330, 333, 334, 344

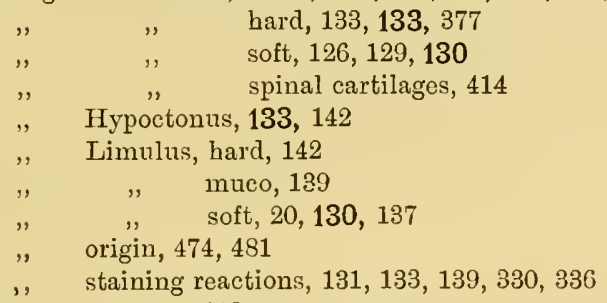

Cavity, atrial, 409,413

", cœlomic, $167,251,266,320,399,391,408,422,430,472$

Cells, free-living, 463

Centre, vaso-motor, 468

Cephalaspis, diverticula of gut, 109

" eyes, lateral, 75,275

" $\quad$ " median, 75

, head-shield, $327,328,330,338$

," muscles on head-shield, 269

", resemblance to Ammoccetes, 145, 291, 326, 329, 338, 348, 414

", Arthropod, 29

Ceratodus, 148

segmentation, 339

Cephalization, 51

Cephalodiscus, 438

Cephalopod, 23

Cerebellum, 47, 50

Chætopoda, 395

Chamber, oral, of Ammocoetes, $243,287,458$

Cheliceræ, 235

Chiasma, optic, 101

Chilaria, 235, 238, 291, 301, 458

Chitin, 85, 119, 139, 205, 206, 302, 329, 346, 359, 440, 443

Cilia, 206

Circulation, branchial, 174

Cirri, 357

Clarke's column, 467

Clepsine, nephridial glands, 423

Cochlea, 378

Cœlenterata, 465, 472

Cololepidæ, 344 
Cœlom, 167, 251, 400, 472, 481

Cœlomata, 472

Colomocoela, 472, 475

Cœlomostomes, 477,481

Colleneytes, 474

Commissure, anterior, 49

$$
\text { " csophageal, } 14
$$

" posterior, 48,280

Comparison of brains of Ammocœtes and Arthropod, 61

" , = invertebrate from Branchipus to Ammocœtes, 54

,9

" cranial and spinal segmental, 152

nervous systems of Vertebrate and Arthropod, 36

pineal gland of vertebrates and median eyes of Arthropod, 63, 456

pituitary body and coxal glands, 246, 319, 321

prosoma and mesosoma of Limulus and Ammocœtes, 140, 141

prosomatic region of Ammocœtes and Euryptcrus, 244, 333

retina in Ammocetes and Musea, 97

, compound in Arthropod and Vertebrate, 87

skeleton of Limulus and Ammocœetes, 126, 136

sense-organs of Arthropod appendages with auditory organs of

Vertebrate, 375

thyroid with endostyle, 198

Corpora quadrigemina, 47 
Corpuscles, Pacinian, Herbst, Grandry, etc., 470

Coxal glands, $242,246,319,321,389,398,403,429$

Cranium, 121, 145, 339

Crayfish, 442, 489

Crest, neural, 281

Cromatophores of frog, 470

Crura cerebri, 14

Crustacea, first appearance, 27

" eyes, 76,87

" retina, 100

, segmental glands, 422

Ctenophora, 474

Cyathaspis, 29, 326, 340, 343

Cyclostomata, 165, 229, 343, 353, 424

Cysts, 50

DAPHNia, 112

Degeneration, 17, 19, 59, 74, 78, 94, 107, 212, 309, 333, 336, 343

Deiters' nucleus, 489

Dendrites, 72

Development, parallel, 497

$$
\text { " of two types of eye, } 73
$$

" vertebrate retina, 101

Diaphragms, 161, 167

Didymaspis, 327, 338

Digestion, 441

Dinosaurs, 17

Dipnoans, 23, 45, 148

Diptera, 89, 369

Diverticula, optic, 102

Dogfish, skull, 121, 123

Drepanaspis, $344,345,450$

Drepanopterus Bembycoides, 238

ECTOGNATH, 238, 242, 271, 304, 342, 381

Eel, 488

Elasmobrauchs, 23, 343, 423

Elastin, 435

Embryo, head of dogfish, 121, 123

$$
\text { " skull of pig, } 121
$$

Embryology, principles of, 455

Encepalomeres, 262

Endognath, 238, 271, 304, 381

Findostoma, 241, 306

Endostyle, 198, 212

Entapophysis of Limulus, 139

Enterocœla, 472

Enteropneusta, 438, 494

Entochondrites, 377

Entosclerite, 222, 271

Entosternite, 143

Epiblast, 444, 445, 459 
Epithelium cells of Ammocœtes, 347

, of central nervous system of vertebrates, 38,457

, cœlomic spaces in annelids, 421

", optic diverticula, 103

" peritoneal, pleural, and pericardial cavities, 477

, velum of Ammocœtes, 301, 302

Equilibration, 358

Eukeraspis, 326

Eurypterus, 26, 150, 191, 237

" appendages, $150,236,237$

" classification, 249

" comparison with Ammocœetes, 170, 323

" diagram of sagittal median section, 240, 245

" endostoma, 241, 306

" eyes, 275

" mesosomatic segments, 192

" muscles of carapace, 269

" operculum, 150, 190, 212

Evidence of alimentary canal, innervation, 446

" auditory apparatus and lateral line organs, 355

") coelomic cavities in Limulus, 251

". degeneracy in Ammocœtes, 59, 94, 343

", embryology, cartilage, 20, 129

" , " eye-muscles, 263

,

,

,

,

", prosomatic musculature, 247

,. respiratory apparatus, 148

" segmentation in head-shield, 339

" skeleton, 119

Evolution, 8, 15, 20, 149, 482, 497 
Evolution of brain in brain-case, 210

cranium of Vertebrate, 342

excretory orgaus, 389

eye of Vertebrate, 114

nervous system, central, 34

tissues, 19

Eyes, 68

Vertebrate from Balanoglossus and Amphioxus, 33

"lateral, 87, 105, 108

, median or pineal, $74,77,78,79$

FAT-CELLs in muco-cartilage, 332

Fat-column of Ammocœtes, 181, 182

Fibres, Mauthnerian, 488

„, Müllerian, of Ammocœtes central nervous system, 489

9

retina, 96, 107

Fishes, classification, 218

, ancient, classification, 326, 343

" , cloacal region, 450

" " , dominance, 23

" " $\quad$ ", eyes, 75

" " head-shields. See Head-shields

", ". pleural folds, 414

Fissure, posterior, 43

Fittest, survival of, 16, 34

Flabellum, 359, 360, 362, 363, 366

Folds, pleural, 410, 414

Function of auditory organ, double, 358

, lateral line sense-organs, 357

" nerves, 448

thyroid, 212, 215

Fusion of ganglia, 52

Galeodes, 230

" brain, and camerostome, 222, 223

" primordial cranium, 341

, racquet-organs, 369,375

Ganglia, infraœsophageal, 4, 12, 14, 51, 221

" supracesophageal, $4,12,14,49,52,221,225$

" origin of, of cranial and spinal nerves, 281

Ganglion, epibranchial, 164, 282

," habenulæ, 48,78

" optic of retina, $72,89,97$

", of posterior root, 466

", cells of sympathetic system, $424,428,448$

Ganoids, 23, 345

Gastrula theory, 165, 459

Genital corpuscles, 470

Geological record, 20

, strata, 22

Geotria australis, 80

Germ-band, 482 
Germ-cells, 471

Giant-fibres, 489

Gigantostraca, 25, 234

Gills, 148, 161, 185, 214, 494

Glabellum, 339

Glands, carotid, 427

" coxal, 242, 246, 319, 321, 425, 429

". ductless, 418

" generative, of Limulus, 209

" internal secretion of, 214

$" \quad$ lymphatic, 418

$" \quad$ pineal, $15,63,75,456$

" pituitary, 244, 246, 319, 425

", segmental, of Crustacea, 422

", submaxillary, 466

11 sweat, 448

" thymus, 425

" thyroid, of Ammocoetes, 193, 194, 196, 201, 205, 429

" tissue round brain of Ammoccetes, 209, 379

"uterine, of Scorpion, 202, 203, 204, 205

Gnathostomata, 60, 343

Goblet, 359, 360, 373

Goitre, 215

Gonad, 475, 479

Gonocœle, 475, 481

Grooves, ciliated, 188, 197, 212

" hyper-pharyngeal of Amphioxus, 410

". ventral, of apus and trilobites, 436

Gymnophiona, 393

Hæirocytes, 472

Head of embryo dogfish, 121, 123

Head-shield, dorsal, of Ammocœtes, 330, 331, 338

\begin{tabular}{|c|c|}
\hline , & Auchenaspis, 29, 31, 338 \\
\hline , & Cephalaspis, $327, \mathbf{3 2 8}, \mathbf{3 3 0}, \mathbf{3 3 8}, 348$ \\
\hline$"$ & Cyathaspis, 340 \\
\hline , & Didymaspis, 338 \\
\hline$"$ & evidence of segmentation, 339 \\
\hline , & Keraspis, 328 \\
\hline$"$ & Ostreostraci, 327,348 \\
\hline , & Palæostracan, 348 \\
\hline$"$ & Pteraspis, 29 \\
\hline$"$ & $\begin{array}{l}\text { Thyestes, } 29,31,327,332,338,340,341,348 \\
\text { caphaspis, } 349\end{array}$ \\
\hline
\end{tabular}

Heart, nerves, 2, 447

" origin of vertebrate, $179,451,459$

" relative position in vertebratc and invertebrate, 175

" veins forming vertebrate, 180

Hemiaspis, 24, 25, 249, 250, 351, 414

Hemispheres, cerebral, 47

Hepatopancreas of Ammocœtes, 452 
Heterostraci, 29, 275, 326, 343

Hirudinea, 478

Histolysis in transformation of the lamprey, 59

Homology of branchial region of vertebrate and invertebrate, 149

" ductless glands and nephridial organs, 418

", external genital ducts of arthropods and nephridia of ammelids, 429

" germinal layers in all Metozoa, 459

" pituitary body of Ammocotes and coxal glands of Limulus, 319

" tubular muscles of Ammocoetes and veno-pericardial muscles of Limulus, 309

ventral aorta of vertebrate and longitudinal venous sinuses of Limulus, 178

Hydra, 441, 465, 472, 476

Hydrophilus larva, eye, 84

Hyoid segment in Ammocœtes, 186, 267

Hypoblast, 434, 438, 444, 445, 459

Hypoctonus, eartilage cells in entosternite, 133

Hypogastric plexus, 3

operculum, 189, 207

Hypogeophis, 393

Hypophysis, 229, 244, 317, 318, 340

INFUNDIBULUM, position, 122, 132

" tube, the ancestral œesophagus, 4, 37, 214, 318

" " relation to neural canal, $14,36,318,440,457$

" " " notochord, $318,435,440$

" " " " olfactory tube, $220,228,318,340$

Insects, chordotonal organs, 364, 370

Invertebrate, heart, 175,179

$$
\begin{array}{ll}
" & \text { excretory organs, } 418 \\
" & \text { nervous system, } 13,54 \\
\text { " } & \text { segmental nerves, } 152
\end{array}
$$

Keraspis, $75,328,338$

Kidney, $420,459,476$

" nerves, 477

King-crab, $v$. Limulus

Labyrinthodont, 21, 28

Lamina terminalis, 49

Lamprey, $v$. Ammoectes and Petromyzon

Larra, $v$. Transformation of the Lamprey

Lateral line system, 261, 355, 411, 470

Law of Progress, 19

,, Recapitulation, 434, 456, 498

Layer, germinal, 459

," laminated, 347,348

Leech, 421

Lens, formation, 83, 115

Lepidosiren, 148, 461, 466

Limulus or king-crab, 25, 140, 236, 240

" appendages, branehial, 138, 164, 175 
Limulus appendages, prosomatic, 381

" brain, 54

, circulation, 174,176

" classification, 26,249

" cœlomic cavities, 252,328

" coxal glands, 321, 389, 397, 403, 429

" eyes, median, $62,74,81$

" entosternite or plastron, 142, 143

" flabellum, 360, 362, 363, 380, 381

"generative organs and ducts, 189, 202, 208, 209, 380

". heart, 180

" musculature, branchial, 170

" $\quad$ prosomatic, 247

" $\quad$ veno-pericardial, 177, 297, 309, 313

$"$ nerves, appendage, 140, 157

" $\quad$ " cardiac, 314

" " segmental, tripartite division of, $157,235,267,355$

" segments, branchial, 152

" " $\quad$ first mesosomatic, 188

" " prosomatic, 233

" operculum, 189, 202, 235, 295

", sense-organs, poriferous, of appendages, 359

Lip, lower, of Ammocœtes, 246, 289, 297, 458

" upper, " $\quad 228,243,303,336$

Liver, Ammocœtes, 452

" Limulus, 209, 211

Lizard, pineal eye, 80

$" \quad$ suprarenals, 424

" tail, 50

Lobes, optic, 101

Lobster, 489

Lungs, 148

Lung-books of scorpions, 150

Lymph, 474

Lymph-corpuscles, 463, 490

Lymphocytes, 472

Malapterurus, 470

Mammal, dominance of, 21

Man, dominance of, 17

Marsipobranchs, 23, 35

Medullation of nerve-fibres, 20, 267, 467, 477.

Membranes, basement, 436

Meroblastic egg, 485

Merostomata, 25, 249, 321

Mesencepalon, 48

Mesoblast, 444, 455, 459

Nesoglœea, 474

Mesonephros, 389, 400, 424, 429

Mesosoma, 52

Mesothelium, 472, 477

Metanephros, 389 
Mctasoma, 52, 387, 411

Metastoina, 239, 246, 272, 289, 342, 458

Metazoa, 444, 459, 471, 472

Meynert's bundle, 48, 77

Mollusca, dominance of, 23

Mouth, old, or palæostoma, 14, 317, 322, 440, 458

, vertebrate, 317

Muco-cartilage, $v$. Cartilage

Muscles, antagonistic, 447

" branchial, 170

" connection of, with central nervous system, 464

", eye, and their nerves, 263

", prosomatic, 243,247

" phylogeny of origin of skeletal, 478

" rudimentary, in Ammocœtes, 289

, somatic trunk, origin of, 406

., striated, 20, 155

" tubular, of Ammocœtes, 309

" unstriped, 20, 447, 491

", visceral and parietal, 155, 172

"veno-pericardial of Limulus and Scorpion, 177, 297, 309

Muscle-spindles, 267

IIygalidæ, stomach, 109

" segmentation, 249,306

Myomeres, 262, 337, 414, 479

Myotomes, 332, 337, 339, 391, 407, 408

Mysis, eyes, 100

"ductless glands, 422

Myxine, 220, 392, 402, 419

Nebalia, 144,422

Nemertina, 475

Nephridia, 395, 421, 429

Nephrocœle, 430

Nephrotome, 393

Nerves, abducens, 155, 263, 266

auditory, 356, 376

autonomic, 3

facial, 155, 156, 186, 188, 19: 311, 356, 378

" ramus branchialis profundus, 311

to flabellum, in Limulus, 361, 375

glossopharyngeal, 155, 156, 186, 356

hypoglossal, 156

inhibitory, 447

inedullation of, $20,267,467,477$

occulomotor, $155,234,263,274$

olfactory, 229

optic, 101, 104

, of pineal eye, 79

origin of ganglia of cranial and spinal, 281

to pecten of Scorpion, 375, 376

preganglionic, 2 
Nerves, of prosoma in Limulus, 235, 355

" regeneration of, 469

, roots, of Limulus, 157

". sacral, 448

" segmental, 152, 156

, segmental nature of cranial, 259,411

, spinal, absence of lateral roots in, 388

, spinal accessory, 154

". trigeminal, 151, 155, 156, 234, 243, 257, 279

". $\quad$ motor nucleus of, 280

". $\quad$ of Ammocotes, 288

," tripartite arrangement of cranial nerves, $154,157,235,267,355$

", trochlear, 48, 155, 234, 263, 276

$"$ vagus, $151,154,156,173,186,356,447,449$

Nervous system, central, comparison of Vertebrate and Arthropod, 36, 457

" $\quad$, connection of, with muscular and epithelial tissues, 464

" $\quad, \quad$ with retina, 71

" $\quad$ disease of, 50

$, \quad, \quad$ evidence of, 8

", $\quad$, evolution of, 34

" $\quad$ " importance of, $16,463,482,498$

,, $\quad$,. invertebrate, $10,13,54$

", $\quad$ " $\quad$ origin of, 480

" " " $\quad$ " relation of germ-band to, 483

" " $\quad$ segmentation of vertebrate, 51

". $\quad$ ". $\quad$ tube of, $36-51,102,211,433,455,457$

" " $\quad$ " vertebrate, $10,13,40,41,152$

", enteric, 447

„, sympathetic, $2,424,428,448,491$

Neurenteric canal, 37

Neuroblast, 465

Neuromeres, 55, 247, 262, 312, 316

Neurones, 72, 92, 465

Neuropil, 71, 91

Neuropore, 220, 457

Nose, 219

, of Osteostraci, 329, 352, 458

Notochord, 120, 122, 180, 181, 220, 244, 295, 318, 405, 417, 433, 436, 494

OCELLI, 70

(Hsophagus of Ammocœtes, 405

" Arthropod, compared to tube of infundibulum, 4, 244, 440

Olfactory apparatus, evidence of the, 218

, organs of the Scorpion group, 220

" tube of Ammocoetes, 219, 225, 241, 317

Oligochæta, 421,478

Operculum of Eurypterus, 191, 212, 291

," Limulus, 189, 202, 235, 295

, Phrynus, 191

, Scorpion, 189, 206, 212, 372

", Thelyphonus, 189, 190, 206

Organs, arrangement of, 10 
Organs, auditory, of arachnids and Insects, $36 \mathrm{~s}$

", branchial, innervation of vertebrate, 151

" " $\quad$ sense-organs of embryo vertebrate, 261, 281

," chordotonal, of insects, $364,369,370$

, electric, 470

," generative, of Limulus, 208, 209

" $\quad$ connection between Thyroid gland and, 215

". genital, of sea-scorpions, 206

" lateral line, 355,411

", lyriform, of arachnids, 364, 369

" olfactory, of Scorpion group, 220

", phagocytic, 420

"racquet, of Galeodes, 369,375

". segmental excretory, 339, 391, 408, 418, 459, 477

, sense, of appendages of Limulus, 355

" restigial, 456

,, of vision, evidence of, 68

, vital, 57

Origin of alimentary canal, 444

, arthropods from annelids, 395

", atrial cavity, 409

," auditory capsules and parachordals, 377

., colom, 475, 481

" ductless glands, 428

", free cells, 472

, heart of vertebrate, 179

, lateral line organs, 356

, muscles, 478

, musculatnre, branchial, 170

" $\quad$ somatic trunk, 406

," nervous system, central, 480

" notochord, 434

,. segmental excretory organs, 389

, skoleton of vertebrates, 119

" vertebrates, $9,36,351,433,493$

Ostracodermata, 326, 343

Osteostraci, 29, $75,275,326,343$

Otoliths, 378

Orum, 473

Pacinian bodies, 470,477

Palæmon, 20, 422

Palæontology, evidence of, 20, 497

Palæostoma, 317

Palæostraca, 27, 396

$$
\begin{array}{ll}
, & \text { median eyes, } 74 \\
" & \text { mesosomatic appendages, } 188 \\
\text { olfactory organs, } 221 \\
, \quad & \text { segments, compared to Ammocotes, } 308
\end{array}
$$

Pantopoda, glands, 423

Parachordals, 121, 132, 377

Parapodia, 357 
Parapodopsis, foot glands, 422

Parathymus, 427

Parathyroids, 427

Parietal organ, 76

Pecten of scorpion, 114, 359, 366, 371, 372, 373, 374

Pedipalpi, 190

Periblast, 471

Peripatus, 396, 399, 400, 411, 421, 429

Petromyzon, alimentary caual, 405, 445

, auditory organ, 378

, $\quad$ branchial segments, 169

, life-history, 59

, $\quad$ olfactory tube, 219,226

, pronephric duct, 402

, retina and optic nerve, 95

," skeleton, 125

, suctorial apparatus, 287, 304

Phagocytes, 420, 471

transformation, $v$. Transformation of the Lamprey

Pharynx of Amphioxus, 410

Phoronis, 439

Vertebrate, 440

Phrynus, brain, 53

, caudal brain, 450

, carapace and carapace removed, 250

, cceal diverticula, 109

" evidence of segmentation of carapace, $249,250,341$

", operculum, 191

" prosomatic appendages, 306

" crossing of dorso-ventral muscles, 271,277

," stridulating apparatus, 368

Phyllodoce, 395

Phyllopoda, 321

Pigment, in Ammocotes, in position of atrial cavity, 412

,. epithelial lining of central nervous system, 43,457

, $\quad$ choroid of vertebrate eye, 104, 107

" between glandular cells round brain of Ammocœetes, 211, 379

" tapetal layer of retina, 70

, white, of right pineal eye of Lamprey, 76,80

Pineal body, 14, 15

$"$ eyes, $74,233,244$

", ", of Ammocœtes, 80, 78, 85

" gland, 63, 75, 456

Pits, epithelial, of diaphragms in Ammocœetes, 164

" $\quad$ skin in Ammocœtes, 173, 200

Pituitary body, 244, 246, 319, 321, 425, 430

Plasma-cells, 471

Plakodes, 283

Planarians, 475

Plastron, formation of cranial walls from the, $86,322,341$

" of Limulus, 136, 142, 143

"I'alæostracan, compared to trabeculæ of Ammocœtes, 145, 377 
Plastron, muscles attached to the, 270

, of Thelyphonus, 143

Platyhelmia, 475

Pleuron, 410, 415

Plexus, of Auerbach, 447

" choroid, $38,45,49,103$

, hypogastric, 3

Polychæta, 357, 395

Pores, abdominal, 430

Porifera, 473

Pouch, formation of gill, 165, 166

Prestwichia, 24, 25, 249, 351

Principle of concentration and cephalization, 51

Pristiurus, 424 embryology, 455

Progress, law of, 19

" result of, 56

Pronephros, 389, 397, 419, 424, 449

Prosencephalon, 48

Prosoma, 52

Protopterus, 148

Protostraca, 27, 396, 417

, dominance of, 28

Protozoa, 166, 479

Pseudoniscus, 25, 249

Pteraspis, 29, 30, 275, 326, 343, 344, 350

Pterichthys, 29, 31, 239, 326, 351

Pterygoid, pedicle of, 295

Pterygotus, 25, 27, 56, 170, 191, 221, 235, 238, 249, 276

Ptychodera, 494, 495

RAMUS branchialis profundus of facial nerve, 311

" communicaus, 2,3

Raphe, 46

Recapitulation, law of, $434,456,498$

Regeneration of nerves, 469

Reptiles, dominance of, 21

Retina, compound, 71

" development of, 101

" inversion of, in Vertebrates, 114

" inverted, 70

, layers of compound, 73

" $\quad$ in Crustacean eye, 100

" of lateral eye of Ammocoetes, 93, 95, 111

, Musca, 89

" Pecten and Spondylus, 114

" upright compound, 72

Rhabdites, 69,81

$$
\text { simple, } 69
$$

SACCUS vasculosus, 244,322

Scales, 345 
Seaphaspis, 349

Schwanm, sheath of, 469

Sclerotomes, 388

Scorpion, brain, 54

" branchial lamellæ, 175

", development, 482

" entochondrites, 377

" excretory organs, 397

" cyes, 75

" lung-books, 150, 170

", Iymphatie glands, 423

" museles, oblique, 278

, ", recti, 271

" $\quad$ " respiration, 171

,. $\quad$ " veno-pericardial, 177

, museular system, 247, 268, 269

"nerves to Cheliceræ, 237

, olfactory organs, 220

", opereulum of male, 189, 206, 212

". peeten, $359,366,371,373,374,377$

" under surface, 372

" uterus, 189, 202, 203, 204, 205, 212

Sea-scorpions, 25, 26, 27, 56, 150, 170, 191, 208, 221, 232, 235, 2t1, 349, 359

Segmentation, branchiomeric, 124

" body-museles in vortebrate, 388

" eye-museles, 248

" of head, double, $155,157,173,234,258,411,459$

" of head-shield, 339

" history of eranial, 258

Segments, brauchial of Ammocoetes, 161, 178, 186

", hyoid, in Ammoecetes, double, 186, 201, 267, 300

", innervation of branchial, 151

" first mesosomatie, in Limulus and its allies, 188

" mesosomatie, of Eurypterus, 192

" prosomatic of Limulus and its allies, 233, 249

" $\quad$ " Ammocetes, 286

" of spinal region of Vertebrates, 388

" of trigeminal nerve-group, 257, 279

" tubular museles of hyoid, 299

Sense-organs of Amphioxus, 34

", branchial, of Limulus, 359,360

" lateral, of Annelids, 357, 367

Serum, 492

lateral-line system, $356,411,470$

Significance of the optic diverticula, 102

Silurus, 488

Sinus, longitudinal venous, of Limulus, $176,312,451$

"rhomboidal of bird, 46

Skeleton, Ammocotes, 126, 296, 335

$\begin{array}{lll}" & , & \text { branchial, 126, 126 } \\ " & " & \text { basi-cranial, 132 } \\ \text { " muco-cartilaginous, 291, 296, 330, } 331\end{array}$


Skeleton, aponeurotic, 414

". Cephalaspis, 414,415

" evidence of the, 119

" Limulus, cartilaginous, 126, 136

," , mesosomatic, 137

, " prosomatic, 142

, Petromyzon, 125

" Vertebrate, commencement of bony, 120, 121

Skin, digestive power of cells of, in Ammocates, 58, 442

, of Ammocotes, 346

,. nerves of, 448

Skull of dogfish, 123

,. pig-cmbryo, 121

Slimonia, 27, 56, 170, 235, 238, 249, 276, 303

Solenocytes, 395,477

Solpugidæe, 109

Sphæroma serratum, brain, 62, 90, 101, 225

Spiders, eyes, 75

, stomach, 109

Spina bifida, 50

Spinal cord, difference between brain and, 45

" " region of, 385

" " termination in bird-embryo, 51

Spondylus, retina of, 114

Squilla, eyes, 100

,. glauds, 422

Stomach, cephalic, 4, 43, 102, 244

Stylonurus Lagani, 27, 235, 239, 249

Substantia gelatinosa Rolandi, 44

Suprarenal body, 423

Surfaces, dorsal and ventral, 11 reversal of, $15,29,36,87,175,352,433,484$

Synapse, 72

Syncytium, 464, 471, 479

TaIL of lizards, 50

Tapetum, 69

Teleosteans, 23, 345, 420, 424

Tendon-organs, 470

Tentacles of Ammocœtes, 246, 289, 303

Tergo-coxal muscles, 247

Test, biological, of relationship of animals, 492

Thalamencephalon, 48

Thelodus, 344

Thelyphonus, 231

$\begin{array}{ll}, & \text { brain, } 53,54,56,224 \\ " & \quad \quad \quad \text { caudal, } 450 \\ " & \text { coecal diverticula, } 109 \\ " & \text { entosternite, } 143 \\ " & \text { genital organs, } 206 \\ " & \text { lyriform organs, } 363 \\ " & \text { olfactory passage, 226, } 306\end{array}$


Thelyphonus, operculum, 189, 190, 206, 207

Theory, gastræa, 444, 461

Theories of the origin of vertebrates, $9,411,433,457$

Thionin reaction, $131,139,213,330,336$

Throat, formation of, 179

Thyestes, 30, 31, 275, 326, 328, 329, 339, 340, 341

Thymus, 425,430

Thyroid gland of Ammocetes, $61,127,192,194,196,429,459$

" $\quad$ evidence of the, 185

" , function of, in Ammocoetes, 213

Tissues, connective, $471,474,481$

" evolution of, 19

$"$ notochordal, 435

"two groups of, 463

Tongue of Ammocœetes, 246, 303

Tonsils, 427, 430

Torpedo, 262, 392, 470

Trabeculæ, 121, 132, 133, 145, 277, 295, 377

Transformation of the Lamprey, 18, 35, 59, 61, 125, 168, 193, 199, 200, 220, 227, 228, $287,291,304,307,309,331,336,347,349,389,445$

Tremataspis, $32,75,275,326,351,352$

Trilobites, 24, 25, 26, 437

" appendages, 351,437

. diagram of section through a trilobite-like animal, 413

, dominance of, 26

", excretory organs, 396

". eyes, 74,88

, $\quad$ glabellum, 339

," relations of, 249,283

", respiratory apparatus, 170

" ventral surface, 437

Tube of central nervous system, 37, 38, 42, 102, 211, 433, 455, 457

" from IVth ventricle to surface of brain in Ammocœtes, 209

"Fallopian, 431

," hypophysial, 229, 244, 317, 440

" meeting of four tubes in vertebrate, 318,440

" notochord originally a, 436, 440

", olfactory, of Ammocœtes, 219, 225, 317, 440

", unsegmented, in segmented animal, 439

Tunicata, 16

, $\quad$ budding of, 441

" degeneration, 12, 17, 19, 60

,. endostyle, 198, 212

", hypophysis, 425

", notochord, 438

" position of, 494

UNIT, appendage, in non-branchial segments, 185

" branchial, 161, 165, 168, 185

Ureters, nerves of, 448

Uterus of Scorpion group, 189, 202, 203, 204, 205, 214

"vertebrate, nerves of, 448 
VALVE, ileo-colic, 449

" of Vieussens, 48

Variation in dominant races, 21,88

" meristic, in spinal nerves, 154, 387

Veins, forming vertebrate heart, 180

Velum, 228, 289, 298, 302

Vertebrates, alimentary cana], innervation of, 446

," atrial cavity, 410

". auditory apparatus and lateral-line system, 356

, body-cavity, 401,430

", brains, 40

", branchial organs, 151

", cœlomic cavities in head region, 251, 266

", cranium, evolution of, 342

", egg of, 483

" evolution of, 11

" excretory organs, 389, 391, 408

" glands, ductless, 418

" $\quad$ interual secretion of, 215

" heart, $175,179,180$

" muscles, evidence of segmentation of eye, 248

" , oblique, 278

",$\quad$ origin of somatic trunk, 406

" nerrous system, central, 13

". nerves, segmental, 152

" notochord and gut, 434

", organs of, 10

" $\quad$ origin of, $9,411,433,457$

" segments, prosomatic, 257

". skeleton, commencement of bony, 120,458

" $\quad$ spinal cord and medulla oblongata, 44.

" spinal region, 385

thyroid, connection between generative organs and, 215

" tubes, meeting of four, 318, 440

Vesicles, cerebral, formation of, 48,458

Vitellophags, 471, 483

Volvox, 479

WOLFFIAN BODY, 390

Xiphosura, 24, 26, 249

YoLK, 482 
IRINTFD BY

WILliam CloNES AND SONS, LJMITED, LONDON AND BECCIES 
, 




